Acquisitions and

Bibliographic Services Branch

395 Wellington Street

Ottawa. Ontario

KIA ON4
Bibliothèque nationale

du Canada

Direction des acquisitions et

des services bibliographiques

395, rue Wellington

Ontawa (Ontario)

KIA ON4
Your tire Voire téterence

Our the Notre reference

NOTICE

AVIS

The quality of this microform is heavily dependent upon the quality of the original thesis submitted for microfilming. Every effort has been made to ensure the highest quality of reproduction possible.

If pages are missing, contact the university which granted the degree.

Some pages may have indistinct print especially if the original pages were typed with a poor typewriter ribbon or if the university sent us an inferior photocopy.
La qualité de cette microforme dépend grandement de la qualité de la thèse soumise au microfilmage. Nous avons tout fait pour assurer une qualité supérieure de reproduction.

S'il manque des pages, veuillez communiquer avec l'université qui a conféré le grade.

La qualité d'impression de certaines pages peut laisser à désirer, surtout si les pages originales ont été dactylographiées à l'aide d'un ruban usé ou si l'université nous a fait parvenir une photocopie de qualité inférieure.

La reproduction, même partielle, de cette microforme est soumise à la Loi canadienne sur le droit d'auteur, SRC 1970, c. C-30, et ses amendements subséquents.
Reproduction in full or in part of this microform is governed by the Canadian Copyright Act, R.S.C. 1970 , c. C-30, and subsequent amendments. 


\title{
LABORATORY AND ANALYTICAL INVESTIGATION OF SLEEVE REINFORCED STONE COLUMNS
}

\author{
BY \\ NABIL M. A. AL-JOULANI \\ B.S. , KING ABDUL AZIZ UNIVERSITY, 1984 \\ M.Sc. UNIVERSITY OF PETROLEUM AND MINERALS, 1987
}

\author{
A thesis Submitted to the \\ Faculty of Graduate Studies and Research \\ in partial fulfilment of the requirement \\ for the degree of
}

DOCTOR OF PHILOSOPHY

\author{
in \\ Civil Engineering* \\ Carleton University \\ Ottawa, Canada K1S 5B6 \\ March, 1995 \\ (C) copyright \\ 1995, Nabil Al-Joulani
}

* The Doctor of Philosophy Program in Civil Engineering is a joint program between Carleton
University and the University of Ottawa, which is administered by the Ottawa-Carleton Institute
for Civil Engineering. 
National Library
of Canada

Acquisitions and Bibliographic Services Branch

395 Wellington Street Ottawa, Ontario

K1A ON4
Bibliothèque nationale

du Canada

Direction des acquisitions et

des services bibliographiques

395, rue Wellington

Ottawa (Ontario)

K1A ON4

Your file Votre relorence

Our file Notre reference

THE AUTHOR HAS GRANTED AN IRREVOCABLE NON-EXCLUSIVE LICENCE ALLOWING THE NATIONAL, LIBRARY OF CANADA TO REPRODUCE, LOAN, DISTRIBUTE OR SELL COPIES OF HIS/HF : THESIS BY ANY MEANS AND IN ANY FORM OR FORMAT, MAKING THIS THESIS AVAILABLE TO INTERESTED PERSONS.

THE AUTHOR RETAINS OWNERSHIP

OF THE COPYRIGHT IN HIS/HER THESIS. NEITHER THE THESIS NOR SUBSTANTIAL EXTRACTS FROM IT MAY BE PRINTED OR OTHERWISE REPRODUCED WITHOUT HIS/HER PERMISSION.
L'AUTEUR A ACCORDE UNE LICENCE IRREVOCABLE ET NON EXCLUSIVE PERMETTANT A LA BIBLIOTHEQUE NATIONALE DU CANADA DE REPRODUIRE, PRETER, DISTRIBUER OU VENDRE DES COPIES DE SA THESE DE QUELQUE MANIERE ET SOUS QUELQUE FORME QUE CE SOIT POUR METTRE DES EXEMPLAIRES DE CETTE THESE A LA DISPOSITION DES PERSONNE INTERESSEES.

L'AUTEUR CONSERVE LA PROPRIETE DU DROIT D'AUTEUR QUI PROTEGE SA THESE. NI LA THESE NI DES EXTRAITS SUBSTANTIELS DE CELLECI NE DOIVENT ETRE IMPRIMES OU AUTREMENT:EPRODUITS SANS SON AUTORISATION.

ISBN $\quad 0-612-02941-7$

\section{Canadá}


Name NabiL M Ai-Joillam

Dissertation Abstracts International is ariurnged by broad, general subject categories. Please select the one subject which most nearly describes the content of your dissertation. Enter the corresponding four-digit code in the spaces provided.

Civil Enanering

SUBJECT TERM

\section{$[1545] 3$ U.M.I}

SUBJECT CODE

\section{Subject Categories}

\section{THE HUMANITIES AND SOCIAL SCIENCES}

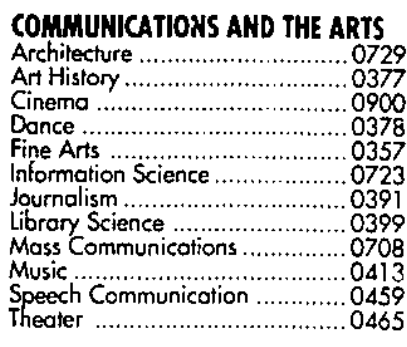

\section{EDUCATION}

General ................................ 0515

Adult and Continuing ....................0516

Agricultural ............................ 0517

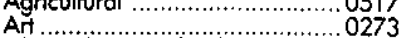

Bitingual and Mulricultural ............ 0282

Business ................................ 0688

Community College ..................0275

Early Childhood ....................... 0518

Elementory ............................ 0524

Finance ............................. 0277

Guidance and Counseling .........0519

Health ................................... 0680

Higher ................................. 0745

Home Economies ......................... 027

Industrial ................................ 0521

Languoge and Literature ........... 0279

Mathematics ........................028

Music .................................... 0522

Philosophy of ............................ 0998

Physical ..................................... 0523

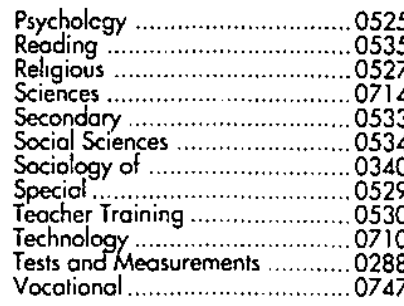

\section{LANGUAGE, LITERATURE AND} LINGUISTICS

Longuage

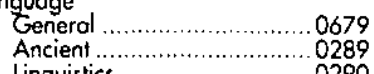

Linguistics ............................... 0290

Modern .............................. 0291

Literature

General ....................... 0401

Classical ............................. 0294

Comparative ....................... 0295

Medieval ............................ 0297

Modern ............................. 0298

African ............................. 0316

American .........................059

Asion ........................... 0305

Conadian (French) ............035

English (French) ..............0355

Germonic ............................. 0311

Latin Americon ...................0312

Middle Eastern ................... 0315

Slovic and Easi European ..... 0314

\section{PHILOSOPHY, RELIGION AND}

THEOLOGY

Philosophy .............................. 0422

Religion

General .......................... 0318

Biblical Studies .......................032

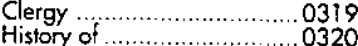

Philosophy of ....................... 0322

Theology ............................... 0469

\section{SOCIAL SCIENCES}

American Studies ................... 0323

Anthropology

Archoeology .................... 0324

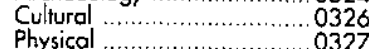

Business Administrotion

Generd...

Accounting

Banking

Manogement

Morketing

Economics

General ........

........ 0503

.

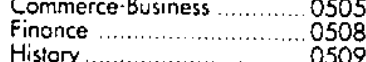

History

Theory

Folklore.

Geography

Geroniology

Genero

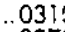

0272

.0770

.0338

0385

050

0509

0511

0511

0366

0578

\section{THE SCIENCES AND ENCINERRING}

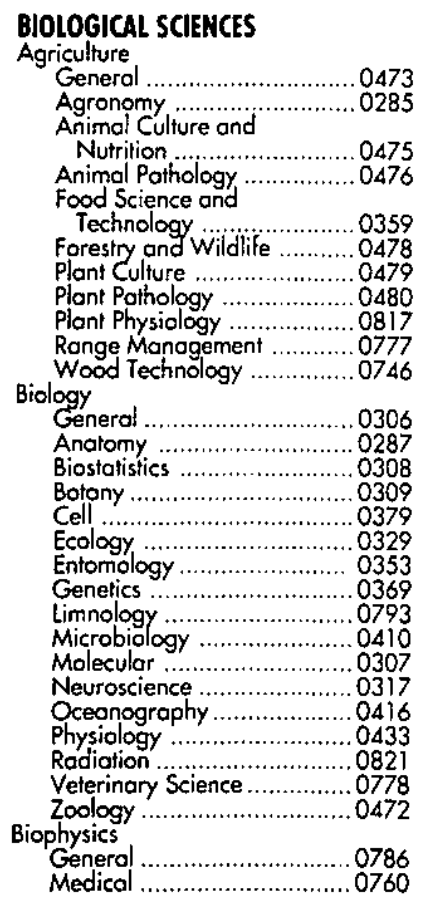

EARTH SCIENCES

Biogeochemistry
Geodesy ............................... 0370

Geology .............................. 0372

Geophysies …....................... 0373

Hydrology ........................... 0388

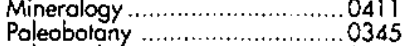

Poleoecology ............................ 0426

Paleontology ........................... 0418

Paleozoology ........................... 0985

Palynology ........................... 0427

Physical Geography ................ 0368
Physical Oeeanography ........... 0415

HEALTH AND ENVIRONMENTAL

\section{SCIENCES}

Environmental Sciences ............0768 Health Sciences

General ........................... 0566

Audiology ......................... 0300

Chemotherapy .................. 0992

Education ............................. 0350

Hospital Monagement ............. 0769

Humon Development ........... 0758

Human Development ............ 0758
Immunology ......................0982

Medicine and Surgery .......... 0564

Menia! Health ..................... 0347

Nursing ......................... 0569

Nutrition ........................... 0570

Obstetrics and Gynecology .. 0380

Occupational Health and

Therapy ...........................0354

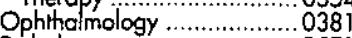

Pathology …...................... 0571

Pharmocology ..................... 0419

Physical therapy ................... 0382

Public Heolth ......................... 0573

Radiology ............................ 0574

Recreation ............................ 0575
Speech Pothology .............. 0460
Toxicology ....................... 0383 Home Economics ..................... 0386

\section{PHYSICAL SCIENCES}

Pure Sciences

Chemistry

General .........

Anricultural

Brochemistry

Inorganic

Nuclear

Organic....

Phormaceutical

Physical

Polymer.

Physics

General ..................................

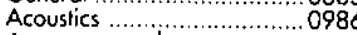

Astronomy and

Astrophysics ...................0606

Almospheric Science............ 0608

Alomic ............................ 0748

Elementary Particles and

itigh Energy................. 0798

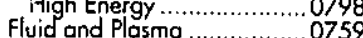

Molecular ............................ 0609

Nuciear .................................0610

Optics ................................. 0752

Solid State ........................................ 0611

Statistics ...................................... 0463

Applied Sciences

Applied Mechanics .0346

Computer Science

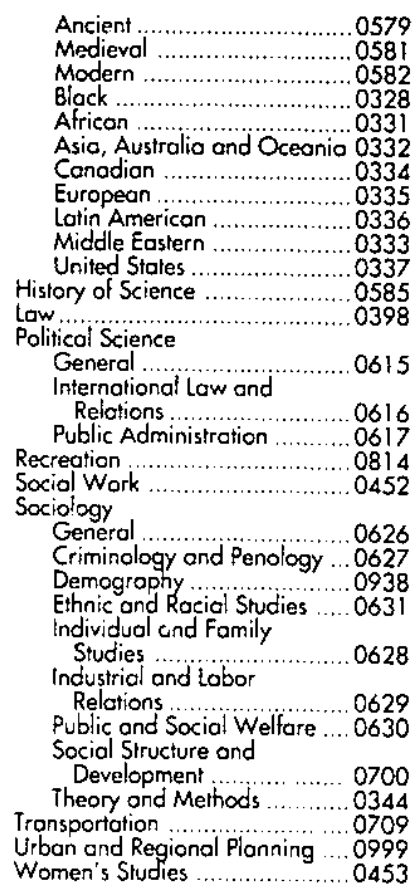

Engineering

Generd ........................ 0537

Aerospace $\ldots \ldots \ldots \ldots \ldots \ldots \ldots . . . \ldots 538$

Automolive ..................... 0540

Biomedicel .......................... 0541

Chemical ........................ 0542

Civit ................................. 0543

Electronies ond Electrical ....... 0544

Heat and Thermodynamics... 0348

Hydrautic ......................... 0545

Industrial .......................... 0546

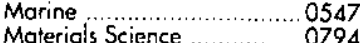

Mechanical ......................... 0548

Metallurgy ..........................0743 074

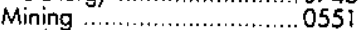

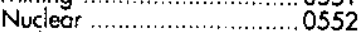

Packaging .............................. 0549

Petroleum ........................ 0765

Sanitary and Municipal ........ 0554

System Science .................. 0790

Geotechnology ...................... 0428

Operations Reseorch .................0796

Plastics Technology ...................0795
Textile Technology ...................0994

PSYCHOLOGY

General ...............................0621

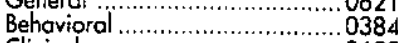

Clinical ........................................0622

Developmentol ............................0620

Experimenta! ................................. 0623

Industrial ......................................... 0624

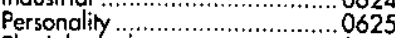

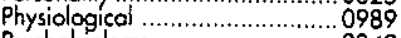

Psychobiology ......................... 0349

Psychometries ........................ 0632

Social ..................................... 045 


\section{Carleton University}

Ottawa, Canada K1S 5.5

$8)^{19+12-1 ! n 2}$

Thesis contains black and white and/or coloured graphs/tables/photographs which when microfilmed may lose their significance. The hardcopy of the thesis is available upon request from Carleton University Library. 
The undersigned hereby recommend to the Faculty of Graduate Studies and Research acceptance of the thesis,

\title{
LABORATORY AND ANALYTICAL INVESTIGATION OF SLEEVE REINFORCED STONE COLUMNS
}

\author{
submitted by
}

Nabil M. A. Al-Joulani, B.S., M.Sc.

in partial fulfilment of the requirements

for the degree of Doctor of Philosophy

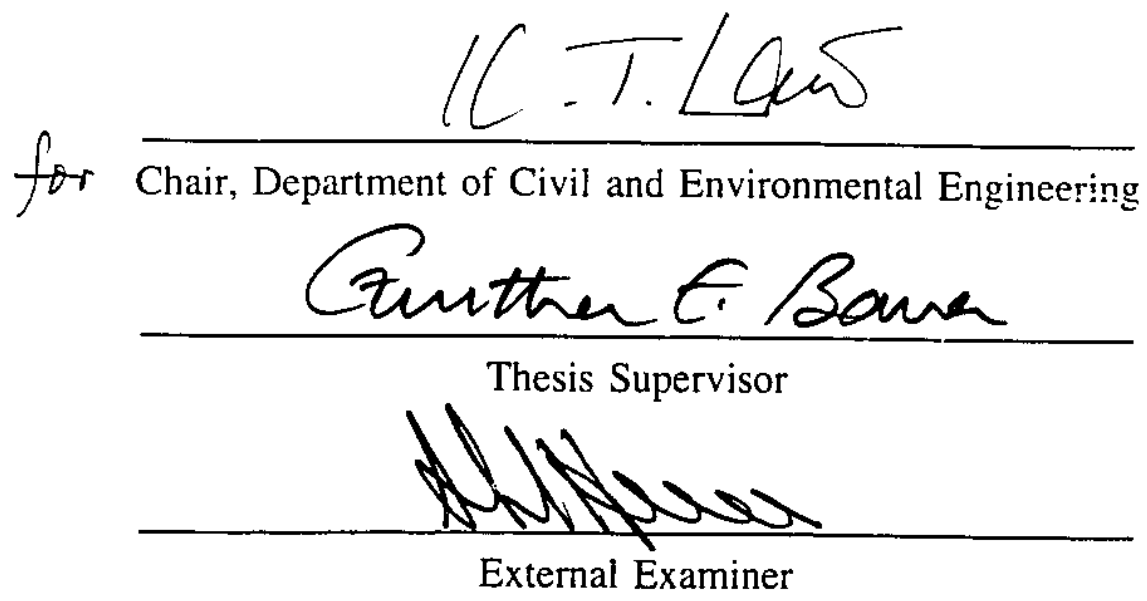

Carleton University

March, 1995 


\begin{abstract}
The technique of stone columns or compaction piles to improve the mechanical properties of marginal soils is well established. However, the use of stone columns is usually associated with excessive deformation due to lack of lateral support from the surrounding soil. The strength and stiffness properties of a natural stone column can be improved using a polymer geogrid sleeve. A literature review has revealed that there is hardly any data available on the strength and deformation behaviour of sleeve reinforced stone columns.

This thesis presents a new concept of providing additional confinement to a stone column using a polymer sleeve as external reinforcement. An extensive laboratory investigation was carried out in which natural and reinforced stone columns were tested under controlled conditions. The effect of different variables on the stone column behaviour was investigated. These variables included the type of polymer sleeve. type of column aggregate, confining pressure and loading condition.

The experimental program consisted of two stages. In the first stage over 40 triaxial sleeve reinforced and unreinforced specimens were tested. The size of column. type of polymer sleeve, aggregate type and loading condition were investigated using three confining pressures. The second experimental stage consisted of 12 uniaxial sleeve reinforced columns. The column diameter/height ratio, strain rate and loading condition were varied. The experimental results were presented and discussed.

A theoretical analysis was carried out by using the hyperbolic stress-strain model to analyse the behaviour of natural and sleeve reinforced columns. In this study it was assumed that the contribution of the surrounding weak soil to the stiffness of the stone columns was marginal. Therefore, the research concentrated mainly on the improvement of the stone column load capacity using polymer sleeves. For this reason, stone columns without soil confinement were tested. The specimens were tested under static and cyclic loading conditions. It was concluded that sleeve reinforcement enhanced the stone column capacity and minimized lateral bulging.
\end{abstract}




\section{ACKNOWLEDGEMENT}

The author wishes to express his sincere gratitude and appreciation to his supervisor, Professor G. E. Bauer for his guidance, encouragement and financial support throughout the course of this study. His reviewing and patient critique of the manuscript was of great assistance in the preparation of the thesis.

Special thanks are due to Professors K.T Law, A.O.A Halim and A.G. Razaqpur for their constant guidance and help during the experimental program and for their constructive comments.

The author would like to thank Messrs S. Conley, K. McMartin and J. Plavka for their assistance during the experimental work of this research. Thanks are due to my friends and colleagues for motivating and assisting me to complete this work.

Finally, the author would like to express his appreciation to his wife, Ahlam, without whose complete dedication and consiant encouragement the doctoral program could never have been completed. She maintained control of her three children, Hosam, Leila and Hebah, while their father dedicated his time to his research. In spite of the hardships of the student's life, she remained a loyal, loving companion. 


\section{TABLE OF CONTENTS}

Abstract $\ldots \ldots \ldots \ldots \ldots \ldots \ldots \ldots \ldots \ldots \ldots \ldots \ldots \ldots \ldots \ldots$ iii

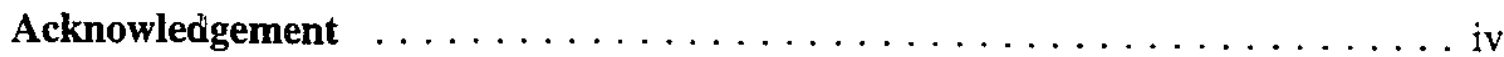

Table of Contents $\ldots \ldots \ldots \ldots \ldots \ldots \ldots \ldots \ldots \ldots \ldots$

List of Tables $\ldots \ldots \ldots \ldots \ldots \ldots \ldots \ldots \ldots \ldots \ldots \ldots \ldots \ldots \ldots \ldots \ldots$

List of Figures $\ldots \ldots \ldots \ldots \ldots \ldots \ldots \ldots \ldots \ldots \ldots \ldots \ldots \ldots \ldots \ldots \ldots$

CHAPTER 1. Introduction $\ldots \ldots \ldots \ldots \ldots \ldots \ldots \ldots \ldots \ldots \ldots \ldots$

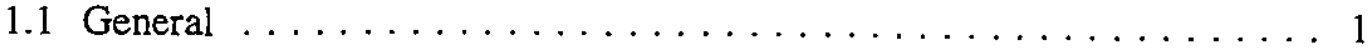

1.1.1 Single stone columns $\ldots \ldots \ldots \ldots \ldots \ldots \ldots \ldots$

1.1.2 Stone column groups $\ldots \ldots \ldots \ldots \ldots \ldots \ldots$

1.2 The use of stone columns to improve soils $\ldots \ldots \ldots \ldots \ldots \ldots \ldots$

1.3 The use of polymer grids in earth work $\ldots \ldots \ldots \ldots \ldots \ldots$

1.4 Problem definition $\ldots \ldots \ldots \ldots \ldots \ldots \ldots \ldots \ldots \ldots \ldots \ldots$

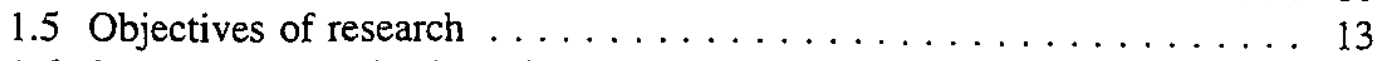

1.6 Scope and organization of thesis $\ldots \ldots \ldots \ldots \ldots \ldots \ldots \ldots$

CHAPTER 2. Literature Review $\ldots \ldots \ldots \ldots \ldots \ldots \ldots \ldots \ldots \ldots$

2.1 General . . . . . . . . . . . . . . . . . . 16

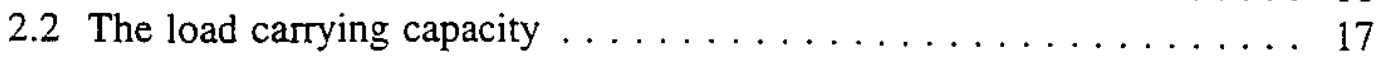

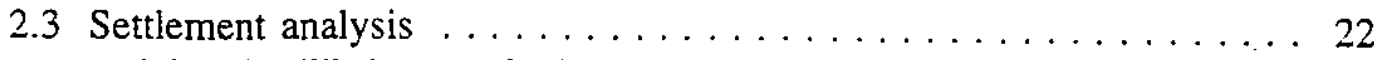

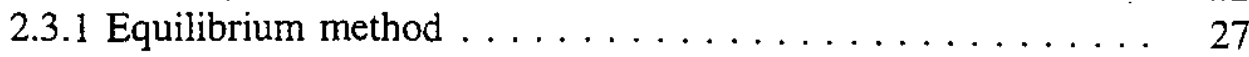

2.3 .2 Vibroflotation method $\ldots \ldots \ldots \ldots \ldots \ldots \ldots \ldots \ldots . \ldots \ldots 27$

2.3.3 Finite element method $\ldots \ldots \ldots \ldots \ldots \ldots \ldots \ldots \ldots \ldots$

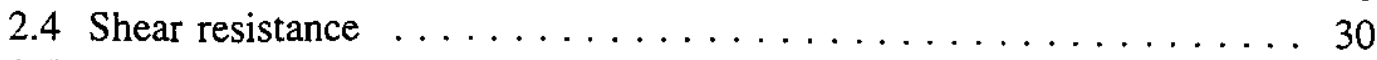

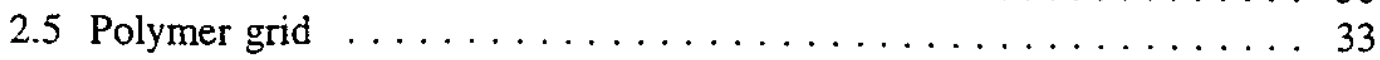

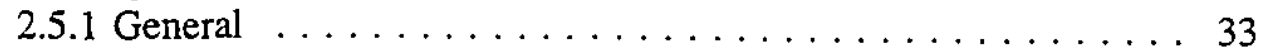

2.5.2 Influence of polymer grid on soil behaviour . . . . . . 33

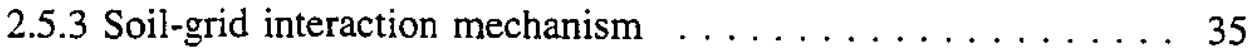

2.5.4 Mobilization of soil-grid strength $\ldots \ldots \ldots \ldots \ldots \ldots . \ldots 39$

2.6 Triaxial tests with grid reinforcement $\ldots \ldots \ldots \ldots \ldots \ldots \ldots \ldots 40$

2.6.1 Enhanced confining pressure concept ........... 43

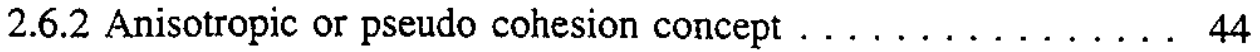

2.7 Creep behaviour of polymer grid $\ldots \ldots \ldots \ldots \ldots \ldots \ldots \ldots \ldots 45$

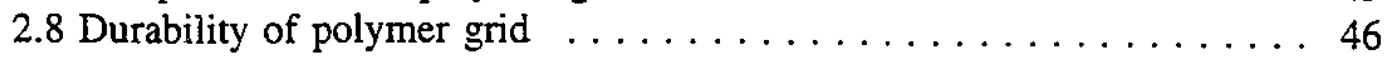

2.9 Construction techniques of stone columns $\ldots \ldots \ldots \ldots \ldots \ldots \ldots$ 


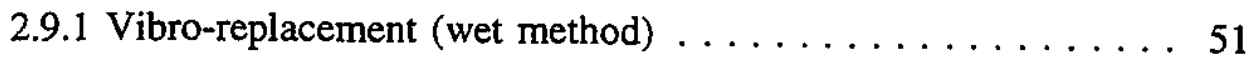

2.9.2 Vibro-displacement (dry method) $\ldots \ldots \ldots \ldots \ldots \ldots \ldots . \ldots \ldots$

2.10 Conclusions of literature review $\ldots \ldots \ldots \ldots \ldots \ldots \ldots \ldots \ldots$

CHAPTER 3. Theoretical Consideration $\ldots \ldots \ldots \ldots \ldots \ldots \ldots \ldots$

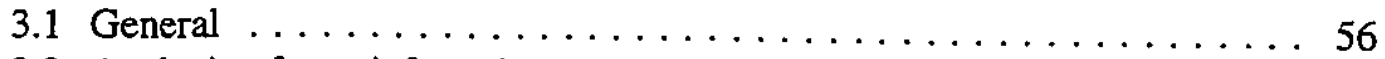

3.2 Analysis of unreinforced stone columns $\ldots \ldots \ldots \ldots \ldots \ldots \ldots 57$

3.2 .1 Ultimate load capacity . . . . . . . . . . . . . . . 57

3.2 .2 Vertical settlement $\ldots \ldots \ldots \ldots \ldots \ldots \ldots \ldots \ldots . \ldots \ldots$

3.3 Analysis of reinforced stone columns $\ldots \ldots \ldots \ldots \ldots \ldots \ldots 62$

3.3 .1 General . . . . . . . . . . . . . . . 62

3.3.2 Hyperbolic stress-strain relationship for granular material . . . 62

3.3.3 Hyperbolic stress-strain relationship for polymer grids . . . . . 69

3.3.4 Hyperbolic stress-strain relationship for the interface shear stress 70

CHAPTER 4. Experimental Program $\ldots \ldots \ldots \ldots \ldots \ldots \ldots \ldots 77$

4.1 General . . . . . . . . . . . . . . . . . . . . . . 77

4.1.1 Advantages of large triaxial tests . . . . . . . . . . 79

4.1.2 Objectives of triaxial stone column tests . . . . . . . . 79

4.1.3 Objectives of uniaxial stone column tests . . . . . . . 79

4.2 Equipment $\ldots \ldots \ldots \ldots \ldots \ldots \ldots \ldots \ldots \ldots \ldots \ldots \ldots$

4.2.1 Triaxial cell $\ldots \ldots \ldots \ldots \ldots \ldots \ldots \ldots \ldots \ldots \ldots$

4.2 .2 Compaction equipment $\ldots \ldots \ldots \ldots \ldots \ldots \ldots \ldots \ldots 2$

4.2 .3 Lateral deformation clips $\ldots \ldots \ldots \ldots \ldots \ldots \ldots \ldots 8$

4.2 .4 Volume gauge $\ldots \ldots \ldots \ldots \ldots \ldots \ldots \ldots \ldots \ldots . \ldots \ldots$

4.3 Materials . . . . . . . . . . . . . . 84

4.3.1 Soils $\ldots \ldots \ldots \ldots \ldots \ldots \ldots \ldots \ldots \ldots \ldots \ldots$. 84

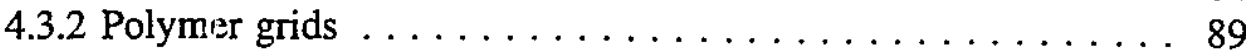

4.4 Column specimens for triarial and uniaxial testing $\ldots \ldots \ldots \ldots . \ldots 6$

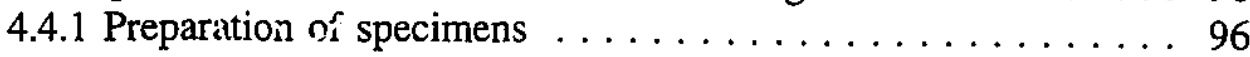

4.4.2 Uniaxial specimens $\ldots \ldots \ldots \ldots \ldots \ldots \ldots \ldots \ldots . \ldots \ldots$

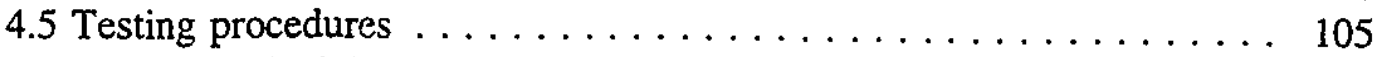

4.5.1 Triaxial test procedure $\ldots \ldots \ldots \ldots \ldots \ldots \ldots \ldots \ldots$

4.5.2 Uniaxial test procedure $\ldots \ldots \ldots \ldots \ldots \ldots \ldots \ldots 110$

CHAPTER 5. Experimental Results $\ldots \ldots \ldots \ldots \ldots \ldots \ldots \ldots \ldots \ldots$

5.1 General . . . . . . . . . . . . . . . . . . . 113

5.2 Triaxial stone column test results $\ldots \ldots \ldots \ldots \ldots \ldots \ldots \ldots 113$

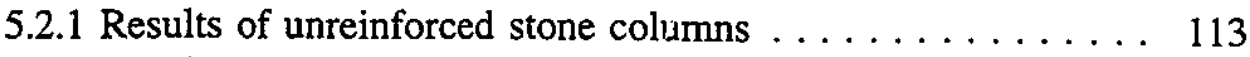

5.2.2 Results of sleeve reinforced triaxial stone columns . . . . . 119

5.2.2.1 Stone columns with Tensar and Conwed sleeves .. 119 
5.2.2.2 Stone columns with fiber glass (GB\#10) sleeves . . 122

5.2.2.3 Results of small triaxial specimens . . . . . . . . 124

5.2.3 Effect of aggregate type on colurnn behaviour . . . . . . 126

5.2.3.1 Unreinforced stone columns . . . . . . . . . 126

5.2.3.2 Sleeve reinforced stone columns . . . . . . . . . 127

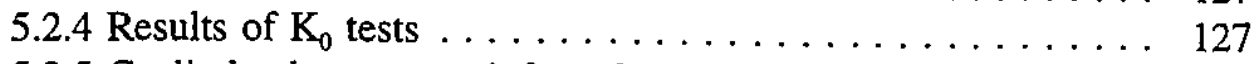

5.2.5 Cyclic load tests on reinforced stone columns . . . . . . . 132

5.3 Results of uniaxial stone column tests $\ldots \ldots \ldots \ldots \ldots \ldots \ldots 135$

5.3.1 Results of static loaded uniaxial stone columns . . . . . 135

5.3.2 Results of cyclic loaded uniaxial stone columns . . . . . 138

5.3.3 Resuits of rapidly loaded uniaxial stone columns . . . . . 138

5.3.4 Stress-strain-volume change of uniaxial stone columns . . . 145

5.3.5 Local strains in polymer grid sleeves . . . . . . . . 151

CHAPTER 6. Theoretical Analysis $\ldots \ldots \ldots \ldots \ldots \ldots \ldots \ldots \ldots$

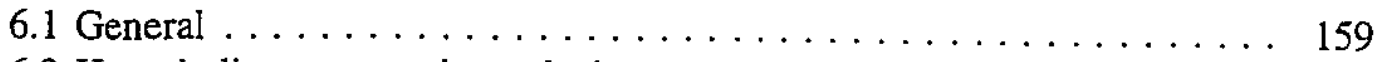

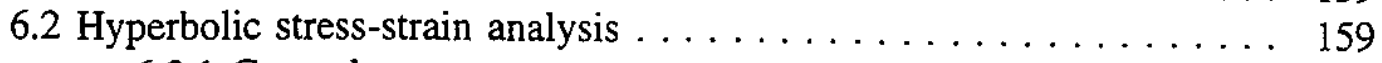

6.2 .1 General . . . . . . . . . . . . . . . . . 159

6.2.2 Model parameters and analysis $\ldots \ldots \ldots \ldots \ldots \ldots 161$

CHAPTER 7. Comparison and Discussion of Results . . . . . . . . . . 193

7.1 General . . . . . . . . . . . . . . . . . . . . . 193

7.2 Triaxial stone column tests $\ldots \ldots \ldots \ldots \ldots \ldots \ldots \ldots \ldots 194$

7.2.1 Comparison of stress-strain relations . . . . . . . . . . 194

7.2.2 Strength increase ratio (S.I.R.) . . . . . . . . . . . 199

7.2.3 Comparison of the angle of shearing resistance ... . . 205

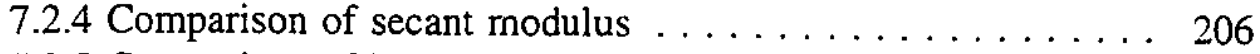

7.2.5 Comparison of $\mathrm{K}_{0}$ test results $\ldots \ldots \ldots \ldots \ldots \ldots \ldots 217$

7.2.6 Comparison of lateral deformation . . . . . . . . . 219

7.2.7 Hoop stress in polymer sleeve . . . . . . . . . . . 221

7.3 Uniaxial stone column tests $\ldots \ldots \ldots \ldots \ldots \ldots \ldots \ldots \ldots 231$

7.3.1 Comparison of stress-strain relations $\ldots \ldots \ldots \ldots \ldots 231$

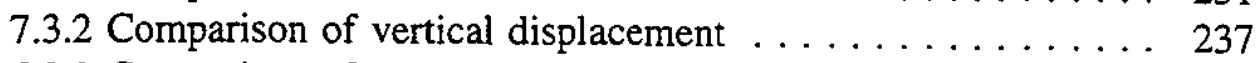

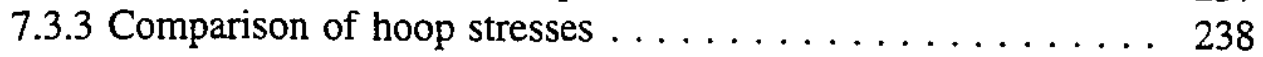

7.4 Comparison of deformation modes . . . . . . . . . . . 249

CHAPTER 8. Summary, Conclusions and Recommendations $\ldots \ldots \ldots 256$

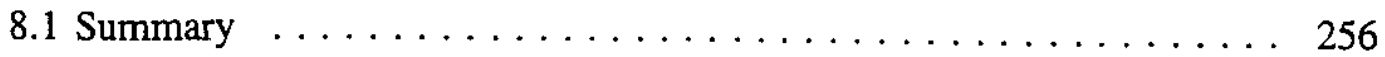

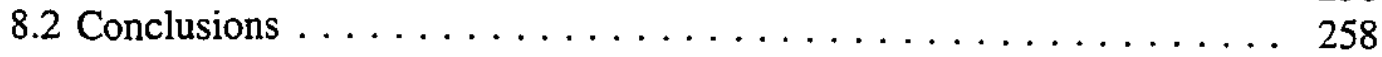

8.3 Recommendations for future work $\ldots \ldots \ldots \ldots \ldots \ldots \ldots 260$ 
APPENDIX A: Computer Program $\ldots \ldots \ldots \ldots \ldots \ldots$

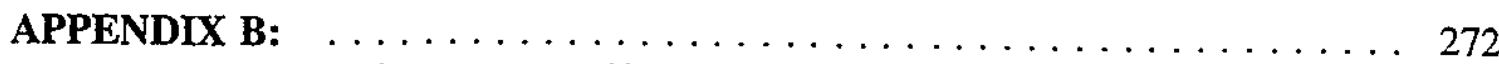

1) Strain gauge specifications $\ldots \ldots \ldots \ldots \ldots \ldots \ldots \ldots \ldots \ldots$

2) Details of load transducers . . . . . . . . . . . . . 273

3) Calibration curves of the load transducers . . . . . . . . . 274

4) Calibration curves of volume change device . . . . . . . 277

5) Calibration curves of lateral strain clips . . . . . . . . 278

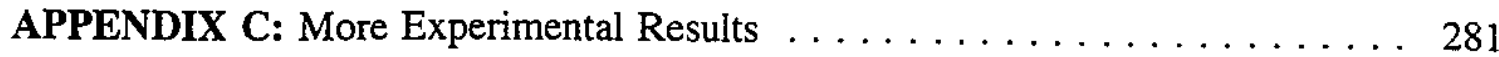




\section{LIST OF TABLES}

Table 2.1: Approximate range of design loads used in practice for stone columns . 19

Notes: 1. In general, when stone column loads are given all the applied load is considered to be carried by the stone column.

2. Typical design loads for foundations on cohesive soils are 15 to 30 tons.

3. Unit Conversions : 1 psf $=47.9 \mathrm{~N} / \mathrm{m}^{2}$

1 ton $=9.807 \mathrm{kN}$

Table 2.2: Some of the major projects world wide used for the consideration of $\quad .31$ both bearing capacity and earthquake resistant design

(After Dobson, 1987)

Table 2.3: Degradation resistance of various synthetic fibres $\ldots \ldots \ldots \ldots \ldots$ (After Cannon, 1976)

Table 2.4: Recommended factor of safety values for determining allowable . . . . 52 tensile strength of geogrids (After Koerner, 1990)

Table 4.1: Grain size characteristics of aggregates used in the tests $\ldots \ldots \ldots 8$

Table 4.2: Physical and mechanical properties of Tensar UX-1500 and UX-1600 . 91 (Koerner, 1990)

Table 4.3: Strength and stiffness properties of Conwed 9027 (Razaqpur, 1990) . . 96

Table 4.4: Summary of triaxial stone column tests . . . . . . . . . . . . 109

Table 4.5 : Summary of uniaxial stone column tests $\ldots \ldots \ldots \ldots \ldots \ldots$

Table 5.1: Resuits of large unreinforced triaxial stone columns $\ldots \ldots \ldots \ldots \ldots 117$ (3/8" aggregate, $\left.\varepsilon_{\mathrm{a}}=10 \%\right)$

Table 5.2: Results of large unreinforced triaxial stone columns at peak strength .117 (granular "A" aggregate, $\varepsilon_{\mathrm{a}}=10 \%$ )

Table 5.3: Results of small unreinforced triaxial specimens $\ldots \ldots \ldots \ldots \ldots \ldots \ldots \ldots$ $\left(3 / 8\right.$ " aggregate, $\left.\varepsilon_{\mathrm{a}}=8.8 \%\right)$

Table 5.4: Results of triaxial stone columns with Tensar UX-1500 sleeve, . . . . . . 121 (granular "A" aggregate, $\varepsilon_{\mathrm{a}}=10 \%$ ) 
Table 5.5: Results of triaxial stone columns with Conwed 9027 sleeve (granular "A" aggregate, $\varepsilon_{\mathrm{a}}=10 \%$ )

Table 5.6: Results of triaxial stone columns with Tensar UX-1500 sleeve, (3/8" aggregate, $\varepsilon_{\mathrm{a}}=10 \%$ )

Table 5.7: Results of triaxial stone columns with Conwed 9027 sleeve, ( $3 / 8^{\prime \prime}$ aggregate, $\varepsilon_{\mathrm{a}}=10 \%$ )

Table 5.8: Results of triaxial stone columns with fiber glass (GB \#10), . . . . . . . . 124 (3/8" aggregate, $\varepsilon_{\mathrm{a}}=10 \%$ )

Table 5.9: Results of small triaxial specimens reinforced with Tensar UX-1500, _ . . 126 (Soil sieved from $3 / 8^{\prime \prime}$ aggregate, $\varepsilon_{\mathrm{a}}=8.8 \%$ )

Table 5.10: Results of small triaxial specimens reinforced with Conwed 9027, $\ldots \ldots \ldots 126$ (Soil sieved from $3 / 8^{\prime \prime}$ aggregate, $\varepsilon_{\mathrm{a}}=8.8 \%$ )

Table 6.1: Values of axial strain $\left(\varepsilon_{\mathrm{a}}\right)$ versus $\varepsilon_{\mathrm{a}} /\left(\sigma_{1}-\sigma_{3}\right)$ for $\sigma_{3}=103 \mathrm{kPa}$,

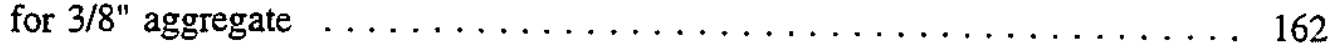

Table 6.2: Values of axial strain $\left(\varepsilon_{\mathrm{a}}\right)$ versus $\varepsilon_{\mathrm{a}} /\left(\sigma_{1}-\sigma_{3}\right)$ for $\sigma_{3}=207 \mathrm{kPa}$,

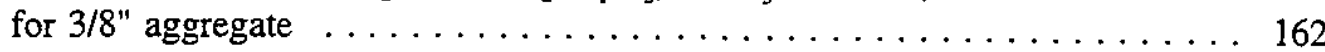

Table 6.3: Values of axial strain $\left(\varepsilon_{\mathrm{a}}\right)$ versus $\varepsilon_{\mathrm{a}} /\left(\sigma_{1}-\sigma_{3}\right)$ for $\sigma_{3}=345 \mathrm{kPa}$,

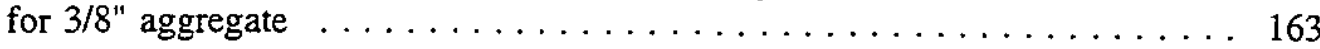

Table 6.4: Values of axial strain $\left(\varepsilon_{3}\right)$ versus $\varepsilon_{\mathrm{a}} /\left(\sigma_{1}-\sigma_{3}\right)$ for $\sigma_{3}=103 \mathrm{kPa}$,

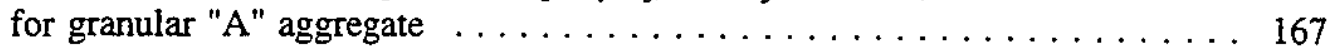

Table 6.5: Values of axial strain $\left(\varepsilon_{\mathrm{a}}\right)$ versus $\varepsilon_{\mathrm{s}} /\left(\sigma_{1}-\sigma_{3}\right)$ for $\sigma_{3}=207 \mathrm{kPa}$,

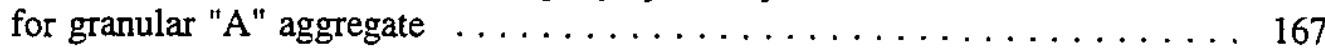

Table 6.6: Values of axial strain $\left(\varepsilon_{\mathrm{a}}\right)$ versus $\varepsilon_{\mathrm{a}} /\left(\sigma_{1}-\sigma_{3}\right)$ for $\sigma_{3}=345 \mathrm{kPa}$,

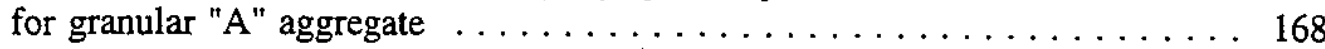

Table 6.7: Values of axial strain $\left(\varepsilon_{\mathrm{a}}\right)$ versus $\varepsilon_{\mathrm{a}} /\left(\sigma_{1}-\sigma_{3}\right)$ for $\sigma_{3}=103 \mathrm{kPa}$, for $3 / 8^{\prime \prime} \ldots 173$ aggregate+Tensar UX-1500

Table 6.8: Values of axial strain $\left(\varepsilon_{3}\right)$ versus $\varepsilon_{3} /\left(\sigma_{1}-\sigma_{3}\right)$ for $\sigma_{3}=207 \mathrm{kPa}$, for $3 / 8 " \ldots 173$ aggregate+Tensar UX-1500

Table 6.9: Values of axial strain $\left(\varepsilon_{2}\right)$ versus $\varepsilon_{a} /\left(\sigma_{1}-\sigma_{3}\right)$ for $\sigma_{3}=345 \mathrm{kPa}$, for $3 / 8^{\prime \prime} \ldots \ldots$ aggregate+Tensar UX-1500

Table 6.10: Values of axial strain $\left(\varepsilon_{\mathrm{a}}\right)$ versus $\varepsilon_{\mathrm{a}} /\left(\sigma_{1}-\sigma_{3}\right)$ for $\sigma_{3}=103 \mathrm{kPa}$, for $3 / 8 " \ldots 178$ aggregate+Conwed 9027 
Table 6.11: Values of axial strain $\left(\varepsilon_{\mathrm{a}}\right)$ versus $\varepsilon_{2} /\left(\sigma_{1}-\sigma_{3}\right)$ for $\sigma_{3}=207 \mathrm{kPa}$, for $3 / 8 " \ldots \ldots 179$ aggregate+Conwed 9027

Table 6.12: Values of axial strain $\left(\varepsilon_{2}\right)$ versus $\varepsilon_{\mathrm{x}} /\left(\sigma_{\mathrm{I}}-\sigma_{3}\right)$ for $\sigma_{3}=345 \mathrm{kPa}$, for $3 / 8^{\prime \prime} \ldots 179$ aggregate+Conwed 9027

Table 6.13: Summary of hyperbolic stress-strain parameters for granular "A" $\ldots \ldots \ldots 183$ aggregates with polymer grid sleeves

Table 7.1: Comparison of lateral strains $(\%)$ of stone columns at $\ldots \ldots \ldots \ldots 220$ different confining pressure and axial strains for uniform $3 / 8$ " aggregate.

Table 7.2: Comparison of lateral strains $(\%)$ of stone columns at $\ldots \ldots \ldots \ldots 220$ different confining pressure and axial strains for granular "A"

Table 7.3: Summary of results for short and long uniaxial columns $\ldots \ldots \ldots 234$ 


\section{LIST OF FIGURES}

Figure 1.1 : Stresses on a friction pile under load $\ldots \ldots \ldots \ldots \ldots \ldots$

Figure 1.2 : Stresses on a stone column under load $\ldots \ldots \ldots \ldots \ldots$

Figure 1.3 : Failure mechanism of a single stone column in a homogeneous . . . . 5 soft layer (After Barksdale and Bachus, 1983)

Figure 1.4 : Bulging failure of long stone column groups $\ldots \ldots \ldots \ldots \ldots$ (After Barksdale and Bachus, 1983)

Figure 1.5 : Failure modes of short stone column groups $\ldots \ldots \ldots \ldots \ldots \ldots$ (After Barksdale and Bachus, 1983)

Figure 1.6 : Selected applications of stone columns in geotechnical engineering . . 8

Figure 1.7 : Illustration of the proposed use of polymer grid with stone columns . 11

Figure 1.8 : Stresses and strength of naturaal and reinforced stone columns $\ldots \ldots 12$

Figure 2.1 : Stone column field test at Santa Barbara, USA $\ldots \ldots \ldots \ldots \ldots$ (After Barksdale and Bachus, 1983)

Figure 2.2 : Summary of Analytical Approaches used to determine $\ldots \ldots \ldots 23$ the load carrying capacity of stone columns.

(After Greenwood and Kirsh, 1984)

Figure 2.3 : Summary of elastic theories used to calculate settlement $\ldots \ldots 26$ of stone columns (After Greenwood and Kirsh, 1984)

Figure 2.4 : Stone columns used to improve slope stability $\ldots \ldots \ldots \ldots \ldots 2$ (After Aboshi et al, 1979)

Figure 2.5 : Area of mesh opening versus total maximum pull-out strength at . . 36 $20.7 \mathrm{kN} / \mathrm{m}^{2}$ surcharge load (After Mowafy, 1986)

Figure 2.6 : Area of mesh opening versus pull-out strength components at $\ldots .37$ $20.7 \mathrm{kN} / \mathrm{m}^{2}$ surcharge load (After Mowafy, 1986)

Figure 2.7 : Mechanisms of resisting direct sliding of polymer grid $\ldots \ldots \ldots 38$ (After Jewell et al, 1984) 
Figure 2.8 : Results of triaxial tests on Muskegan dune sand reinforced with . . . 42 different layers of fabric reinforcement (After Gray and Ohashi, 1983)

Figure 2.9 : Typical creep curve for a geogrid tested "in-air" $\ldots \ldots \ldots \ldots \ldots 47$ (After Razaqpur et al, 1992)

Figure 2.10 : Displacement-time relationship for load controlled pull-out $\ldots \ldots 48$ test of confined Conwed (After Juran et al, 1991)

Figure 3.1: Predicted load-settlement curve for $730 \mathrm{~mm}$ diameter column . . . . . 60 compared with observed results (Hughes et al, 1975)

Figure 3.2: Schematic diagram of reinforcement and column $\ldots \ldots \ldots \ldots 63$ deformation before and after loading

Figure 3.3: Hyperbolic stress-strain curve $\ldots \ldots \ldots \ldots \ldots \ldots \ldots \ldots \ldots 66$

Figure 3.4: Transformed hyperbolic stress-strain curve $\ldots \ldots \ldots \ldots \ldots \ldots 66$

Figure 3.5: Variation of initial tangent modulus with confining pressure . . . . . . 67 for granular " $\mathrm{A}$ " aggregate

Figure 3.6: Experimental and predicted behaviour of dense sand (Experimental . . 71 data and parameters adopted from Duncan and chang, 1970)

Figure 3.7: Experimental and calculated stress-strain behaviour of $\ldots \ldots \ldots \ldots 72$ an unreinforced column using the hyperbolic model

Figure 4.1: Strength envelope of aggregates tested in a large triaxial $\ldots \ldots \ldots 78$ cell form other research (After Huber, 1978)

Figure $4.2:$ Triaxial cell $\ldots \ldots \ldots \ldots \ldots \ldots \ldots \ldots \ldots \ldots \ldots \ldots \ldots$

Figure 4.3: Components of compaction mould and vibrating table $\ldots \ldots \ldots 83$

Figure 4.4: Grain size distribution of the two aggregates. $\ldots \ldots \ldots \ldots \ldots$

Figure 4.5: Mohr-Coulomb strength envelope for granular materials. . . . . . . 87

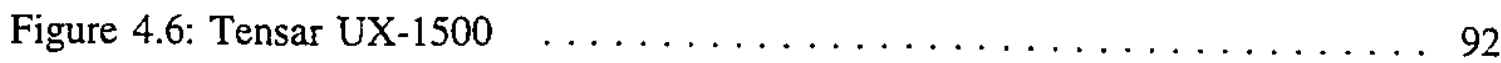

Figure 4.7: Force-deformation characteristic for Tensar UX-1500 $\ldots \ldots \ldots 92$

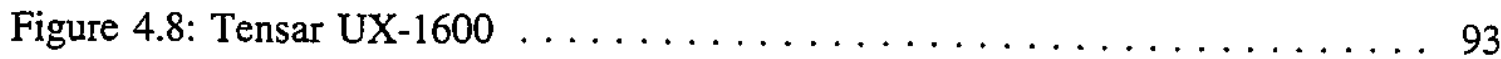




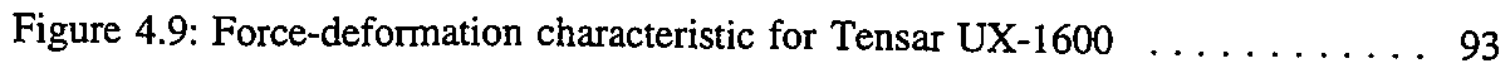

Figure 4.10: Conwed $9027 \ldots \ldots \ldots \ldots \ldots$. . . . . . . . . . 94

Figure 4.11: Force-deformation characteristic for Conwed $9027 \ldots \ldots \ldots$. . . . 94

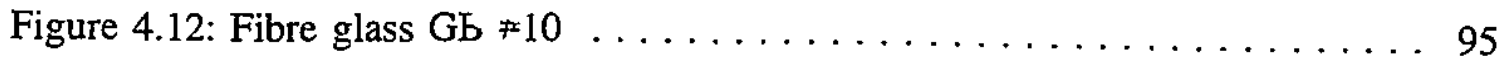

Figure 4.13: Force-deformation characteristic for fibre Glass GB \#10 . . . . . . 95

Figure 4.14: Polymer grid sleeves with different connections . . . . . . . . . 98 (A) Conwed 9027 (B) Tensar UX-1500 (C) GB \#10

Figure 4.15: Triaxial specimen after compaction and removal of mould . . . . . 99

Figure $4.16:$ Setup of laboratory triaxial test $\ldots \ldots \ldots \ldots \ldots 1$

Figure 4.17 : Electric compaction hammer $\ldots \ldots \ldots \ldots 103$

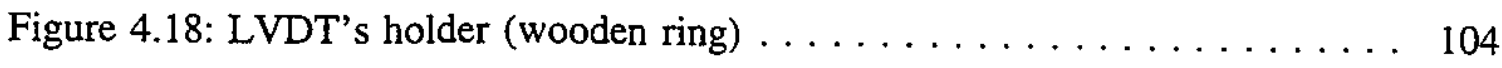

Figure 4.19: Setup of uniaxial stone column test $\ldots \ldots \ldots \ldots$

Figure 5.1 : Stress-strain-volume change behaviour of granular "A" . . . . . . . 114 aggregate at different confining pressures

Figure 5.2 : Stress-strain-volume change behaviour of $3 / 8^{\prime \prime}$ aggregate $\ldots \ldots \ldots 115$ at different confining pressures

Figure 5.3 : Stress-strain-volume change behaviour of small size $\ldots \ldots \ldots \ldots$ specimens at different confining pressures

Figure 5.4 : Stress-strain-volume change behaviour of granular " $\mathrm{A}$ " . . . . . . 120 reinforced stone columns at $\sigma_{3}=103 \mathrm{kPa}$.

Figure 5.5 : Stress-strain-volume change behaviour of uniform aggregate $\ldots \ldots 123$ $\left(3 / 8^{\prime \prime}\right)$ with fiber glass (GB \#10) sleeves

Figure 5.6 : Effect of Tensar UX-1500 and Conwed 9027 sleeves on the $\ldots \ldots 125$ behaviour of small sand specimens $\left(\sigma_{3}=100 \mathrm{kPa}\right)$

Figure 5.7 : Effect of aggregate type on the behaviour of unreinforced . . . . 128 stone columns $\left(\sigma_{3}=103 \mathrm{kPa}\right)$ 
Figure 5.8 : Effect of aggregate type on the behaviour of reinforced . . . . . 129 stone columns with Tensar UX-1500 sleeves $\left(\sigma_{3}=103 \mathrm{kPa}\right)$

Figure 5.9 : Effect of stone column size on the stress-strain-volume $\ldots \ldots \ldots 130$ change behaviour at $\sigma_{3}=103 \mathrm{kPa}$ (Tensar sleeves)

Figure $5.10: \mathrm{K}_{\mathrm{o}}$ tests for reinforced and unreinforced columns $\ldots \ldots \ldots \ldots 131$ (Granular "A" aggregate)

Figure 5.11 : Cyclic loading stress-strain-volume change behaviour of sleeve reinforced stone column (Conwed 9027 grid) . . . . . . . . . 133

Figure 5.12 : Cyclic loading stress-strain-volume change behaviour of stone column reinforced with Tensar UX-1500 sleeve . . . . . . . . 134

Figure 5.13 : Load-deformation behaviour of uniaxial stone column $\ldots \ldots \ldots 136$ confined with Tensar UX-1600 sleeve (Diameter $=0.33 \mathrm{~m}$, Height $=0.68 \mathrm{~m}$ )

Figure 5.14 : Load-deformation behaviour of uniaxial stone column $\ldots \ldots \ldots 137$ confined with Tensar UX-1600 sleeve (Diameter $=0.38 \mathrm{~m}$, Height $=1.32 \mathrm{~m}$ )

Figure 5.15 : Load-deformation behaviour of stone column confined with $\ldots .139$ Tensar UX-1600 sleeve (Diameter $=0.33 \mathrm{~m}$, Height $=0.68 \mathrm{~m}$ )

Figure 5.16 : Load-deformation behaviour of stone column confined with $\ldots . .140$ Tensar UX-1600 sleeve (Diameter $=0.38 \mathrm{~m}$, Height $=1.32 \mathrm{~m}$ )

Figure 5.17 : Bulged long sleeve reinforced stone column $\ldots \ldots \ldots \ldots \ldots 14$ (Diameter $=0.38 \mathrm{~m}$, Height $=1.32 \mathrm{~m}$ )

Figure 5.18 : Bulged short sleeve reinforced stone column $\ldots \ldots \ldots \ldots 142$ (Diameter $=0.33 \mathrm{~m}$, Height $=0.68 \mathrm{~m}$ )

Figure 5.19 : Cyclic loading behaviour of stone column confined with $\ldots \ldots \ldots 143$ Tensar UX-1600 sleeve (Diameter $=0.33 \mathrm{~m}$, height $=0.68 \mathrm{~m}$ )

Figure 5.20 : Cyclic loading behaviour of stone column confined with . . . . . 144 Tensar UX-1600 sleeve (Diameter $=0.33 \mathrm{~m}$, height $=0.68 \mathrm{~m}$ )

Figure 5.21 : Load-deformation behaviour of rapidly strained stone column $\ldots .146$ with granular "A" aggregate and Tensar UX-1600 sleeve 
Figure 5.22 : Load deformation behaviour of rapidly strained stone column . . . 147 with $3 / 8$ " aggregate and Tensar UX-1600 sleeve

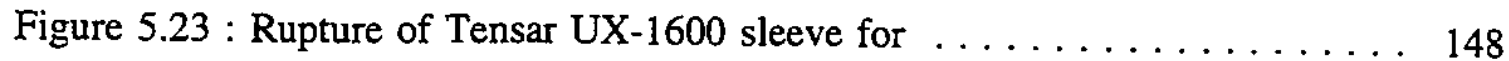
the stone column in figure $\mathbf{5 . 2 2}$

Figure 5.24 : Stress-strain behaviour of short uniaxial stone column $\ldots \ldots \ldots 149$ with Tensar UX-1500 sleeve (Diameter $=0.28 \mathrm{~m}$, Height $=0.62 \mathrm{~m}$ )

Figure 5.25 : Volume change behaviour of stone column in figure $5.24 \ldots \ldots 150$

Figure 5.26 : Cyclic s .s-strain behaviour of stone column confined with . . . 152 Tensar UX-1600 sleeve (Diameter $=0.33 \mathrm{~m}$, height $=0.68 \mathrm{~m}$ )

Figure 5.27 : Volume change behaviour of stone column in figure $5.26 \ldots 153$

Figure 5.28 : Cyclic stress-strain behaviour of rapidly strained stone column $\ldots 154$ with Tensar UX-1600 sleeve (Diameter $=0.33 \mathrm{~m}$, height $=0.68 \mathrm{~m}$ )

Figure 5.29 : Volume change behaviour of stone column in figure $5.28 \ldots \ldots$

Figure 5.30 : Variation of local tensile strain in polymer grid strands, . . . . . 156 with axial deformation at midheight

Figure 5.31 : Variation of local tensile strain in polymer grid strands, . . . . . 157 with axial deformation at different height levels

Figure 5.32 : Variation of local tensile strain in polymer grid strands, . . . . . 158 with axial deformation at different height levels

Figure 6.1 : Schematic diagrams of stone column confinement $\ldots \ldots \ldots 160$ for theoretical analysis

Figure 6.2: Transformed stress-strain curves for uniform aggregate $\ldots \ldots \ldots \ldots 4$ at different confining pressures

Figure 6.3 : Variation of initial tangent modulus with confining $\ldots \ldots \ldots \ldots$ pressure for uniform aggregate

Figure 6.4: Experimental and calculated stress-strain behaviour of unreinforced . 166 stone column using the hyperbolic model

Figure 6.5: Transformed stress-strain curves for granular "A" . . . . . . . . . 169 aggregate at different confining pressures 
Figure 6.6: Variation of initial tangent modulus with confining $\ldots \ldots \ldots \ldots$ pressure for granular "A" aggregate

Figure 6.7: Experimental and calculated stress-strain behaviour of natural $\ldots \ldots 171$ stone column using the hyperbolic model

Figure 6.8: Transformed stress-strain curves of stone columns with $\ldots \ldots \ldots \ldots 175$ 3/8" aggregate and Tensar UX-1500 sleeves at different confining pressures

Figure 6.9: Variation of initial tangent modulus with confining $\ldots \ldots \ldots 176$ pressure for a stone columns with $3 / 8$ " aggregate and Tensar UX-1500 sleeves

Figure 6.10: Experimental and calculated stress-strain behaviour of sleeve $\ldots \ldots 177$ reinforced stone column using the hyperbolic model

Figure 6.11: Transformed stress-strain curves of stone columns with $\ldots \ldots \ldots 180$ 3/8" aggregate and Conwed 9027 sleeves at different confining pressures

Figure 6.12: Variation of initial tangent modulus with confining $\ldots \ldots \ldots \ldots 1$ pressure for stone column with 3/8" aggregate and Conwed 9027 sleeves

Figure 6.13: Experimental and calculated stress-strain behaviour of sleeve $\ldots \ldots 182$. reinforced stone column using the hyperbolic model

Figure 6.14: Experimental and calculated stress-strain behaviour of sleeve . . . 184 reinforced stone column using the hyperbolic model

Figure 6.15: Experimental and calculated stress-strain behaviour of sleeve . . . . 185 reinforced stone column using the hyperbolic model

Figure 6.16: Experimental and calculated stress-strain behaviour of sleeve $\ldots \ldots 186$ reinforced stone column using the hyperbolic model

Figure 6.17: Experimental and calculated stress-strain behaviour of $\ldots \ldots \ldots 188$ uniaxial column using the hyperbolic model

Figure 6.18: Experimental and calculated stress-strain behaviour of long $\ldots \ldots 189$ uniaxial column using the hyperbolic model 
Figure 6.19: Observed and calculated load-strain behaviour of $\ldots \ldots \ldots \ldots 190$ Tensar UX-1500 grid

Figure 6.20: Observed and calculated load-strain behaviour of $\ldots \ldots \ldots \ldots 191$ Tensar UX-1600 grid

Figure 7.1 : Normalized stress-strain relationships of unreinforced and Tensar sleeve reinforced columns at different confining pressures (3/8" aggregate) $\ldots \ldots \ldots \ldots \ldots \ldots \ldots \ldots \ldots \ldots \ldots \ldots$

Figure 7.2 : Normalized stress-strain relationships of unreinforced and Conwed sleeve reinforced columns at different confining pressures (3/8" aggregate) $\ldots \ldots \ldots \ldots \ldots \ldots \ldots \ldots \ldots \ldots \ldots$

Figure 7.3 : Normalized stress-strain relationships of unreinforced and Conwed sleeve reinforced columns at different confining pressures (granular "A" aggregate) .

Figure 7.4 : Normalized stress-strain relationships of unreinforced and Tensar sleeve reinforced columns at different confining pressures (granular "A" aggregate) $\ldots \ldots \ldots \ldots \ldots \ldots \ldots \ldots \ldots \ldots$

Figure 7.5 : Variation of strength increase ratio with axial strain for different confining pressures (granular "A" + Tensar sleeves)

Figure 7.6 : Variation of strength increase ratio with axial strain for different confining pressures (granular "A" + Conwed sleeves) . . . . . . . . . . . . . . . . 202

Figure 7.7 : Variation of strength increase ratio with axial strain for different confining pressures (3/8" aggregate + Tensar sleeves) . . . . . . . . . . . . . . 203

Figure 7.8 : Variation of strength increase ratio with axial strain for different confining pressures (3/8" aggregate + Conwed sleeves)

Figure 7.9 : Mohr-Coulomb strength envelope for unreinforced and sleeve reinforced stone columns (granular "A") . . 
Figure $7.10:$ Mohr-Coulomb strength envelope for unreinforced and sleeve reinforced stone columns (3/8" aggregate) . . . . 208

Figure 7.11 : Mohr-Coulomb strength envelope for sleeve reinforced columns at $15 \%$ axial strain . . . . . . . . . 209

Figure 7.12 : Mohr-Coulomb strength envelope for sleeve reinforced columns at $15 \%$ axial strain $\ldots \ldots \ldots \ldots \ldots \ldots 210$

Figure 7.13 : Variation of secant modulus with confining pressure at $5 \%$ axial strain (granular "A")

Figure 7.14 : Variation of secant modulus with confining pressure at $5 \%$ axial strain ( $3 / 8 "$ aggregate)

Figure 7.15 : Variation of secant modulus with axial strain at different confining pressures (3/8" aggregate) $\ldots \ldots \ldots \ldots \ldots 213$

Figure 7.16 : Variation of secant modulus with axial strain at different confining pressures (granular "A") . . . . . . . . 214

Figure 7.17 : Comparison of secant modulus for stone columns with $3 / 8$ " aggregate and reinforcing sleeves $\left(\sigma_{3}=103 \mathrm{kPa}\right) \ldots \ldots \ldots 215$

Figure 7.18 : Comparison of secant modulus for stone columns with granular "A" aggregate and reinforcing

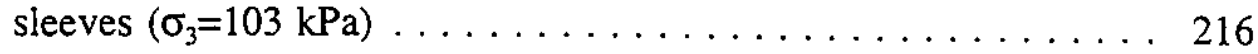

Figure 7.19 : Comparison of $\mathrm{K}_{0}$ test results for unreinforced and reinforced stone columns $\ldots \ldots \ldots \ldots \ldots \ldots \ldots 218$

Figure 7.20: Variation of Poisson's ratio for granular "A" and reinforced . . . 222 specimens (lateral strain measured at mid-height)

Figure 7.21: Variation of Poisson's ratio for uniform aggregate and reinforced . . 223 specimens (lateral strain measured at mid-height)

Figure 7.22: Average lateral strain behaviour of natural and sleeve reinforced columns $\left(\sigma_{3}=207 \mathrm{kPa}\right)$

Figure 7.23 : Average lateral strain behaviour of natural and sleeve reinforced columns $\left(\sigma_{3}=207 \mathrm{kPa}\right) \ldots \ldots \ldots \ldots .225$ 
Figure 7.24 : Tensile forces in grid ribs of a reinforced stone column compared to in-air tension tests . . . . . . . . . . . 227

Figure 7.25 : Tensile forces in grid ribs of a reinforced stone

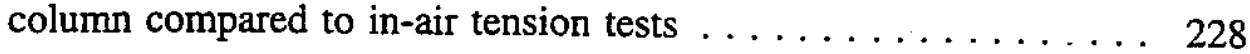

Figure 7.26 : Variation of maximum tensile forces with confining pressure for different sleeves . . . . . . . . . . 229

Figure 7.27 : Tensile strength vs. confining pressure (Data from Leshchinsky and Feild, 1987) . . . . . . . . . . 230

Figure 7.28 : Comparison of the stress-strain behaviour of short uniaxial columns with different types of aggregate $\ldots \ldots \ldots 232$

Figure 7.29 : Comparison of the stress-strain behaviour of long uniaxial columns with different types of aggregate $\ldots \ldots \ldots 233$

Figure 7.30 : Comparison of strain behaviour of short uniaxial columns with different types of aggregate (data points and linear approximation) $\ldots \ldots \ldots \ldots \ldots \ldots 235$

Figure 7.31 : Comparison of strain behaviour of long uniaxial columns with different types of aggregate (data points and linear approximation) $\ldots \ldots \ldots \ldots \ldots \ldots 236$

Figure 7.32 : Comparison of cyclic stress-strain behaviour of uniaxial columns $($ Diameter $=0.33 \mathrm{~m}$, Height $=0.68 \mathrm{~m}) \ldots \ldots \ldots \ldots . . . .239$

Figure 7.33 : Comparison of vertical displacement for a uniaxial column at different heights (granular "A" + Tensar sleeve) . . . . . . 240

Figure 7.34 : Comparison of vertical displacement for a uniaxial column at different heights $\left(3 / 8^{\prime \prime}\right.$ aggregate + Tensar sleeve) $\ldots \ldots \ldots 241$

Figure 7.35 : Comparison of vertical strain distribution at the middle of each layer of the column (granular "A" + Tensar sleeve) . . . . 242

Figure 7.36 : Comparison of vertical strain distribution at the middle of each layer of the column (3/8" aggregate + Tensar sleeve) $\ldots \ldots 243$

Figure 7.37 : Comparison of lateral strain behaviour of uniaxial and triaxial sleeve reinforced columns (3/8" aggregate) $\ldots \ldots \ldots 245$ 
Figure 7.38 : Comparison of tension forces mobilized in the grid sleeves of uniaxial and triaxial columns (3/8" aggregate) $\ldots \ldots \ldots \ldots 246$

Figure 7.39 : Tensile stress calculated from strain gauges attached at locations 1 and 2 on sleeve of uniaxial column . . . . . . 247

Figure 7.40 : Tensile stress calculated from strain gauges attached at locations 1 and 2 on sleeve of uniaxial column . . . . . . 248

Figure 7.41 : Comparison of tensile stress from strain gauges and calculated from the lateral strain of the stone column $\ldots \ldots \ldots 250$

Figure 7.42 : Comparison of tensile stress from strain gauges and calculated from the lateral strain of the stone column $\ldots \ldots \ldots 251$

Figure 7.43 : Failure mode observed in a triaxial specimen of granular "A" aggregate without grid. . . . . . . . . . . 252

Figure 7.44 : Bulging observed in a triaxial specimen reinforced with Conwed 9027 sleeve . . . . . . . . . . . . . . 254

Figure 7.45 : Uniform bulging observed in a triaxial specimen reinforced with Tensar UX-1500 sleeve . . . . . . . . . 255 


\section{CHAPTER 1}

\section{INTRODUCTION}

\subsection{GENERAL}

Stone columns are defined as the structural compression members which consist of granular material compacted in long cylindrical holes to improve the strength and consolidation characteristics of soft soils. The stone columns technique was developed in Germany about 50 years ago. In 1939, Steuermann has claimed that using stone columns could double the bearing capacity of a site. Hughes and Withers (1974) have reported that stone columns were well known in France in the 1830's and were used to support heavy foundations of ironworks at the artillery arsenal in Bayonne. Stone columns have been regularly used in Europe since 1950's and in North America since 1972.

Stone columns are usually used where moderate increase in bearing capacity or reduction in settlement is required. The stone column technique is applicable to foundations of lightly-loaded structures such as storage tanks, one or two story buildings and low embankments. The application of stone columns to improve marginal soils has the following advantages:

- to increase the bearing capacity of the foundation soil

- to reduce settlement and accelerate consolidation

- to increase the slope stability of a supported embankment

- to dissipate pore pressures and to prevent liquefaction of subsurface soils

The most common use of stone columns is to increase the bearing capacity of foundation loads supported on weak or compressible soil. Generally, the density of the granular column material is relatively high and acts as a compression pile to transfer the load to a firmer bearing layer. However, the behaviour of a column is different from that of a pile since the mechanism of interaction is that of a restrained expansion to the surrounding soil. Figures 1.1 and 1.2 show the applied load and stresses acting on a "friction bearing" pile and on a stone column respectively. 


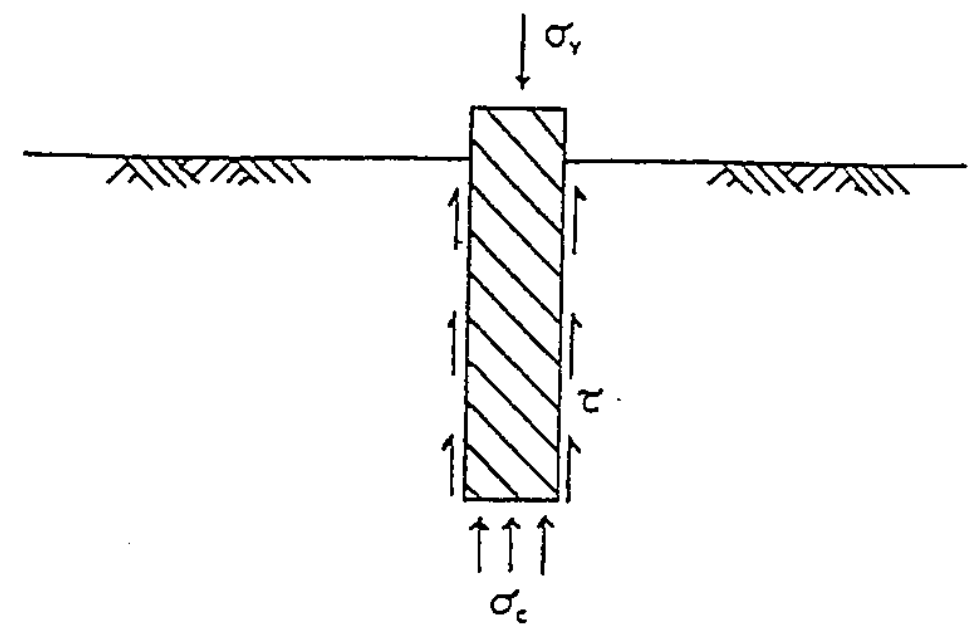

Figure 1.1 : Stresses on a friction pile under load.

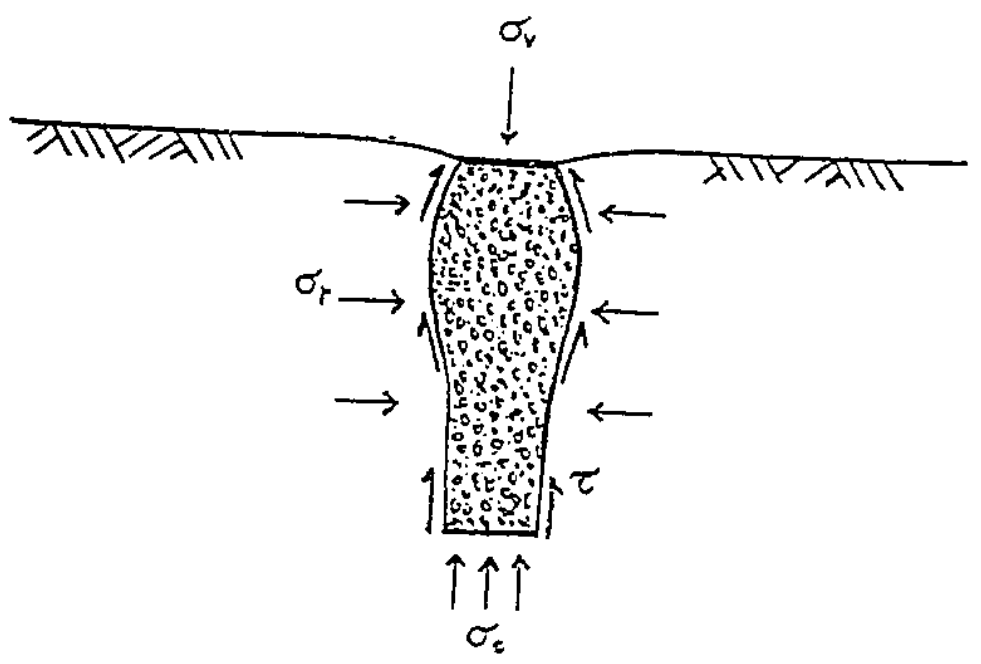

Figure 1.2 : Stresses on a stone column under load. 


\subsubsection{Single stone columns}

Stone columns may be constructed as either end bearing on a firm stratum underlying soft soil, or as floating columns with the foot of the column embedded within a soft layer. In practice, however, end bearing stone columns have predominantly been used in the past.

A long end bearing stone column loaded over just the area of the column (Figure 1.3a) will fail in bulging. This is a common failure mechanism for long stone columns whether they have end bearing or a free floating foot (Hughes and Withers, 1974). A very short column bearing on a firm support will undergo either a general or local bearing capacity failure at the surface (Figure 1.3b). A floating stone column less than about 2 to 3 diameters in length may fail in end bearing in weak underlying soil before a bulging failure can develop (Figure 1.3c). For the subsurface conditions generally encountered in practice, however, bulging is usually the controlling failure mechanism 3arksdale and Bachus, 1983).

Small scale model studies have shown that the bearing capacity and settlement behaviour of a single stone column is affected by the method of applying the load. When the stone column is loaded vertically, the load distribution between the column and the parent soil is determined by a complex interaction relationship. If the load is small, relative to the confining pressure provided by the in situ soil, then failure or plastic flow within the column will not occur. If the load becomes very large and sufficient confining pressure is not provided, then the strength of the column material will be exceeded and failure or plastic flow will occur within the column (bulging), (Goughnour, 1983).

If the load is applied through a rigid foundation over an area greater than the stone column, the vertical and lateral stresses in the surrounding soil increase. The increase in lateral confining stress on the stone column will results in less bulging and a greater ultimate load capacity of the column.

\subsubsection{Stone column group}

The average load capacity of a column within a group might be greater than the capacity of a single isolated column. In a group, as the surrounding columns are added 
to form a group, the interior columns become confined by the surrounding columns. This results in an increase in the ultimate load capacity per column (Barksdale and Bachus, 1983). A group of end bearing stone columns in soft soil probably undergoes a combination of bulging and local bearing type failure in the upper part (Figure 1.4). A local bearing failure is the punching of a relatively rigid stone column (or group) into the surrounding soft soil. Floating stone column groups having short column length may fail in end bearing (Figure 1.5) or perhaps undergo a bearing capacity failure of individual stone columns similar to the failure mode of short, single stone columns. The previous failure mechanisms of a single stone column or groups of columns are idealized, assuming uniform soil properties.

\subsection{THE USE OF STONE CC -UMNS TO IMPROVE SOILS}

Stone columns present a useful technique for stabilizing sites for soils ranging from soft clays to loose silty sand. However, the use of stone columns in soft clays of high sensitivity is not recommended due to the remoulding effect of the installation process on the shear strength of the parent soil. Also, stone columns have both a reinforcing role offering high resistance to compression and to shearing and a drainage role when it is founded in a fine saturated soft soil.

The use of stone columns in civil engineering applications has many advantages and the economical aspect is the most important advantage. Munfakh (1984) has reported that the use of stone columns in Jourdan Road Terminal (New Orleans, USA) have realized an estimated saving of 1.25 million dollars in the construction cost of Berth 4 of the Terminal as compared to the cost of a conventional pile supported structure. Some applications of stone columns are presented in Figure 1.6 as selected from different places of the world.

The first major use of stone columns on the west coast of the USA was in 1975 and 1976. Huber (1978), Mitchell and Huber (1985) have reported an extensive use of stone columns in Santa Barbara, California to support a 11 million gallon/day waste water 

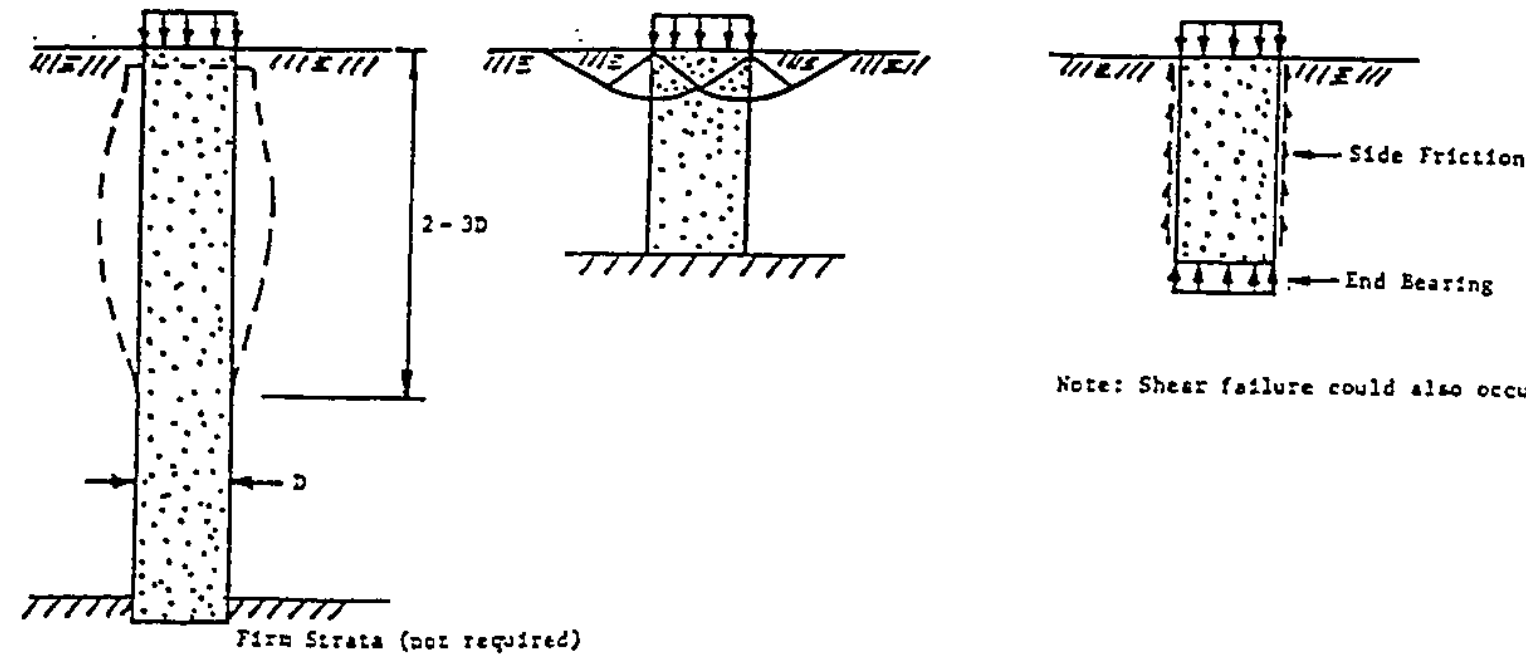

Note: Shear fallure could also occur

(a) Long Stone colue Wih fire or Flocting Suppoze - Eulzing Fa:lure

(b) Shore collan wi:h ings Eare: Shear

(c) Short Flesting Coluegi Pinchiog Fellus:

Figure 1.3 : Failure mechanism of a single stone column in a homogeneous soft layer (After Barksdale and Bachus, 1983) 


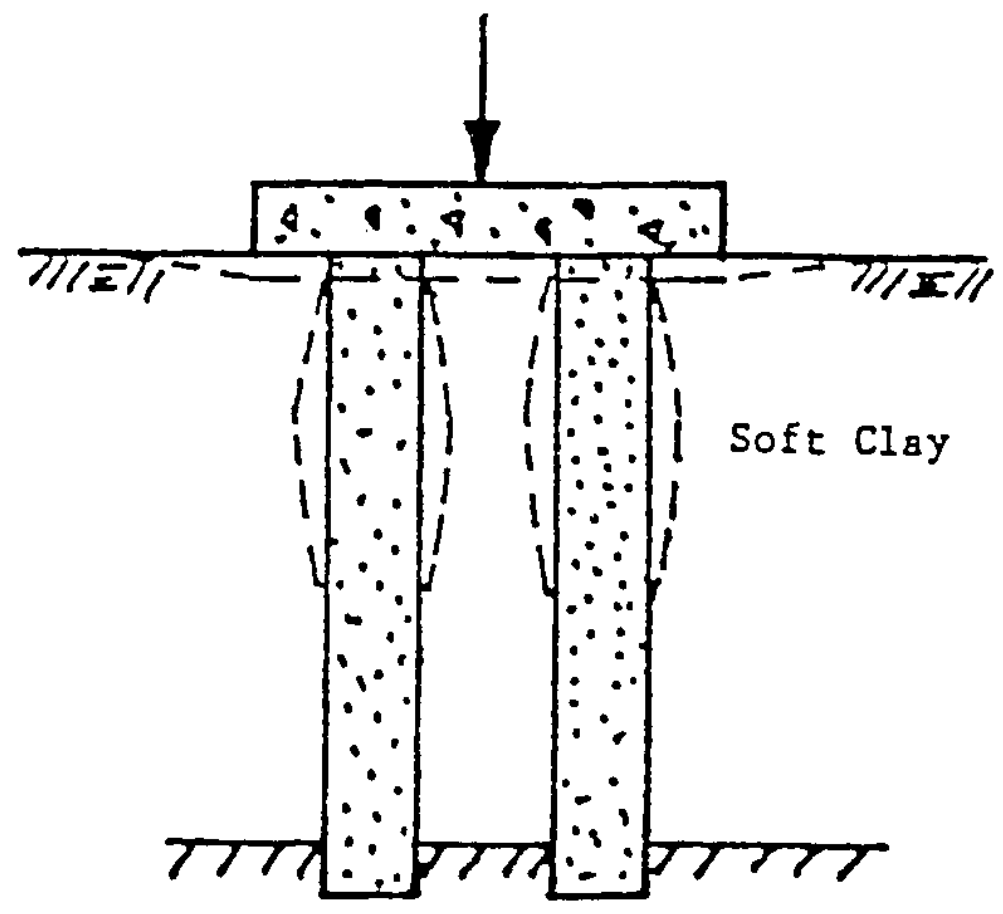

Figure 1.4 : Bulging failure of long stone column groups (After Barksdale and Bachus, 1983) 


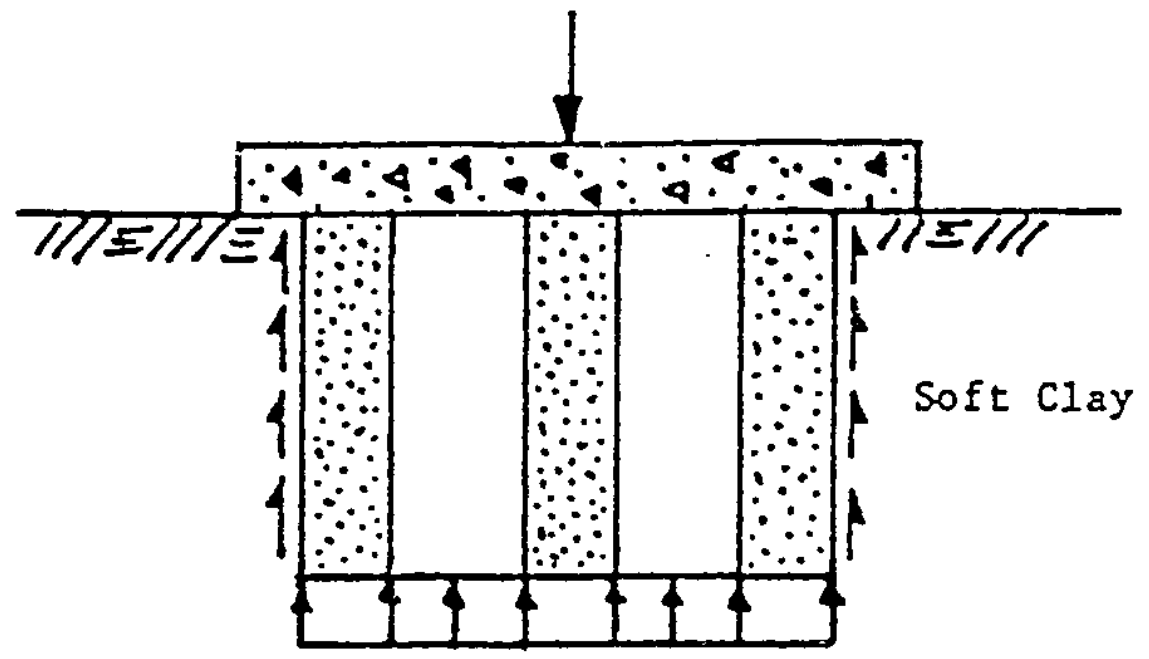

Figure 1.5 : Failure modes of short stone column groups (After Barksdale and Bachus, 1983) 


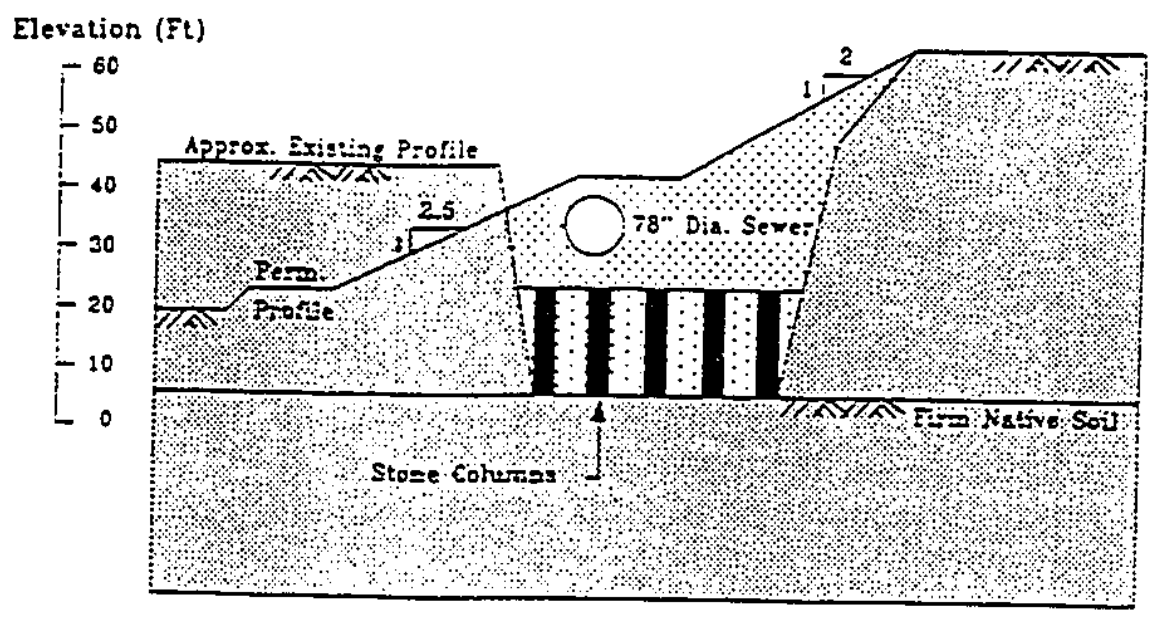

A) San Diego River, California U.S.A

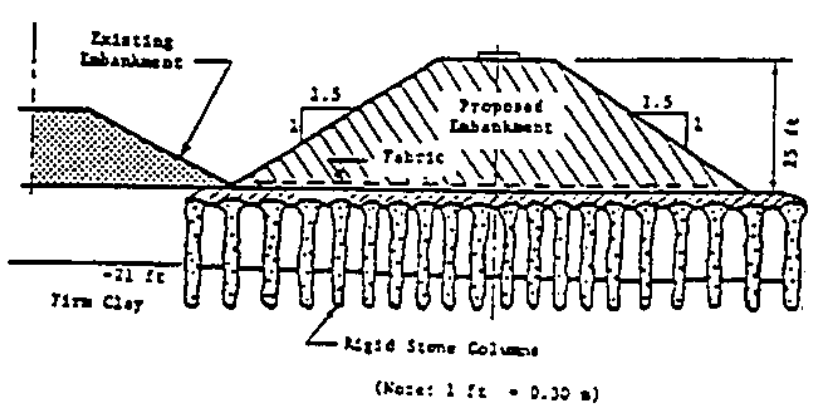

B) Embaniment Section at Murich, Germany
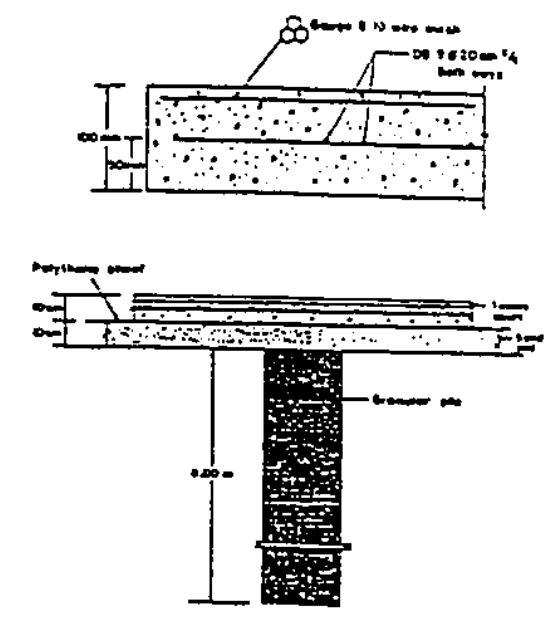

D) Tennis Court Pavement Supported by Stone Columns (Áfter Bergado et al, 1987)

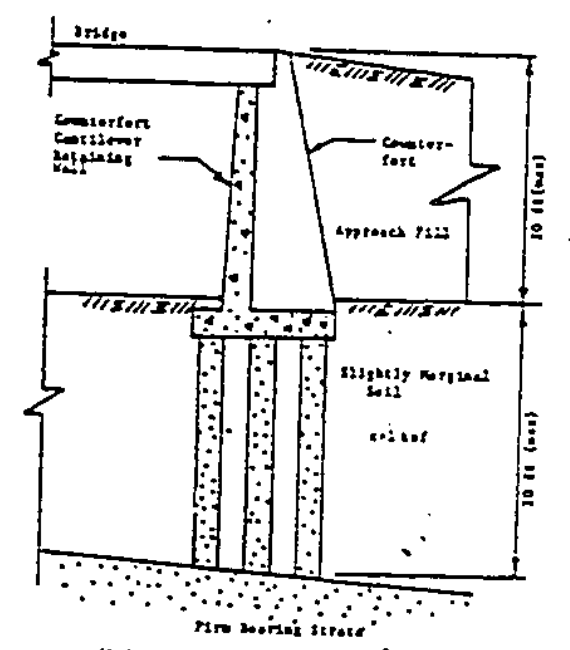

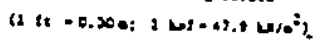

C) Support of Bridge Abument on Stone Columns, England

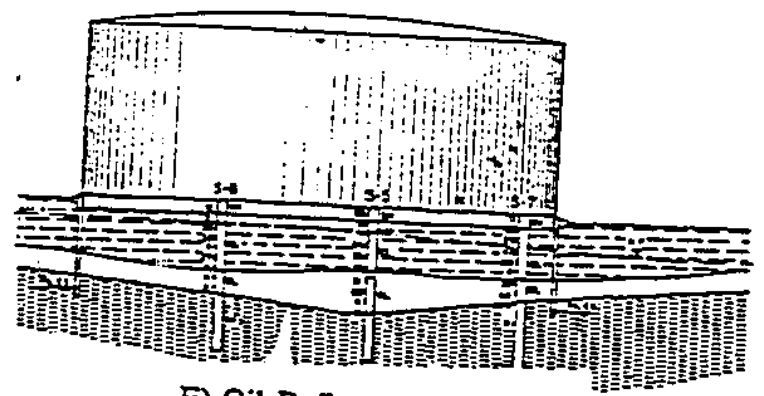

E) Oil Refinery-South Spain (Afler M. Romana,1983)

Figure 1.6 : Selected applications of stone columns in geotechnical engineering 
plant. A total of 6525 stone columns were installed in a 12-acre site to support various structures of a total size up to $76 \mathrm{~m} \times 152 \mathrm{~m}(250 \times 500 \mathrm{feet})$ with uniform foundation loads of up to $145 \mathrm{kPa}$.

In 1975 Mckenna et al have reported a case study where the stone columns have been used to support a high embankment on soft alluvium. The stone columns were supposed to reduce the settlement and accelerate the pore water pressure dissipation. According to the reported results the stone columns were not successful for that site and the authors have attributed the ineffectiveness of the stone columns in reducing the settlement of the embankment to two reasons.

a- The grading of the stone column's material (38 mm crushed limestone) which was used to form the columns was too coarse to act as a filter and as a result, the voids in the gravel backfill probably became filled with clay slurry which prevented them from acting as drains. In addition, the method of construction (vibroflotation by using a water jetting technique) did probably remould the adjacent soft clay and damaged the natural drainage paths, so nullifying any potential drainage provided by the stone columns.

b- The backfill was so coarse that when the embankment load came on to the columns the crushed stone forming each column was not restrained by the surrounding soil and so the columns expanded and the soft clay squeezed into the voids.

\subsection{THE USE OF POLYMER GRIDS IN EARTH WORK}

The use of polymer grids in earth work has become a common phenomenon in the last few years due to several factors, including economical and engineering reasons. The production cost of polymer grids is low compared to other materials used for soil reinforcement, such as steel bars, steel sheets and other man-made materials. The reasons for the increased implementation of polymer grids as soil reinforcement include the following:

- deformability and high tensile strength

- durability and high resistance to environmental conditions 
- ability to produce polymer grids in different shapes, strength and other characteristics for good interlock with granular soils

- ability to bond and interlock with soil particles or aggregates and hence ensure composite action.

Polymer grids have been successfully used in slopes or embankments, retaining walls, pavements and many other applications. As no research to date has dealt directly with the unique case of stone columns confined with polymer grids, this research study will focus on the potential use of polymer grids to enhance the performance of stone columns. Figure 1.7 illustrates the proposed use of polymer grids for confining the stone column material and Figure 1.8 presents the stresses and strength of natural and sleeve reinforced columns.

\subsection{PROBLEM DEFINITION}

When the vertical load on a stone column exceeds the elastic limit of the foundation soil, assuming an elasto-plastic behaviour, local shear failure occurs in the soil due to large deformations. These large deformations will accelerate until the plastic limit (ultimate bearing capacity) of the foundation soil is exceeded and general shear failure occurs. One problem associated with the use of stone columns is the excessive vertical settlement and lateral deformation under sustained loads. Another consideration is the spreading and loss of the stone column material to the surrounding soil.

General shear failure of the foundation soil may be prevented by confinement of the stone column material with polymer grid cylinders. Confinement refers to the ability of a geogrid to minimize the displacements caused by local shear failure, thus allowing the stone columns to carry loads close to their plastic limits. Therefore, the lateral deformation tends to be less and the stiffness of stone columns will be increased by the confinement provided by the geogrid.

It should be noted that the interaction between a stone column and the surrounding soil in the field is a complex geotechnical problem. The application of polymer sleeves 


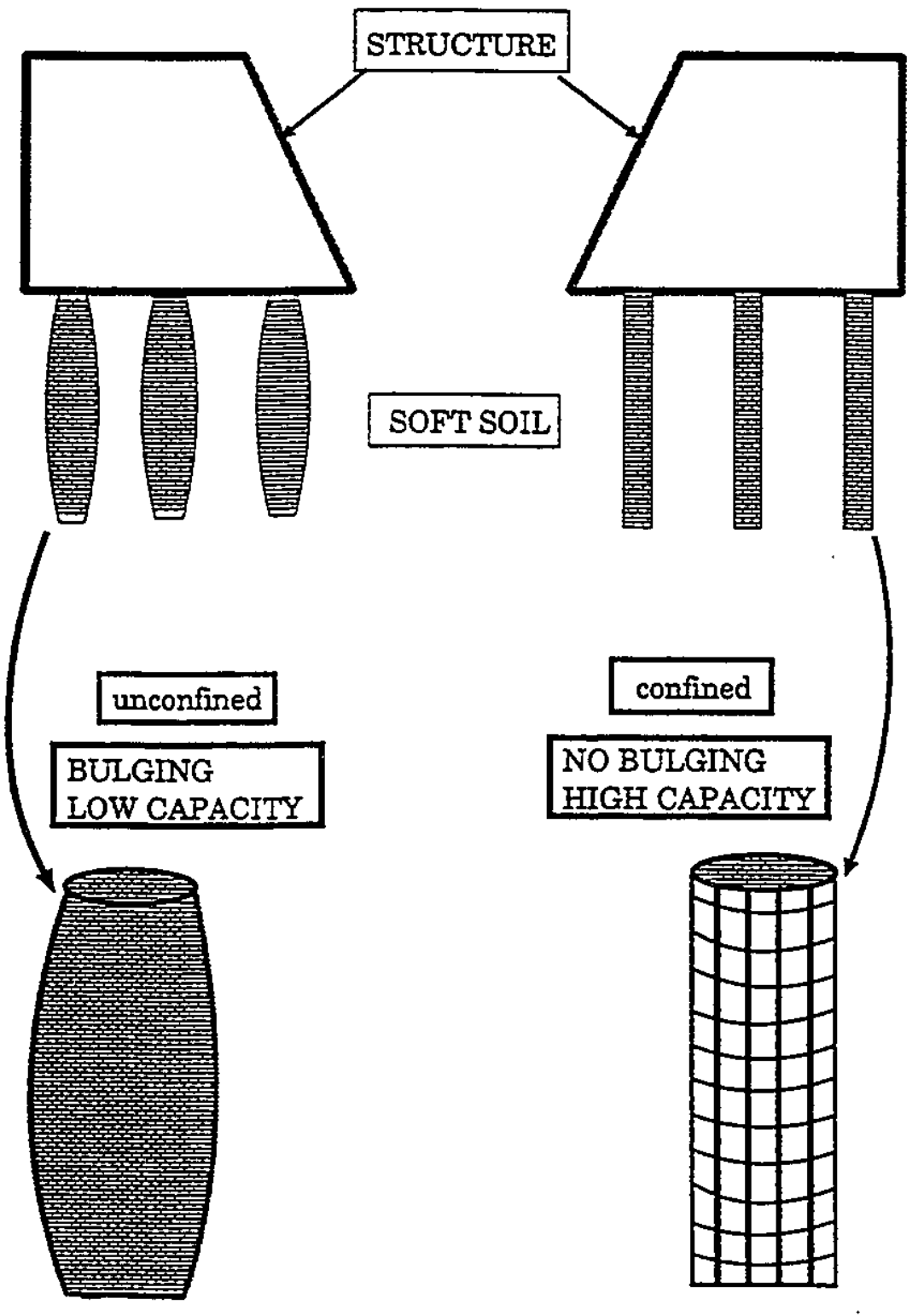

Figure 1.7 : Illustration of the proposed use of polymer grid with stone columns 

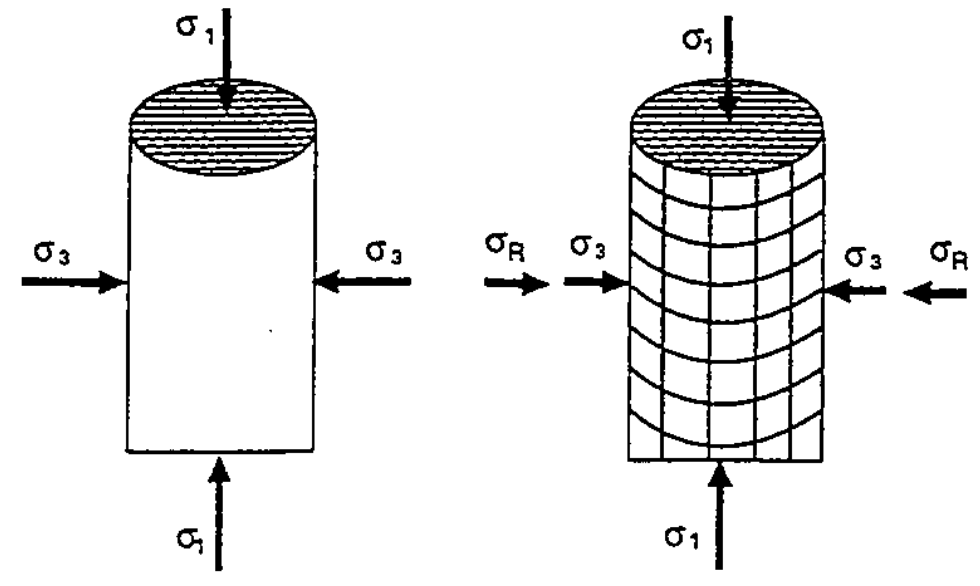

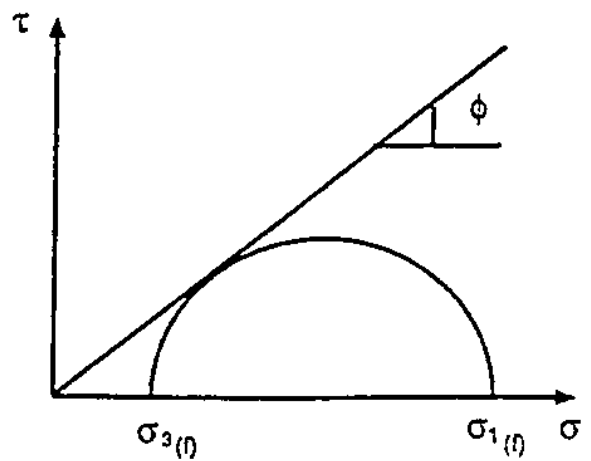

A) Natural Stone Column

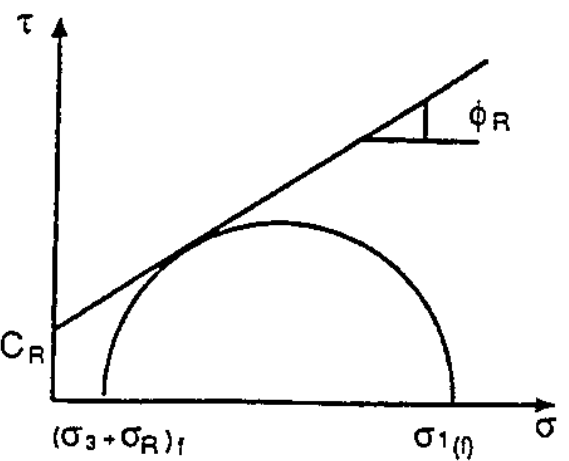

B) Reinforced Stone Column

Figure 1.8 : Stresses and strength of natural and reinforced stone columns 
to improve the confinement of stone columns in the field will further complicate this geotechnical problem which is not the subject of this study. Therefore, it is necessary to distinguish between the complex geotechnical problem in the field and this laboratory study which is aimed to investigate the structural behaviour of single stone columns confined with polymer sleeves without considering the interactive influence of the surrounding soil.

\subsection{OBJECTIVES OF RESEARCH}

The main objective of this research was to investigate the behaviour of isolated single sleeve reinforced stone columns irrespective of any surrounding soil. The stone columns were supported on a rigid base and loaded on the top surface. The columns were

confined by polymer sleeves of the same size as the column. The specific objectives of this research were as follows:

- to present laboratory data illustrating the stiffening and strength gained by the stone columns due to the confinement provided by the polymer sleeves and

- to investigate the effect of the following factors on the structural capacity and lateral deformation of a single stone column considering the following variables
a) type of polymer grid (three types)
b) type of aggregate (two types)
c) confining pressure (103 kPa, $207 \mathrm{kPa}$ and $345 \mathrm{kPa})$
d) loading condition (static and cyclic)

- to investigate the validity of the hyperbolic stress-strain model to simulate the behaviour of sleeve reinforced stone columns. 


\subsection{SCOPE AND ORGANISATION OF THESIS}

To achieve the previous objectives an extensive experimental research program has been carried out where the influence of each variable on the behaviour of stone columns has been investigated by changing one variable at a time. It was decided that both triaxial and uniaxial stone columns tests should be used in this research in order to gain a better understanding of the reinforced column behaviour. The experimental program consisted of the following stages:

a- triaxial testing of small size (55 $\mathrm{mm}$ in diameter and $110 \mathrm{~mm}$ in height) soil specimens with and without polymer grid confinement

b- triaxial testing of large size ( $230 \mathrm{~mm}$ in diameter and $460 \mathrm{~mm}$ in height) granular columns with and without polymer grid confinement and

c- uniaxial testing and performance monitoring of different sizes of stone columns confined with polymer grid only.

The hyperbolic stress-strain model was used for the theoretical analysis of sleeve reinforced stone columns and its validity was verified against experimental results.

The following is a brief outlines of the remaining chapters of the thesis.

Chapter 2 presents a historical background of stone columns and discusses different theories to analyze the load carrying capacity and settlement of stone columns. A tabulation of major projects worldwide where stone columns have been used is also given. The second part of chapter 2 discusses briefly the production technique of poiymer grids and the influence of these grids on soil behaviour. The different mechanisms of soilpolymer grid interaction are discussed and the factors which affects the mobilization of soil-polymer grid strength are presented. A review of triaxial tests of grid reinforced specimens is made with a brief discussion of the various concepts proposed to account for the effect of grid reinforcement. Finally, some important aspects related to long term use of polymer grid for earth reinforcement are discussed, such as long term creep behaviour and durability. 
Chapter 3 deals with the theoretical part of this research. The theories of analysis of unreinforced and reinforced stone columns are discussed. The hyperbolic stress-strain relationships for granular materials and for polymer grid reinforcement are presented.

Chapter 4 focuses on the experimental program of this research. It discusses the equipment and materials used in the research, such as the triaxial cell and accessories, the compaction equipment, the lateral deformation measuring clips and the vclume gauge. Also, included in this chapter is a description of material properties of the aggregates and the polymers. Details of the experimental program such as sample preparation and instrumentation, type and number of tests, test procedures and data acquisition system are described in this chapter.

Chapter 5 describes the results of the testing program and compares the performance of polymer grid reinforced stone columns to the corresponding unreinforced specimens for both small and large columns. The results of triaxial and uniaxial compression tests are presented in terms of load-deformation and stress-strain-volume change relationships.

The experimental results of chapter 5 are analyzed in chapter 6 . The analysis includes the results of triaxial and uniaxial tests. The analysis are performed by using the hyperbolic stress-strain model to simulate the behaviour of unrienforced and sleeve reinforced stone columns. Comparison of the experimental and theoretical results are presented and discussed.

Chapter 7 presents more interpretation of the experimental results and gives a discussion. A summary of the research is given in chapter 8 . General conclusions and recommendations for future work are included in two separate sections of this chapter. 


\section{CHAPTER 2 \\ LITERATURE REVIEW}

\subsection{GENERAL}

The stone column technique has shown to be successful in (1) increasing the bearing capacity, (2) improving the slope stability of embankments and natural slopes, (3) reducing the total and differential settlement, (4) increasing the time rate of settlement and (5) reducing the liquefaction potential of sands, (Barksdale and Bachus, 1983). Stone columns are used to support structures overlying both soft to firm cohesive soils in addition to loose silty sands having more than $15 \%$ fines. Most of the stone columns projects reported in the U.S. have been constructed in silty sands rather than cohesive soils. Stone columns have been used in North America in many applications such as embankment fill support for highways, interchanges and bridge approaches, box culverts, a seven-story concrete library, a two-story medical building, warehouses, shipbuilding facility, sewage treatment plants and parking garages. In Europe stone columns have been used considerably more extensively than either U.S. or Canada. Generally speaking, stone columns in Europe have been used extensively for the support of structures such as warehouses, tanks and buildings rather than embankments, (Barksdale and Bachus, 1983).

The design and analysis of stone columns was reported for different methods ranging from experience based on empirical expressions to advanced finite element analyses.

Analytical models have been proposed by some authors (Goughnour, 1983; Wallays et al, 1983; Gerrard et al, 1984) while a laboratory model test presented by other groups of researchers (Charles and Watts, 1983; Bachus and Barksdale, 1984) and a fullscale field tests were carried out by a third group of researchers (Goughnour and Bayuk, 1979; Colleselli et al, 1983; Bergado et al 1984; Munfakh, 1984).

Vautrain (1977) and Aboshi et al (1979) have conducted a full scale experiment to assess the effect of surface loading on embankments and rigid footings on soil 
settlement. It was shown in the two studies that the vertical displacement of the ground surface were practically uniform. Consequently the distribution of the load is characterized by a vertical stress concentration on the column. The stress concentration ratio $\left(\mathrm{n}=\sigma_{c} / \sigma_{s}\right)$ (where $\sigma_{c}$ and $\sigma_{s}$ are the vertical stresses respectively in the column and in the surrounding soil) is a fundamental parameter which depends on several factors including the replacement factor $a=A_{c} / A$ (where $A_{c}$ is the area of the stone column; and $A$ is the area of the soil around the stone column). It was found from laboratory studies and full scale experiments that the value of stress concentration ratio at the ground surface is generally 3 to 5 .

Munfakh et al (1984) have measured a stress ratio of 2.5 to 3.5 at the surface of the loaded area immediately after application of the load. At the end of the consolidation period, the measured stress ratios had increased to between 4 and 5 . However, as was shown by Vautrain (1977) it can reach values as high as 50 for deep columns in the case of very soft clay.

\subsection{THE LOAD CARRYING CAPACITY}

The ultimate capacity of stone columns are usually determined by field load tests. This load test has other purposes such as (1) to evaluate settlement characteristics (2) shear strength of the stone column or the composite stone column-soil strength, and (3) to verify the adequacy of the overall construction process. The ultimate load capacity of a stone column varies depending on site conditions, from about 15 to about 60 tons, (Barksdale and Bachus, 1983). Typical design loads of a single stone column are 20 to 30 tons in soft to medium stiff clays (Mitchell, 1981). Figure 2.1 illustrates a typical stone column field test at Santa Barbara, and Table 2.1 presents an approximate range in design loads used in practice for stone columns.

The load carrying capacity of a stone column as individual and as a group has been analyzed by many researchers and many methods have been proposed. The theory 


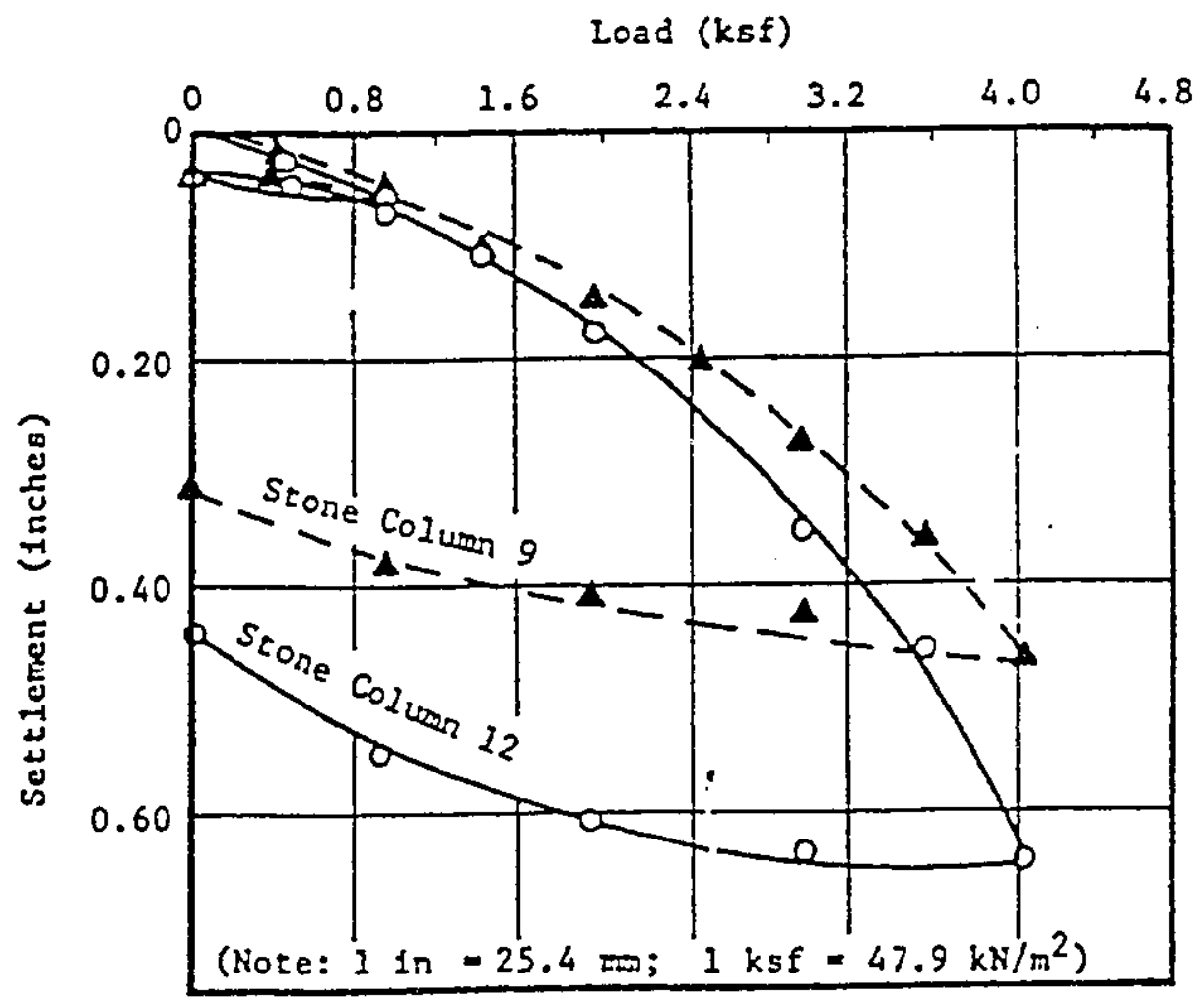

Figure 2.1 : Stone column field test at Santa Barbara, USA (After Barksdale and Bachus, 1983) 
Table 2.1 : Approximate range of design loads used in practice for stone columns

\begin{tabular}{|l|c|c|}
\hline \multirow{2}{*}{ Soll Type } & \multicolumn{2}{|c|}{ Approximate Design Load (tons) } \\
\cline { 2 - 3 } & Fdn. Design (1) & Stability (I) \\
\hline 1. Cohesive Soil (2) \\
400 psf $\leq c \leq 600$ psf \\
600 psf $\leq c \leq 1000$ pst \\
$c>1000$ psf & $25-45$ & $20-45$ \\
& $35-60$ & $30-60$ \\
2. Cohesionless Soil & 20-180 & $40-70$ \\
\hline
\end{tabular}

liotes: 1. In general, when stone colum loads are given all the applied load is considered carried by the stone colum.

2. Typical de:sign loads for foundations on cohesive soils are 15 to 30 tons.

3. Unit Conversions: I psE $=47.9 \mathrm{~N} / \mathrm{m}^{2}$. 
of cavity expansion by Vesic (1972) has been accepted by many authors (Hughes and Withers, 1974,1975; Wallays et al, 1983; to simulate the individual stone column behaviour during loading and it produced results of reasonable accuracy.

In 1970, Greenwood has proposed the following formula to obtain the ultimate capacity of a stone column

$$
\sigma_{v}=\sigma_{x} K_{p s}
$$

where:

$$
\sigma_{x}=\gamma z K_{p c}+2 c \sqrt{K_{p c}}
$$

$\mathrm{K}_{\mathrm{ps}}=\tan ^{2}\left(45^{\circ}+\phi / 2\right)$

$\phi=$ the angle of shearing resistance of the granular material

$\mathrm{K}_{\mathrm{pc}}=$ the Rankine coefficient of passive earth pressure for clay

$\gamma, \mathrm{C}=$ the unit weight and cohesion of clay

$\mathrm{Z}=$ the depth

The ultimate capacity of a single stone column may be estimated by expressing it in terms of the allowable vertical stress applied over the column, such as

$$
\sigma_{v}=\frac{N_{s c} C_{u}}{F . S .}
$$

where: $C_{u}=$ undrained strength of the soil

$\mathrm{N}_{\mathrm{sc}}=$ Bearing capacity factor

F.S. = Factor of safety, generally assumed to be 3

The value of $\mathrm{N}_{\mathrm{sc}}$ ranges from 18 to 22 (Barksdale and Bachus, 1983) and 25 (Mitchell, 1981). The effect of group action on the load carrying capacity of a stone column has been reported by Barksdale and Bachus (1983) and can be estimated by multiplying the ultimate capacity of a single stone column by the number of columns in the group. An isolated single column compared to a stone column group has a slightly smaller ultimate 
capacity per column than in the group. Usually the interior columns will be surrounded and confined with the other columns in the group and hence somewhat stiffened by the effect of the exterior columns. This results in a slight increase in the ultimate capacity per column. Small-scale model studies show, for groups having 1 and 2 rows of stone columns, that only a small increase in capacity per column occurs with increase number of columns (Barksdale and Bachus, 1983).

In 1991, Briaud has presented a formula for the ultimate stress that can be placed on a stone column. The formula depends on the assumptions made by Hughes and Withers (1974) and the limit pressure obtained from a pressuremeter test. Therefore, if the column is considered to be loaded in a way similar to a triaxial test, the ratio between the vertical effective stress $\sigma_{1}^{\prime}$ and the horizontal effective stress $\sigma_{3}^{\prime}$ at failure is given by

$$
\sigma_{1}^{\prime}=R_{p} \sigma_{3}^{\prime}
$$

where $\mathrm{K}_{\mathrm{p}}$ is the coefficient of passive earth pressure.

In the case of stone columns the horizontal stress $\left(\sigma_{3}\right)$ is limited by the maximum horizontal pressure which can be resisted by the soil, the effective stress pressuremeter limit pressure $\mathrm{P}_{L}^{\prime}$ and $\sigma_{1}^{\prime}$ is given by

$$
\sigma_{1}^{\prime}=K_{p} p_{L}^{\prime}
$$

The effective stress limit pressure $P_{L}^{\prime}$ is given by

$$
P_{L}^{\prime}=P_{L}-u
$$

Where $\mathrm{u}$ is the pore pressure generated during the pressuremeter test at the limit pressure $\mathrm{P}_{\mathrm{L}}^{\prime}$. If a drained pressuremeter test is performed then the value of $\mathrm{u}$ can be considered as the hydrostatic pressure. The pressure versus time curve obtained from the pressuremeter test can be extrapolated to the drained, long term $\mathrm{P}_{\mathrm{L}}$. Then $\mathrm{P}_{\mathrm{L}}^{\prime}$ is obtained as

$$
P_{L}^{\prime}=P_{L}-\gamma_{\mathbb{w}} b
$$

Where $h$ is the distance from the pressuremeter test to the ground water level and $\gamma_{w}$ is 
the unit weight of water. If $\mathrm{K}_{\mathrm{p}}$ is of the order of 3 , then the maximum pressure $\sigma_{1}^{\prime}$ and the ultimate load that can be placed on a stone column are estimated by

$$
\begin{gathered}
\sigma_{1}^{\prime}=3 P_{I}^{\prime} \\
Q_{u}=3 P_{L} A
\end{gathered}
$$

Where $P_{L}^{\prime}$ is the pressuremeter effective long term limit pressure for the soil to be improved by the stone columns and $\mathrm{A}$ is the cross section area of the column. It should be noted that equations [2.8 and 2.9] would give conservative results if the spacing between the stone columns is small (Briaud, 1991).

In 1978, Brauns has compared the results of a number of analytical approaches to determine the load carrying capacity of stone columns. The results are shown in Figure 2.2 as reproduced by Greenwood and Kirsch (1984) and Munfakh et al, (1987).

\subsection{SETTLEMENT ANALYSIS}

The settlement of a singular stone column for wide spread loadings have been studied in the past twenty years using both pseudo-elastic and elasto-plastic analyses (Munfakh et al, 1987). Most of the studies consider the unit cell concept (i.e specific area around one stone column).

Hughes et al, (i $>75$ ) presented a simple method for the estimation of settlements of stone columns. The stone columns was divided into several layers and the settlement at the top of the pile $(\rho)$ is the sum of the settlement of each layer $(\delta)$

$$
\rho=\sum_{i=1}^{m} \delta_{t}=\sum_{i=1}^{m}\left(2 H_{t}\right)\left(\frac{2 \delta_{x t}}{d_{s}}\right)
$$

where: $\mathrm{H}_{\mathrm{i}}=$ the layer thickness 


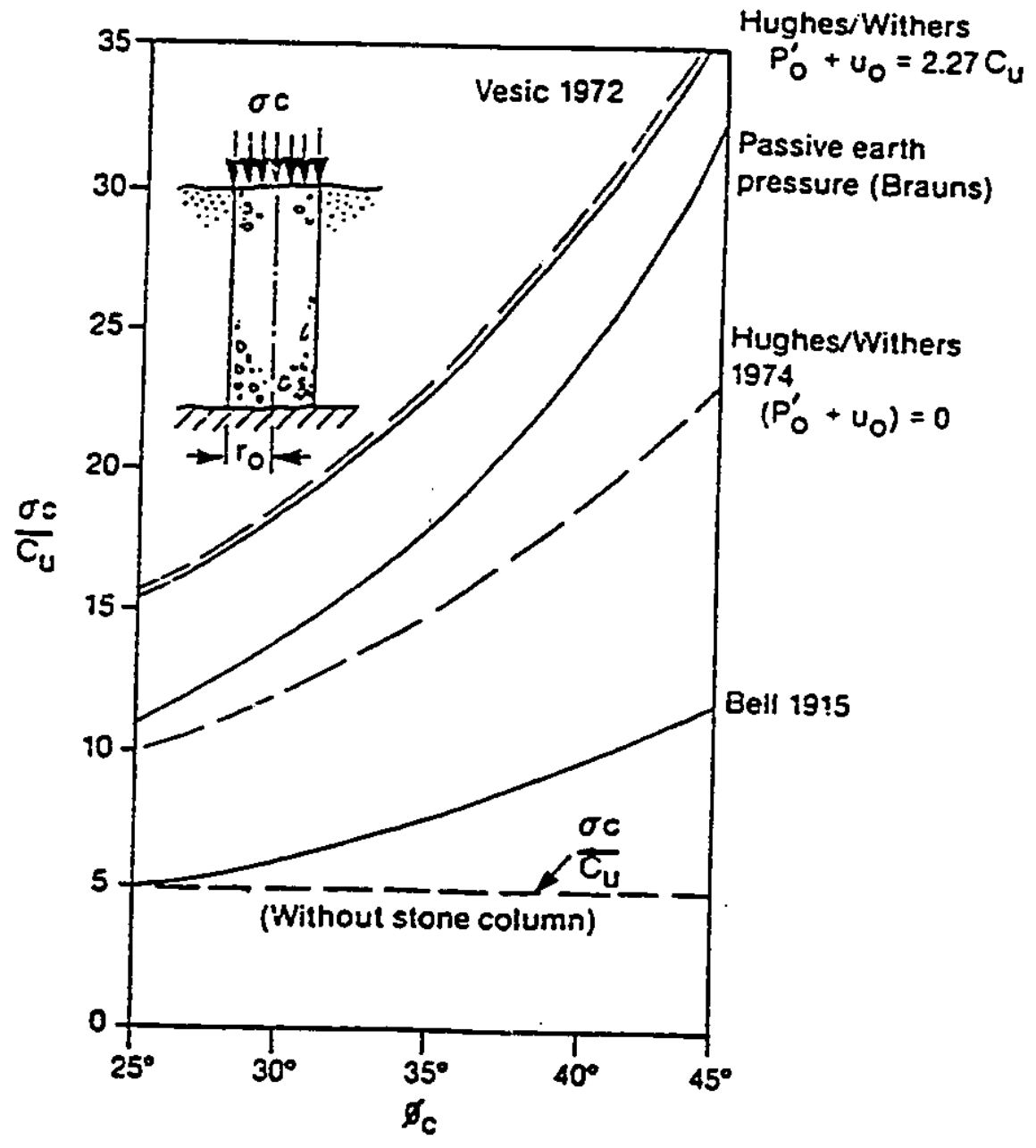

Figure 2.2 : Summary of Analytical Approaches used to determine the load carrying capacity of stone columns.

(After Greenwood and Kirsh, 1984). 
$2 \delta_{r i} / d_{s}=$ the radial strain of the ith layer

$d_{s}=$ diameter of the stone column

the radial strain can be obtained from a pressuremeter or triaxial tests.

The equilibrium method has been used in Japan to estimate the settlement of snft ground stabilized by sand compaction piles, (Aboshi et al, 1979). The stress acting on the soil was estimated as a function of the applied load, the stress ratio and the area replacement ratio ( area of stone column divided by total area within the unit cell).

In 1976, Priebe considered incompressible column material within a cylindrical elastic half space without changes in lateral stress with depth and without peripheral shear stress. The author has developed curves relating the settlement improvement ratio (settlement without column/settlement with column) to the area ratio within the unit cell.

Brown et al (1979) have conducted a parametric finite element study on an isolated single stone column and he concluded that, settlement of a stone column at less than one-third of the ultimate load may be approximated by the following empirical equation for the range of parameters normally encountered in practice

$$
\rho=\frac{q_{a} D}{\left[F \tan \phi_{s}^{\prime} \frac{S_{u}}{\sigma_{v}^{\prime}}\right]}
$$

$\mathrm{F}=70 \mathrm{MPa}$ for undrained loading

$=35 \mathrm{MPa}$ for drained loading

$\sigma_{v}{ }^{\prime}=$ effective overburden stress

$\phi_{s}^{\prime}=$ effective angle of shearing resistance of column material

$\mathrm{q}_{\mathrm{a}}=$ applied axial stress $(\mathrm{kPa})$

$\rho=$ settlement of column at ground level (meters)

$S_{u}=$ undrained clay shear strength

$\mathrm{D}=$ initial diameter of column (meters) 
Munfakh et al (1987) have presented design curves which were developed by Priebe (1976) and reproduced by Greenwood and Kirsch (1984). Figure 2.3 may be used to find the ratio of settlement with and without stone columris. Settlement improvement ratios between 1.5 and 4.2 were presented by Besancon (1984) based on results of 13 case histories.

In 1991, Briaud has presented a formula to calculate the settlement in a stone column subjected to vertical loading. The settlement may be estimated using pressuremeter test results on the surrounding soil along with triaxial tests with volume change measurements on the stone column material. Based on Hughes and Withers (1974) deformed stone column shape, the following formula was suggested to calculate the stone column settlement

$$
S=2 B\left[1-\frac{\left(1+\frac{\Delta v}{v_{0}}\right)}{\left(1+\frac{\Delta B}{B}\right)^{2}}\right]
$$

The quantity $\triangle \mathrm{B} / \mathrm{B}$ is obtained from the pressuremeter tests while the relative change in volume $\Delta \mathrm{V} / \mathrm{V}_{0}$ can be obtained from a triaxial test on the stone column material.

In 1979, Goughnour and Bayuk have considered an elasto-plastic analysis by assuming the stone column material being incompressible in the plastic state. The approach used by the authors considered the stress-strain relationship of the composite to behave elastically at the beginning of loading, then it behaves as a plastic material with increasing strain. In addition, they have used a modified Terzaghi consolidation theory to accommodate both radial and vertical strains. Also, the authors have shown that the shear stresses generated at the soil-column interface are rather small and practically do not affect the state of stress in the soil. Also, they stated that the installation of stone columns causes an initial compression of the surrounding soft soil and thus increases the value of $\mathrm{K}_{\mathrm{o}}$. In 1983, Goughnour has presented charts for calculating settlement by using the approach proposed in 1979. 


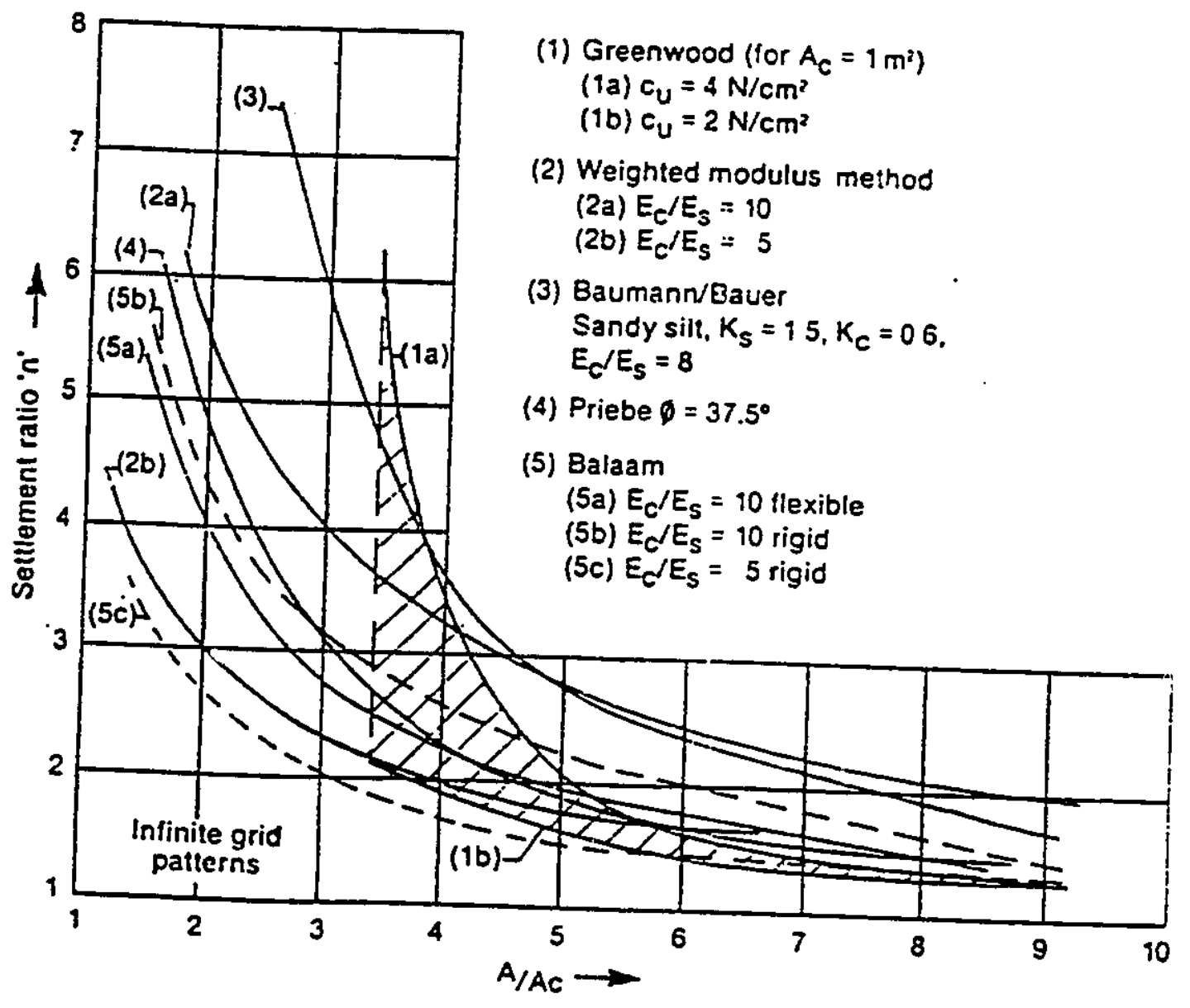

Figure 2.3 : Summary of elastic theories used to calculate settlement of stone columns (After Greenwood and Kirsh, 1984). 
Other researchers (Barksdale and Bachus, 1983) have used a non-linear finite element analysis and the concept of the unit cell to develop design curves for predicting the settlement of stone columns. In 1983, Balaam and Poulos presented a method based on the assumption of elasto-plastic material behaviour. The finite element with loading path method was used to analyze a single isolated stone column. The conventional sanddrain theory for time-settlement computation has been used by Goughnour and Bayuk (1979). Balaam and Booker (1980) presented an analysis for settlement for flexible and rigid rafts resting on a stone column reinforced foundation. The soil-stone column system was assumed to behave as an elastic material. However, Balaam and Poulos (1983) have assumed the soil-stone columns system to behave as an elasto-plastic material according to the Mohr-Coulomb failure criteria.

A brief description of the methods used to predict settlement have been presented by Barksdale and Goughnour (1984) and Munfakh et al (1987). The following are some remarks on each method.

2.3.1 Equilibrium method (Aboshi et al, 1979)

1- This method uses conventional soil mechanics parameters directly in its application and is no more difficult to apply than a conventional settlement analysis. It also gives a physical feel for the problem.

2- In the equilibrium method the stress concentration factor, $n=\sigma_{c} / \sigma_{s}$, was chosen based on experience. The effects of radial deformation of the in situ material as the column bulges, the stress-strain behaviour of the column material, and the increased confining pressure on the column with depth are neglected except through the effect of this factor. Therefore, the user's "skill" in choosing $\mathrm{n}$ is very important.

3- The equilibrium method was found to overestimate the measured settlement.

\subsubsection{Vibroflotation method (Goughnour, 1983)}

1- The vibroflotation method uses conventional soil mechanics parameters directly 
in its application.

2- Direct solution of the equations requires a programmable calculator or computer. The use of the design curves (Goughnour, 1983), however, makes this method very easy to apply.

3- This method considers both radial and vertical compression of the in situ soil, both elastic and plastic material behaviour, and the effect of increased soilconfining pressure with depth.

4- Soil properties and stress levels can vary with depth using this method.

5- Excellent results are usually obtained using this method

2.3.3 Finite element method (Barksdale and Bachus, 1983)

1- This method considers both radial and vertical compression of the in situ soil, both elastic and plastic material behaviour, and the effect of increased soilconfining pressure with depth.

2- This method is most versatile and theoretically accurate if a computer solution is applied to individual problems; it can easily consider changing soil parameters and stress levels with depth.

3- The design curves are relatively easy to apply but some versatility is lost because the design curves cannot accommodate different column material properties, although this is probably not a serious limitation in practice.

4- Good results may be obtained if care is taken in the analysis.

In 1984, Barksdale and Goughnour have studied the settlement performance of stone columns by the last three methods. The authors have found that the vibroflotation method gave excellent results when compared to the observed values. However, the method is based mainly on the assumption that both stone column and the surrounding clay settle equally under the external load.

The vertical and lateral displacements in the clay and sand were measured by Hughes and Withers (1974) by taking radiographs of lead shot markers placed inside the stone column and the surrounding soil. It has been indicated from the radial displacement 
results that only the soil within a cylinder with a diameter of about two and a half times that of the column is significantly affected by the loading. This suggest that the columns could act independently if placed more than two and a half diameters apart. Therefore, the stone columns may be spaced at more than 2.5 times the diameter if they intend to operate individually or at a distance less than 2.5 times the diameter for group effect.

The development of stone column technique for soil improvement came at the same time during the understanding and realization of the liquefaction potential of sands and silty sands and the concept of earthquake design as established by Seed et al $(1967,1971)$. As the understanding of the liquefaction process induced by earthquakes increased, civil engineers more recognized the fact that, the risk of liquefaction could be minimized by compacting the soils beyond their liquefaction potential.

In 1975, Engelhardt and Golding have conducted a large scale field study of stone columns to demonstrate their performance in a highly seismic susceptible area. The study was the first attempt in the USA to use the stone columns for prevention of liquefaction at Santa Barbara in California. The study was conducted to demonstrate the following:

a) in the process of stone column installation, sand lenses in the predominantly cohesive subsoil were sufficiently densified with respect to liquefaction potential;

b) the combined mass of stone columns and native, intervening soil developed sufficient shear strength to resist safely horizontal forces resulting from a ground acceleration of $0.25 \mathrm{~g}$.

In the study, stone columns were successfully used to resist the horizontal stresses induced by seismic load during earthquake by significantly increase the over all resistance to shearing of the composite soil mass.

Housner (1985) claimed that the introduction of stone columns to highly potential liquefaction soil will provide a shorter drainage paths and very rapid dissipation of the pore water pressure induced by the earthquake. More recently, stone columns have been 
employed, not only to provide a short drainage paths, but also to minimize the potential catastrophic failure by containment of the existing structures. Containment prevents the flow of the liquified soil by the formation of a barrier formed by densified soil, or stone columns. Stone columns have been used for consideration of both bearing capacity and earthquake resistance design in many places all over the world. Dobson (1987) has presented some of the major projects all over the world as shown in Table 2.2. Barksdale (1987) has presented example calculations for liquefaction, local bearing failure and setilement of soils reinforced with stone columns.

The performance of the stone columns in the field is dependent on the installation method. In 1988, Madhav and Thiruselvam have studied the effect of installation methods on the behaviour of stone columns, their study consisted of two approaches in the laboratory, the first approach was to study the effect of cased and uncased bore holes, number of lifts and compaction energy per lift given to the stone column and spacing. The results of the study showed that the load carrying capacity of a single stone column and a group of columns was more and the settlement was less for cased than uncased bore holes. Similarly, the greater the compaction energy and number of lifts, and the closer the spacing, the better the effectiveness of the stone columns.

\subsection{SHEAR RESISTANCE}

When stone columrs are used to stabilize a slope or embankment, a conventional slip circle analysis can be used taking into account the undrained shear strength of the clay, the frictional resistance of the column, area replacement ratio and the loading condition (Munfakh, 1984).

In 1979, Aboshi et al have used a weighted average material property to determine the composite shearing resistance of the reinforced soil at any point along the sliding surface. Figure 2.4 is a typical stone columns used to improve slope stability of an embankment where the stone columns are subjected to direct shear forces in the vicinity of the sliding surface. 


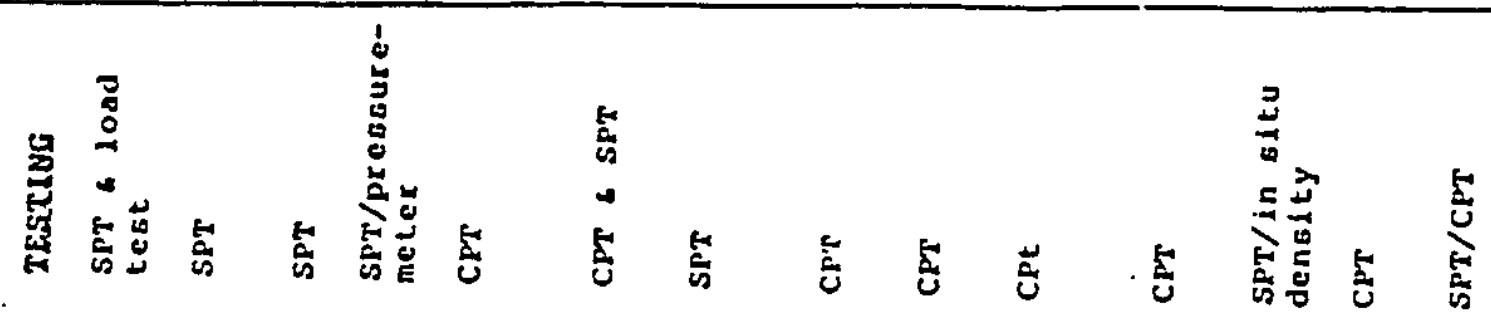

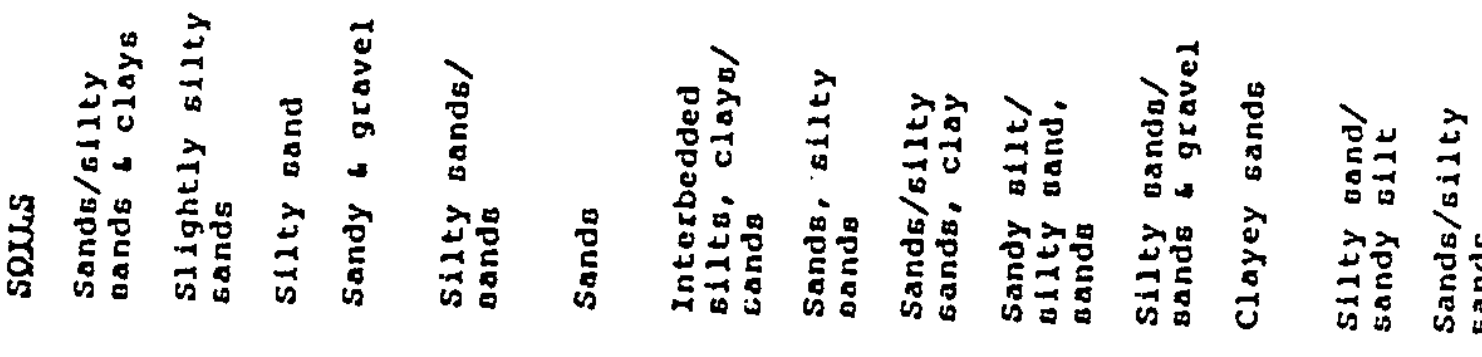

옹영

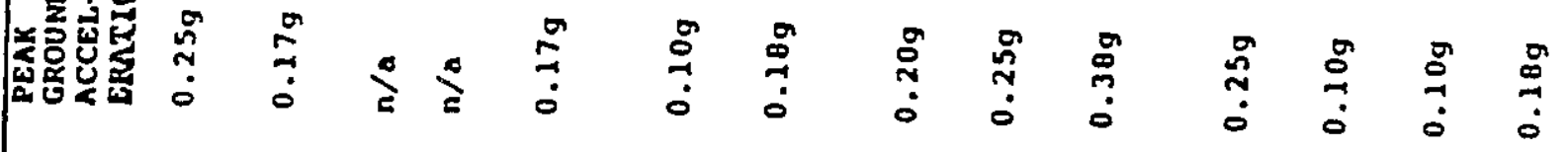

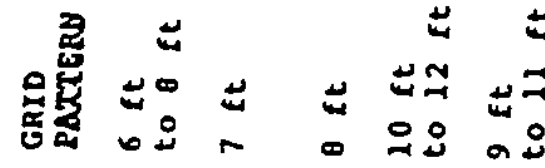

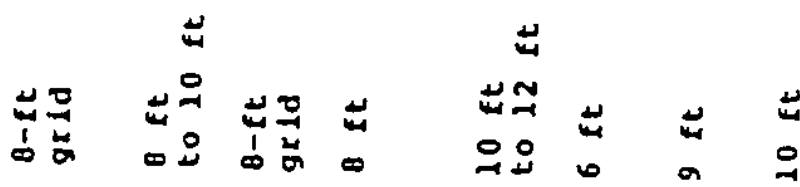

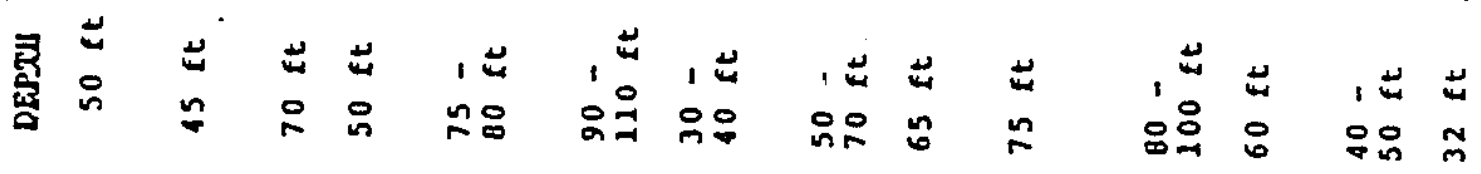

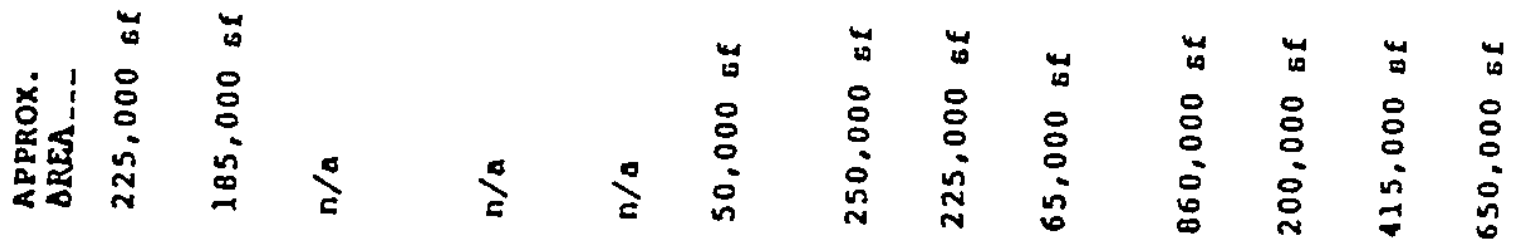

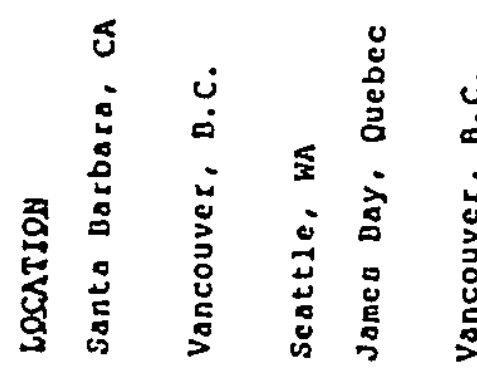

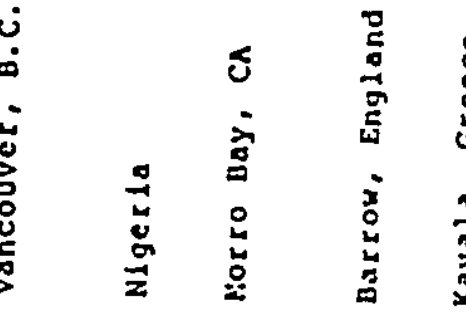

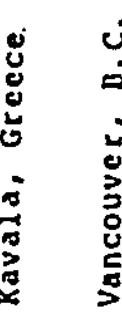

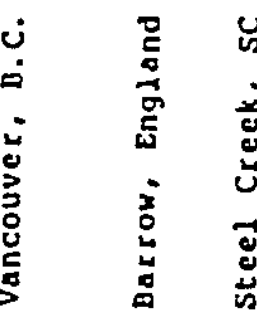

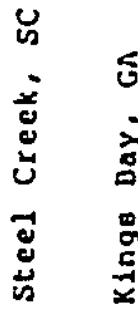

$\begin{array}{ll}5 & \\ \vdots & 0 \\ \vdots & 0 \\ 0 & 0 \\ 0 & 0 \\ 0 & 0 \\ \vdots & 0\end{array}$

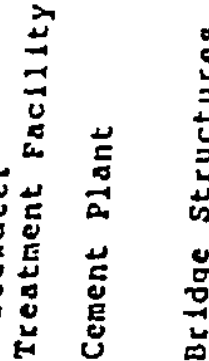

总

立

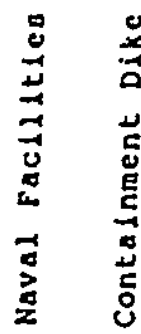

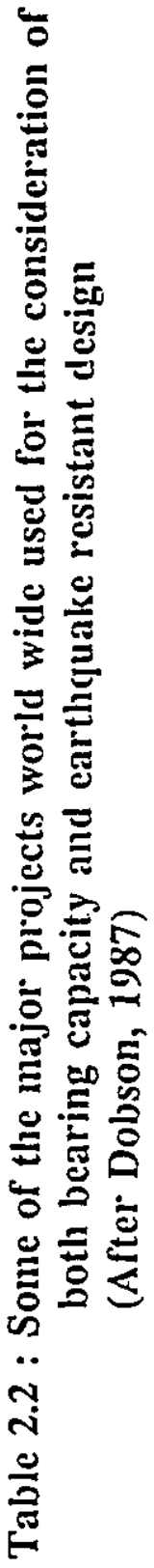




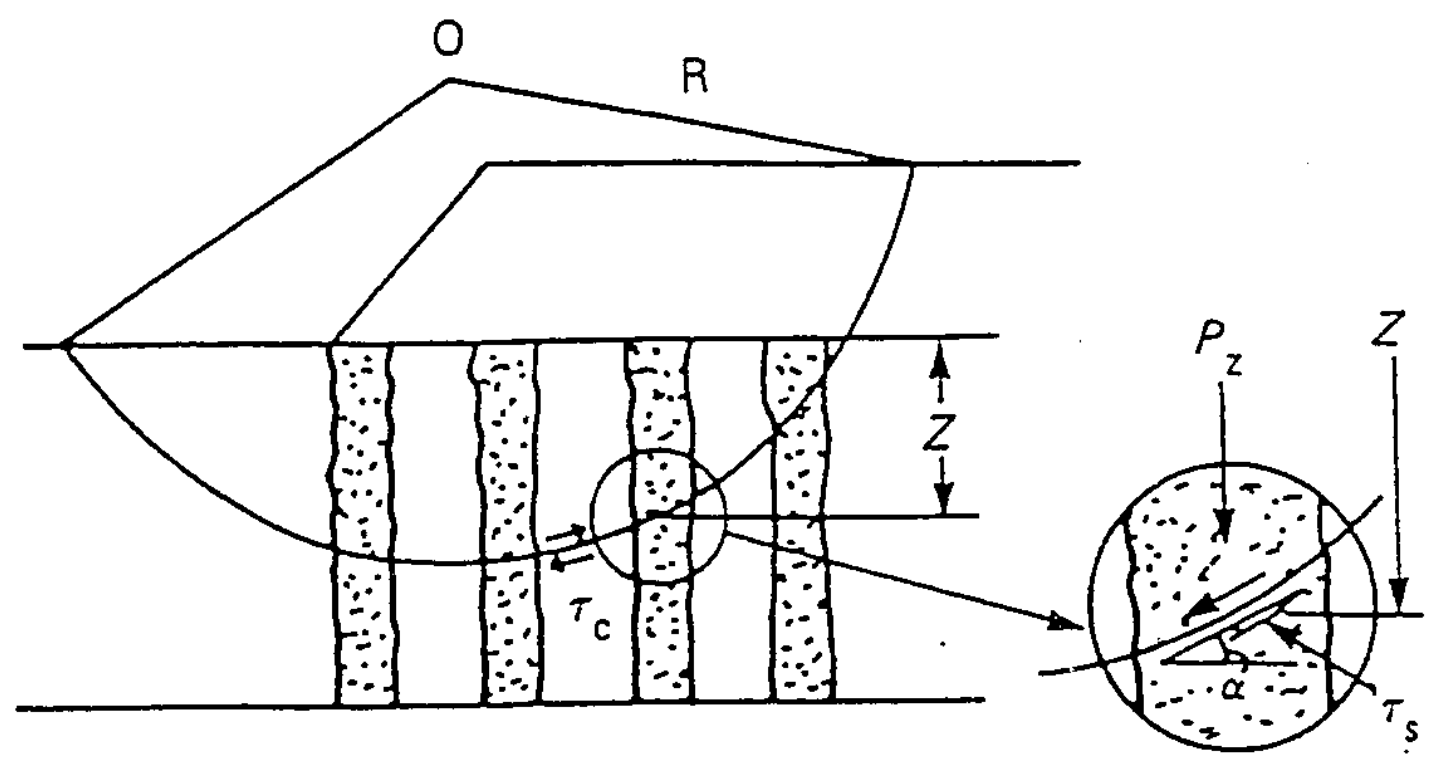

Figure 2.4: Stone columns used to improve slope stability (After Aboshi et al, 1979) 
Another approach was used by Chambosse and Dobson (1982), they proposed a lumped moment method for determining the safety factor of a selected trial circle. The driving and resisting moments in this method are calculated from the untreated soil. The resisting and the driving moments due to the stone columns are calculated separately and then added to estimate the safety factor of the reinforced soil.

\subsection{POLYMER GRIDS}

\subsubsection{General}

Polymer grids are manufactured from polyethylene and polypropylene sheets or fibres. In the case of production of geogrids from sheets, the first stage involves precise punching of holes at a regular pattern into a sheet. This is followed by carefully controlled stretching of the sheet which aligns the polymer's long chain molecules in the direction of stretch, giving the grid a high tensile stiffness in this direction. If further processing is carried out a uniaxial grid with narrow rectangular apertures is formed. The term "uniaxial" arises from the alignment of the stretched polymer ribs and the greatest strength properties in one direction.

The grids may be produced by incorporating a second stretching stage in the transverse direction to give a biaxial grid with a square aperture shape. In this case the term "biaxial" refers to the fact that both the stretched ribs and the strength properties are aligned in two directions.

The selection of a specific polymer grid for any application depends on the type of media to be reinforced, the required strength and hence the aperture size of grid, and the method of construction employed.

\subsubsection{Influence of polymer grids on soil behaviour}

Stone columns are inclusions which can withstand both compression and shearing. They are generally used as compression resistance soil improvement but their response to loading is mainly controlled by the confining pressure mobilized in the surrounding 
soft soil to restrain their bulging. The use of polymer grids with stone columns is intended to enhance the confinement of the stone columns materials and consequently the carrying capacity. Because of the difference in relative deformation of the composite (i.e. the native soils, polymer grid and stone column) most of the outward load is transferred to those columns. However, polymer grid will deform less than stone columns in the lateral direction. Therefore, the polymer grid sleeve will be the stronger component of the composite to carry and resist the lateral deformation of the stone columns due to the external vertical load.

As the stone column tends to deform laterally under the external (vertical) load, the polymer grid is expected to reduce lateral deformation due to interlock with the aggregate and the mobilization of hoop strisses. The lateral stresses in the surrounding soils will increase up to a certain level after which the tensile stresses in the polymer grid will continue to mobilized and consequently an increase in confinement will result.

Also, the grid's tensile stiffness adds to the stiffness of the foundation soil to resist the lateral movement of the stone column due to imposed vertical stresses. Therefore, the vertical stresses will be distributed differently through the soil due to the presence of the polymer grid sleeve between the stone column and the foundation soil (i.e composite of three materials with different moduli of elasticity and different behaviour under loading).

As the lateral deformation of the reinforced stone column occurs, due the vertical loading, the polymer grid will be strained. In a stretched flexible material having a circular shape, normal stresses against its convex face are higher than normal stresses acting on its concave face. This phenomenon is known as the "tension membrane effect". This action provides two beneficial effects, confinement of the stone column material, as discussed earlier, and reduction of the stress applied by the stone column to the surrounding soil.

The degree of confinement depends on the physical properties of the polymer sleeve as well as the size of the aperture and on the size and shape of the soil particles. Mowafy (1986) has studied the behaviour of different types of polymer meshes with different types of granular soils. He found that the best interlock forces may be obtained when the polymer grid aperture to the particle size is not greater than 3 , because at this 
or smaller ratios the particles will not penetrate through the mesh openings. Relationships between mesh opening and maximum pull-out strength for different particle sizes are presented in Figures 2.5 and 2.6.

\subsubsection{Soil-grid interaction mechanisms}

Three mechanisms of interaction between soil and grid reinforcement have been identified to provide a framework for understanding and interpreting laboratory and field measurements (Jewell et al, 1984). Primarily the grids mobilizes resistance by shearing on the interface along the planar surface. The strength mobilized mainly depends on the amount of soil involved in interlocking within the fabric. The interaction mechanisms can be identified as follows:

1- Soil shearing on plane surfaces of the reinforcement which are parallel to the direction of relative movement of the soil.

2- Soil bearing on (bearing) surfaces of the reinforcement which are substantially normal to the direction of relative movement of the soil.

3- Soil shearing over soil through the apertures in a reinforcement grid.

The frictional and bearing interaction mechanisms, Figure 2.7, have been presented graphically by Jewell et al (1984). The frictional resistance is mobilized by the soil shearing on plane surface area of the geogrid and the bearing resistance is mobilized by the soil bearing on the geogrid bearing surface normal to the direction of relative movement between soil and geogrid.

Mowafy (1986) has classified the interaction mechanisms into primary and secondary. The primary mechanism consists of the following components (1) mechanical properties of the mesh; (2) interlock between mesh and soil; (3) the confinement provided by the mesh properties. The mobilisation of the primary mechanism depend on the properties of the mesh and the aggregates. The following are the major parameters which contribute to this mechanism:

- Properties of the mesh such as elasticity modulus, tensile strength and deformation.

- Geometry and configuration of the mesh. 


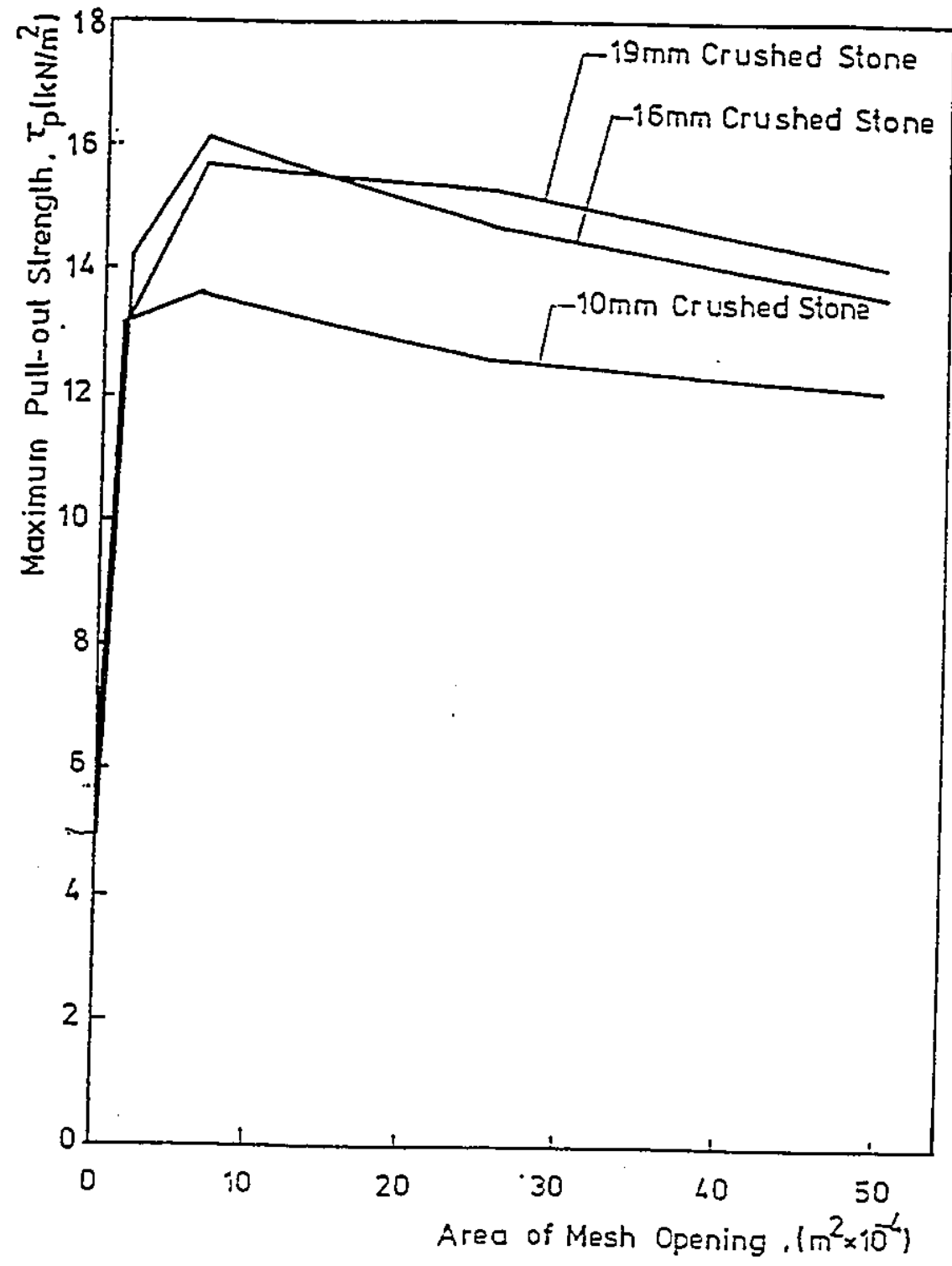

Figure 2.5 : Area of mesh opening versus total maximum pull-out strength at $20.7 \mathrm{kN} / \mathrm{m}^{2}$ surcharge load (After Mowafy, 1986) 


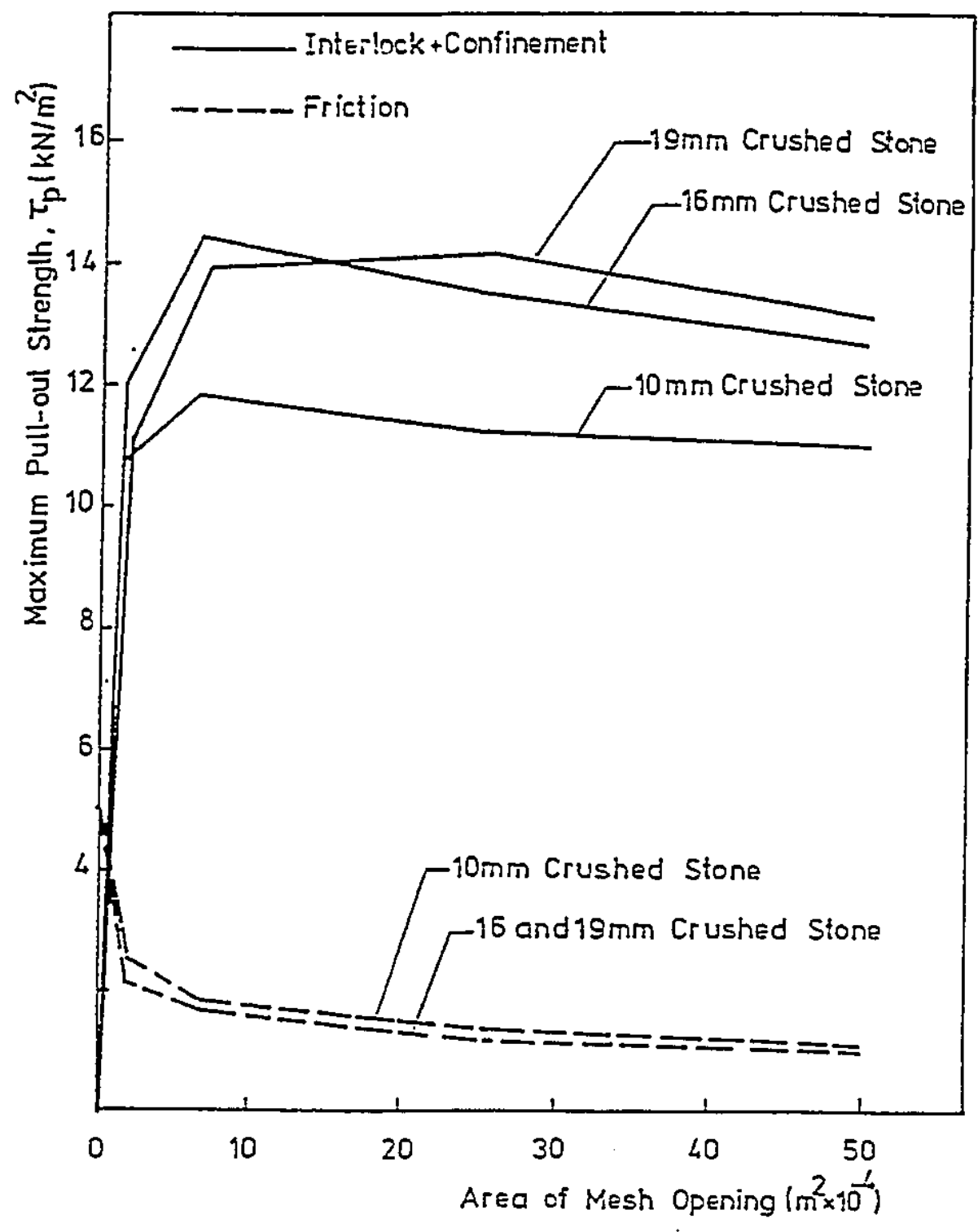

Figure 2.6 : Area of mesh opening versus pull-out strength components at $20.7 \mathrm{kN} / \mathrm{m}^{2}$ surcharge load (After Mowafy, 1986) 


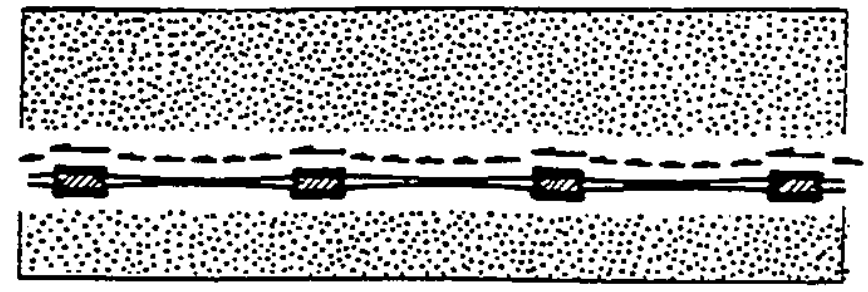

a. Shear between soil and plane reinforcement surfaces
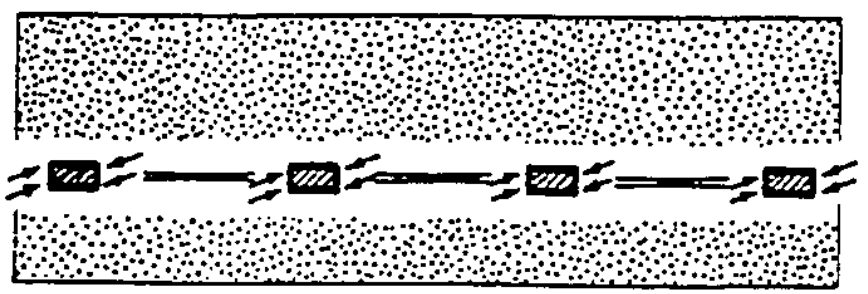

b. Soil bearing on grid reinforcement bearing surfaces

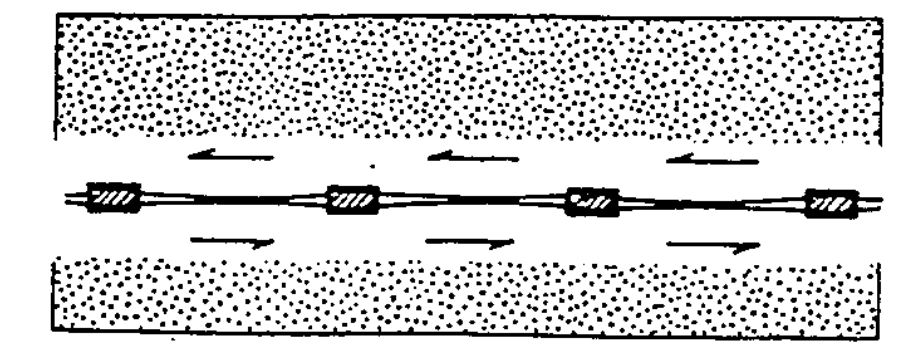

c. Soil shearing over soil through the reinforcement grid apertures

Figure 2.7 : Mechanisms of resisting direct sliding of polymer grid (After Jewell et al, 1984) 
- Size and shape of aggregate; and

- Density of soil.

The secondary mechanism is mainly attributed to the friction between the mesh and the soil. However; the contribution of this mechanism to the overall mobilized resistance in the grid is little. This is mainly due to some reasons such as the contact area between the aggregate and the grid mesh is quite minimal and the coefficient of friction of the mesh material is quite low. The texture, hardness and shape of the aggregate are factors which affect to this mechanism. Also, the surface shape and mesh material are factors that influence the secondary mechanism.

The factors that influence the measured interaction properties, includes the testing equipment procedure, boundary conditions, soil and reinforcement type, soil placement and compaction, soil dilatancy behaviour and the confining pressure.

\subsubsection{Mobilization of soil-gird strength}

In 1988, Makiuchi and Miyamori have studied the frictional properties of the soilgrid systems under controlled condition in the laboratory. The authors have investigated several types of fabric in contact with cohesive and non-cohesive soils using a friction testing apparatus. The result of the study showed that the mobilized friction parameters of grids are mostly lower than those of soil itself and are affected by the following factors:

- Surface texture of grids

- Thickness of grids

- Type of grid

- Density and moisture content of soil

Also, the study has shown that the friction-shear displacement relationships between soil and geogrid are markedly affected by the following:

- Soil and geogrid and their combination

- Moisture and compaction conditions of the soil

- Confining stress level

In the case of sand-grid interface, Makiuchi and Miyamori (1988) have observed that the 
residual friction are almost the same for all sands tested and similar behaviour can be obtained for other geogrid-sand systems. Finally, it was found that increasing the void ratio of the sand, $e=0.80$ to 0.65 was reflected in an increase of the peak angle of shearing resistance. However, no significant difference in the angles of residual friction was observed. It was also found that the thicker the polymer grid the higher the angle of shearing resistance.

In 1988, Chalatumyk et al have indicated that the presence of a polymer grid in an embankment slope reduced the soil strength, which must be mobilized for stability of the slope. This is probably due that a large portion of the sliding surface occurred along the geogrid (i.e. "lubrication effect").

\subsection{TRIAXIAL TESTS WITH GRID REINFORCEMENT}

The literature lacks any detailed information about polymer grids in conjunction with stone columns. However, series of triaxial compression tests have been conducted by many researchers to investigate the increase in axial loading induced by insertion of horizontal layers of fabric disks.

Broms (1977) conducted a series of triaxial tests on sand samples reinforced with circular disks of fabric. The specimens were $69 \mathrm{~mm}$ in diameter and $137 \mathrm{~mm}$ high. The results indicated that the ultimate strength and the failure strain of reinforced samples increased with increasing number of fabric disks and confining pressure.

Gray and Ohashi (1983) conducted a series of triaxial compression tests on Muskegon dune sand reinforced with layers of fabric. The conclusion of their study were consistent with those from Broms (1977), however, they claimed that the angle of shearing resistance of the sand was not affected by the presence of fabric disks (Figure 2.8). Geotextiles found to limit, significantly, the loss of post peak strength of the reinforced samples. Gray and Ohashi (1983) derived a simple equation to describe the mobilized tensile stress of fabric in the reinforced sample.

Al-Refeai (1985) has presented results of quasi uniaxial compression tests on 61 
$\mathrm{mm}$ diameter and $140 \mathrm{~mm}$ high specimens of dry Muskegon dune sand encapsulated in two types of woven geotextile sleeves, namely Geolon 400 and Geolon 200. The tests were conducted to investigate and compare the effect of internally and externally reinforced sand specimens on the stress-strain behaviour. The sand specimens were reinforced internally by circular disks of fabric.

Kabir and Alamgir (1988) have presented the results of what they described as a novel analysis and design method for newly envisaged "jacketed" stone columns. The authors have used triaxial samples of $100 \mathrm{~mm}$ in diameter and $200 \mathrm{~mm}$ long wrapped in rubber membranes. The samples were prepared from uniform size aggregates (9 to 12 $\mathrm{mm})$. No information was given about the types of geotextile or geogrid used nor their physical properties. The study mainly concentrated on a hyperbolic representation of stress-strain behaviour for all three materials, stone aggregates, jacketing geotextile or geogrid and clay soils.

In 1988, Fukushima et al have studied the properties of soils that were reinforced with different types of grids using a large $(120 \mathrm{~cm}$ in diameter and $240 \mathrm{~cm}$ in height) triaxial compression cell. The study was aimed to investigate the strength and deformation characteristics of sand reinforced with geogrid, non-woven fabric and metal strips all arranged in horizontal layers at equal intervals through the specimen depth. The study has shown that, among the three reinforcements used, the geogrid reinforcement had the greatest reinforcing effect, but the stress ratio $\left(\sigma_{1} / \sigma_{3}\right)$ dropped sharply after the shearing deformation reached a certain value. They attributed the sharp drop in strength to the rupture of the geogrids.

In 1989, Gray et al have studied the stress-deformation response of geotextile reinforced granular structures. The stress-deformation response of embedded granular structures reinforced with both woven and non-woven geotextiles was determined by a finite element analysis. The analysis was used to investigates the axisymmetric case of a fabric encapsulated triaxial specimens and plane strain case of a granular trench reinforced with a horizontal layer of fabric. Results of the analysis showed that geotextile encapsulation and/or reinforcement significantly improved the bearing capacity of embedded granular structures. 


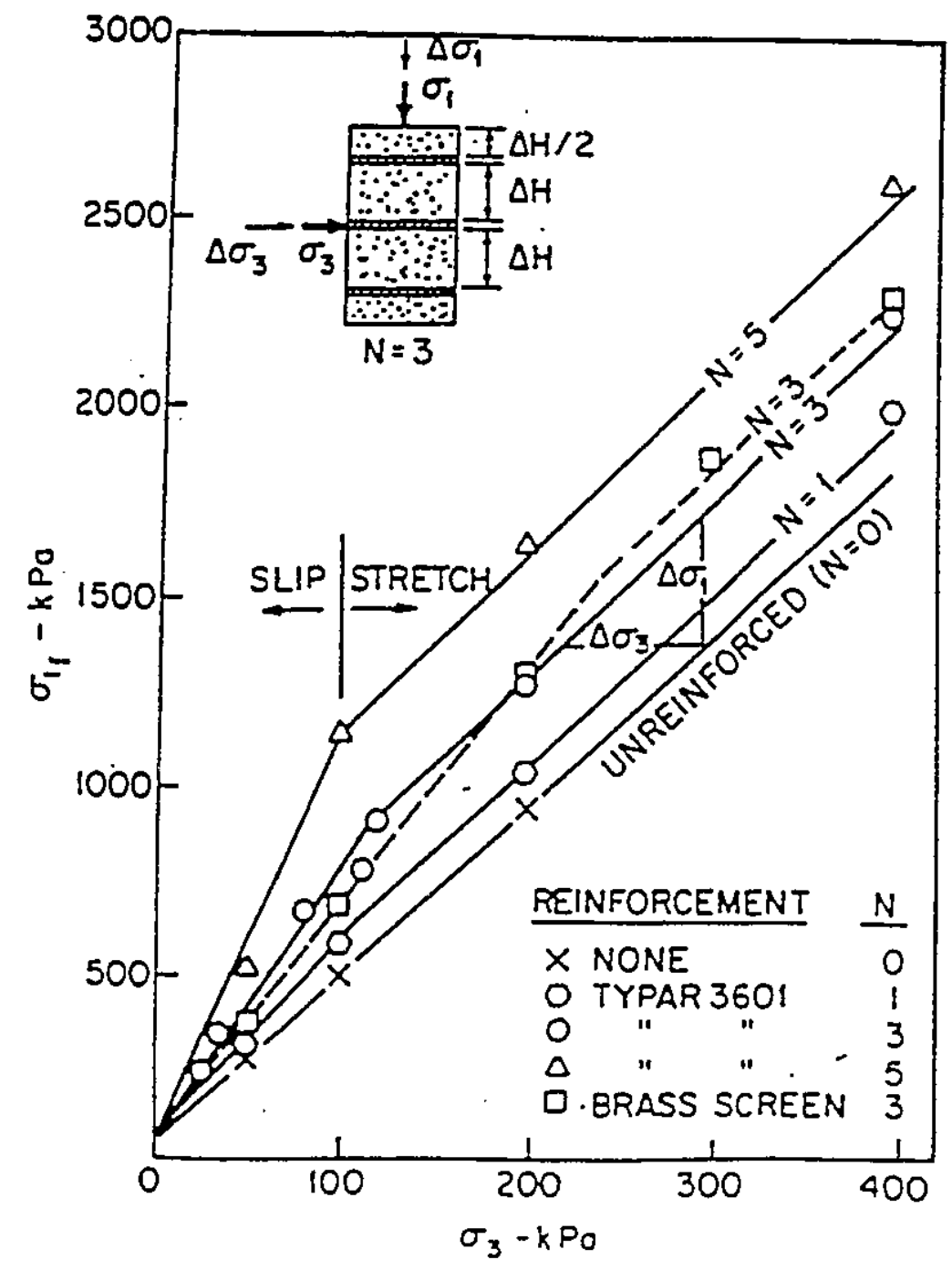

Figure 2.8 : Results of triaxial tests on Muskegan dune sand reinforced with different layers of fabric reinforcement (After Gray and Ohashi, 1983) 
Different concepts have been proposed to describe the mechanics of fabric reinforced soil (Schlosser and Long, 1972, 1974; Yang, 1972; Hausmann, 1976). Mitchell and Schlosser (1979) and Ingold (1982) discussed in full detail these concepts. Two concepts derived from triaxial tests on reinforced sand based on limit equilibrium theory have been proposed by Yang (1972) and Schlosser and Long (1974) respectively. A brief description of the two concepts is given below.

\subsubsection{Enhanced confining pressure concept}

In 1972, Yang conducted a series of triaxial tests reinforced with horizontal layers of fibre glass nets. It was assumed that the reinforced sand failed at a constant effective stress ratio

$$
\left(\frac{\sigma_{3}}{\sigma_{1}}\right)_{f}=\tan ^{2}\left(45-\frac{\phi}{2}\right)
$$

The increase in axial stress $\sigma_{1 f}$ at failure in the reinforced triaxial sample was due to an equivalent increase in confining stress $\Delta \sigma_{3}$. The previous assumption was based on the hypothesis that tensile restraint provided by the fabric reinforcement induced this equivalent in confining stress. From a Mohr-Coulomb formulation for the strength of a cohesionless material it follows that

$$
\sigma_{1 f}=\sigma_{3 f} N_{\Phi}=\left(\sigma_{3}+\Delta \sigma_{3}\right) N_{\phi}
$$

where

$$
\begin{aligned}
& \sigma_{1 \mathrm{f}}=\text { maximum major principal stress of the reinforced sample, } \\
& \sigma_{3 \mathrm{f}}=\text { equivalent minor principal stress of the reinforced sample, } \\
& \sigma_{3}=\text { initial confining stress, } \\
& \Delta \sigma_{3}=\text { equivalent minor principal stress increase in the reinforced sample, } \\
& N_{\phi}=\tan ^{2}\left(45+\phi_{\mathrm{s}} / 2\right) ; \\
& \phi_{\mathrm{s}}=\text { angle of shearing resistance the unreinforced sand. }
\end{aligned}
$$




\subsubsection{Anisotropic or pseudo cohesion concept}

In 1974 Schlosser and Long conducted a series of triaxial tests on sand with layers of circular aluminum foil disks. They assumed that the increase of strength in the reinforced soil samples was induced by an anisotropic or pseudo cohesion, $C_{R}$, which was a function of their spacing and tensile strength. This anisotropic or pseudo cohesion, $C_{R}$, was computed from a force equilibrium analysis of the reinforced composite. The strength of the reinforced sand was defined as

$$
\sigma_{1 f}=\left(\sigma_{1}+\Delta \sigma_{1}\right)=\sigma_{3} N_{\phi}+2 C_{R V} \sqrt{N_{\phi}}
$$

where

$\sigma_{1}=$ maximum major principal stress of the unreinforced sample,

$\Delta \sigma_{1}=$ increase of major principle stress in the reinforced sample.

The additional strength $\Delta \sigma_{1}$ in the specimens was attributed to the effect of pseudo cohesion developed in the new composite material and may be computed as follows

$$
C_{R}=\left(\frac{R_{T}}{\Delta H}\right)\left(\frac{\sqrt{N_{\phi}}}{2}\right)
$$

where

$$
\begin{aligned}
& R_{T}=\text { force per unit width of reinforcement at failure, } \\
& \Delta H=\text { spacing between reinforcement layers. }
\end{aligned}
$$

Comparing Equation [2.13] and [2.14] with Equation [2.15] indicates a direct correspondence between Yang's $\Delta \sigma_{3}$ and the $\Delta \sigma_{1}$ or $C_{R}$ proposed by Schlosser and Long. Equations [2.13] and [2.14] yield

$$
\Delta \sigma_{3} N_{\phi}=2 C_{E} \sqrt{N_{\phi}}
$$

or

$$
C_{R}=\Delta \sigma_{3} \frac{\sqrt{N_{\phi}}}{2}
$$

Equations [2.15] and [2.17] yield 


$$
\Delta \sigma_{3}=\frac{R_{T}}{\Delta H}
$$

Therefore, either of these two concepts (i.e $\Delta \sigma_{3}$ or $C_{R}$ ) could be used with the same result of analysing the behaviour of composite earth reinforced with layers of fabrics. The ultimate strength was assumed to be achieved by breaking of the reinfor:e. ment rather than by pull-out.

\subsection{CREEP BEHAVIOUR OF POLYMER GRID}

Polymer grids in general exhibit creep under sustained loading. Unfortunately, there is no standardized creep test method at this time. The extent of creep significantly affects the overall performance of polymer grids in the field. The creep behaviour depends on the type of polymer grid used, stress level, loading duration and frequency, the ambient soil conditions, humidity and installation procedure.

During the past few years extensive studies of the creep and recovery behaviour of polymer grid have been carried out at Leed's University (Ward, 1984). The aim of the work was to establish criteria for creep failure and to identify structural factors which lead to improvement in creep performance. The results of the studies have been of direct relevance to the manufacturers of grids and have provided guidelines for engineering applications. The most impritant finding of the studies was that for each polymer grid, a critical stress can be defined, below which permanent flow is negligible and on unloading, recovery is virtually complete. This concept has been used to select a suitable polymer grid and to establish load reduction factors.

Creep tests on polymer grids are usually performed in two different methods. The first method is performed under "in-air" condition. In this method, polymer grids are tested by fixing one end of the mesh and subjecting a sustained load to the other end over a long period of time. The other method is by testing the polymer grid creep behaviour under "in-soil" conditions. In this method the beneficial influence of confining pressure 
is introduced into the test. McGown et al (1982) have noticed that a significant reduction of long term strains occurred for nonwoven geotextiles when they were tested under "insoil" conditions.

Razaqpur (1990) and Razaqpur et al (1992) have reported tests results of short term creep behaviour of Conwed geogrids. The creep tests were conducted, in-air, under controlled conditions. The results were reported as strain versus time curves for the geogrids subjected to $50 \%$ of its tensile strength. It was observed (Figure 2.9) that the creep strain is only $1.83 \%$ after 1800 hours of sustained load. The creep coefficient ( total strain minus the initial strain divided by the initial strain) was found to be 0.23 based on 1800 hours of testing.

Juran et al (1991) have presented tests results of short and long term creep behaviour of Conwed geogrds. The creep tests were conducted, in-soil, under confined condition. The results (Figure 2.10) are reported as displacement versus time curves for different load levels. The authors have interpreted their results by utilizing the creep model proposed by Singh and Mitchell (1968) for soils. They concluded that the model was able to evaluate the long term pull-out displacement under load levels smaller than the critical creep pull-out load. The critical creep pull-out load was defined as the load below which creep failure is unlikely to occur.

\subsection{DURABILITY OF POLYMER GRID}

The long-term design life of reinforced earth structures have raised questions about the durability of polymer grids. The durability issue addresses in addition to creep effect, some other environmental factors such as site damage, chemical degradation, biological degradation and ultraviolet light on polymer grids. Cannon (1976) have presented some of the environmental factors and their effect on the common polymer grids (Table 2.3). Adequate assessment of polymer grid durability and resistance to each type of degradation 


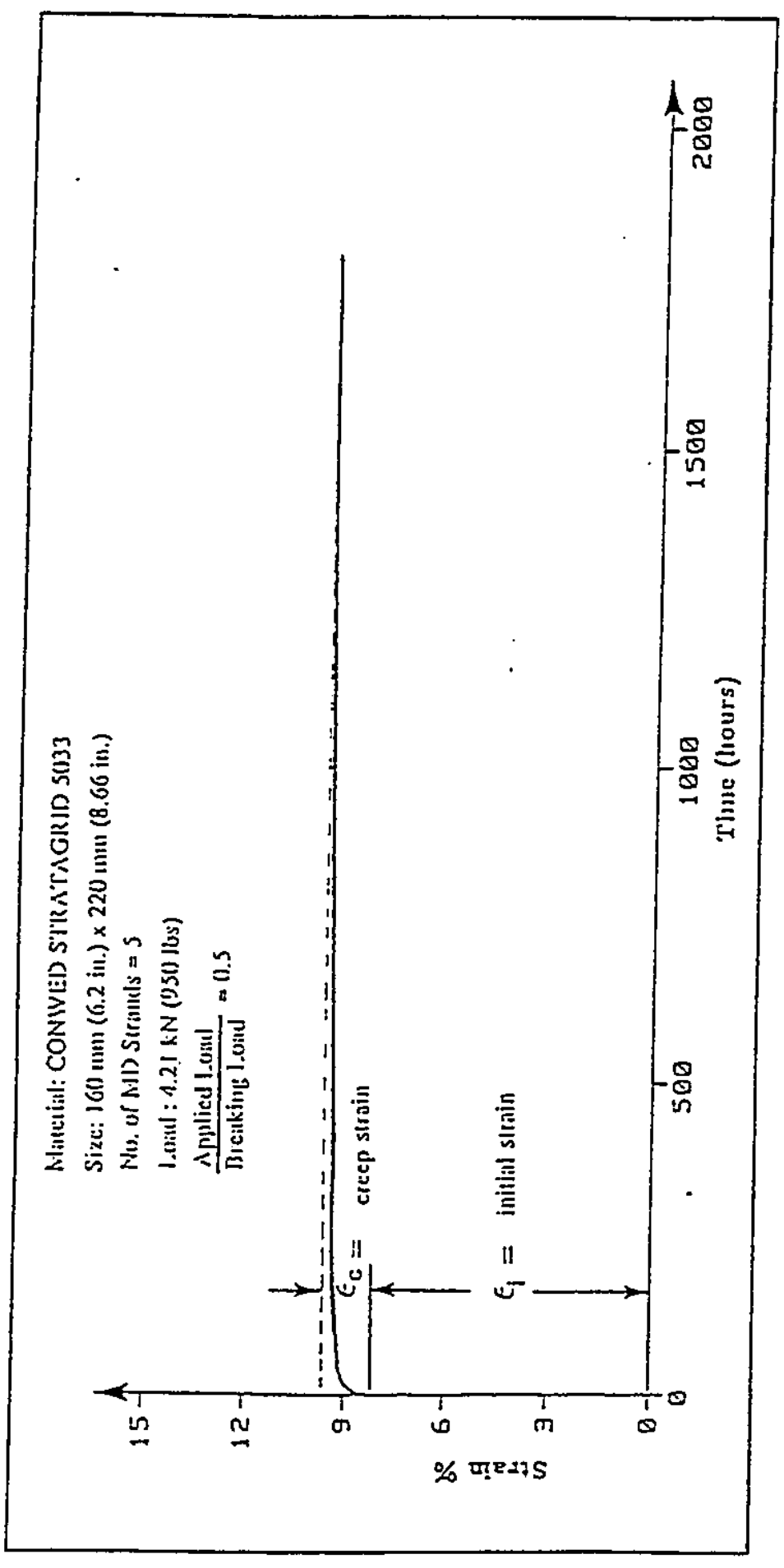

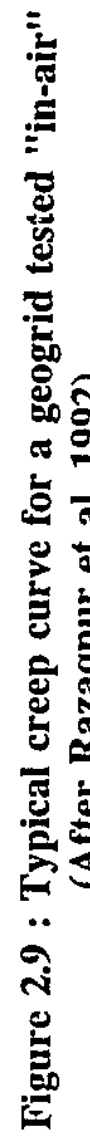




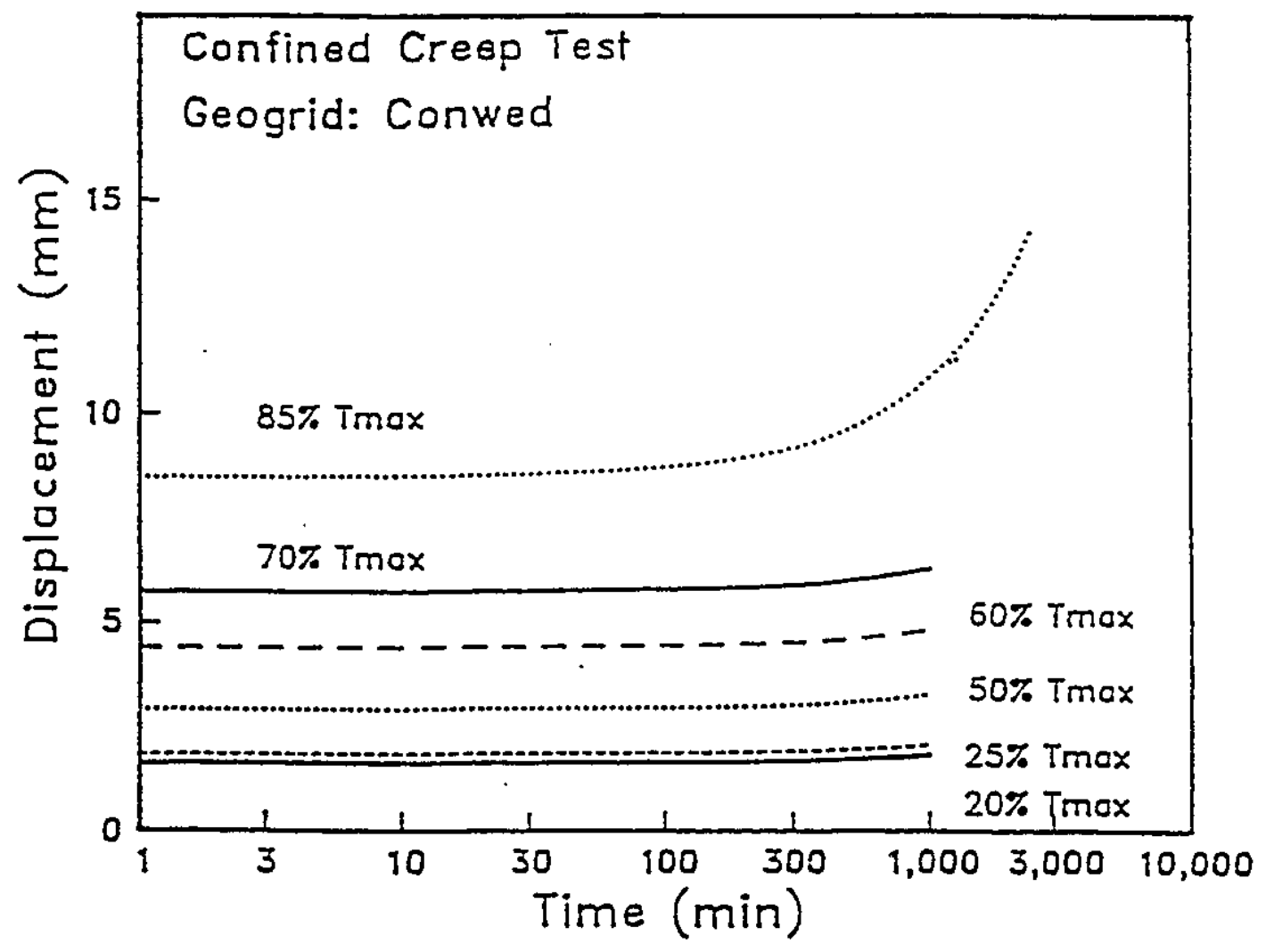

Figure 2.10 : Displacement-time relationship for load controlled pull-out test of confined Conwed (After Juran et al, 1991) 
is essential in any earth reinforcement application. For design purposes the basic concept is to established a factor of safety. For polymer grids the factor of safety takes the following form (Koerner, 1990)

$$
F_{g}=\frac{T_{a I I}}{T_{r a q}}
$$

$F_{s}=$ the factor of safety (to handle unknown conditions or uncertainties in design methods)

$\mathrm{T}_{\mathrm{all}}=$ the tensile strength from laboratory testing, and

$\mathrm{T}_{\text {req }}=$ the required tensile strength as obtained from design of the actual system.

The laboratory test tensile strength is usually an ultimate value. These values must be reduced before being used in design (i.e. $\mathrm{T}_{\text {all }}<\mathrm{T}_{\mathrm{utt}}$ ). One way of reducing the ultimate tensile strength of the reinforcement is by placing preliminary factors of safety on each of the items not adequately modelled in the laboratory test. Koerner (1990) have suggested the following equation to be used

$$
T_{a 11}=T_{u 1 t}\left[\frac{1}{F S_{I D} \times F S_{C R} \times F S_{C D} \times F S_{B D}}\right]
$$

where

$\overline{\mathrm{I}}_{\text {utt }}=$ the ultimate tensile strength from a standard in-isolation test,

$\mathbf{T}_{\text {all }}=$ the allowable tensile strength to be used in equation [2.20] for final design purposes,

$\mathrm{FS}_{\mathrm{ID}}=$ the factor of safety for installation damage,

$\mathrm{FS}_{\mathrm{CR}}=$ the factor of safety for avoiding creep over the duration of the structure's lifetime,

$\mathrm{FS}_{\mathrm{CD}}=$ the factor of safety against chemical degradation, and

$\mathrm{FS}_{\mathrm{BD}}=$ the factor of safety against biological degradation. 


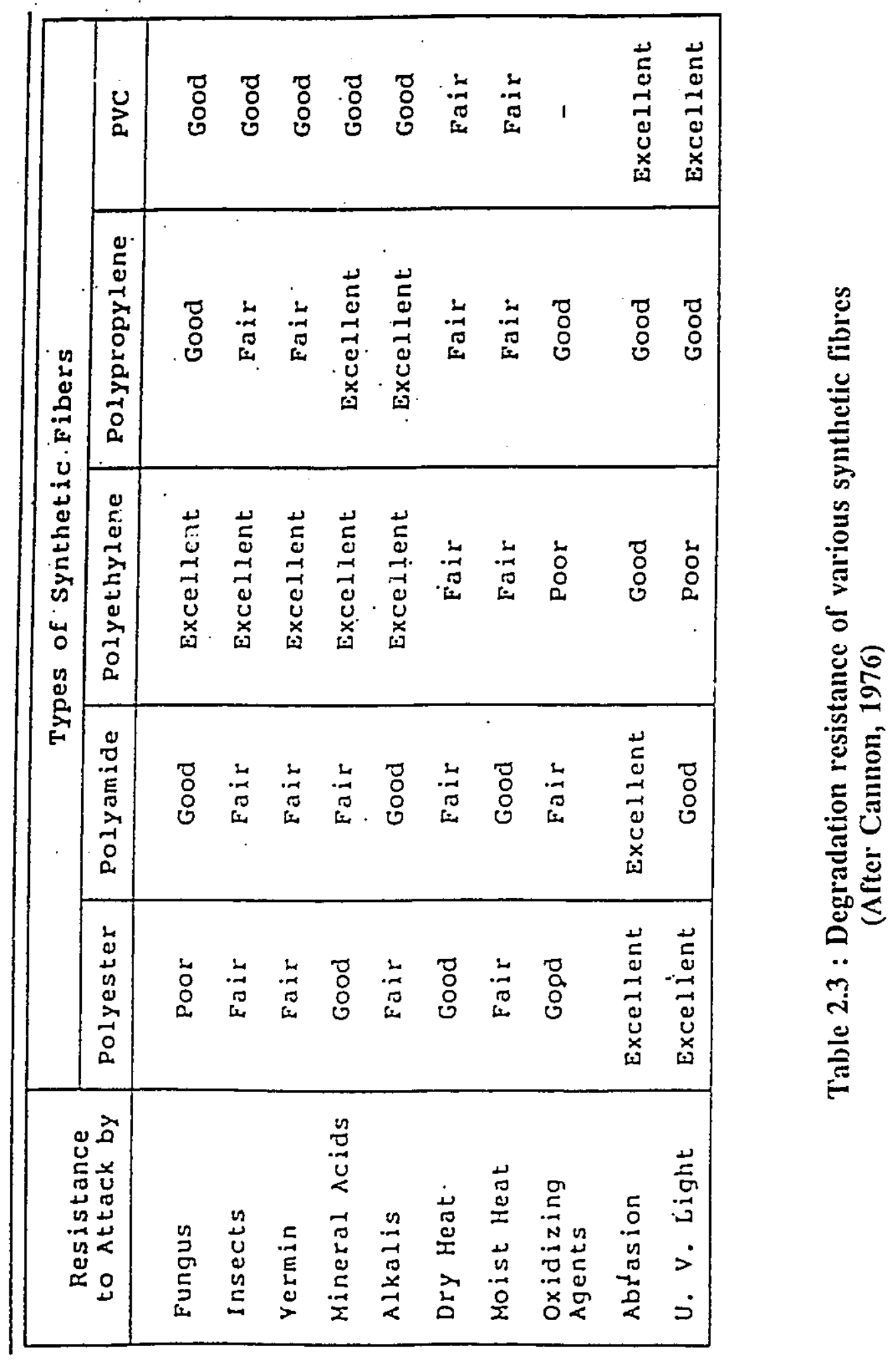


It should be noted that some of these values may be 1.0 or slightly above 1.0 , and may therefore be inconsequential. Equation [2.21] may be modified to incorporate partial factor of safety for joints and for ultraviolet degradation. Table 2.4 presents the recommended preliminary factor of safety values for determining allowable tensile strength of geogrids.

\subsection{CONSTRUCTION TECHNIQUES OF STONE COLUMNS}

The behaviour of stone columns depend largely of the construction techniques. The construction details of stone columns in the field are presented by Barksdale (1987). Usually, stone columns are formed by forming a hole in one of two techniques:

\subsubsection{Vibro-replacement (wet method)}

In this procedure, water jetted from the bottom of the vibroflot is used to scour out a portion of the weak material as the vibroflot is lowered. The water is kept flowing throughout construction in order to stabilize the hole sidewalls. The vibro-replacement method is applicable to very soft to firm cohesive soils ; silty sands ( $>15 \%$ fines); this method is used for most stability settlement, liquefaction applications.

The advantages and disadvantages of the vibro-replacement (wet) method has been presented by Barksdale (1987) as follows:

\section{Advantages of vibro-replacement (wet) method}

* It is the conventional method

* More positive hole support than dry method

* High coefficient of earth pressure $(\mathrm{k})$ value may allow the dissipation of pore water pressure during earthquake

* Design load capacity is typical 20-60 tons

* Higher capacity in silty sands 
Table 2.4 : Recommended factor of safety values for determining allowable tensile strength of geogrids (After Koerner, 1990)

\begin{tabular}{|l|c|c|c|c|}
\hline \multirow{2}{*}{ Application area } & \multicolumn{4}{|c|}{ Factor of safety value for Equation [2.21] } \\
\cline { 2 - 5 } & $F S_{I D}$ & $F S_{C R}$ & $F S_{C D}{ }^{*}$ & $F S_{B D}$ \\
\hline Unpaved roads & 1.1 to 1.6 & 1.5 to 2.5 & 1.0 to 1.5 & 1.0 to 1.2 \\
Paved roads & 1.2 to 1.5 & 1.5 to 3.0 & 1.1 to 1.6 & 1.0 to 1.2 \\
Embankments & 1.1 to 1.4 & 2.0 to 3.5 & 1.0 to 1.4 & 1.0101 .3 \\
Slopes & 1.1 to 1.4 & 2.0 to 3.5 & 1.0 to 1.4 & 1.0 to 1.3 \\
Walls & 1.1 to 1.4 & 2.0 to 3.5 & 1.0 to 1.4 & 1.0 to 1.3 \\
Bearing capacity & 1.2 to 1.5 & 2.0 to 3.5 & 1.0 to 1.6 & 1.0 to 1.3 \\
\hline
\end{tabular}

*The low end of the range refers to results that have compensated for creep in the performance of the tests. 
Disadvantages of vibro-replacement (wet) method

* Some uncertainty exists concerning support of hole in very soft to soft soils

* Not suitable in peat layers more than one column diameter in thickness

* Must use large stone which may be expensive

* Must dispose of silty effluent

* Not suitable if sensitivity $>6$

* Intrusion might occur.

\subsubsection{Vibro-displacement (dry method)}

In this method, the vibroflot is hydraulically advanced or pushed via the weight of the heavy flower tubes into the subsurface soil, displacing the soil laterally and forming an open hole. When the hole is ready by any of the last two method, stone is placed in the preformed hole by dumping stone from the ground surface and allowing it to fall between the vibroflot and the sidewalls of the hole. The vibro-displacement (dry method) is applicable to partially saturated cohesive soils; use where environmental restrictions exclude vibro-replacement; use in partially saturated clay fills; stability, settlement and liquefaction applications.

The advantages and disadvantages of the vibro-displacement (dry) method has been presented by Barksdale (1987) as follows:

The advantages of vibro-displacement (dry) method

* No silty water to dispose

* May be slightly cheaper than wet as a result of smaller column diameter

* The design load capacity is $15-40$ tons

Disadvantages of vibro-replacement (drv) method

* Smaller load capacity and column diameter than wet method

* Limited to partially saturated soils which will not collapse

* More smear than wet method. 


\subsection{CONCLUSIONS OF THE LITERATURE REVIEW}

The preceding review of the available literature on stone columns and the applications of polymer grid reinforcement in civil engineering allows some conclusions to be drawn with respect to the use of stone columns and the potential use of polymer grids to strengthen and enhance the performance of stone columns. The major observations of the literature survey is summarized in the following paragraphs.

- Stone columns are suitable for improving soft silts, clays and loose silty sands. Stone columns offer a valuable technique under specific conditions for (1) increasing bearing capacity and slope stability, (2) reducing settlement and increasing the time-rate of consolidation and (3) reducing liquefaction potential. Applications of stone columns include the support of embankments, bridge abutments, sewer facility, tanks and to stabilize existing slopes.

- Using of stone columns in sensitive soils should be given special care. However, the use of stone columns in highly compressible peat and organic soils is not recommended.

- The design and analysis of stone columns include the ultimate capacity and settlement. Stone columns design and analysis was given by different methods ranging from experience based empirical expressions to advanced finite element analyses.

- The excessive vertical settlement and lateral deformation of stone columns, under sustained load, suggests that additional confinement is necessary to improve the load carrying capacity and to increase the stiffness.

- Polymer grids have been successfully and effectively used in slopes or embankments, retaining walls, pavements and many other applications.

- The successful use of polymer grids to stabilize slopes and retaining walls suggests their use in buried structures such as stone columns to increase lateral confinement and reduce vertical settlement. 
- Polymer grids have shown to be a cost effective altemative to conventional earth reinforcement techniques.

- The physical properties and durability of polymer grids, including high tensile strength, resistance to chemical, climatic, and biological attacks, make the use of these grids in buried stone columns attractive.

The major conclusion of the literature review is that, a need still exists for research to investigate the potential use of polymer grids to enhance the confinement of stone columns and for theoretical analysis to model the behaviour of sleeve reinforced stone columns. 


\section{CHAPTER 3 \\ THEORETICAL CONSIDERATIONS}

\subsection{GENERAL}

The stone column analysis is an axisymmetric problem. The behaviour of stone columns in the field is best simulated, in the laboratory, by triaxial or uniaxial tests on granular aggregates compacted in cylindrical shape. Since experimental tests are usually time consuming and cannot consider all variables, it is therefore, desirable to develop an analytical technique to represent the stress-strain behaviour of both natural and reinforced columns. Natural stone columns have been analyzed in the past by the limit equilibrium method which takes into consideration the interaction effect of the column aggregate and the surrounding soil. Several theories have been proposed to calculate the ultimate load capacity and settlement of natural stone columns, such as the concept proposed by Hughes and Withers (1974).

Modelling the load transfer mechanism between the stone column and sleeve reinforcement during triaxial and uniaxial tests is extremely complex. A three dimensional finite element analysis would be one method to simulate this mechanism. The formulation of this model is complicated especially when the varying properties of the surrounding soft soil and the grid sleeve are included in the analysis. Therefore, simplified analytical models are preferred to simulate the stress-strain behaviour of a reinforced stone column.

In this chapter the analytical model of Hughes and Withers is presented for the analysis of ultimate load capacity of an isolated unreinforced stone columns. Also, the hyperbolic stress-strain relationship proposed by Duncan and Chang (1970) is employed to simulate the behaviour of unreinforced and sleeve reinforced stone columns. A separate hyperbolic stress-strain relationship, suitable to represent the behaviour of polymer grids is presented. A set of hyperbolic equations are also given to simulate the shear stresses at the interface between the stone column and the surrounding soil. 


\subsection{ANALYSIS OF UNREINFORCED STONE COLUMNS}

\subsubsection{Ultimate load capacity:}

The parameters required to estimate the ultimate load capacity of an isolated stone column are :

- the shear strength parameters of the soil surrounding the column

- the radial stress/deformation characteristics of the surrounding soil

- the angle of shearing resistance of the column material

- the initial diameter of the column, and

- the force-strain curve and physical properties of the polymer sleeves (for reinforced columns only).

Two basic models of calculation are in common use. The first model (Hughes and Withers, 1974 and 1975 and Aboshi et al, 1979) does not take into account the group effect and considers a single, incompressible, rigid-plastic column in a semi-infinite rigidplastic soft soil. The limiting confining pressure is determined from triaxial compression and/or pressuremeter tests. This type of model assumes that both the column and the surrounding soil are at failure.

The second type of model (Priebe, 1976; Goughnour and Bayuk, 1979) considers the behaviour of a "unit cell" containing a single column and its surrounding tributary soil. It is assumed that this unit cell is confined by a rigid frictionless wall and that the vertical strain at any horizontal level is uniform.

The ultimate capacity of an isolated stone column loaded concentrically is govemed primarily by the maximum lateral resistance of the soil at the bulging zone and, therefore, the extent of vertical movement within the column is limited. For some particular soil the vertical movement does not exceed four times the column diameter. For this type of soil, if the length to diameter ratio is less than four, the column would fail in end bearing before bulging (Hughes and Withers, 1974). If lateral bulging is idealised as a cylindrical expansion into the soil then it resembles a pressuremeter test in which a cylinder is expanded against the side of a borehole. If the soil is treated as an elasto- 
plastic material, then the limiting stress can be expressed by the following equation according to Gibson and Anderson (1961) as reproduced and confirmed by Hughes and Withers (1974)

$$
\sigma_{x}=\sigma_{x 0}+c\left(1+\log _{a} \frac{E_{1}}{2 c(1+\mu)}\right)
$$

where $\sigma_{\mathrm{ro}}, \mathrm{E}_{\mathrm{i}}, \mu$ and $\mathrm{c}$ are, respectively, the total in situ lateral stress, the initial tangent modulus, Poisson's ratio and the undrained shear strength of the soil. In other words, the stone column can be thought of as being confined in a triaxial stress system where the cell pressure is limited. Therefore, there is an ultimate load the column can carry. From a detailed examination of many field records Hughes and Withers (1974) have found that equation [3.1] can be represented in another form, as

$$
\sigma_{x}=\sigma_{x 0}+4 C+u
$$

where $u$ is the pore water pressure in the surrounding soil. If the soil in the bulged region near the top of the column is at critical state of stress then

$$
\sigma_{\mathrm{v}}^{\prime}=\left(\frac{1+\sin \left(\phi^{\prime}\right)}{1-\sin \left(\phi^{\prime}\right)}\right)\left(\sigma^{\prime} x\right)
$$

where

$$
\begin{aligned}
& \phi^{\prime}=\text { angle of shearing resistance of the column material } \\
& \sigma_{\mathrm{v}}^{\prime}=\text { effective vertical stress } \\
& \sigma_{\mathrm{r}}^{\prime}=\text { effective lateral stress }
\end{aligned}
$$

Therefore, according to Hughes and Withers (1974), the ultimate vertical stress which a column can carry, as it bulges laterally, is given by

$$
\sigma_{v}^{\prime}=\left(\frac{1+\sin \left(\phi^{\prime}\right)}{1-\sin \left(\phi^{\prime}\right)}\right)\left(\sigma_{x o}+4 C-u\right)
$$

This equation is valid only when the ratio of diameter of the stone column $\left(d_{c}\right)$ to the loaded area (B) is unity. In 1979, Madhav et al have modified equation [3.4] to be applicable to any area ratio $\left(d_{c} / B\right)$ from 0 to 1 as follows 


$$
\sigma_{v}^{\prime}=\frac{(1+s \ln \phi)}{(1-\sin \phi)}\left(\Delta C+\sigma_{x 0}+K_{0} g_{s}\right)-\left(\frac{d c^{2}}{B^{2}}\right)+\left(1-\frac{d c^{2}}{B^{2}}\right) g_{s} \quad[3.5]
$$

where $\mathrm{q}_{\mathrm{s}}$ is the bearing capacity of the surrounding soil which can be expressed as follows $\mathrm{q}_{\mathrm{s}}=(2 / 3) \mathrm{c} \mathrm{N}_{\mathrm{c}}$

$\mathrm{K}_{0}=$ coefficient of earth pressure at rest

$\mathrm{N}_{\mathrm{c}}=$ bearing capacity factor

$c=$ cohesion of the surrounding soil

Madhav et al (1979) have presented charts for $N_{c}$ for different values of $d_{c} / B$ and different cohesion ratios of the column material and the soil surrounding the column. For the purpose of this research the value of $d_{c} / B=1$, and the ratio of the stone column material's cohesion $\left(c_{1}\right)$ to the surrounding soil cohesion $\left(c_{2}\right)$ is taken as zero. Therefore, the maximum values of $\mathrm{N}_{c}$ will vary from 12 to 20 for angles of shearing resistance between $35^{\circ}$ and $45^{\circ}$.

Hughes et al (1975) have used equation [3.4] to estimate the load settlement behaviour of a $730 \mathrm{~mm}$ diameter stone column. Figure 3.1 shows a comparison of results when the effect of shear stress at the interface between the stone column and the surrounding soil was first ignored and then included in the calculation. The Cambridge pressiremeter was used to establish the radial stress-strain curve of the surrounding soil. This approximation was the best among different attempts using different testing devices to establish the lateral stress-strain curve. Equation [3.4] can be used to compute the ultimate capacity of a single isolated unreinforced stone column.

\subsubsection{Vertical settlement}

The method proposed by Hughes et al (1975), can also be used to calculate the compression of the natural stone column due to external load. The theory was based on the assumption that the column base is supported on a rigid layer and the stone column will fail in bulging. This assumption is true in the case of triaxial tests where the stone column is supported on a rigid base. In order to simplify the analysis the column usually is divided into horizontal layers and the total settlement is then related to the sum of the 


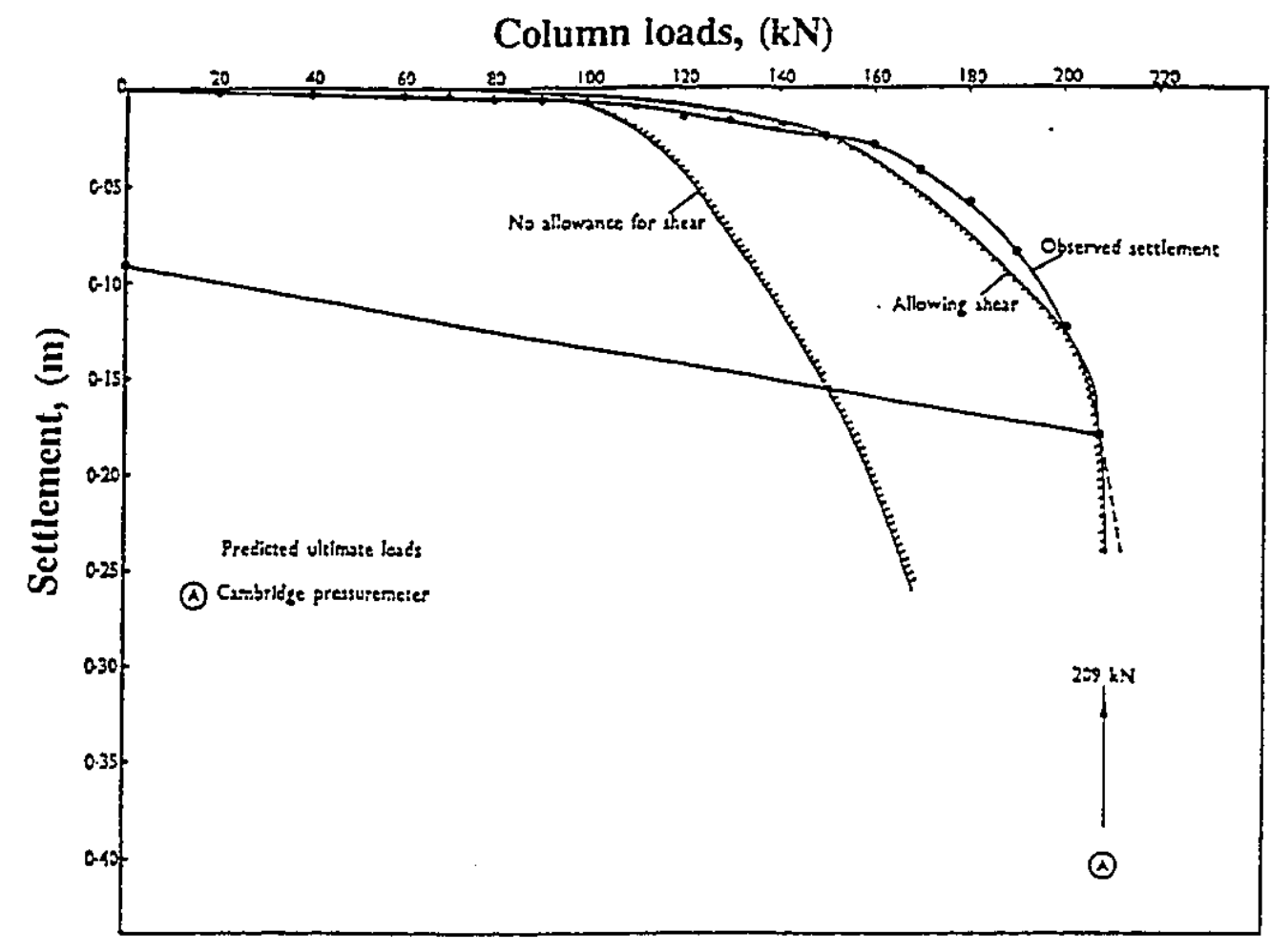

Figure 3.1: Predicted load-settlement curve for $730 \mathrm{~mm}$ diameter column compared with observed results (Hughes et al, 1975) 
contributions from each layer as

$$
\delta_{v}=\delta_{1}+\delta_{2} \ldots+\delta_{n}
$$

where

$$
\delta_{n}=\frac{2 H_{n} \delta_{x n}}{I}
$$

$H_{n}$ is the thickness of the layer considered and $\delta_{m} / r$ is the radial strain in the middle of the layer. If the analysis is to be carried out for actual stone columns in the field, the settlement of the surrounding soil can be calculated from the method proposed by Baumann and Buler (1974) as follows

$$
S=\sum_{0}^{B}\left(\frac{\Delta \mathbf{0}}{E_{d}}\right) \Delta z
$$

where $E_{d}$ and $\Delta \sigma$ are, respectively, the drained modulus of deformation and the increase in vertical stress at any depth $\mathrm{z}$ from the surface of the tcp soil layer. $H$ is the thickness of the compressible soil layer. The modulus of deformation, $E_{d}$, is related to the coefficient of volume compressibility, $\mathrm{m}_{v}$, as follows

$$
E_{d}=\frac{1}{m_{v}}
$$

The values of $E_{d}$ or $m_{v}$ are determined from drained triaxial or consolidation tests respectively. If the value of $E_{d}$ is determined form consolidation test it is usually termed the constrained modulus. In this research the stone columns were tested without any surrounding soil. Therefore, the settlement (compression) of the natural stone column material can be calculated by dividing the column into equal horizontal layers and the total settlement is the sum of the contribution from each layer. 


\subsection{ANALYSIS OF REINFORCED STONE COLUMNS}

\subsubsection{General}

Reinforced stone columns are composites elements consisting of aggregate, polymer sleeve and surrounding soil. In the field the surrounding soil will interact with the composite stone column elements and the hole process will be a complex interaction between three different materials. The granular aggregate is composed of particles of different sizes and has even after compaction, a relatively low deformation modulus. The sleeve reinforcement is made of a strong polymer with a high deformation modulus. The surrounding soil has physical parameters which can be determined experimentally.

As the stone column is subjected to a compressive axial force, the soil particles tend to be displaced in lateral and vertical directions. The presence of the polymer sleeve will restrain the aggregate from lateral movement and consequently the vertical compression of the column is reduced.

The presence of a polymer sleeve will also change the state of stress in the column material and will affect the strength and deformation properties of the column. The lateral stress of the column aggregate will develop additional confining stresses in the sleeve reinforcement. These additioral confining stresses are attributed to the hoop tension generated in the horizontal ribs of the sleeve. The degree of improvement of the column strength properties depends largely on the amount of the additional confining stress which can be generated by the polymer sleeve during loading. Figure 3.2 illustrate the principle of confinement supplied by the grid sleeve.

\subsubsection{Hyperbolic stress-strain relationship for granular material}

The behaviour of sleeve reinforced stone columns may be idealized as a hyperbolic nonlinear elastic material. This technique was originally proposed by Kondner and Zelasko (1963) for granular materials and based on triaxial test results. Later Duncan and Chang (1970) proposed a simplified stress-strain relationship which takes into account the 


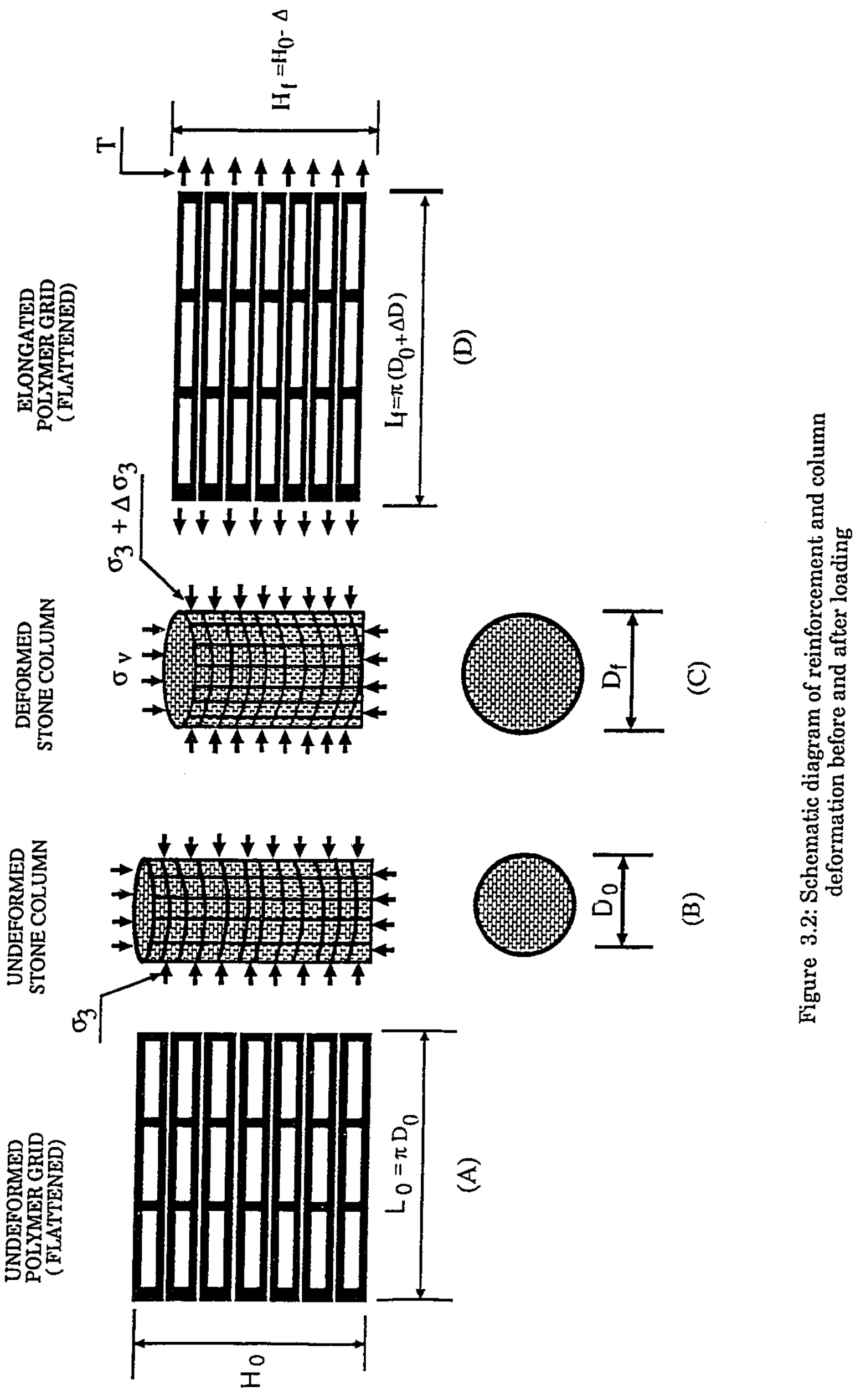


nonlinearity, stress dependency and inelasticity of the soil behaviour.

According to Duncan and Chang (1970), the hyperbolic stress-strain relation fora triaxial tests can take the following form

$$
\left(\sigma_{1}-\sigma_{3}\right)=\frac{\epsilon}{(a+b \epsilon)}
$$

The transformed linear form of equation $[3.10]$ will be as follows

$$
\frac{\epsilon}{\left(\sigma_{1}-\sigma_{3}\right)}=a+b \epsilon
$$

where,

$\mathrm{a}=$ the intercept of the transformed hyperbolic stress-strain curve (Figure 3.4)

$\mathrm{b}=$ the slope of the transformed hyperbolic stress-strain curve (Figure 3.4)

$\varepsilon=$ axial strain

The applicability of the hyperbolic relation to represent the stress-strain response for unreinforced and reinforced stone columns is indicated by the agreement between the straight line and the experimental data in the transformed hyperbolic form. By examining Figure 3.3 it is noticed that the asymptotic value of $\left(\sigma_{1}-\sigma_{3}\right)$ is larger than the compressive strength of the soil by a small amount. This should be expected, because the hyperbola remains below the asymptote at all infinite values of strain. The asymptotic value may be related to the compressive strength, however, by means of a factor $R_{f}$, termed the failure ratio

$$
R_{f}=\frac{\left(\sigma_{1}-\sigma_{3}\right)_{f}}{\left(\sigma_{1}-\sigma_{3}\right)_{u l t}}
$$

in which

$$
\begin{aligned}
& \left(\sigma_{1}-\sigma_{3}\right)_{\mathrm{f}}=\text { the compressive strength, or stress difference at failure } \\
& \left(\sigma_{1}-\sigma_{3}\right)_{\mathrm{ult}}=\text { the asymptotic value of stress difference, }
\end{aligned}
$$

The value of $R_{f}$ was found to vary between 0.75 and 1.0 , and is essentially independent of the confining stress (Duncan and Chang, 1970). The values of $a$ and $b$, in the 
transformed hyperbolic stress-strain curve in Figure 3.4, may be related to the initial value of the tangent modulus and the compressive strength. Therefore, equation [3.10] may be rewritten as

$$
\left(\sigma_{1}-\sigma_{3}\right)=\left[\frac{\epsilon}{\left(\frac{1}{E_{i}}+\frac{\epsilon R_{f}}{\left(\sigma_{1}-\sigma_{3}\right)_{f}}\right)}\right]
$$

For consolidated drained triaxial compression tests, the tangent modulus value and the compressive strength of soils depends on the confining pressure employed in the test. Experimental studies by Janbu (1963) have shown that the relationship between initial tangent modulus and confining pressure may be expressed as

$$
E_{i}=k p_{a}\left(\frac{\sigma_{3}}{p_{a}}\right)^{n}
$$

where

$\mathrm{E}_{\mathrm{j}}=$ the initial tangent modulus

$\sigma_{3}=$ the minor principle stress (confining pressure)

$\mathrm{p}_{\mathrm{a}}=$ atmospheric pressure expressed in the same pressure units as $\mathrm{E}_{\mathrm{i}}$ and $\sigma_{3}$.

$\mathrm{k}=\mathrm{a}$ modulus number

$\mathrm{n}=$ the exponent determining the rate of variation of $\mathrm{E}_{\mathrm{i}}$ with $\sigma_{3}$

Both $\mathrm{k}$ and $\mathrm{n}$ are dimensionless numbers. Values of the parameters $\mathrm{k}$ and $\mathrm{n}$ may be determined from the results of triaxial tests by plotting the value of $E_{i}$ against $\sigma_{3}$ on a log$\log$ scale and fitting a straight line to the data, as shown in Figure 3.5.

It is possible to determine the values of tangent modulus corresponding to any point on the stress-strain curve. If the value of the minor principle stress is constant, the tangent modulus $E_{1}$ may be expressed as

$$
E_{i}=\frac{\partial\left(\sigma_{1}-\sigma_{3}\right)}{\partial \epsilon}
$$

differentiating equation [3.13] leads to the following expression for tangent modulus 


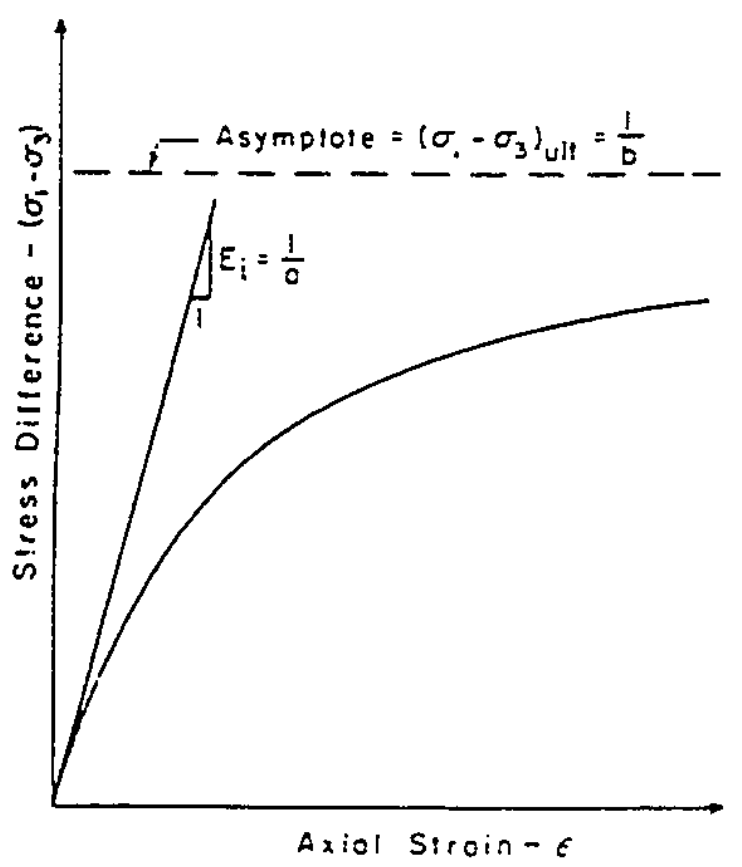

Figure 3.3: Hyperbolic stress-strain curve

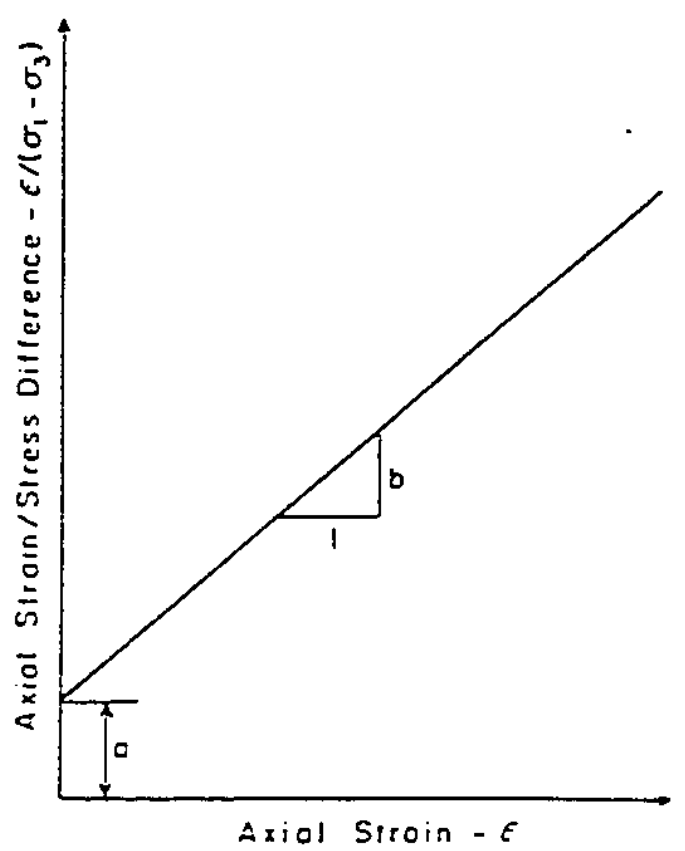

Figure 3.4: Transformed hyperbolic stress-strain curve 


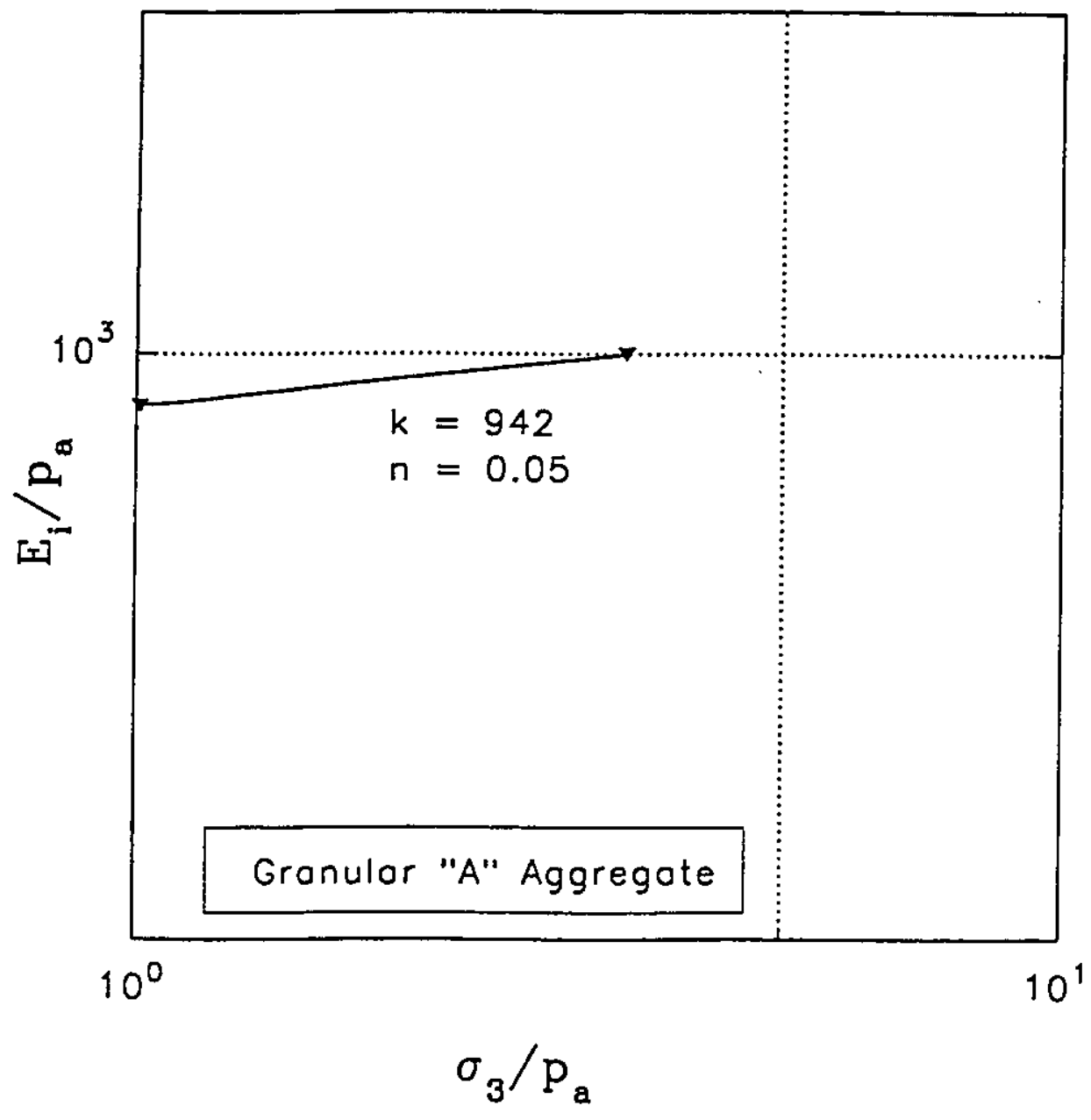

Figure 3.5: Variation of initial tangent modulus with confining pressure for granular " $A$ " aggregate 


$$
E_{t}=\left[\frac{\frac{1}{E_{i}}}{\left(\frac{1}{E_{i}}+\frac{R_{f} \epsilon}{\left(\sigma_{1}-\sigma_{3}\right)_{f}}\right)^{2}}\right]
$$

According to Duncan and Chang (1970), this expression has one significant shortcoming: the value of the tangent modulus, $E_{v}$, is related to both stress difference and strain $\left[\left(\sigma_{1}-\sigma_{3}\right)\right.$ and $\varepsilon$ ], which may have different reference states. The reference of $\left(\sigma_{1}-\sigma_{3}\right)=0$ can be easily specified accurately, but the state for strain $(\varepsilon=0)$ is completely arbitrary. For the purpose of analysing the effect of newly applied external loads, the initial condition could be chosen as the reference state for strain but not for stress difference. Therefore, the expression for tangent modulus may be made more generally useful if it is made independent of stress or independent of strain.

Because the stress may be calculated more accurately than strain in many soil mechanics problems, Duncan and Chang (1970) have suggested that it is more logical to eliminate strain and express the tangent modulus value in terms of stress only. The strain may be eliminated from equation [3.16] by rewriting equation [3.13] as

$$
\epsilon=\left[\frac{\sigma_{1}-\sigma_{3}}{E_{i}\left[1-\frac{R_{f}\left(\sigma_{1}-\sigma_{3}\right)}{\left(\sigma_{1}-\sigma_{3}\right)_{f}}\right]}\right]
$$

substituting equation [3.17] into equation [3.16] and simplifying the resulting expression, $E_{\imath}$ may be expressed as

$$
E_{t}=\left(1-R_{f} S\right)^{2} E_{i}
$$

where

$$
S=\frac{\left(\sigma_{1}-\sigma_{3}\right)}{\left(\sigma_{1}-\sigma_{3}\right)_{f}}
$$

is the stress level, or fraction of strength mobilized. The value of $E_{i}$ is given in equation 
[3.14]. The relationship between compressive strength and confining pressure may be expressed in terms of the Mohr-Coulomb failure criteria as

$$
\left(\sigma_{1}-\sigma_{3}\right)_{f}=\left[\frac{2 c \cos (\phi)+2 \sigma_{3} \sin (\phi)}{(1-\sin (\phi))}\right]
$$

substituting equations, [3.14, 3.19 and 3.20] into equation [3.18], the tangent modulus value for any stress condition may be expressed as

$$
E_{t}=\left[1-\frac{R_{f}(1-\sin (\phi))\left(\sigma_{1}-\sigma_{3}\right)}{2 c \cos (\phi)+2 \sigma_{3} \sin (\phi)}\right]^{2} k p_{a}\left(\frac{\sigma_{3}}{p_{a}}\right)^{n}
$$

equation [3.21] can be used to calculate the tangent modulus at any stress level for granular material forming the stone column.

For this research a computer program was written to solve the hyperbolic stressstrain relationship using the appropriate parameters. The program was initially calibrated by substituting known parameters from Duncan and Chang (1970) for dense sand. These parameters in the initial simulation were as follows: $\phi=36^{\circ}, C=0.0, R_{f}=0.91, k=2000$ and $n=0.54$. The result of the calculation is shown in Figure 3.6. A similar analysis was performed for the granular material used in this research. The results are shown in Figure 3.7 for granular "A" material. The different parameters used in this analysis will be presented later in chapter 6.

Using the hyperbolic stress-strain relationship, the behaviour of polymer grid and the aggregate will be analyzed separately. Also, the behaviour of the sleeve reinforced stone columns will be analyzed with the same technique using the corresponding parameters obtained from drained triaxial tests on sleeve reinforced specimens.

\subsubsection{Hyperbolic stress-strain relationship for polymer grids}

The force-strain relationship of polymer grid may be idealized by a nonlinear, elastic hyperbolic model. Chalaturnyk et al (1988) have proposed the following relationship to represent the polymer grid behaviour 


$$
F=G_{i} \epsilon_{a}\left(1-\frac{\epsilon_{a}}{2 \epsilon_{a f}}\right)
$$

where

$$
\begin{aligned}
\mathrm{F} & =\text { axial load per unit width, } \mathrm{kN} / \mathrm{m} \\
\mathrm{G}_{\mathrm{i}} & =\text { initial load modulus, } \mathrm{kN} / \mathrm{m} \\
\varepsilon_{\mathrm{a}} & =\text { axial strain } \\
\varepsilon_{\mathrm{af}} & =\text { axial strain at failure }
\end{aligned}
$$

The values of these parameters are different for various polymer grids and can be obtained form the force-strain relationship. Chalaturnyk et al (1988) have used the following parameter for Tensar SR2

$$
\begin{aligned}
\mathrm{G}_{\mathrm{i}} & =778 \mathrm{kN} / \mathrm{m} \\
\mathrm{G}_{\mathrm{un}} & =1556 \mathrm{kN} / \mathrm{m} \text { (Unloading Modulus) } \\
\varepsilon_{\mathrm{a}} & =18 \%
\end{aligned}
$$

A similar equation will be used with the appropriate parameters to simulate the behaviour of the polymer grids used in this study. The corresponding parameters will be determined experimentally from the force-strain test on polymer grid specimens.

\subsubsection{Hyperbolic stress-strain relationship for the interface shear stress}

The shear stress at the interface between a stone column or pile and the surrounding soil has been studied by several investigators (Hughes and Withers, 1974; Goughnour et al 1989). In many cases the vertical shaar stress developed along the side of the pile was ignored or assumed to be equal to the average shear strength of the surrounding soil.

For short stone piles $(L / D<4)$ the interface shear stress can be neglected without affecting the accuracy of the load capacity calculation. However, in longer piles the accumulated load transfer from these shear stresses could be significant. In this research no surrounding soil was used and the stone columns were generally short. Therefore, it is not possible to present experimental results regarding the interface stresses. However, for such a case and for practical purpose the interface stress could be conveniently 


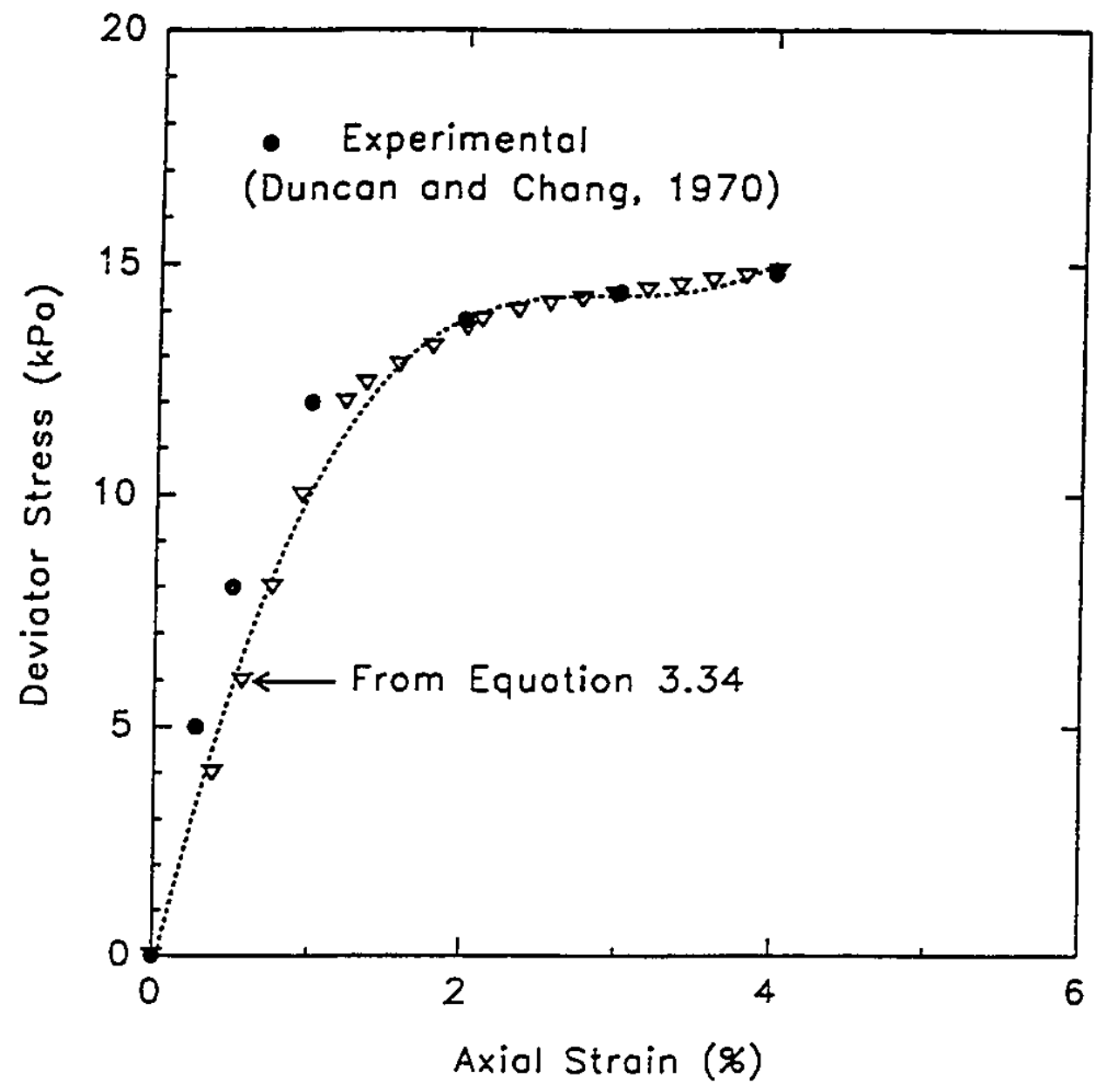

Figure 3.6: Experimental and predicted behaviour of dense sand (Experimental data and parameters are adopted from Duncan and chang, 1970) 


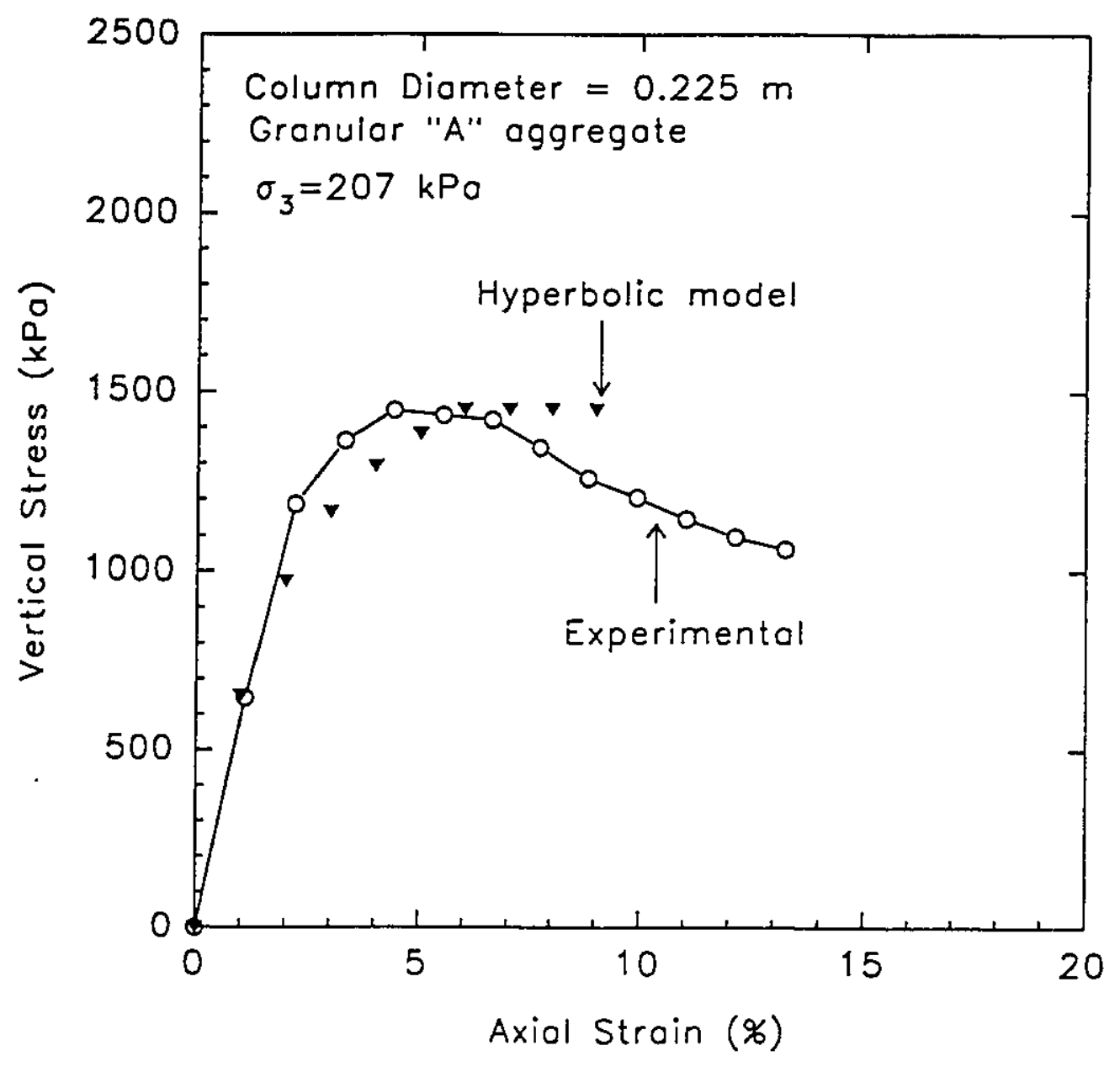

Figure 3.7: Experimental and predicted stress-strain behaviour of an unreinforced column using the hyperbolic model 
represented by means of equations similar to those developed by Clough and Duncan (1971). The nonlinear stress-displacement relationship may be approximated by a hyperbola having an equation of the form

$$
\tau=\left[\frac{\Delta_{s}}{a+b \Delta_{s}}\right]
$$

where $\tau=$ interface shear stress; $\Delta=$ interface shear displacement; and $a$ and $b$ are empirical coefficients whose values are determined experimentally as explained earlier. The values of these coefficients may be determined by plotting the stress-displacement data from pull-out or direct shear tests on the polymer mesh sandwiched between one layer of soil and another layer of granular materiai. This relationship may be transformed to another set of axes on which the hyperbola of equation [3.23] plots as a straight line according to

$$
\frac{\Delta_{s}}{\tau}=a+b \Delta_{s}
$$

if values for $\Delta_{s} \tau$ are plotted against values of $\Delta_{s}$, the resulting variation will be a straight line. The straight line may be fitted between $70 \%$ and $95 \%$ of the maximum shear stress values (Duncan and Chang, 1970). The coefficient $a$ is the intercept, and coefficient $b$ $\left(1 / \tau_{\mathrm{ult}}\right)$ is the slope of the straight line on the transformed plot. The reciprocal of coefficient a is the initial tangent of the load-displacement curve, and is analogous to the initial tangent modulus of a stress-strain curve. This value may be termed as the initial shear stiffness, $\mathrm{K}_{\mathrm{s}}$, and has units of $\mathrm{kN} / \mathrm{m}^{2}$. Both the initial shear stiffness and the shear strength of the interface depend on the vertical stress applied to the stone column and, consequently, the confining pressure and the type (stiffness) of polymer grid sleeve. The variation of the shear stiffness with confining pressure may be expressed using an equation of the general form suggested by Janbu (1963)

$$
k_{s i}=Q_{p}\left(\frac{\sigma_{3}}{p_{a}}\right)^{r}
$$

where $Q$ is the dimensionless stiffness number; $r$ is the stiffness exponent and $p_{a}$ is the 
atmospheric pressure expressed in the same units as the confining pressure. $\mathrm{Q}$ and $\mathrm{r}$ may be determined in a similar manner like $\mathrm{k}$ and $\mathrm{n}$ of equation [3.14].

The shear strength at the interface is proportional to the normal stress. The strength characteristics of the interface may be given in terms of the interface shearing resistance between the soil and polymer grid according to the following expression

$$
\tau_{f}=\sigma_{n} \tan (\delta)
$$

the value of $\delta$ may be found from triaxiai tests on a sleeve reinforced stone column, interface direct shear test or from pullout tests. Alternatively, the value of $\delta$ may be assumed to be equal to the angle of shearing resistance of the stone column aggregate. The failure shear stress $\tau_{\mathrm{f}}$ is usually related to the ultimate shear stress $\tau_{\text {ult }}$ by a factor $\left(\mathbf{N}_{\mathrm{f}}\right)$ with a value less than one according to the following expression

$$
N_{f}=\left(\frac{\tau_{f}}{\tau_{u l t}}\right)
$$

Substituting the values of $a$ and $b$ and equation [3.27] into equation [3.23] the variation of shear stress with displacement may be expressed as follows

$$
\tau=\left[\frac{\Delta_{s}}{\frac{1}{k_{s}}+\frac{N_{f} \Delta_{s}}{\tau_{f}}}\right]
$$

Using this equation, the variation of shear stress with displacement at the interface of the stone column may be calculated for any value of normal stress. The values of $Q, r, N_{f}$ and $\delta$ may be determined from a series of drained triaxial compression tests with different confining pressures or from direct shear test under different normal stresses. For an incremental stress analysis, equation [3.28] is differentiated with respect to $\Delta_{s}$, and the value of $\Delta_{s}$ is eliminated from the resulting equation. The tangent stiffness at any stress level may be expressed as follows 


$$
K_{s t}=K_{s i}\left(1-\frac{N_{f}^{\tau}}{\tau_{f}}\right)^{2}
$$

The tangent suiffness is calculated at the beginning of each increment based on the values of $\sigma_{\mathrm{n}}$ and $\tau$. This equation takes care of the bearing capacity due to friction resistance at the interface between the polymer sleeve and the aggregate of the stone column as well as the surrounding soils in the field.

Wilson-Fahmy and Koerner (1994) have suggested that the capacity due to bearing of the transverse ribs of the polymer grid should be considered and they proposed an equation similar to equation [3.29] as follows

$$
K_{b t}=\left[1-\frac{\left(R_{b} \sigma_{b}\right)}{\left(\sigma_{n} N_{q}\right)}\right]^{2} K_{b}
$$

where $K_{b}=$ the initial tangent slope; $\sigma_{b}=$ the bearing stress of the transverse ribs; $R_{b}=$ a constant less than one and $\mathrm{N}_{\mathrm{q}}$ is a bearing capacity factor. The initial tangent bearing stiffness is related to the confining pressure as follows

$$
K_{b}=D P_{a}\left(\frac{\sigma_{3}}{P a}\right)^{m}
$$

where $\mathrm{D}$ and $\mathrm{m}$ are constants determined in a similar manner like $\mathrm{k}$ and $\mathrm{n}$ shown earlier in equation [3.14].

The bearing stress may be obtained by back-analysis of pull-out tests on short relatively inextensible geogrids (Wilson-Fahmy and Koerner 1994). The bearing capacity factor $\mathrm{N}_{\mathrm{q}}$ is determined from the following equation after Jewell (1991)

$$
N_{q}=\tan \left(\frac{\pi}{4}+\frac{\phi}{2}\right) \exp \left[\left(\frac{\pi}{2}+\phi\right) \tan \phi\right]
$$

where $\phi=$ the angle of shearing resistance of the soil within the geogrid apertures. Wilson-Fahmy and Koerner (1994) found that the values of $\mathrm{N}_{\mathrm{q}}$ vary between 24.3 and 28.8 with an average of 25.5 and this average value corresponds to a soil shearing angle 
of $45^{\circ}$. The interface shear stress is depending on the friction between polymer grid, aggregate and the surrounding soil. Also, the bearing stresses of the aggregate and the soil confined in the polymer grid apertures will contribute to the interface shear stresses.

The interface stresses may be determined experimentally by pull-out tests for a free moving polymer grid (i.e not anchored at one end). The grid should be embedded between one layer of the stone column aggregate and another layer of the surrounding soil material as mentioned earlier. The pull-out capacity of the free moving polymer grid is an indication of the interface shear stress between the reinforced stone column and the surrounding soil. The interface shear stresses can be calculated according to

$$
\tau_{i}=\frac{F}{\left(L_{e} B\right)}
$$

where,

$\tau_{\mathrm{i}}=$ interface shear stress $\left(\mathrm{kN} / \mathrm{m}^{2}\right)$

$\mathrm{F}=$ pull-out force $(\mathrm{kN})$

$\mathrm{L}_{e}=$ embedded length of polymer grid (m)

$\mathrm{B}_{e}=$ embedded width of polymer grid (m) 


\section{CHAPTER 4}

\section{EXPERIMENTAL PROGRAM}

\subsection{GENERAL}

Many authors have claimed that the behaviour of stone columns can be simulated by large triaxial compression tests on granular material (Hughes and Withers, 1974 Aboshi et al, 1979 and Mitchell and Huber, 1985). In 1978, Huber conducted a series of large consolidated drained triaxial tests (12 inch in diameter and $30 \mathrm{inch}$ in height). The tests were conducied to establish the stress strain behaviour and the physical properties of the aggre $;$ ates used in the construction of 6552 stone columns for a waste water plant at Santa Barbara, Califomia. The material used for the preparation of the triaxial specimens was similar to the material used in this research. Furthermore, the specimen preparation and loading technique is also similar to the technique followed in this research. Figure 4.1 presents some of the results obtained by Huber (1978) from his large triaxial tests. Over the past few years the availability of polymer grids with high extensional stiffness and resistance to corrosion has increased interest in grid reinforcement for soils. The performance of the reinforced soil is highly dependent on the strength properties of the selected polymer grid.

In 1988, Fukushima et al have studied the properties of soils that were reinforced with different types of grids using a large $(120 \mathrm{~cm}$ in diameter and $240 \mathrm{~cm}$ in height) triaxial compression cell. The study was aimed to investigate the strength and deformation characteristics of sand reinforced with geogrid, non-woven fabric and metal strips arranged in horizontal layers at equal spacing within the specimen depth. The study has shown that, among the three reinforcements used, the geogrid reinforcement had the greatest reinforcing effect, but the stress ratio $\left(\sigma_{1} / \sigma_{3}\right)$ dropped sharply after the shearin deformation reached a certain value and they attributed the sharp drop in strength to the rupture of the geogrid. 


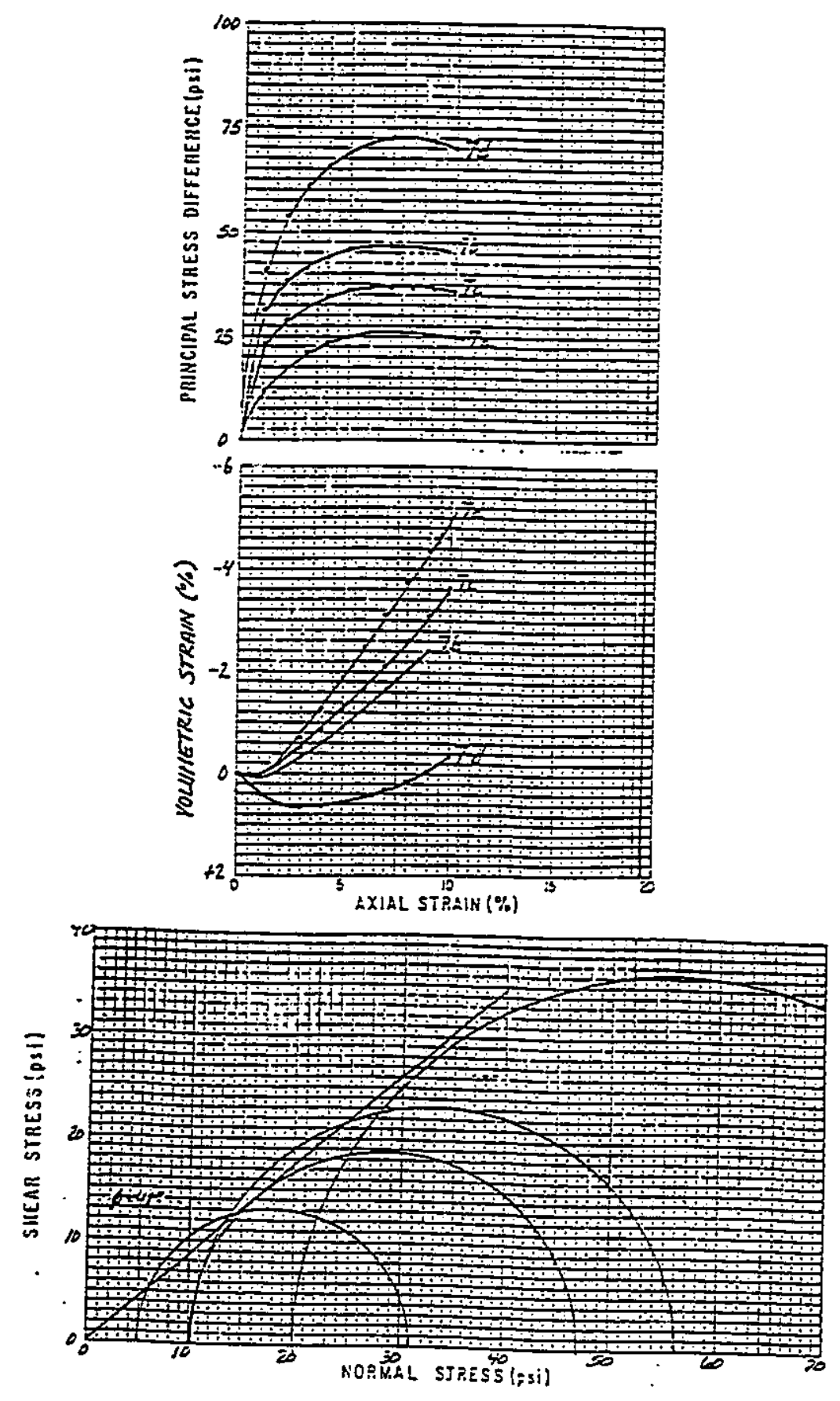

Figure 4.1: Strength envelope of aggregates tested in a large triaxial cell (After Huber, 1978) 
Based on the recommendations from the previous studies and the theoretical considerations presented in chapter 3, large triaxial and uniaxial tests were chosen to investigate experimentally the behaviour of unreinforced and sleeve reinforced stone columns.

\subsubsection{Advantages of large triaxial tests}

- Coarse aggregates can be used

- Representative specimens of reinforcement can be employed

- A large triaxial facility will reduce boundary effects

- The results from large tests could be extrapolated to field performance of the reinforced stone columns

- Instruments can be embedded without serious consequences

- The results from large tests are of particular significance in the experimental and analytical assessment.

\subsubsection{Objectives of triaxial stone column tests}

The objectives of the triaxial stone columns tests were to investigate the following

- Fundamental behaviour of polymer grid sleeve confined stone columns

- Amount of strength increase of reinforced stone columns under triaxial loading condition

- Deformation characteristics and failure modes of unreinforced and reinforced stone columns

- Tensile stress in the sleeves reinforcing the triaxial columns.

\subsubsection{Objectives of the uniaxial stone column tests}

The objectives of the uniaxial stone columns tests were to investigate the following

- To determine the actual load-compression relationship for uniaxial stone columns with polymer sleeves

- To determine the lateral deformation of uniaxial sleeve reinforced stone columns 
- To study the effect of polymer sleeves in providing additional confinement

- To determine the actual deformed shape of the reinforced stone columns under uniaxial loading conditions.

\subsection{EQUIPMENT}

\subsubsection{Triaxial cell}

The apparatus is of typical triaxial design and it could accommodate specimens $230 \mathrm{~mm}$ in diameter and $460 \mathrm{~mm}$ in height. The triaxial cell consisted of five main parts: the Perspex cell, the pedestal, the load transducers, the upper and lower platen and rubber membranes.

The transparent Perspex cylinder was used as the main body of the cell. The cylinder was bolted to the base by means of tie bars that were threaded into the base. The pedestai acted as a support plate between the lower platen and the load transducers. It was made of $38 \mathrm{~mm}$ thick steel plate and had an outer diameter of $257 \mathrm{~mm}$. The load transducers were installed in the base at a spacing of $120^{\circ}$. The top of the transducers were threaded into the pedestal, while the bottom passed through the base and was retained by a nut. Details of the load transducers are presented in Appendix B.

The upper and lower platen were two circular steel plates and acted as top and bottom caps for the triaxial sample. During the test, the surface of the platen was coated with silicone grease and covered with discs of rubber in order to reduce the friction between the soil sample and the platen. Details of the cell are given in Figure 4.2.

The membranes were made of natural latex and had high durability. The average thickness of the membranes was $0.58 \mathrm{~mm}$, the diameter was $225 \mathrm{~mm}$ and the length was $508 \mathrm{~mm}$. 


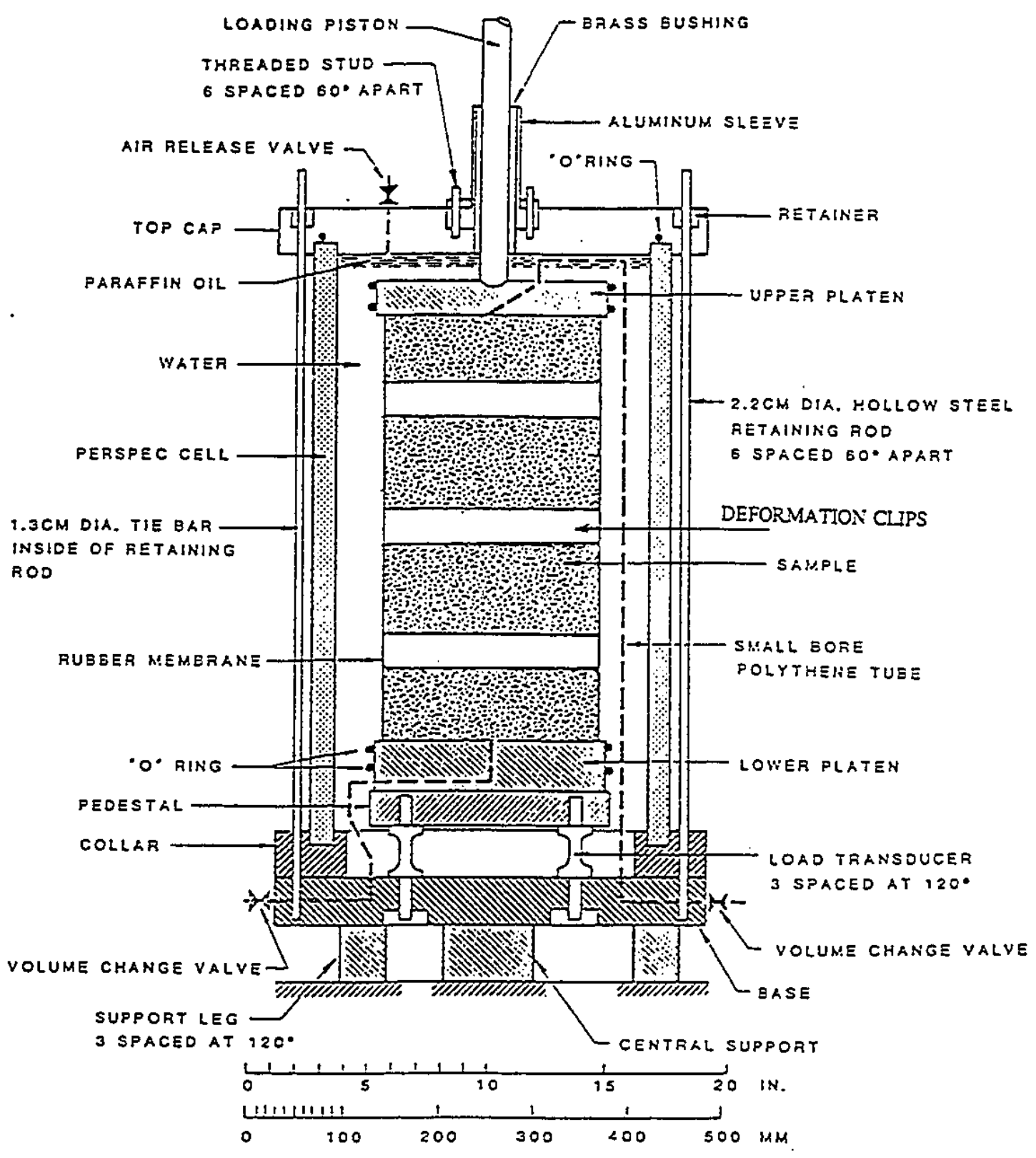

Figure 4.2: Triaxial cell 


\subsubsection{Compaction equipment}

The method of compaction followed in this research was by vibration in accordance with ASTM D2049. Basically the soil was placed in a cylindrical mould in layers; a surcharge weight $(13.8 \mathrm{kPa})$ was applied on top of the aggregate and the whole assembly was vibrated to the required density. The components of the compaction mould and the vibrating table are shown in Figure 4.3. The principle components of the compaction assembly were the lower platen, mould, surcharge weight, guiding sleeve and vibrating table.

\subsubsection{Lateral deformation clips}

The lateral deformation of a specimen during shear was to be measured. The ultimate capacity of a stone column is a function of the lateral deformation. As previously explained (chapter 3 ) the lateral deformation of the column or pile in the field is usually not measured. A method was suggested by Hughes and Withers (1974). They calculated the lateral deformation of the stone columns from representative samples tested in a drained triaxial test. The volume change was used to back-calculate the lateral deformation.

In this research, the lateral deformation was measured directly. Three clips with LVDT,s were used to measure the lateral deformation at three height levels of the column. The clips were made of stainless steel to avsid corrosion. The stainless steel clips were rolled in circular shape of $215 \mathrm{~mm}$ in diameter. The stainless steel clips were mounted with strain gauges at the center. The strain gauges were water proofed and connected to the data acquisition system.

The change in column diameter during loading was monitored and the data was collected by the acquisition system. A calibration factor was established for each gauged stainless steel clip. The calibration curves of three deformation clips are presented in Appendix B. 


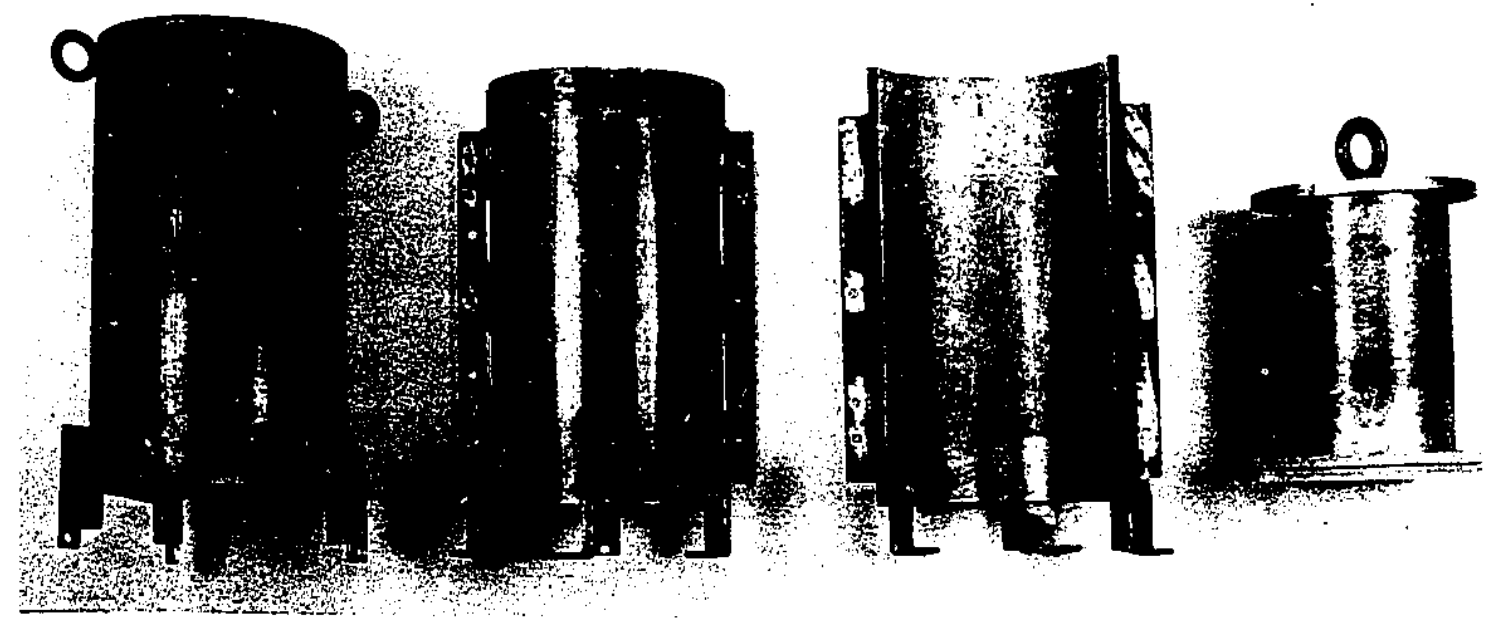

Guiding sleeve

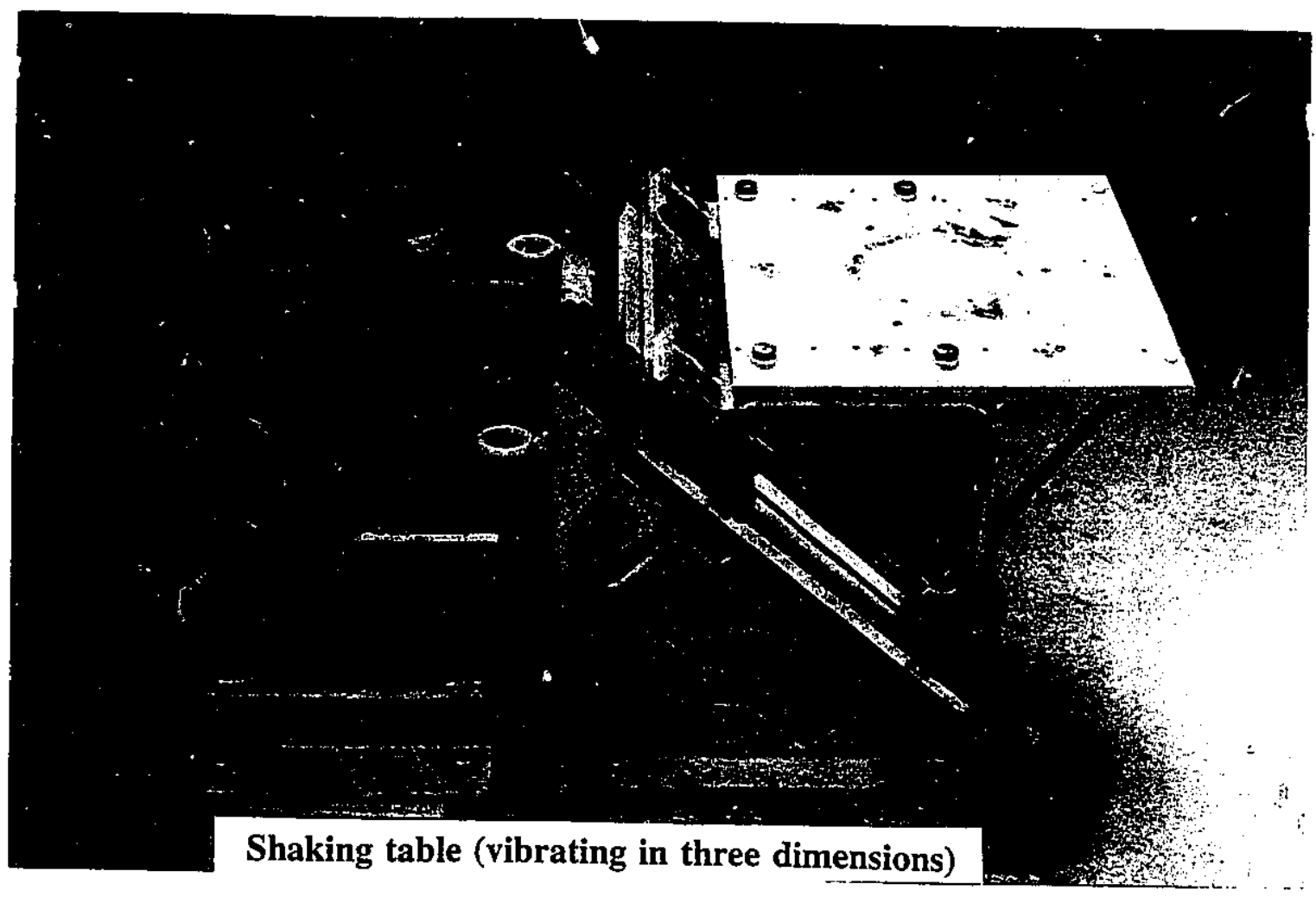

Figure 4.3: Components of compaction mould and vibrating table 


\subsubsection{Volume gauge}

The change in volume of a joil sample is an important quantity during consolidation and during shear in a drained triaxial test. During the consolidation part, the volume change is needed to calculate the actual density of the specimen before the test. Also, the amount of volume change was used to compare the behaviour of the reinforced to the corresponding unreinforced specimen. The approximate volume change of a specimen (225 mm in diameter and $450 \mathrm{~mm}$ in height) was about $300 \mathrm{cc}$.

A volume change apparatus was utilized for this purpose. The device has the capability to measure up to $80 \mathrm{cc}$, but the drainage line can be reversed to obtain continuous volume change measurements. It was slightly modified in order to release the air trapped in the triaxial cell. The apparatus was then calibrated under different pressures 1. - inging from $100 \mathrm{kPa}$ to $400 \mathrm{kPa}$. This was the range of confining pressures selected in this research. The calibration curve was found to be a straight line for these pressures. No hysteresis was observed. The calibration curve factor of the volume change device was inputted in the data acquisition system for automatic recording of volume change. The calibration curve of the volume change device is shown in Appendix B.

\subsection{MATERIALS}

\subsubsection{Soils}

To investigate the effect of soil type on the behaviour of a triaxial specimen, two types of granular aggregates were used. Each aggregate had different characteristics. These included grain size, size distribution and density. The two aggregates are described briefly below.

4.3.1.1 Granular "A" aggregate: A well-graded good quality crushed granular limestone which can meeting the specification of granular "A". This aggregate consisted mainly of hard grey granular particles. This material had been examined by many investigators (Scott et al, 1980; Mowafy, 1986; Zhao, 1993) and its properties are well 
established. The maximum density of this aggregate was $22 \mathrm{kN} / \mathrm{m}^{3}$ determined by the modified Proctor compaction test with an optimum moisture content of $6.8 \%$. In this investigation the granular "A" material was compacted to a density of $18.5 \mathrm{kN} / \mathrm{m}^{3}$ which corresponded to $85 \%$ of maximum. The grain size distribution is shown in Figure 4.4.

4.3.1.2 Uniform crushed stone $3 / 8$ " $(9.5 \mathrm{~mm})$ : The dominant size of this aggregate is between $7-10 \mathrm{~mm}$, therefore, it can be classified as uniformly graded angular material. The maximum density of this aggregate was found to be $17.4 \mathrm{kN} / \mathrm{m}^{3}$ and the minimum density was $14.2 \mathrm{kN} / \mathrm{m}^{3}$; the specific gravity was 2.76 determined from the w/ashed and oven dried aggregate. In this investigation the uniform material was compacted to a density of $17.0 \mathrm{kN} / \mathrm{m}^{3}$ or $89 \%$ of relative density. The ratio between the diameter of the cell and the maximum aggregate size cell was 24 . The grain size distribution of this aggregate is also shown in Figure 4.4.

The two aggregates were selected because they present medium and low compressible materials that are suitable to be used as backfill for the stone columns. The paricles shape of both aggregates were angular. A typical shear stringth envelope for the granular " $\mathrm{A}$ " and the uniform aggregate is shown in Figure 4.5. The angles of shearing resistance were found to be $54^{\circ}$ and $42.5^{\circ}$ for the well graded and uniform stone aggregate respectively. The angles of shearing resistance were obtained from the Mohr-Coulomb failure envelope of three drained triaxial tests for different confining pressures. Table 4.1 shows the physical properties of the two granular materials.

Munfakh et al (1987) stated that the angle of shearing resistance of a stone column material depends on the size and the shape of the aggregate, the installation process and the infiltration of native soil into the column voids. Greenwood (1970) assumed an angle of shearing resistance of $35^{\circ}$ for the evaluation of the column's horizontal shear resistance. However, Greenwood and Kirsch (1984) concluded that the variation of the angle of shearing resistance in the order $5^{\circ}$ has comparatively little influence on the ultimate load capacity and settlement of stone columns. 


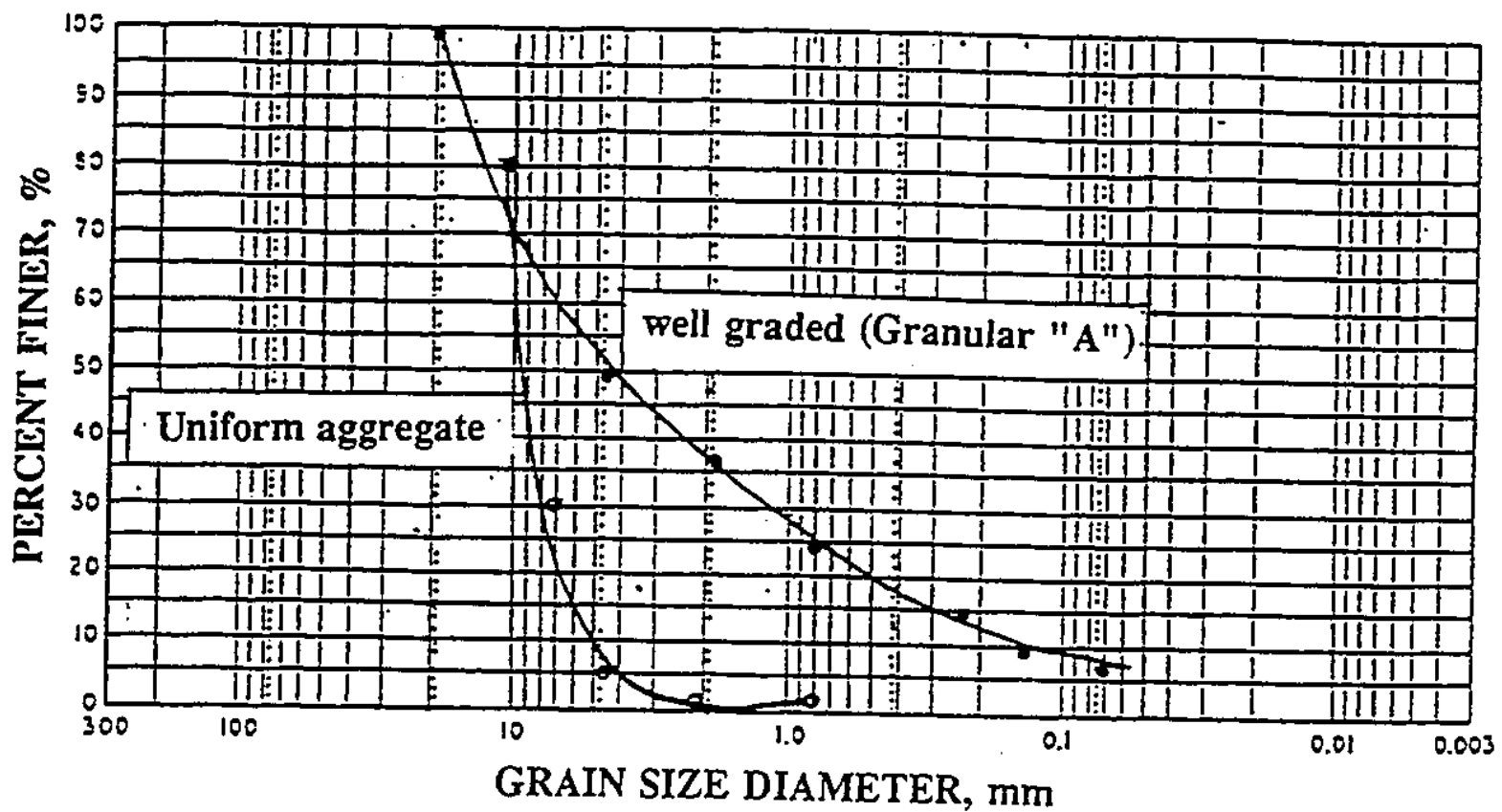

Figure 4.4: Grain size distribution of the two aggregates 


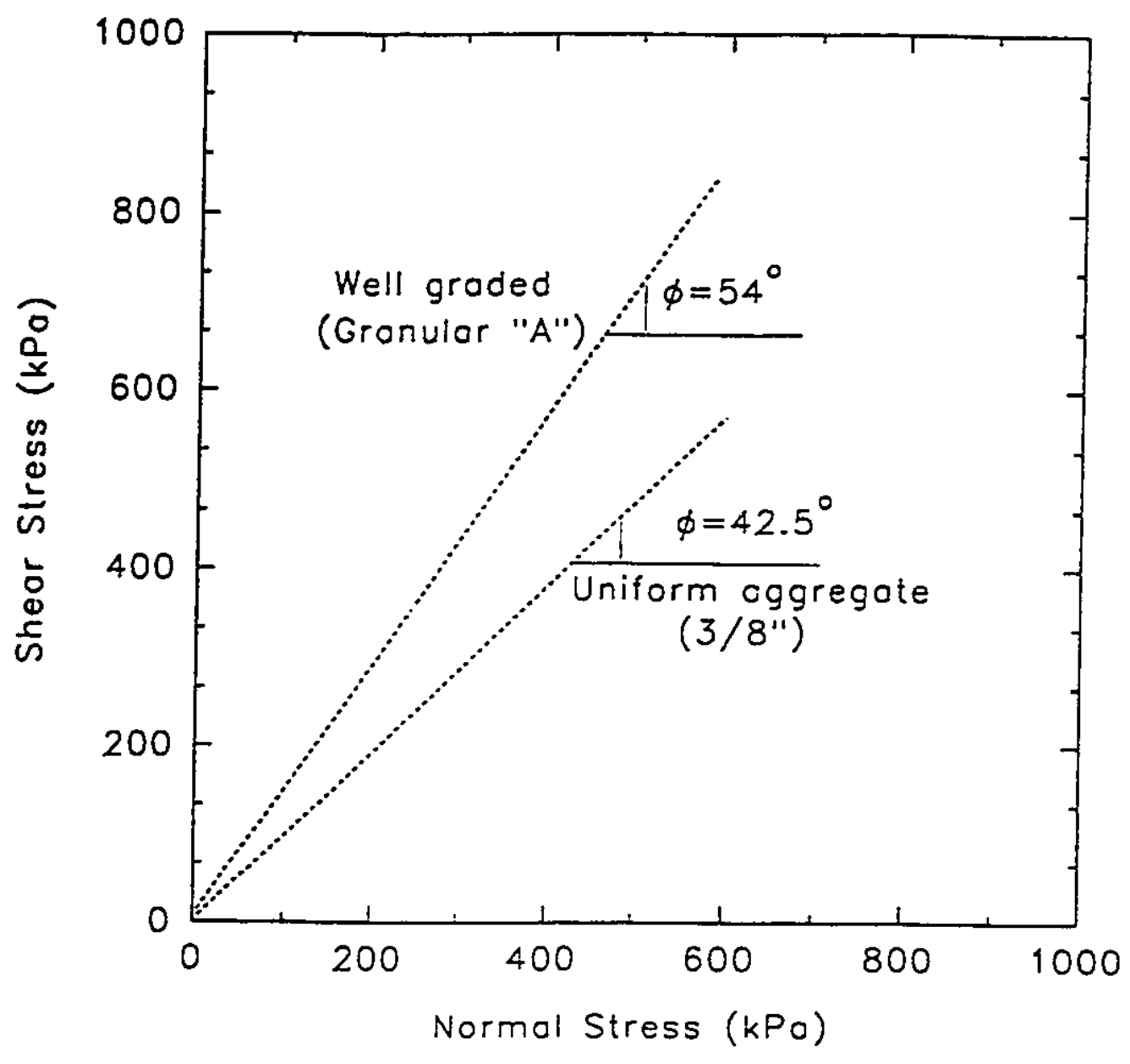

Figure 4.5: Mohr-Coulomb strength envelope for granular materials 


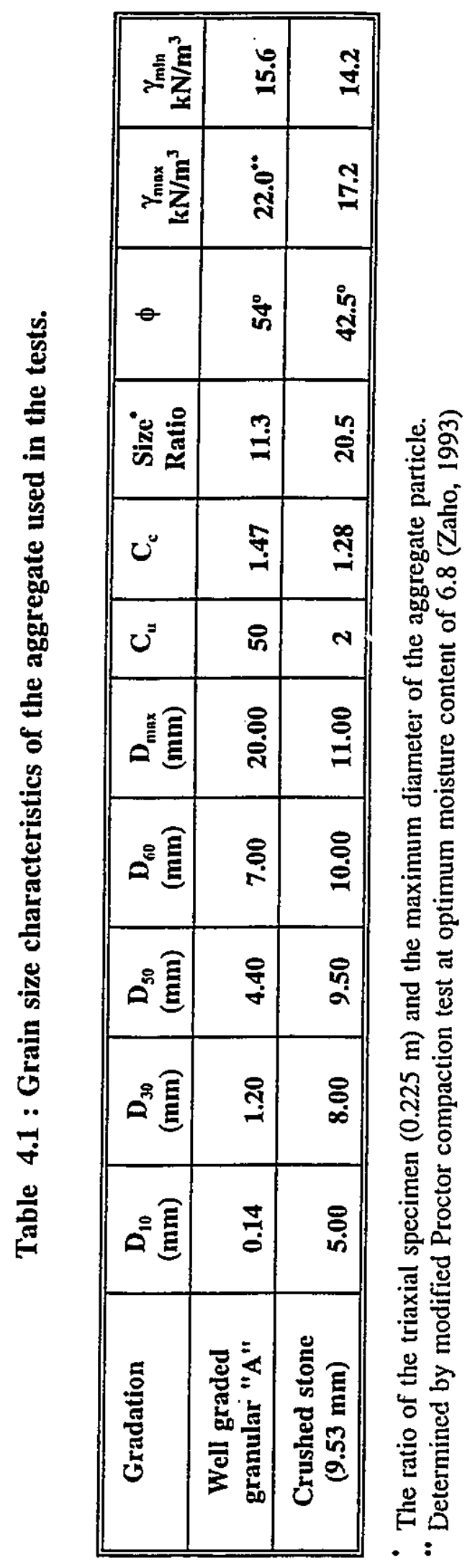




\subsubsection{Polymer grids}

Three types of geogrids were used in this research for triaxial and uniaxial specimens. These geogrids were

- Tensar UX-1500 and UX-1600 (uniaxial polymer grid)

- Conwed 9027

- Fibre glass grid (GB\# 10)

The properties of a polymer grid are mainly controlled by the manufacturing process, the grid type and the chemical composition. The significance of each property depends mainly on the intended application of the grid. There are several physical properties which significantly affect the load-deformation behaviour of a sleeve reinforced

specimen. Some of these properties are strength, ultimate strain, elastic modulus, creep, interface friction interlock and soil adhesion as well as durability.

There are few standardized methods which are globally accepted to measure the various properties of a polymer grid. Also, it is important to note that several properties will differ considerably depending whether the polymer grid is tested under unconfined "in air" or under confined "in soil" condition.

The load-deformation relation of a polymer grid is frequently determined in either of two ways: the strip and the grab tensile tests (Wu, 1987). In a strip tensile test, the grid specimen is gripped along its full width tetween the jaws of a test machine. In the grab tensile test the specimen is wider than the gripping jaw, which allows portion of the specimen to remain beyond the jaw at each side. In the grab tensile test the polymer grid beyond the jaw areas interacts with the adjacent stressed area. Therefore, the tensile strength obtained from a grab test is usually higher than that obtained from a strip test (Wu, 1987).

The disagreement over certain aspects regarding tensile testing of polymer grid includes the jaw system which should be used in the test. The ASTM (D 4595-86) specified the clamming system to be sufficiently wide to grip the entire width of the sample and with appropriate clamping power to prevent slipping or crushing (damage) and uneven stress distribution. At least one clamp should be supported by a free swivel or universal joint which allows the clamp to rotate in the plane of the test specimen.Two 
basic clamp designs were suggested by ASTM and modification is allowed to provide greater ease and speed of clamping.

Razaqpur and Halim (1991) have investigated different jaw systems to determine the most suitable one for tensile strength tests of Tensar UX-1500 and UX-1600 specimens. They used wedge, liquid metal and concrete jaw systems to determine the load-deformation characteristics and strength of Tensar polymer grids. The maximum tensile strength of the UX-1500 was obtained from concrete jaws and the lowest strength was obtained from the wedge jaws. For Tensar UX-1600 the maximum tensile strength was obtained from the liquid metal jaws and the minimum tensile strength was obtained from the wedge jaws. The physical and mechanical properties of Tensar UX-1500 and Tensar UX-1600 are presented in Table 4.2. These results are reported by the manufacturer; no details were given for the clamping technique or strain rate.

The tensile strength and stiffness properties of Conwed 9027 is presented in Table 4.3 as reported by Razaqpur (1990). The specimens were tested by the strip method using a three piston wedge clamping system. The specimens tested had a width of $180 \mathrm{~mm}$ while the specimen lengths depended on the type of grid and varied between $300 \mathrm{~mm}$ and $311 \mathrm{~mm}$. All specimens had eight longitudinal strands and were tested in the direction of stretch (Machine Direction, MD). All tests were performed at a constant strain rate of 25 $\mathrm{mm} / \mathrm{min}$ using a wedge jaw clamping system.

Fibre glass (GB \#10) specimens were tested at a lower strain rate of 0.5 $\mathrm{mm} /$ minute. The specimens had a width of $215 \mathrm{~mm}$ and length of $311 \mathrm{~mm}$. The maximum tensile strain recorded for fibre glass (GB \#10) was $2.4 \%$.

The shape and the force-strain relationship for the four polymer grids are shown in Figures 4.6 to 4.13 . 


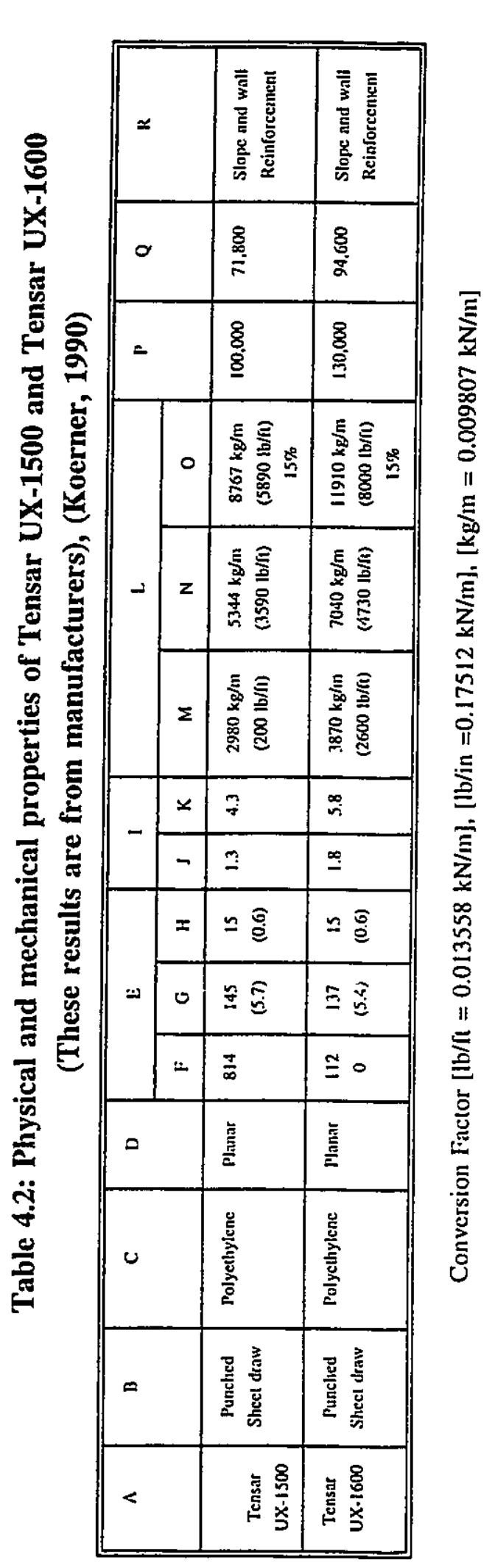

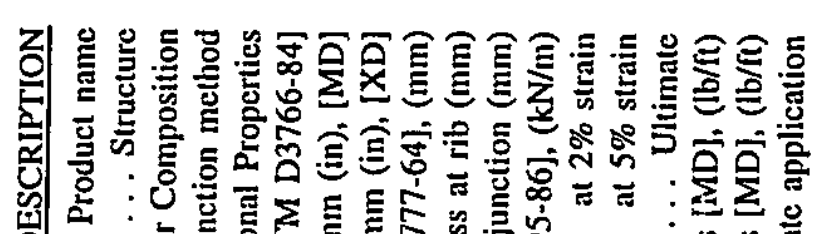

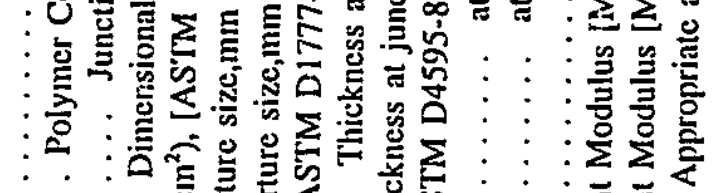

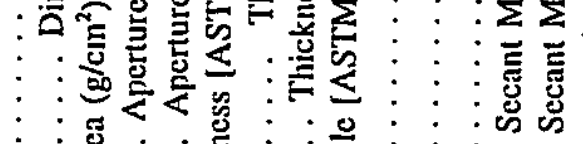
$\vdots \vdots \vdots \vdots \vdots \vdots$ ⿹
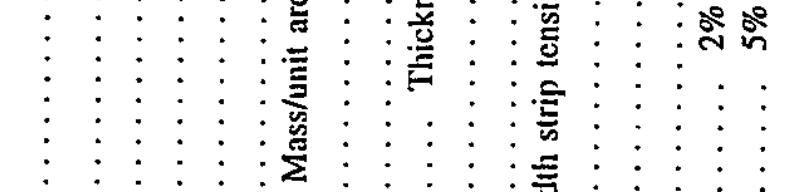

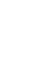




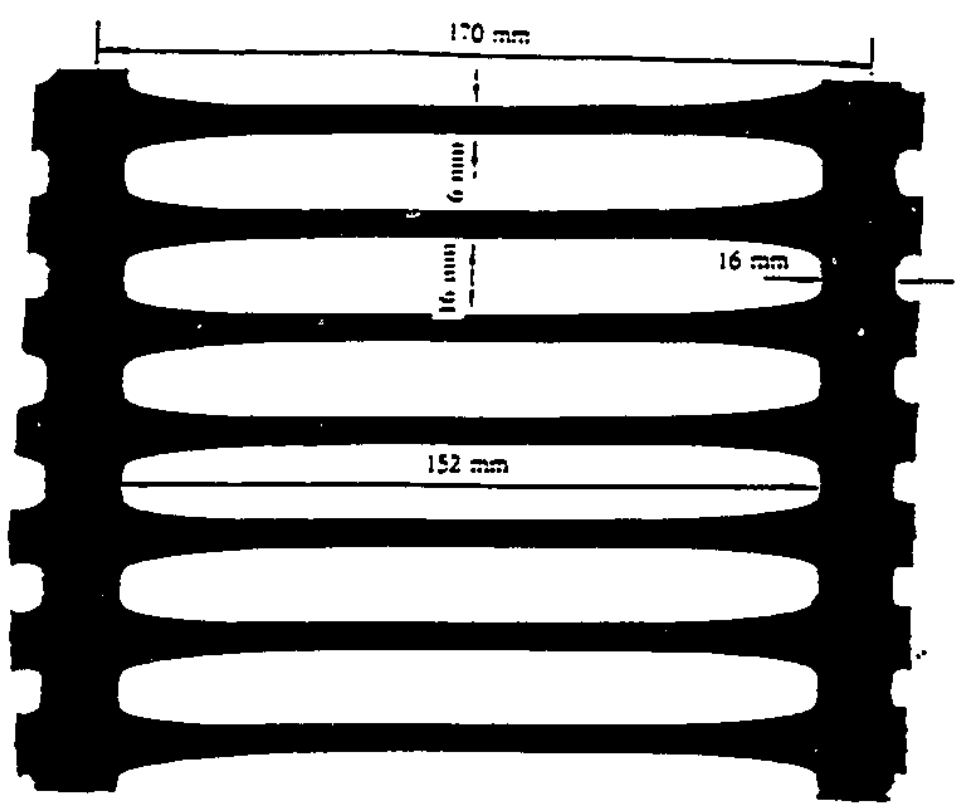

Figure 4.6: Tensar UX-1500

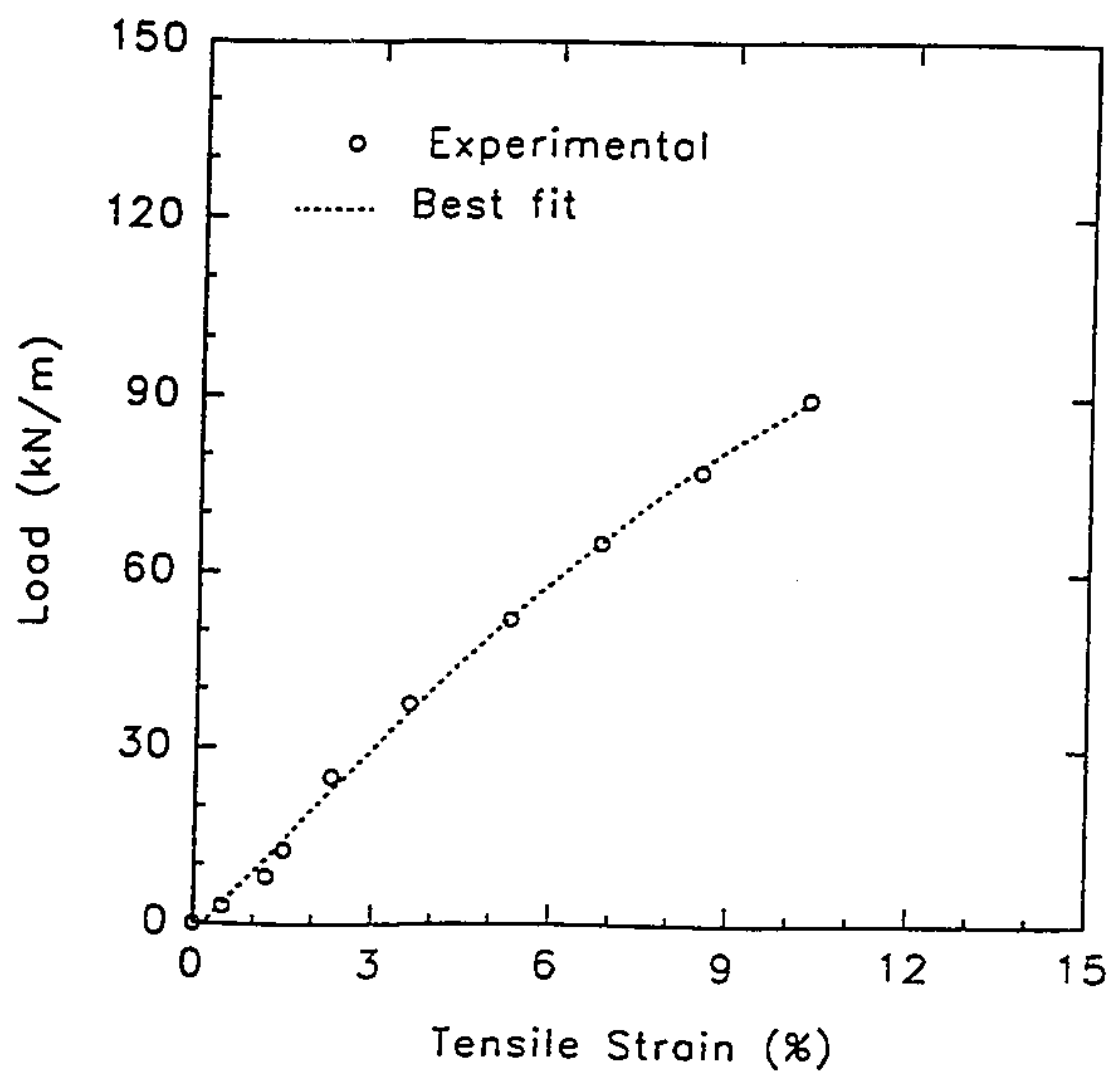

Figure 4.7: Force-deformation characteristic for Tensar UX-1500 


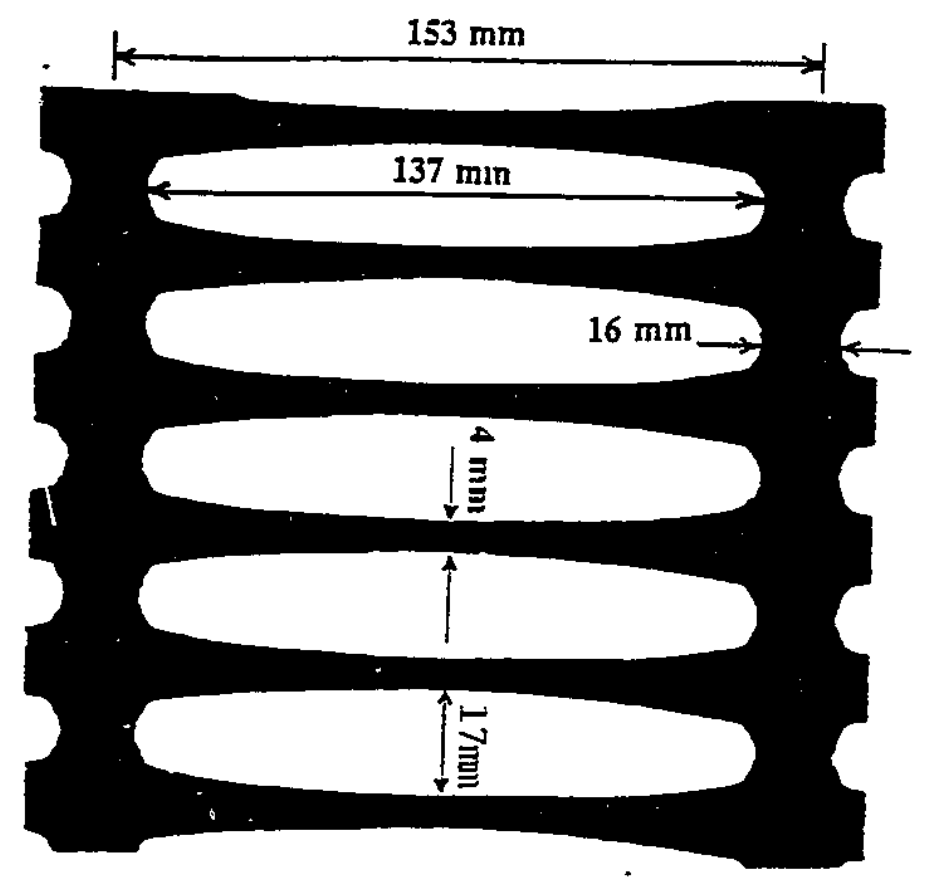

Figure 4.8: Tensar UX-1600

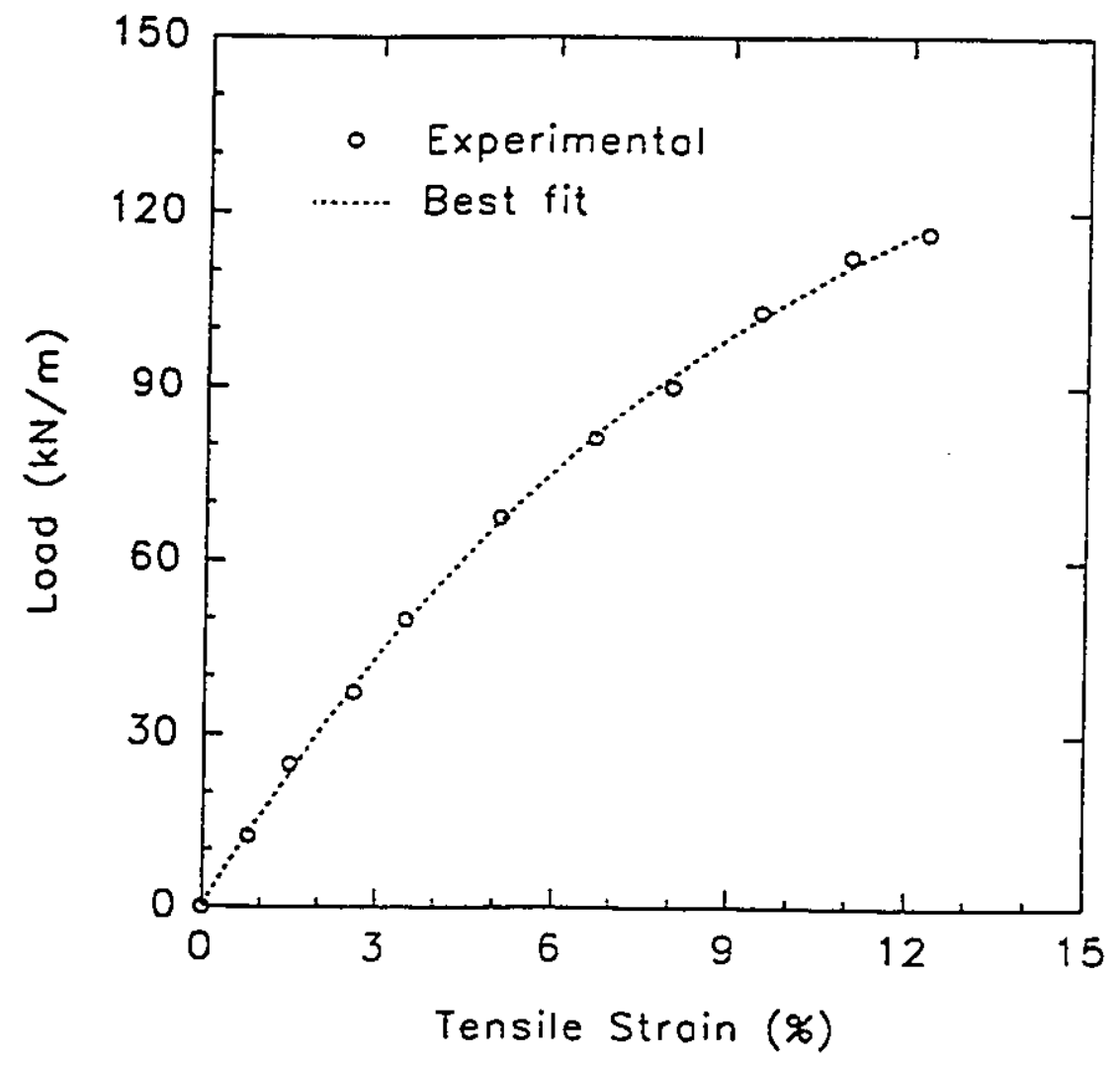

Figure 4.9: Force-deformation characteristic for Tensar UX-1600 


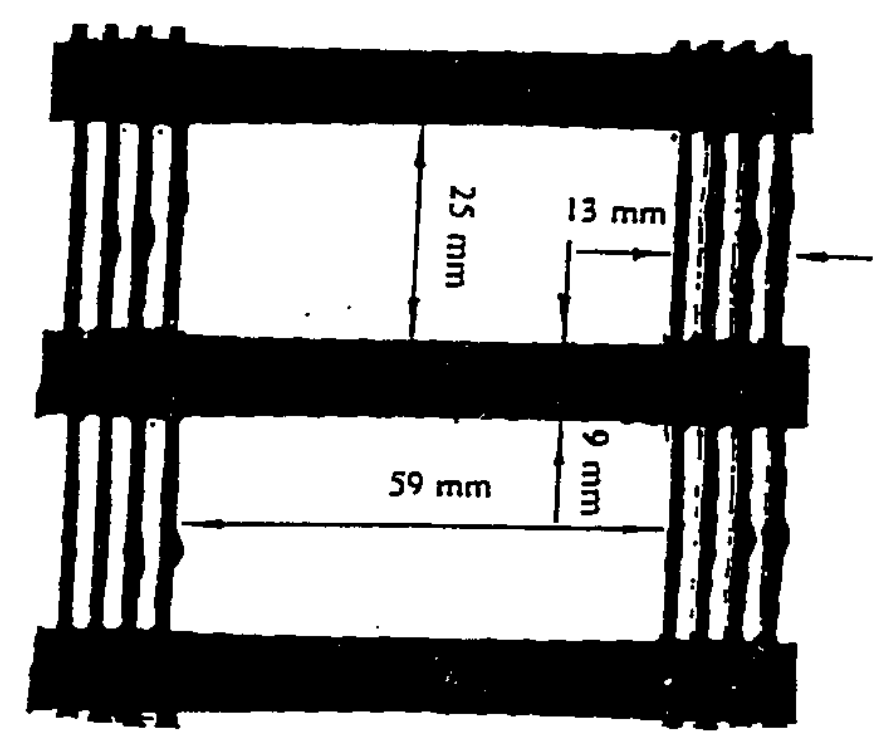

Figure 4.10: Conwed 9027

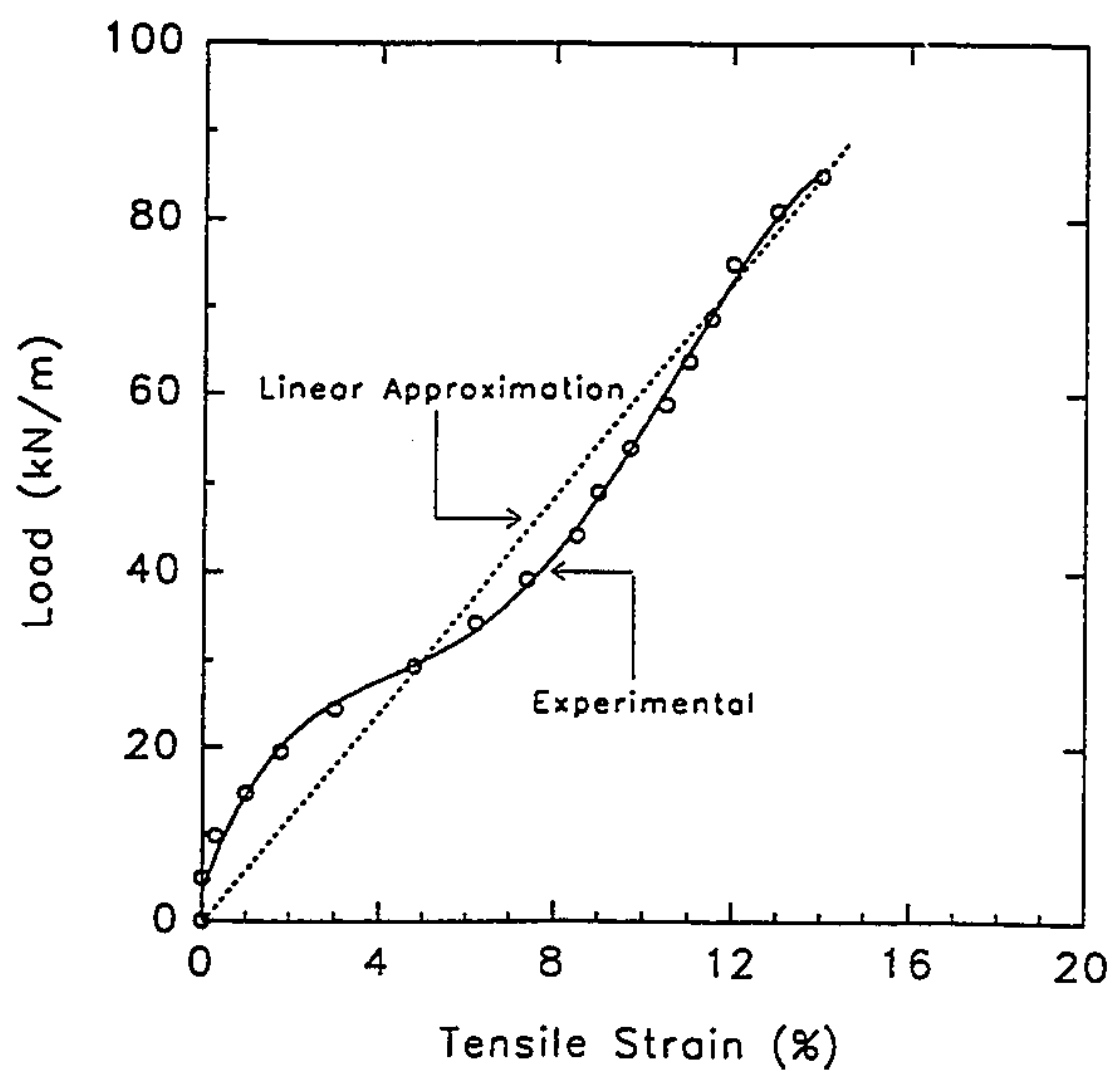

Figure 4.11: Force-deformation characteristic for Conwed 9027 


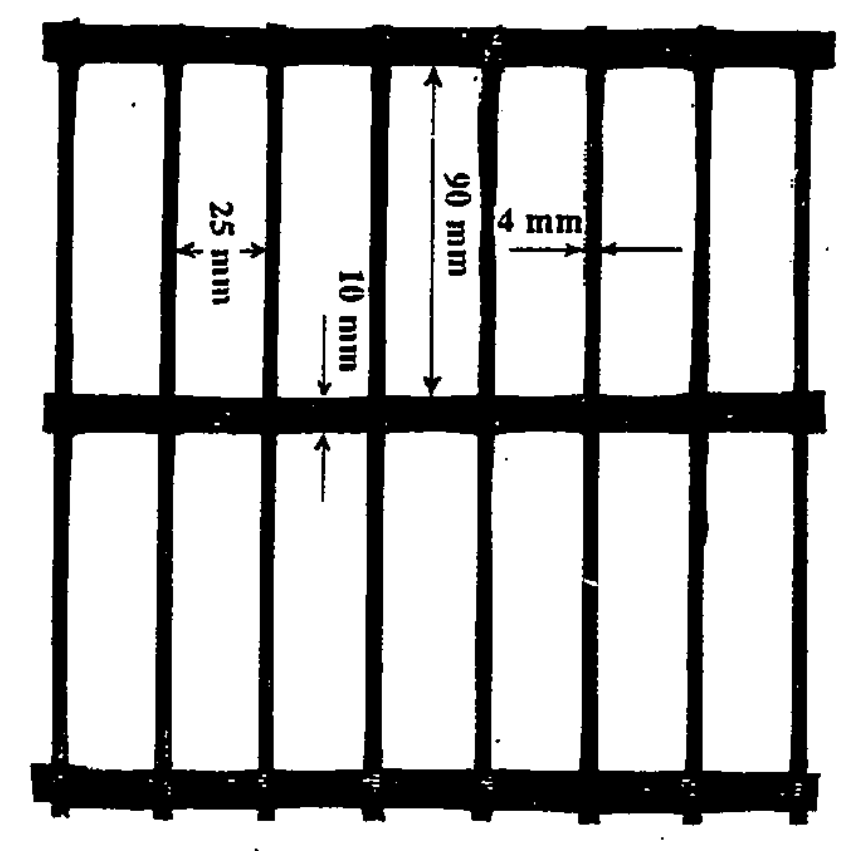

Figure 4.12: Fibre glass GB \#10

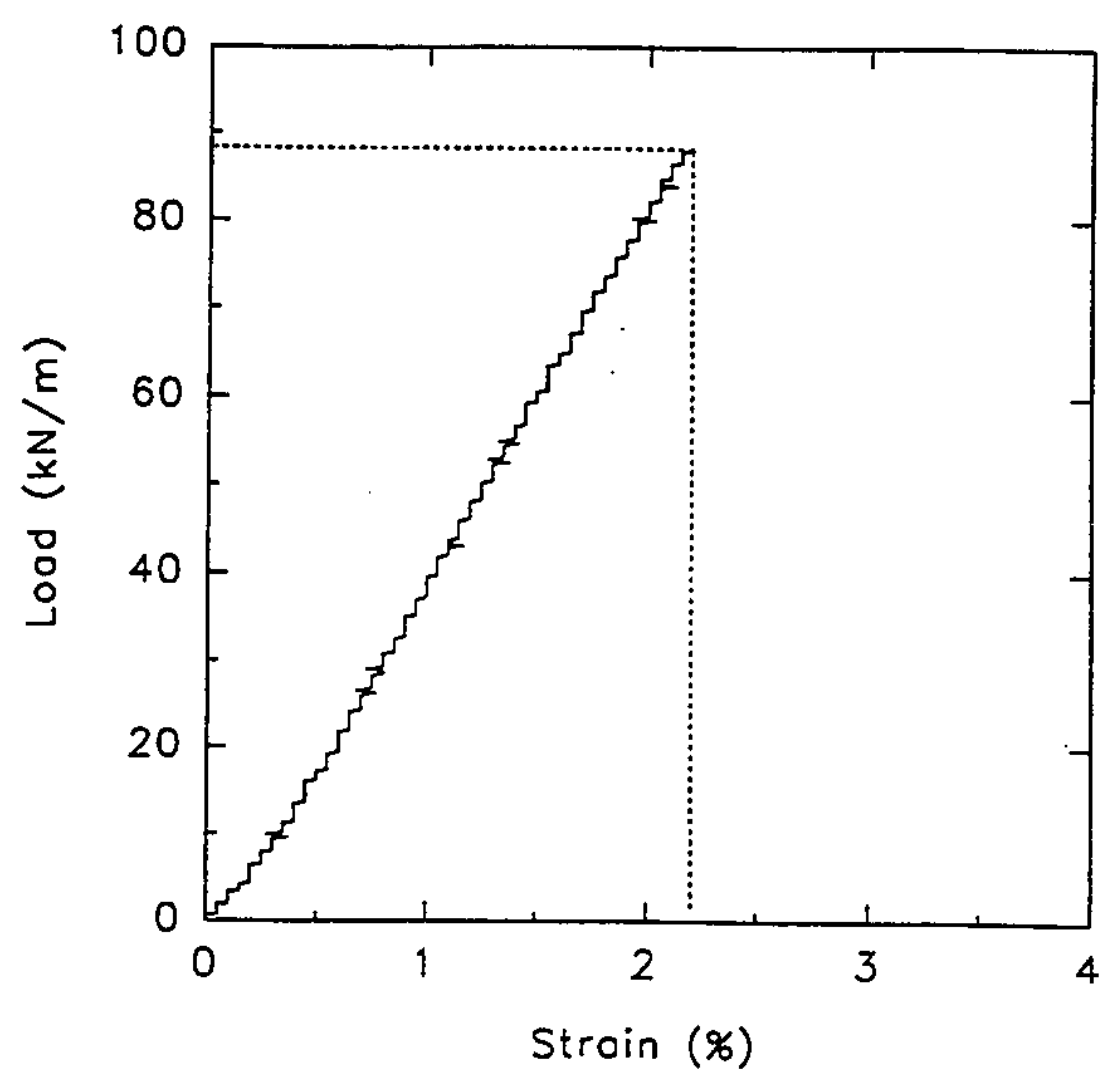

Figure 4.13: Force-deformation characteristic for fibre Glass GB \#10 
For the purpose to make sleeves or jackets, the polymer grid was cut and formed in cylindrical shape with the appropriate diameter for a given specimen. In order to form a strong joint, several connections were investigated, including gluing, machine sewing, rivetting, and tying the butted ends with polyester fishing line. The different junctions for the various grids were tested in tension. Only the joint or butted connection made with the $200 \mathrm{lb}$ fishing line was found to be acceptable. This connection was proved to be stronger than the mesh itself since tensile failure occurred away from the connection. Figure 4.14 shows the three polymer grid sleeves and the connection for each type. The connection used for Tensar UX-1600 and UX-1500 was similar.

Table 4.3: Strength and stiffness properties of Conwed 9027 (Razaqpur, 1990)

\begin{tabular}{|c|c|c|c|c|c|c|c||}
\hline Specimens & \multirow{2}{*}{$\begin{array}{c}\text { No. of } \\
\text { Strands }\end{array}$} & $\begin{array}{c}\text { Length } \\
(\mathrm{mm})\end{array}$ & $\begin{array}{c}\text { Width } \\
(\mathrm{mm})\end{array}$ & $\begin{array}{c}\text { Max. } \\
\text { Strain \% }\end{array}$ & \multicolumn{2}{|c|}{ Strength } & $\begin{array}{c}\text { Secant } \\
\text { Modulus }\end{array}$ \\
\cline { 5 - 8 } & & & & $(\mathrm{T} / \mathrm{m})$ & $(\mathrm{kN} / \mathrm{m})$ & $(\mathrm{kN} / \mathrm{m})$ \\
\hline $\begin{array}{c}\text { Mean of 5 } \\
\text { 10T specimen }\end{array}$ & 5 & 230.6 & 146 & 14.5 & 8.8 & 86.2 & 594.5 \\
\hline $\begin{array}{c}\text { Standard } \\
\text { Deviation }\end{array}$ & 0.0 & 29.3 & 0.0 & 0.8 & 0.2 & 1.8 & 0.3 \\
\hline
\end{tabular}

- Measured at maximum strain of $14.5 \%$. Specimens tested using a wedge clamps at constant strain ratio of $13 \%$. Deformation was measured by means of a clip-on extensometer with gauge length of $50.8 \mathrm{~mm}$.

\subsection{COLUMN SPECIMENS FOR TRIAXIAL AND UNIAXIAL TESTING}

\subsubsection{Preparation of specimens}

The unreinforced triaxial specimens were prepared in a compaction mould fixed to a vibrating table. The lower platen of the triaxial cell was first placed on the vibrating table. A rubber membrane was sealed to the lower platen. The two halves of the mould 
(Figure 4.3) were bolted to the bottom platen. The mould in turn was bolted to the vibrating table. The membrane was then stretched against the mould and the aggregates was placed into the mould by hand to avoid aggregate segregation. The aggregate was compacted in three layers. Each layer was vibrated for 2 minutes after a surcharge was placed on top of the aggregate. After the compaction was complete the surcharge was removed and the membrane was sealed against the top platen which had been placed on the top of the specimen.

The mould containing the sample was transferred to the triaxial cell base using an overhead crane. The specimen with the attached base weighed approximately $0.5 \mathrm{kN}$ (50 $\mathrm{kg}$ ). The mould was centred on the pedestal, the bottom drainage line was connected to the lower platen and a vacuum pump was attached to apply a suction to the inside of the specimen. The suction was applied for several minutes before the mould was removed. The vacuum pump was kept operating until the second membrane was installed and the sample was completely sealed.

Before installing the lateral deformation clips and the pyrex cell, the circumference and height of the specimen was measured. The outer cell was then lowered over the sample and the cell was bolted down. The cell chamber was filled with water. Figure 4.15 shows a sleeve reinforced sample after the removal of the mould and before the lateral deformation rings were attached. For reinforced soil specimens, the preparation was identical except a grid sleeve was inserted next to the steel mould and the rubber membrane was located inside the sleeve.

The prepared sample was transferred to a testing machine (MTS). The sample was then saturated from the bottom up to let the air escape to the top bleeder valve. No back pressure was necessary to saturate the specimens because the vacuum pump had reduced the internal pressure and this suction was sufficient to saturate the specimen. For the well graded granular "A" the saturation time was about two hours and one hour for the uniformly graded aggregate. To insure full specimens saturation, the water inlet line at the bottom platen was kept open over night under a confining pressure of $7 \mathrm{KPa}$. Complete saturation was necessary in order to measure volume changes of the specimen during testing. Any water expelled or sucked in was monitored automatically by the 


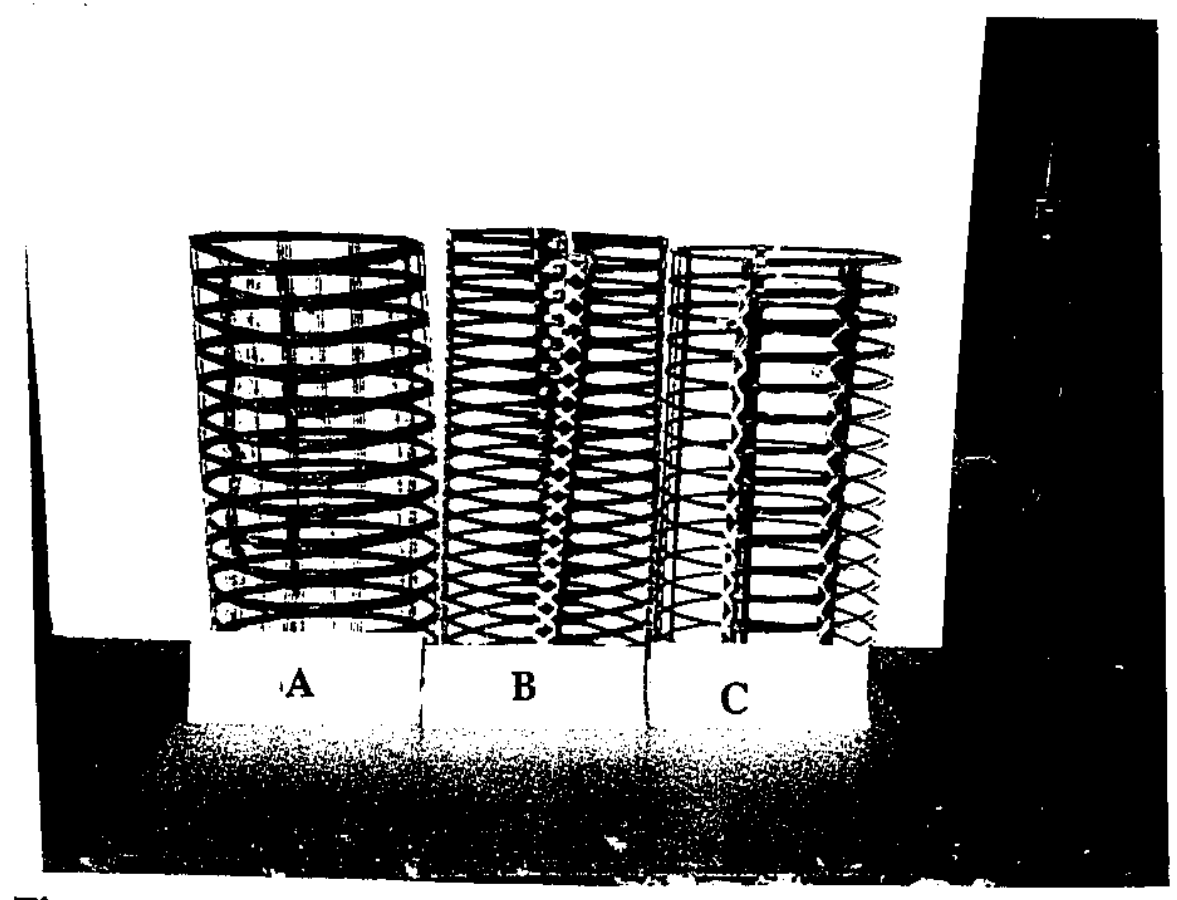

Figure 4.14 : Polymer sleeves with different connections

(A) Conwed 9027 (B) Tensar UX-1500 (C) GB \#10 


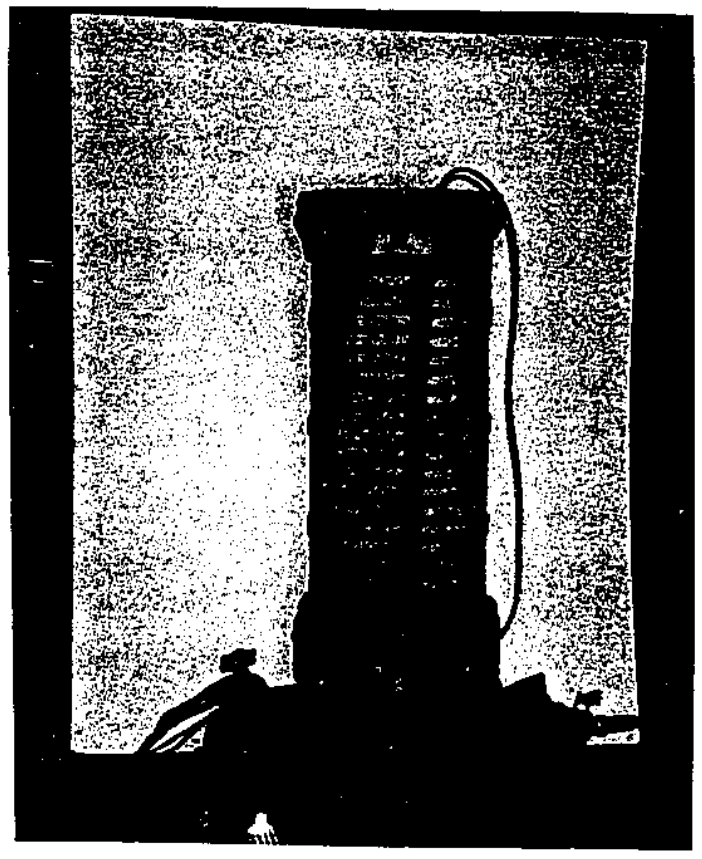

Figure 4.15: Triaxial specimen after compaction and removal of mould 
volume gauge, as discussed earlier, and manually by measuring the amount of water supplied or expelled from the specimen. Measuring the volume change by these two methods served as a check. For most specimens the automated volume gauge data and the graduated cylinder readings were in good agreement.

Before shearing the specimen, the required confining pressure was applied with the drainage line open. The volume change during consolidation was monitored. Figure 4.16 shows the experimental setup of a stone column specimen in a triaxial test.

The load applied to the specimen was monitored by three load cells located at the lower pedestal of the cell and the total load applied to the specimens was recorded by the load cell of the test machine. The applied load was equal to the sum of the load recorded by the three load cells at the base. This indicated that there was no piston friction. The vertical settlement was monitored by Linear-Variable-Displacement-Transformer (LVDT) attached to the plunger (loading piston) and moving against the top surface o triaxial cell. The lateral deformation was measured by means of the three steel clips with strain gauges.

\subsubsection{Uniaxial specimens}

In order study the effect of sleeve grid reinforcement on the behaviour of various lengths and diameters of stone columns, large uniaxial compression tests were performed in the compression machine. The diameter of the stone columns ranged from 0.27 to 0.38 $\mathrm{m}$ and the height was varied between 0.68 and $1.32 \mathrm{~m}$. There were several reasons for choosing these dimensions for the stone column. The diameters were selected in order to compare the results with the triaxial tests. This range of diameters also allowed the use of the bottom platen of the triaxial cell. The height/diameter ratio of the stone columns has varied between 2 and 5 . The low ratio of 2 was the same as in the triaxial specimens. The higher height/diameter ratios were use in order to study any buckling of the unconfined columns. 


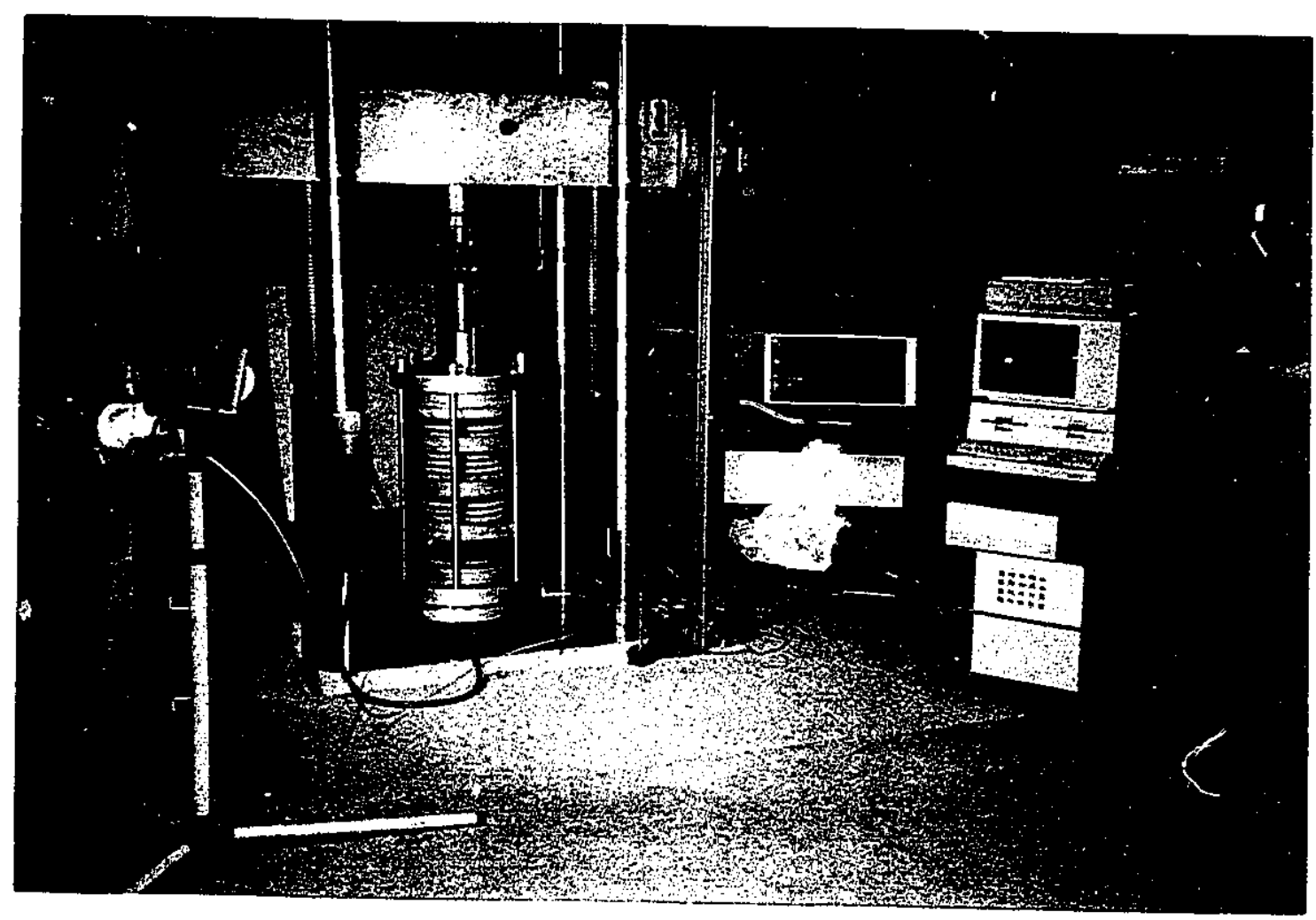

Figure 4.16: Setup of laboratory triaxial test 
The aggregates used to prepare the unconfined column tests were the same as the two materials used in the triaxial tests (i.e. uniformly graded and well graded granular "A" aggregate). The granular material was placed in 3 or 5 layers, depending on the height of the stone column. For long columns $(1.32 \mathrm{~m})$ the aggregate was placed in 5 layers; the thickness of each layer being one fifth of the height. For shorter columns $(0.68$ $\mathrm{m}$ ) the aggregate was placed in three layers. The material was compacted dry to the same condition as in the triaxial test specimens. The approximate volume of the stone column ranged from $0.039 \mathrm{~m}^{3}$ to $0.15 \mathrm{~m}^{3}$ and the approximate amount of aggregates required varied form 0.70 to $2.70 \mathrm{kN}$ ( 70 to $270 \mathrm{~kg}$ ) depending on the size of the column.

The polymer sleeve was inserted inside a casing of stiff card board (sona tube) and the aggregate was placed inside the casing. The first two layers of the long stone columns $(1.32 \mathrm{~m})$ were compacted with a steel tamper weighing $13.5 \mathrm{~kg}$. Each layer was compacted with 25 blows. The remaining three layers of the long stone column were compacted with an electric compaction hammer. Each layer was compacted for five minutes. For short stone columns $(0.68 \mathrm{~m})$ the aggregate was placed in three layers each layer was compacted for 5 minutes with the electric tamper. Figure 4.17 shows the electric compaction hammer. In order to confine the aggregate inside the polymer grid sleeve during the compaction process a plastic membrane was placed inside the sleeve before compaction. The membrane added no confining strength to the stone column because it was easily perforated by the aggregate.

The unconfined stone column was instrumented with sets of LVDT's at three heights to measure the lateral deformation during a test. Each set had three LVDT's spaced at $120^{\circ}$. The transducers at each level were held in place by a circular wooden ring having an internal diameter of $0.5 \mathrm{~m}$. Figure 4.18 shows one ring holding the LVDT's fixed in place.

One ring was located at the center height of the stone column and the other two rings were attached at the quarter height points. During a test the spring loaded LVDT's tips were touching the side surface of the specimen at a smooth contact point. The LVDT's were connected to the data acquisition system. By monitoring the position of the LVDT's tips on the stone column during a test, it was possible to measure the vertical 


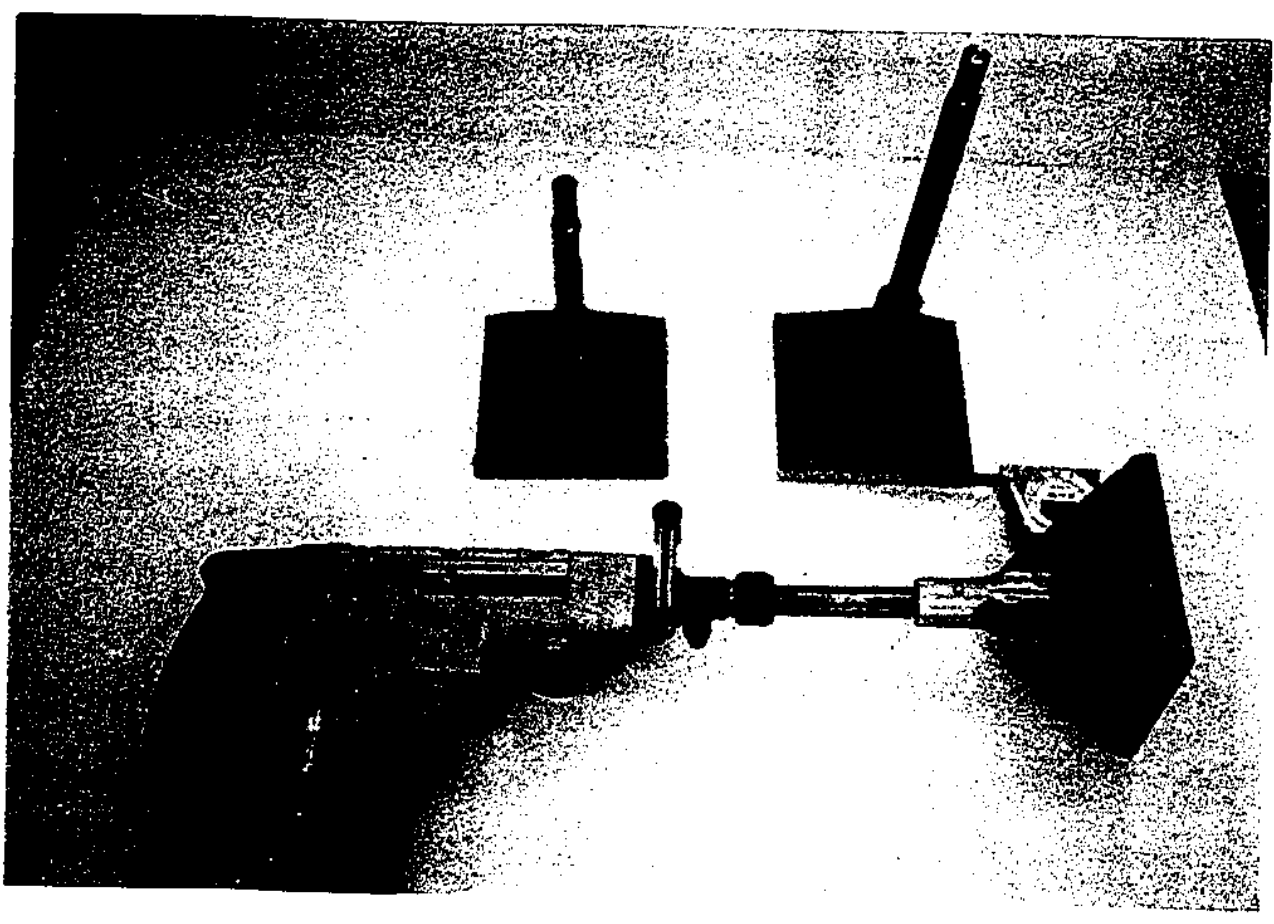

Figure 4.17: Electric compaction hammer 


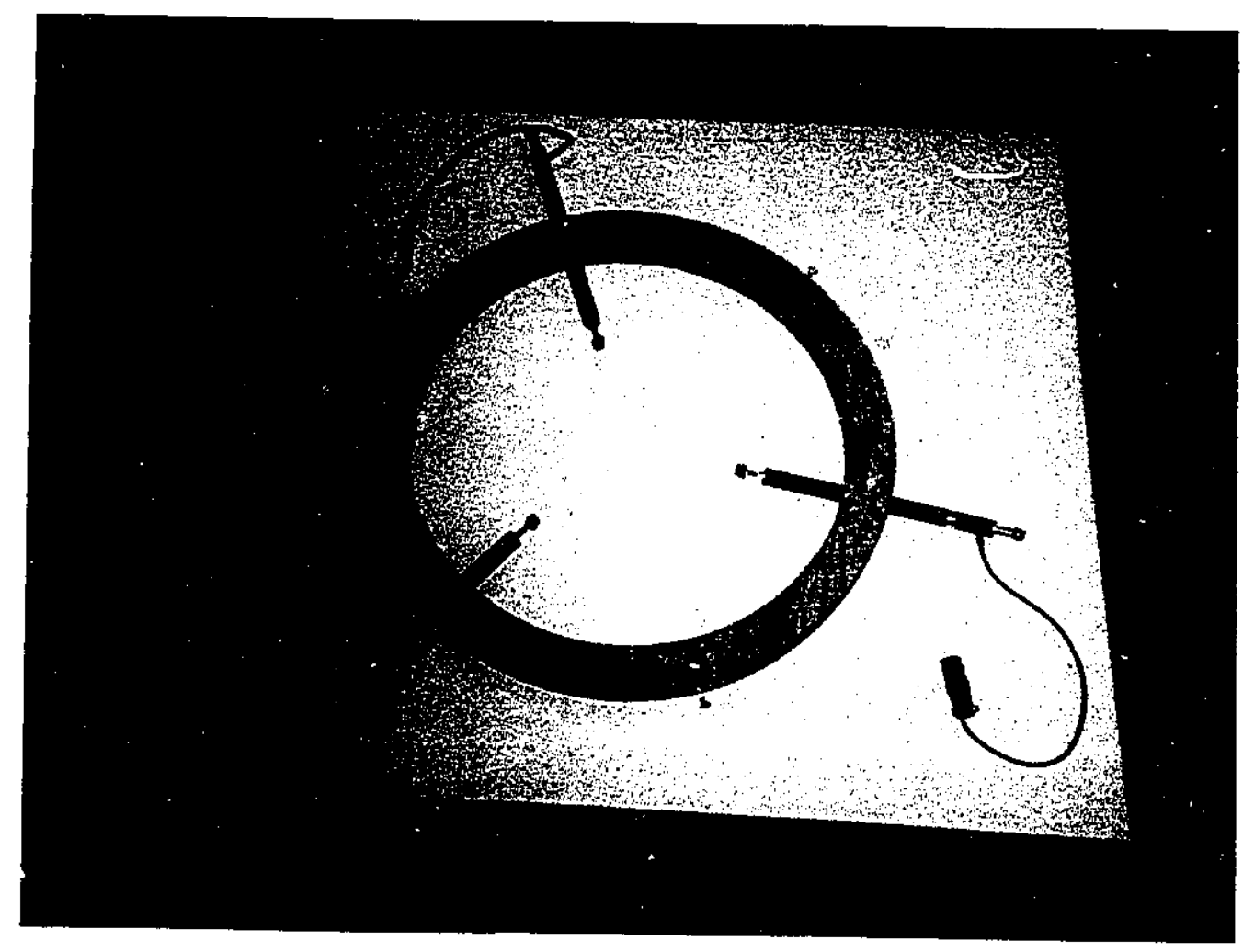

Figure 4.18: LVDT's holder (wooden ring) 
compression of the stone column between the three LVDT's locations. The total vertical compression was monitored by a LVDT located at the top of the specimen. The vertical displacement of the LVDT's tips were used to plot the vertical compression profile of a stone column for different depths during a tests as will be discussed in chapter 7. The load subjected to the stone column was monitored directly by the actuator's load cell which was connected to the data acquisition system.

In order to measure local strains in the horizontal ribs of the polymer sleeve, foil strain gauges were attached at several locations. Continuous strain readings were recorded by the data acquisition system. For most specimens the strain gauges became in-operative after $1.5 \%$ of strain. Elgabroni (1989) has found, in a comparative study of concrete slabs reinforced with steel and Tensar grid, that most of the strain gauges became in-operative after yielding of the steel reinforcement occurred. Tensile strength tests were conducted on individual strands of Tensar UX-1500 and UX-1600 with attached strain gauges at mid-height. This type of test enables one to plot the stress-strain curve for an individual grid strand. The specifications of the strain gauges used to measure the strains in the sleeves of uniaxial columns are presented in Appendix B.

The stone column with the instrumented polymer sleeves was transferred to the compression machine. This transfer of specimen was critical especially for the long stone columns ( $0.38 \mathrm{~m}$ diameter and $1.32 \mathrm{~m}$ length) and was done with a fork lift. Figure 4.19 shows the setup of a uniaxial stone column.

\subsection{TESTING PROCEDURE}

\subsubsection{Triaxial test procedure}

The test procedure was similar as in any drained triaxial test. After saturation the specimen was subjected to the required confining pressure and allowed to consolidate for

thirty minutes before slowly loaded to failure under a constant vertical strain rate. The initial density and volume of the stone column was recalculated after the consolidation process taking into consideration the amount of volume change due to consolidation. The 


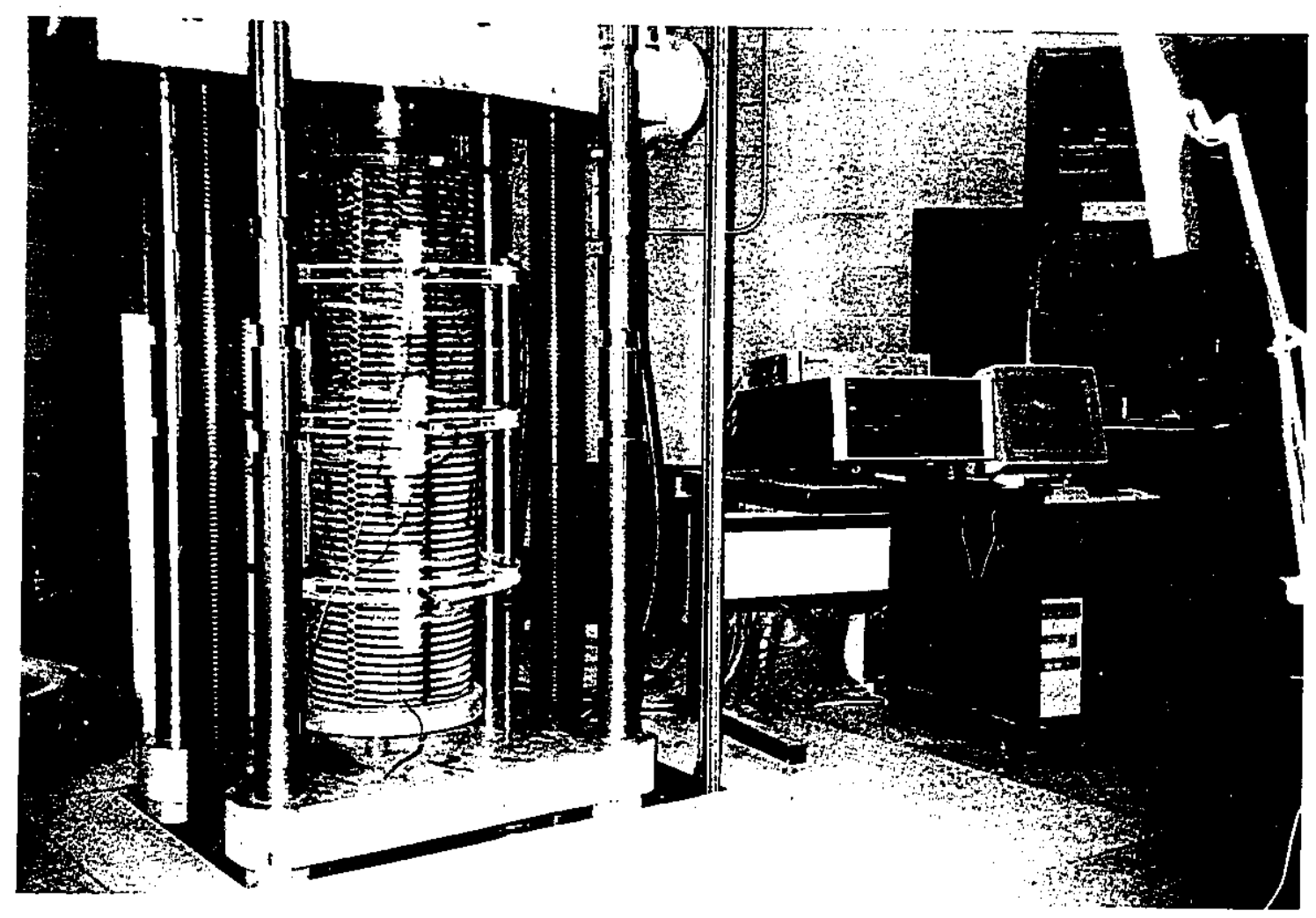

Figure 4.19: Setup of uniaxial stone column test 
strain rate was $0.3 \mathrm{~mm} / \mathrm{min}$. This slow strain rate was selected in order to allow for full drainage and to avoid any excess pore pressure build-up.

Three series of triaxial tests were performed in order to establish the stress-strain behaviour and the properties of the column material. Series I consisted of nine small (55 $\mathrm{mm}$ in diameter and $110 \mathrm{~mm}$ high) drained triaxial tests on oven dried soil sieved down from the uniformly graded aggregates. The soil was sieved down in order to keep the same ratio of sample diameter to maximum particle size. The small triaxial tests were performed for three confining pressures, namely 100,200 and $300 \mathrm{kPa}$. This test series was considered as preliminary in order to establish a method for preparation and testing the larger triaxial specimens.

In series II and III, two types of aggregates were used, as explained earlier, a well graded and a uniformly graded material. In these two series a large triaxial specimens (i.e stone columns) were tested. These tests were performed over a range of confining pressures, which would correspond to field conditions, such as $103.5,207$ and $345 \mathrm{kPa}$ $(15,30$ and $50 \mathrm{psi})$. These confining pressures were selected because at elevated confining pressures, other mechanisms such as, crushing of particles may occur.

Series II consisted of unreinforced stone columns with $0.225 \mathrm{~m}$ diameter and 0.45 $m$ in height. This test series was performed in order to establish strength parameters and deformation properties of the two aggregates. These results served as reference for comparison with results from reinforced stone columns.

Series III consisted of sleeve reinforced stone columns which were $0.225 \mathrm{~m}$ in diameter and $0.45 \mathrm{~m}$ high. Three types of polymer sleeves were used as confinement. These were Tensar UX-1500, Conwed 9027 and fiber glass (GB \#10). The stone columns were tested under constant initial confining pressure and the relationship between deviator stress, axial strain and volume change were investigated. The change in strength properties of the unreinforced stone columns when confined with a sleeve was related to the reinforcement effect. The tension forces and deformation of the mesh ribs were recalculated from the reinforced stone columns results.

In addition to the previous test series which determined the shear strength and shear strain properties of the natural and reinforced stone columns, a special series of $\mathrm{K}_{0}$ 
or zero lateral strain tests were performed on natural and sleeve reinforced columns to determine the compression under one-dimensional loading. All the tests were performed at the same soil density as the other stone column tests. The stress-strain behaviour of natural and reinforced stone columns, under zero lateral deformation was determined by slowly increasing the axial load while the cell pressure was adjusted by means of a pressure regulator to maintain zero lateral strain.

An additional series of cyclic load tests was carried out on columns with and without polymer grid reinforcement. The purpose of three tests was to determine the effect of sleeve reinforcement on the behaviour of stone columns under cyclic load conditions. Over forty specimens, small and large diameter columns were tested using the two types of aggregates. Table 4.4 shows a list of the triaxial stone column specimens tested under different conditions. 


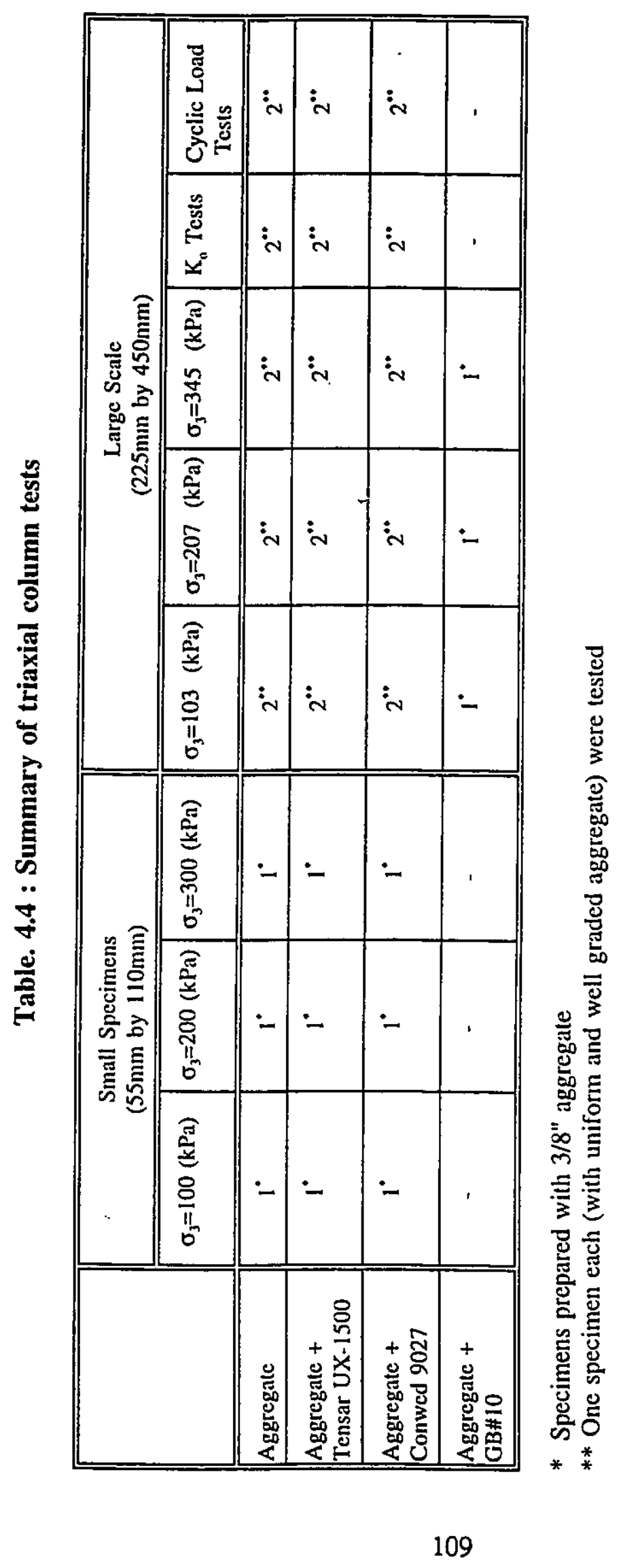




\subsubsection{Uniaxial test procedure}

After compaction of the granular material inside the polymer sleeve, the specimen was moved to the loading machine. The instrumentation was attached as described in section 4.4.2. The assembly of the three LVDT's ring holder was put over the stone column. The LVDT's were then inserted into the holes of the holders and hooked up to the data acquisition system. The tips of the LVDT's were touching the column at smooth thin aluminum sheets attached to the surface of the specimen.

The uniaxial stone column tests were performed similar to an unconfined compression test for cohesive specimens except that the polymer sleeves were providing the confinement for the granular material. The columns were tested at a constant strain rate of $0.5 \mathrm{~mm} / \mathrm{min}$.

Three sets of tests were performed. The first set consisted of seven reinforced stone columns with different length/diameter ratios and were subjected to compression under a constant strain rate. The second set consisted of two reinforced stone columns loaded under cyclic compression conditions. The third set consisted of two reinforced stone columns subjected to loading at a strain rate of $10 \mathrm{~mm} / \mathrm{min}$. Table 4.5 presents a tabulation of the three sets of uniaxial column tests with detailed information about the column dimensions, maximum load and corresponding axial and lateral strains.

In the first set of tests the columns were loaded to an axial strain of $14 \%$ before the tests were terminated. During a test continuous readings of the applied load, lateral and axial strains were recorded by means of the data acquisition system. The behaviour of the specimens were observed for any sign of failure of the sleeve and the mode of failure (i.e buckling) of the specimen.

The second set of tests were subjected to cyclic load conditions. At first cycle the applied load was, approximately, $50 \%$ to $60 \%$ of the maximum capacity obtained in a similar test under static loading. The specimen was then unloaded slowly to zero in order to observe the irrecoverable strain. The second load cycle started after the first load had been completely removed and the specimen stopped dilation. This load cycle was to $70 \%$

of the maximum load obtained in a similar test under static loading. The last three load cycles were performed in the same way as the second one; following each cycle a $10 \%$ 
higher load than the previous one until the maximum load of the specimen was achieved or the test was terminated at an axial strain of $14 \%$. All tests were terminated before rupture of polymer sleeve occurred except the two specimens tested at $10 \mathrm{~mm} / \mathrm{min}$. These two specimens were loaded to rupture of the polymer sleeve. The purpose of these tests was to investigate the capacity of the columns at rupture of the sleeve and to compare the behaviour of specimens under slow and fast strain rates. 


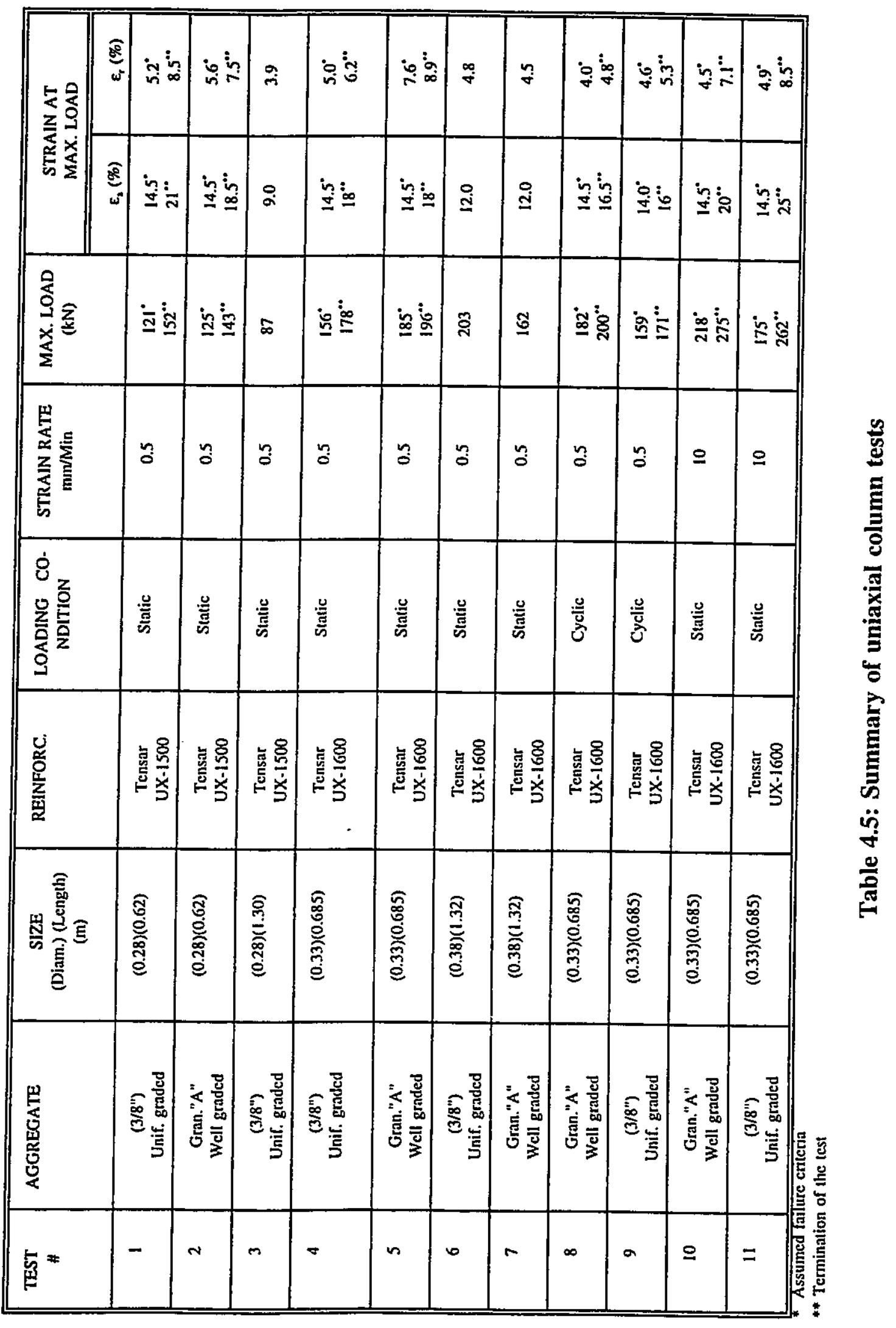




\section{CHAPTER 5}

\section{EXPERIMENTAL RESULTS}

\subsection{GENERAL}

In this chapter the experimental results obtained from laboratory testing are presented. The results are organized in a manner to show the effect of each individual variable on the stress-strain-volume change behaviour of the stone columns. A large number of relationships were obtained from the experimental program, some of the results will be presented in this chapter and more results will be presented in Appendix $\mathrm{C}$. It should be noted that the columns capacities or vertical stresses determined in this chapter and through the thesis are with respect to the structural integrity of the unreinforced and sleeve reinforced stone columns since no surrounding soil was used in the tests. Therefore, the results presented in this chapter are attributed to the structural behaviour of a single unreinforced and sleeve reinforced columns. The triaxial stone column results will be presented in the following section.

\subsection{TRIAXIAL STONE COLUMN TESTS RESULTS}

\subsubsection{Results of unreinforced stone columns}

The stress-strain relationships of granular "A" (well graded) and 3/8" (uniformly graded) aggregates for the $0.225 \mathrm{~m}$ diameter stone columns are preserted in Figures 5.1 and 5.2 respectively. These results will be used as reference for comparison to the results for sleeve reinforced stone columns. From these two Figures a number of observation can be made.

a- The deviator stresses of the well graded aggregate (granular "A") were found to be higher than those for the uniformly graded aggregate at corresponding confining pressures. This behaviour was observed for all specimens with granular "A" aggregate. 


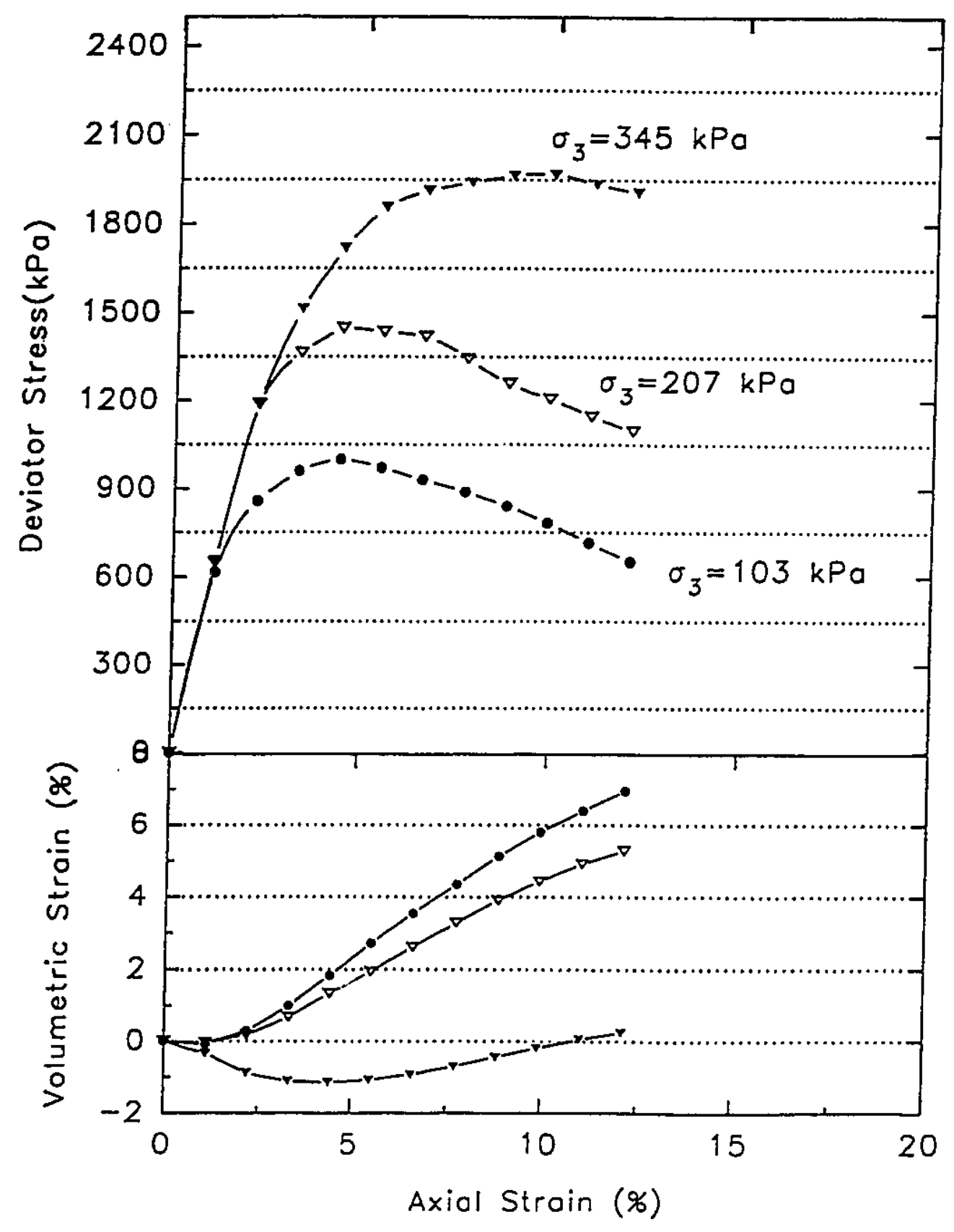

Figure 5.1 : Stress-strain-volume change behaviour of granular " $A$ " aggregate at different confining pressures 


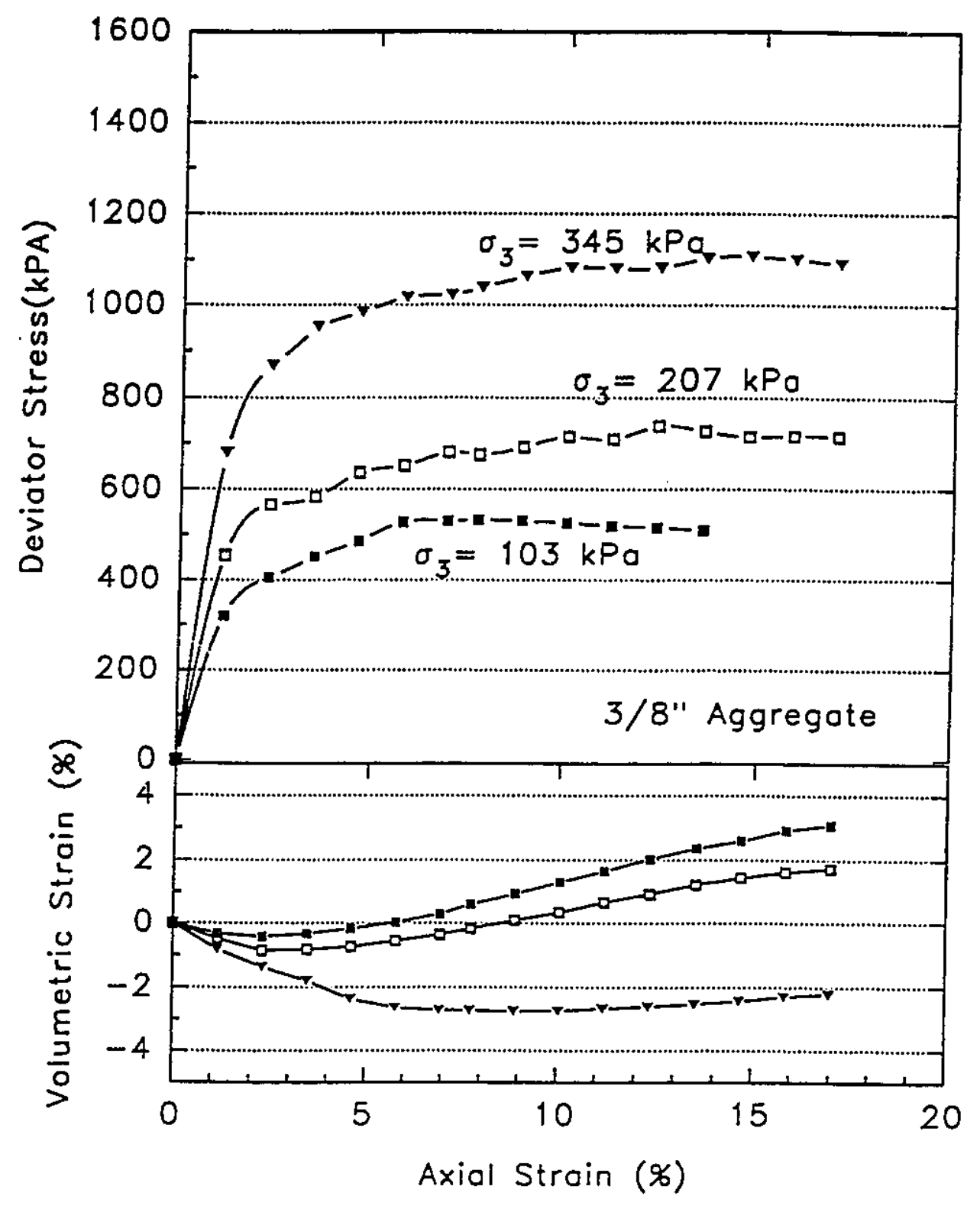

Figure 5.2 : Stress-strain-volume change behaviour of 3/8" aggregate at different confining pressures 
b- The stress-strain curves of the well graded columns exhibited defined peak values between $4.5 \%$ and $10 \%$ axial strain. The peak values for confining pressures of 103 $\mathrm{kPa}$ and $207 \mathrm{kPa}$ occurred, at approximately the same axial strain (4.5\%). The peak value for a confining pressure $345 \mathrm{kPa}$ occurred at $9.5 \%$ of axial strain. The stressstrain curves decreased gradually with increase of axial strain beyond peak. The residual deviator stresses had not been reached when the tests were terminated at $12 \%$ of axial strain.

c- The stress-strain curves of uniformly graded aggregate increased gradually with axial strain until the ultimate strength was attained. No peak values were observed for any of the test specimens regardless of confining pressure. The ultimate strength of this aggregate was achieved at $6 \%, 10 \%$ and $12 \%$ for confining pressures of $103 \mathrm{kPa}, 207$ $\mathrm{kPa}$ and $345 \mathrm{kPa}$ respectively.

d- The axial strain at peak, in general, increased with confining pressure for both aggregates. For the granular " $A$ " columns the axial strain at failure was lower than for uniformly graded aggregate (3/8") for all tests.

e- The specimens with granular " $\mathrm{A}$ " aggregate exhibited large dilation at lower confining pressure. However, the dilation decreased at higher confining pressures for all specimens.

f- The specimens with uniform aggregate (3/8") exhibited contraction below $6 \%$ and $8 \%$ axial strain for confining pressures of $103 \mathrm{kPa}$ and $207 \mathrm{kPa}$ respectively. Beyond these axial strains the specimens exhibited dilation. At higher confining pressure $(345 \mathrm{kPa})$ the specimen exhibited contraction between $0 \%$ and $18 \%$ axial strain.

g- Generally speaking, all specimens developed uniform bulges up to the axial strain of the test $(\approx 15 \%)$. No distinctive failure planes could be observed in any specimen. The bulging mode of failure was more obvious for the specimens with granular " $\mathrm{A}$ " due to the dilative nature of this aggregate.

Tables 5.1 and 5.2 summarise the results of the unreinforced stone column tests with uniformly graded and well graded aggregates respectively. 
Table 5.1 : Results of large unreinforced triaxial stone columns $\left(3 / 8\right.$ " aggregate, $\left.\varepsilon_{\mathrm{a}}=10 \%\right)$

\begin{tabular}{||c|c|c|c|c|c||}
\hline $\begin{array}{c}\text { Confining } \\
\text { Pressure } \\
(\mathrm{kPa})\end{array}$ & $\begin{array}{c}\text { Deviator } \\
\text { stress } \\
\left(\sigma_{1}-\sigma_{3}\right),(\mathrm{kPa})\end{array}$ & $\begin{array}{c}\text { Volumetric } \\
\text { strain } \\
\left(\Delta \mathrm{V} / \mathrm{V}_{0}\right), \%\end{array}$ & $\begin{array}{c}\mathrm{q}=\left(\sigma_{1}-\sigma_{3}\right) / 2 \\
(\mathrm{kPa})\end{array}$ & $\begin{array}{c}\mathrm{p}=\left(\sigma_{1}+\sigma_{3}\right) / 2 \\
(\mathrm{Kpa})\end{array}$ & $\begin{array}{c}\text { Secant } \\
\text { modulus } \\
(\mathrm{kPa})\end{array}$ \\
\hline 103 & 526.4 & $+1.3^{*}$ & 263.2 & 366.2 & 5264 \\
\hline 207 & 709.0 & +0.66 & 354.5 & 561.5 & 7090 \\
\hline 345 & 1082.2 & -2.74 & 541.1 & 886.1 & 10822.3 \\
\hline
\end{tabular}

Table 5.2 : Results of large unreinforced triaxial stone columns at axial strains corresponding to peak stress (granular "A" aggregate)

\begin{tabular}{||c|c|c|c|c|c|c|}
\hline $\begin{array}{c}\text { Confining } \\
\text { Pressure } \\
(\mathrm{kPa})\end{array}$ & $\begin{array}{c}\text { Deviator } \\
\text { stress } \\
\left(\sigma_{1}-\sigma_{3}\right),(\mathrm{kPa})\end{array}$ & $\begin{array}{c}\text { Axial } \\
\text { Strain } \\
\left(\varepsilon_{\mathrm{a}}, \%\right)\end{array}$ & $\begin{array}{c}\text { Volumetric } \\
\text { strain } \\
\left(\Delta \mathrm{V} / \mathrm{V}_{0}\right), \%\end{array}$ & $\begin{array}{c}\mathrm{q}=\left(\sigma_{1}-\sigma_{3}\right) / 2 \\
(\mathrm{kPa})\end{array}$ & $\begin{array}{c}\mathrm{p}=\left(\sigma_{1}+\sigma_{3}\right) / 2 \\
(\mathrm{kPa})\end{array}$ & $\begin{array}{c}\text { Secant } \\
\text { modulus } \\
(\mathrm{kPa})\end{array}$ \\
\hline 103 & 999.91 & 4.41 & $+1.83^{*}$ & 499.5 & 602.5 & 22673.7 \\
\hline 207 & 1447.3 & 4.41 & +1.34 & 723.7 & 930.7 & 32818.8 \\
\hline 345 & 1969.3 & 9.91 & -0.19 & 984.7 & 1329.7 & 19871.9 \\
\hline
\end{tabular}

-ve value means contraction +ve value means dilation

Figure 5.3 presents the stress-strain-volume change behaviour for the small unreinforced specimens $(55 \mathrm{~mm} \times 110 \mathrm{~mm})$. The soil used in the preparation of these tests was sieved down from the uniform aggregate to have the same diameter ratio (aggregate/specimen diameter) as the large triaxial stone columns. Again these stress-strain-volume change curves serve as reference for comparison with corresponding reinforced specimens. Well defined peak strength values were observed at an axial strain $\left(\varepsilon_{a}\right)$ of $8.8 \%$. The residual strength of these specimens was not clearly defined at confining pressures of $200 \mathrm{kPa}$ and $300 \mathrm{kPa}$. However, a residual value was obtained for the $100 \mathrm{kPa}$ confining pressure. 


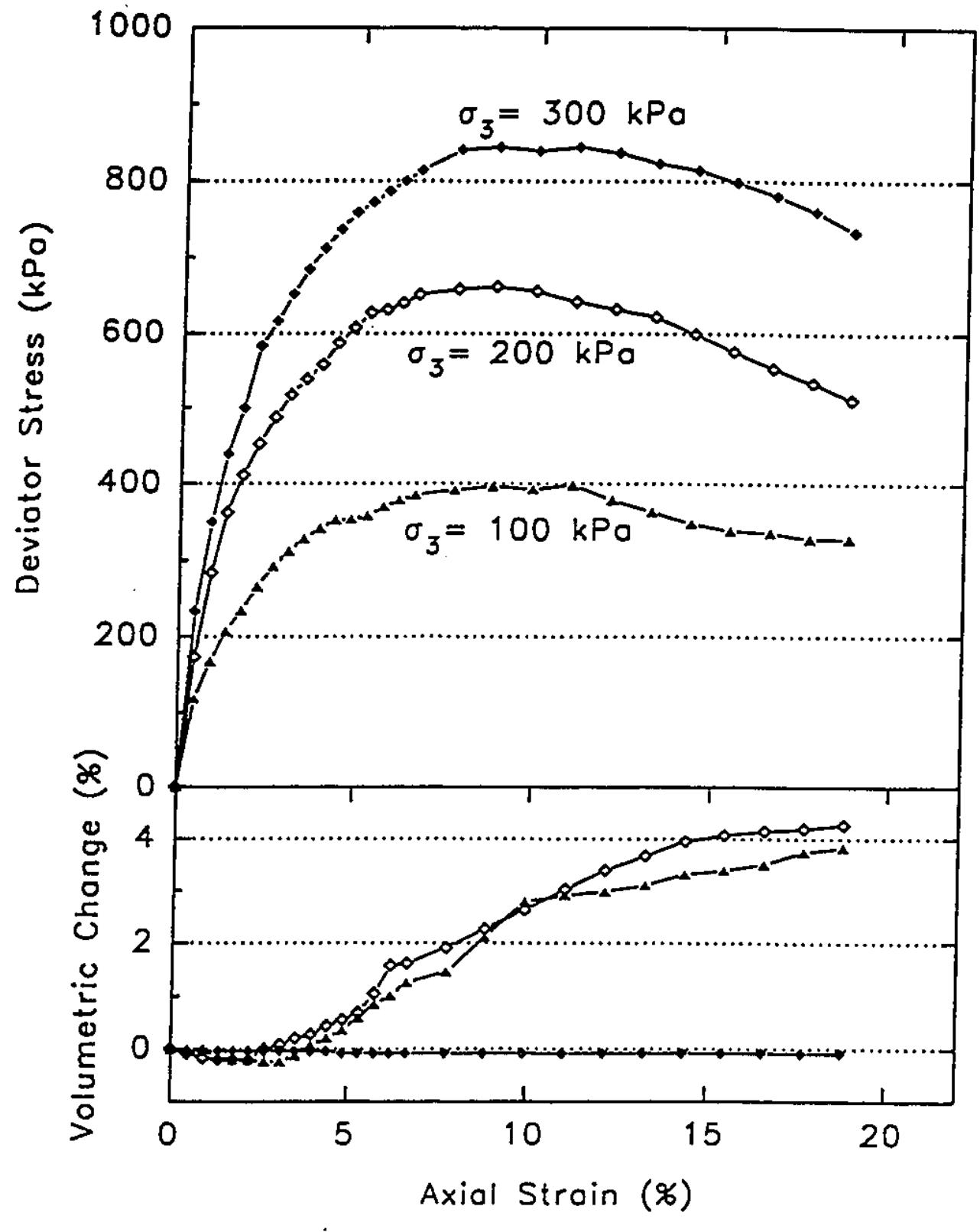

Figure 5.3 : Stress-strain-volume change behaviour of small size specimens at different confining pressures 
Table 5.3 summarises the results of the unreinforced small triaxial specimens.

Table 5.3 : Results of small unreinforced triaxial specimens (3/8" aggregate, $\varepsilon_{\mathrm{a}}=\mathbf{8 . 8 \%}$ )

\begin{tabular}{|c|c|c|c|c|c|}
\hline $\begin{array}{c}\text { Confining } \\
\text { Pressure } \\
(\mathrm{kPa})\end{array}$ & $\begin{array}{c}\text { Deviator } \\
\text { stress } \\
\left(\sigma_{1}-\sigma_{3}\right),(\mathrm{kPa})\end{array}$ & $\begin{array}{c}\text { Volumetric } \\
\text { strain } \\
\left(\Delta \mathrm{V} / \mathrm{N}_{0}\right), \%\end{array}$ & $\begin{array}{c}\mathrm{q}=\left(\sigma_{1}-\sigma_{3}\right) / 2 \\
(\mathrm{kPa})\end{array}$ & $\begin{array}{c}\mathrm{p}=\left(\sigma_{1}+\sigma_{3}\right) / 2 \\
(\mathrm{kPa})\end{array}$ & $\begin{array}{c}\text { Secant } \\
\text { modulus } \\
(\mathrm{kPa})\end{array}$ \\
\hline 100 & 396.4 & $+2.1^{*}$ & 198.2 & 298.4 & 4489.2 \\
\hline 200 & 661.6 & +2.26 & 330.8 & 530.8 & 7492.6 \\
\hline 300 & 844.2 & -0.08 & 442.1 & 722.1 & 9560.6 \\
\hline
\end{tabular}

- -ve value means contraction +ve value means dilation

\subsubsection{Results of sleeve reinforced triaxial stone columns}

\subsubsection{Stone columns with Tensar and Conwed sleeves}

The stress-strain behaviour of stone columns confined with Tensar UX-1500 and Conwed 9027 sleeves is presented in Figure 5.4 for granular " $\mathrm{A}$ " at confining pressure of $103 \mathrm{kPa}$. Similar results at confining pressures of $207 \mathrm{kPa}$ and $345 \mathrm{kPa}$ are presented in Appendix C. In these figures the results of sleeve reinforced stone columns were compared with the results of the unreinforced columns at the same confining pressure.

Stone columns with granular "A" aggregate and Tensar sleeve exhibit higher strength and initial tangent modulus than similar columns with 3/8" aggregate for confining pressure of $103 \mathrm{kPa}$. However, at the same confining pressure (103 $\mathrm{kPa})$ beyond $15 \%$ axial strain the deviator stresses for sleeve reinforced columns tend to become constant.

The presence of polymer sleeves have restrained the dilation of the stone column material. The effect of sleeve reinforcement is more significant at a low confining stress $\left(\sigma_{3}=103 \mathrm{kPa}\right)$ where the dilation of granular "A" aggregate is high. A Tensar sleeve is more effective in reducing dilation than a Conwed sleeve. Comparing the volume change of unreinforced and sleeve reinforced at an axial strain of $10 \%$, reveals that the volume 


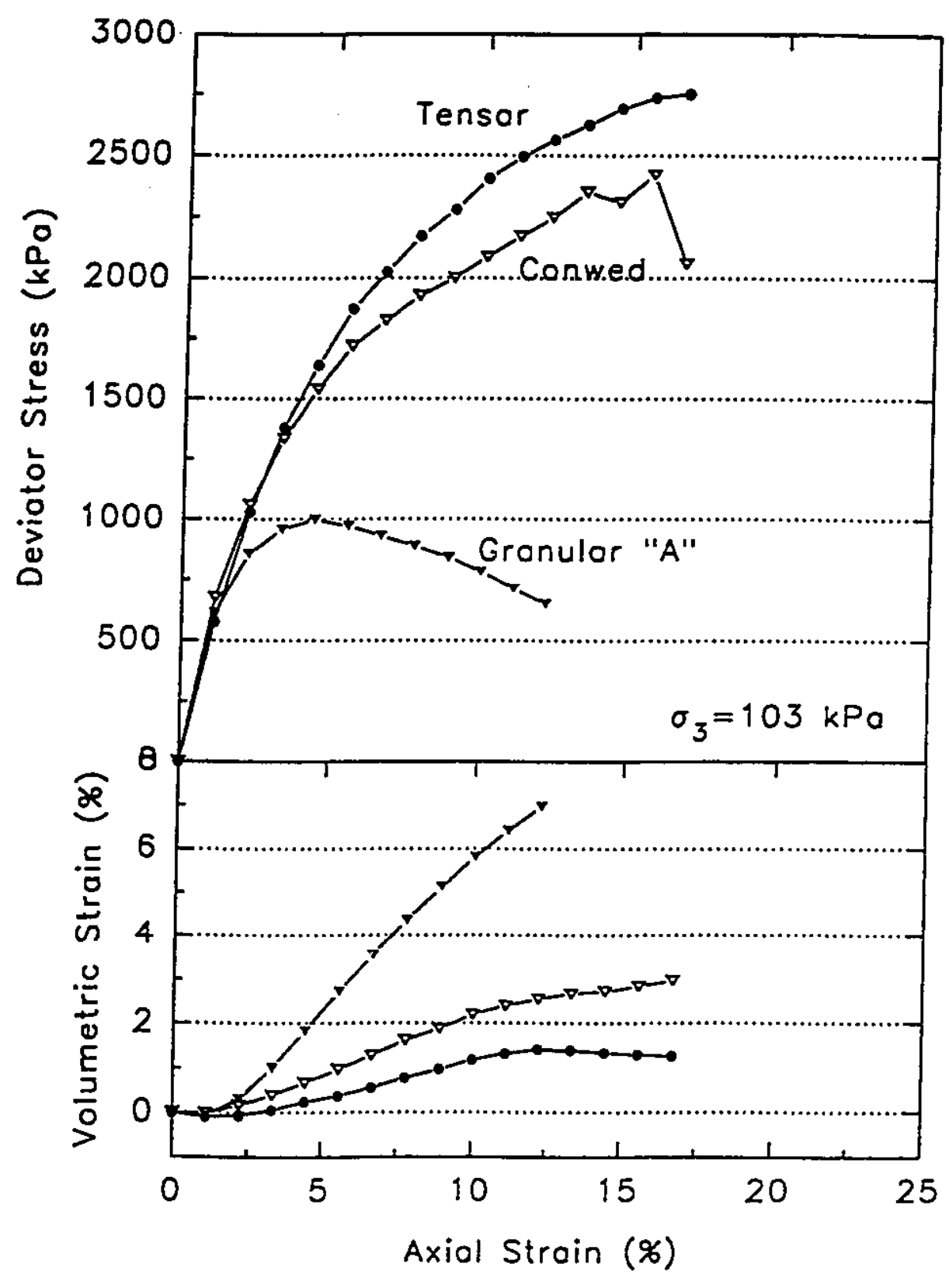

Figure 5.4 : Stress-strain-volume change behaviour of granular " $\mathrm{A}$ " reinforced stone columns at $\sigma_{3}=103 \mathrm{kPa}$. 
has been reduced by $81 \%$ and $63 \%$, due to Tensar UX-1500 and Conwed 9027 sleeves, respectively. The strain hardening behaviour noticed in the stress-strain curves of sleeve reinforced stone columns is attributed to the mobilization of sleeve strength. As shown in Figure 5.4, the strength continued to increase until rupture of the sleeve occurred as indicated by the sudden drop in the deviator stress for the Conwed 9027 sleeve. Tables 5.4 to 5.7 summarise the results of the large reinforced triaxial specimens $(0.225 \mathrm{~m}$ diameter) for the two aggregates with Tensar and Conwed sleeves respectively.

Table 5.4 : Results of triaxial stone columns with Tensar UX-1500 sleeve (granular " $A$ " aggregate, $\varepsilon_{2}=10 \%$ )

\begin{tabular}{|c|c|c|c|c|c|}
\hline $\begin{array}{c}\text { Confining } \\
\text { Pressure } \\
(\mathrm{kPa})\end{array}$ & $\begin{array}{c}\text { Deviator } \\
\text { stress } \\
\left(\sigma_{1}-\sigma_{3}\right),(\mathrm{kPa})\end{array}$ & $\begin{array}{c}\text { Volumetric } \\
\text { strain } \\
\left(\Delta \mathrm{V} / \mathrm{N}_{0}\right), \%\end{array}$ & $\begin{array}{c}\mathrm{q}=\left(\sigma_{1}-\sigma_{3}\right) / 2 \\
(\mathrm{kPa})\end{array}$ & $\begin{array}{c}\mathrm{p}=\left(\sigma_{1}+\sigma_{3}\right) / 2 \\
(\mathrm{kPa})\end{array}$ & $\begin{array}{c}\text { Secant } \\
\text { modulus } \\
(\mathrm{kPa})\end{array}$ \\
\hline 103 & 2406.4 & $1.18^{*}$ & 1203.3 & 1306.2 & 24064 \\
\hline 207 & 2471.2 & 0.08 & 1235.6 & 1442.6 & 24712 \\
\hline 345 & 3047.5 & -0.81 & 1523.8 & 1868.8 & 30475 \\
\hline
\end{tabular}

$\cdot$-ve value means contraction

+ve value means dilation

Table 5.5 : Results of triaxial stone columns with Conwed 9027 sleeve (granular "A" aggregate, $\varepsilon_{\mathrm{a}}=\mathbf{1 0} \%$ )

\begin{tabular}{|c|c|c|c|c|c||}
\hline $\begin{array}{c}\text { Confining } \\
\text { Pressure } \\
(\mathrm{kPa})\end{array}$ & $\begin{array}{c}\text { Deviator } \\
\text { stress } \\
\left(\sigma_{1}-\sigma_{3}\right),(\mathrm{kPa})\end{array}$ & $\begin{array}{c}\text { Volumetric } \\
\text { strain } \\
\left(\Delta \mathrm{V} / \mathrm{N}_{0}\right), \%\end{array}$ & $\begin{array}{c}\mathrm{q}=\left(\sigma_{1}-\sigma_{3}\right) / 2 \\
(\mathrm{kPa})\end{array}$ & $\begin{array}{c}\mathrm{p}=\left(\sigma_{1}+\sigma_{3}\right) / 2 \\
(\mathrm{kPa})\end{array}$ & $\begin{array}{c}\text { srcant } \\
\text { modulus } \\
(\mathrm{kPa})\end{array}$ \\
\hline 103 & 2086.1 & $2.19^{*}$ & 1043.1 & 1146.1 & 20861 \\
\hline 207 & 2296.4 & 0.4 & 1148.2 & 1355.2 & 22964 \\
\hline 345 & 2917.0 & -1.09 & 1458.5 & 1803.5 & 29170 \\
\hline
\end{tabular}

-ve value means contraction

+ve value means dilation 
Table 5.6 : Results of triaxial stone columns with Tensar UX-1500 sleeve (3/8" aggregate, $\varepsilon_{\mathrm{a}}=10 \%$ )

\begin{tabular}{|c|c|c|c|c|c||}
\hline $\begin{array}{c}\text { Confining } \\
\text { Pressure } \\
(\mathrm{kPa})\end{array}$ & $\begin{array}{c}\text { Deviator } \\
\text { stress } \\
\left(\sigma_{1}-\sigma_{3}\right),(\mathrm{kPa})\end{array}$ & $\begin{array}{c}\text { Volumetric } \\
\text { strain } \\
\left(\Delta \mathrm{V} / \mathrm{V}_{0}\right), \%\end{array}$ & $\begin{array}{c}\mathrm{q}=\left(\sigma_{1}-\sigma_{3}\right) / 2 \\
(\mathrm{kPa})\end{array}$ & $\begin{array}{c}\mathrm{p}=\left(\sigma_{1}+\sigma_{3}\right) / 2 \\
(\mathrm{kPa})\end{array}$ & $\begin{array}{c}\text { Secant } \\
\text { modulus } \\
(\mathrm{kPa})\end{array}$ \\
\hline 103 & 1568.2 & $-2.28^{*}$ & 784.1 & 887.1 & 15682 \\
\hline 207 & 1832 & -4.12 & 916 & 1123 & 18320 \\
\hline 345 & 1967.6 & -4.34 & 983.8 & 1328.8 & 19676 \\
\hline
\end{tabular}

-ve value means contraction $+\mathrm{ve}$ value means dilation

Table 5.7 : Results of triaxial stone columns with Conwed 9027 sleeve (3/8" aggregate, $\varepsilon_{2}=10 \%$ )

\begin{tabular}{|c|c|c|c|c|c|}
\hline $\begin{array}{c}\text { Confining } \\
\text { Pressure } \\
(\mathrm{kPa})\end{array}$ & $\begin{array}{c}\text { Deviator } \\
\text { stress } \\
\left(\sigma_{1}-\sigma_{3}\right),(\mathrm{kPa})\end{array}$ & $\begin{array}{c}\text { Volumetric } \\
\text { strain } \\
\left(\Delta \mathrm{V} / \mathrm{N}_{0}\right), \%\end{array}$ & $\begin{array}{c}\mathrm{q}=\left(\sigma_{1}-\sigma_{3}\right) / 2 \\
(\mathrm{kPa})\end{array}$ & $\begin{array}{c}\mathrm{p}=\left(\sigma_{1}+\sigma_{3}\right) / 2 \\
(\mathrm{kPa})\end{array}$ & $\begin{array}{c}\text { Secant } \\
\text { modulus } \\
(\mathrm{kPa})\end{array}$ \\
\hline 103 & 1212.5 & $-2.12^{*}$ & 606.3 & 709.3 & 12125 \\
\hline 207 & 1666.5 & -2.19 & 833.3 & 1040.3 & 16665 \\
\hline 345 & 1709.9 & -3.82 & 854.95 & 1200 & 17099 \\
\hline
\end{tabular}

- -ve value means contraction +ve value means dilation

\subsubsection{Stone columns with fiber glass (GB\#10) sleeves}

The stress-strain and volume change relations of triaxial stone columns confined with fiber glass (GB \#10) sleeves are presented in Figure 5.5. This type of reinforcement was used only with uniformly graded aggregate ( $\left.3 / 8^{\prime \prime}\right)$ because the dilation of this aggregate is less than granular " $\mathrm{A}$ " aggregate. The confining effect of fiber glass sleeves is less than the other types of polymer sleeves used. The overall strength of the fiber glass sleeve reinforced columns is less than the corresponding values for the polymer sleeve columns.

Stone columns with fiber glass sleeves exhibited higher contraction than the columns with Tensar and Conwed sleeves. This behaviour is attributed to the low tensile strain but high tensile 


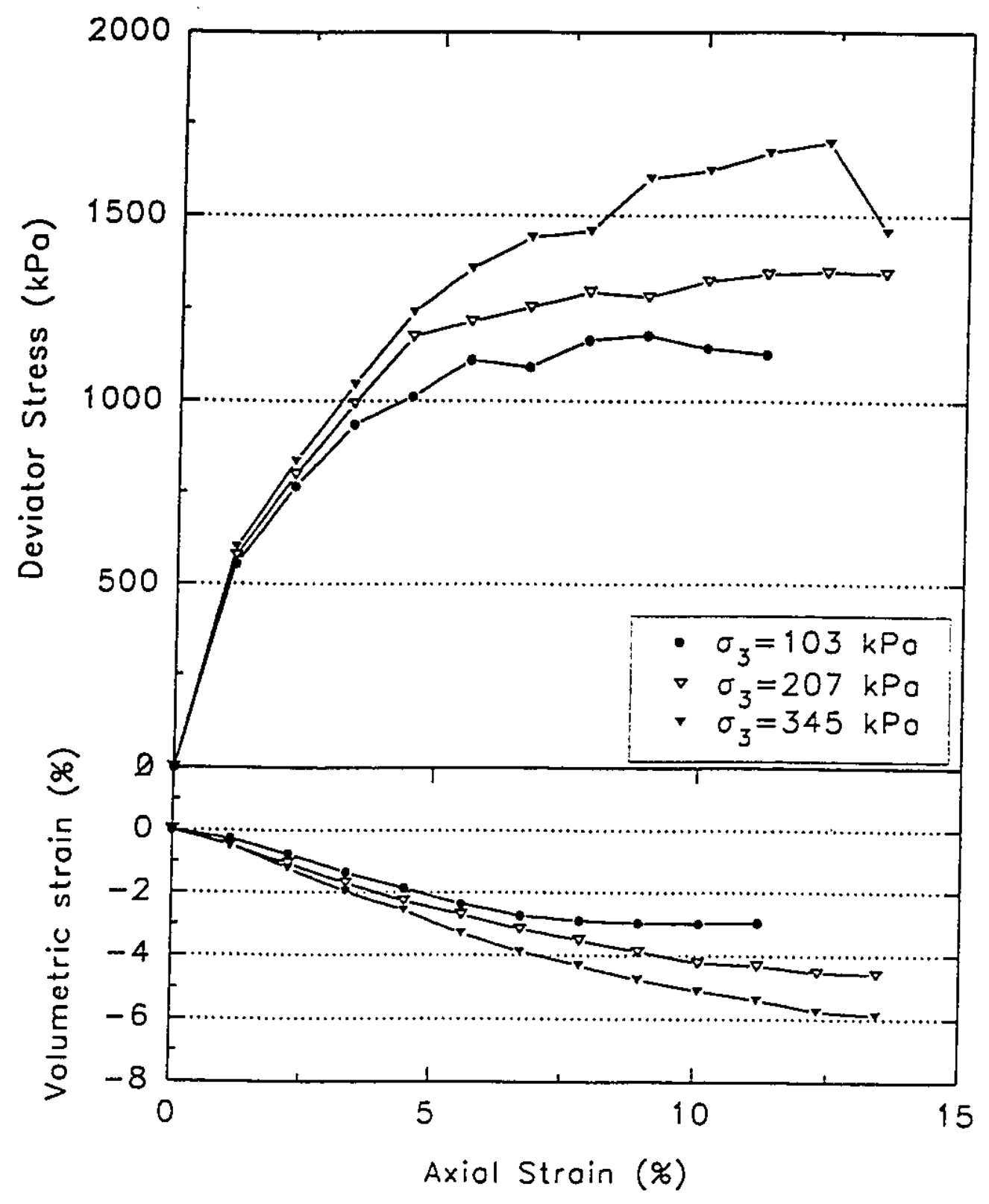

Figure 5.5 : Stress-strain-volume change behaviour of stone columns with uniform aggregate and fiber glass (GB \#10) sleeves 
strength of fiber glass.

Fiber glass (GB \#10) has a high tensile stresses but is very brittle and fractures easily under bending. Therefore, the reinforcing sleeves started to break at an early stage of the tests as the ultimate bending stress of the fiber glass was exceeded. During a test, the breakage of a horizontal fiber glass rib was quite sudden.

In Figure 5.5 the breakage of fiber glass ribs is indicated by the irregular behaviour of the stress-strain relationship beyond $5 \%$ of axial strain at all confining pressures. Table (5.8) summarises the results of the triaxial stone columns reinforced with fiber glass sleeves.

Table 5.8 : Results of triaxial stone columns with fiber glass (GB \#10) (3/8" aggregate, $\varepsilon_{2}=10 \%$ )

\begin{tabular}{||c|c|c|c|c|c|}
\hline $\begin{array}{c}\text { Confining } \\
\text { Pressure } \\
(\mathrm{kPa})\end{array}$ & $\begin{array}{c}\text { Deviator } \\
\text { stress } \\
\left(\sigma_{1}-\sigma_{3}\right),(\mathrm{kPa})\end{array}$ & $\begin{array}{c}\text { Volumetric } \\
\text { strain } \\
\left(\Delta \mathrm{V} / \mathrm{N}_{0}\right), \%\end{array}$ & $\begin{array}{c}\mathrm{q}=\left(\sigma_{1}-\sigma_{3}\right) / 2 \\
(\mathrm{kPa})\end{array}$ & $\begin{array}{c}\mathrm{p}=\left(\sigma_{1}+\sigma_{3}\right) / 2 \\
(\mathrm{kPa})\end{array}$ & $\begin{array}{c}\text { Secant } \\
\text { modulus } \\
(\mathrm{kPa})\end{array}$ \\
\hline 103 & 1145.2 & $-3.0^{*}$ & 572.6 & 675.6 & 11452 \\
\hline 207 & 1324.4 & -4.22 & 662.2 & 869.2 & 13244 \\
\hline 345 & 1621.6 & -5.09 & 810.8 & 1155.8 & 16216 \\
\hline
\end{tabular}

-ve value means contraction +ve value means dilation

\subsubsection{Results of small triaxial specimens}

The results of the small specimens $(55 \mathrm{~mm} \times 110 \mathrm{~mm}$ ) reinforced with Tensar UX1500 and Conwed 9027 are shown in Figure 5.6 for a confining pressure of $100 \mathrm{kPa}$. Similar results at other confining pressures are presented in Appendix C.

Comparing the results of reinforced specimens at an axial strain of $8.8 \%$ which corresponds to peak strength of the unreinforced specimens revealed that the strength almost doubled. The volume change reverted from dilation to contraction for $100 \mathrm{kPa}$ and $200 \mathrm{kPa}$ confining pressures respectively. A summary of the results using the two types of reinforcement is given in Tables 5.9 and 5.10 corresponding to the peak strength of the unreinforced specimens. 


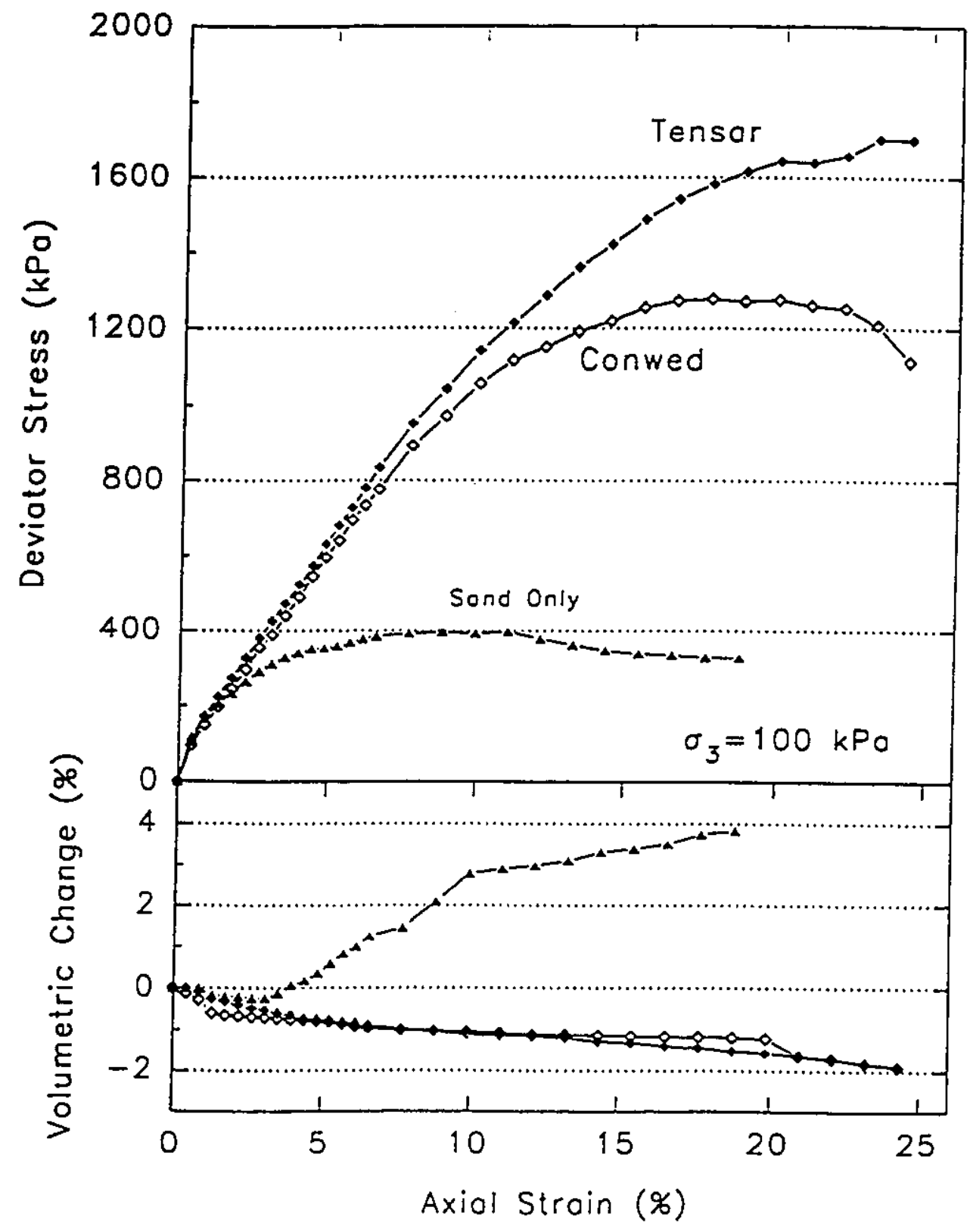

Figure 5.6 : Effect of Tensar UX-1500 and Conwed 9027 sleeves on the behaviour of small sand specimens $\left(\sigma_{3}=100 \mathrm{kPa}\right)$ 
Table 5.9 : Results of small triaxial specimens reinforced with Tensar UX-1500 (Soil sieved from 3/8" aggregate, $\varepsilon_{\mathrm{a}}=8.8 \%$ )

\begin{tabular}{|c|c|c|c|c|c||}
\hline $\begin{array}{c}\text { Confining } \\
\text { Pressure } \\
(\mathrm{kPa})\end{array}$ & $\begin{array}{c}\text { Deviator } \\
\text { stress } \\
\left(\sigma_{1}-\sigma_{3}\right),(\mathrm{kPa})\end{array}$ & $\begin{array}{c}\text { Volumetric } \\
\text { strain } \\
\left(\Delta \mathrm{V} / \mathrm{V}_{0}\right), \%\end{array}$ & $\begin{array}{c}\mathrm{q}=\left(\sigma_{1}-\sigma_{3}\right) / 2 \\
(\mathrm{kPa})\end{array}$ & $\begin{array}{c}\mathrm{p}=\left(\sigma_{\mathrm{r}}+\sigma_{3}\right) / 2 \\
(\mathrm{kPa})\end{array}$ & $\begin{array}{c}\text { Secant } \\
\text { modulus } \\
(\mathrm{kPa})\end{array}$ \\
\hline 100 & 1044 & $-1.05^{*}$ & 522 & 622 & 11823.3 \\
\hline 200 & 1339.3 & -3.39 & 669.7 & 869.7 & 15167.6 \\
\hline 300 & 1647.1 & -3.21 & 823.6 & 1123.6 & 18653.5 \\
\hline
\end{tabular}

-ve value means contraction

$+v e$ value means dilation

Table 5.10 : Results of small triaxial specimens reinforced with Conwed 9027 (Soil sieved from $3 / 8^{\prime \prime}$ aggregate, $\varepsilon_{\mathrm{a}}=8.8 \%$ )

\begin{tabular}{|c|c|c|c|c|c||}
\hline $\begin{array}{c}\text { Confining } \\
\text { Pressure } \\
(\mathrm{kPa})\end{array}$ & $\begin{array}{c}\text { Deviator } \\
\text { stress } \\
\left(\sigma_{1}-\sigma_{3}\right),(\mathrm{kPa})\end{array}$ & $\begin{array}{c}\text { Volumetric } \\
\text { strain } \\
\left(\Delta \mathrm{V} / \mathrm{V}_{0}\right), \%\end{array}$ & $\begin{array}{c}\mathrm{q}=\left(\sigma_{1}-\sigma_{3}\right) / 2 \\
(\mathrm{kPa})\end{array}$ & $\begin{array}{c}\mathrm{p}=\left(\sigma_{1}+\sigma_{3}\right) / 2 \\
(\mathrm{kPa})\end{array}$ & $\begin{array}{c}\text { Secant } \\
\text { modulus } \\
(\mathrm{kPa})\end{array}$ \\
\hline 100 & 972.2 & $-1.03^{*}$ & 486.1 & 586.1 & 11010.2 \\
\hline 200 & 1259.1 & -1.45 & 629.6 & 829.6 & 14259.3 \\
\hline 300 & 1478.4 & -1.57 & 739.2 & 1039.2 & 16742.9 \\
\hline
\end{tabular}

+ve value means dilation

\subsubsection{Effect of aggregate type on column behaviour}

\subsubsection{Unreinforced stone columns}

The stress-strain behaviour of unreinforced stone columns depends largely on the type of aggregate, the density and the confining pressure. Therefore, using a well compacted granular "A" aggregate resulted in a stiff stone column with high dilation (volume increase ) behaviour. On the other hand, the uniformly graded aggregate at a lower density of the column material underwent contraction (volume decrease) at high axial strains. The results for the unreinforced stone columns with the two aggregates are presented in Figure 5.7 for a confining pressure of $103 \mathrm{kPa}$. 


\subsubsection{Sleeve reinforced stone columns}

The stress-strain behaviour for the two aggregates with Tensar sleeves are shown in Figure 5.8 for a confining pressure of $103 \mathrm{kPa}$. In the case of granular "A" aggregate, the dilative nature of the aggregate mobilized the tensile stresses in the polymer sleeve at low axial strains. The sleeve resisted the dilation tendency and consequently limited the lateral expansion of the stone column. The overall volume change (dilation) was therefore, less than the unreinforced column. In the case of the uniform aggregate the strength of he polymer sleeve was mobilized at higher axial strains due to the contractive nature of this aggregate.

In summary, the type of aggregate will, therefore, play an important role in the magnitude of confinement and in the mobilization of polymer grid strength. For the same deviator stress of $2000 \mathrm{kPa}$ (Figure 5.8) the column with a granular "A" backfill would compress or settle about $60 \%$ less than the column with the uniform aggregates.

The results of small triaxial compression specimens (small size $55 \mathrm{~mm}$ by $110 \mathrm{~mm}$ ) are compared in Figure 5.9 to the large $(225 \mathrm{~mm}$ by $450 \mathrm{~mm})$ triaxial reinforced columns. The confining pressure in both test series was approximately the same $(100 \mathrm{kPa}$ and 103 $\mathrm{kPa}$ ). However; it should be noted here that the material used in the small samples were sieved form the $3 / 8$ " aggregates to keep thie same (aggregates/specimen) diameter ratio. The results in Figure 5.9 indicates that, the large size stone columns will have a slightly higher strength than the small specimens. Both sizes of specimens exhibited approximately the same initial tangent modulus. This suggests that the performance of the grid sleeve will not change by changing the specimen size. The difference in strength between the two column sizes may be attributed to the slightly higher confining pressure for the large stone column.

\subsubsection{Results of $K_{0}$ tests}

Figure 5.10 represents the relationship between the major principal stress and the minor principal stress at zero lateral strain for the $0.225 \mathrm{~m}$ diameter columns. The resulting 


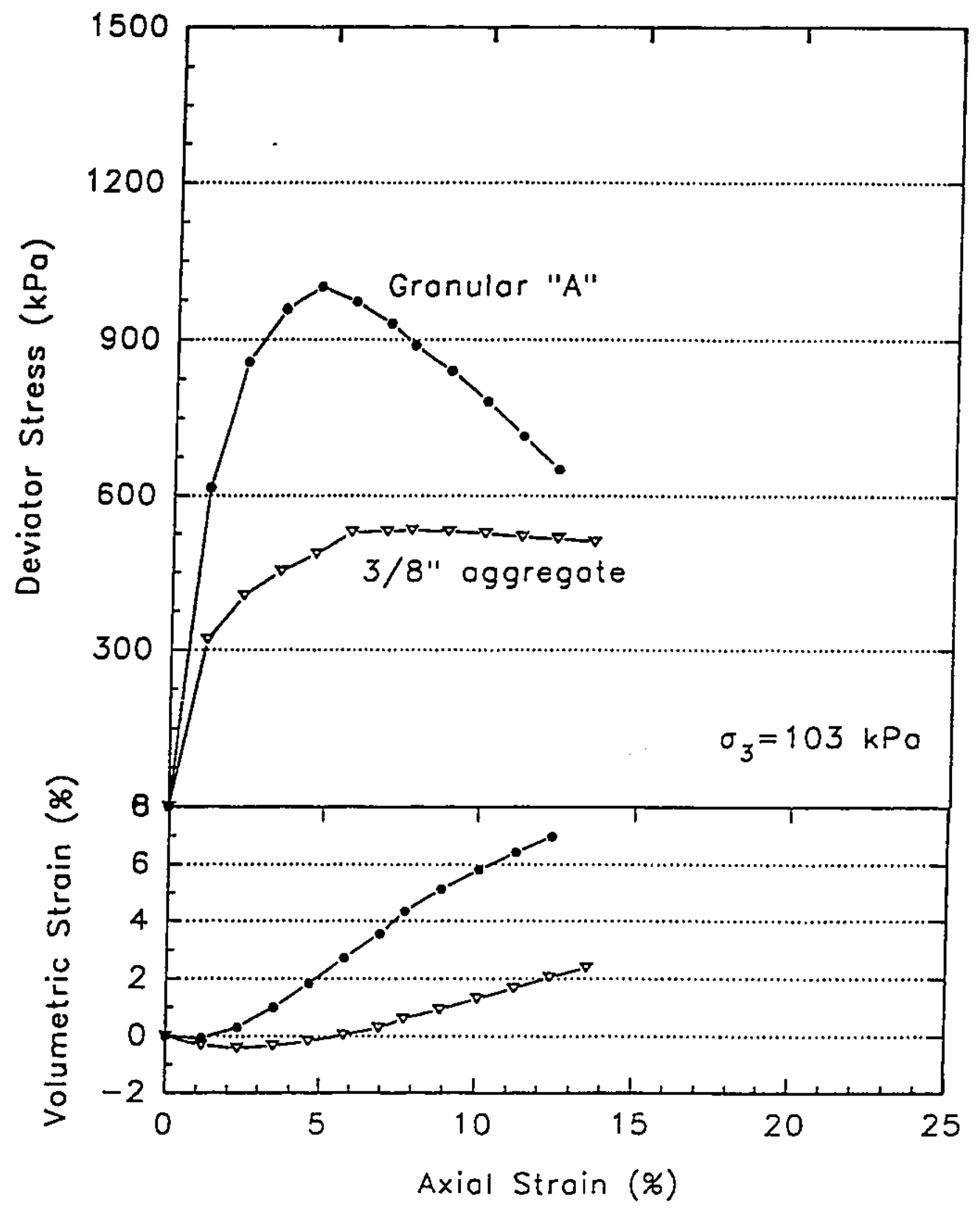

Figure 5.7 : Effect of aggregate type on the behaviour of unreinforced stone columns $\left(\sigma_{3}=103 \mathrm{kPa}\right)$ 


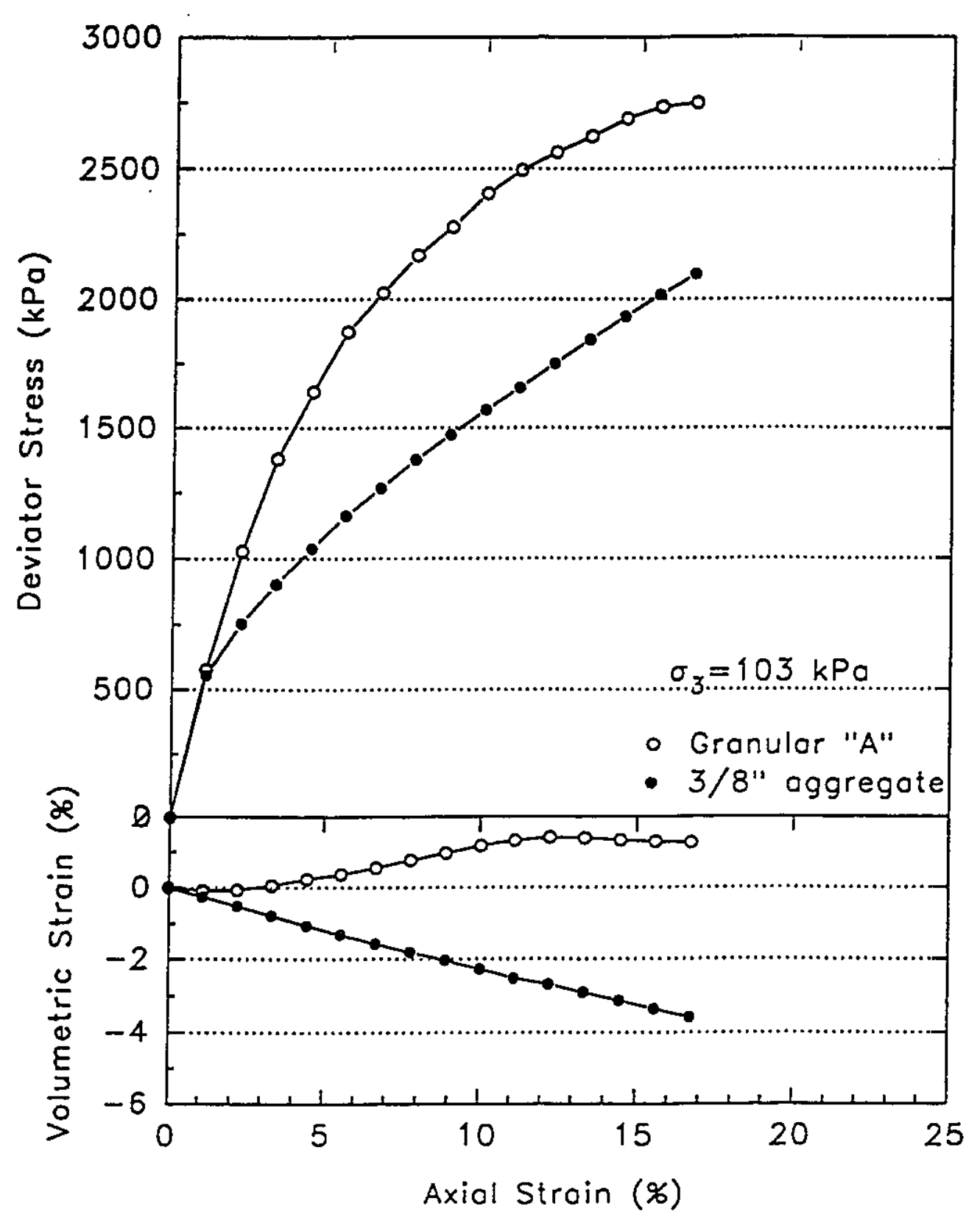

Figure 5.8 : Effect of aggregate type on the behaviour of reinforced stone columns with Tensar UX-1500 sleeves $\left(\sigma_{3}=103 \mathrm{kPa}\right)$ 


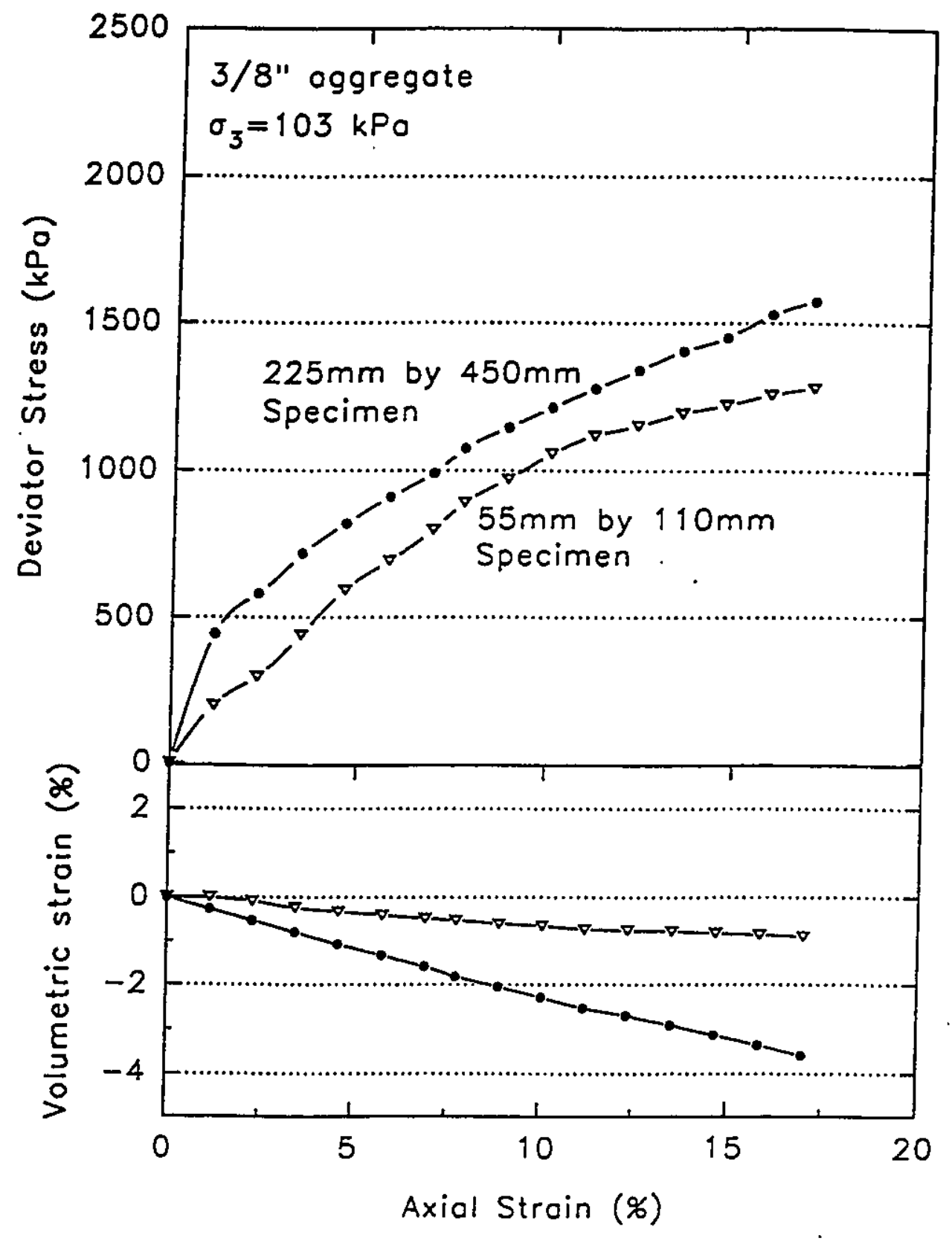

Figure 5.9 : Effect of stone column size on the stress-strain-volume change behaviour at $\sigma_{3}=103 \mathrm{kPa}$ (Tensar sleeves) 


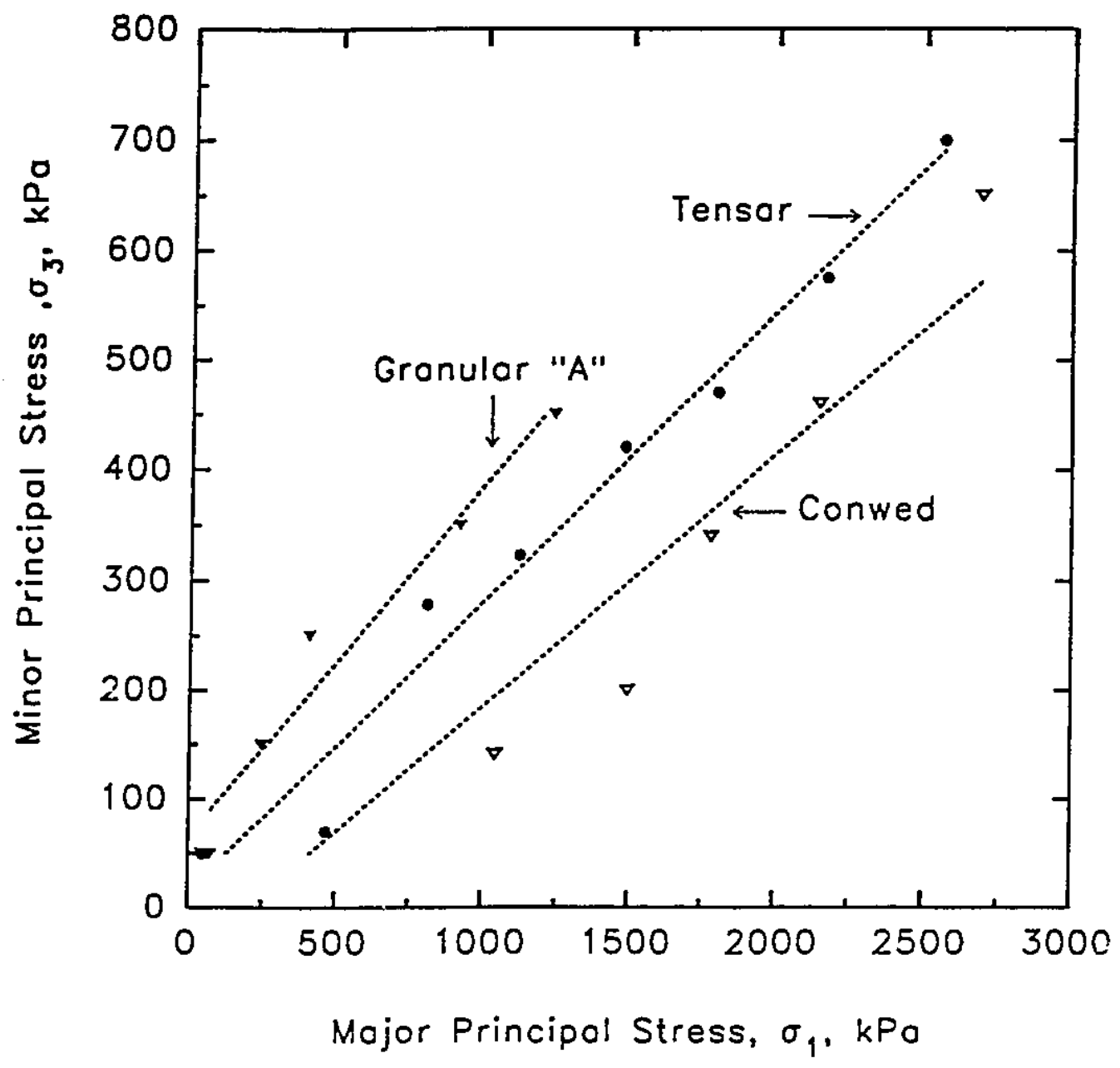

Figure $5.10: \mathrm{K}_{\mathrm{o}}$ tests for reinforced and unreinforced columns (Granular "A" aggregate) 
$\mathrm{K}_{0}$ value was 0.34 for granular " $\mathrm{A}$ ". With a Tensar sleeve the value of $\mathrm{K}_{0}$ was 0.26 and for granular " $A$ " with a Conwed sleeve it was 0.21 . Similar values of $K_{0}$ for granular "A" aggregate was reported by $S c o t t$ et al (1980). Their average $\mathrm{K}_{0}$ value for granular " $\mathrm{A}$ " was 0.35. Comparison of $\mathrm{K}_{0}$ test results of this research with other published data will be presented in chapter 7 .

\subsubsection{Cyclic load tests on reinforced stone columns}

The cyclic load behaviour of reinforced stone columns $(0.225 \mathrm{~m}$ diameter and $0.45 \mathrm{~m}$ high) was studied by subjecting the triaxial specimens to several loading and unloading cycles. At the beginning of the test the columns were subjected to $K_{0}$ loading by increasing the vertical stress and adjusting the confining stress simultaneously to maintain zero lateral strain. After a $\mathrm{K}_{\mathrm{o}}$ test, the specimens were subjected to a confining pressure of $103 \mathrm{kPa}$ and the vertical load was applied in a cyclic mode.

The advantage of releasing the deviator stress between stages of test are to prevent from further creep of the soil structure and that part of the accumulated strain can be restored through elastic recovery. An "elastic" modulus may therefore be obtained from any loading cycle because, after the first cycle, the slope of the loading/unloading curves are quite constant. The total amount of axial strain mobilized in the specimens after three cycles was between 2 and $2.5 \%$. All specimens of the cyclic loading tests were loaded for 70 to $75 \%$ of the maximum load obtained for similar specimens under static loading. It was envisaged that three cycles were sufficient to determine the behaviour of sleeve reinforced stone columns under cyclic loading. Figures 5.11 and 5.12 illustrate the cyclic stress-strain-volume change behaviour of stone columns reinforced with Tensar and Conwed sleeves for the uniformly graded and well graded aggregate respectively. The specimens were subjected to a confining stress of $103 \mathrm{kPa}$. The reloading moduli which were determined for the different loading/unloading cycles were consistent. Also, the volumetric strain during the cyclic loading was consistent for both stone columns confined by Tensar and Conwed sleeves. The volume change behaves linearly for each individual loading/unloading cycle. Similar cyclic loading behaviour of unreinforced and sleeve reinforced stone columns are presented in Appendix C. 


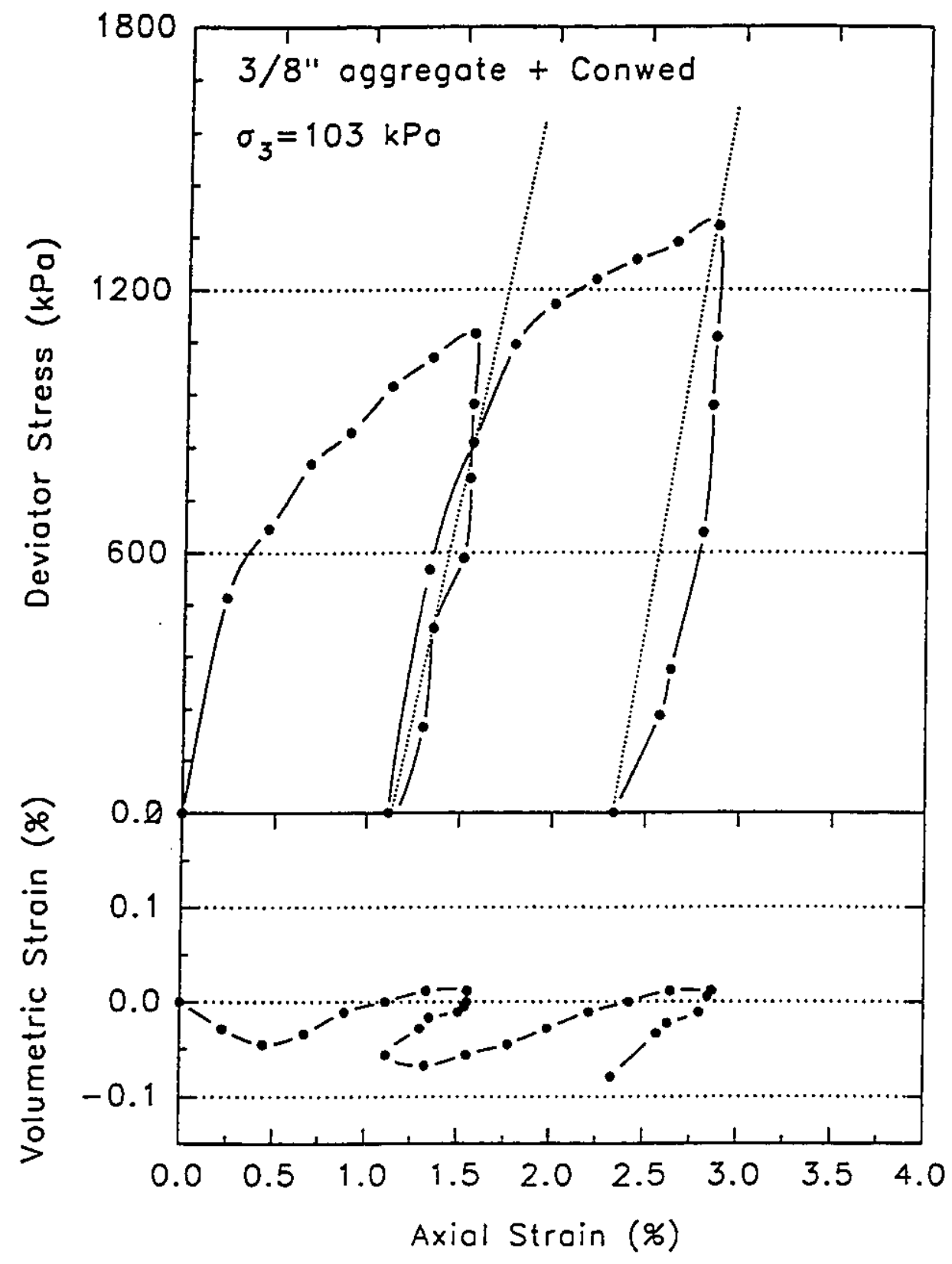

Figure 5.11 : Cyclic loading stress-strain-volume change behaviour of sleeve reinforced stone column (Conwed 9027 grid) 


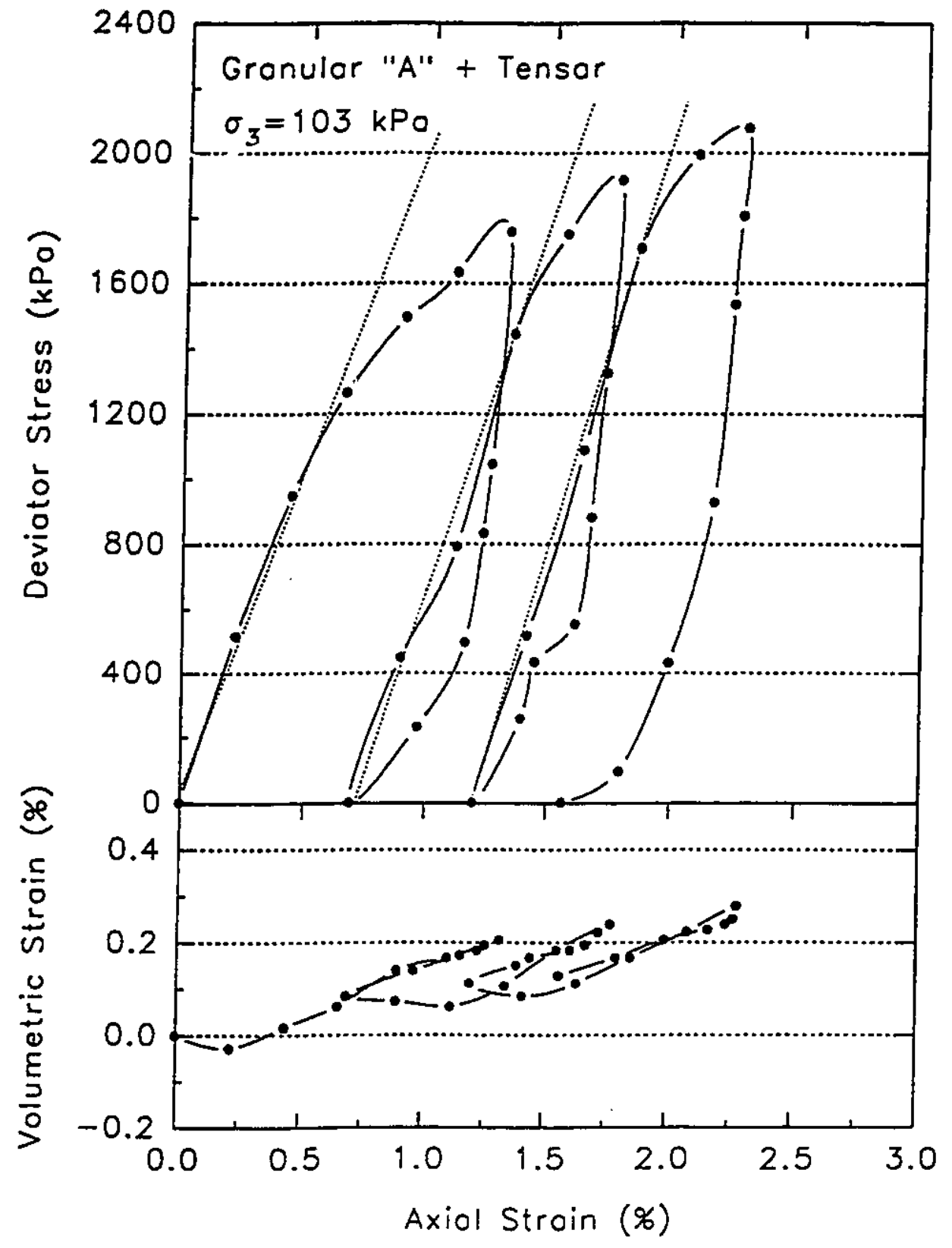

Figure 5.12 : Cyclic loading stress-strain-volume change behaviour of stone column reinforced with Tensar UX-1500 sleeve 


\subsection{RESULTS OF UNIAXIAL STONE COLUMNS TESTS}

In this section the test results for uniaxial stone columns are presented. The first set of figures will show the results of the load-deformation relationship and the second set will present the stress-strain and volume change relationship. The volume change of a uniaxial stone column was calculated from the LVDT's readings for the lateral deformation and from the axial strain during loading. Local strains in selected horizontal polymer strands were recorded with strain gauges that were attached to the grid. The results will be presented as strains in the polymer strands versus axial deformation of the stone column. The experimental results will be presented in the following sections.

\subsubsection{Results of static loaded uniaxial stone columns}

The load-deformation relationship of a reinforced stone column is presented in Figure 5.13 for the uniform aggregate. The diameter of the stone column was $0.33 \mathrm{~m}$ and the height was $0.68 \mathrm{~m}$. It was reinforced with a Tensar sleeve. The test was terminated at $120 \mathrm{~mm}$ of axial deformation ( $\left.\varepsilon_{\mathrm{a}}=17.5 \%\right)$ corresponding to a load of $175 \mathrm{kN}$. The load deformation relationship may be divided into two portions, the first part ranges from zero to $20 \mathrm{~mm}$ axial deformation ( 0 to $3 \%$ axial strain) corresponding to a nonlinear relation. In the second part, beyond $20 \mathrm{~mm}$ axial deformation, the slope was linear and the load continued to increase linearly to $120 \mathrm{~mm}$ axial deformation (17.5\% axial strain). A similar behaviour was observed (Figure 5.14) for the stone column with a diameter of $0.38 \mathrm{~m}$ and a height of $1.32 \mathrm{~m}$. The stone column was also made with uniform aggregate and a Tensar UX-1600 sleeve. It was loaded to $12 \%$ of axial strain corresponding to a load of $160 \mathrm{kN}$. Similarly, the first portion of the load deformation relation between zero and $25 \mathrm{~mm}$ axial deformation (0 to $1.9 \%$ axial strain) was non-linear. At this loading level the strength of the aggregate is believed to be fully mobilized. The second portion of the relationship, from 25 to $158 \mathrm{~mm}$ deformation ( 1.9 to $12 \%$ axial strain), is fairly linear. In this range the global behaviour can be considered strain hardening due to the mobilization of polymer grid sleeve strength. 


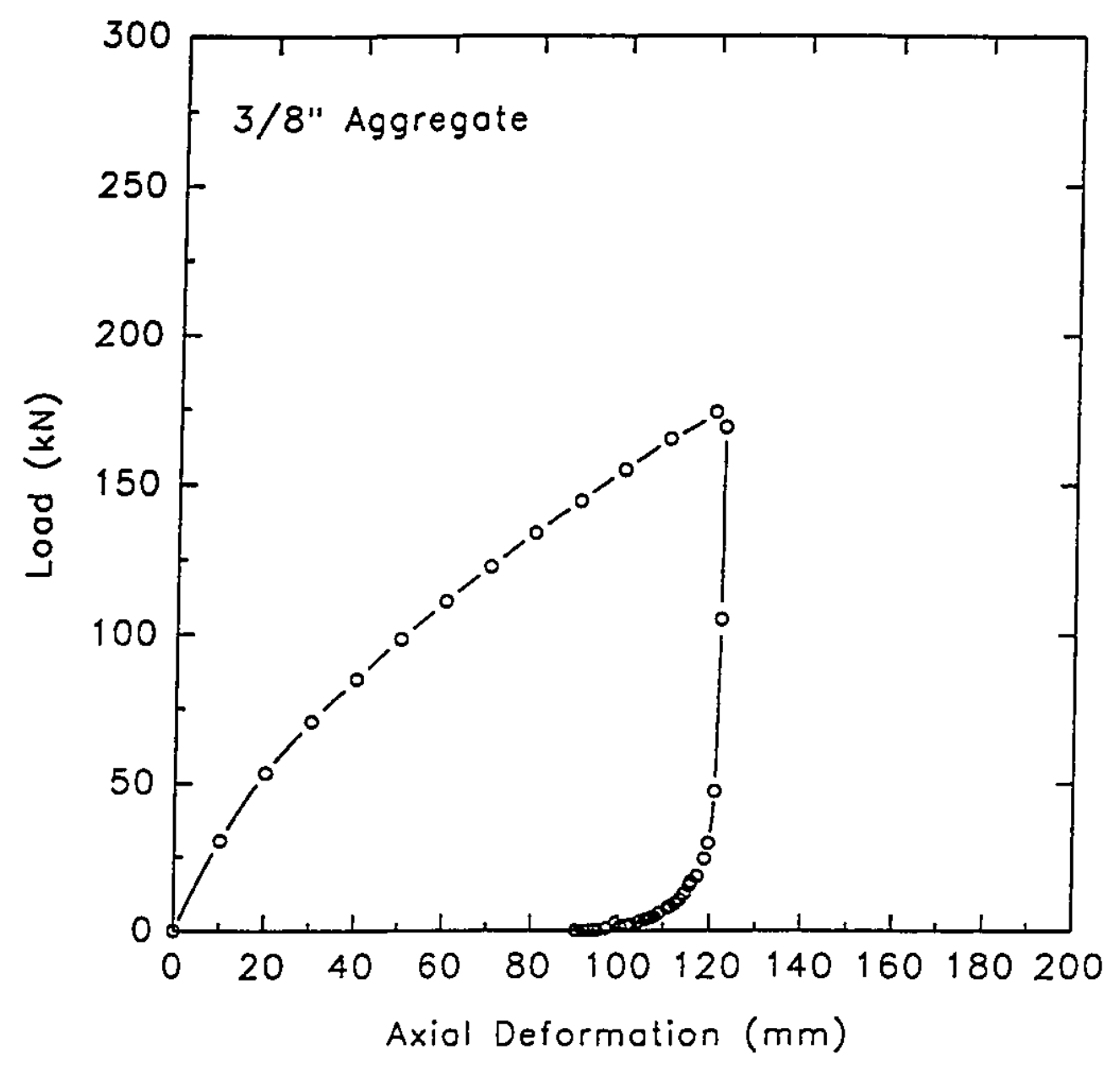

Figure 5.13 : Load-deformation behaviour of uniaxial stone column confined with Tensar UX-1600 sleeve

(Diameter $=0.33 \mathrm{~m}$, Height $=0.68 \mathrm{~m}$ ) 


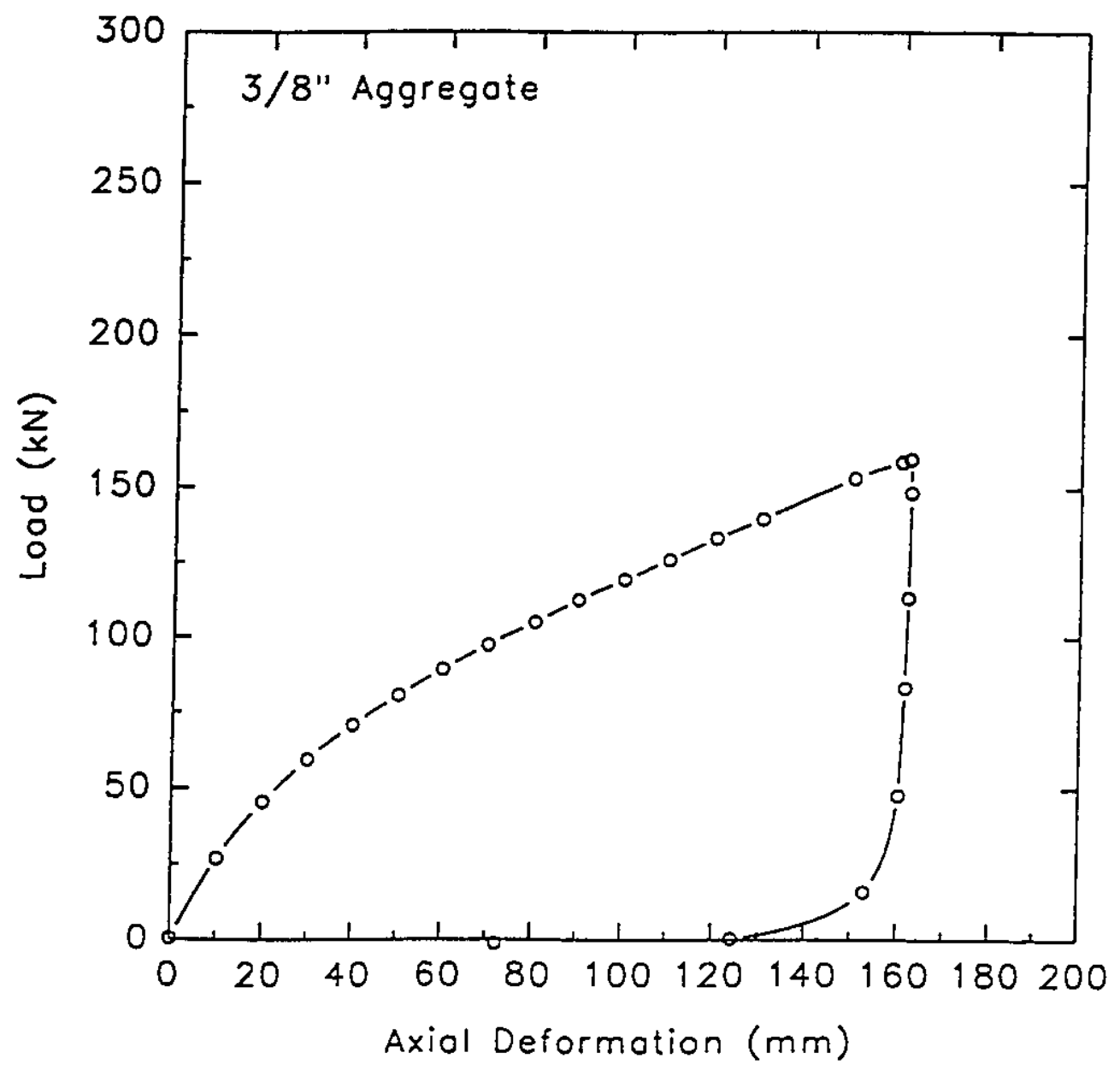

Figure 5.14 : Load-deformation behaviour of uniaxial stone column confined with Tensar UX-1600 sleeve

(Diameter=0.38 m, Height=1.32 m) 
Similar results of stone columns prepared with granular "A" aggregate are shown in Figure 5.15 for a short sleeve column ( $0.33 \mathrm{~m}$ in diameter and $0.68 \mathrm{~m}$ high) and in Figure 5.16 for a long sleeve column ( $0.38 \mathrm{~m}$ in diameter and $1.32 \mathrm{~m}$ high).

The mode of deformation for the long and short columns reinforced with Tensar (UX-1600) sleeves are presented in Figures 5.17 and 5.18. The columns bulged uniformly under static loading. The bulging was more dominant at mid-height due to the restraining effect of the end caps.

\subsubsection{Results of cyclic loaded uniaxial stone columns}

As mentioned before, in certain engineering applications the stone columns will be subjected to cyclic loading. Some of these applications include the support for water tanks and/or transportation systems. The cyclic load-deformation behaviour of short stone columns are presented in Figures 5.19 and 5.20 for both uniformly graded and well graded aggregates respectively. It is important to notice that the unloading part of the curves are, almost, vertical and that the strain starts to recover at a very low stress level $(25 \mathrm{kN})$.

The stone columns were subjected to five cycles. In the first cycle the columns were loaded to $25 \%$ of the maximum load obtained from a similar test under static loading. In the additional four cycles the load was raised at equal increments until the same maximum load as the static stone column was achieved.

The test with the uniform aggregate was terminated at a load of $175 \mathrm{kN}$ which corresponded to $110 \mathrm{~mm}$ of axial deformation ( $16 \%$ axial strain). The test with the well graded aggregate was terminated at a load of $200 \mathrm{kN}$ which corresponded also to an axial deformation of $110 \mathrm{~mm}$ (16\% axial strain).

\subsubsection{Results of rapidly loaded uniaxial stone column}

The uniaxial stone columns were considered to be tested under drained conditions as they were tested under a slow strain rate $(0.5 \mathrm{~mm} / \mathrm{min})$. However, under certain circumstances, such as shock waves, the stone columns would experience sudden loading. For this reason, and since no standard test procedure is available for polymer grid 


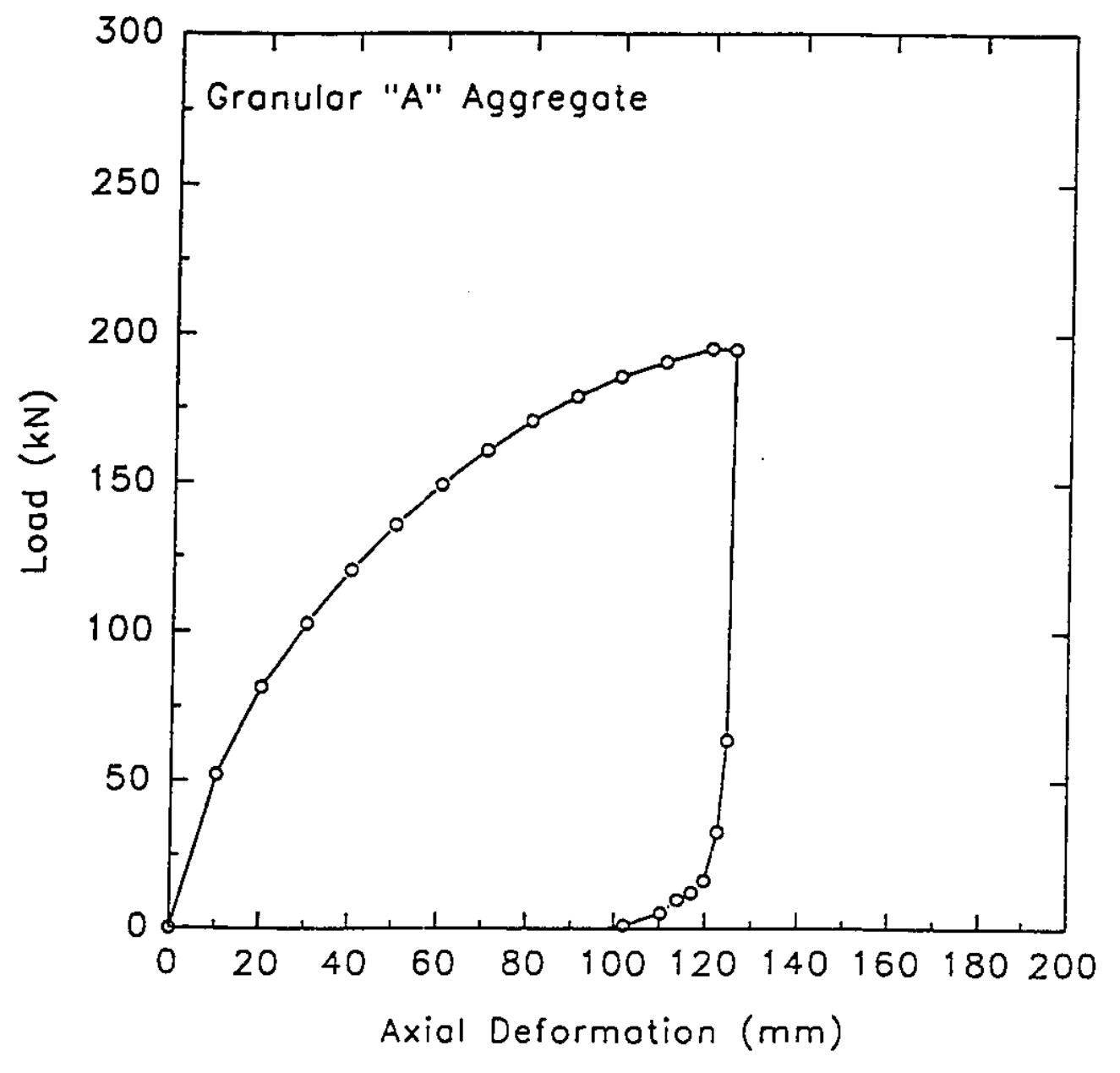

Figure 5.15 : Load-deformation behaviour of stone column confined with Tensar UX-1600 sleeve (Diameter $=0.33 \mathrm{~m}$, Height=0.68 m) 


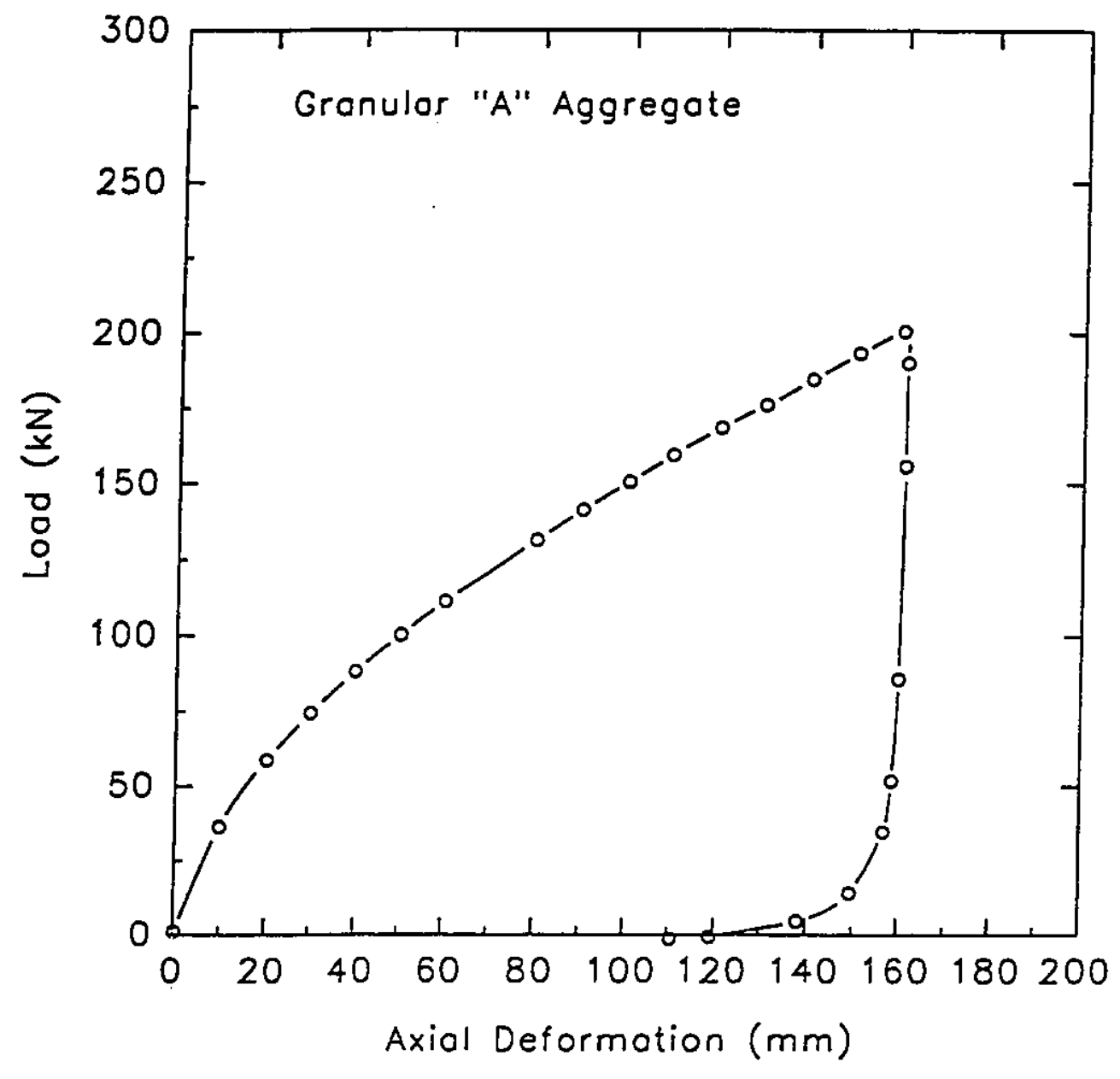

Figure 5.16 : Load-deformation behaviour of stone column confined with Tensar UX-1600 sleeve (Diameter $=0.38 \mathrm{~m}$, Height=1.32 m) 


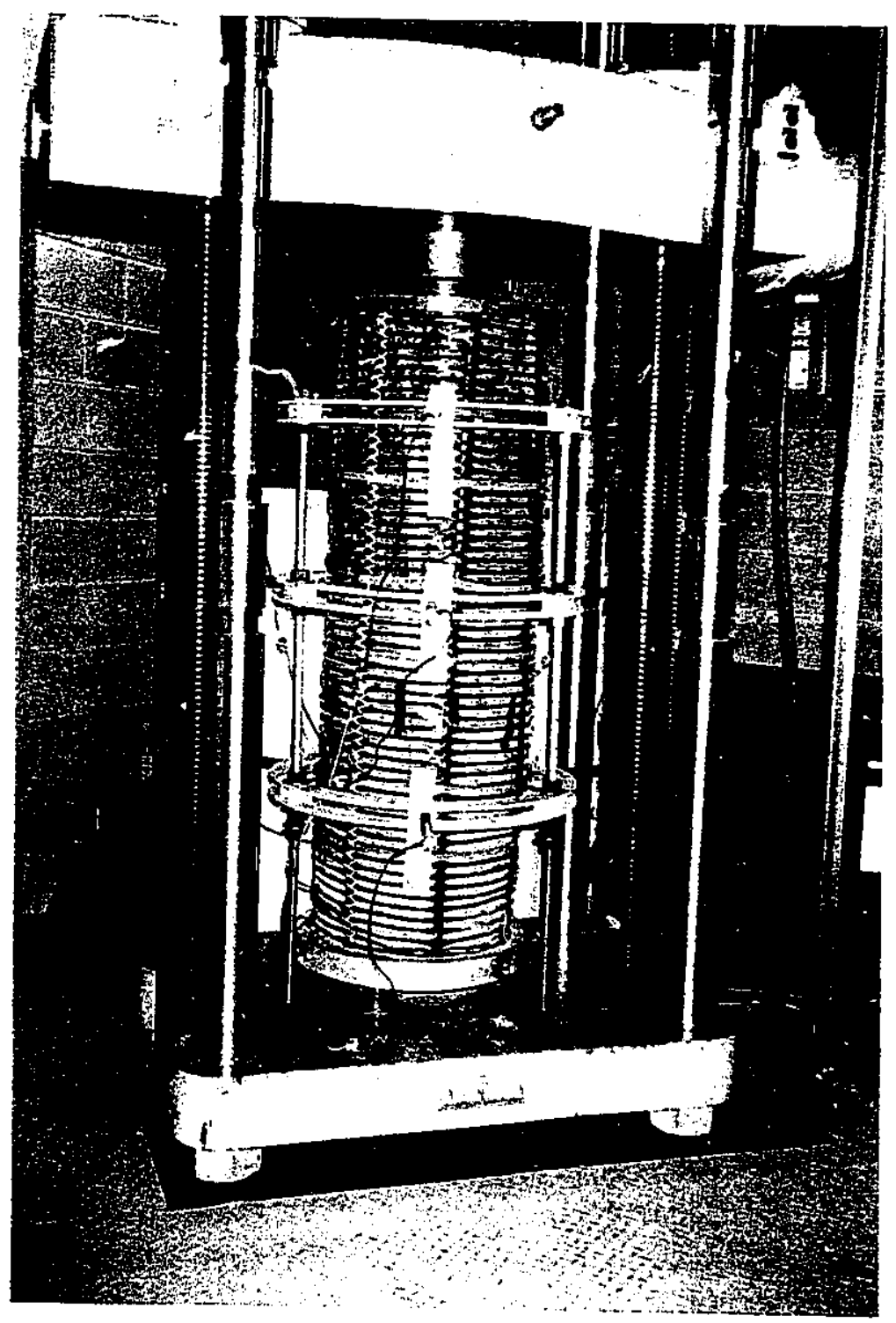

Figure 5.17: Bulged long sleeve reinforced stone column (Diameter $=0.38 \mathrm{~m}$, Height $=1.32 \mathrm{~m}$ ) 


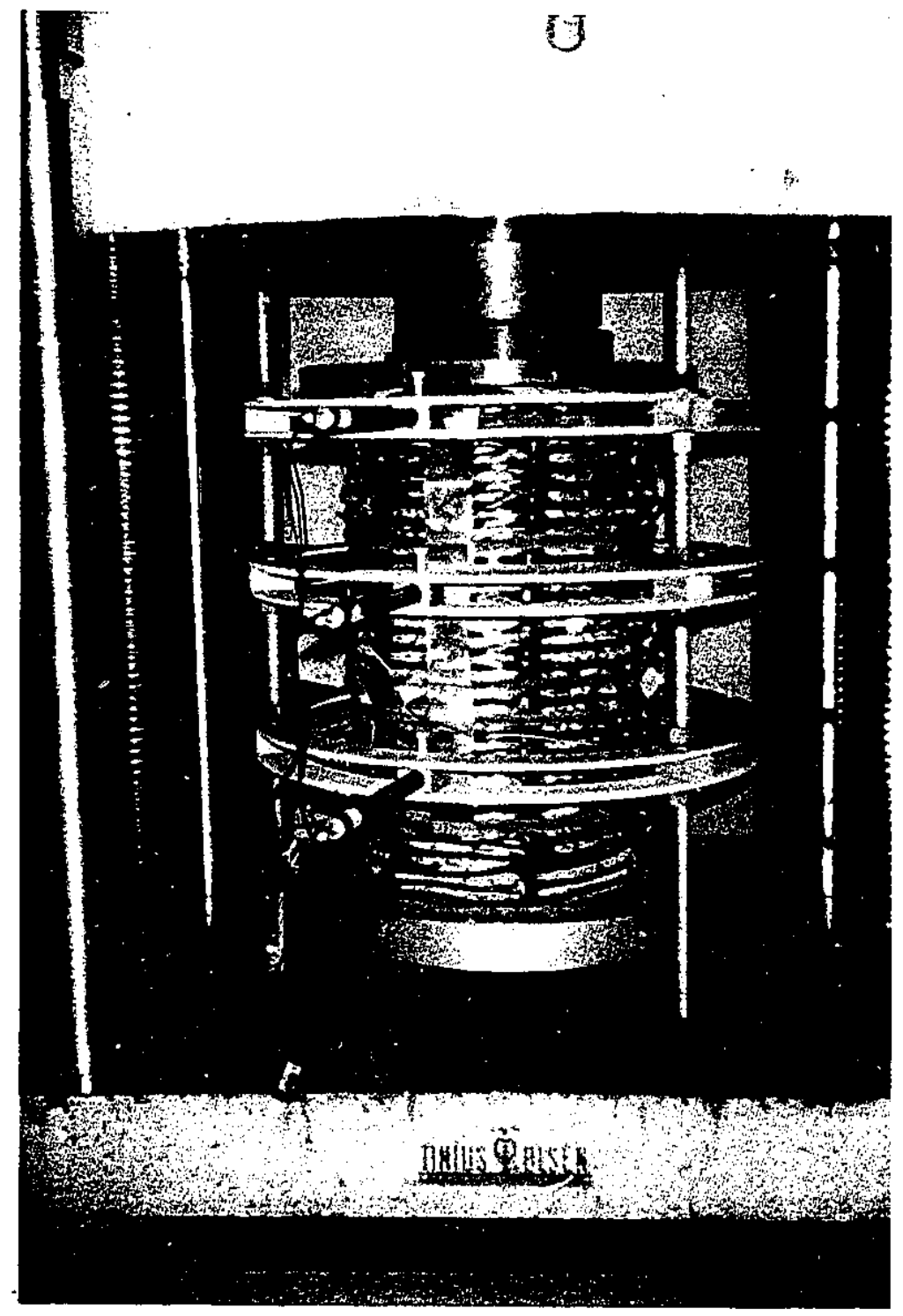

Figure 5.18 : Bulged short sleeve reinforced stone column (Diameter $=\mathbf{0 . 3 3} \mathrm{m}$, Height $=\mathbf{0 . 6 8} \mathrm{m}$ ) 


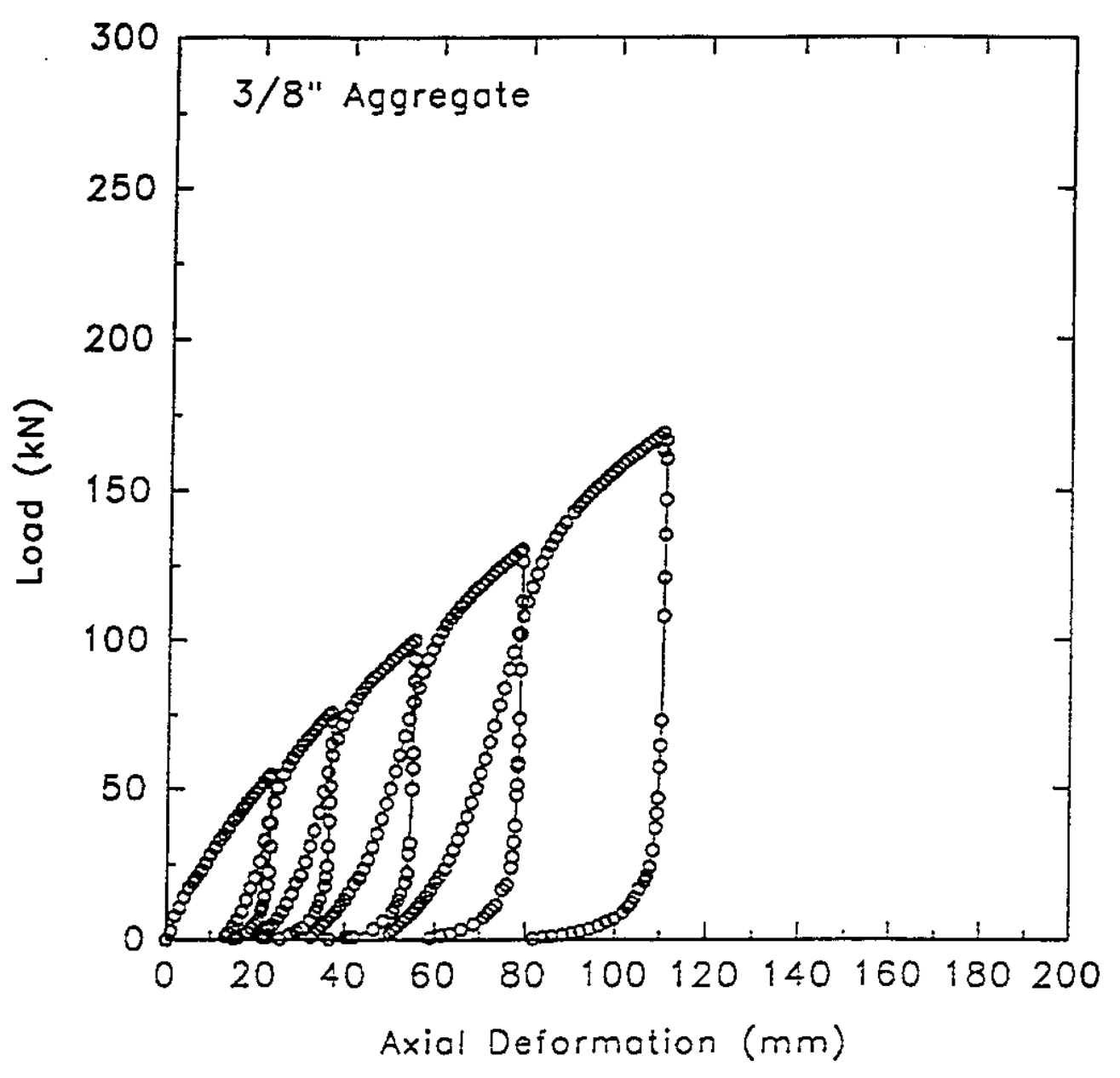

Figure 5.19 : Cyclic loading behaviour of stone column confined with Tensar UX-1600 sleeve (Diameter $=0.33 \mathrm{~m}$, height $=0.68 \mathrm{~m}$ ) 


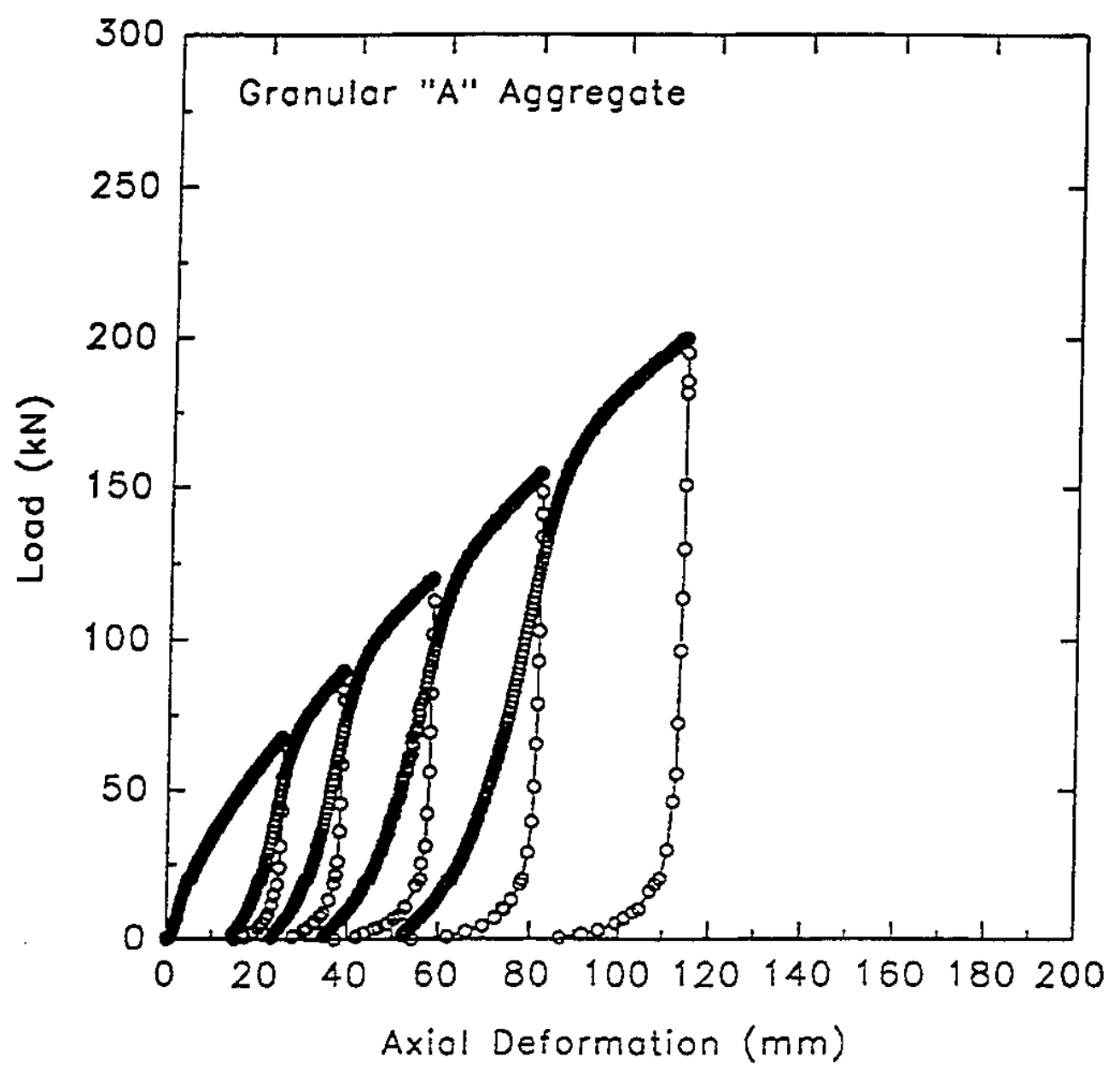

Figure 5.20 : Cyclic loading behaviour of stone column confined with Tensar UX-1600 sleeve (Diameter $=0.33 \mathrm{~m}$, height $=0.68 \mathrm{~m}$ ) 
reinforced stone columns, the behaviour of stone columns under fast strain rates were investigated. Figures 5.21 and 5.22 presents the load-deformation behaviour of reinforced stone columns for granular "A" and 3/8" aggregates respectively. The specimens had identical diameters of $0.33 \mathrm{~m}$ and heights of $0.68 \mathrm{~m}$ and were tested at strain rate of $10 \mathrm{~mm} / \mathrm{min}$. The columns were loaded in two stages. In the first stage they were loaded to a stress level close to failure. The columns were then unloaded gradually to zero and then reloaded from zero until failure (i.e rupture) of the polymer sleeves. These two specimens were the only ones which were loaded to grid rupture. The purpose was to determine the safe loading range when using this type of polymer sleeves and also to demonstrate the performance of the sleeve connection. It should be noted, that the rupture occurred within the horizontal ribs of the sleeve and not in the connection. The break of the grid strand was indicated by a sharp drop in the sustained load as is shown in Figure 5.22. The bulged shape and rupture of the grid sleeve of the short stone column is shown in Figure 5.23.

\subsubsection{Stress-strain-volume change of uniaxial stone columns}

In the previous sections the results were given in terms of load deformation relations for the uniaxial reinforced stone columns. In this section the results are shown in terms of stress-strain and volume change relationships. Vertical stresses in the stone column were calculated by dividing the applied load $(\mathrm{kN})$ by the corrected area. The corrected area was calculated from the initial cross sectional area of the column and the average lateral deformations which were obtained from the LVDT's measurements at a corresponding axial strain. The volume change of the column during a test was calculated from the recorded lateral and axial deformation. Figure 5.24 illustrates the stress-strain behaviour of a short uniaxial stone column with a Tensar UX-1500 sleeve and Figure 5.25 shows the volume change behaviour of the same stone column. The stress-strain and volume change relationships of short and long uniaxial reinforced columns are presented in Appendix C for both aggregate type and Tensar UX-1600 sleeves. The stress-strain and volume change behaviour of cyclic loaded uniaxial column are presented in Figures 5.26 and 5.27. The specimen was reinforced with Tensar UX-1600 sleeve and granular "A" 


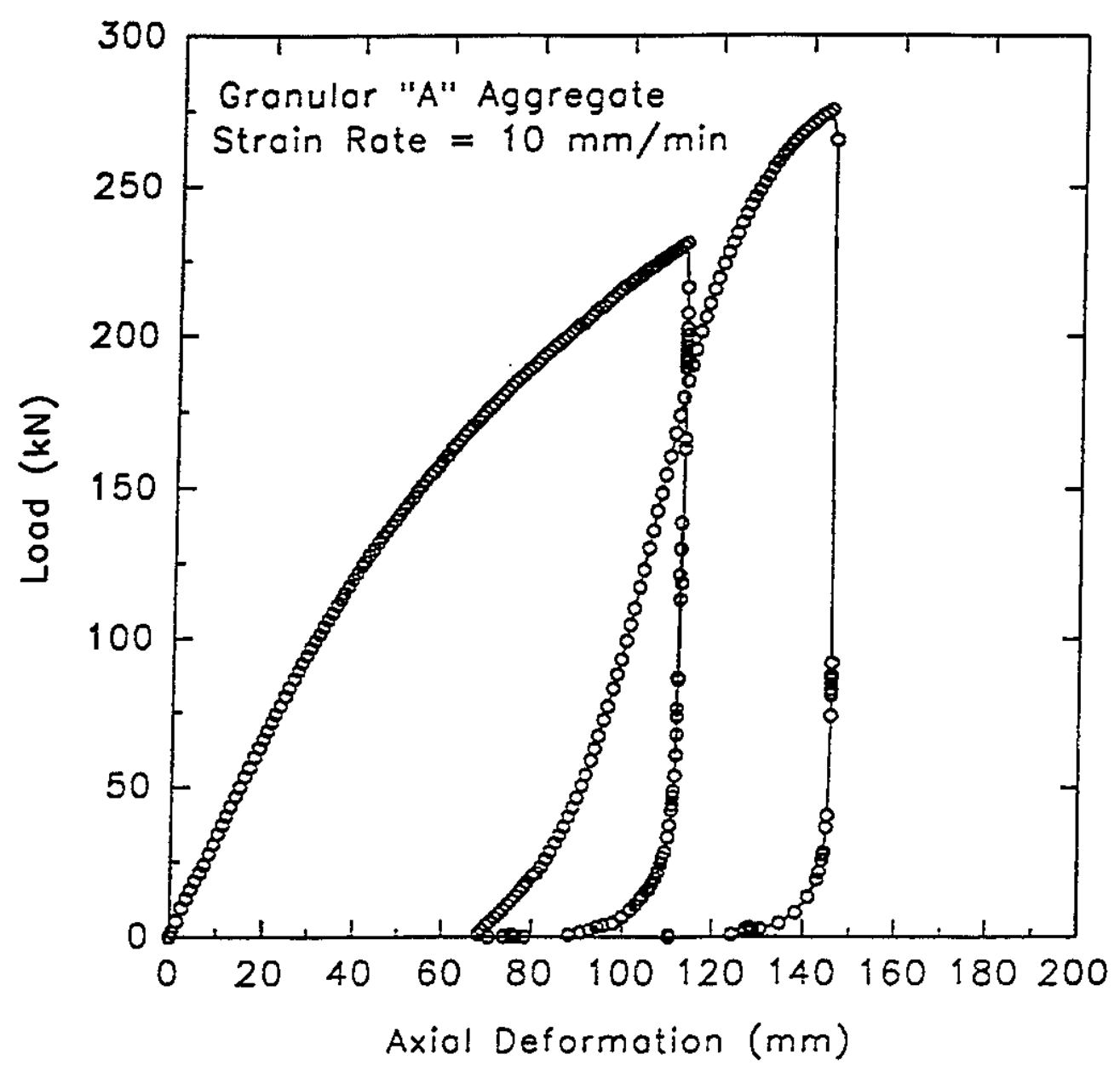

Figure 5.21 : Load-deformation behaviour of rapidly strained stone column with granular "A" aggregate and Tensar UX-1600 sleeve 


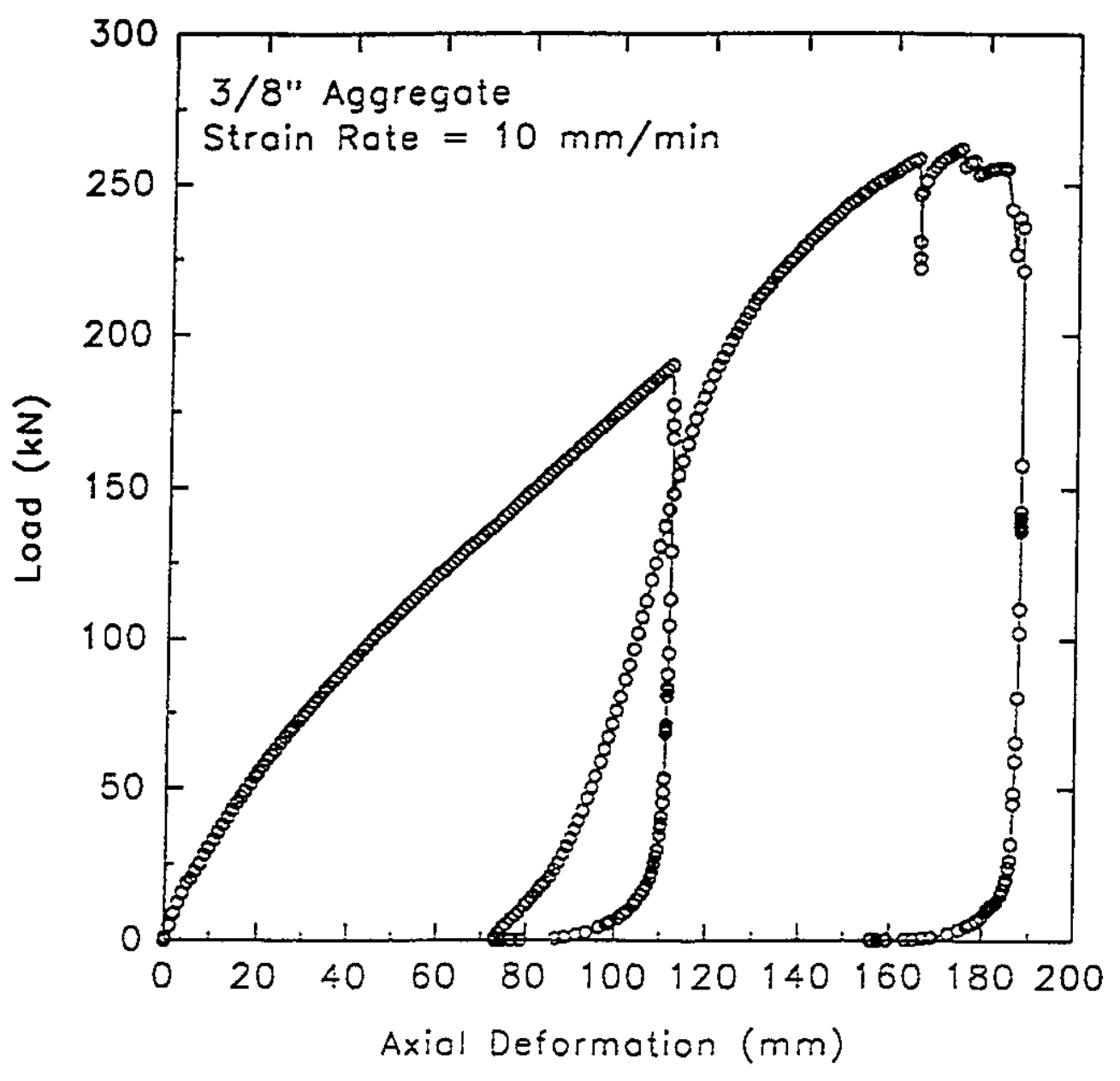

Figure 5.22 : Load-deformation behaviour of rapidly strained stone column with $3 / 8^{\prime \prime}$ aggregate and Tensar UX-1600 sleeve 


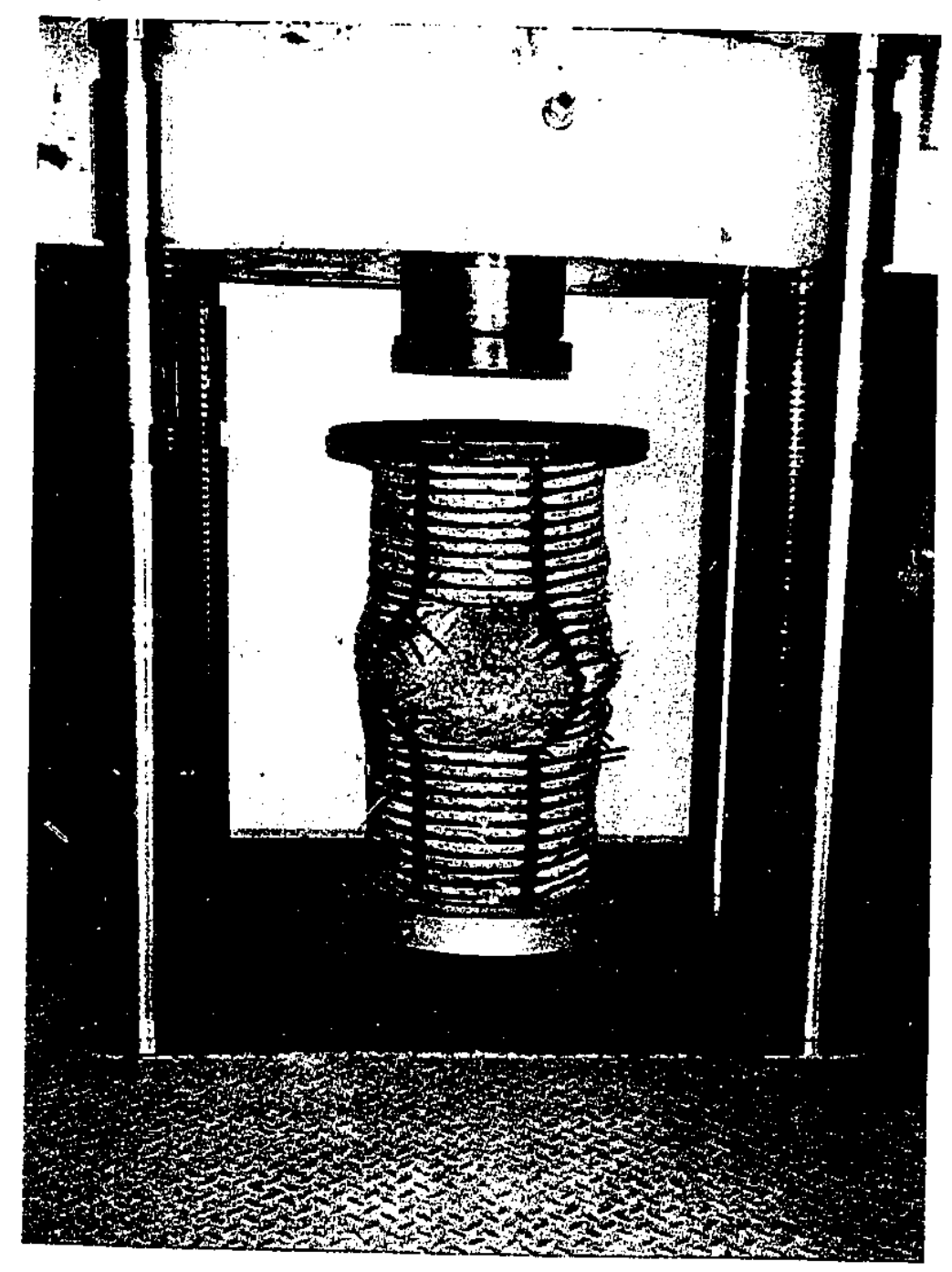

Figure 5.23 : Rupture of Tensar UX-1600 sleeve for the stone column in figure 5.22 


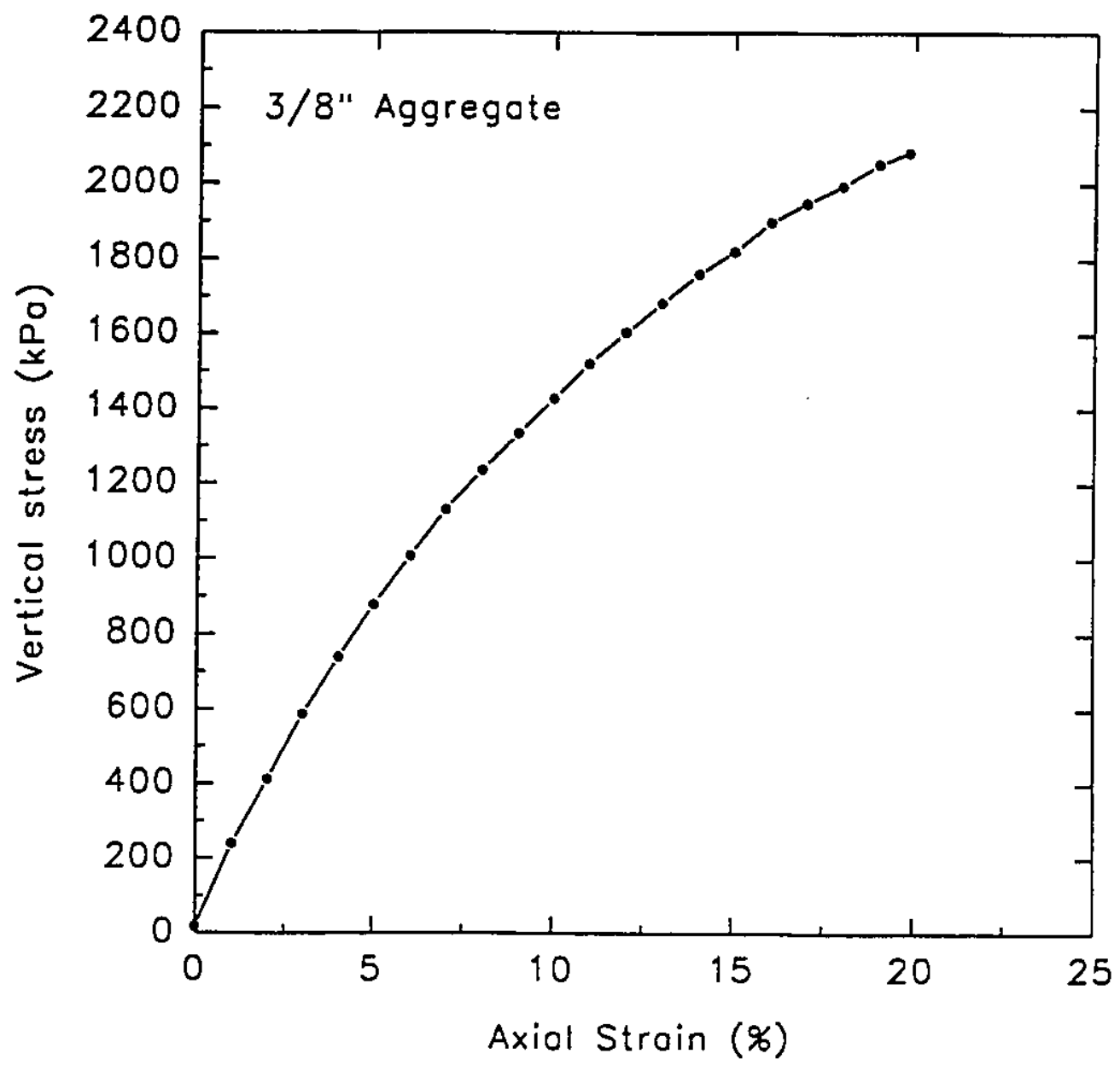

Figure 5.24 : Stress-strain behaviour of short uniaxial stone column with Tensar UX-1500 sleeve (Diameter $=0.28 \mathrm{~m}$, Height $=0.62 \mathrm{~m}$ ) 


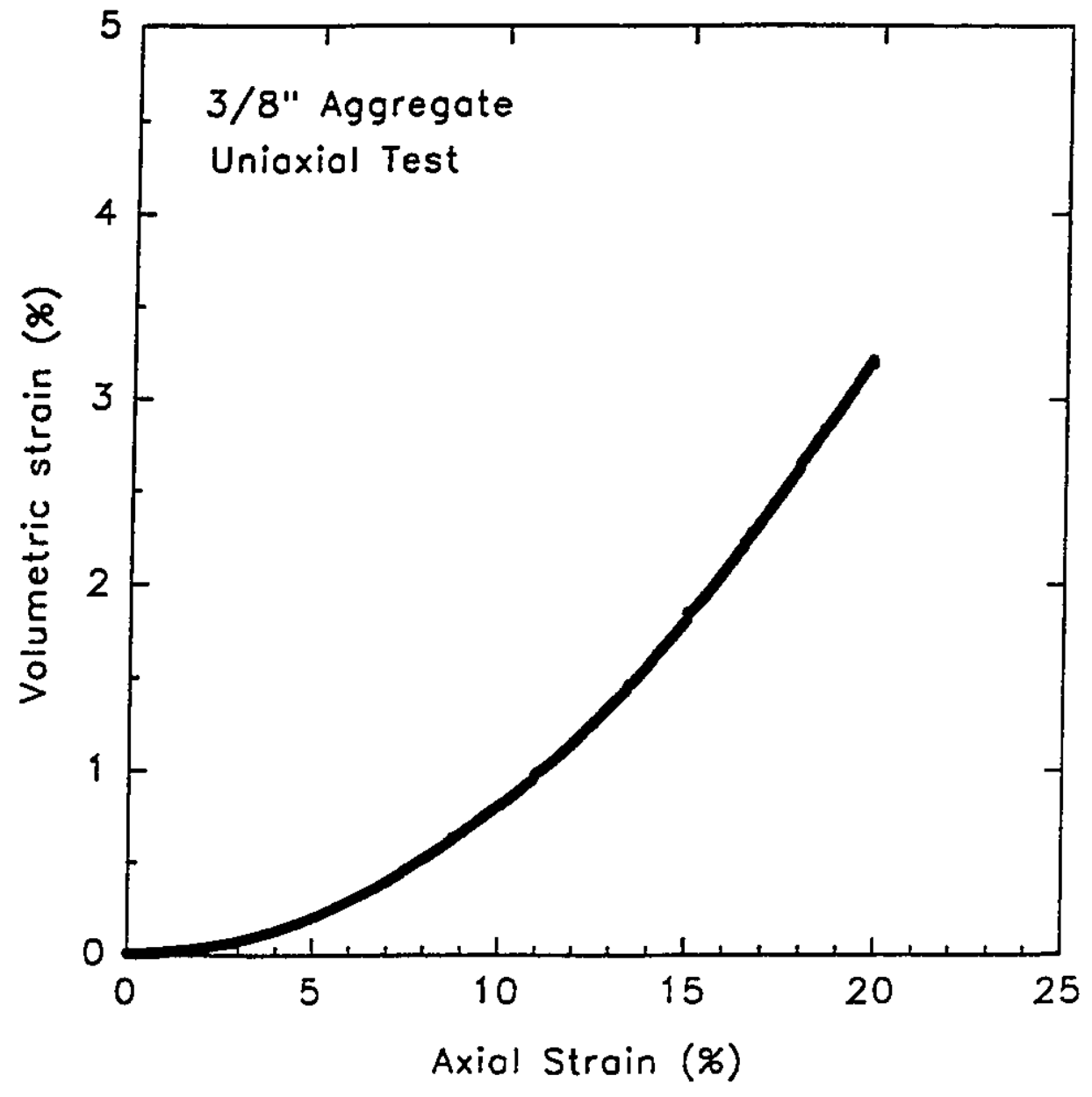

Figure 5.25 : Volume change behaviour of stone column in figure 5.24 
was used as backfill. Similar results are presented in Appendix C for columns with uniform aggregate and Tensar sleeves. The stress-strain volume change behaviour of the rapidly strained uniaxial stone columns are presented in Figures 5.28 to 5.29 for granular "A" aggregate. The failure of the polymer grid sleeves, was indicated by a sudden increase in volume as shown in Figure 5.29. Similar results for uniaxial column with uniform aggregate and Tensar UX-1600 sleeve are presented in Appendix C.

\subsubsection{Local strains in polymer grid sleeves}

Attempts were made to measure local strains with resistance gauges at specific locations of the polymer sleeve. The purpose in monitoring there strains was to calculate the tension forces at different locations in the polymer sleeve. The information obtained from the strain gauges was used to plot the tension mobilized in the ribs of the polymer grid against the axial strain.

Figures 5.30 to 5.32 present the local strains measured in these horizontal strands of the sleeve. Figure 5.30 shows tensile strains for two strands at mid height. Figures 5.31 and 5.32 present the tensile strains for strands at different heights of the column. It should be noted that the resistance strain gauges were only reliable to a maximum strain of $1.5 \%$. Therefore, the portion (linear) up to this strain and the corresponding axial deformation was used only in the analysis of the tensile stresses.

This chapter presented the various experimental resuits and demonstrated clearly the pronounced effect of the polymer grid sleeves on the stiffening and strength gain. Also, the effect of type of polymer grid, aggregate type and loading conditions on the stress-strain and volume change of stone columns has been presented at different confining pressures. These experimental results can be used for the calibration of analytical models and as guidelines for any further studies or practical applications of sleeve reinforcement.

The experimental results presented in this chapter fulfilled the first and second objectives of this research. Comparison of results and more discussion will be shown in chapter 7 . The next chapter presents the results of theoretical analysis using the hyperbolic stress-strain model. 


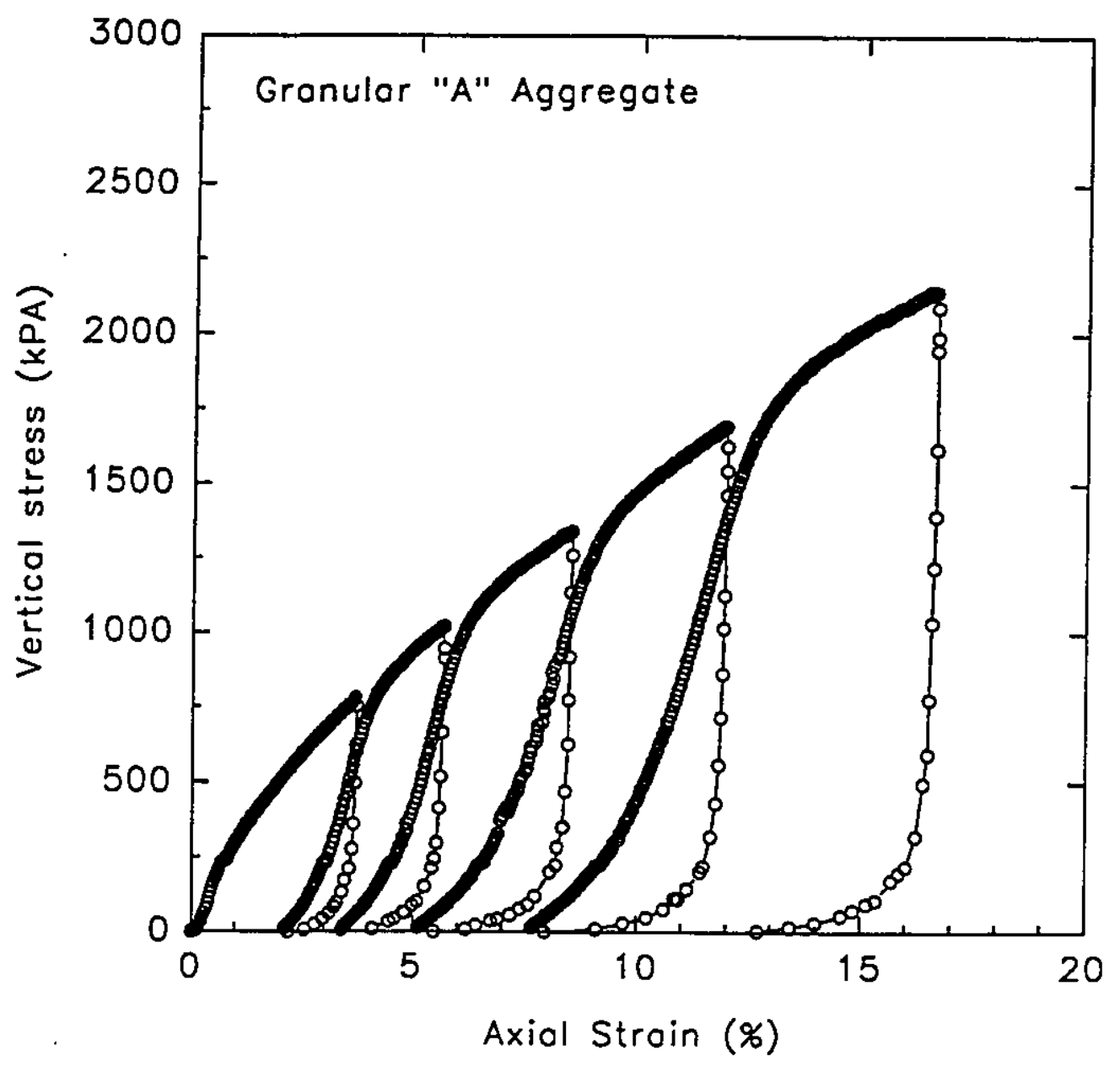

Figure 5.26 : Cyclic stress-strain behaviour of stone column confined with Tensar UX-1600 sleeve (Diameter $=0.33 \mathrm{~m}$, height $=0.68 \mathrm{~m}$ ) 


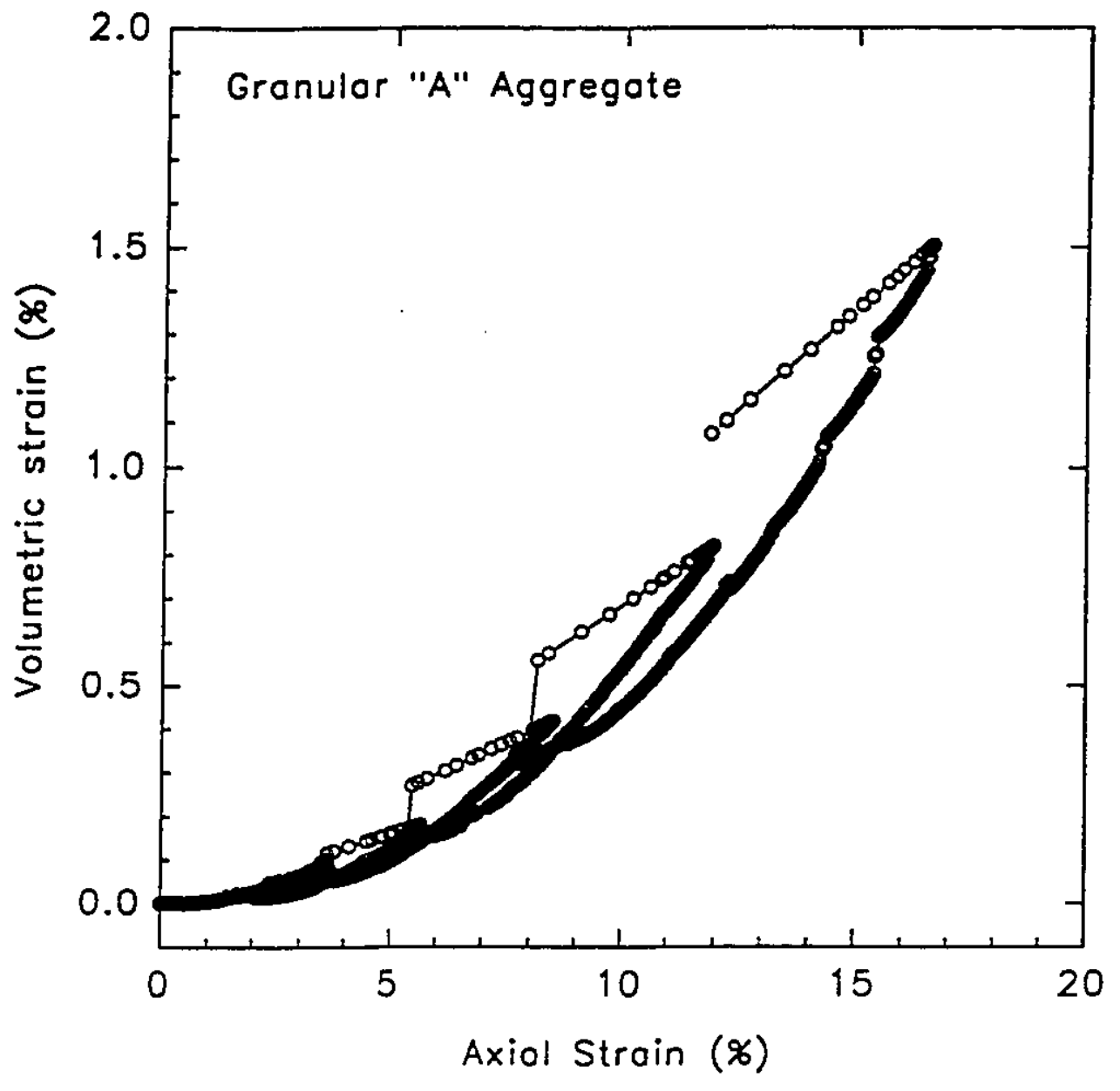

Figure 5.27 : Volume change behaviour of stone column in figure 5.26 


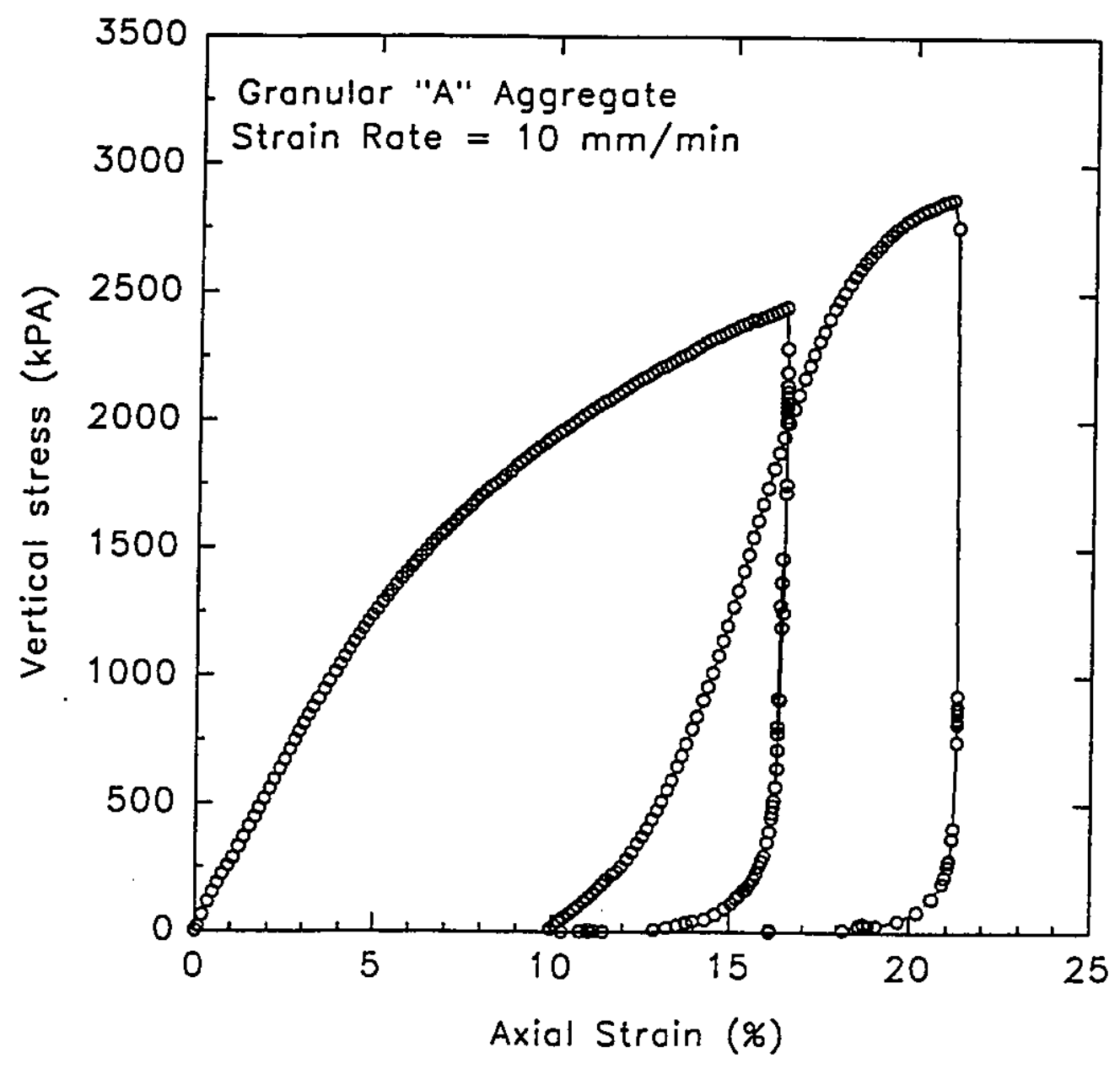

Figure 5.28 : Cyclic stress-strain behaviour of rapidly strained stone column with Tensar UX-1600 sleeve (Diameter $=0.33 \mathrm{~m}$, height $=0.68 \mathrm{~m}$ ) 


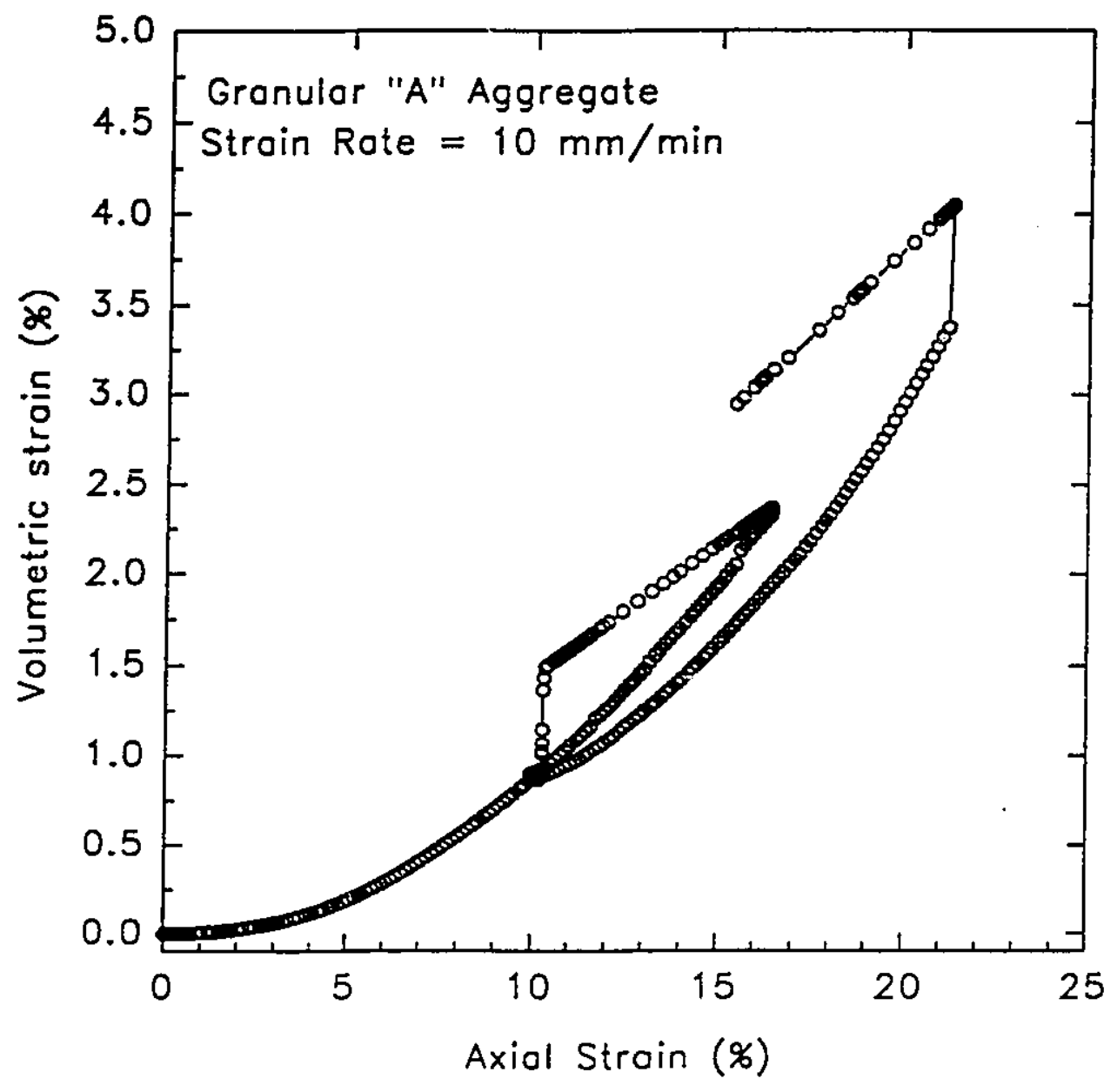

Figure 5.29 : Volume change behaviour of stone column in figure 5.28 


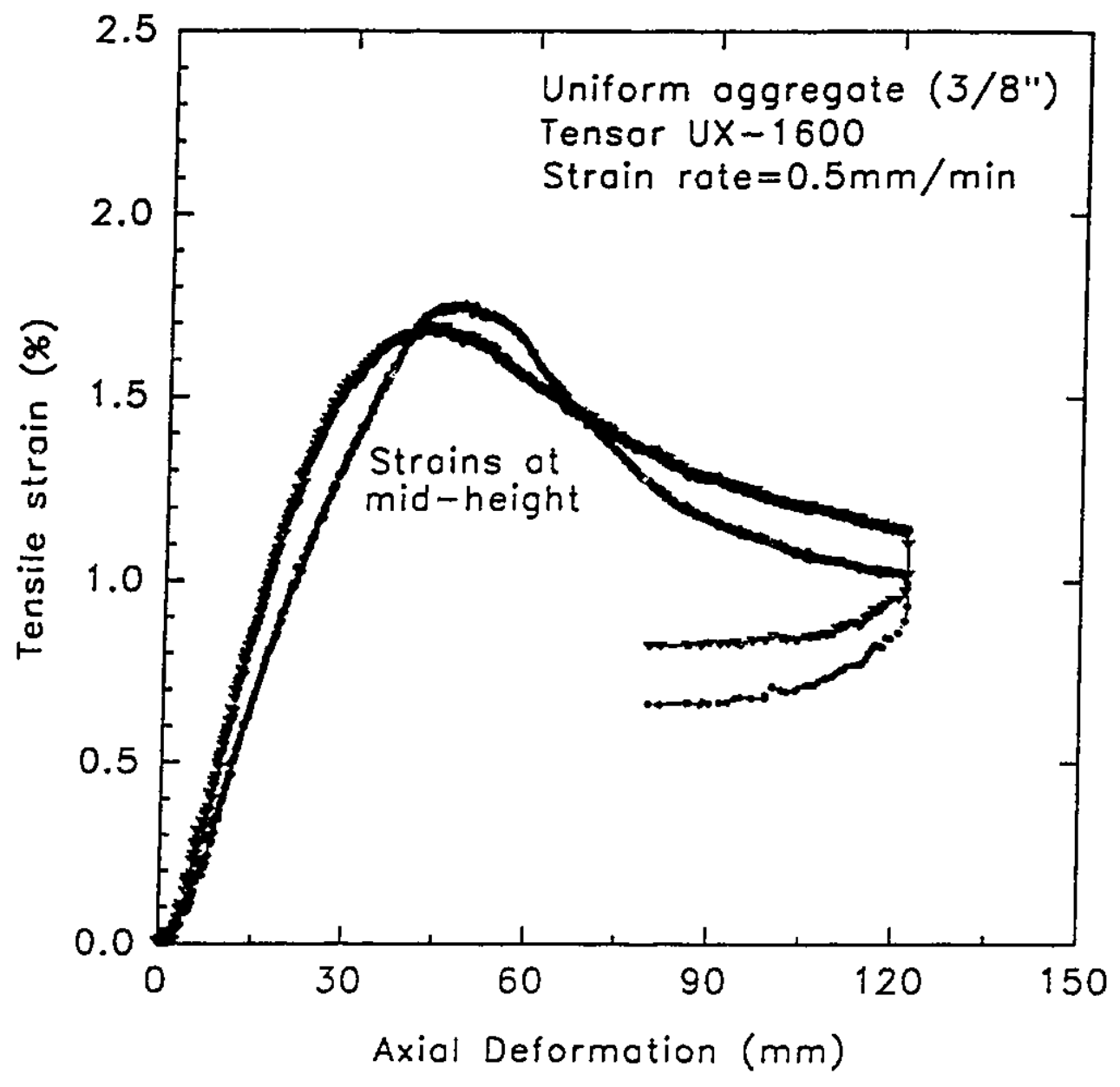

Figure 5.30 : Variation of local strain in polymer grid strand, with axial deformation at midheight 


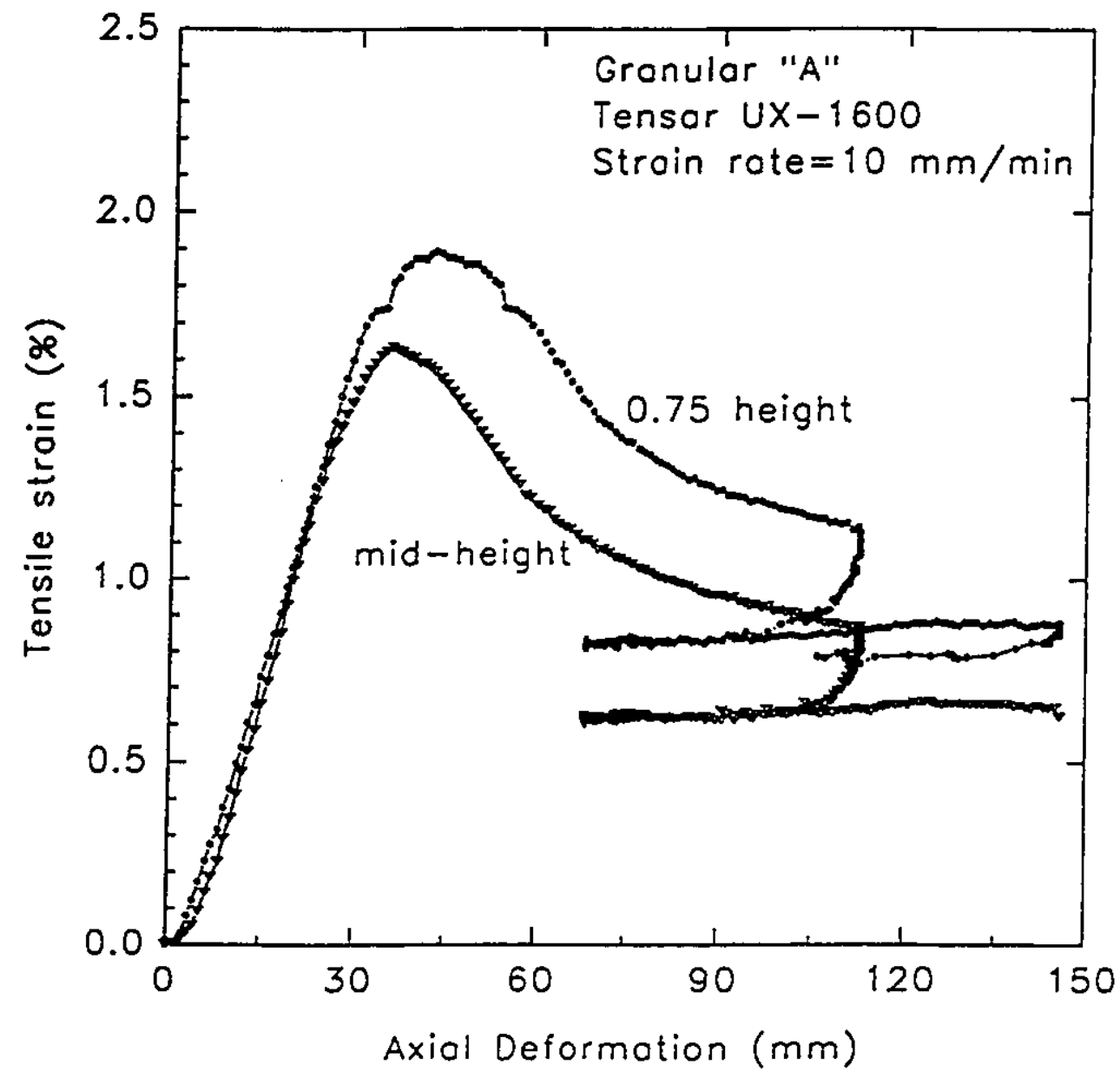

Figure 5.31 : Variation of local strain in polymer grid strands, with axial deformation at different height levels 


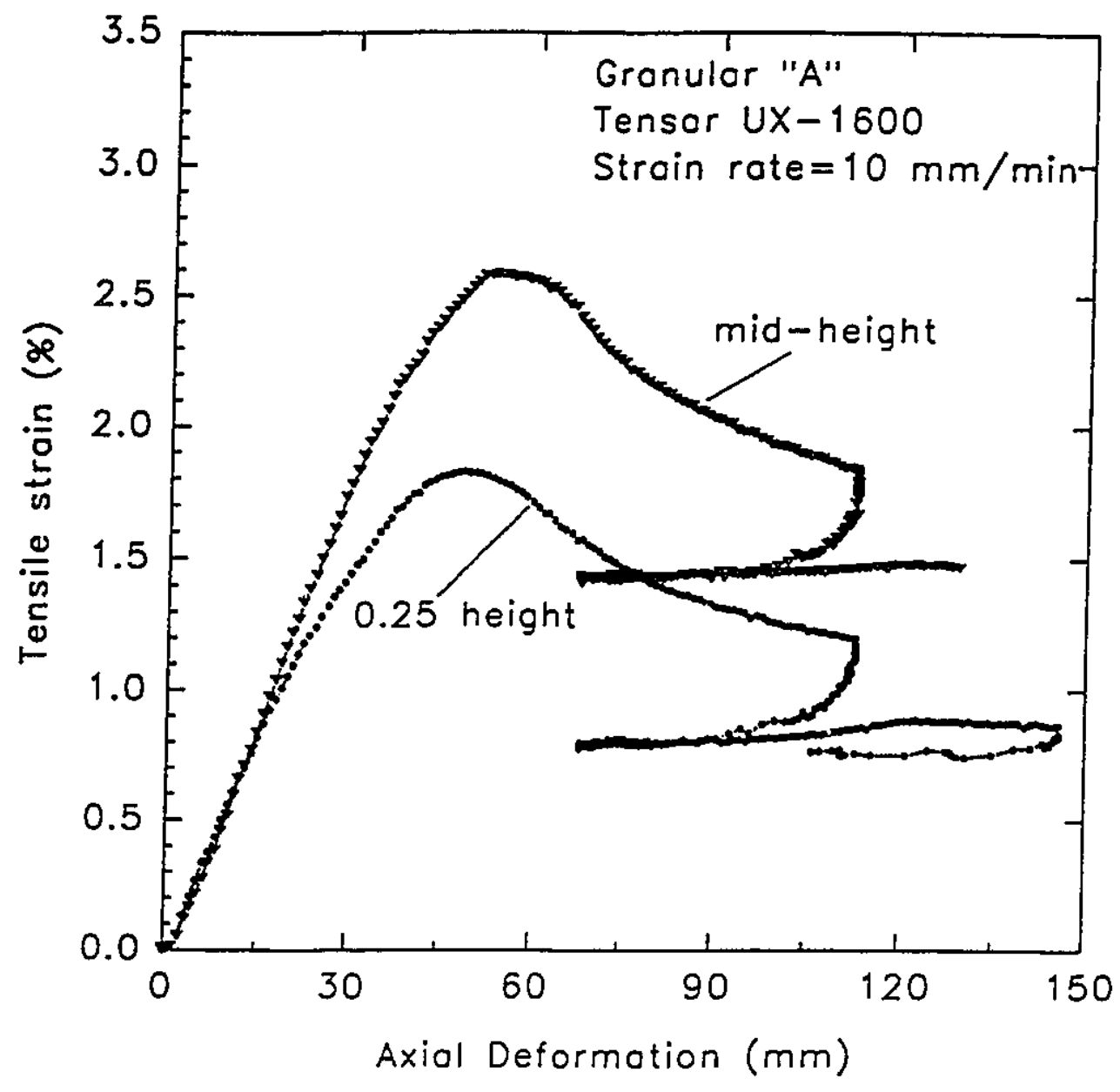

Figure 5.32 : Variation of local strain in polymer grid strands, with axial deformation at different height levels 


\section{CHAPTER 6}

\section{ANALYSIS OF TEST RESULTS}

\subsection{GENERAL}

In the previous chapter the experimental results of natural and sleeve reinforced stone columns were presented. The stress-strain-volume change relationships of triaxial and uniaxial column tests were of primary concern. In this chapter, the analysis of the results is presented using the hyperbolic stress-strain model.

The necessary hyperbolic relationships for granular material and for polymer grid were presented in chapter three. The appropriate parameters required for the analysis were derived from drained triaxial tests for unreinforced and sleeve reinforced specimens. It should be noted that no surrounding soil is considered in this analysis since the columns were tested in the laboratory under triaxial and uniaxial loading conditions.

The analysis presented in this chapter includes the following cases as shown in Figure 6.1.

a) Granular column under triaxial stress (Figure 6.1(a))

b) Uniaxial stone column with sleeve reinforcement (Figure 6.1(b))

c) Sleeve reinforced triaxial stone column (Figure 6.1(c))

\subsection{HYPERBOLIC STRESS-STRAIN ANALYSIS}

\subsubsection{General}

The stress-strain behaviour of any type of soil depends on a number of factors which include density, structure, drainage condition, stress conditions (triaxial or plane strain), loading duration, stress history and confining pressure. Controlled laboratory testing can control some of these factors by selecting representative soil specimens and testing procedures which may simulate strain and stress conditions in the field. 

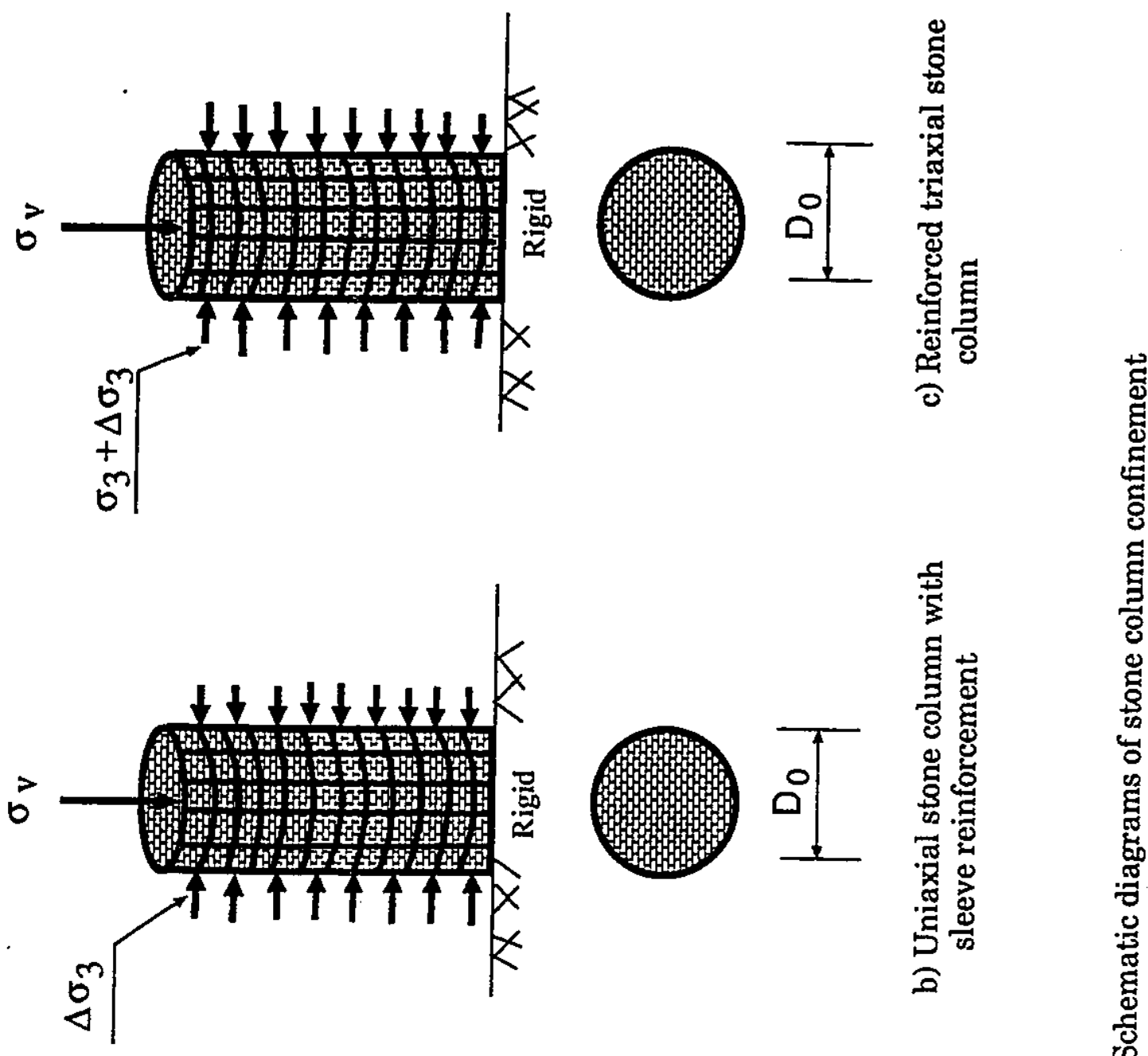

委

I

疍

禺

용

患

ए :

沓

2

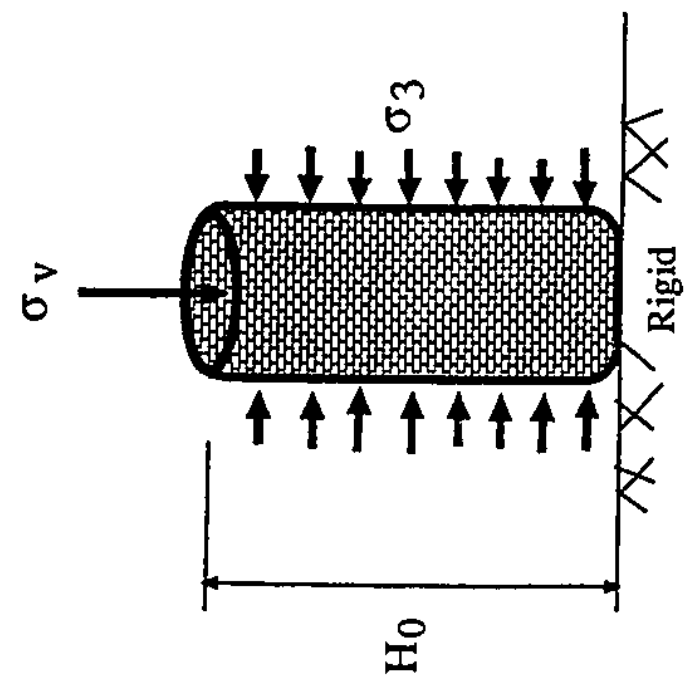

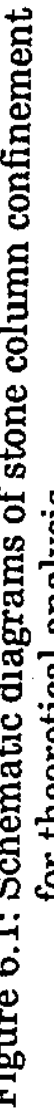

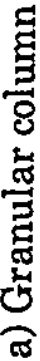


This method of duplicating field conditions in the laboratory may account for several factors governing the stress-strain behaviour of the soil. However, over a wide range of confining stresses the load deformation behaviour of the soil is non-linear and inelastic. Therefore, theoretical stress-strain relationships are highly desirable.

A hyperbolic stress-strain simulation procedure has been found to be quite adequate to predict the behaviour of soil under triaxial stress conditions. The necessary relationships were originally developed by Kondner (1963) and later modified by Duncan and Chang (1970). The hyperbolic stress-strain model was also found to be applicable to simulate the experimental behaviour presented in this research. The experimental parameters necessary for the constitutive model are readily obtained for unreinforced and sleeve reinforced stone columns. The analytical relationships have been presented in chapter three. In the remaining part of this chapter implementation and verification of the hyperbolic model to predict the behaviour of unreinforced and sleeve reinforced stone column will be presented.

\subsubsection{Model parameters and analysis}

The first version of the hyperbolic model was developed for a variable tangent modulus, constant Poisson's ratio and constant confining pressure. The hyperbolic model needs the following parameters: $\phi, c, R_{f}, n$ and $K$. These parameters are determined from a series of triaxial drained tests. These parameters were fed into a computer program together with the corresponding values for the confining pressure of the stone column under consideration. The program utilizes equation [3.21] to calculate the tangent modulus for incremental stress analysis.

$$
E_{t}=\left[1-\frac{R_{f}(1-\sin (\phi))\left(\sigma_{1}-\sigma_{3}\right)}{2 c \cos (\phi)+2 \sigma_{3} \sin (\phi)}\right]^{2} k p_{a}\left(\frac{\sigma_{3}}{p_{a}}\right)^{n}
$$

Tables 6.1 to 6.3 gives the experimental stress-strain results obtained from triaxial tests. 
Table 6.1: Values of axial strain $\left(\varepsilon_{\mathrm{a}}\right)$ versus $\varepsilon_{\mathrm{a}} /\left(\sigma_{1}-\sigma_{3}\right)$ for $\sigma_{3}=103 \mathrm{kPa}$, for $3 / 8$ " aggregate

\begin{tabular}{||c|c|c|}
\hline \multicolumn{3}{|c|}{$\sigma_{3}=103 \mathrm{kPa}$} \\
\hline$\varepsilon_{\mathrm{a}}(\%)$ & $\sigma_{1}-\sigma_{3}(\mathrm{kPa})$ & $\varepsilon_{\mathrm{a}} /\left(\sigma_{1}-\sigma_{3}\right)(\mathrm{kPa})^{-1}$ \\
\hline 1.15 & 320 & 0.00361 \\
2.31 & 405 & 0.00571 \\
3.47 & 452 & 0.00768 \\
4.63 & 486 & 0.00953 \\
5.79 & 528 & 0.01100 \\
6.95 & 530 & 0.01310 \\
7.74 & 533 & 0.01450 \\
8.90 & 530 & 0.01680 \\
10.10 & 526 & 0.01910 \\
11.20 & 519 & 0.02160 \\
12.40 & 516 & 0.02390 \\
13.50 & 510 & 0.02650 \\
\hline
\end{tabular}

Table 6.2: Values of axial strain $\left(\varepsilon_{\mathrm{a}}\right)$ versus $\varepsilon_{\mathrm{a}} /\left(\sigma_{1}-\sigma_{3}\right)$ for $\sigma_{3}=207 \mathrm{kPa}$, for $3 / 8^{\prime \prime}$ aggregate

\begin{tabular}{||c|c|c||}
\hline \multicolumn{3}{|c|}{$\sigma_{3}=207 \mathrm{kPa}$} \\
\hline$\varepsilon_{\mathrm{a}}(\%)$ & $\sigma_{1}-\sigma_{3}(\mathrm{kPa})$ & $\varepsilon_{\mathrm{a}} /\left(\sigma_{1}-\sigma_{3}\right)(\mathrm{kPa})^{-1}$ \\
\hline 1.15 & 454 & 0.00254 \\
2.31 & 566 & 0.00408 \\
3.47 & 583 & 0.00595 \\
4.63 & 636 & 0.00729 \\
5.79 & 651 & 0.00889 \\
6.95 & 681 & 0.01020 \\
7.74 & 675 & 0.01150 \\
8.90 & 691 & 0.01290 \\
10.10 & 714 & 0.01410 \\
11.20 & 709 & 0.01580 \\
12.40 & 738 & 0.01670 \\
13.50 & 726 & 0.01860 \\
14.70 & 715 & 0.02050 \\
15.80 & 716 & 0.02210 \\
17.00 & 715 & 0.02380 \\
\hline
\end{tabular}


Table 6.3: Values of axial strain $\left(\varepsilon_{\mathrm{a}}\right)$ versus $\varepsilon_{\mathrm{a}} /\left(\sigma_{1}-\sigma_{3}\right)$ for $\sigma_{3}=345 \mathrm{kPa}$, for $3 / 8^{\prime \prime}$ aggregate

\begin{tabular}{||c|c|c|}
\hline \multicolumn{3}{|c|}{$\sigma_{3}=345 \mathrm{kPa}$} \\
\hline$\varepsilon_{\mathrm{a}}(\%)$ & $\sigma_{1}-\sigma_{3}(\mathrm{kPa})$ & $\varepsilon_{\mathrm{a}} /\left(\sigma_{1}-\sigma_{3}\right)(\mathrm{kPa})^{-1}$ \\
\hline 1.15 & 679 & 0.00170 \\
2.31 & 870 & 0.00266 \\
3.47 & 953 & 0.00364 \\
4.63 & 985 & 0.00470 \\
5.79 & 1020 & 0.00569 \\
6.95 & 1020 & 0.00680 \\
7.74 & 1040 & 0.00745 \\
8.90 & 1060 & 0.00837 \\
10.10 & 1080 & 0.00930 \\
11.20 & 1080 & 0.01040 \\
12.40 & 1080 & 0.01140 \\
13.50 & 1100 & 0.01230 \\
14.70 & 1110 & 0.01330 \\
15.80 & 1100 & 0.01440 \\
17.00 & 1090 & 0.01560 \\
\hline
\end{tabular}

Figure 6.2 presents the transformed stress-strain relationships for a unreinforced stone column with 3/8" aggregate. Best fit lines were obtained passing through points of $70 \%$ and $95 \%$ of maximum deviator stress. Figure 6.3 shows the variation of the initial tangent modulus with confining pressures on a log-log plot. The experimental results of two triaxial tests at confining pressures of $103 \mathrm{kPa}$ and $345 \mathrm{kPa}$ were used to establish this relationship. The values of $\mathrm{n}$ and $\mathrm{K}$ were determined from Figure 6.3 as the slope of the line and the intercept on the $y$-axis at atmospheric pressure $(101.3 \mathrm{kPa})$.

The parameters used in the analysis for unreinforced stone columns with $3 / 8^{\prime \prime}$ aggregate were as follow: $\phi=33^{\circ}, c=0, n=0.79, k=582$, and $R f=0.94$. Results of this analysis is presented in Figure 6.4 for a unreinforced stone colunn at a confining pressure of $207 \mathrm{kPa}$. The calculated and experimental results agree quite well.

A similar analysis was performed for stone columns with granular "A" aggregate. The experimental stress-strain data from triaxial tests are shown in Tables 6.4 to 6.6 and 


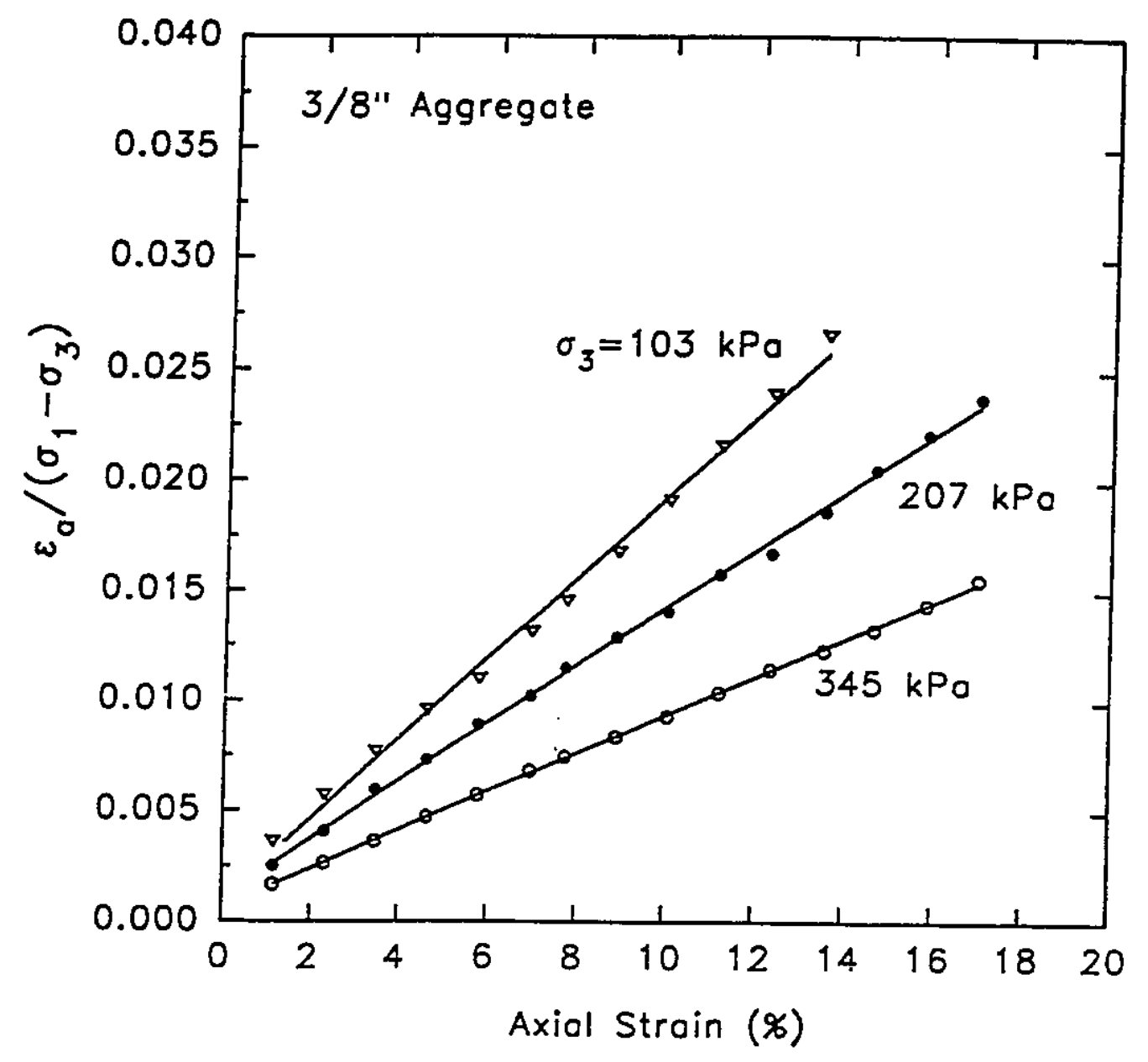

Figure 6.2: Transformed stress-strain curves for uniform aggregate at different confining pressures 


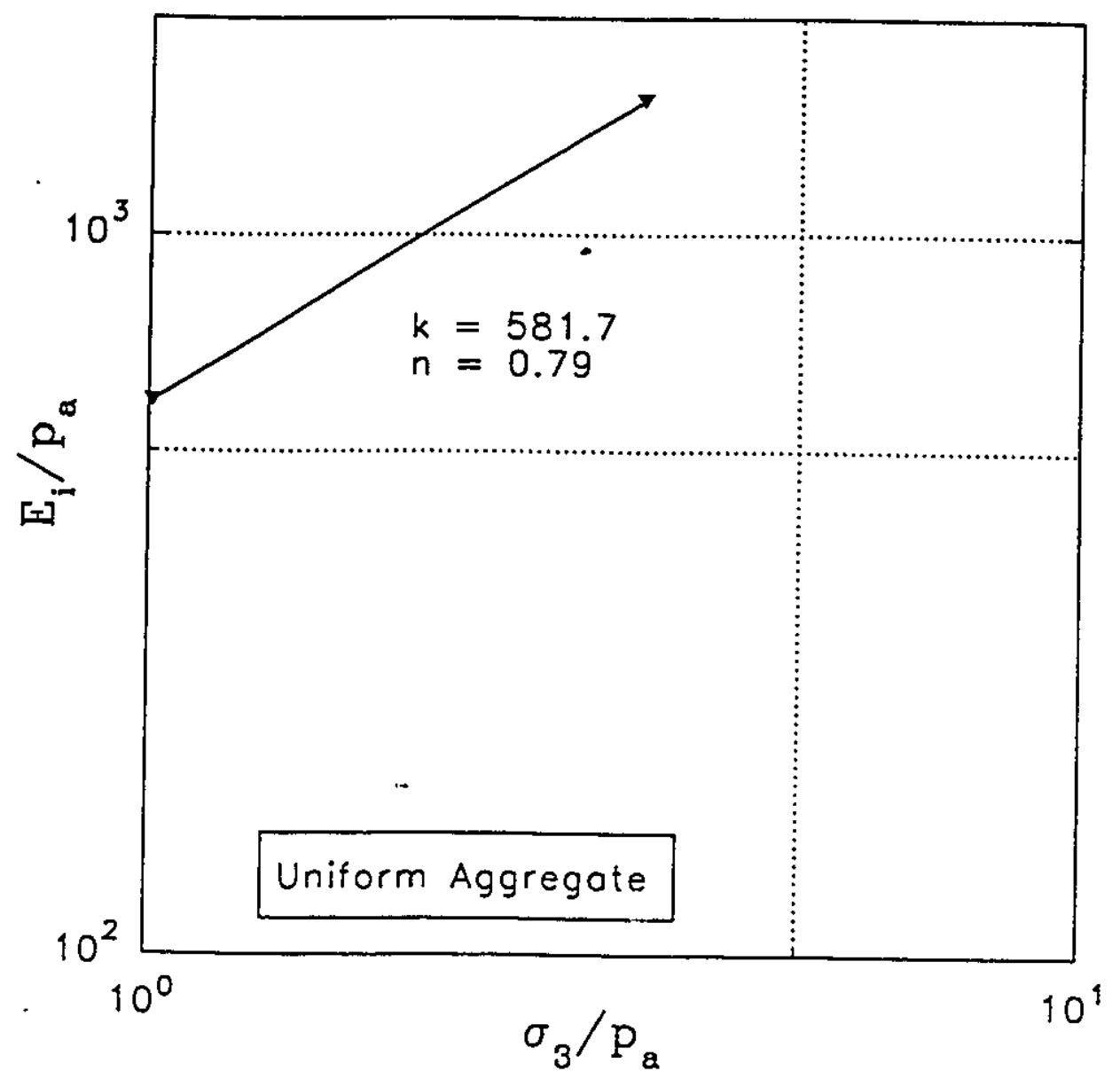

Figure 6.3: Variation of initial tangent modulus with confining pressure for uniform aggregate 


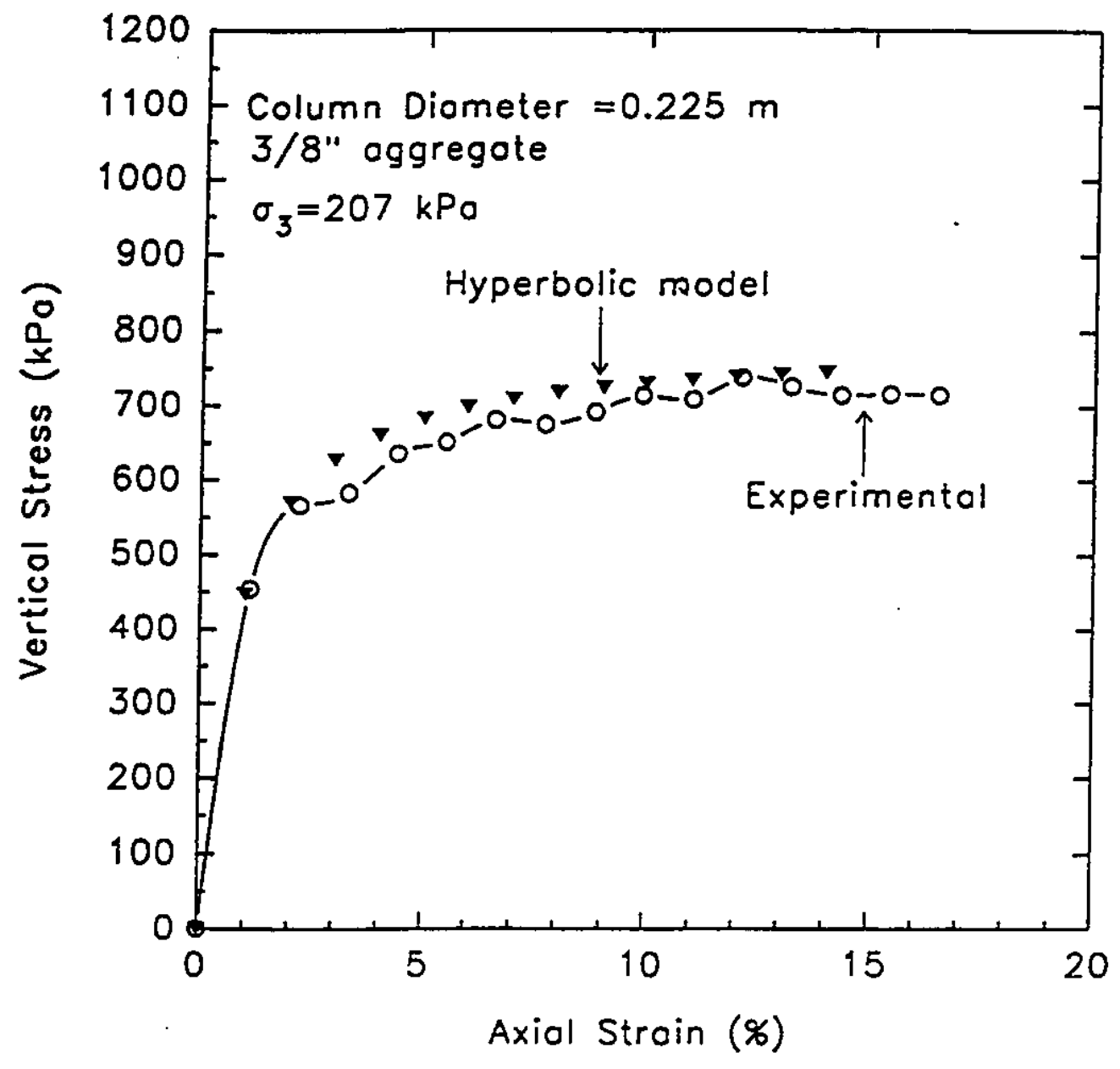

Figure 6.4: Experimental and calculated stress-strain behaviour of unreinforced stone column using the hyperbolic model 
Table 6.4: Values of axial strain $\left(\varepsilon_{\mathrm{a}}\right)$ versus $\varepsilon_{\mathrm{a}} /\left(\sigma_{1}-\sigma_{3}\right)$ for $\sigma_{3}=103 \mathrm{kPa}$, granular "A" aggregate

\begin{tabular}{|c|c|c||}
\hline \multicolumn{3}{|c|}{$\sigma_{3}=103 \mathrm{kPa}$} \\
\hline$\varepsilon_{\mathrm{a}}(\%)$ & $\sigma_{1}-\sigma_{3}(\mathrm{kPa})$ & $\varepsilon_{\mathrm{a}} /\left(\sigma_{1}-\sigma_{3}\right)(\mathrm{kPa})^{-1}$ \\
\hline 1.1 & 615 & 0.0018 \\
2.2 & 857 & 0.0026 \\
3.31 & 959 & 0.0034 \\
4.41 & 989 & 0.0044 \\
5.51 & 971 & 0.0057 \\
6.61 & 931 & 0.0071 \\
7.71 & 889 & 0.0087 \\
8.81 & 841 & 0.0105 \\
9.91 & 782 & 0.0127 \\
11.00 & 715 & 0.0154 \\
12.10 & 651 & 0.0186 \\
\hline
\end{tabular}

Table 6.5: Values of axial strain $\left(\varepsilon_{\mathrm{a}}\right)$ versus $\varepsilon_{2} /\left(\sigma_{1}-\sigma_{3}\right)$ for $\sigma_{3}=207 \mathrm{kPa}$, granular "A" aggregate

\begin{tabular}{|c|c|c||}
\hline \multicolumn{3}{|c||}{$\sigma_{3}=207 \mathrm{kPa}$} \\
\hline$\varepsilon_{\mathrm{a}}(\%)$ & $\sigma_{1}-\sigma_{3}(\mathrm{kPa})$ & $\varepsilon_{\mathrm{a}} /\left(\sigma_{1}-\sigma_{3}\right)(\mathrm{kPa})^{-1}$ \\
\hline 1.1 & 646 & 0.0017 \\
2.2 & 1187 & 0.0019 \\
3.31 & 1363 & 0.0024 \\
4.41 & 1447 & 0.0030 \\
5.51 & 1434 & 0.0038 \\
6.61 & 1419 & 0.0047 \\
7.71 & 1343 & 0.0057 \\
8.81 & 1257 & 0.0070 \\
9.91 & 1205 & 0.0082 \\
11.00 & 1145 & 0.0092 \\
12.10 & 1095 & 0.0111 \\
\hline
\end{tabular}


Table 6.6: Values of axial strain $\left(\varepsilon_{2}\right)$ versus $\varepsilon_{\mathrm{a}} /\left(\sigma_{1}-\sigma_{3}\right)$ for $\sigma_{3}=207 \mathrm{kPa}$, granular "A" aggregate

\begin{tabular}{||c|c|c|}
\hline \multicolumn{3}{|c|}{$\sigma_{3}=345 \mathrm{kPa}$} \\
\hline$\varepsilon_{\mathrm{a}}(\%)$ & $\sigma_{1}-\sigma_{3}(\mathrm{kPa})$ & $\varepsilon_{\mathrm{a}} /\left(\sigma_{1}-\sigma_{3}\right)(\mathrm{kPa})^{-1}$ \\
\hline 1.1 & 654 & 0.0017 \\
2.2 & 1191 & 0.0019 \\
3.31 & 1512 & 0.0022 \\
4.41 & 1718 & 0.0026 \\
5.51 & 1857 & 0.0030 \\
6.61 & 1915 & 0.0035 \\
7.71 & 1942 & 0.0041 \\
8.81 & 1965 & 0.0046 \\
9.91 & 1969 & 0.0051 \\
11.00 & 1936 & 0.0058 \\
12.10 & 1908 & 0.0065 \\
\hline
\end{tabular}

the transformed stress-strain curves are presented in Figure 6.5. The variation of the initial tangent modulus with confining pressure is presented in Figure 6.6 for unreinforced columns with granular " $\mathrm{A}$ " aggregate. The following model parameters were derived from the experimental results and used in the analysis, $\phi=44^{\circ}, c=0, n=0.05, K=942$ and $R_{f}=0.74$. Results of this analysis is presented in Figure 6.7 for an unreinforced stone column at confining pressure of $207 \mathrm{kPa}$. The stress-strain curves of stone columns with granular "A" aggregates consists of two parts: the first part is a hyperbola extending up to the point were the full strength of the aggregates is mobilized. At larger strains, the hyperbola indicated larger values than the compressive strength, therefore, each stress-strain curve is represented by an approximate horizontal line.

It should be mentioned that in each of the previous analysis the stress-strain curves were known from the triaxial tests, therefore, it was unnecessary to employ the hyperbolic relationships in a finite element analysis for predicting the stress changes.

Instead a simple computer program was used to simulate the stress-strain behaviour of the stone columns. Description of the computer program will be presented in Appendix A.

In reality, the confining pressure $\left(\sigma_{3}\right)$ of sleeve reinforced stone columns was not 


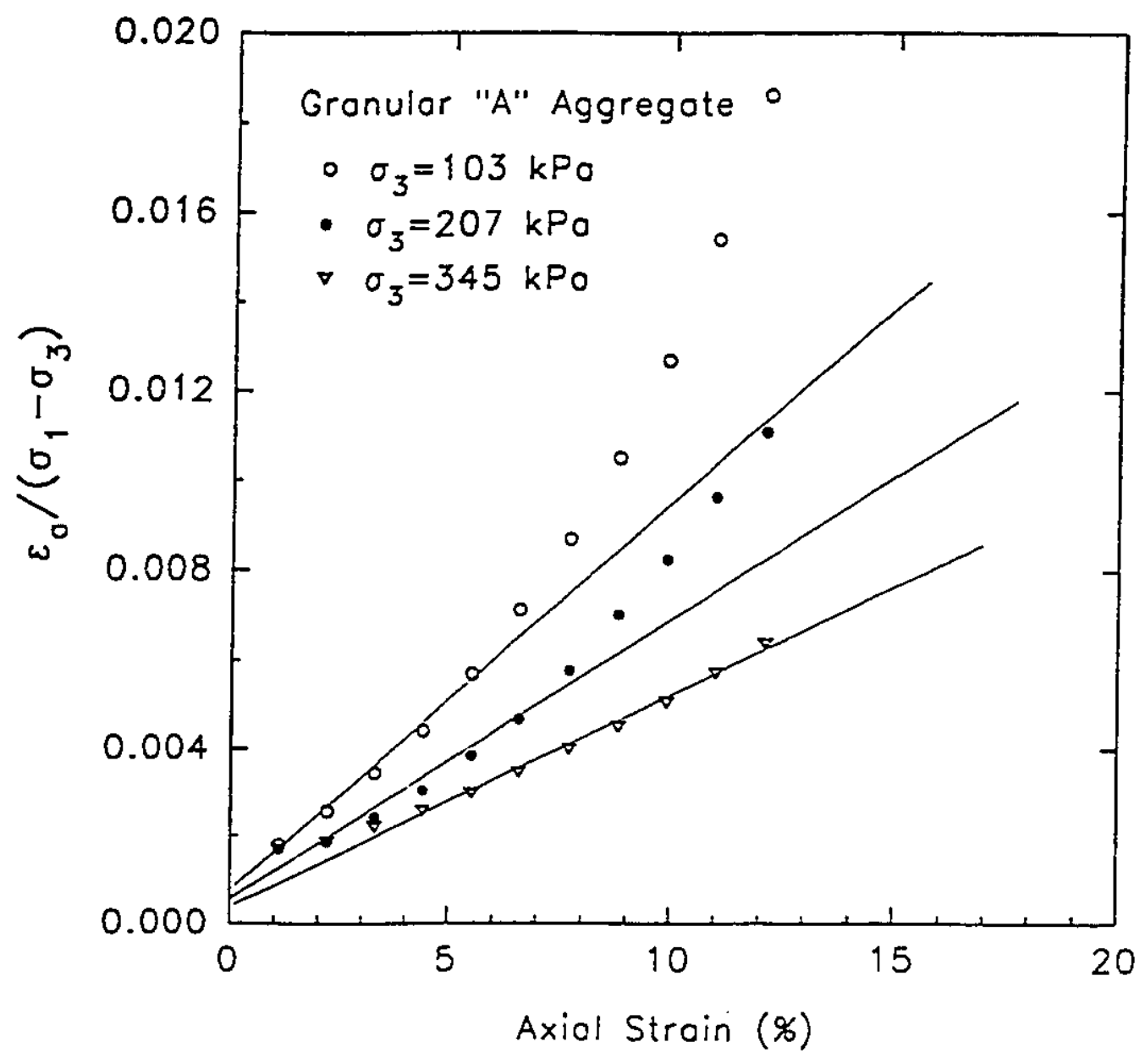

Figure 6.5: Transformed stress-strain curves for granular " $A$ " aggregate at different confining pressures 


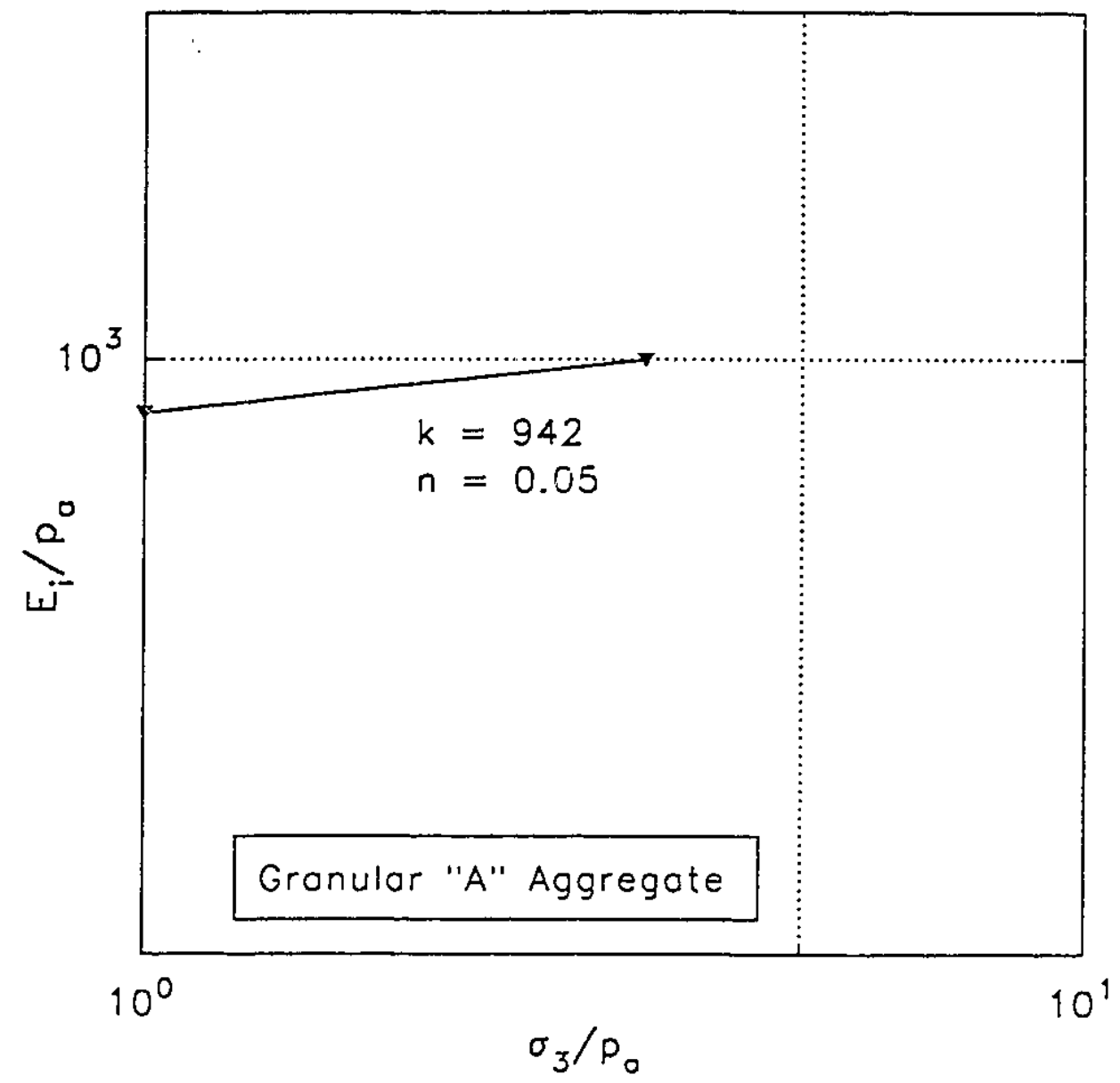

Figure 6.6: Variation of initial tangent modulus with confining pressure for granular " $A$ " aggregate 


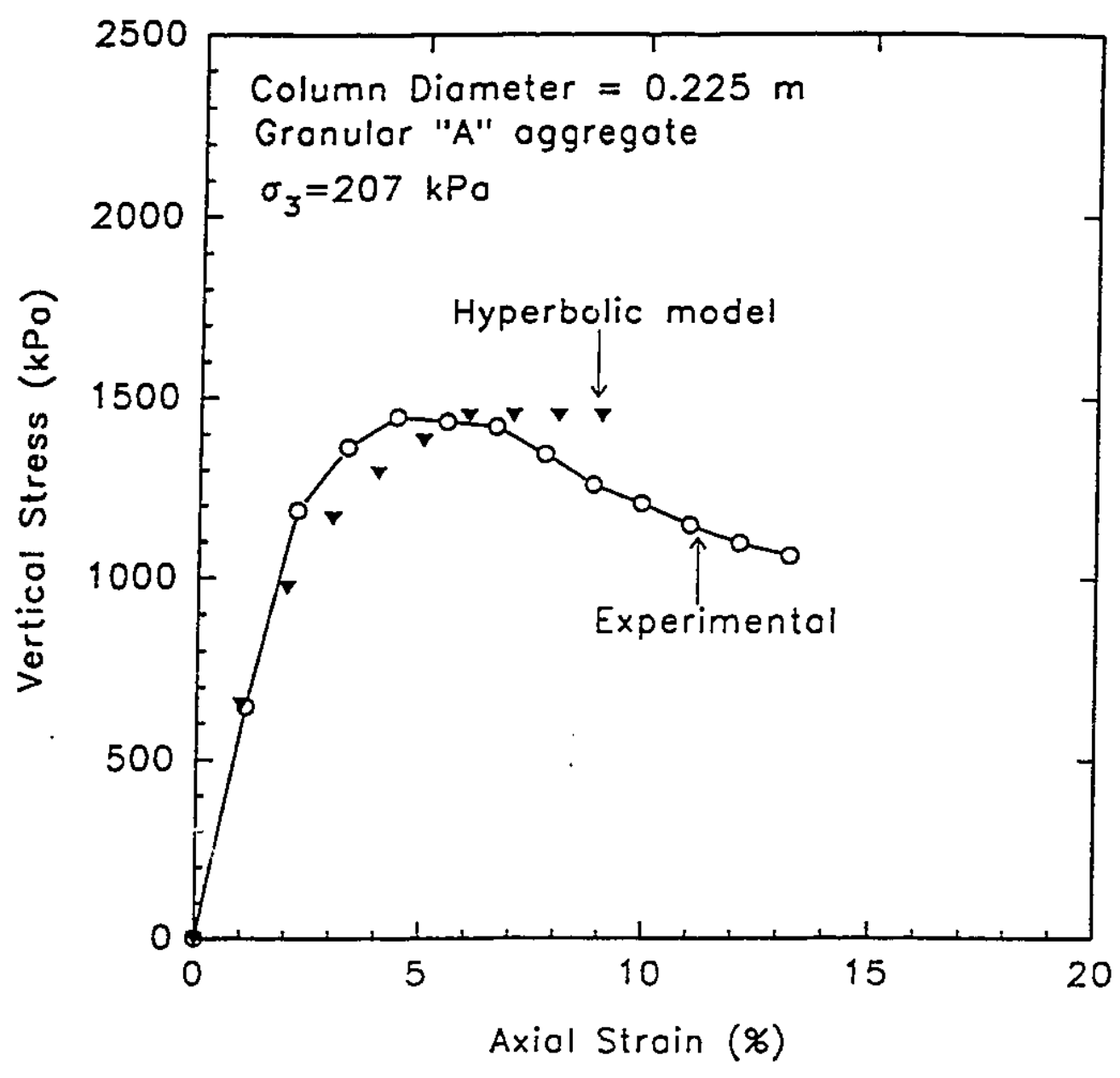

Figure 6.7: Experimental and calculated stress-strain behaviour of natural stone column using the hyperbolic model 
constant due to the extra confinement $\left(\Delta \sigma_{3}\right)$ provided by the grid sieeves during loading. This extra confinement was proportional to the strength of the grid and the initial diameter of the stone column. Cases of changing confining pressures were analyzed by Duncan and Chang (1970) for granular material only. The average values of $\sigma_{3}$ were used to evaluate the tangent modulus and the same parameters derived from constant confining pressure tests were used to evaluate the strains of the soil under conditions of changing confining pressures.

The behaviour of sleeve reinforced stone columns may be analyzed in a similar fashion using the hyperbolic model. The value of $\sigma_{3}$ was assumed to be constant and the model parameters were derived from the corresponding sleeve reinforced triaxial specimens. It should be noted $i$ at the effect of grid confinement $\left(\Delta \sigma_{3}\right)$ was assumed to be accounted for by the model parameters which were derived from the appropriate sleeve reinforced triaxial tests.

The experimental results of sleeve reinforced stone columns for of 3/8" aggregate and Tensar UX-1500 sleeves are shown in Tables 6.7 to 6.9. The transformed stress-strain relationships are presented in Figure 6.8. The initial tangent modulus versus confining pressure relationship is shown in Figure 6.9. The model parameters used in this analysis were as follows: $\phi_{R}=43.5^{\circ}, c_{R}=115 \mathrm{kPa}, \mathrm{n}=0.38, \mathrm{~K}=266$ and $\mathrm{R}_{\mathrm{f}}=0.61$. It should be noted that the values of angle of shearing resistance and the apparent cohesion were determined from the average failure envelope of three sleeve reinforced triaxial tests at different confining pressures. Bauer and Zhao (1993) have stated that the effect of sci-geogrid reinforcement can be presented in terms of an apparent angle of shearing resistan: $e\left(\phi_{R}\right)$ and an apparent cohesion $\left(c_{R}\right)$. Comparisons of the failure envelopes of unrt.nturced and sleeve reinforced stone columns will be presented in chapter seven.

Comparison using the hyperbolic stress function and the corresponding experimental stress-strain behaviour are shown in Figure 6.10 for a stone column reinforced with a Tensar UX-1500 sleeve at a confining pressure of $207 \mathrm{kPa}$. The agreement is quite good. 
Table 6.7: Values of axial strain $\left(\varepsilon_{\mathrm{a}}\right)$ versus $\varepsilon_{\mathrm{a}} /\left(\sigma_{1}-\sigma_{3}\right)$ for $\sigma_{3}=103 \mathrm{kPa}, 3 / 8^{\prime \prime}$ aggregate+Tensar UX-1500

\begin{tabular}{||c|c|c|}
\hline \multicolumn{3}{|c|}{$\sigma_{3}=103 \mathrm{kPa}$} \\
\hline$\varepsilon_{\mathrm{a}}(\%)$ & $\sigma_{1}-\sigma_{3}(\mathrm{kPa})$ & $\varepsilon_{\mathrm{a}} /\left(\sigma_{1}-\sigma_{3}\right)(\mathrm{kPa})^{-1}$ \\
\hline 1.15 & 555 & 0.0021 \\
2.31 & 753 & 0.0031 \\
3.47 & 903 & 0.0038 \\
4.63 & 1039 & 0.0045 \\
5.79 & 1163 & 0.0050 \\
6.95 & 1269 & 0.0055 \\
7.74 & 1377 & 0.0056 \\
8.90 & 1473 & 0.0060 \\
10.10 & 1569 & 0.0064 \\
11.20 & 1655 & 0.0068 \\
12.40 & 1750 & 0.0071 \\
13.50 & 1843 & 0.0073 \\
14.68 & 1931 & 0.0076 \\
15.85 & 2016 & 0.0079 \\
\hline
\end{tabular}

Table 6.8: Values of axial strain $\left(\varepsilon_{\mathrm{a}}\right)$ versus $\varepsilon_{2} /\left(\sigma_{1}-\sigma_{3}\right)$ for $\sigma_{3}=207 \mathrm{kPa}, 3 / 8^{\prime \prime}$ aggregate+Tensar UX-1500

\begin{tabular}{|c|c|c||}
\hline \multicolumn{3}{|c|}{$\sigma_{3}=207 \mathrm{kPa}$} \\
\hline$\varepsilon_{\mathrm{a}}(\%)$ & $\sigma_{1}-\sigma_{3}(\mathrm{kPa})$ & $\varepsilon_{\mathrm{a}} /\left(\sigma_{1}-\sigma_{3}\right)(\mathrm{kPa})^{-1}$ \\
\hline 1.1 & 560 & 0.0020 \\
2.2 & 816 & 0.0027 \\
3.31 & 993 & 0.0033 \\
4.41 & 1164 & 0.0038 \\
5.51 & 1298 & 0.0042 \\
6.61 & 1427 & 0.0046 \\
7.72 & 1541 & 0.0050 \\
8.82 & 1641 & 0.0054 \\
9.92 & 1747 & 0.0057 \\
11.02 & 1833 & 0.0060 \\
12.12 & 1934 & 0.0063 \\
13.22 & 2023 & 0.0065 \\
14.34 & 2119 & 0.0068 \\
15.43 & 2207 & 0.0070 \\
16.54 & 2292 & 0.0072 \\
\hline
\end{tabular}


Table 6.9: Values of axial strain $\left(\varepsilon_{\mathrm{a}}\right)$ versus $\varepsilon_{\mathrm{a}} /\left(\sigma_{1}-\sigma_{3}\right)$ for $\sigma_{3}=345 \mathrm{kPa}, 3 / 8^{\prime \prime}$ aggregate+Tensar UX-1500

\begin{tabular}{||c|c|c|}
\hline \multicolumn{3}{|c|}{$\sigma_{3}=345 \mathrm{kPa}$} \\
\hline$\varepsilon_{\mathrm{a}}(\%)$ & $\sigma_{1}-\sigma_{3}(\mathrm{kPa})$ & $\varepsilon_{\mathrm{a}} /\left(\sigma_{1}-\sigma_{3}\right)(\mathrm{kPa})^{-1}$ \\
\hline 1.15 & 748 & 0.0015 \\
2.31 & 988 & 0.0023 \\
3.47 & 1180 & 0.0029 \\
4.63 & 1343 & 0.0035 \\
5.79 & 1493 & 0.0039 \\
6.95 & 1623 & 0.0043 \\
7.74 & 1770 & 0.0044 \\
8.90 & 1863 & 0.0048 \\
10.10 & 1968 & 0.0051 \\
11.20 & 2059 & 0.0054 \\
12.40 & 2140 & 0.0060 \\
13.50 & 2249 & 0.0060 \\
14.68 & 2330 & 0.0063 \\
15.85 & 2428 & 0.0065 \\
\hline
\end{tabular}




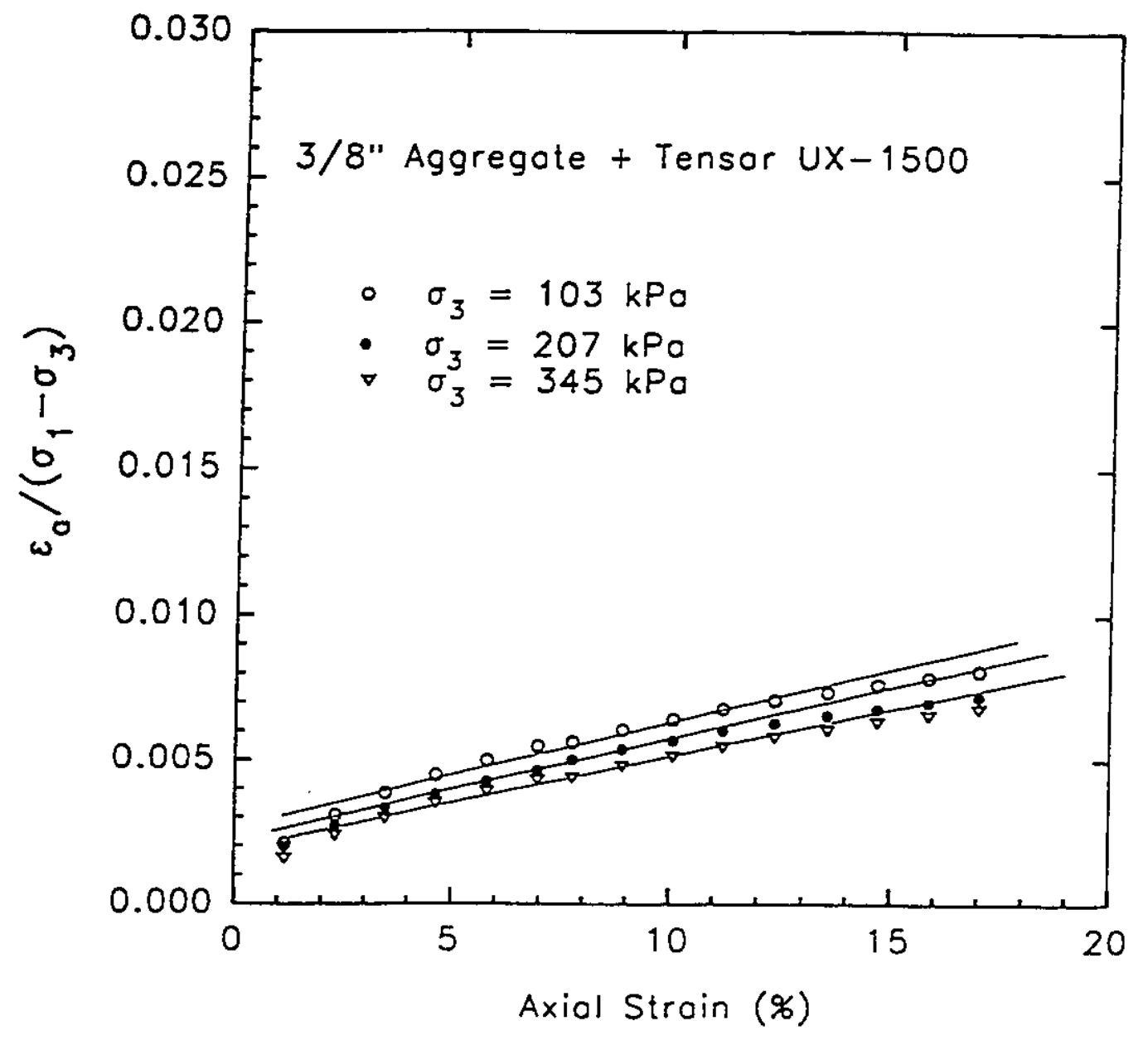

Figure 6.8: Transformed stress-strain curves of stone columns with uniform aggregate and Tensar UX-1500 sleeves at different confining pressures 


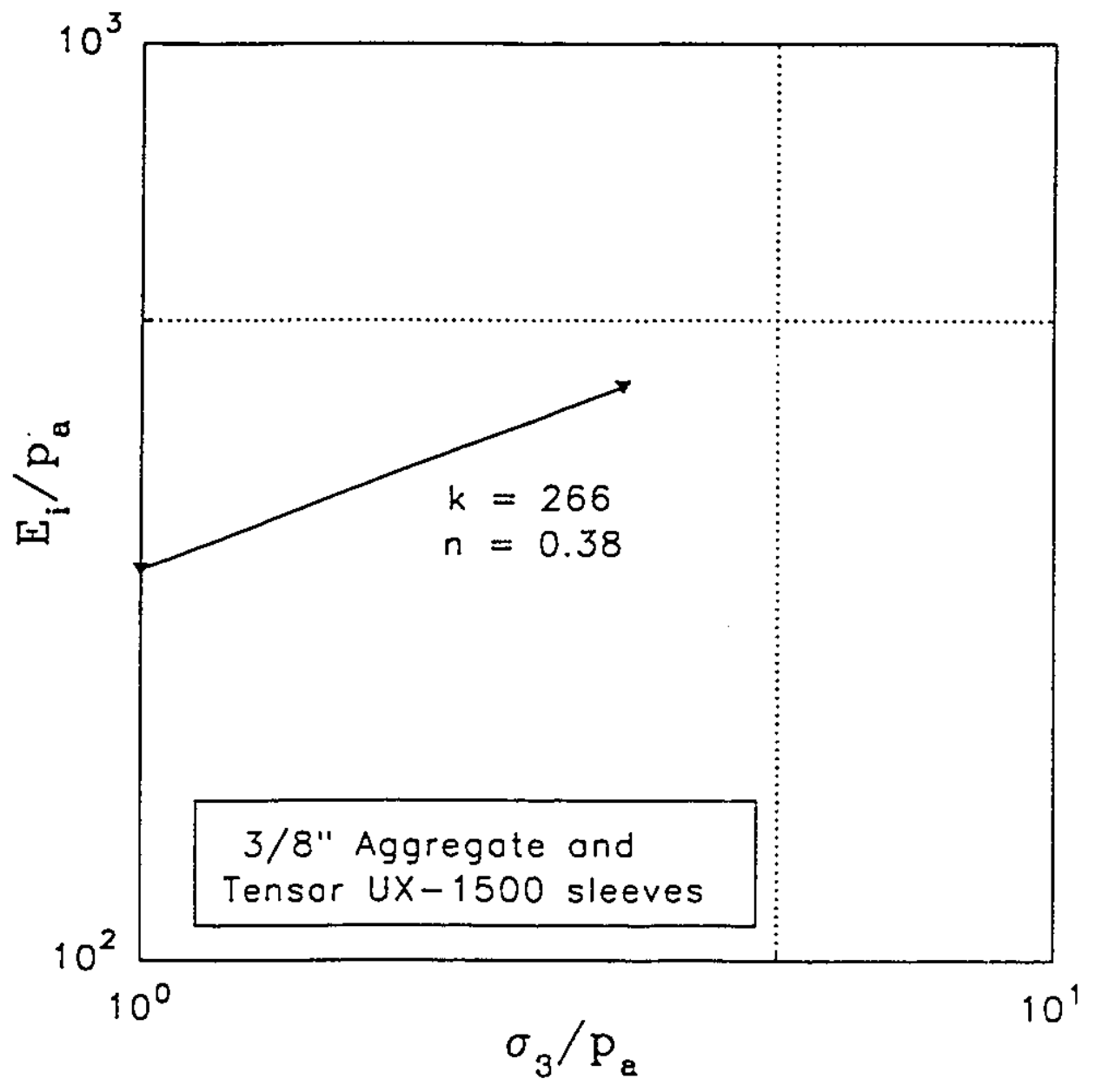

Figure 6.9: Variation of initial tangent modulus with confining pressure for stone columns with $3 / 8^{\prime \prime}$ aggregate and Tensar UX-150n sleeves 


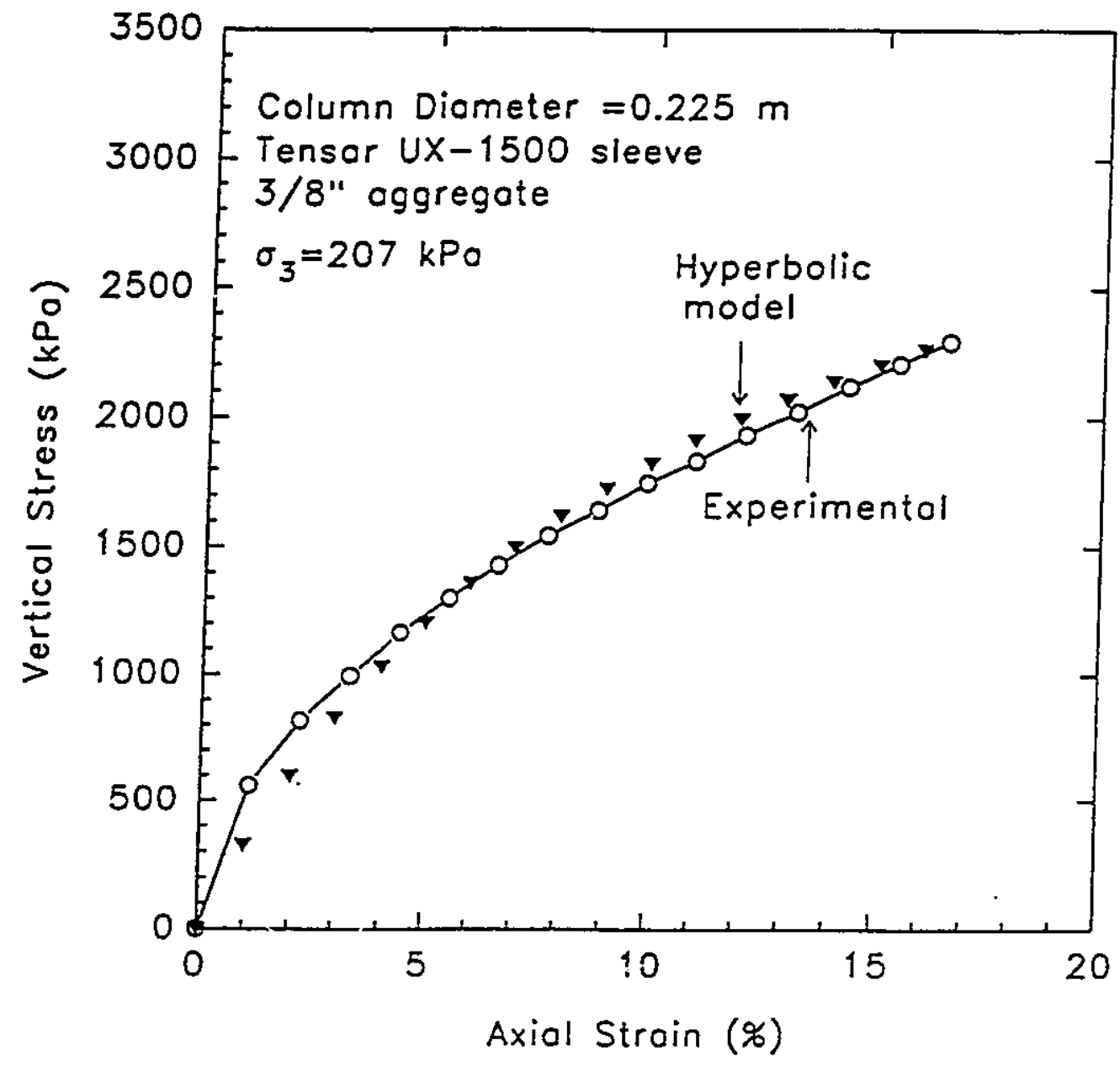

Figure 6.10: Experimental and calculated stress-strain behaviour of sleeve reinforced stone column using the hyperbolic model 
Similar analyses were performed for stone columns with $3 / 8^{\prime \prime}$ aggregate reinforced with Conwed 9027 sleeves. The experimental stress strain results of this set of triaxial tests are presented in Tables 6.10 to 6.12 for different confining pressures. The transformed stress-strain curves are presented in Figure 6.11. The relationship between the initial tangent modulus and confining pressures is presented in Figure 6.12. The model parameters used in this analysis were as follows, $\phi=43^{\circ}, c=65 \mathrm{kPa}, \mathrm{n}=0.33, \mathrm{~K}=236$ and $R_{\mathrm{f}}=0.64$. The values of shearing angle and apparent cohesion were obtained from the failure envelope of the sleeve reinforced triaxial specimens. Figure 6.13 shows a comparison of the calculated and observed stress-strain behaviour for a triaxial stone column reinforced with a Conwed 9027 sleeve at a confining pressure of $207 \mathrm{kPa}$. The same observation can be made as for the stone columns with Tensar grids. The model behaviour of this stone column agrees quite well with the observed behaviour for the entire stress-strain range.

Table 6.10: Values of axial strain $\left(\varepsilon_{\mathrm{a}}\right)$ versus $\varepsilon_{\mathrm{a}} /\left(\sigma_{1}-\sigma_{3}\right)$ for $\sigma_{3}=103 \mathrm{kPa}, 3 / 8^{\prime \prime}$ aggregate+Conwed 9027

\begin{tabular}{|c|c|c|}
\hline \multicolumn{3}{|c|}{$\sigma_{3}=103 \mathrm{kPa}$} \\
\hline$\varepsilon_{\mathrm{a}}(\%)$ & $\sigma_{1}-\sigma_{3}(\mathrm{kPa})$ & $\varepsilon_{\mathrm{a}} /\left(\sigma_{1}-\sigma_{3}\right)(\mathrm{kPa})^{-1}$ \\
\hline 1.15 & 555 & 0.0026 \\
2.31 & 753 & 0.0040 \\
3.47 & 903 & 0.0048 \\
4.63 & 1039 & 0.0056 \\
5.79 & 1163 & 0.0070 \\
6.95 & 1269 & 0.0072 \\
7.74 & 1377 & 0.0078 \\
8.90 & 1473 & 0.0083 \\
10.10 & 1569 & 0.0088 \\
11.20 & 1655 & 0.0092 \\
12.40 & 1750 & 0.0096 \\
13.50 & 1843 & 0.0101 \\
14.68 & 1931 & 0.0104 \\
15.85 & 2016 & 0.0108 \\
\hline
\end{tabular}


Table 6.11: Values of axial strain $\left(\varepsilon_{\mathrm{a}}\right)$ versus $\varepsilon_{\mathrm{a}} /\left(\sigma_{1}-\sigma_{3}\right)$ for $\sigma_{3}=207 \mathrm{kPa}, 3 / 8^{\prime \prime}$ aggregate+Conwed 9027

\begin{tabular}{||c|c|c|}
\hline \multicolumn{3}{|c|}{$\sigma_{3}=207 \mathrm{kPa}$} \\
\hline$\varepsilon_{\mathrm{a}}(\%)$ & $\sigma_{1}-\sigma_{3}(\mathrm{kPa})$ & $\varepsilon_{\mathrm{a}} /\left(\sigma_{1}-\sigma_{3}\right)(\mathrm{kPa})^{-1}$ \\
\hline 1.1 & 560 & 0.0024 \\
2.2 & 816 & 0.0032 \\
3.31 & 993 & 0.0038 \\
4.41 & 1164 & 0.0043 \\
5.51 & 1298 & 0.0047 \\
6.61 & 1427 & 0.0052 \\
7.72 & 1541 & 0.0056 \\
8.82 & 1641 & 0.0059 \\
9.92 & 1747 & 0.0063 \\
11.02 & 1833 & 0.0066 \\
12.12 & 1934 & 0.0069 \\
13.22 & 2023 & 0.0072 \\
14.34 & 2119 & 0.0075 \\
15.43 & 2207 & 0.0078 \\
16.54 & 2292 & 0.0080 \\
\hline
\end{tabular}

Table 6.12: Values of axial strain $\left(\varepsilon_{\mathrm{a}}\right)$ versus $\varepsilon_{\mathrm{a}} /\left(\sigma_{\mathrm{l}}-\sigma_{3}\right)$ for $\sigma_{3}=345 \mathrm{kPa}, 3 / 8^{\prime \prime}$ aggregate+Conwed 9027

\begin{tabular}{|c|c|c|}
\hline \multicolumn{3}{|c|}{$\sigma_{3}=345 \mathrm{kPa}$} \\
\hline$\varepsilon_{\mathrm{a}}(\%)$ & $\sigma_{1}-\sigma_{3}(\mathrm{kPa})$ & $\varepsilon_{\mathrm{a}} /\left(\sigma_{1}-\sigma_{3}\right)(\mathrm{kPa})^{-1}$ \\
\hline 1.15 & 748 & 0.0016 \\
2.31 & 988 & 0.0025 \\
3.47 & 1180 & 0.0031 \\
4.63 & 1343 & 0.0037 \\
5.79 & 1493 & 0.0043 \\
6.95 & 1623 & 0.0049 \\
7.74 & 1770 & 0.0051 \\
8.90 & 1863 & 0.0056 \\
10.10 & 1968 & 0.0059 \\
11.20 & 2059 & 0.0062 \\
12.40 & 2140 & 0.0066 \\
13.50 & 2249 & 0.0070 \\
14.68 & 2330 & 0.0073 \\
15.85 & 2428 & 0.0076 \\
\hline
\end{tabular}




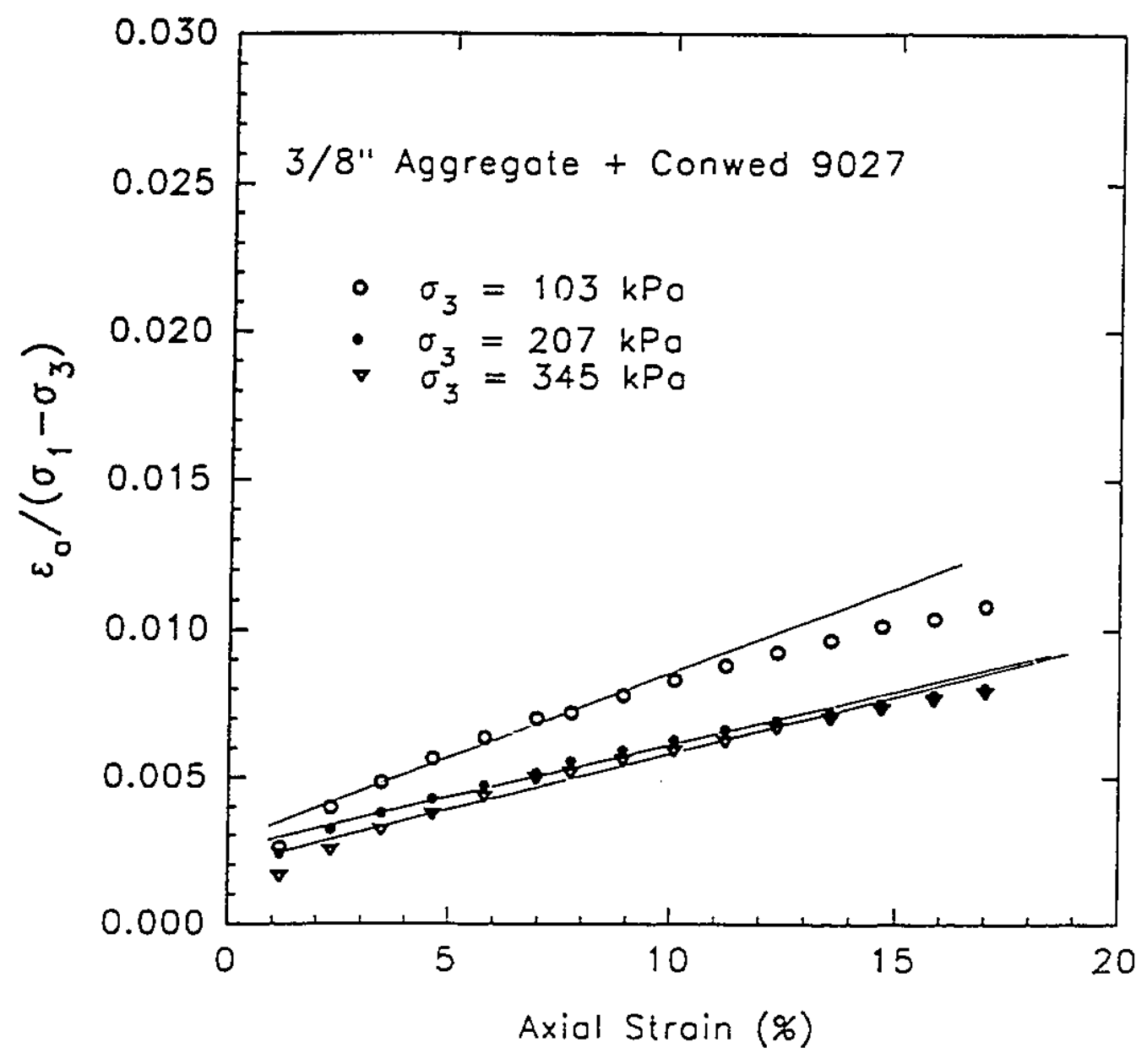

Figure 6.11: Transformed stress-strain curves of stone columns with 3/8" aggregate and Conwed 9027 sleeves at different confining pressures 


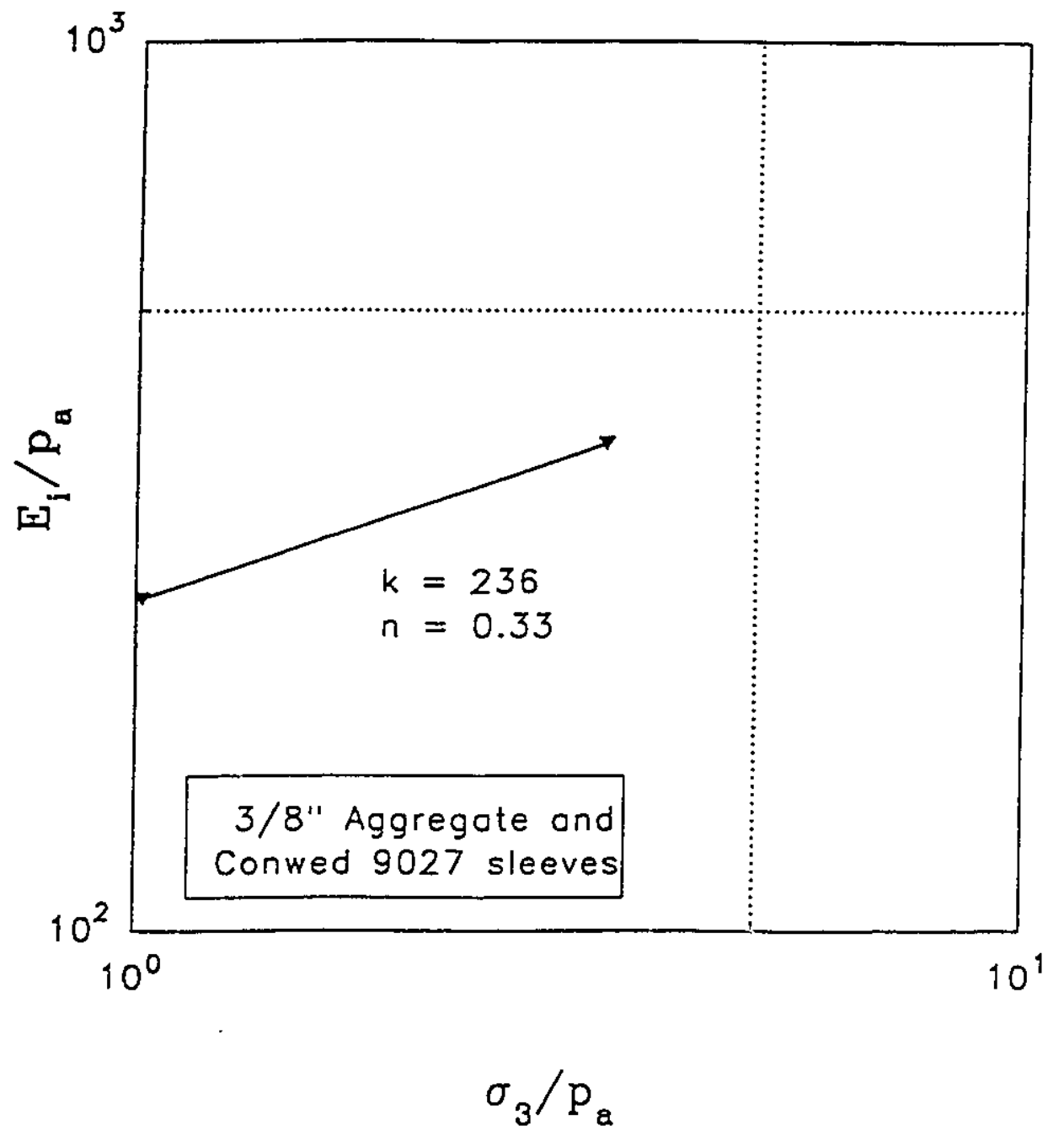

Figure 6.12: Variation of initial tangent modulus with confining pressure for stone column with $3 / 8$ " aggregate and Conwed 9027 sleeves 


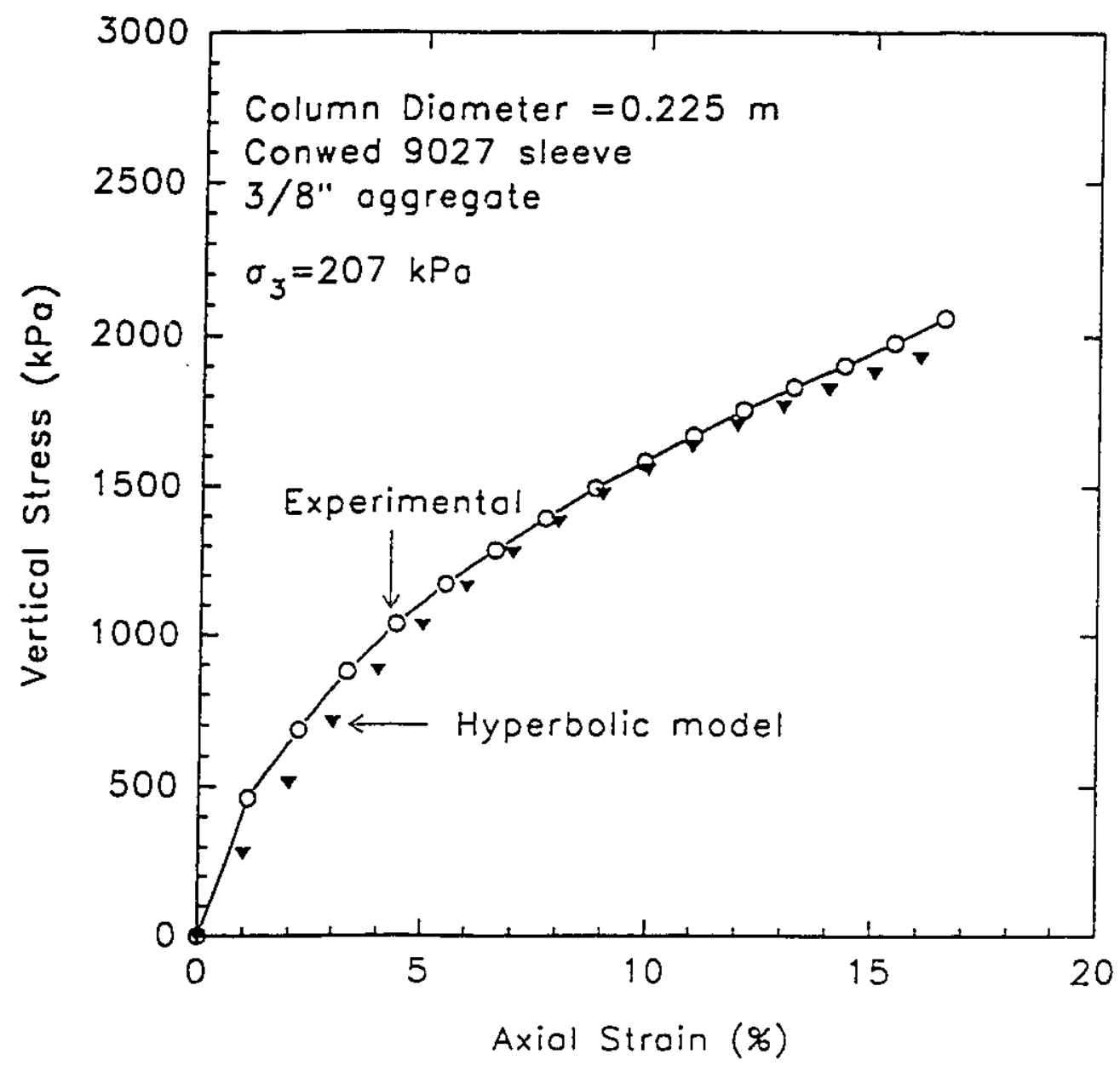

Figure 6.13: Experimental and calculated stress-strain behaviour of sleeve reinforced stone column using the hyperbolic model 
The same procedure was followed for the analysis of stone columns with granular "A" aggregates reinforced with Tensar UX-1500 and Conwed 9027 sleeves. Tables of the experimental stress-strain data are presented in Appendix C. A summary of the model parameters derived from the reinforced triaxial test results of granular " $\mathrm{A}$ " series are presented in Table 6.13 for stone columns for both Tensar and Conwed sleeves.

Table 6.13: Summary of hyperbolic stress-strain parameters for granular "A" aggregates with polymer sleeves

\begin{tabular}{|l|c|c|c|c|c||}
\hline & $\phi$ (degree) & $c(\mathrm{kPa})$ & $\mathrm{R}_{f}$ & $\mathrm{~K}$ & $\mathrm{n}$ \\
\hline $\begin{array}{l}\text { Columns with } \\
\text { Tensar UX-1500 }\end{array}$ & 55.5 & 105 & 0.76 & 661 & 0.3 \\
\hline $\begin{array}{l}\text { Columns with } \\
\text { Conwed 9027 }\end{array}$ & 52.5 & 100 & 0.77 & 692 & 0.24 \\
\hline
\end{tabular}

Typical results of this analysis are presented in Figures 6.14 and 6.15 for stone columns reinforced with Tensar UX-1500 and Conwed 9027 at confining pressure of $207 \mathrm{kPa}$. For both types of sleeves, the model behaviour agrees well with the observed behaviour.

An attempt was made to analyze stone columns reinforced with fiber glass (GB \#10) sleeves. The following model parameters were derived from the appropriate triaxial tests, $\phi=32.5^{\circ}, c=249 \mathrm{kPa}, \mathrm{k}=662, \mathrm{n}=-0.072$ and $\mathrm{R}_{\mathrm{r}}=0.76$. The predicted and measured stress-strain behaviour are shown in Figure 6.16 for a stone column of $0.225 \mathrm{~m}$ diameter at confining pressure of $207 \mathrm{kPa}$. Again, as can be seen from the results, the model behaviour was in good agreement with the actual stress-strain curve.

The behaviour of uniaxial sleeve reinforced stone columns was analysed by using the hyperbolic stress-strain model. For the purpose of analysis the confining pressure $\left(\sigma_{3}\right)$ was assumed to be equal to the atmospheric pressur ( $101.3 \mathrm{kPa}$ ) for all uniaxial sleeve reinforced columns. The model parameters derived from triaxial tests with Tensar UX1500 sleeves were used in this analysis $\left(\phi_{R}=43.5^{\circ}, c_{R}=115 \mathrm{kPa}, \mathrm{n}=0.38, \mathrm{~K}=266\right.$ and $R_{\mathrm{f}}=0.61$ ) to model the behaviour of uniaxial sleeve reinforced columns. 


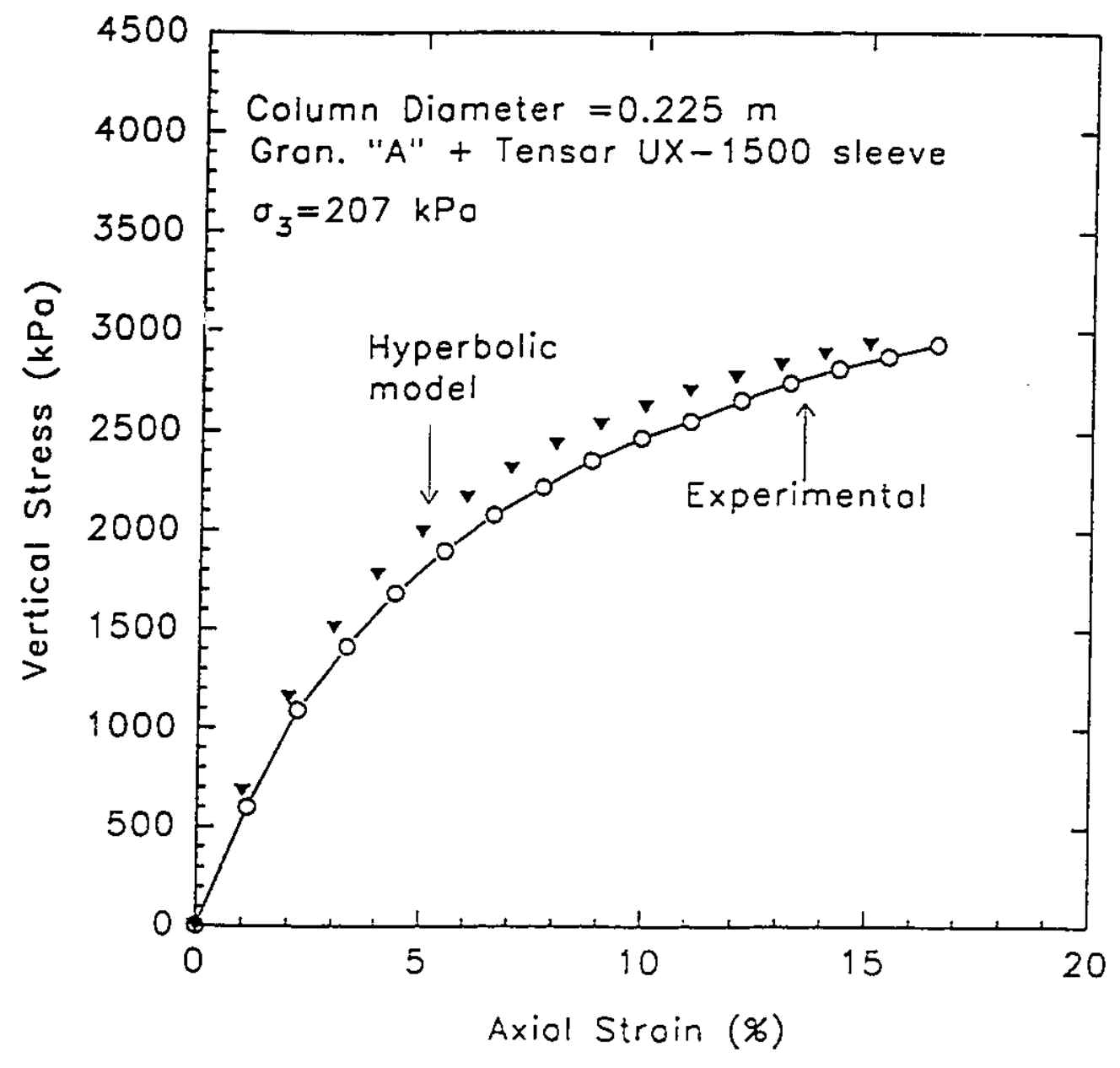

Figure 6.14: Experimental and calculated stress-strain behaviour of sleeve reinforced stone column using the hyperbolic model 


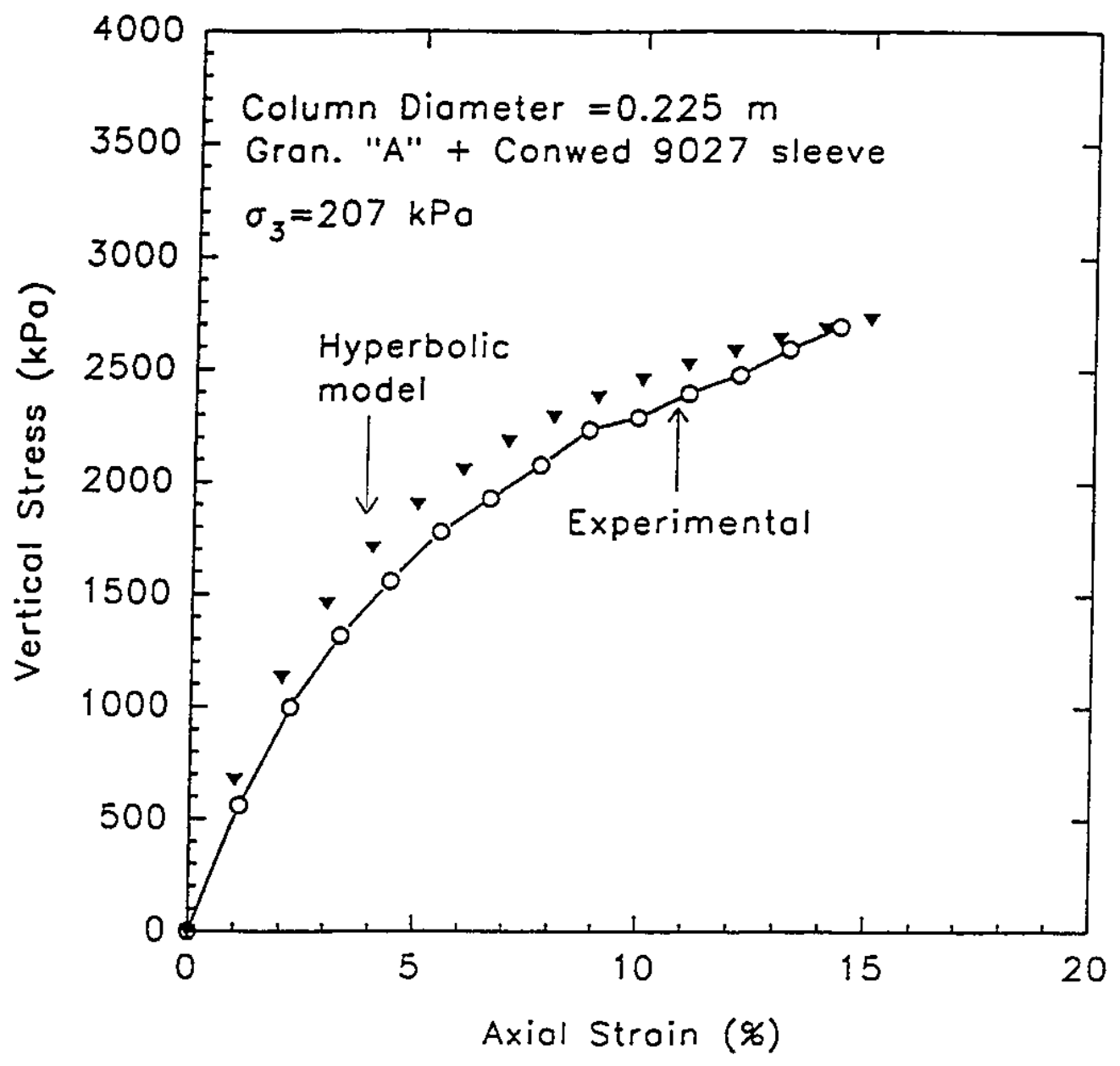

Figure 6.15: Experimental and calculated stress-strain behaviour of sleeve reinforced stone column using the hyperbolic model 


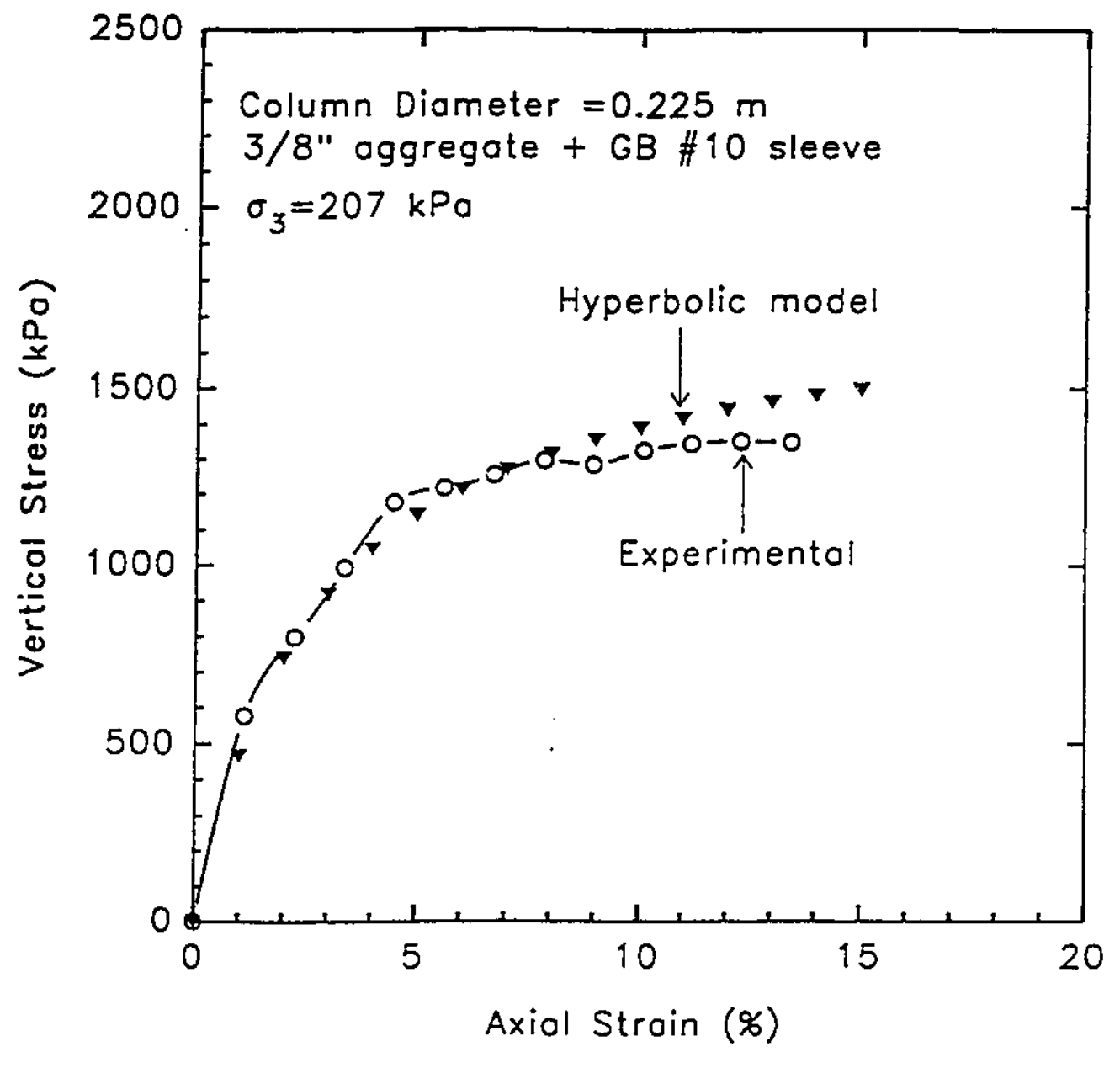

Figure 6.16: Experimental and calculated stress-strain behaviour of sleeve reinforced stone column using the hyperbolic model 
Figure 6.17 presents the test results versus the calculated stress-strain behaviour of a short uniaxial stone column $(0.33 \mathrm{~m}$ diameter and in $0.68 \mathrm{~m}$ height) reinforced with Tensar UX1600 sleeve. Similar results are shown in Figure 6.18 for a long uniaxial stone column ( $0.38 \mathrm{~m}$ diameter and $1.32 \mathrm{~m}$ in height) reinforced with Tensar UX-1600 sleeve. These results reveal that, although two different types of grid were used in triaxial and uniaxial columns, the model parameters derived from triaxial tests with Tensar UX-1500 sleeves were appropriate to predicted the behaviour of uniaxial columns with Tensar UX-1600 sleeves.

At the beginning of this chapter the behaviour of the two types of aggregates without reinforcement were analyzed using the hyperbolic stress-strain model. The same model was used to analyze the behaviour of composite stone columns (aggregates with grid sleeves). The behaviour of polymer grid as individual component was analyzed using a hyperbolic expression similar to the one shown in equation [3.22].

$$
F=G_{i} \epsilon_{a}\left(\frac{1-\epsilon_{a}}{b \epsilon_{a f}}\right)
$$

The equation's parameters were defined in chapter three and they have the following values for Tensar UX-1500 grid

$$
\begin{aligned}
\mathrm{G}_{\mathrm{i}} & =1111 \mathrm{kN} / \mathrm{m} \\
\varepsilon_{\mathrm{af}} & =0.1035 \\
\mathrm{~b} & =4.5
\end{aligned}
$$

The observed and calculated behaviour are compared in Figure 6.19 for Tensar UX-1500. Similar analyses were performed for Tensar UX-1600 using the following values

$$
\begin{aligned}
\mathrm{G}_{\mathrm{i}} & =1515 \mathrm{kN} / \mathrm{m} \\
\varepsilon_{\mathrm{af}} & =0.1235 \\
\mathrm{~b} & =2.6
\end{aligned}
$$

The observed and calculated relationships are shown in Figure 6.20 for Tensar UX-1600. As can be seen from these results the predicted Load-strain behaviour quite agree with the measured behaviour for both types of grid. 


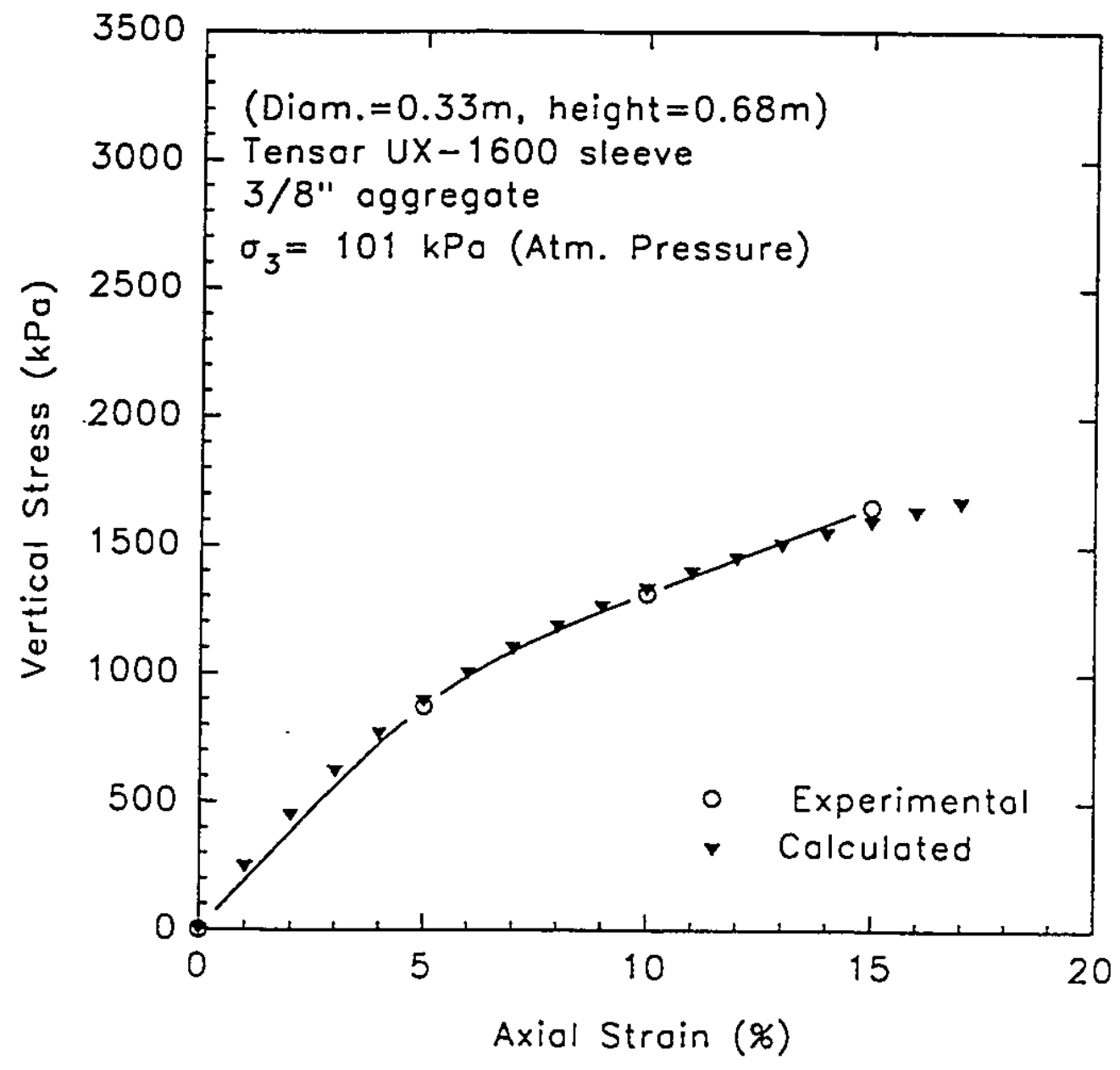

Figure 6.17: Experimental and calculated stress-strain behaviour of uniaxial column using the hyperbolic model 


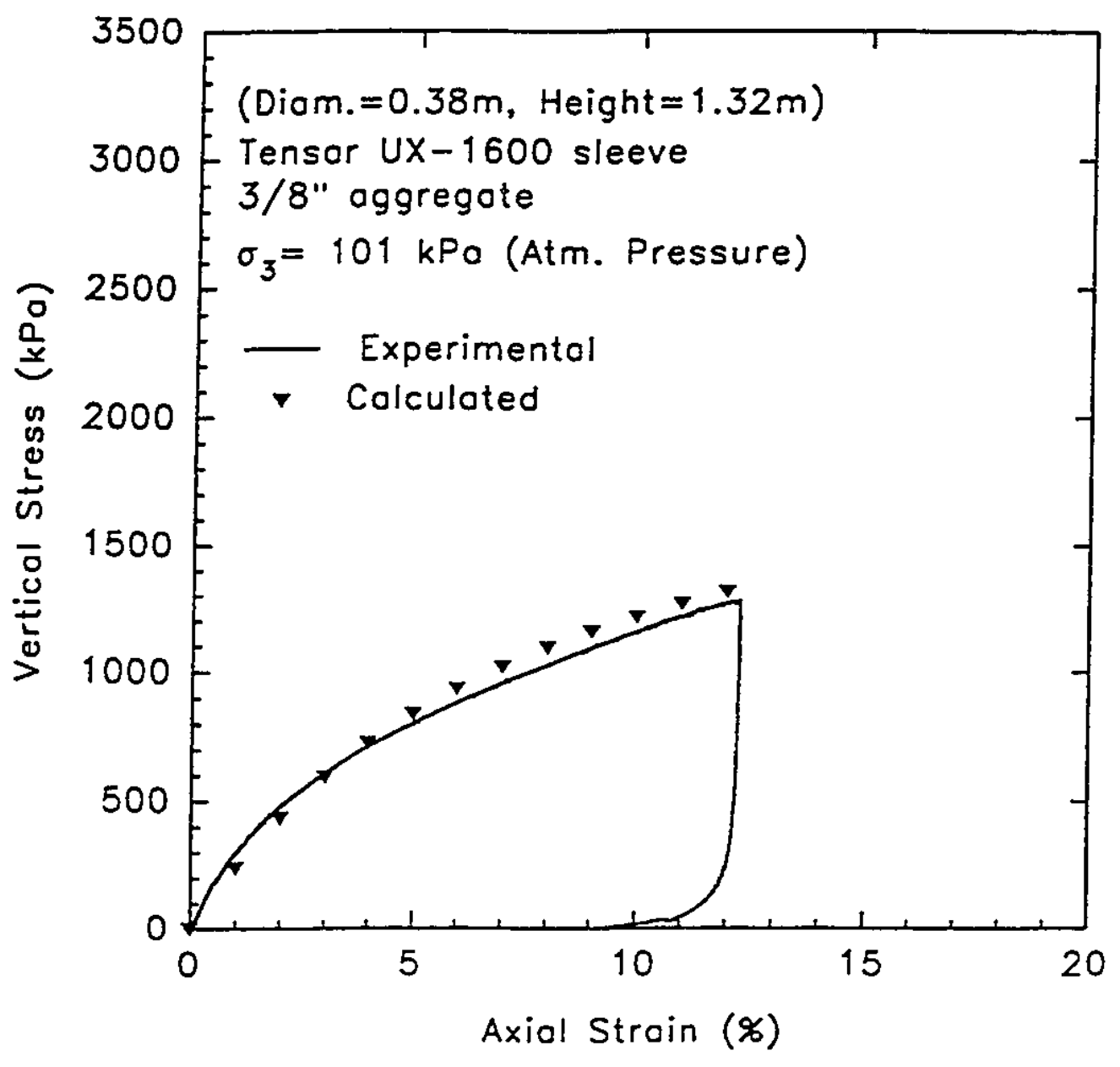

Figure 6.18: Experimental and calculated stress-strain behaviour of long uniaxial column using the hyperbolic model 


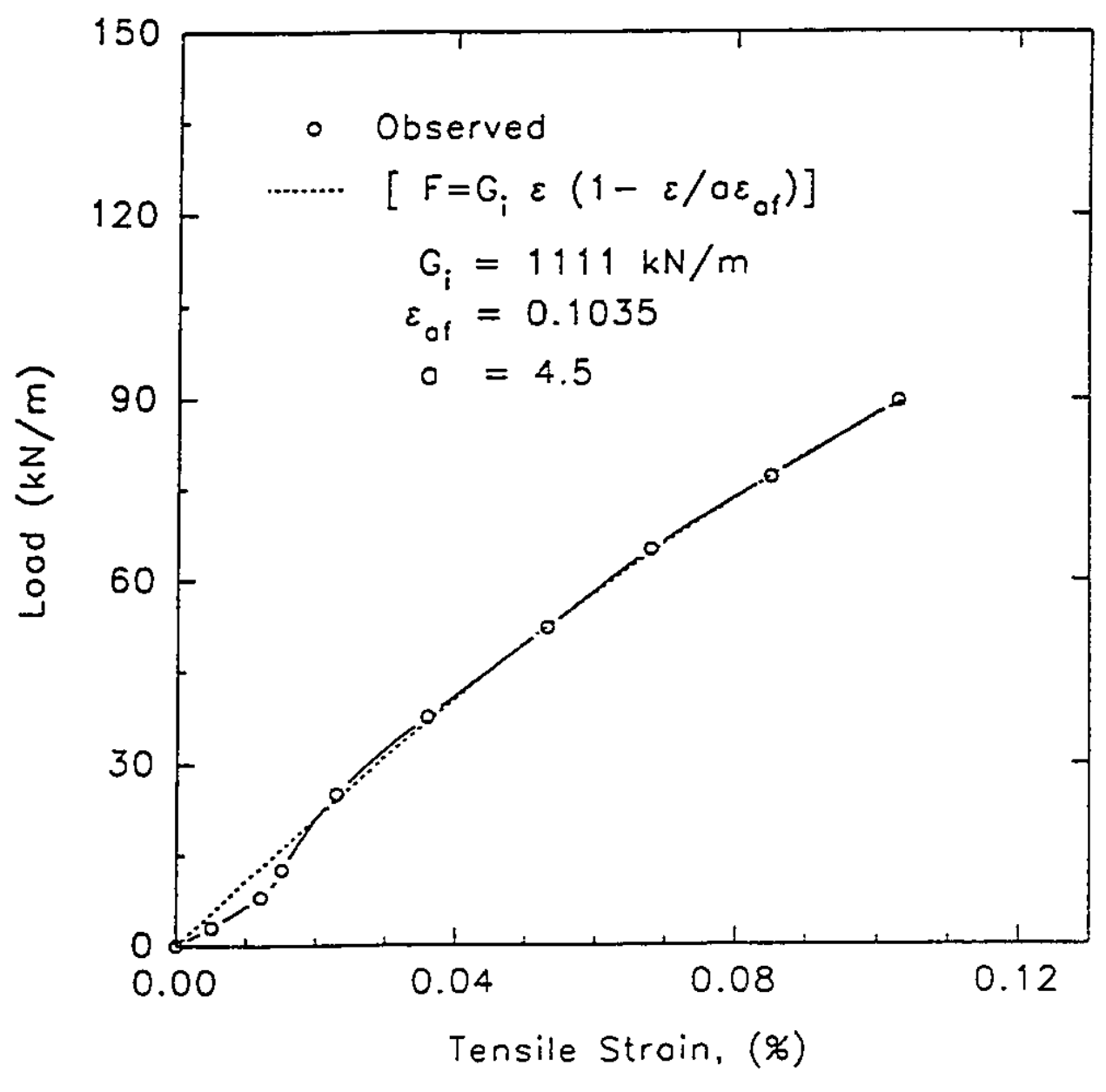

Figure 6.19: Observed and calculated load-strain behaviour of Tensar UX-1500 grid 


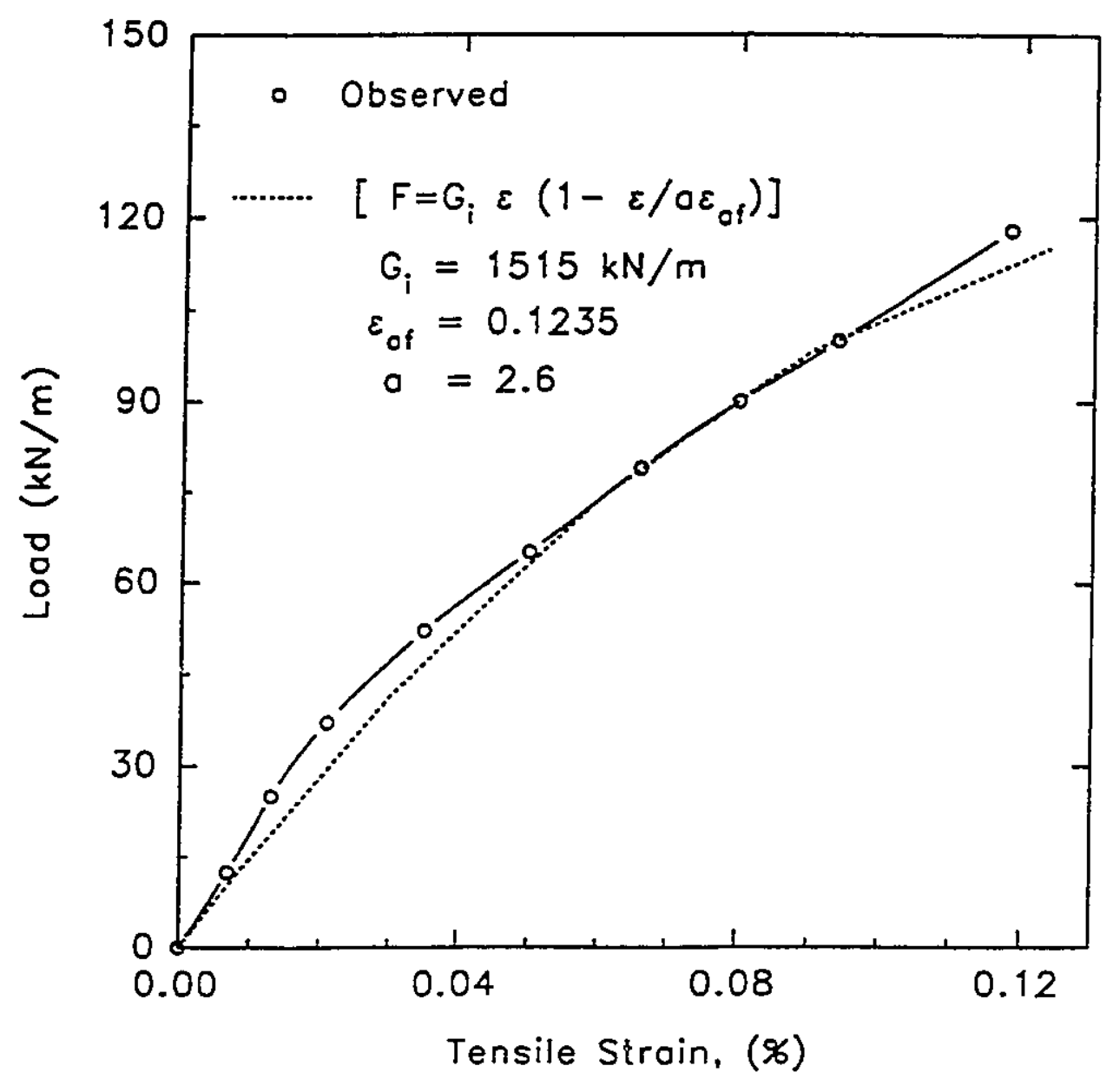

Figure 6.20: Observed and calculated load-strain behaviour of Tensar UX-1600 grid 
To conclude this chapter it can be stated that the hyperbolic stress-stain model have been employed for the analysis of unreinforced and sleeve reinforced stone columns behaviour. The theoretical results were compared with the observed behaviour of the stone columns in the laboratory and found to agree quite good.

This conclusion fulfilled the objective of this research which related to the theoretical investigation and the validation of the hyperbolic stress-strain model for the sleeve reinforced stone columns. 


\section{CHAPTER 7}

\section{COMPARISON AND DISCUSSION OF RESULTS}

\subsection{GENERAL}

In this chapter, the interpretation and comparison of the experimental results are presented and discussed. The results include the normalized stress-strain behaviour of stone columns with both aggregates at different confining pressures and with two types of reinforcement. Two regression analysis models were used to fit curves to the experimental results. Comparison of the regression analysis results and the experimental data are presented and discussed for both aggregates. The strength increase ratio (S.I.R.) which represents the increase of column capacity due to grid sleeves are compared at different confining pressures for Tensar and Conwed sleeves.

The effect of sleeve reinforcement on the global and secant angle of shearing resistance are compared and discussed for columns with granular " $\mathrm{A}$ " and uniform aggregates, respectively. The secant moduli of sleeve reinforced columns are compared at different confining pressures. Also, the variation of secant modulus with axial strain is presented and compared for reinforced and unreinforced stone columns.

The coefficients of earth pressure $\left(\mathrm{K}_{0}\right)$ are compared and discussed for sleeve reinforced and unreinforced columns. Comparison of lateral strains of sleeve reinforced and unreinforced stone columns are presented. Subsequently, the lateral strains used in the calculation of tensile forces mobilized in the polymer grid sleeves during loading of a stone column are discussed. The variation of maximum tensile forces mobilized in the grid, which correspond to the maximum axial strain of the stone columns, is shown and discussed with regard to confining pressures. Also, the lateral deformation behaviours of triaxial and uniaxial stone columns are compared.

The local tensile strains at selected strands of the grid sleeve are reported and 
compared. The local tensile forces in the strands are then calculated and compared to the corresponding measured tensile strains. Finally, the modes of failure of unreinforced granular columns are compared with the mode of failure of reinforced columns.

\subsection{TRIAXIAL STONE COLUMN TESTS}

\subsubsection{Comparison of the stress-strain relations}

The normalized stress-strain relationships of unreinforced triaxial and sleeve reinforced columns are summarized in Figures 7.1 to 7.4 for uniform aggregate (3/8") and granular "A" aggregate respectively. These figures demonstrate the general trend of the stress-strain behaviour for unreinforced and sleeve reinforced columns.

The stress-strain curves of unreinforced columns with 3/8" aggregate achieved an ultimate strength beyond 5\% axial strain (Figures 7.1 and 7.2). However, the stress-strain relationships of sleeve reinforced columns with uniform aggregate (3/8") can be identified by the strain hardening behaviour and the continuous development of strength without any peak value even beyond $15 \%$ axial strain. This behaviour is due to the contractive nature of this type of aggregate. The maximum normalized stress ratio of unreinitorced columns for uniform aggregate (3/8"), varied between 2.5 and 5 for confining pressures of $345 \mathrm{kPa}$ and $103 \mathrm{kPa}$ respectively. The maximum stress ratio of sleeve reinforced columns varied between 6.5 and 21 for confining pressures of $345 \mathrm{kPa}$ and $103 \mathrm{kPa}$ respectively.

The behaviour of unreinforced columns with granular "A" aggregate (Figures 7.3 and 7.4) exhibited a peak (maximum stress ratio) at axial strains between $4 \%$ and $5 \%$ for confining pressures of $345 \mathrm{kPa}$ and $103 \mathrm{kPa}$ respectively. The stress-strain relationships of sleeve reinforced columns can be identified by the strain hardening behaviour between axial strains of $0 \%$ and $15 \%$. Beyond $15 \%$ axial strains, the stress-strain relations tend toward ultimate stress ratio. It should be noted that this behaviour is mainly caused by the presence of the grid sleeve; for unreinforced columns the strain hardening behaviour was noticed between $0 \%$ and $5 \%$ axial strain. Also, the unreinforced columns exhibited residual strengths beyond $5 \%$ axial strain at confining pressures of $103 \mathrm{kPa}$ and 


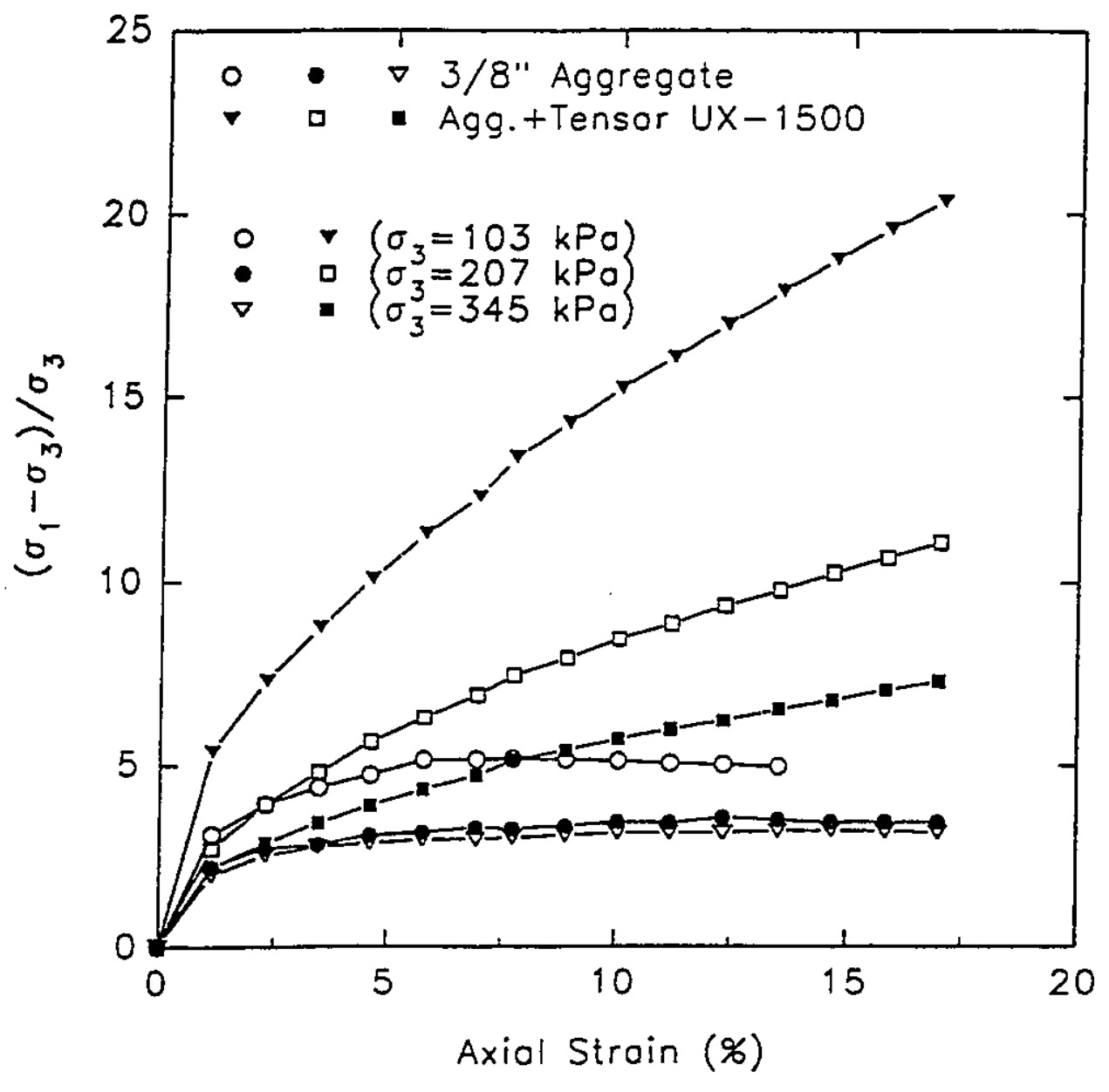

Figure 7.1 : Normalized stress-strain relationships of unreinforced and Tensar sleeve reinforced columns at different confining pressures (uniform aggregate) 


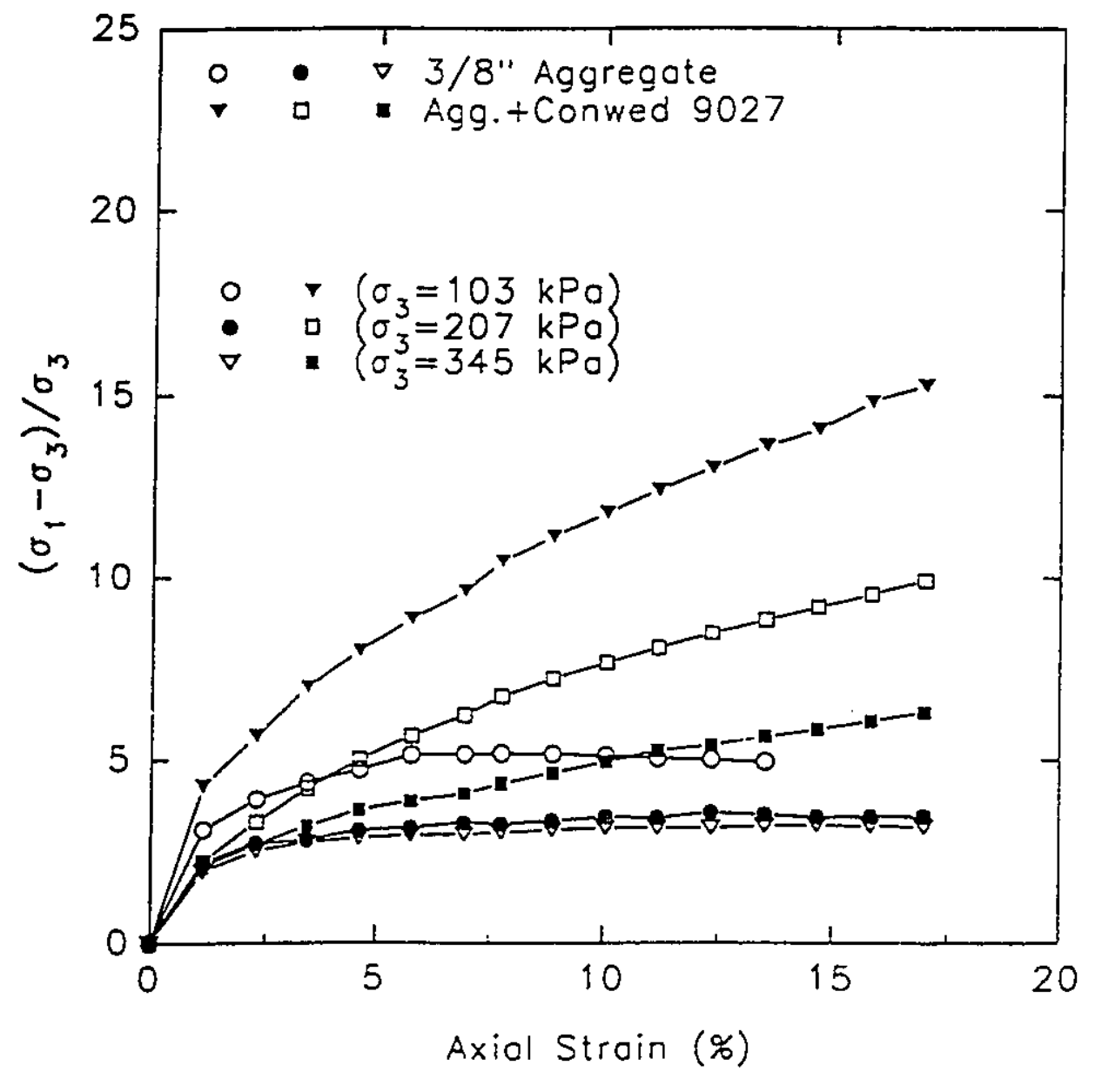

Figure 7.2 : Normalized stress-strain relationships of unreinforced and Conwed sleeve reinforced columns at different confining pressures (uniform aggregate) 


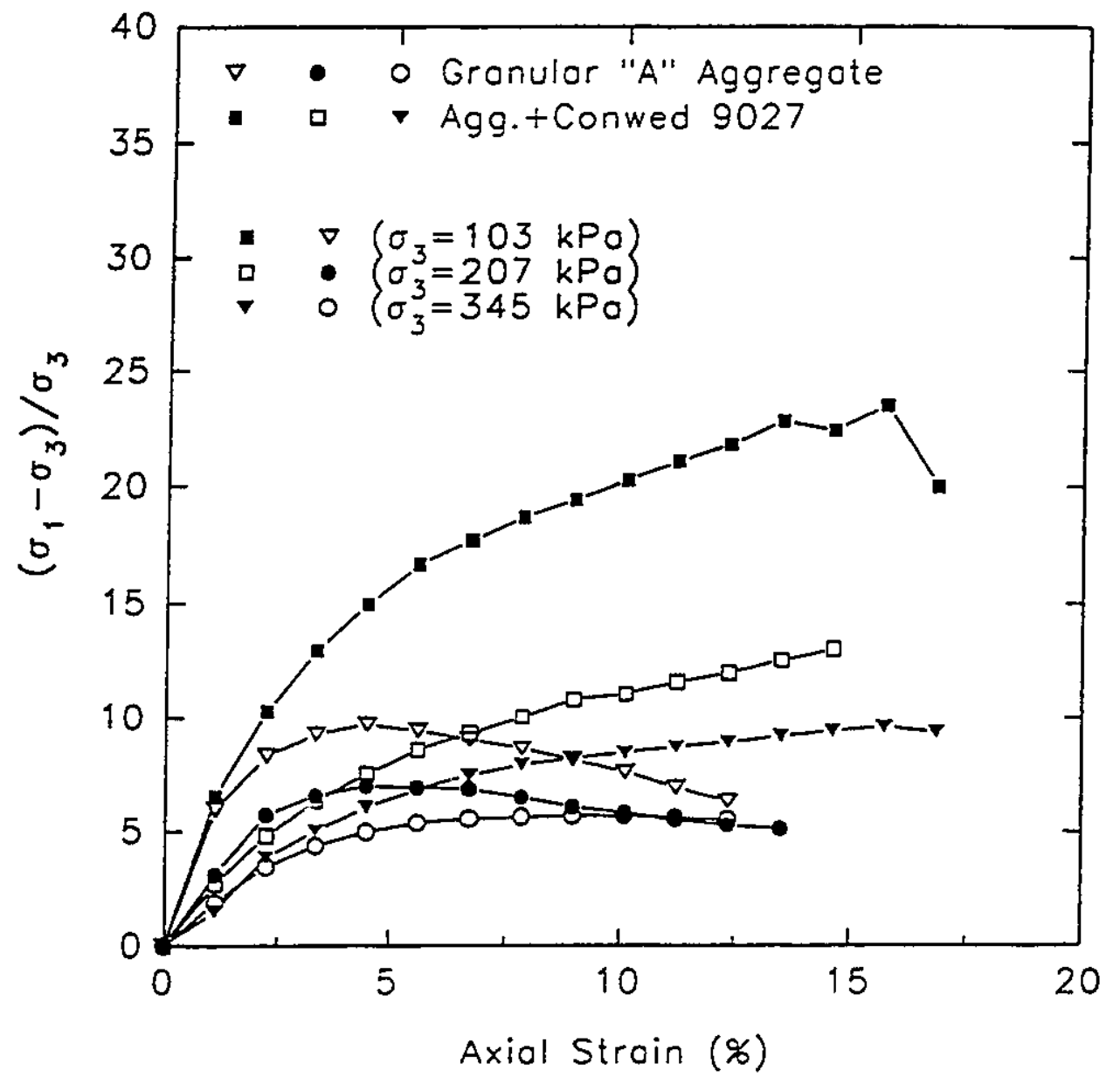

Figure 7.3 : Normalized stress-strain relationships of unreinforced and Conwed sleeve reinforced columns at different confining pressures (granular "A" aggregate) 


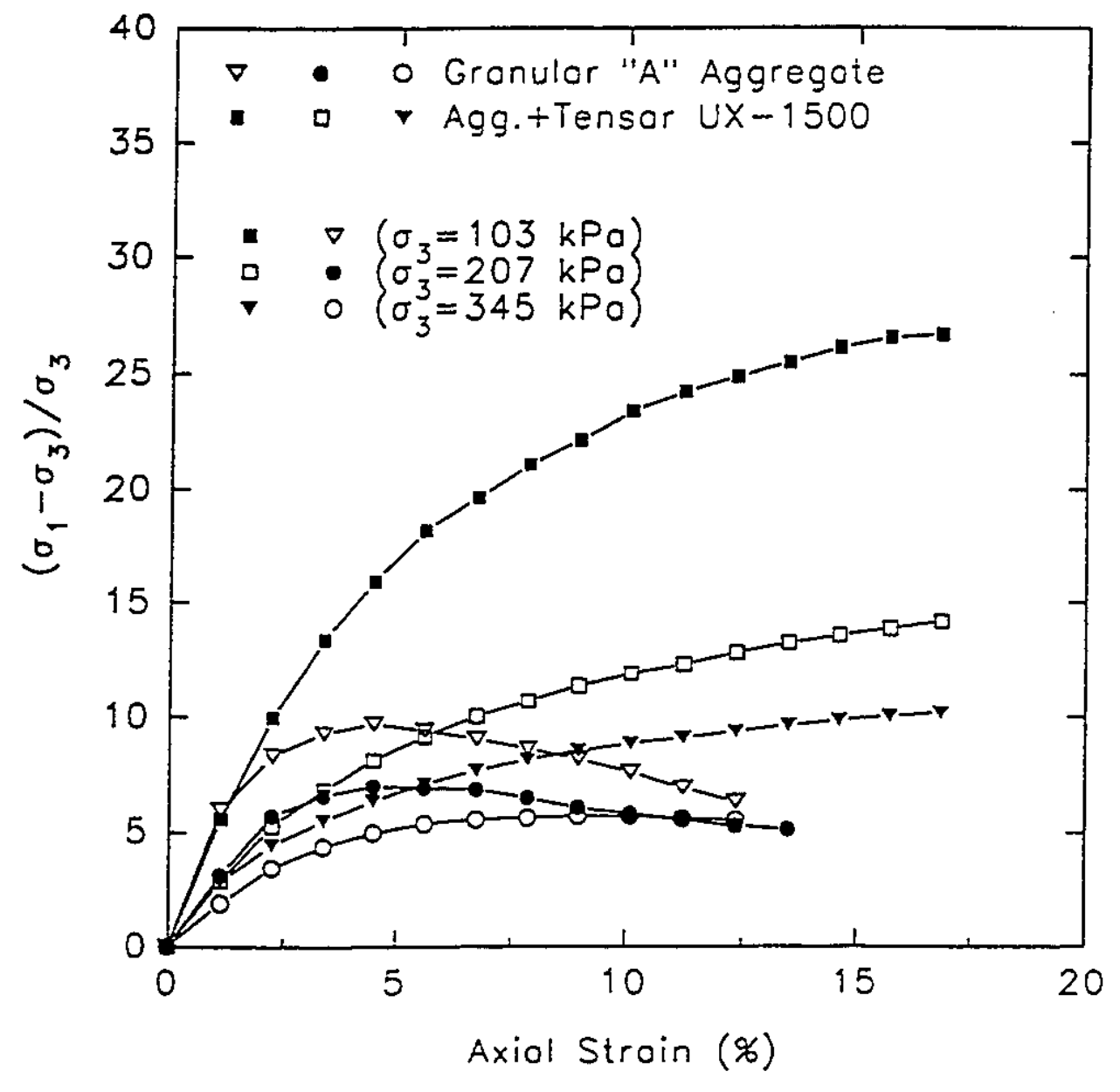

Figure 7.4 : Normalized stress-strain relationships of unreinforced and Tensar sleeve reinforced columns at different confining pressures (granular "A" aggregate) 
$207 \mathrm{kPa}$. No residual strength was noticed in any of the reinforced columns at any axial strain.

The normalized stress ratio , $\left(\sigma_{1}-\sigma_{3}\right) / \sigma_{3}$, of unreinforced columns with granular "A" aggregate varied between 5.5 to 9.6 for confining pressures of $345 \mathrm{kPa}$ and $103 \mathrm{kPa}$ respectively. However, the stress ratio of the sleeve reinforced columns varied jetween 9.5 and 27 for confining pressure of $345 \mathrm{kPa}$ and $103 \mathrm{kPa}$ respectively. It shouid be noted that Figures 7.1 to 7.4 have two sets of legends, one set to represent the different test under different confining pressures and the other set of legends to represent the type of aggregate and polymer grid sleeve used in these tests.

\subsubsection{Strength increase ratio (S.I.R.)}

The strength increase ratio is a concept introduced here to evaluate the effect of geogrid confinement on the strength of natural stone columns. The strength increase ratio (S.I.R.) is a deviator stress ratio of the natural and sleeve reinforced columns at the same axial strain. The actual values of the S.I.R. can be calculated from the triaxial test results on natural and sleeve reinforced columns. However, it is possible to estimate a theoretical value of the S.I.R. by using the calculated stresses of sleeve reinforced columns and the actual stresses of the natural columns. The S.I.R. depends on certain factors such as axial strain, confining pressure, type of grid sleeve and aggregate used in the test.

The strength increase ratio at any axial strain is defined as follows

$$
\text { S.I.R. }=\frac{\left[\left(\sigma_{1}-\sigma_{3}\right) / \sigma_{3}\right]_{(\text {Rerinforced) }}}{\left[\left(\sigma_{1}-\sigma_{3}\right) / \sigma_{3}\right]_{(\text {Naturat) }}}
$$

For the same confining pressure equation [7.1] will read as

$$
\text { S.I.R. }=\frac{\left(\sigma_{1}-\sigma_{3}\right)_{(\text {Reinforced) }}}{\left(\sigma_{1}-\sigma_{3}\right)_{(\text {Natural })}}
$$

The normalized triaxial tests results presented in Figures 7.1 to 7.4 were used to calculate the strength increase ratio for all stone columns. Comparison of the of S.I.R. at different confining pressure is plotted in Figures 7.5 and 7.6 for columns with granular 
"A" aggregate confined with Tensar UX-1500 and Conwed 9027 sleeves. Similar analysis was carried out for columns with uniform aggregate and grid sleeves. Figures 7.7 and 7.8 compare the S.I.R. at different confining pressures.

The results given in Figures 7.5 to 7.8 show that the strength ratio decreases with the increase of confining pressure. At high confining pressures (207 $\mathrm{kPa}$ and $345 \mathrm{KPa})$ the S.I.R. behaves more linearly than at low confining pressure. This behaviour may be related to the fact that at low confining pressure the grid sleeve rapidly mobilizes the tensile stresses and, therefore, the strength of the columns increases non-linearly. The S.I.R. tends to be constant at high confining pressures which means that the effect of the grid sleeve will be less dominant. This will occur under certain conditions where both the natural and sleeve reinforced columns are very consistent in density and where exactly the same higher confining pressure is applied in both tests. In this case the influence of the grid sleeve will be less prominent and the S.I.R. will tend to be unity.

The maximum S.I.R. is obtained at $12 \%$ of axial strain for granular "A" aggregate with Tensar UX-1500 sleeve at $\sigma_{3}=103 \mathrm{kPa}$ (Figure 7.5). The minimum S.I.R. was obtained for the uniform aggregate with a Conwed 9027 sleeve at $\sigma_{3}=207 \mathrm{kPa}$ (Figure 7.6). 


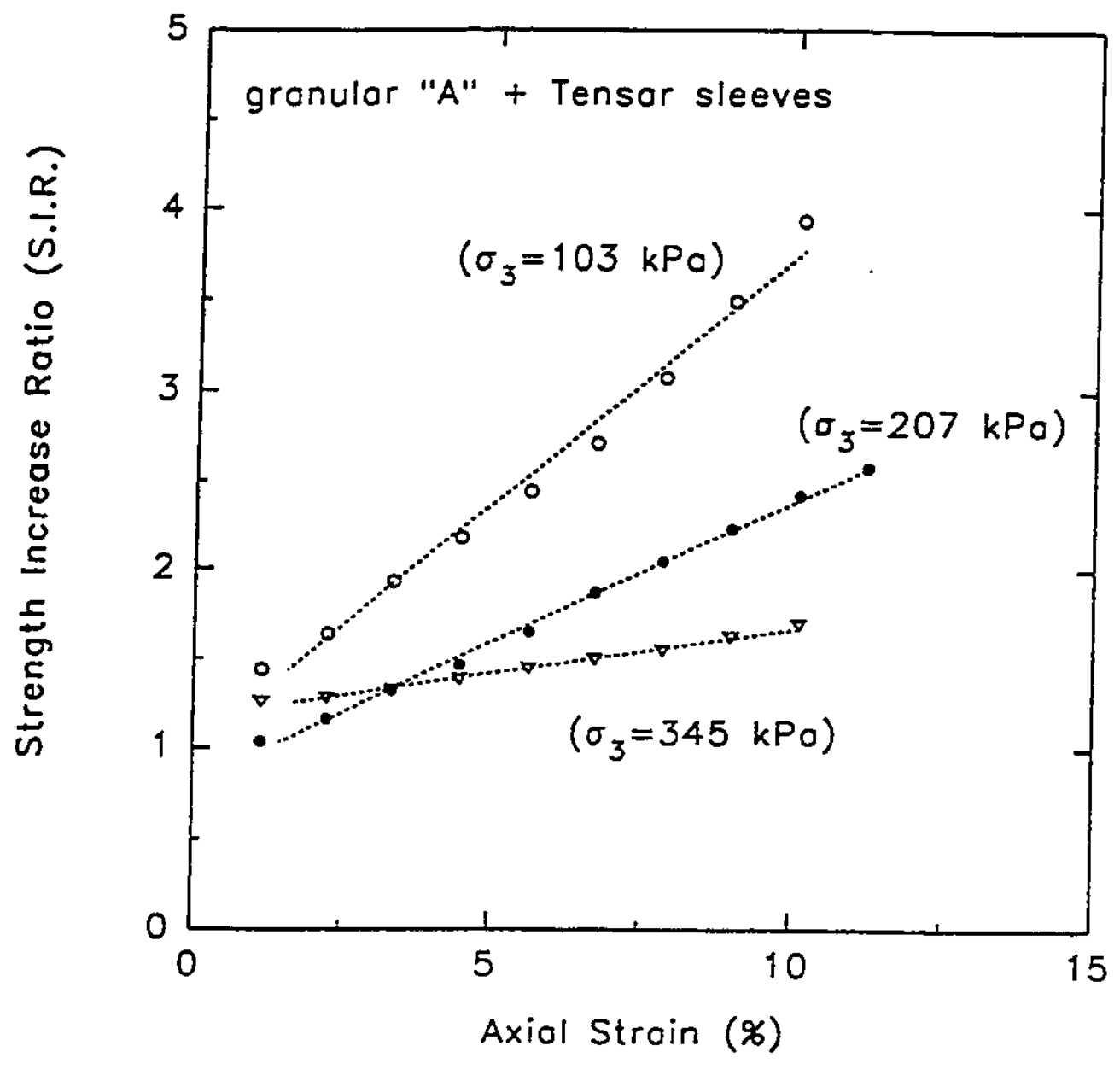

Figure 7.5 : Variation of strength increase ratio with axial strain for different confining pressures (granular "A" + Tensar sleeves) 


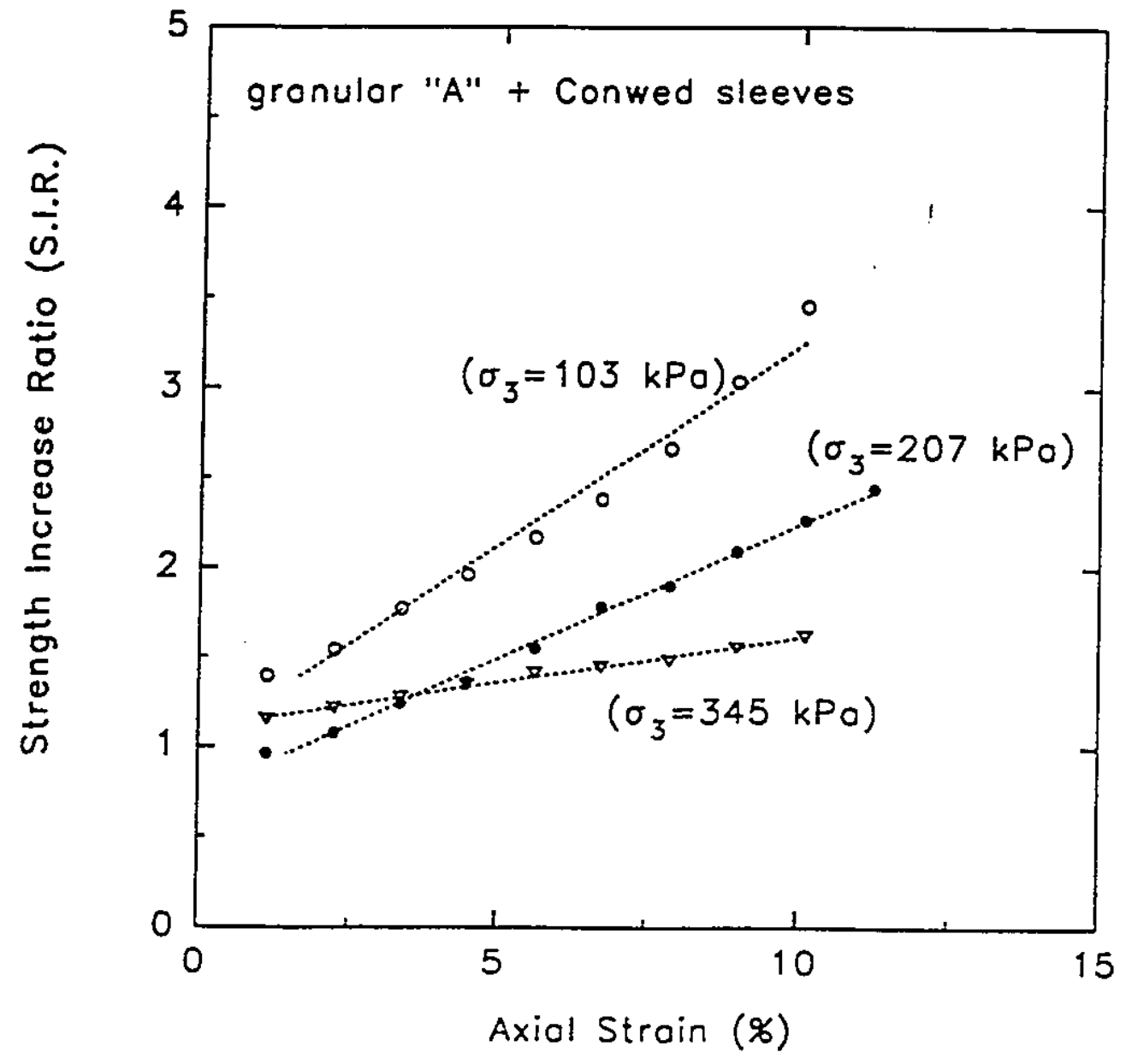

Figure 7.6 : Variation of strength increase ratio with axial strain for different confining pressures (granular " $\mathrm{A}$ " + Conwed sleeves) 


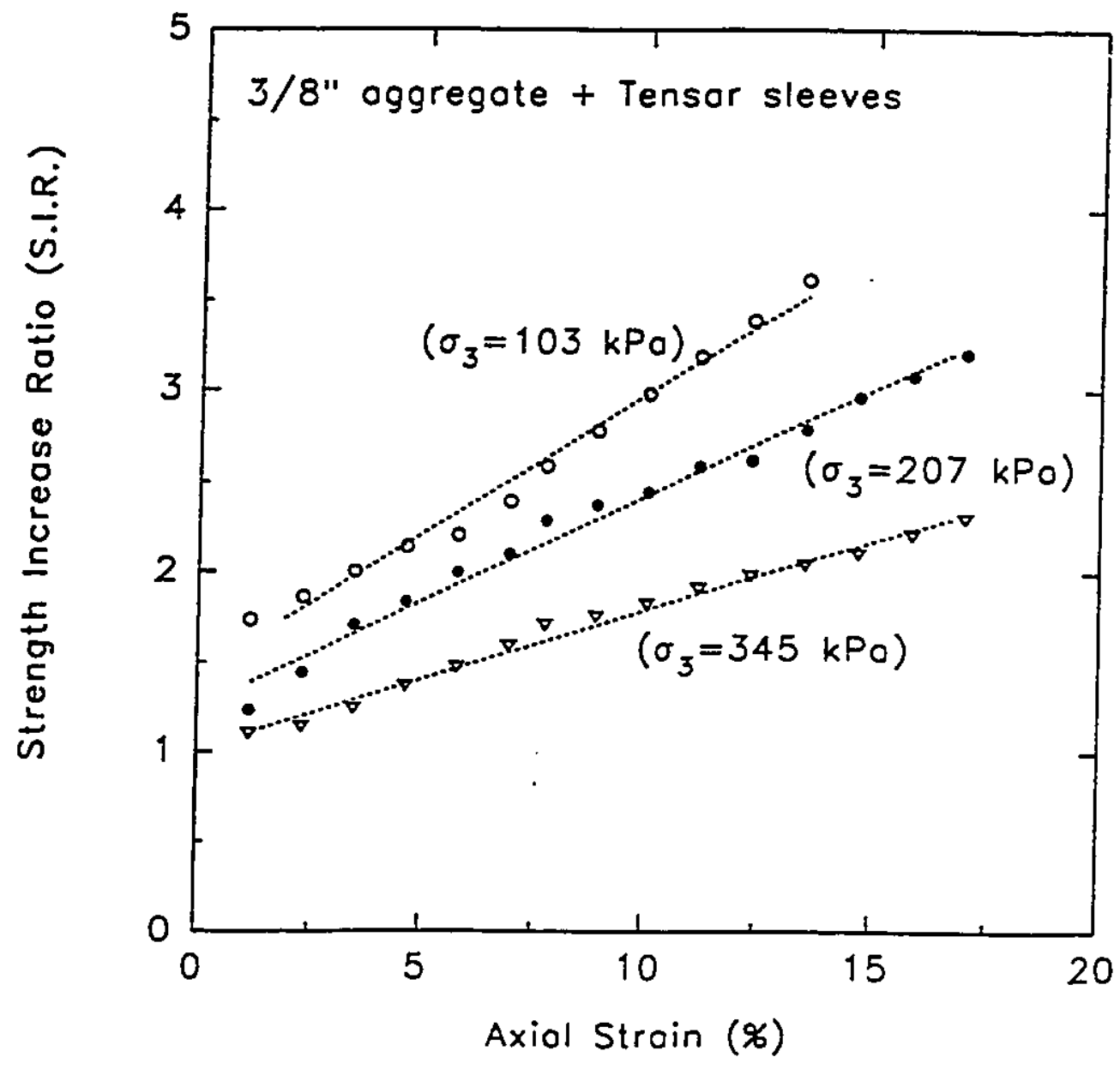

Figure 7.7 : Variation of strength increase ratio with axial strain for different confining pressures (3/8" aggregate + Tensar sleeves) 


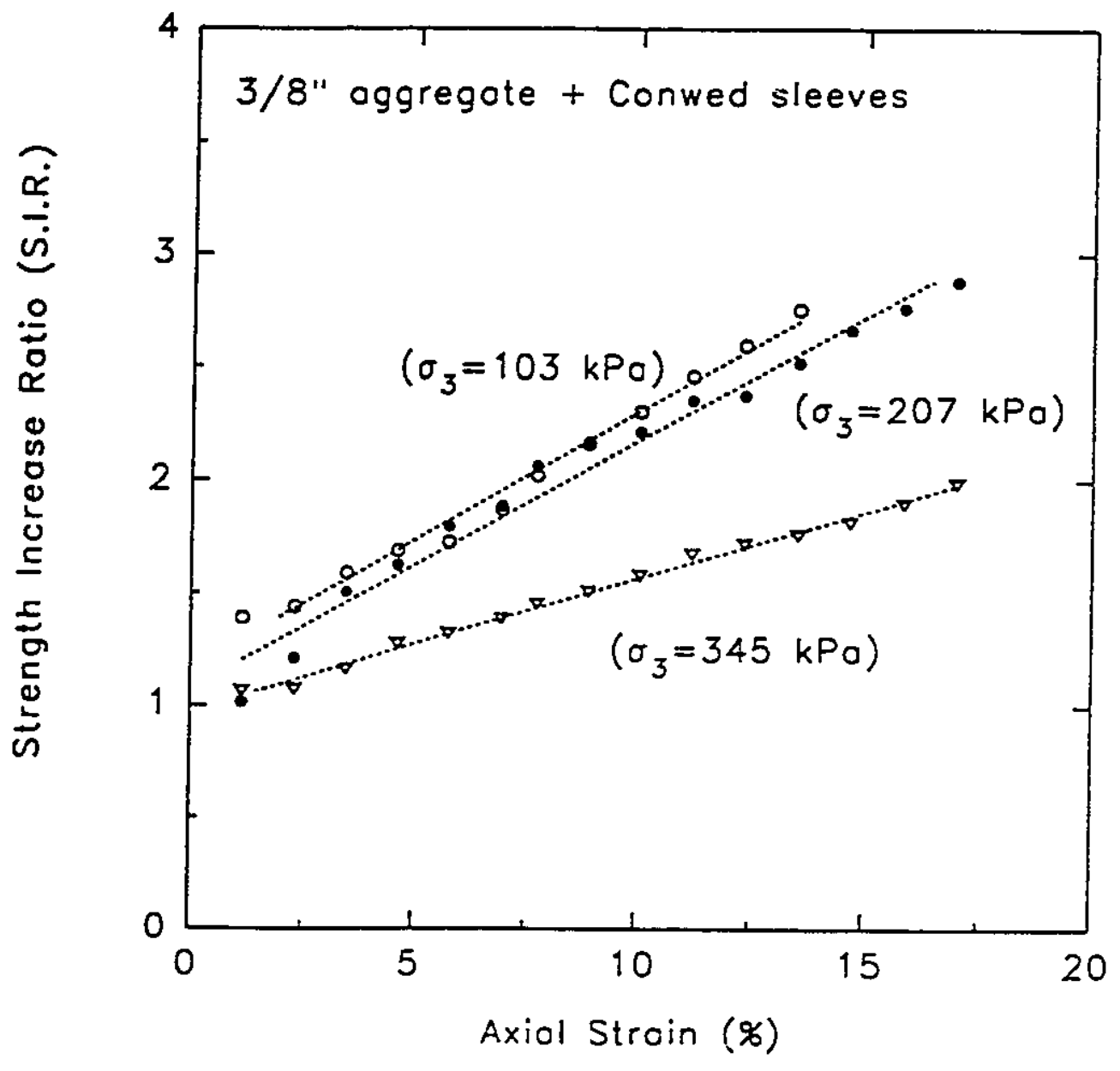

Figure 7.8 : Variation of strength increase ratio with axial strain for different confining pressures (3/8" aggregate + Conwed sleeves) 


\subsubsection{Comparison of the angles of shearing resistance}

A comparison of the angles of shearing resistance of unreinforced columns with the global angle of shearing resistance of the sleeve reinforced columns is shown in Figures 7.9 and 7.10 for the well graded and the uniform aggregates respectively. Since stress-strain relations for the reinforced columns did not yield a peak value, the shearing angle for the reinforced column was calculated at axial strains corresponding to the peak deviator stress of the unreinforced column at these strains. The grid sleeves do not significantly change the angles of shearing resistance obtained for the natural aggregate.

To confirm the previous observation the angles of shearing resistance were determined at axial strain (15\%) beyond the peak stress of the granular "A" aggregate and the ultimate stress of the uniform aggregates. The corresponding values for the columns with granular "A" aggregate are $39.5^{\circ}$ and $40.5^{\circ}$ for Tensar and Conwed sleeves respectively (Figure 7.11). The corresponding angles of shearing resistance for the columns with uniform aggregate are $43.5^{\circ}$ and $44^{\circ}$ for Tensar and Conwed sleeves respectively (Figure 7.12).

The global angles of shearing resistance for columns with granular " $\mathrm{A}$ " aggregate decreases more than $10^{\circ}$ when calculated at axial strains beyond the peak $\left(\varepsilon_{\mathrm{a}}=15 \%\right)$. This considerable tremendous decrease in the shearing angle may be attributed to the strain softening behaviour of this aggregate beyond $5 \%$ axial strain. The apparent cohesion intercepts (at $\varepsilon_{\mathrm{a}}=15 \%$ ) were higher than the values determined at axial strains correspon-

ding to the peak stress of the natural aggregates. Therefore, it can be stated that although higher strengths were obtained in the stone columns with granular " $\mathrm{A}$ " at higher axial strain due to the mobilization of higher tensile stresses in the grid sleeve, the global angle of shearing resistance was decreased due to the strain softening behaviour of the well graded aggregate.

The columns with uniform aggregate and grid sleeves exhibited approximately the same global angle of shearing resistance at both $5 \%$ and $15 \%$ axial strain. It should be noted that the uniform aggregate was characterized as a contractive material which exhibited an ultimate stress beyond 5\% axial strain and this was the reason for the constant angle of shearing resistance. 


\subsubsection{Comparison of secant modulus}

The variation of secant modulus with confining pressure is shown in Figures 7.13 and 7.14 for granular " $\mathrm{A}$ " and 3/8" aggregate respectively. For granular "A" aggregate (Figure 7.13) the secant modulus was determined at axial strain of 5\% which, approximately, corresponds to the peak strength of the unreinforced columns. At this strain the secant modulus is dependent on the confining pressure. The modulus was increased two fold when grid sleeves were used at the same confining pressure. The difference in secant modulus for columns reinforced with Tensar and Conwed sleeves is due to the stiffness of each grid. Therefore, it can be stated that the secant modulus is not only dependent on the extra confinement provided by the polymer grid sleeve at a given stress level but also on the physical properties of the geogrid.

The secant modulus for $3 / 8$ " aggregate (Figure 7.14) was also determined at $5 \%$ of axial strain which corresponds to the ultimate strength of unreinforced columns. The secant modulus of unreinforced columns increases with increase of confining pressure. The Tensar sleeve doubled the secant modulus at a low confining pressure (103 $\mathrm{kPa})$ and the Conwed sleeve has increased the modulus by $70 \%$. At a higher confining pressure $(345 \mathrm{kPa})$ the Tensar and Conwed sleeves increased the modulus by an additional $80 \%$ and $60 \%$ respectively. Therefore, the secant modulus is function of both the confining pressure and the type of geogrid.

The variation of secant modulus with axial strain is presented in Figures 7.15 and 7.16 for unreinforced column with $3 / 8$ " and granular "A" aggregate respectively. The results shown in Figure 7.15 reveal that the secant modulus for the 3/8" aggregate approaches a constant value beyond $15 \%$ of axial strain (i.e independent of confining pressure). For unreinforced columns with granular "A" aggregate (Figure 7.16) the secant modulus decreases rapidly with an increase in axial strain. This modulus is also dependent on confining pressure.

The variation of secant modulus with axial strain for sleeve reinforced columns is shown in Figures 7.17 and 7.18, for a confining pressure of $103 \mathrm{kPa}$ for both granular materials. The secant modulus of the composite is higher than that for the unreinforced columns. However, the secant modulus seems to be converting to the same value at axial 


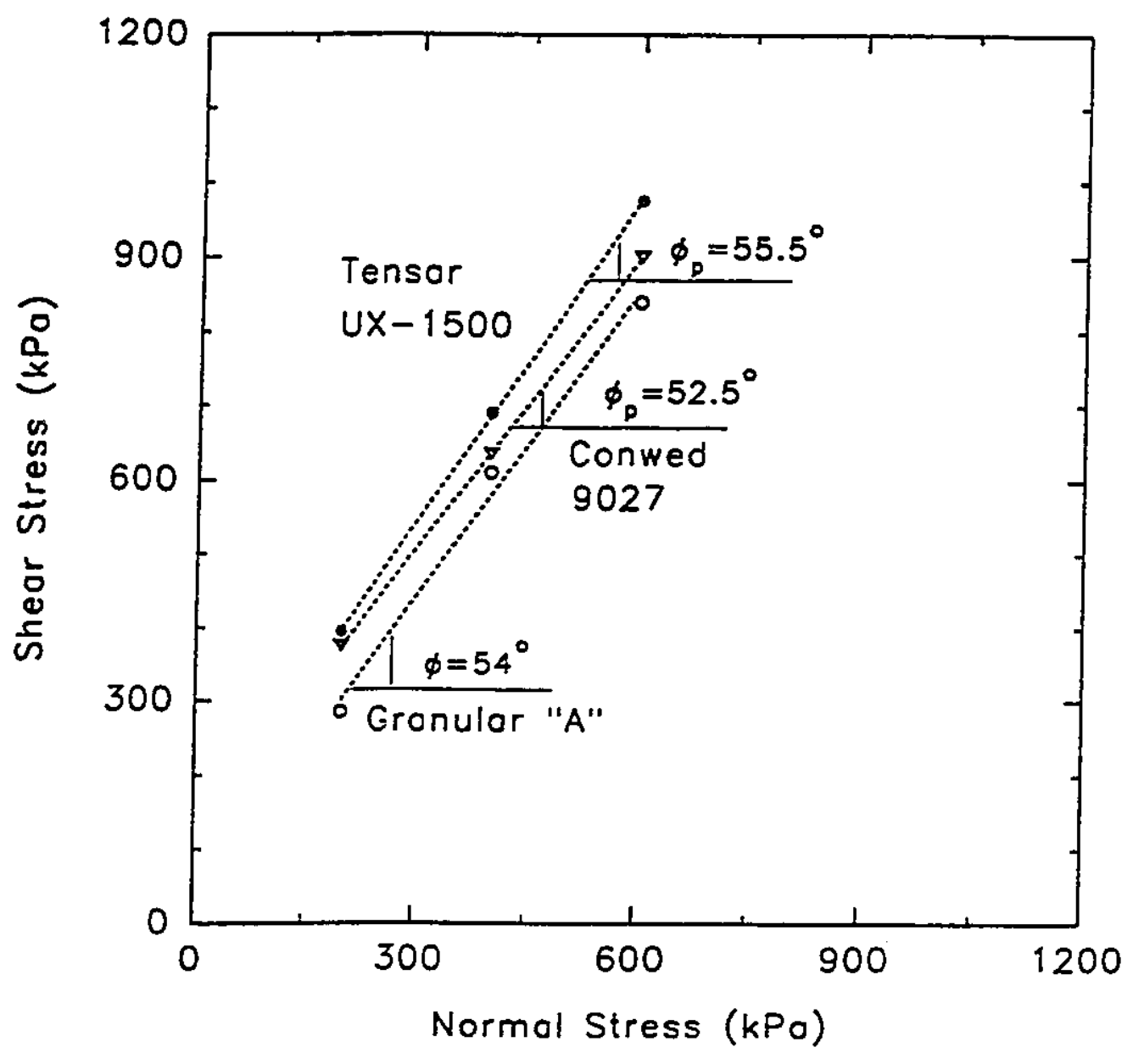

Figure 7.9 : Mohr-Coulomb strength envelope for unreinforced and sleeve reinforced stone columns (granular "A") 


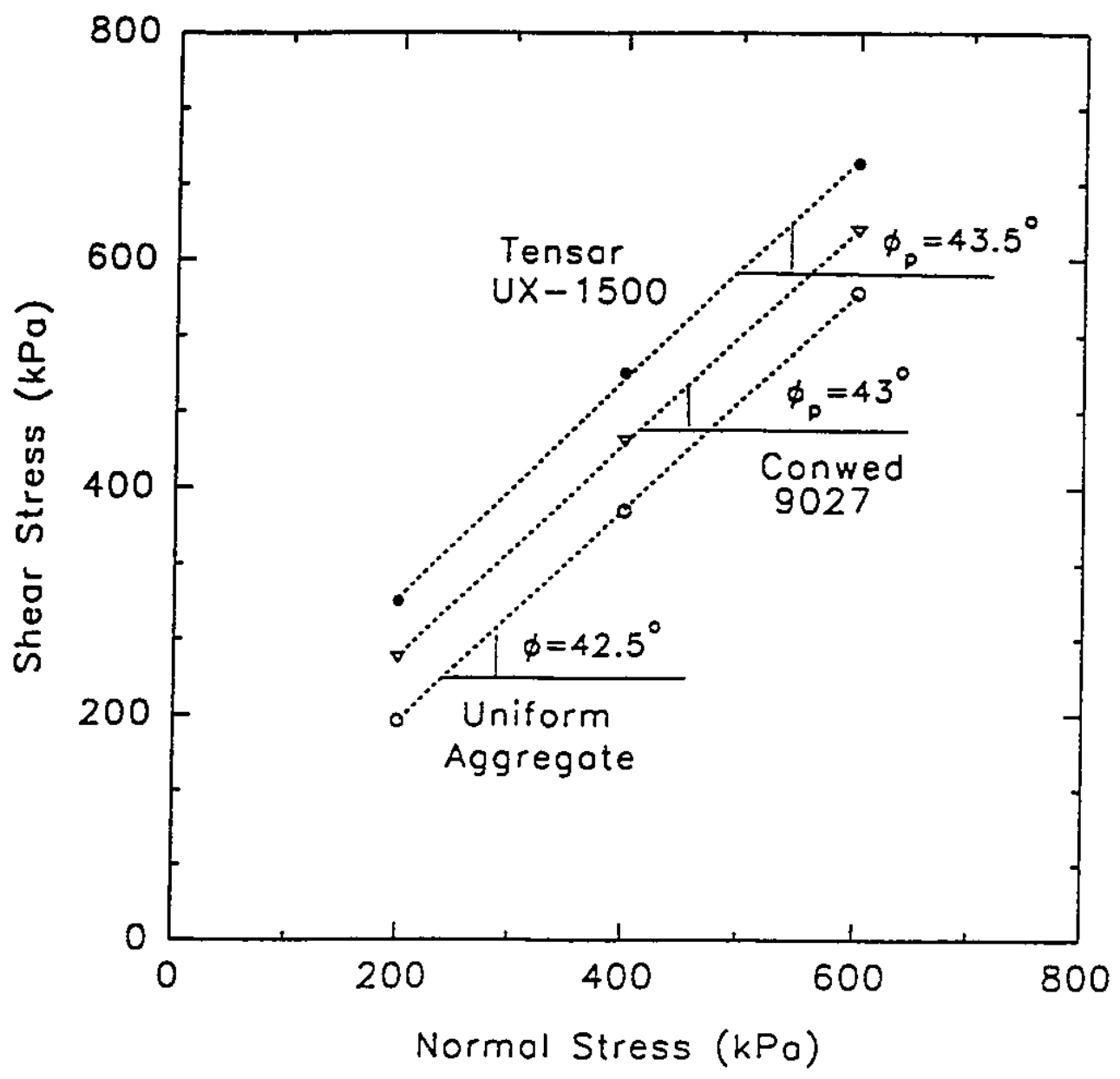

Figure 7.10 : Mohr-Coulomb strength envelope for unreinforced and sleeve reinforced stone columns (3/8" aggregate) 


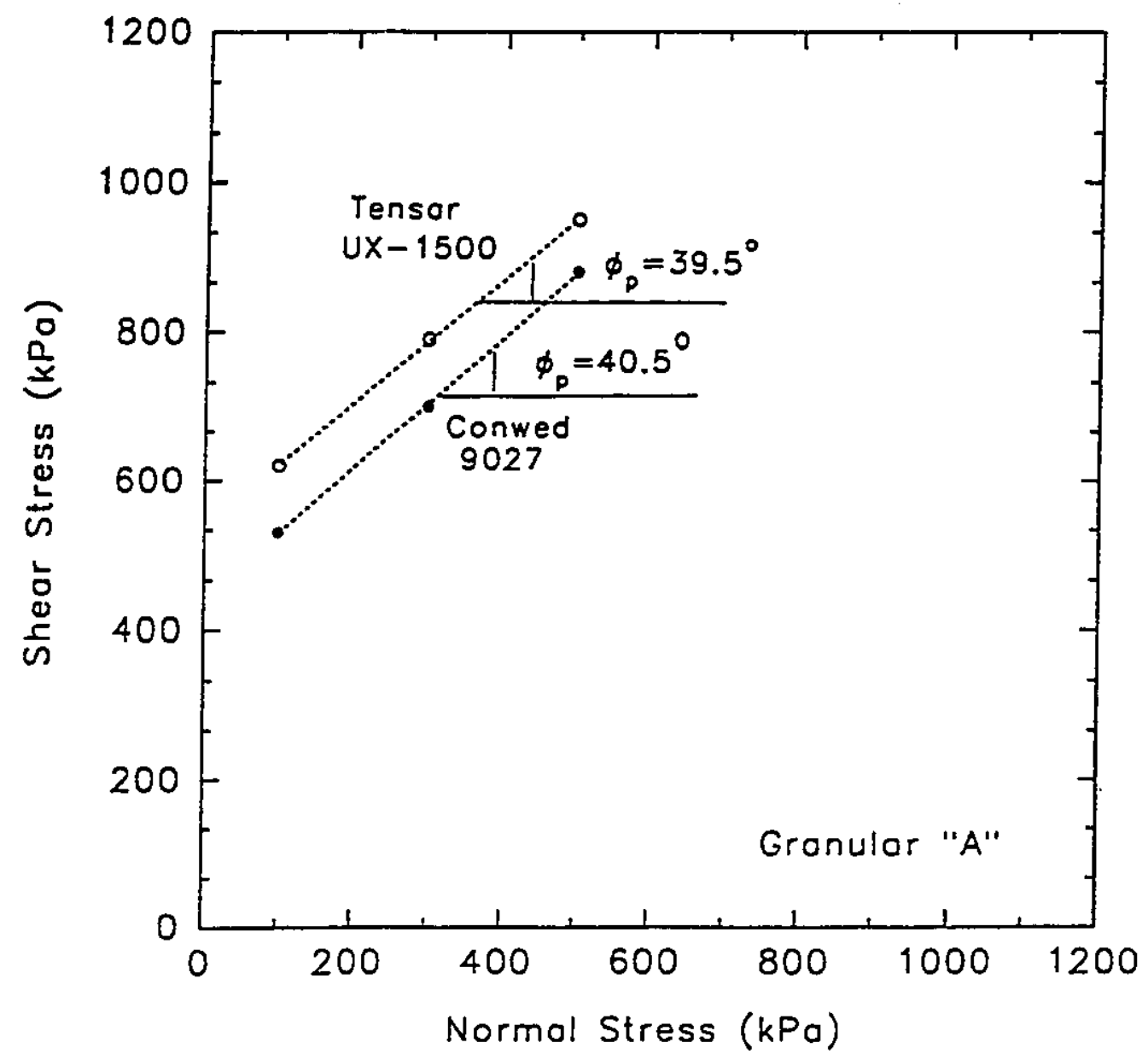

Figure 7.11 : Mohr-Coulomb strength envelope for sleeve reinforced columns at $15 \%$ axial strain 


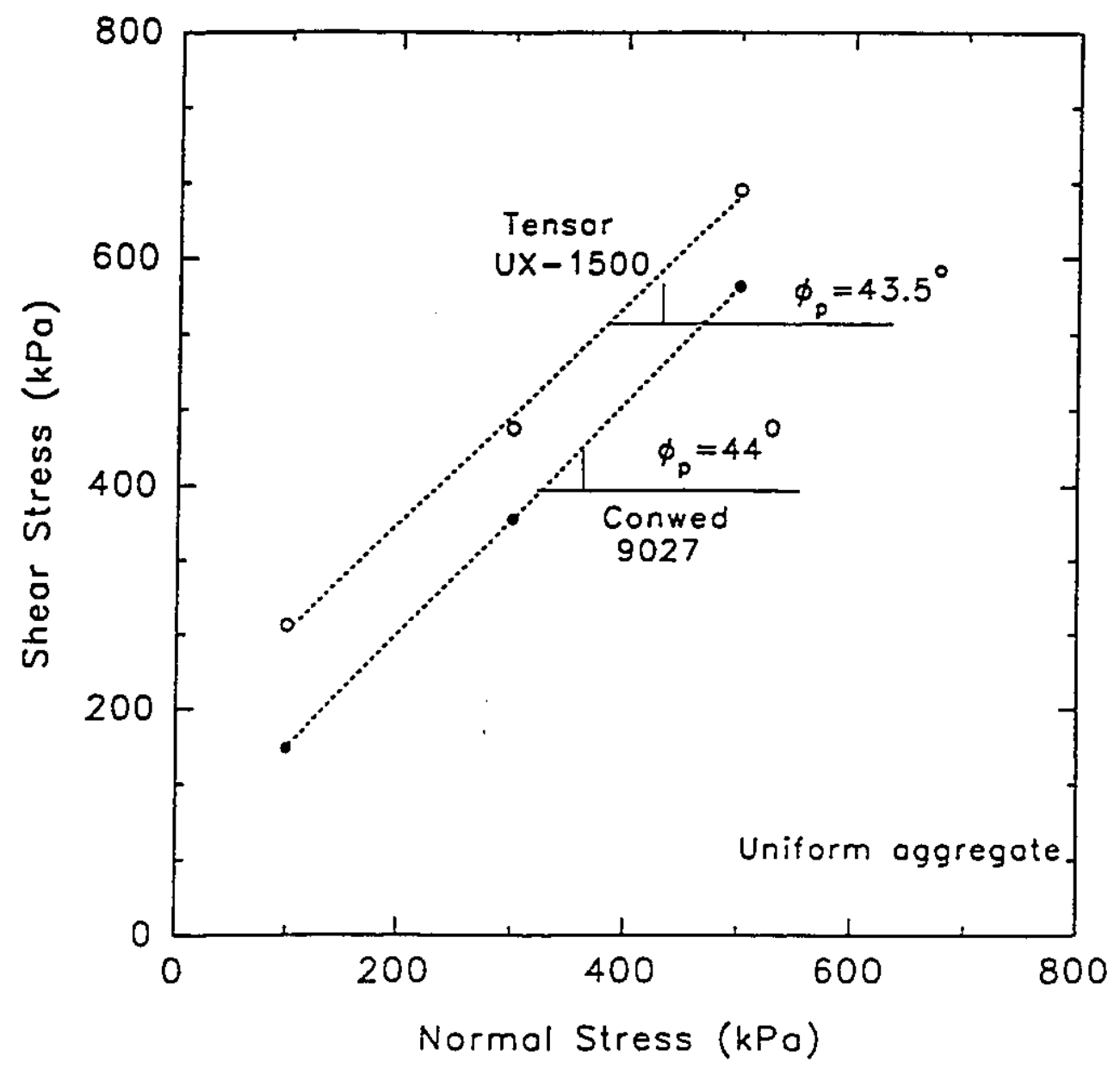

Figure 7.12 : Mohr-Coulomb strength envelope for sleeve reinforced columns at $15 \%$ axial strain 


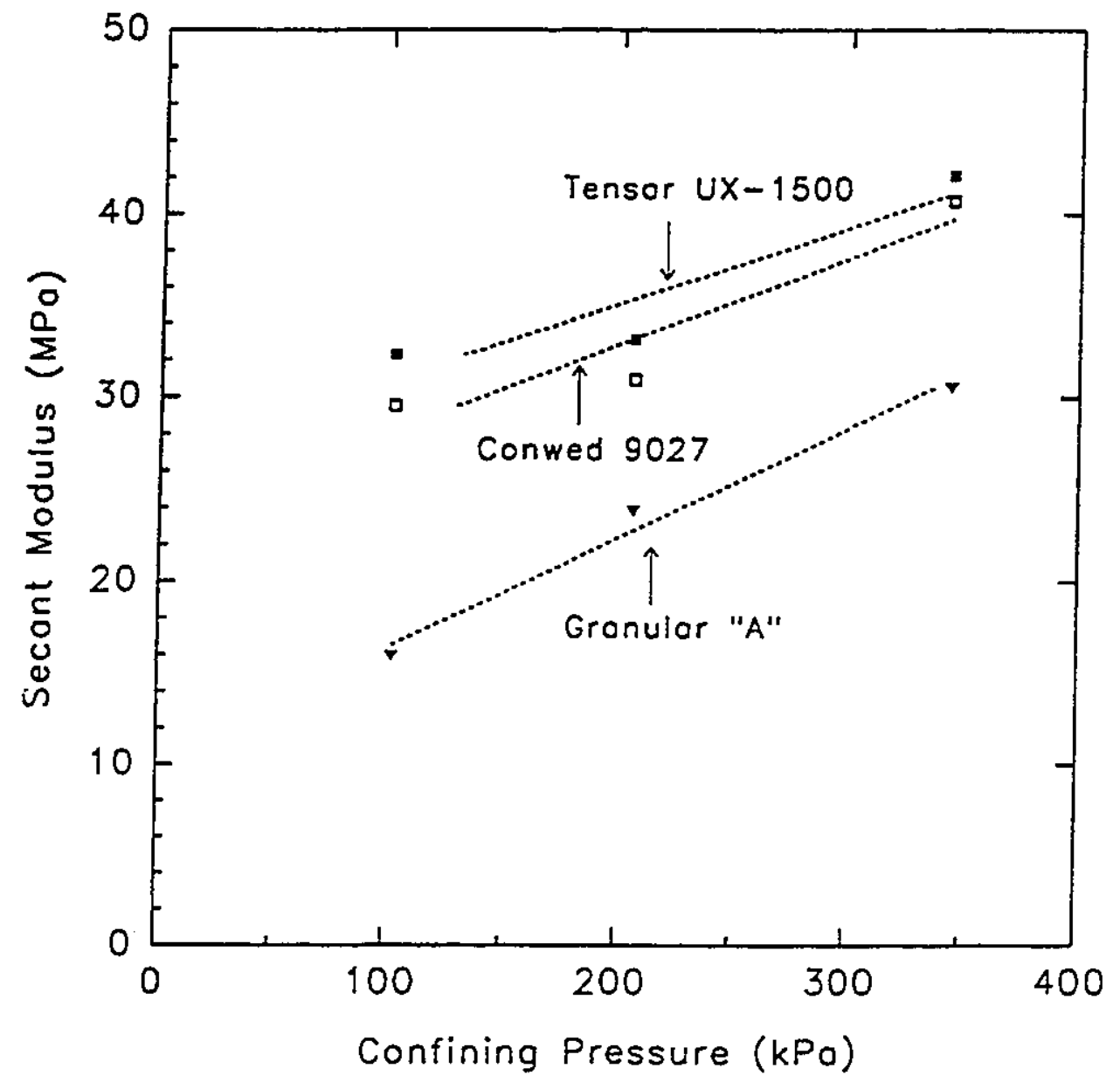

Figure 7.13 : Variation of secant modulus with confining pressure at 5\% axial strain (granular "A") 


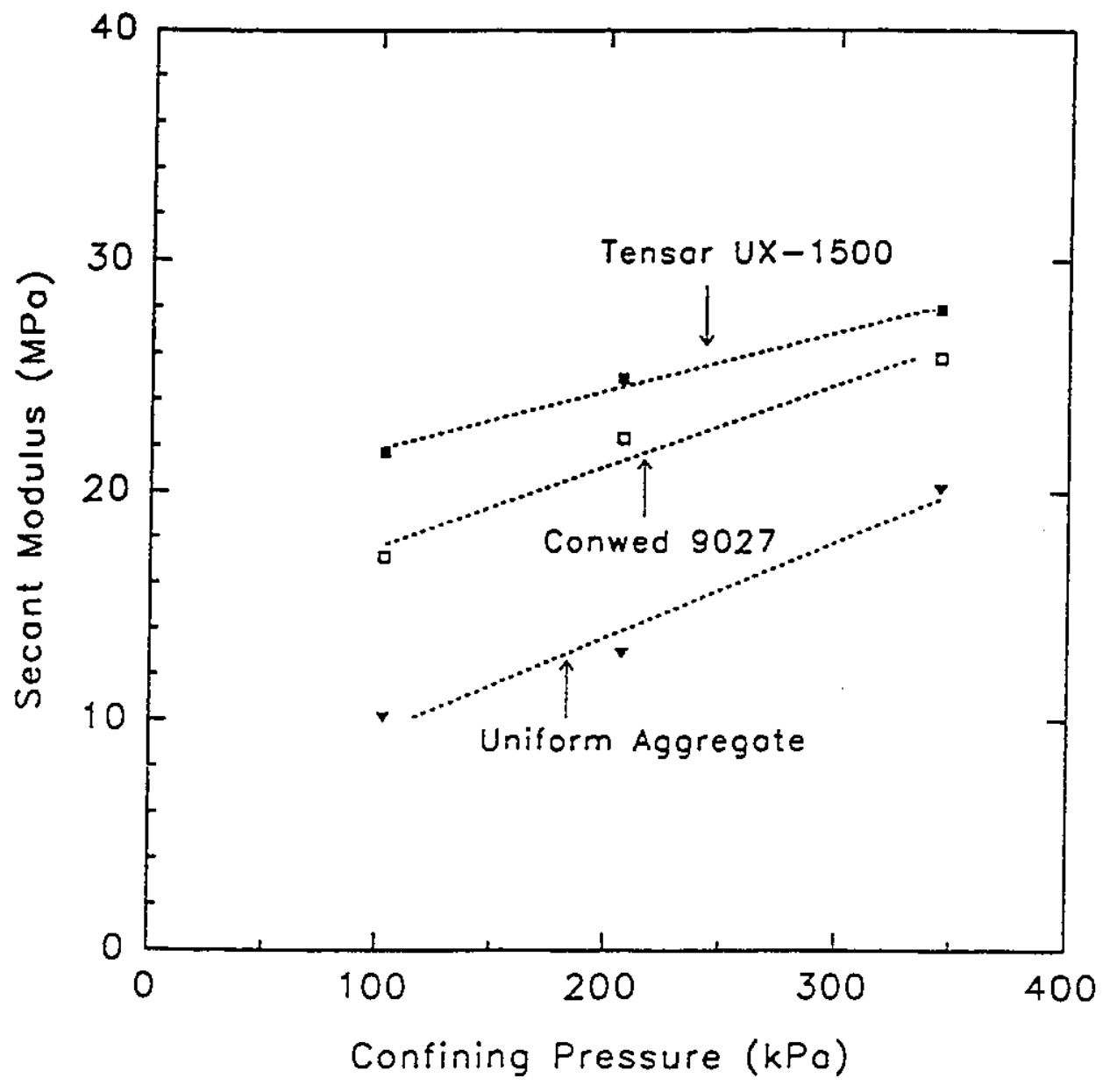

Figure 7.14 : Variation of secant modulus with confining pressure at $5 \%$ axial strain ( $3 / 8$ " aggregate) 


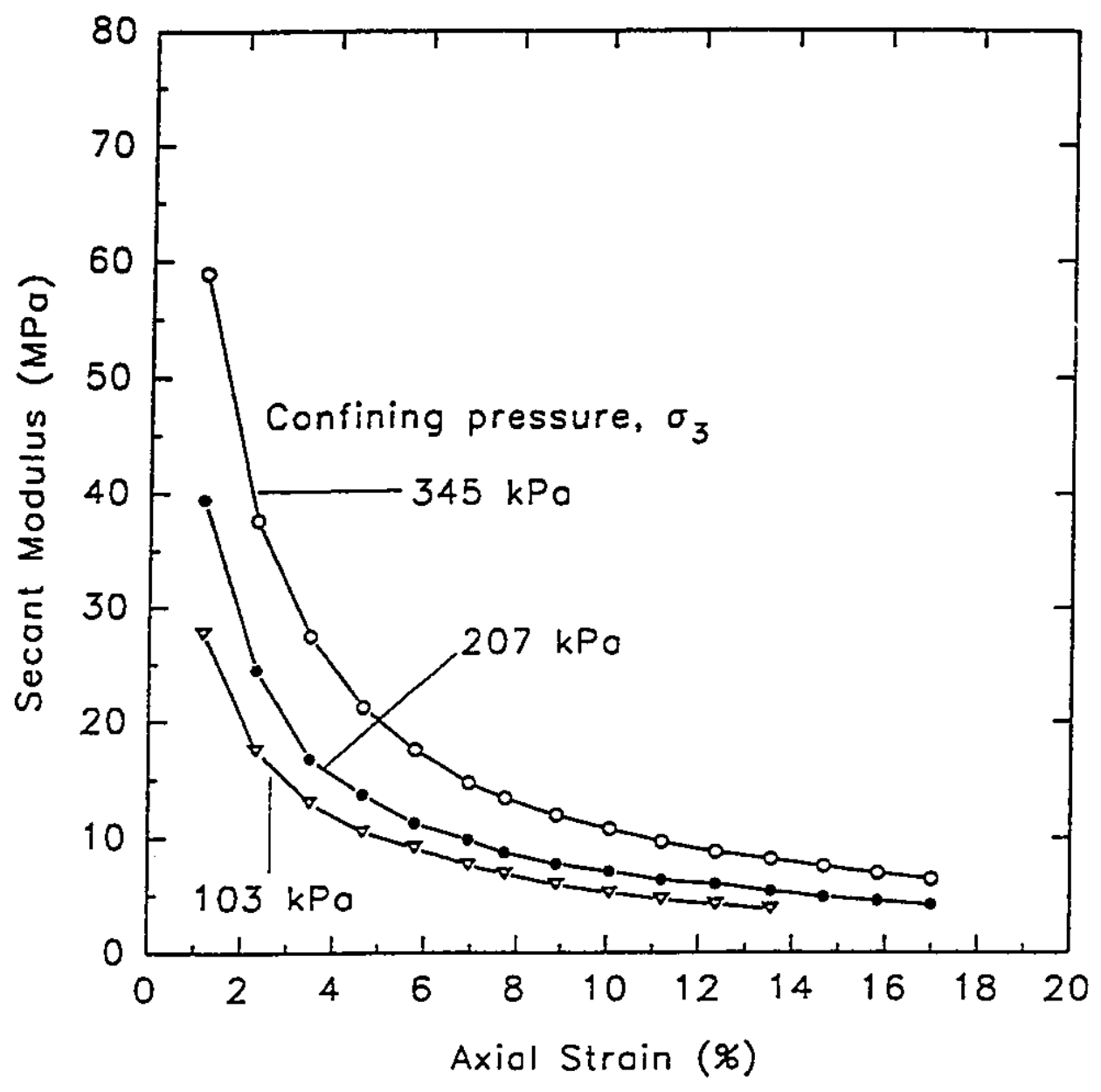

Figure 7.15 : Variation of secant modulus with axial strain at different confining pressures (3/8" aggregate) 


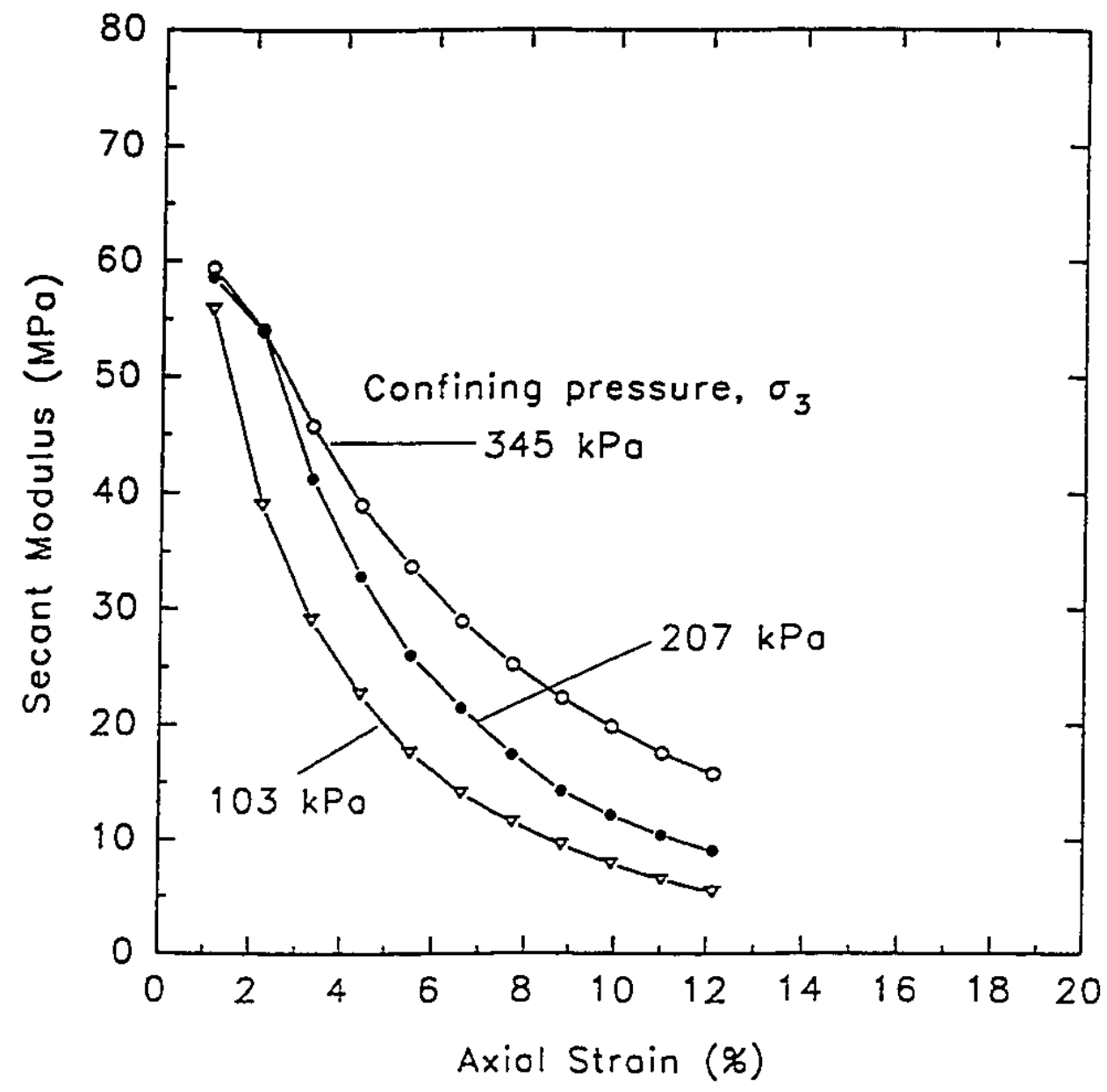

Figure 7.16 : Variation of secant modulus with axial strain at different confining pressures (granular "A") 


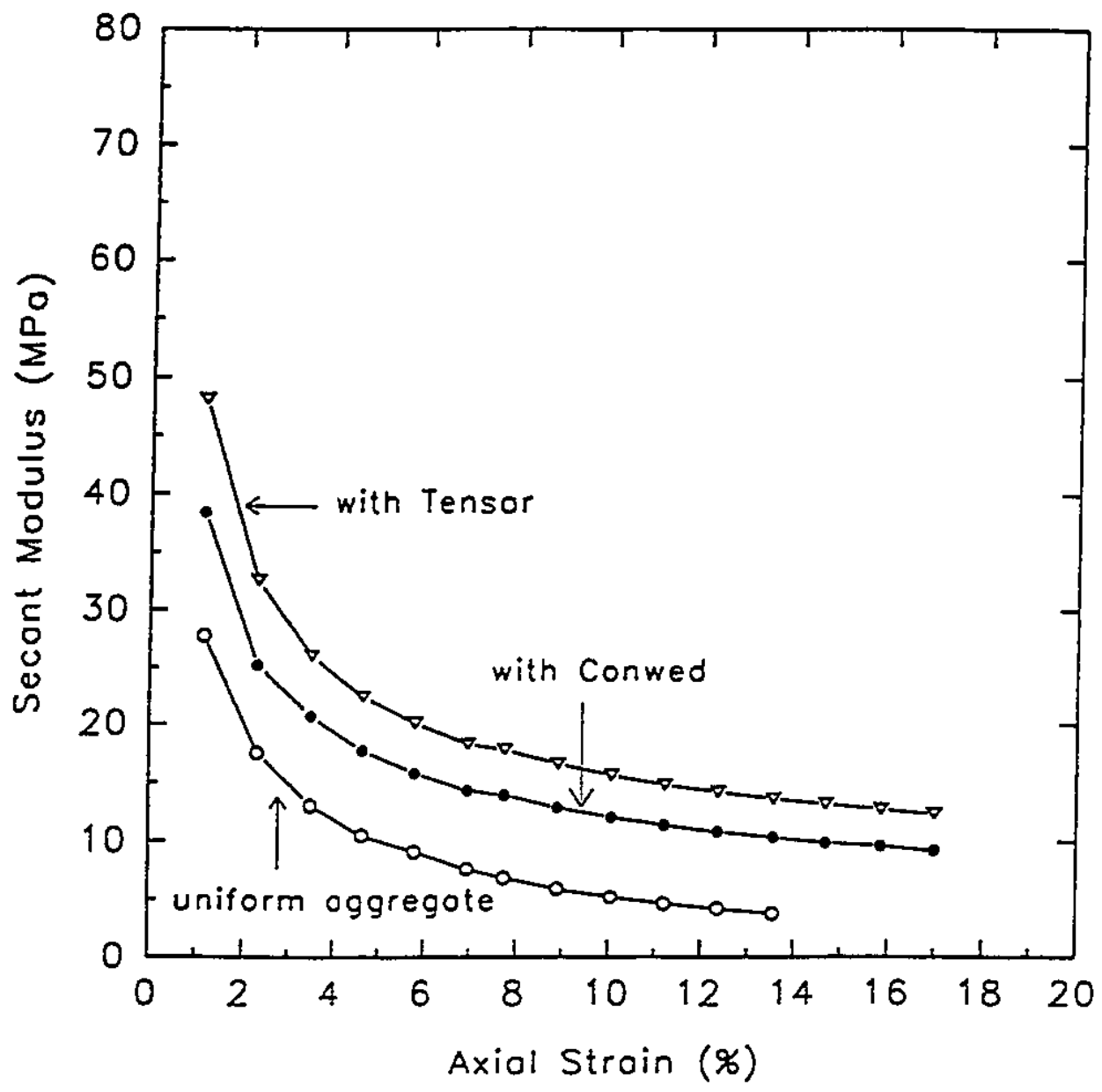

Figure 7.17 : Comparison of secant modulus for stone columns with $3 / 8$ " aggregate and reinforcing sleeves $\left(\sigma_{3}=103 \mathrm{kPa}\right)$ 


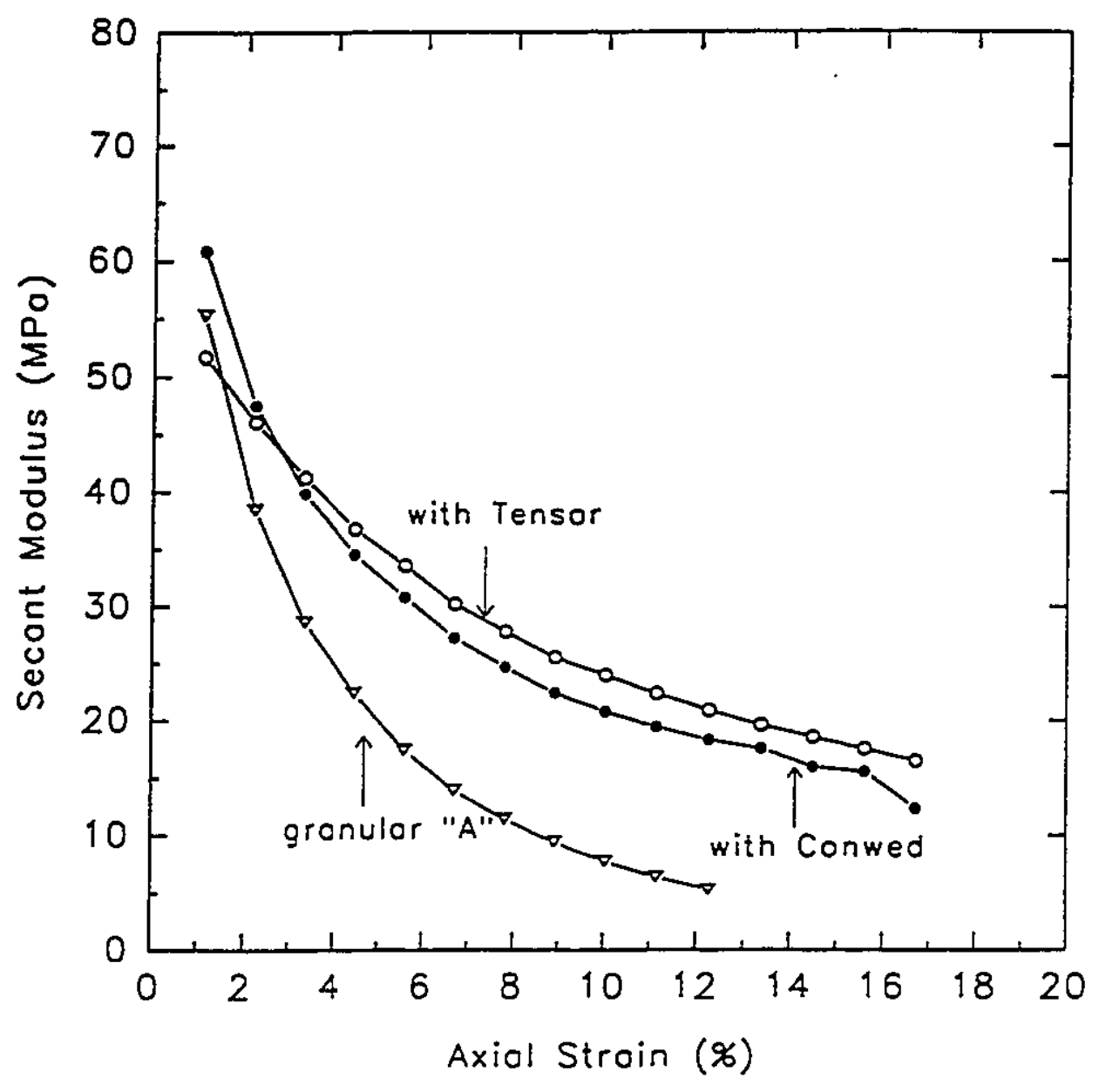

Figure 7.18 : Comparison of secant modulus for stone columns with granular " $A$ " aggregate and reinforcing sleeves $\left(\sigma_{3}=103 \mathrm{kPa}\right)$ 
strains higher than $17 \%$.

In both Figures (7.17 and 7.18) the secant modulus values were higher when Tensar UX-1500 sleeve was used. Therefore, the secant modulus is dependent on the type of polymer grid and, consequently, the additional confinement provided by the sleeve at each stress level. Similar relations like those shown in Figures 7.17 and 7.18 are presented in Appendix $\mathrm{C}$ for other confining pressures.

\subsubsection{Comparison of $\mathbf{K}_{\mathbf{0}}$-test results}

A $\mathrm{K}_{0}$ test is a special triaxial test conducted to investigate the behaviour of a specimen under zero lateral deformation. When a foundation reinforced by stone columns is uniformly loaded the group effect modifies the boundary conditions and requires a zero lateral strain at the limit of the tributary area of each column. This boundary condition can result in a large increase of the mobilized confining pressure.

The procedure for performing this test was presented in chapter four. The variation of minor principal stress with the major principal stress under no lateral strain for unreinforced and sleeve reinforced columns is shown in Figure 7.19. The $\mathrm{K}_{0}$ value of granular " $A$ " in this research was found to be 0.34 ; this value agrees well with the published value of 0.35 for a similar granular material (Scott et al, 1980).

The $K_{0}$ values for sleeve reinforced columns was found to be 0.26 and 0.20 for columns with Conwed and Tensar sleeves, respectively. This means that the minor principal stress required to maintain zero lateral strain for the reinforced specimen is less than that required for unreinforced columns. On the other hand the $K_{o}$ value seems to be dependent on the type of grid sleeve used.

The $K_{0}$ value of the columns with Tensar sleeve was less than for the columns with Conwed sleeves. It should be noted that Tensar sleeves were stiffer than the Conwed sleeves and this probable was the reason for the difference in $\mathrm{K}_{\mathrm{o}}$ values between the two tests. In other words, the extra confinement $\left(\Delta \sigma_{3}\right)$ provided by the Tensar sleeves was higher than that provided by the Conwed sleeves. Therefore, the applied minor principle stress $\left(\sigma_{3}\right)$ required to maintain zero lateral strain was less for the columns with Tensar sleeves. 


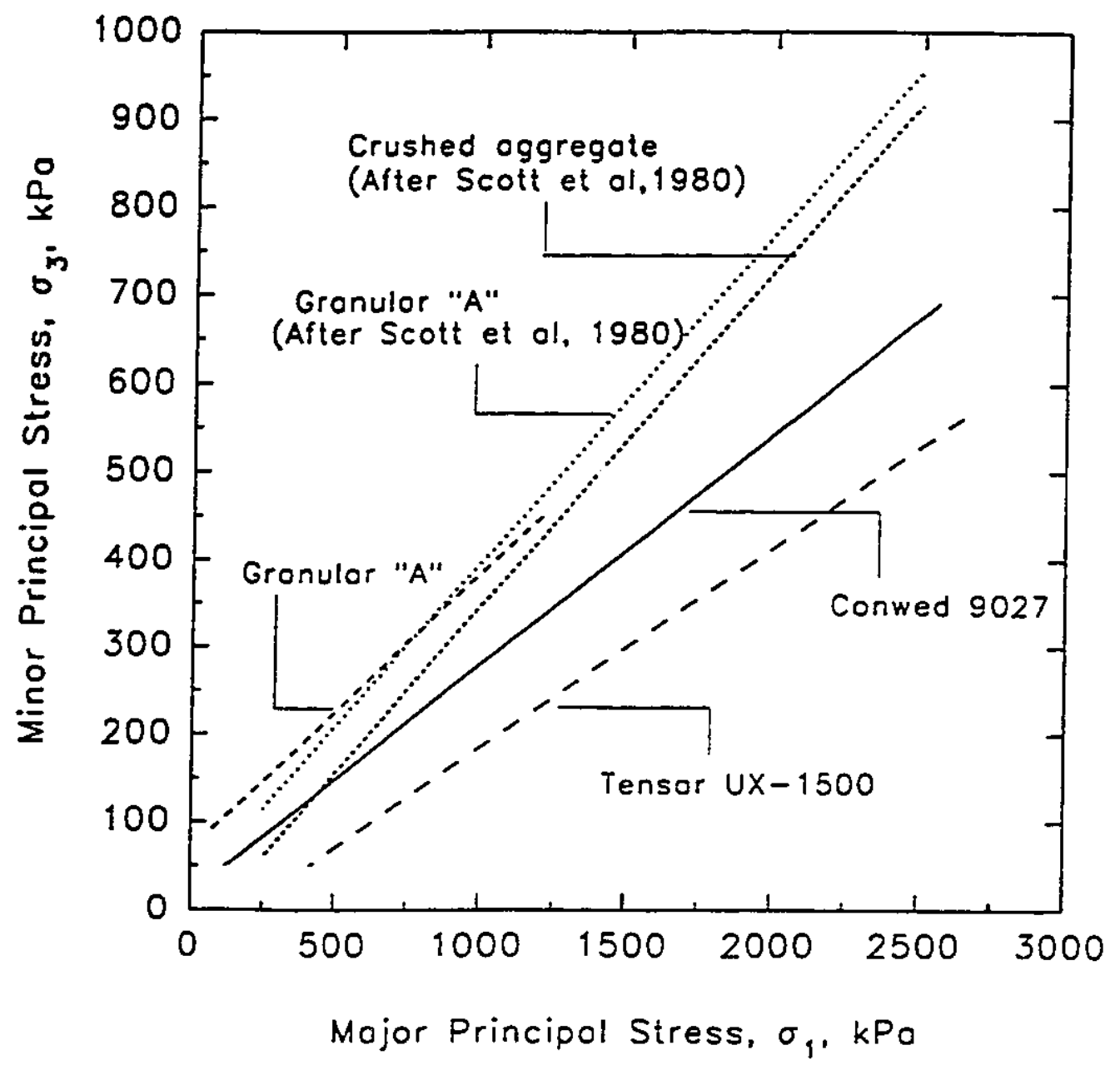

Figure 7.19 : Comparison of $\mathrm{K}_{0}$ test results for unreinforced and reinforced stone columns 


\subsubsection{Comparison of lateral deformation}

Lateral deformation in an unreinforced stone column is necessary up to a certain limit to mobilize the passive resistance of the surrounding soil. Beyond that and as the loading of the column continues, general failure will occur due to lack in confinement from the surrounding soil. For reinforced columns the grid sleeves provide additional confinement in order to restrain excessive lateral strain.

The lateral deformation in the triaxial tests was measured by means of deformation sensors attached to the specimen at one-quarter of the height, mid-height and three quarters of the height. Figures 7.20 to 7.23 compare the results of the average lateral strains on triaxial natural and reinforced specimens. Similar results are presented in Appendix $\mathrm{C}$ for other confining pressures. The lateral strain for unreinforced columns decrease with an increase of confining pressure. The lateral strain of reinforced columns is a function of both confining pressure and the stiffness of sleeve. The maximum lateral strain was obtained for Conwed sleeves and the minimum lateral strain occurred for the brittle fiber glass sleeves.

In general, the effectiveness of sleeves in reducing lateral strain was more pronounced at larger axial strains. A summary of the average lateral strains for unreinforced and sleeve reinforced columns at different confining pressures are shown in Tables (7.1) and (7.2). The lateral strains shown are for axial strains of $5 \%$ and $10 \%$ for both aggregates.

From table 7.1 it can be noticed that for the 3/8" aggregate at a confining pressure of $103 \mathrm{kPa}$, the Tensar sleeve reduced the lateral strains by $32 \%$ and $40 \%$ for axial strains of $5 \%$ and $10 \%$ respectively. At the same confining pressure the Conwed sleeve reduced the lateral strains by $32 \%$ and $34 \%$ for axial strains of $5 \%$ and $10 \%$ respectively. Fiber glass sleeves (GB\#10) reduced the lateral strain by $80 \%$ and $72 \%$ for the same axial strains respectively. From table 7.2 it can be seen that for granular " $\mathrm{A}$ " at a confining pressure of $103 \mathrm{kPa}$ the Tensar sleeves reduced the lateral strain by $53 \%$ and $38 \%$ at axial strains of $5 \%$ and $10 \%$ respectively.

At the same confining pressure Conwed sleeve has reduced the lateral strain by $31 \%$ and $24 \%$ at axial strain of $5 \%$ and $10 \%$ respectively. However, the difference 
Table 7.1: Comparison of lateral strain (\%) at different confining pressures and axial strains for columns with uniform 3/8" aggregate

\begin{tabular}{||l|l|l|l|}
\hline Column materials & $\sigma_{3}(\mathrm{kPa})$ & $\varepsilon_{\mathrm{a}}=5 \%$ & $\varepsilon_{\mathrm{a}}=10 \%$ \\
\hline aggregate (3/8") & 103 & 2.02 & 4.49 \\
& 207 & 1.88 & 3.66 \\
& 345 & 1.35 & 3.13 \\
\hline Tensar UX-1500 & 103 & 1.36 & 2.72 \\
& 207 & 1.08 & 2.31 \\
& 345 & 0.80 & 1.82 \\
\hline Conwed 9027 & 103 & 1.37 & 2.97 \\
& 207 & 1.21 & 3.08 \\
& 345 & 0.88 & 2.26 \\
\hline Fiber Glass (GB\#10) & 103 & 0.40 & 1.24 \\
& 207 & 0.28 & 0.90 \\
& 345 & 0.19 & 0.66 \\
\hline
\end{tabular}

Table 7.2: Comparison of lateral strains $(\%)$ at different confining pressures and axial strains for columns with granular " $A$ "

\begin{tabular}{||l|l|l|l||}
\hline \hline Column materials & $\sigma_{3}(\mathrm{kPa})$ & $\varepsilon_{\mathrm{a}}=5 \%$ & $\varepsilon_{\mathrm{a}}=10 \%$ \\
\hline granular "A" & 103 & 2.90 & 5.42 \\
& 207 & 2.43 & 5.73 \\
& 345 & 1.61 & 3.78 \\
\hline Tensar UX-1500 & 103 & 1.36 & 3.38 \\
& 207 & 1.26 & 3.22 \\
& 345 & 1.21 & 2.54 \\
\hline Conwed 9027 & 103 & 1.99 & 4.10 \\
& 207 & 1.29 & 3.45 \\
& 345 & 1.35 & 3.46 \\
\hline
\end{tabular}


between lateral strains of unreinforced and sleeve reinforced columns at the same confining pressure were higher at low axial strains. This behaviour may be attributed to the volume change behaviour of granular "A" at $5 \%$ and $10 \%$ axial strain.

At a higher confining pressure ( $345 \mathrm{kPa}$ ) the Tensar jacket caused a lateral strain reduction of $42 \%$ and $41 \%$ at axial strains of $5 \%$ and $10 \%$ respectively. In comparison Conwed sleeve reduced the lateral strains by $35 \%$ and $28 \%$ at axial strain of $5 \%$ and $10 \%$ respectively. At the same confining pressure ( $345 \mathrm{kPa}$ ) fiber glass (GB\#10) has reduced the lateral strain by $86 \%$ and $79 \%$ at axial strain of $5 \%$ and $10 \%$ respectively. Again, the reduction of lateral strain was higher at $5 \%$ axial strain because the fiber glass strands broke at early stage of axial strain beyond $5 \%$ and the column ,therefore, lost the confinement of the fiber glass sleeve.

From this observation it can be concluded that the geogrid sleeves caused lateral deformation reduction of the columns by $24 \%$ to $53 \%$ depending on the magnitude of confining pressure, stress level and the type of geogrid used to confine the granular material. However, the Fiber glass sleeves caused a reduction of $86 \%$ in lateral deformation.

\subsubsection{Hoop stress in polymer sleeve}

The hoop stresses mobilized in the circular ribs of the sleeve during loading of the column are a function of the following factors: 1) the stiffness of the polymer sleeve (i.e type of geogrid);2) type of aggregate used as column material and its volumetric strain behaviour; and 3) the stress level in the stone column. These factors have a significant effect on the amount of axial and lateral strains of the columns and consequently the tensile stresses mobilized in the sleeve.

The tensile stress in the circular ribs can be calculated based on the assumption that both the lateral deformation of the sleeve and the column material are the same (strain compatibility). This assumption is reasonable for stone columns with encapsulated grid sleeves. The hoop stress mobilized in the rib of a sleeve $\left(\sigma_{R}\right)$ can be calculated as follows 


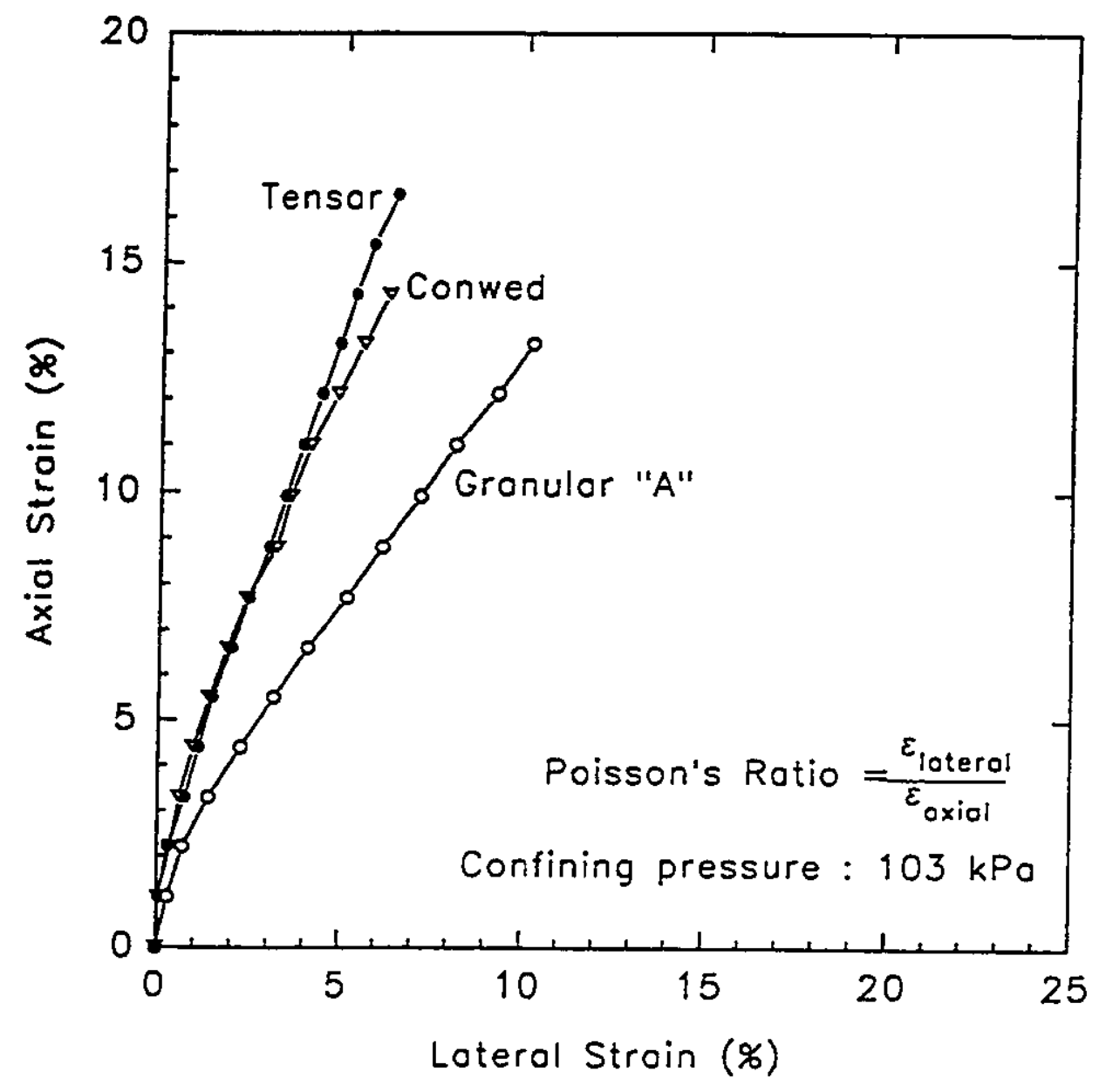

Figure 7.20: Variation of Poisson's ratio for granular "A" and reinforced specimens (lateral strain measured at mid-height) 


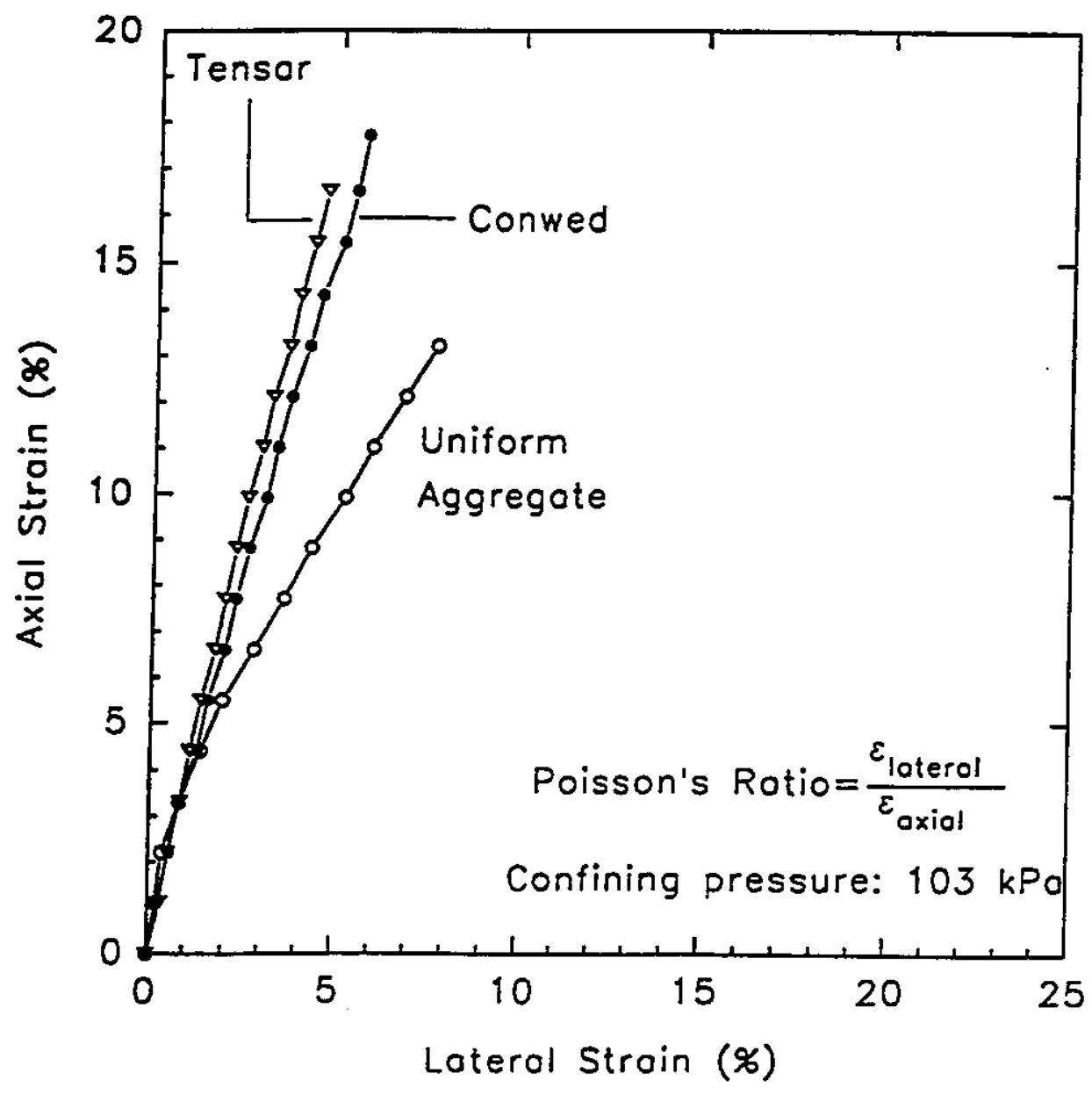

Figure 7.21: Variation of Poisson's ratio for uniform aggregate and reinforced specimens (lateral strain measured at mid-height) 


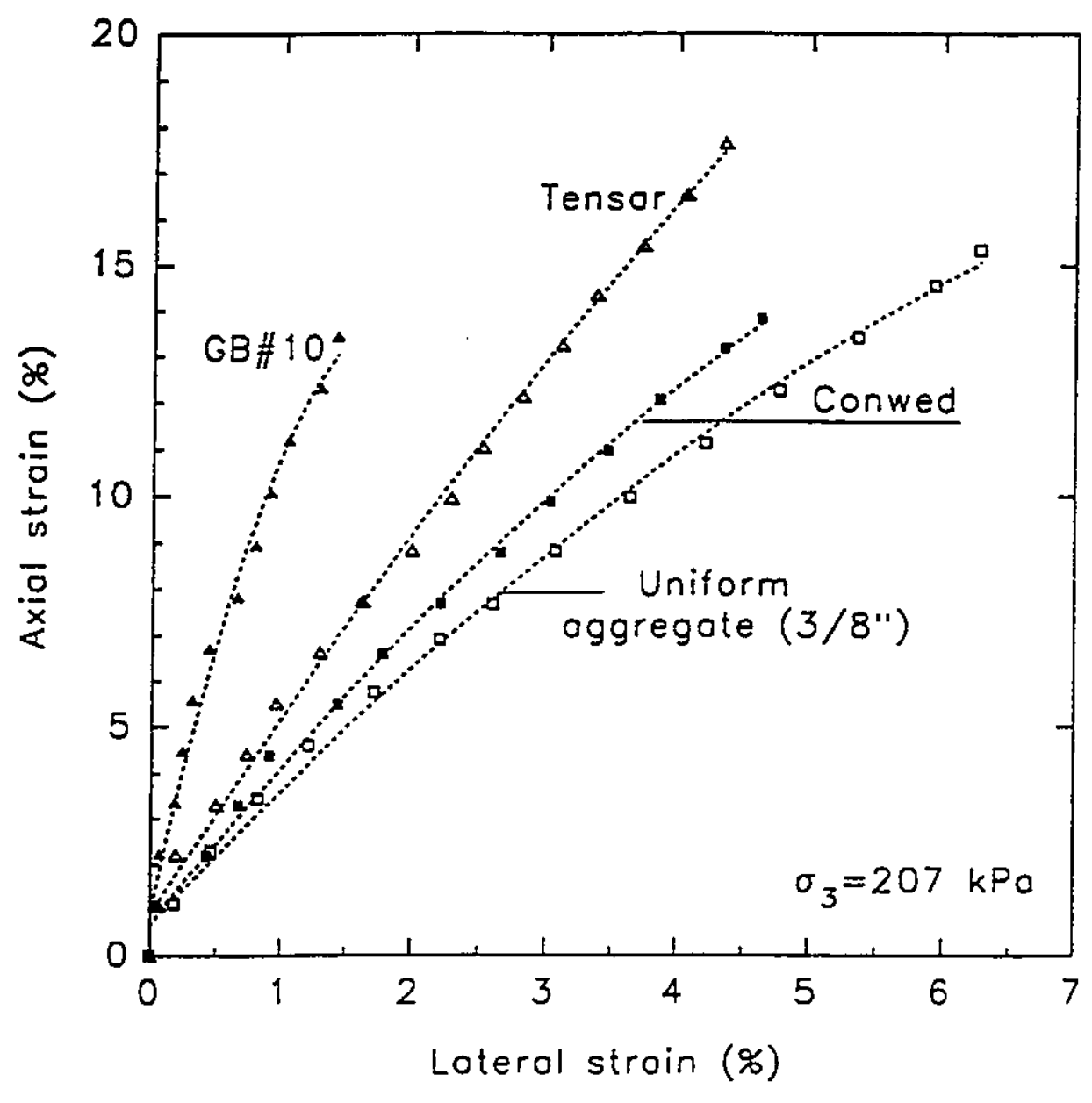

Figure 7.22 : Average lateral strain behaviour of natural and sleeve reinforced columns with uniform aggregate $\left(\sigma_{3}=207 \mathrm{kPa}\right)$ 


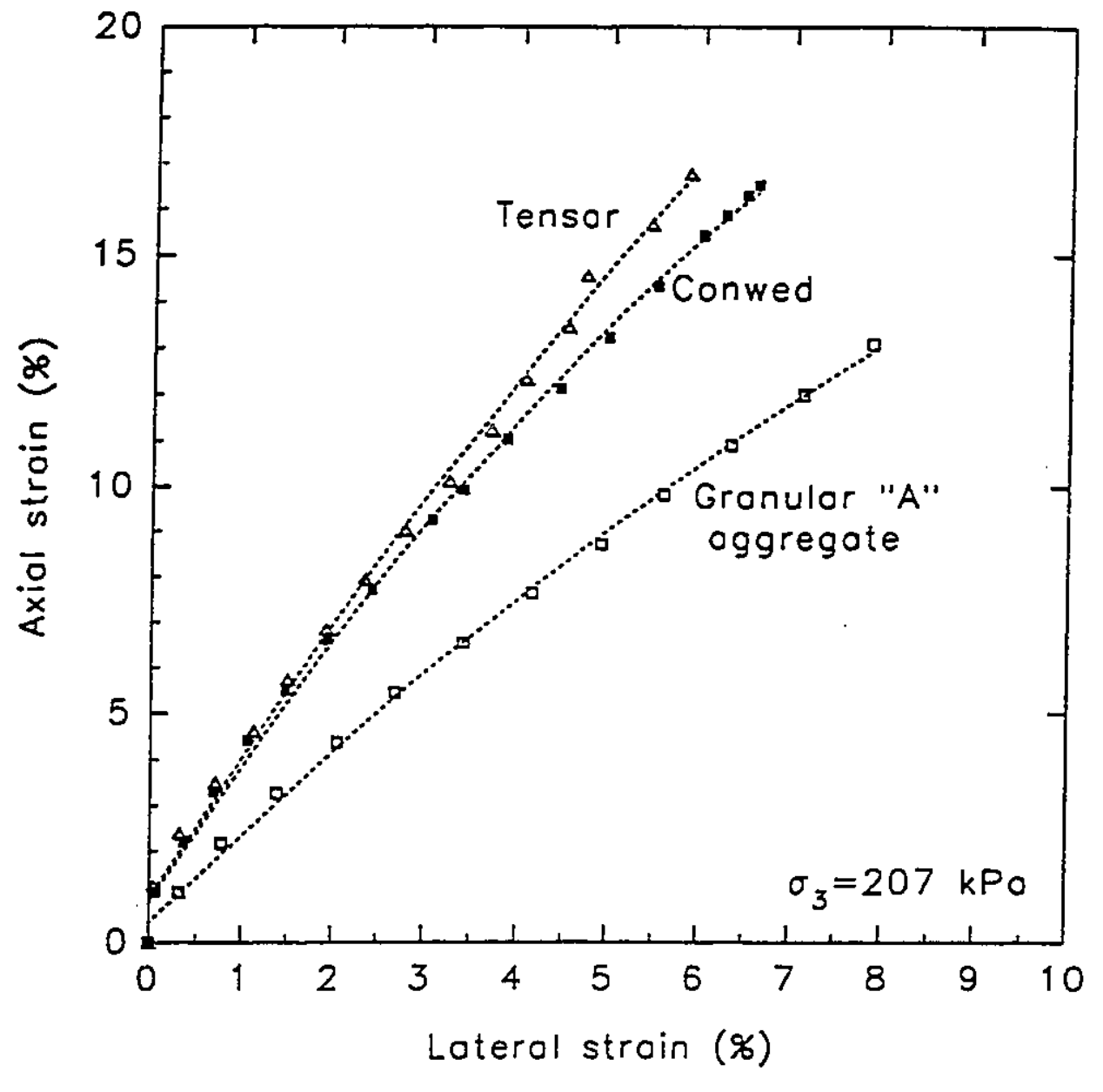

Figure 7.23 : Average lateral strain behaviour of natural and sleeve reinforced columns with granular "A" $\left(\sigma_{3}=207 \mathrm{kPa}\right)$ 


$$
\sigma_{R}=\left(E_{R}\right)\left(\epsilon_{R}\right)
$$

where, $E_{R}$ is the modulus of deformation of the grid and $\varepsilon_{R}$ is the tensile strain in a horizontal geogrid rib. The strains shown in Figures 7.20 to 7.23 can be utilized to calculate the tensile stress mobilized in the ribs at any axial compressive strain of the stone column. Figures 7.24 and 7.25 show the mobilized hoop stresses in the ribs at a confining pressure of $103 \mathrm{kPa}$ for both granular aggregates. The mobilized tensile stresses varied between $15 \%$ and $35 \%$ of the tensile strength of the grid.

It should be noted that the results shown in Figures 7.24 and 7.25 are based on the lateral strains measured at mid-height of the columns (Figures 7.20 and 7.21). Similar analyses can be performed for other confining pressures using the lateral strains relationships and equation [7.3].

The variation of maximum tensile force with confining pressure is shown in Figure 7.26 for three types of sleeves. The tensile forces were determined for lateral strains corresponding to the maximum axial compressive strain of the columns shown in Figures 7.20 to 7.23 and other similar figures in Appendix C. It can be seen from Figure 7.26 that the tensile force decreases slightly with increasing confining pressure for Conwed and GB\#10 grids and remains almost constant for Tensar UX-1500. Leshchinsky and Field, (1987) reported that the tensile stresses obtained for pull-out and direct shear tests on geotextiles increased with normal stress (i.e confining stress). The different behaviour of tensile stresses with confining pressures in triaxial and direct shear tests are explained in the following section.

In a stone column the loads are usually applied concentrically at the top surface and as a result the column deforms vertically and laterally. Therefore, a high confining stress will cause lower tensile stresses to mobilize in the grid sleeves. On the other hand, a low confining pressure will mobilize higher tensile stresses in the sleeve.

In direct shear and pull-out tests the grid is sandwiched between two soil layers and the pull-out force is applied in the direction of the reinforcement. Therefore, pull-out of the grid and consequently the mobilized stresses will be higher for high normal stress and long embedment of the grid mesh (Figure 7.27). 


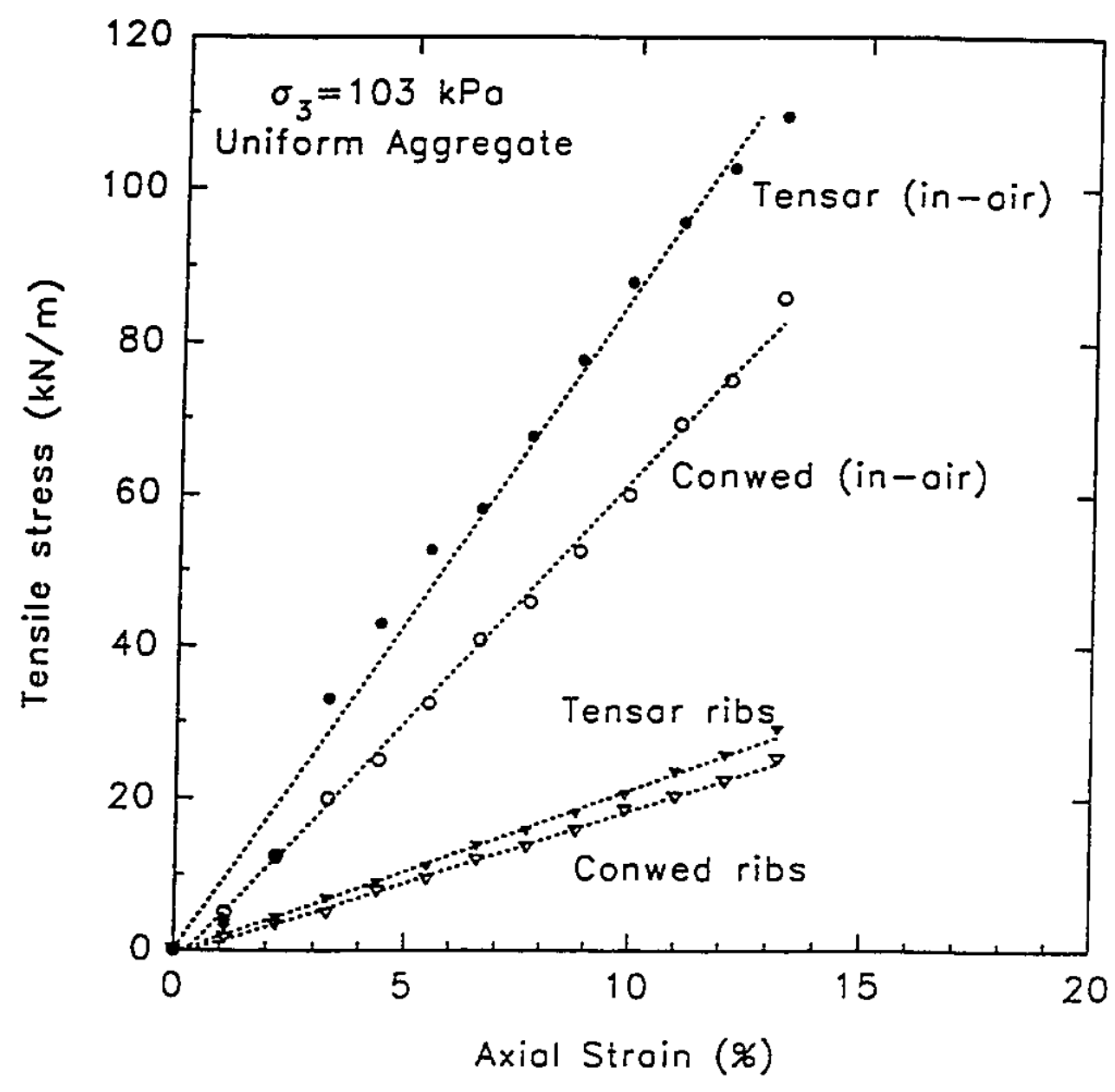

Figure 7.24 : Tensile forces in grid ribs of a reinforced stone column compared to in-air tension tests 


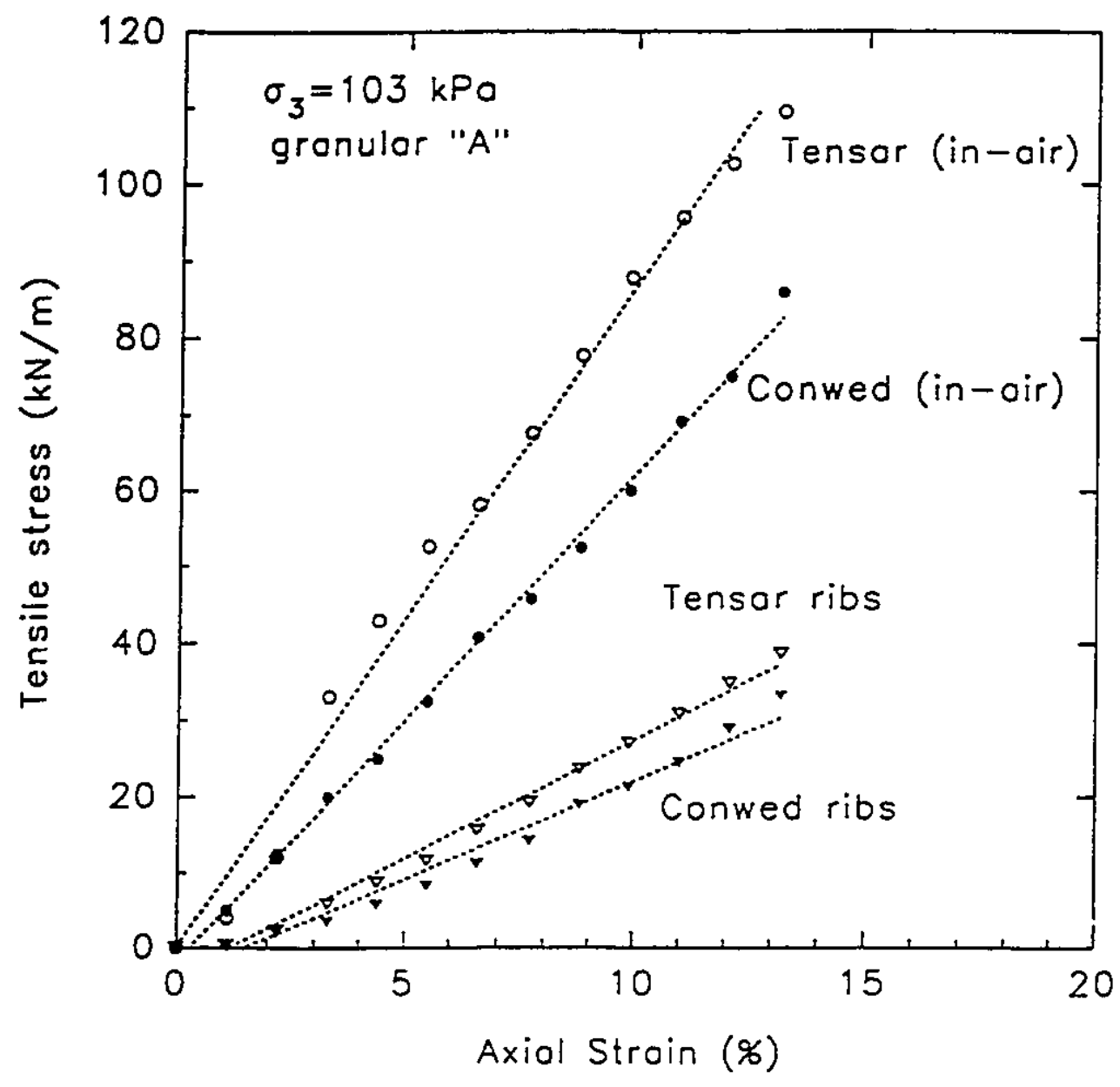

Figure 7.25 : Tensile forces in grid ribs of a reinforced stone column compared to in-air tension tests 


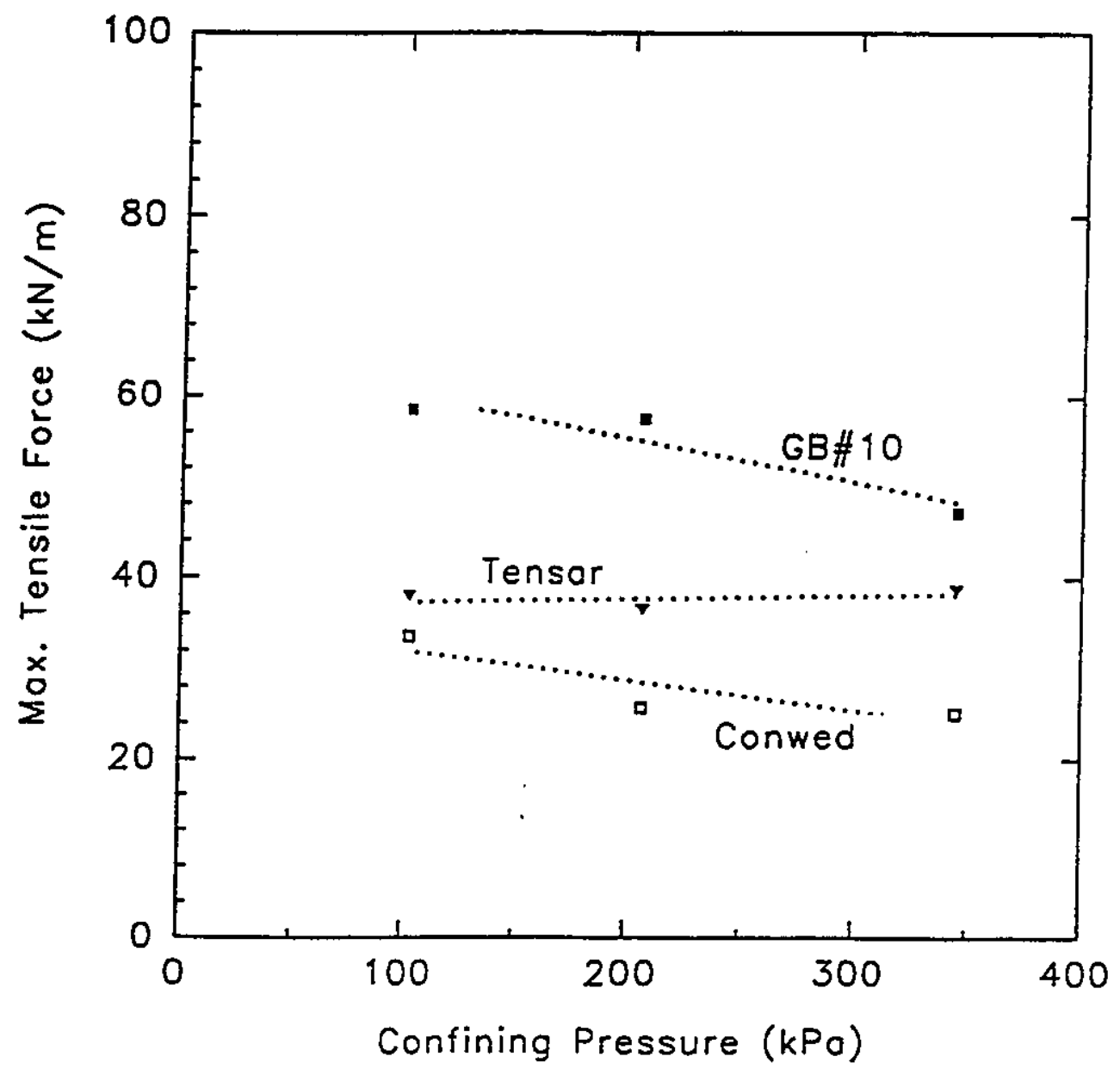

Figure 7.26 : Variation of maximum tensile forces with confining pressure for different sleeves 


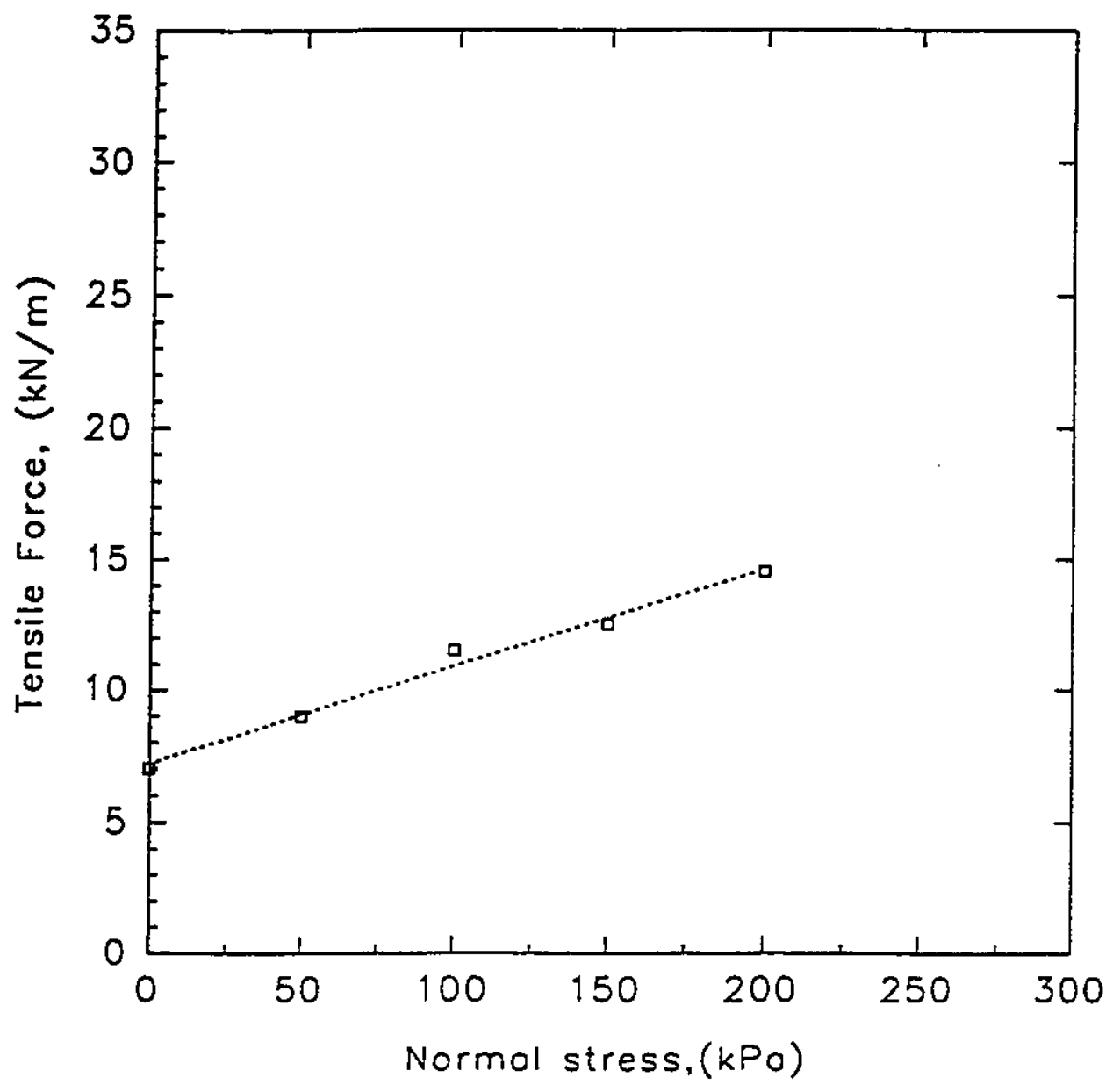

Figure 7.27 : Tensile strength vs. confining pressure

(Data from Leshchinsky and Feild, 1987) 


\subsection{UNIAXIAL STONE COLUMN TESTS}

\subsubsection{Comparison of stress-strain relations}

The stress-strain curves of uniaxial sleeve reinforced columns were presented earlier in chapier 5. In this section the comparison of the stress-strain behaviour of different column sizes will be presented and discussed. Figure 7.28 shows the stress-strain curves of short stone columns (diameter $=0.33 \mathrm{~m}$, height $=0.68 \mathrm{~m}$ ) with granular " $\mathrm{A}$ " and $3 / 8$ " aggregate respectively. This comparison is aimed to show the difference in behaviour of both aggregates under uniaxial loading. The maximum vertical stress of a column with granular "A" aggregate was $2000 \mathrm{kPa}$ at an axial strain of $17.5 \%$. The maximum vertical stress of a specimen with $3 / 8 "$ aggregate was $1800 \mathrm{kPa}$ at an axial strain of $17.5 \%$.

Similar results are shown in Figure 7.29 for long uniaxial columns (diameter $=0.38 \mathrm{~m}$, height $=1.32 \mathrm{~m}$ ) for both granular aggregates. The maximum vertical stresses were 1600 and $1280 \mathrm{kPa}$ for columns with granular " $\mathrm{A}$ " and 3/8" aggregate respectively. It should be noted that the column tests were terminated at a maximum axial strain of $17.5 \%$ and $12.2 \%$ for the short and long columns respectively. These axial strains represent a $120 \mathrm{~mm}$ and $160 \mathrm{~mm}$ axial displacement of the short and long columns respectively. At these axial displacements no sign of failure was observed such as rupture of the sleeve or general failure of the column. Therefore, the tests were terminated at these strains because no information could be obtained from further loading. However, only two stone columns were loaded rapidly and allowed to fail with rupture of the sleeves as will be discussed later in this section.

Comparing the behaviour of short and long uniaxial columns (Figures 7.28 and 7.29 ) at the maximum axial strain (12.2\%) of the short columns, revealed that the shorter samples carried a $12.5 \%$ higher vertical stress than the long columns for both types of aggregate. On the other hand, the initial tangent moduli and the secant moduli at this axial strain were slightly higher for the long uniaxial columns. 


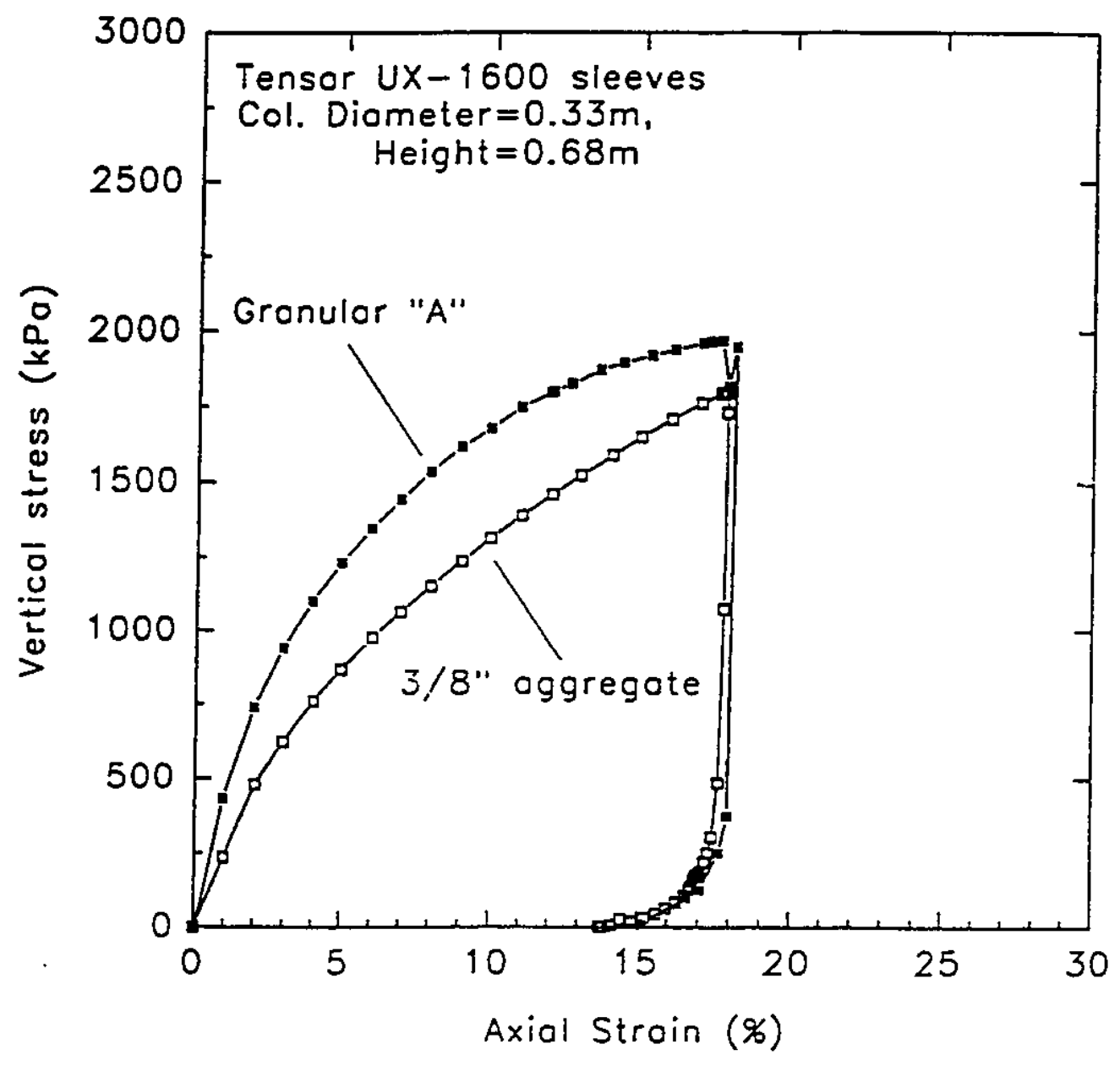

Figure 7.28 : Comparison of the stress-strain behaviour of short uniaxial columns with different types of aggregate 


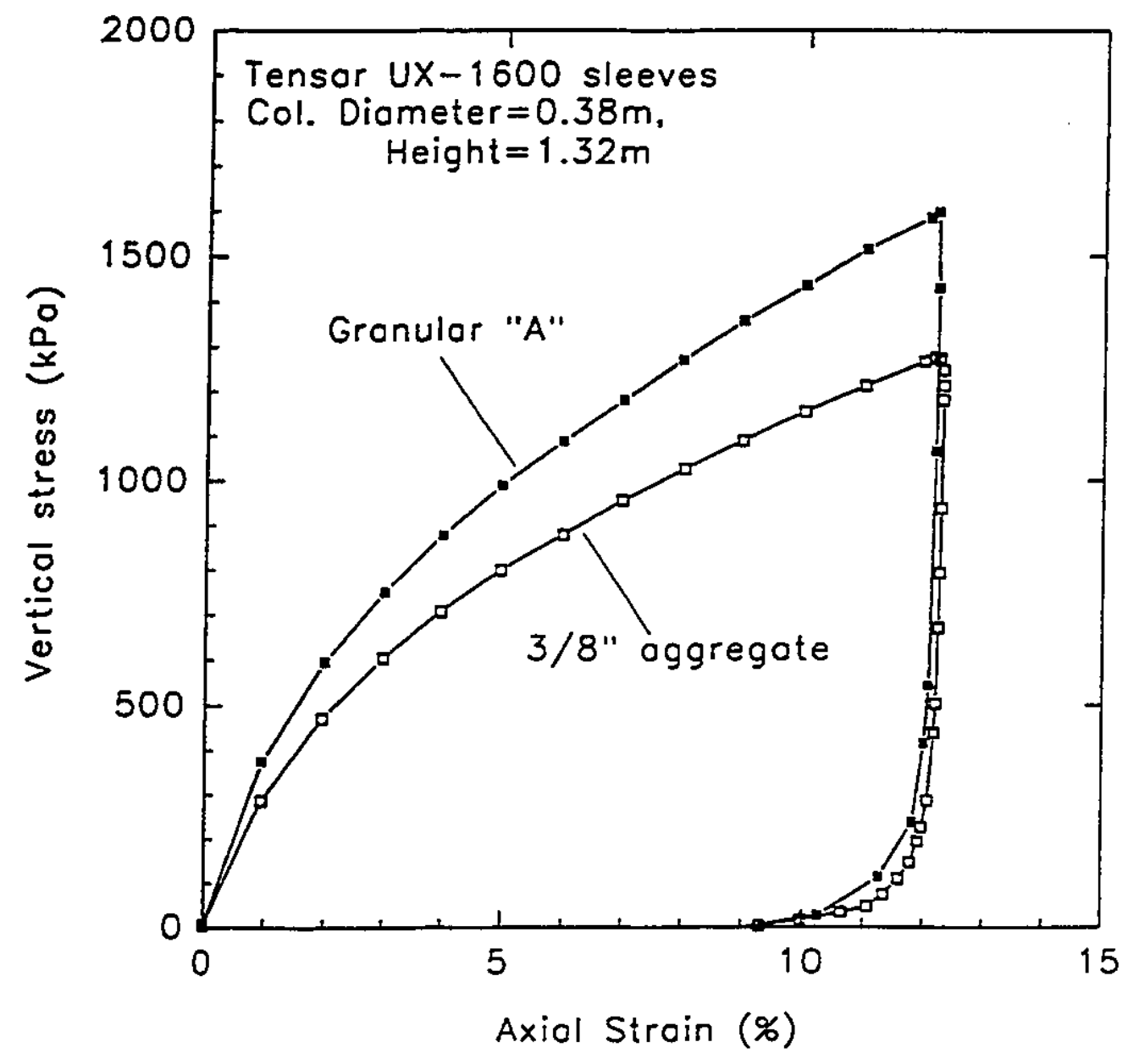

Figure 7.29 : Comparison of the stress-strain behaviour of long uniaxial columns with different types of aggregate 
A comparison of the lateral strains for the columns in Figures 7.28 and 7.29 is presented in Figures 7.30 and 7.31. These lateral strains are the average values recorded (by LVDT's) at nine locations; a set of three LVDT's were spaced at $120^{\circ}$ around the diameter of the column at three height levels $(0.25 \mathrm{H}, 0.5 \mathrm{H}$ and $0.75 \mathrm{H})$. The lateral strain behaviour can be approximated by straight lines for the short and long stone columns indicating a constant Poisson's ratio (Table 7.3). Comparing lateral strains for the short and long columns at $10 \%$ axial strain revealed that the short columns with granular " $\mathrm{A}$ " yielded a $0.5 \%$ higher lateral strain than the long columns. For uniform aggregate $(3 / 8 ")$, the short and long columns exhibited the same lateral strains at $10 \%$ axial strain.

A summary of results for the short and long columns (Figures 7.28 to 7.31 ) is given in Table 7.3.

Table 7.3: Summary of results for short and long uniaxial columns

\begin{tabular}{|c|c|c|c|c|c|c|c|c|}
\hline $\begin{array}{l}\text { Column Size } \\
\text { (D)(H) }\end{array}$ & $\begin{array}{c}\text { Max. } \\
\text { Stress } \\
\mathrm{kPa} \\
\end{array}$ & $\begin{array}{c}\text { Max. axial } \\
\text { Strain, } \varepsilon \\
\%\end{array}$ & $\begin{array}{c}\mathrm{E}_{\mathrm{i}} \\
\mathrm{kPa}\end{array}$ & $\begin{array}{l}\mathrm{E}_{\mathrm{xax}} \cdot \\
\mathrm{kPa}\end{array}$ & $\begin{array}{c}\text { Lat. } \\
\text { Strain at } \\
\varepsilon_{\max } \%\end{array}$ & $\begin{array}{c}\text { Lat. } \\
\text { Strain at } \\
\varepsilon_{\mathrm{a}}=10 \%\end{array}$ & $\begin{array}{c}\text { Poisson's } \\
\text { Ratio }\end{array}$ & $\begin{array}{l}\text { Mode of } \\
\text { deformation }\end{array}$ \\
\hline $\begin{array}{c}\text { Granular "A" } \\
0.33 \mathrm{~m} \times 0.68 \mathrm{~m}\end{array}$ & 2000 & 17.5 & 46154 & 11371 & 7.8 & 5 & 0.45 & $\begin{array}{l}\text { uniform } \\
\text { bulging }\end{array}$ \\
\hline $\begin{array}{l}3 / 8^{\prime \prime} \text { aggregate } \\
0.33 \mathrm{~m} \times 0.68 \mathrm{~m} \\
\end{array}$ & 1800 & 17.5 & 23077 & 10286 & 6.8 & 3.7 & 0.39 & $\begin{array}{l}\text { uniform } \\
\text { bulging }\end{array}$ \\
\hline $\begin{array}{c}\text { Granular "A" } \\
0.38 \mathrm{~m} \times 1.32 \mathrm{~m} \\
\end{array}$ & 1600 & 12.2 & 47619 & 13115 & 5.5 & 4.5 & 0.45 & $\begin{array}{l}\text { uniform } \\
\text { bulging }\end{array}$ \\
\hline $\begin{array}{l}3 / 8^{\prime \prime} \text { aggregate } \\
0.38 \mathrm{~m} \times 1.32 \mathrm{~m}\end{array}$ & 1280 & 12.2 & 27397 & 10492 & 4.5 & 3.7 & 0.37 & $\begin{array}{l}\text { uniform } \\
\text { bulging }\end{array}$ \\
\hline
\end{tabular}

* $\mathrm{D}=$ diameter of the column; $\mathrm{H}=$ height of the column

** Secant modulus at maximum axial strain for each column

In summary, comparison of the short and long uniaxial columns showed that the short columns exhibit higher strength and slightly more lateral deformation than the long columns. This behaviour may be attributed to the length/diameter ratio which will affect the column's capacity. Also, density of a specimen has a significant effect on the behaviour. 


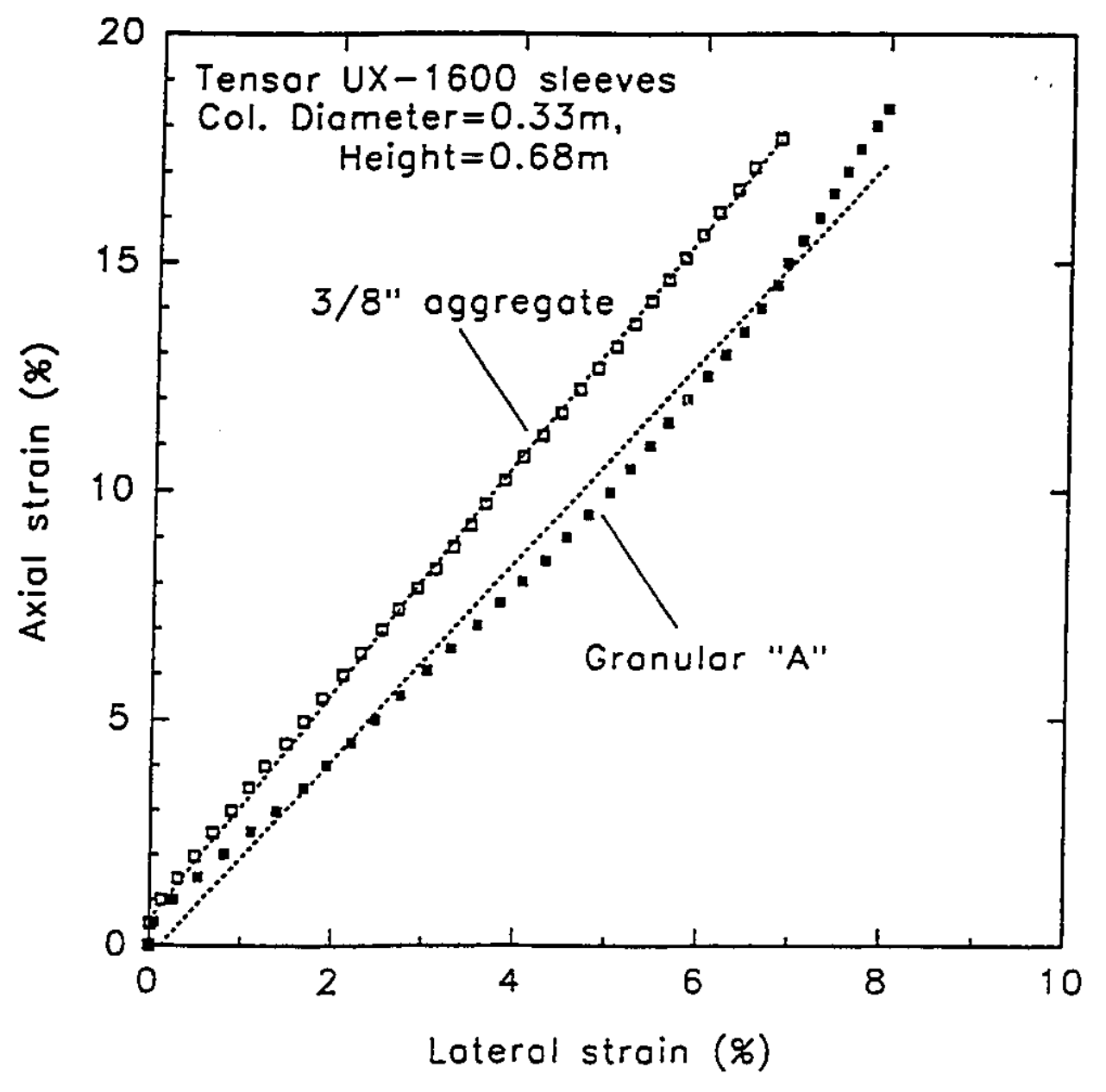

Figure 7.30 : Comparison of strain behaviour of short uniaxial columns with different types of aggregate (data points and linear approximation) 


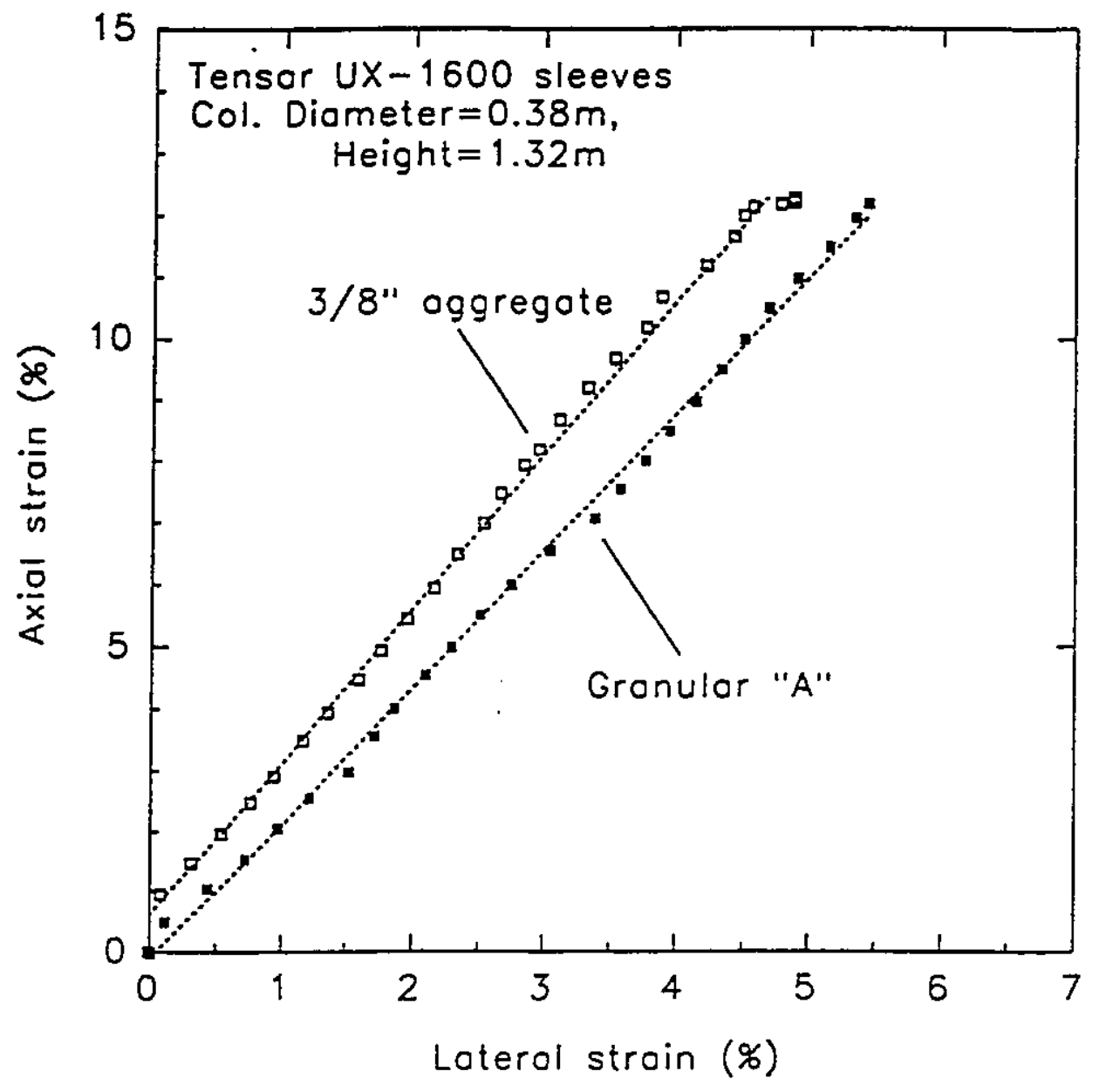

Figure 7.31 : Comparison of strain behaviour of long uniaxial columns with different types of aggregate (data points and linear approximation) 
A comparison of two cyclic load tests is given in Figure 7.32 for columns with granular "A" and 3/8" aggregate. As explained earlier in chapter 5 the cyclic loading behaviour was investigated because stone columns have been used in high seismic areas. In an earthquake, the stone columns will be subjected to rapid loading rate. Also, the stone columns are used in some application such as supports for oil tanks and bridge abutments where cyclic loading is imposed on the columns by the superstructure.

The initial tangent moduli of rapidly loaded columns are 25.4 MPa and 21.4 MPa for the columns with granular " $\mathrm{A}$ " and 3/8" uniform aggregate respectively. The unloading tangent moduli are quit high for both aggregate types. The unloading path is the same for both columns at $16 \%$ axial strain for the first cycle. Recovery of the strain in the columns started at a very low stress level $(200 \mathrm{kPa})$. Approximately six percent of the axial strain was recovered at zero vertical stress in a period of 10 minutes before the second loading cycle started.

During the second loading cycle the stress-strain behaviour was almost the same for both column between axial strain of $10 \%$ to $15 \%$ (i.e, the reloading modulus was same). Beyond $15 \%$ axial strain the two curves started to diverge from each other giving the column with granular " $\mathrm{A}$ " higher stress and secant modulus than the column with $3 / 8$ " aggregate. The reloading moduli were $46.7 \mathrm{MPa}$ and $43.8 \mathrm{MPa}$ for columns with granular " $\mathrm{A}$ " and uniform aggregate respectively. These moduli are 1.8 and 2.0 times higher than the initial tangent moduli of the columns with both aggregates.

Rupture of the grid sleeve occurred at axial strain of $24 \%$ in the column with 3/8" aggregate. The corresponding stress at rupture of the sleeve was $2750 \mathrm{kPa}$. Other results for columns tested at slow strain $(0.5 \mathrm{~mm} / \mathrm{min})$ are presented in chapter 5 .

\subsubsection{Comparison of vertical displacement}

The vertical displacement or shortening of the uniaxial reinforced columns were recorded at the top and at three heights $(0.25 \mathrm{H}, 0.5 \mathrm{H}$ and $0.75 \mathrm{H})$ as shown in Figures 7.33 and 7.34. These figures present the normalized load versus normalized vertical displacement for the uniaxial sleeve reinforced columns for the well graded aggregate and uniform aggregate, respectively. The columns were reinforced with Tensar UX-1600 
sleeves and had a height of $1.32 \mathrm{~m}$ and a diameter of $0.38 \mathrm{~m}$.

The maximum loads applied to the stone column with granular " $\mathrm{A}$ " and uniform aggregate were $200 \mathrm{kN}$ and $158 \mathrm{kN}$, respectively. The maximum vertical displacement which correspond to the maximum load was recorded at $1.0 \mathrm{H}$ and the minimum vertical displacement was recorded at $0.25 \mathrm{H}$.

Comparing the stone columns' compression at the same load level revealed that the column with granular "A" experienced less compression than the column with $3 / 8$ " aggregate. As an example, at $135 \mathrm{kN}$, the compression of the column with granular " $\mathrm{A}$ " was less by $32 \%, 26 \%$ anc $42 \%$ at $0.25,0.5$ and 0.75 of the height respectively.

Using the daia presented in figures 7.33 and 7.34 it was possible to calculate the average vertical strain distribution at the middle of each layer during loading of the column (Figures 7.35 and 7.36). The vertical strain distribution seemed to be uniform at the middle of the top three layers of the column with granular "A" aggregate (Figure 7.35). The vertical strain at the middle of the bottom layer ( 0 to $0.25 \mathrm{H})$ was less than the other three layers. The difference in vertical strain between the bottom layer and the top three layers may be attributed to over compaction (over consolidation) of the bottom layer.

Similar behaviour was observed in the column with uniform aggregate (Figure 7.36). The strain distribution in the top three layers was approximately uniform and the bottom layer $(0$ to $0.25 \mathrm{H})$ experienced less vertical strain. The results presented in Figures 7.33 to 7.36 can be used to predict the vertical settlement of a column for a specific capacity.

\subsubsection{Comparison of hoop stresses}

The procedure to calculate hoop (tensile) stresses in the grid sleeves of a triaxial column was shown earlier in section 7.2.8. The same procedure was applied to the uniaxial specimens where lateral strain in the column material and sleeve was assumed to be the same. Using the lateral strains presented in figures 7.30 and 7.31 and equation [7.3], the tensile stress in the grid sleeves of uniaxial columns can be calculated. For the sake of completeness, the tensile stress in the uniaxial and triaxial columns are compared 


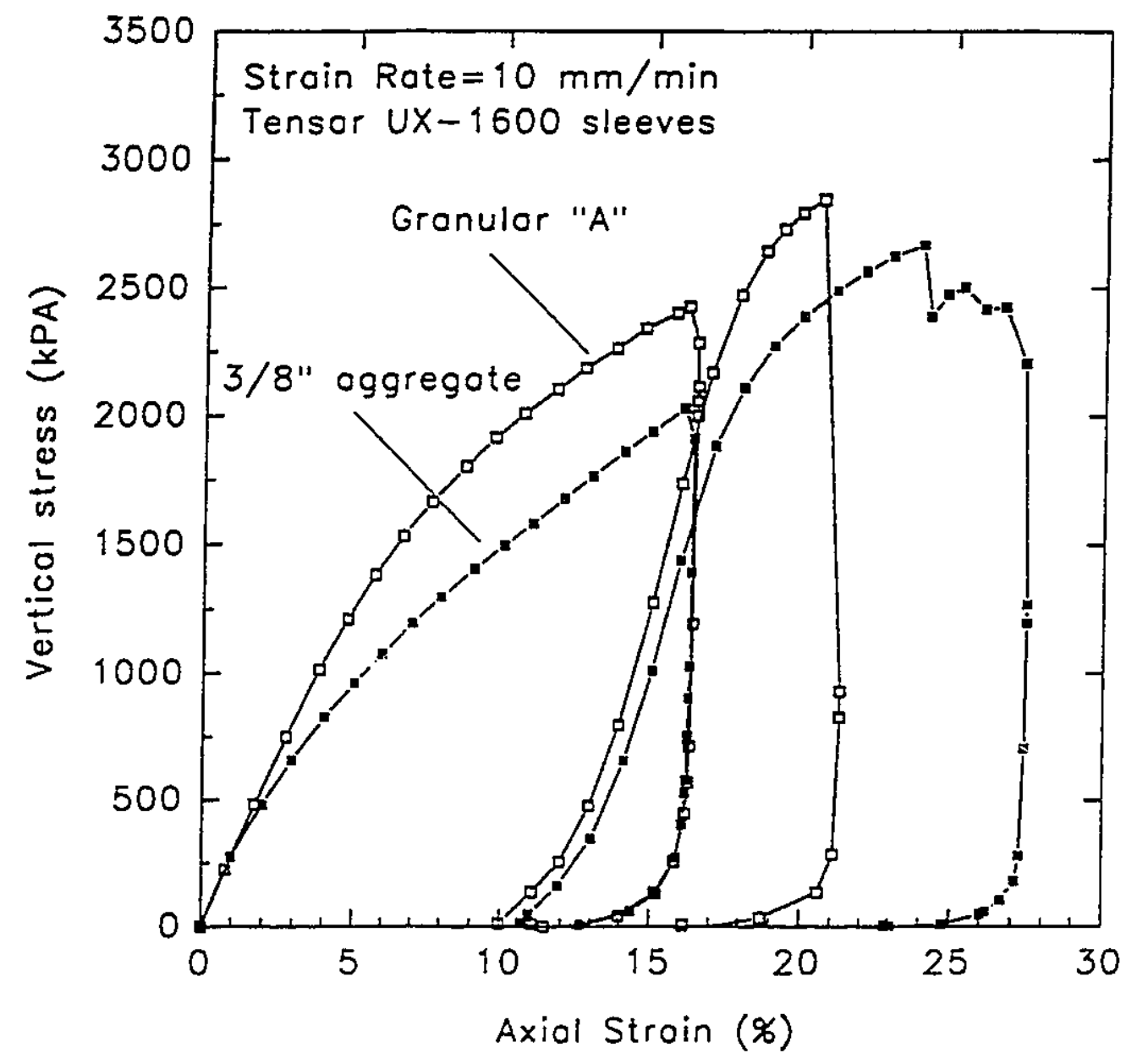

Figure 7.32 : Comparison of cyclic stress-strain behaviour of uniaxial columns (Diameter $=0.33 \mathrm{~m}$, Height $=0.68 \mathrm{~m}$ ) 


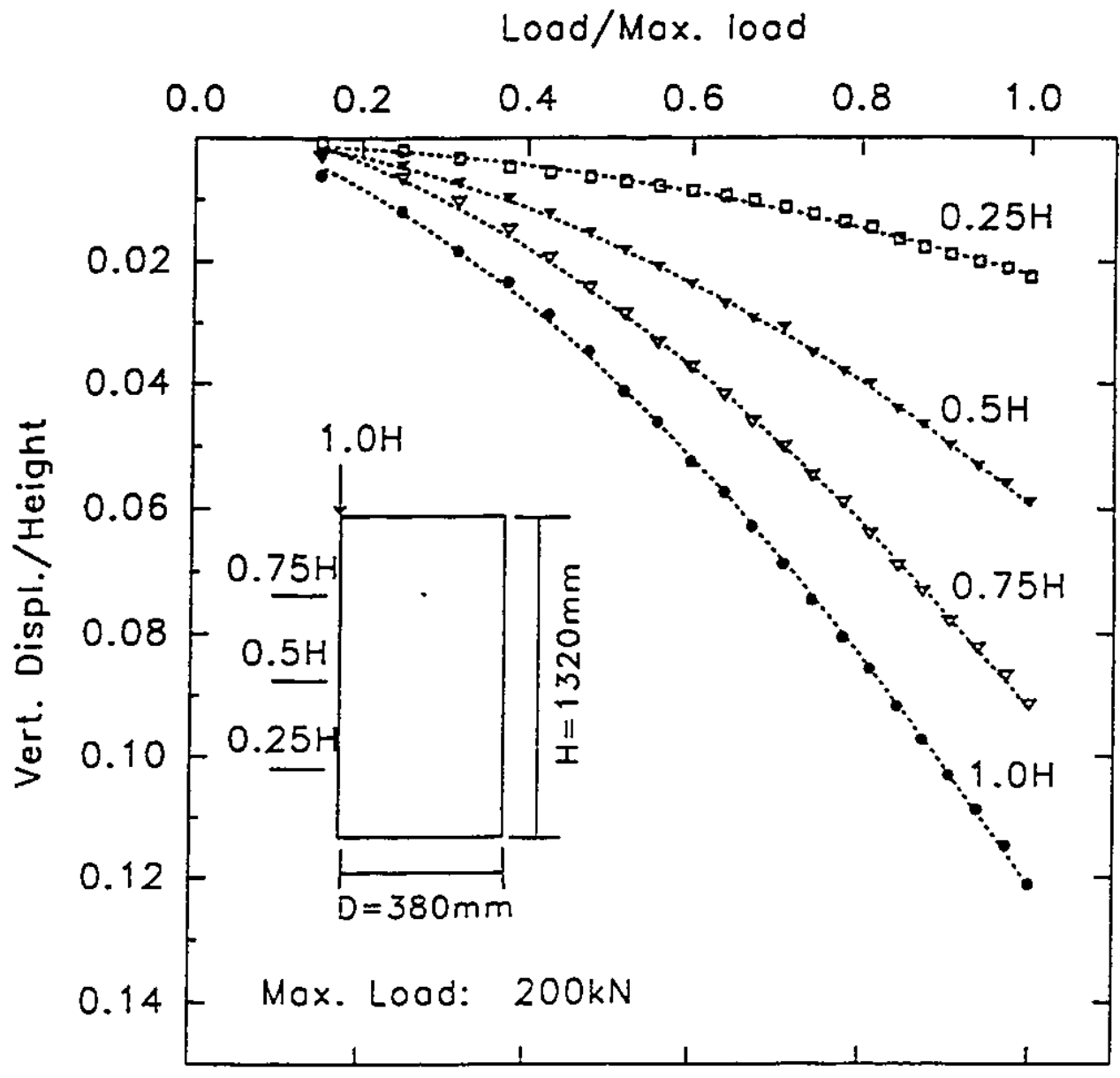

Figure 7.33 : Comparison of vertical displacement for a uniaxial column at different heights (granular " $\mathrm{A}$ " + Tensar sleeve) 


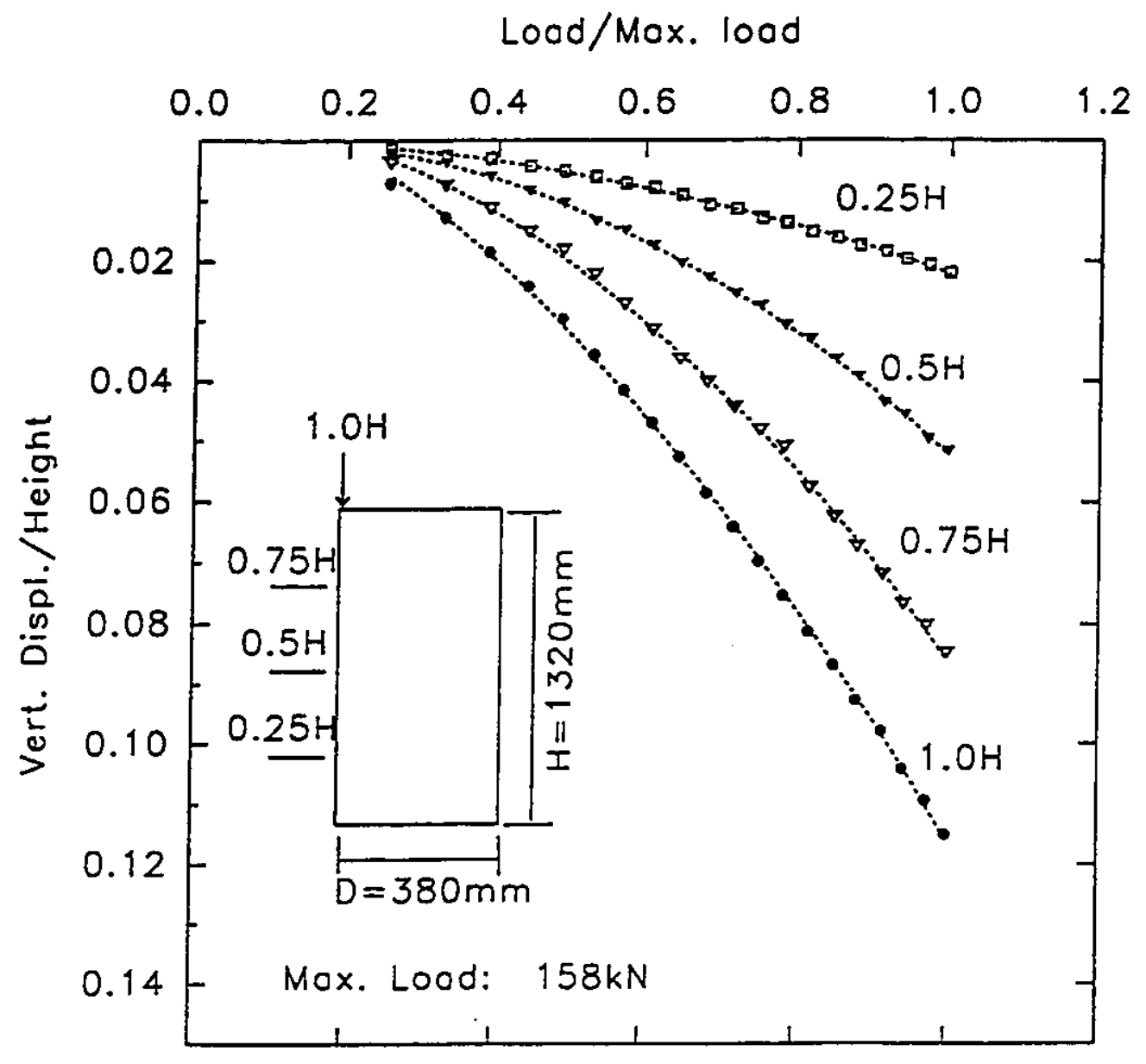

Figure 7.34 : Comparison of vertical displacement for a uniaxial column at different heights (3/8" aggregate + Tensar sleeve) 


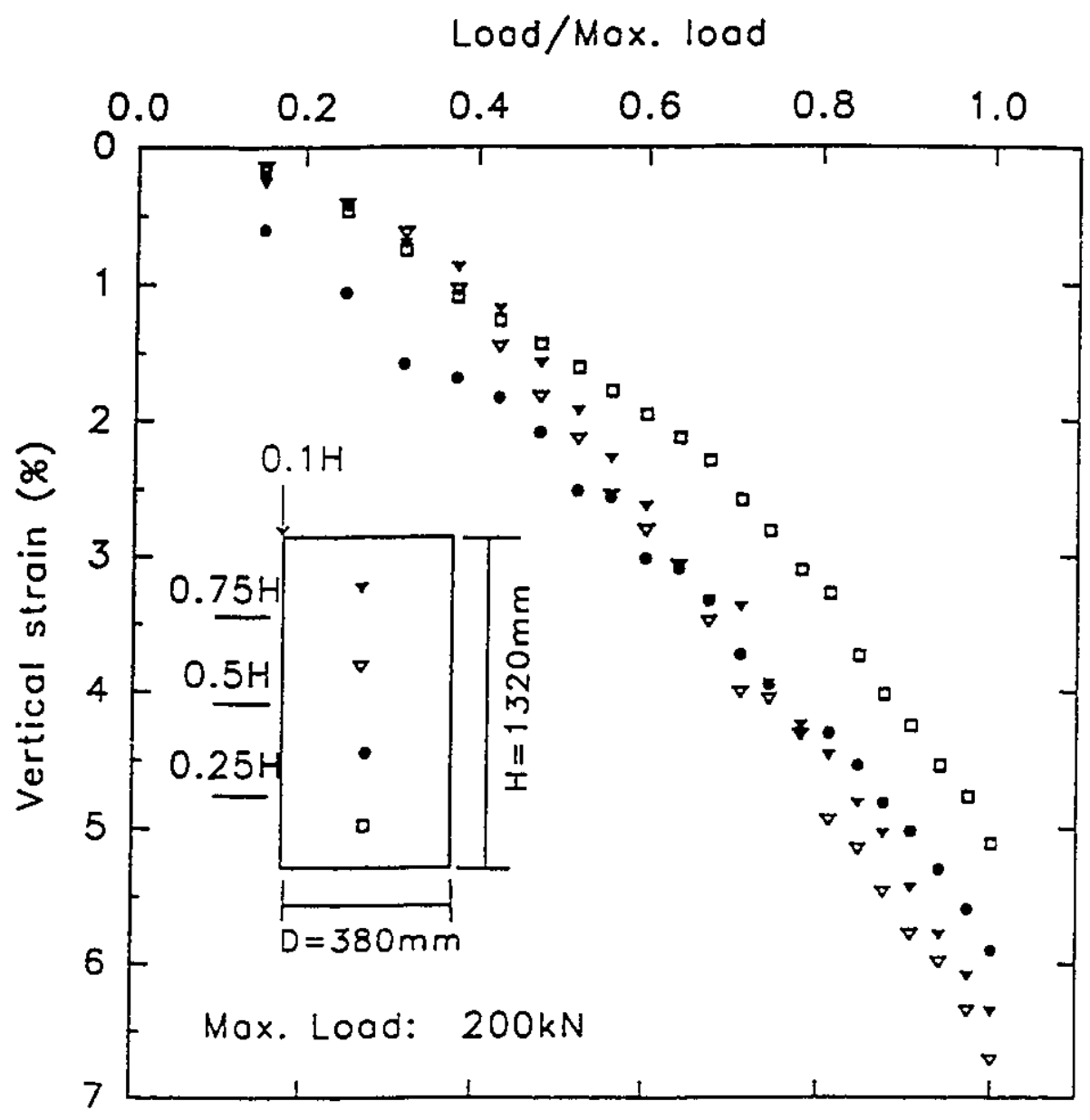

Figure 7.35 : Comparison of vertical strain distribution at the middle of each layer of the column (granular "A" + Tensar sleeve) 


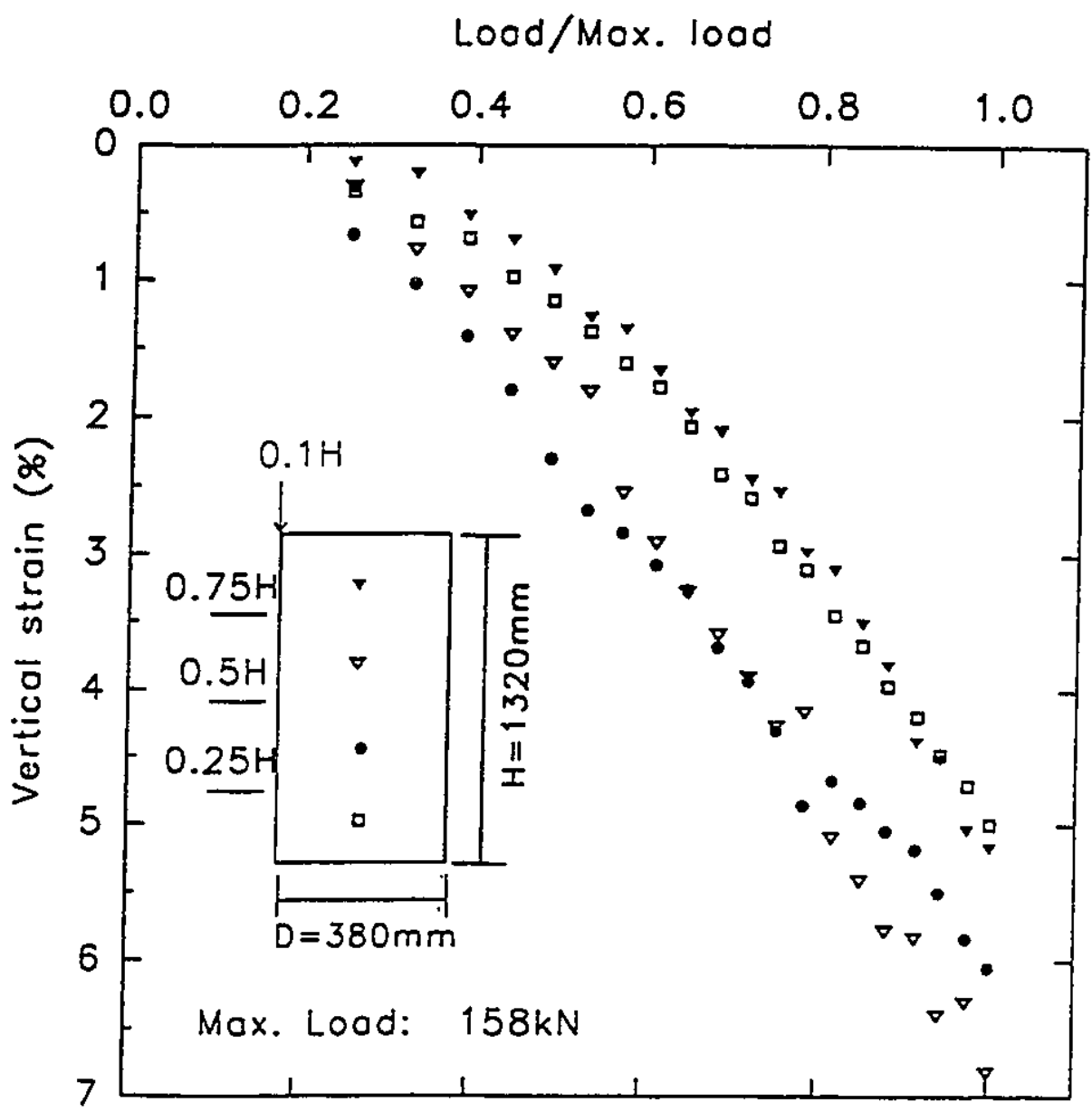

Figure 7.36 : Comparison of vertical strain distribution at the middle of each layer of the column ( $3 / 8$ " aggregate + Tensar sleeve) 
in this section.

Comparison of lateral strains of the uniaxial and triaxial columns are shown in Figure 7.37. The triaxial column with minimum confining pressure $\left(\sigma_{3}=103 \mathrm{kPa}\right)$ is compared with the uniaxial column. The tensile stresses are calculated in the same way by using equation [7.5]. Comparisons of the mobilized tensile stress of uniaxial and triaxial columns are shown in Figure 7.38. As expected, the uniaxial column experienced higher lateral strains and therefore, mobilizes higher tensile stress because no confining pressure was used $\left(\sigma_{3}=0\right)$, and the grid sleeve was the only component capable of stabilizing the column and restraining the lateral strains. The mobilized forces in the grid sleeve of a uniaxial column are almost double of that for the grid sleeve of the triaxial column. This implies that even low confining pressure from the surrounding soil may reduce the rapid mobilization of forces in the grid sleeve and partly confine the columns.

An attempt was made to measure the local tensile strains, that is, the strain at the location of the gauge of the grid sleeves. The strain gauges were attached to selected strands in the sleeves. Some results of the variation of local tensile strains in the grid with axial strain of the stone column are presented in chapter 5 (Figure 5.30 to 5.32). It is an important distinction to make, since the strain is the same in the elastic range before yielding of the strain gauges. Beyond the yield points of the strain gauges, the strain is not reliable and can not be used in the calculation of tensile stress. The strains beyond the elastic range of the strain gauges was caused generally by debonding from the grid strands.

The strain recorded by the strain gauges in the elastic range, before the yielding or debonding of the gauges, were used to calculate the tensile stress mobilized in the grid strands during a test. Comparisons of the tensile stress at locations in the sleeves are shown in Figures 7.39 and 7.40; the results shown in these figures were calculated using the data of Figures 5.30 and 5.31. It is important to notice that the tensile stresses mobilized in the strands at different locations are approximately the same. However, this is not the general case, but the results presented in these two figures support the assumption of uniform lateral strain in the grid mesh which was used in chapter 3 for the theoretical development. 


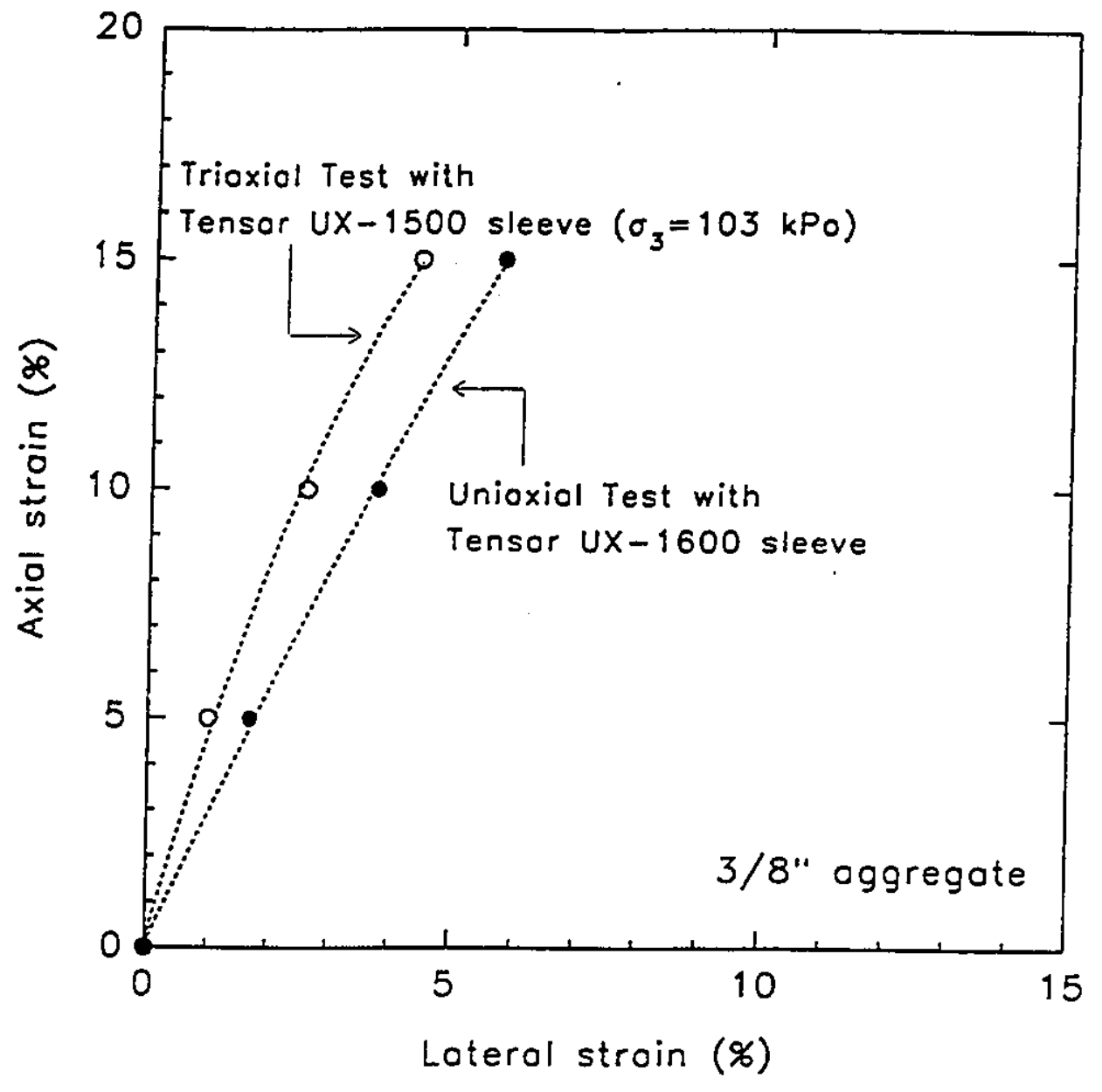

Figure 7.37 : Comparison of lateral strain behaviour of uniaxial and triaxial sleeve reinforced columns ( $3 / 8$ " aggregate) 


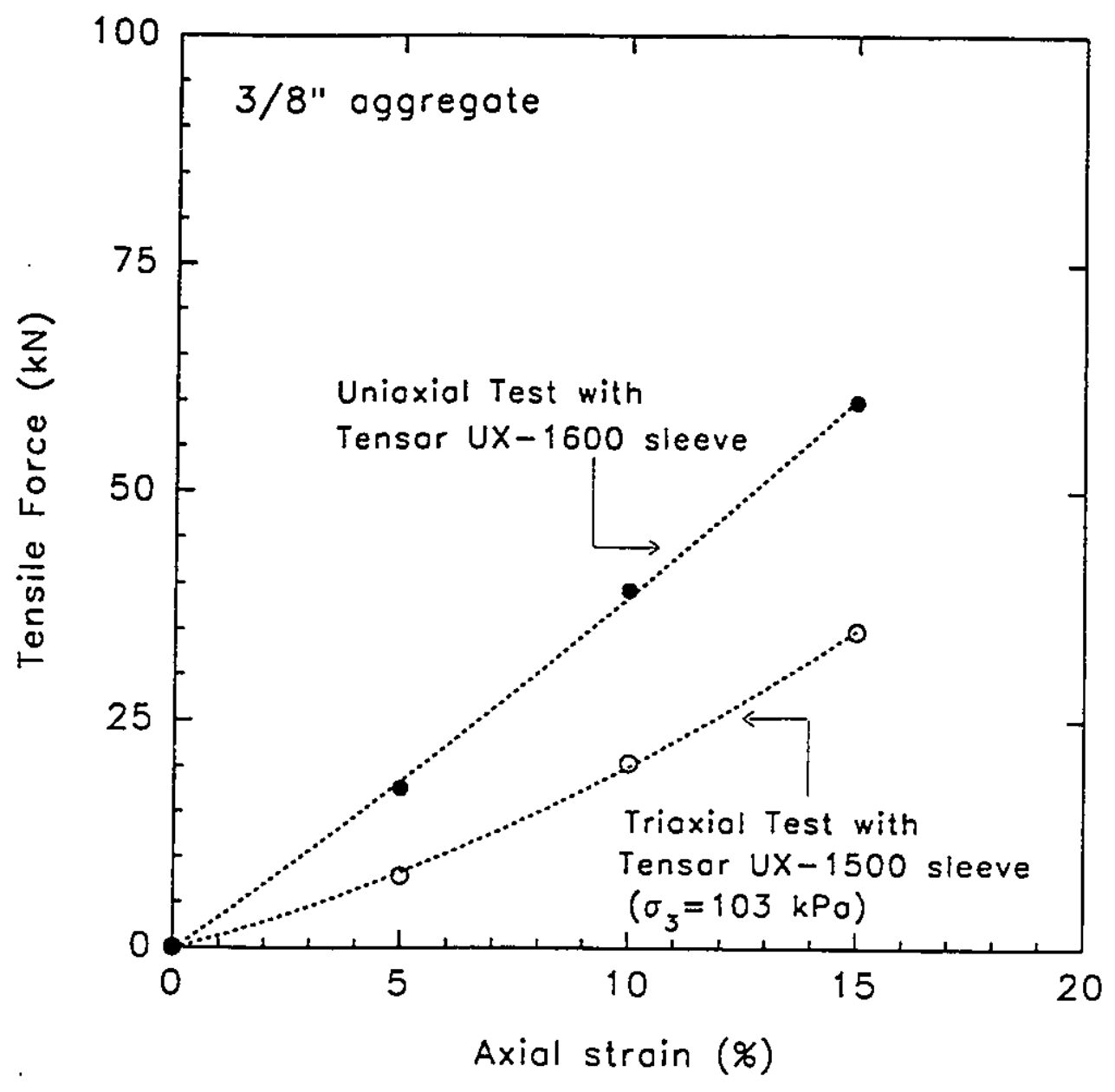

Figure 7.38 : Comparison of tension forces mobilized in the grid sleeves of uniaxial and triaxial columns ( $3 / 8$ " aggregate) 


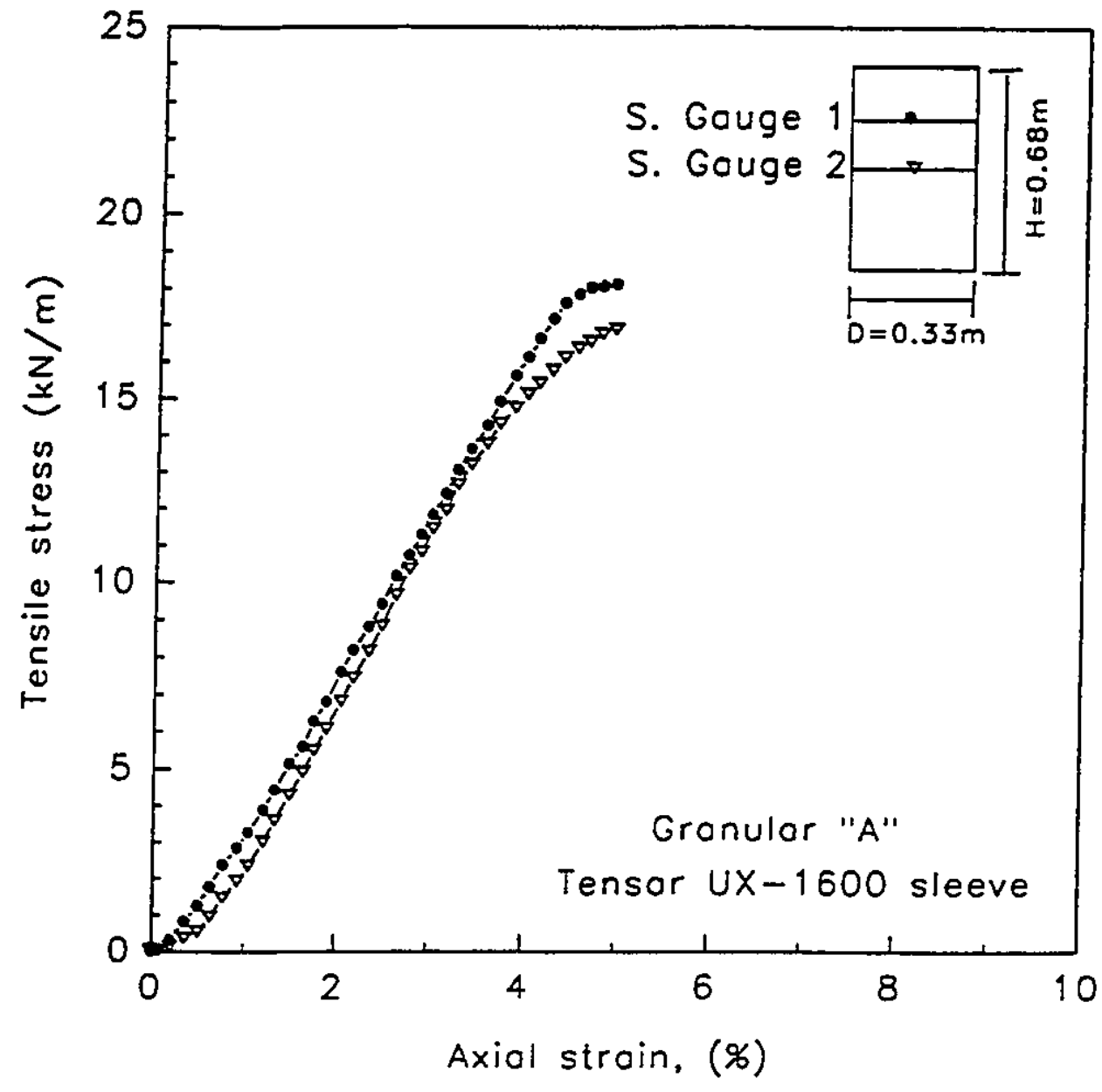

Figure 7.39 : Tensile stress calculated from strain gauges attached at locations 1 and 2 on sleeve of uniaxial column 


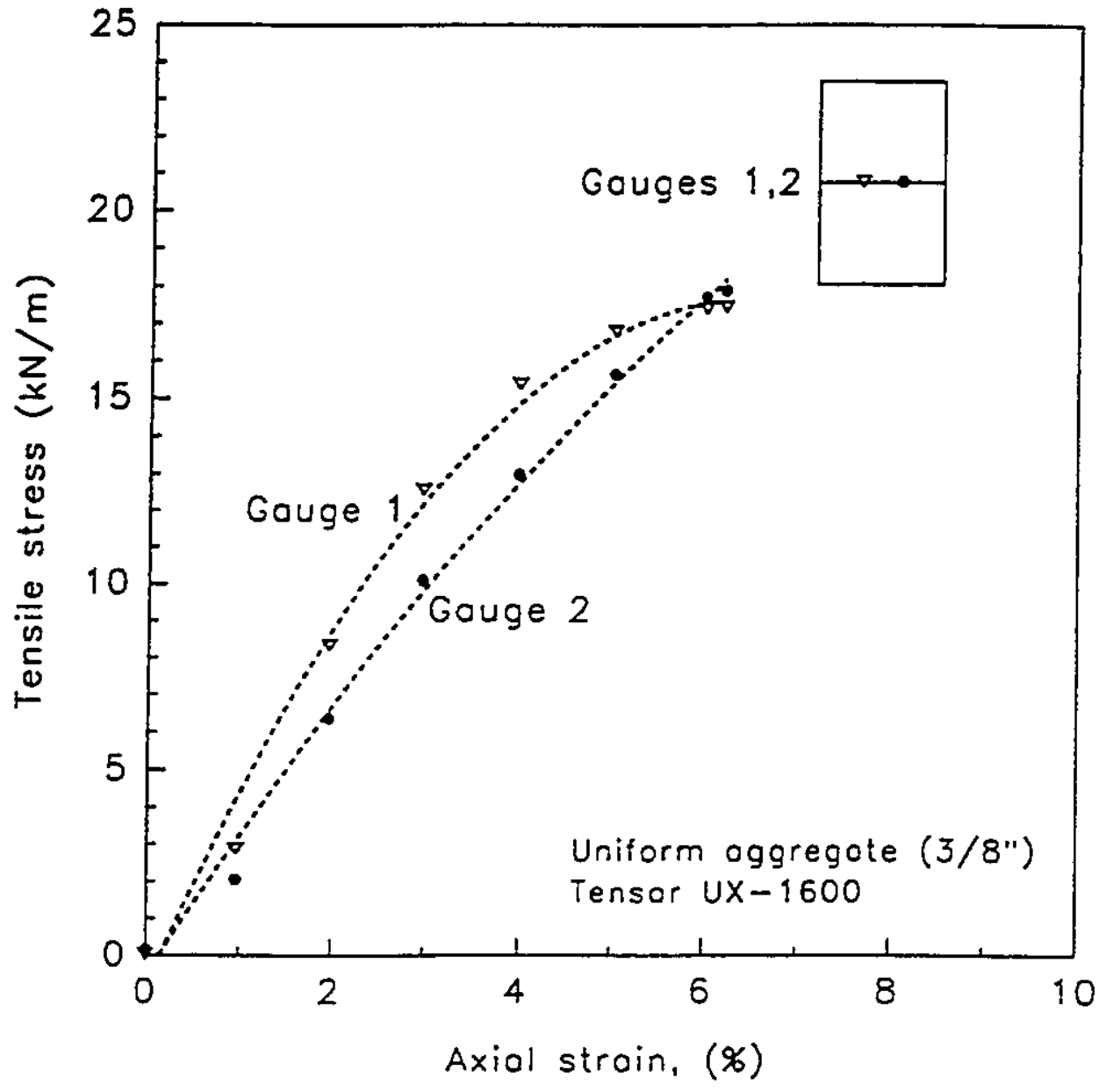

Figure 7.40 : Tensile stress calculated from strain gauges attached at locations 1 and 2 on sleeve of uniaxial column 
Comparing Figures 7.39 and 7.40 reveals that the mobilized stresses are approximately $15 \%$ of the tensile strength of grid. The maximum tensile stresses were mobilized between $5 \%$ and $6 \%$ axial strain of the column.

The tensile stresses calculated from the strains of the strain gauges and from the measured lateral strains of the columns are compared in Figures 7.41 and 7.42 for columns with granular "A" and uniform aggregate respectively. The mobilized tensile stresses were compared in the range between $0 \%$ to $5 \%$ axial strain of the stone column. This was because the only information available from the strain gauges was up to $5 \%$ axial strain (i.e. yield point of the strain gauges used) of the columns. The results presented in figures 7.41 and 7.42 show that the tensile stresses calculated from the strain gauges quite agree with those calculated using the lateral strain of the columns.

\subsection{COMPARISON OF DEFORMATION MODES}

Mode of deformation is usually presented as one of the results of a triaxial test to illustrate the shear planes (i.e., planes of maximum shear stresses). However, the deformed shapes of a unreinforced column is an indication of the tensile zones where reinforcement (different types and shapes) may be located to prevent excessive deformation and to avoid failure of the column. The mode of deformation or failure of unreinforced columns depends on several factors such as:

1- the amount of external load

2- the length of the stone column

3- end bearing or free floating stone column

4- the type and properties of the surrounding soil

5- the type and properties of the stone column material

A typical failure mode of a unreinforced granular " $\mathrm{A}$ " specimen is presented in Figure 7.43. This failure mode can be characterized as bulging with the absence a well defined shear surface. This means that more than one potential failure surface exists for granular "A" aggregate at a confining pressure of $103 \mathrm{kPa}$. At higher confining pressures 


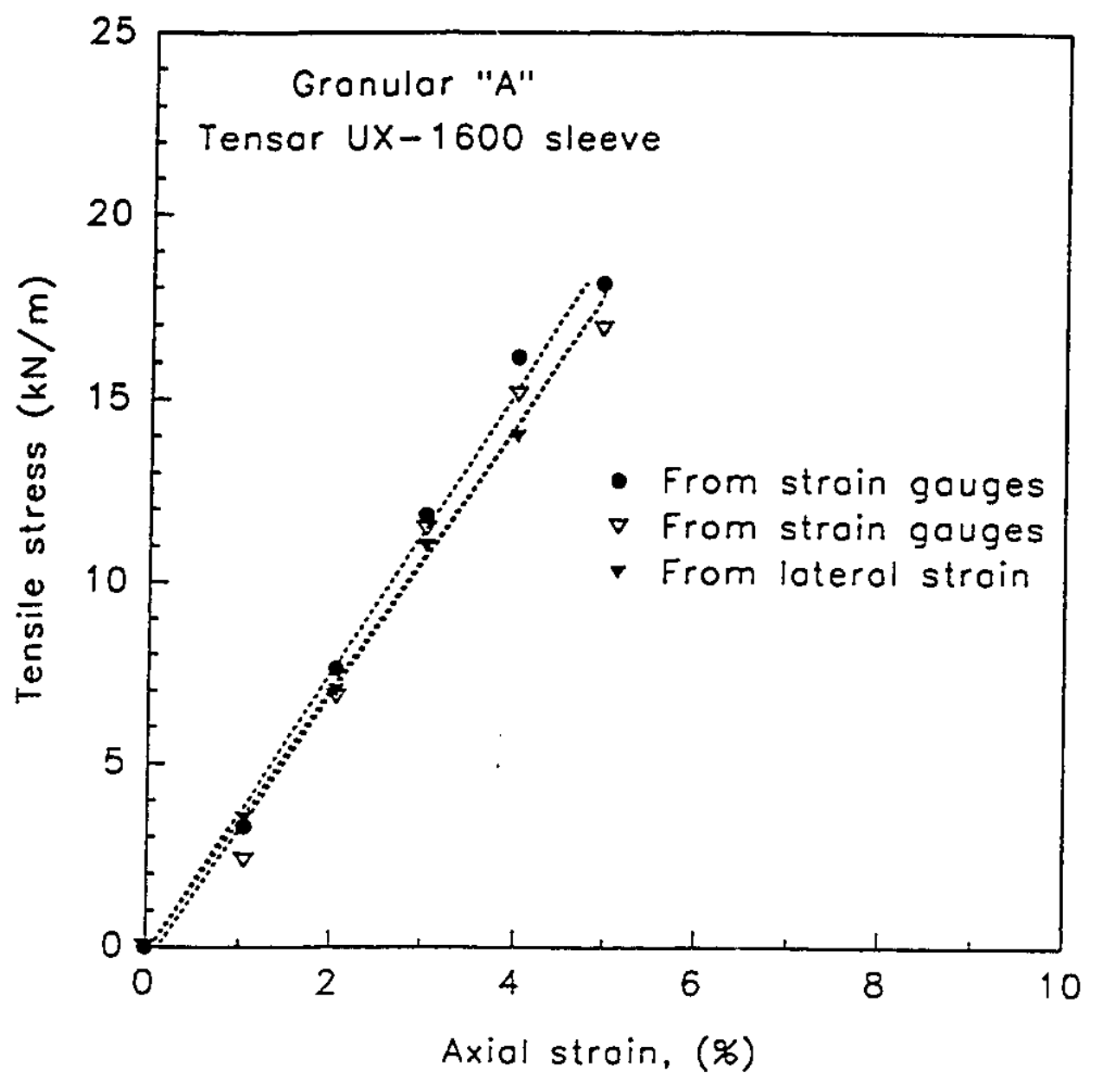

Figure 7.41 : Comparison of tensile stress from strain gauges and calculated from the lateral strain of the stone column 


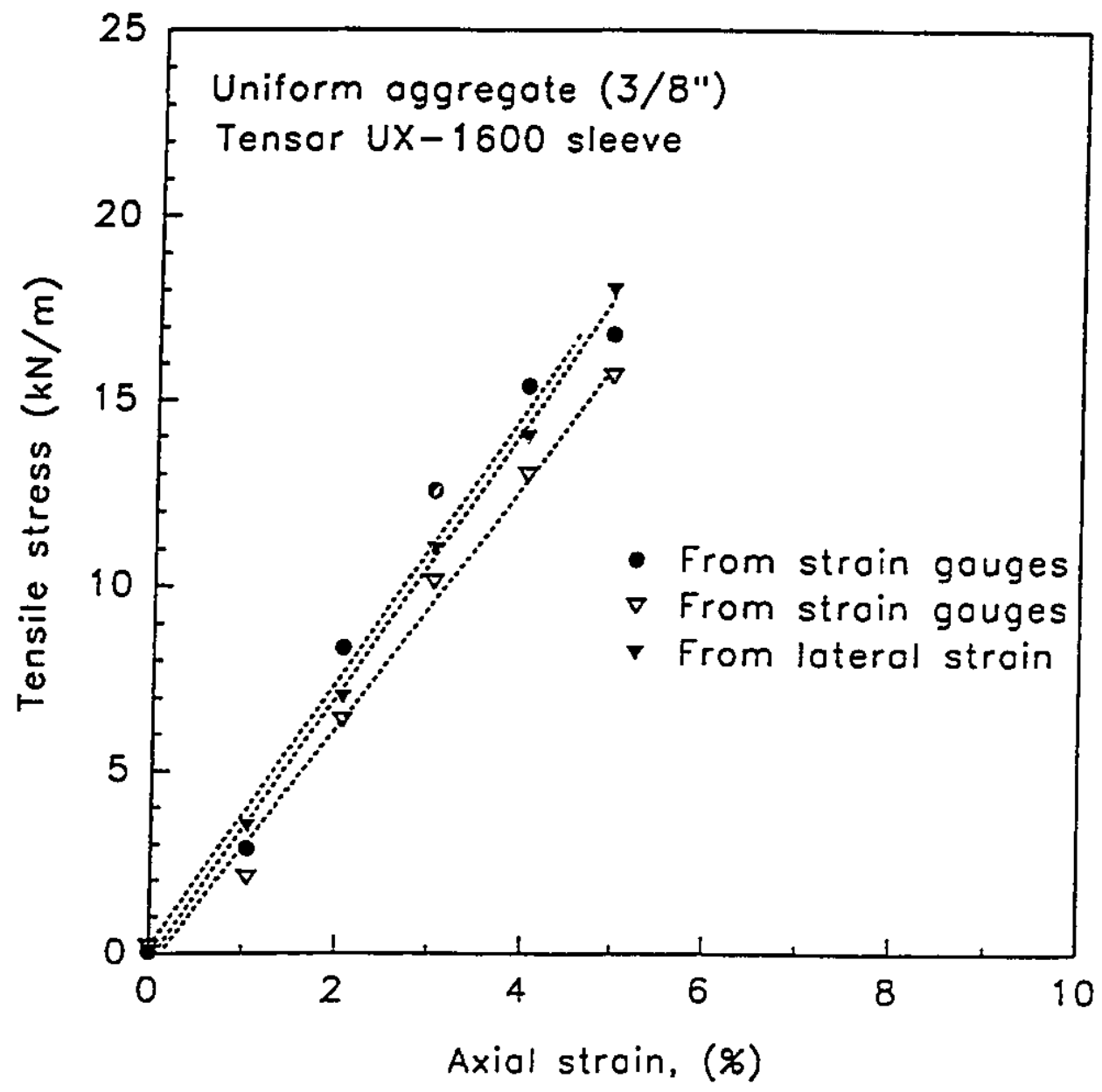

Figure 7.42 : Comparison of tensile stress from strain gauges and calculated from the lateral strain of the stone column 


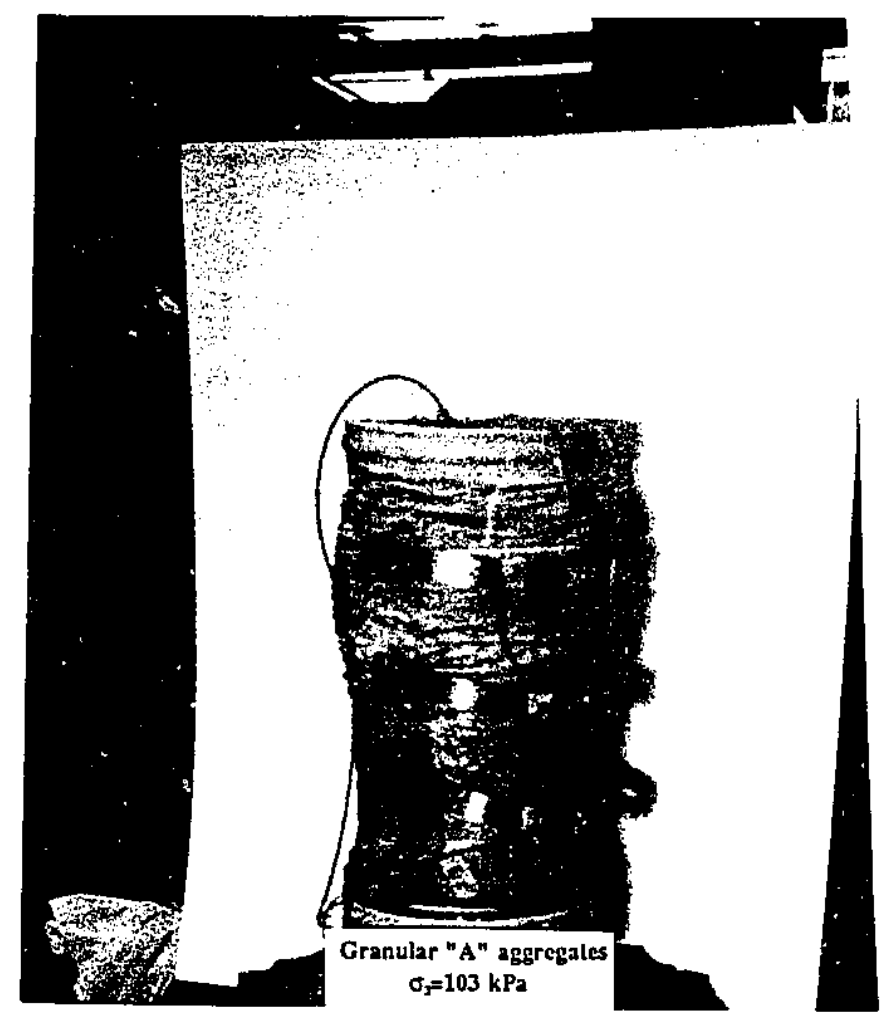

Figure 7.43 : Failure mode observed in a triaxial specimen of granular "A" aggregate without grid 
(207 $\mathrm{kPa}$ and $345 \mathrm{kPa}$ ) the bulged shapes were less evident and no apparent shear planes could be observed. The unreinforced columns with uniform aggregate (3/8") also developed uniform bulged shapes.

The failure mode observed in most unreinforced specimens was bulging. The bulging shape was more pronounced at the middle of the specimens due to the friction effect of the end platens.

In sleeve reinforced columns the shapes may be described in terms of deformation rather than failure because, as mentioned earlier, it was not possible to define definite failure planes before rupture of the geogrid sleeve occurred.

The deformed shapes of sleeve reinforced columns depends on the type and geometry of the grid in addition to the factors mentioned earlier for unreinforced columns. Typical deformed modes of triaxial specimens with Conwed 9027 and Tensar UX-1500 sleeves are shown in Figures 7.44 and 7.45 respectively. This mode can be characterized as uniform bulging with no distinct shear planes. The grid sleeves have restricted the development of definite shear planes which may cause failure of the specimen.

The bulging of a stone column with Conwed sleeve (Figure 7.44) is more obvious at the mid-height of the column because of the end friction effect. On the other hand, the column with Tensar sleeves exhibited uniform bulging (Figure 7.45) because the stiffness of the Tensar sleeve was greater than for the Conwed sleeve. Therefore, the shape and stiffness of the grid sleeve plays an important role in the amount and mode of deformation of reinforced columns.

The deformed shapes of long and short uniaxial columns were presented earlier in chapter five (Figures 5.17 and 5.18). In general, the shapes of a uniaxial sleeve reinforced columns can be characterized as uniform bulging. 


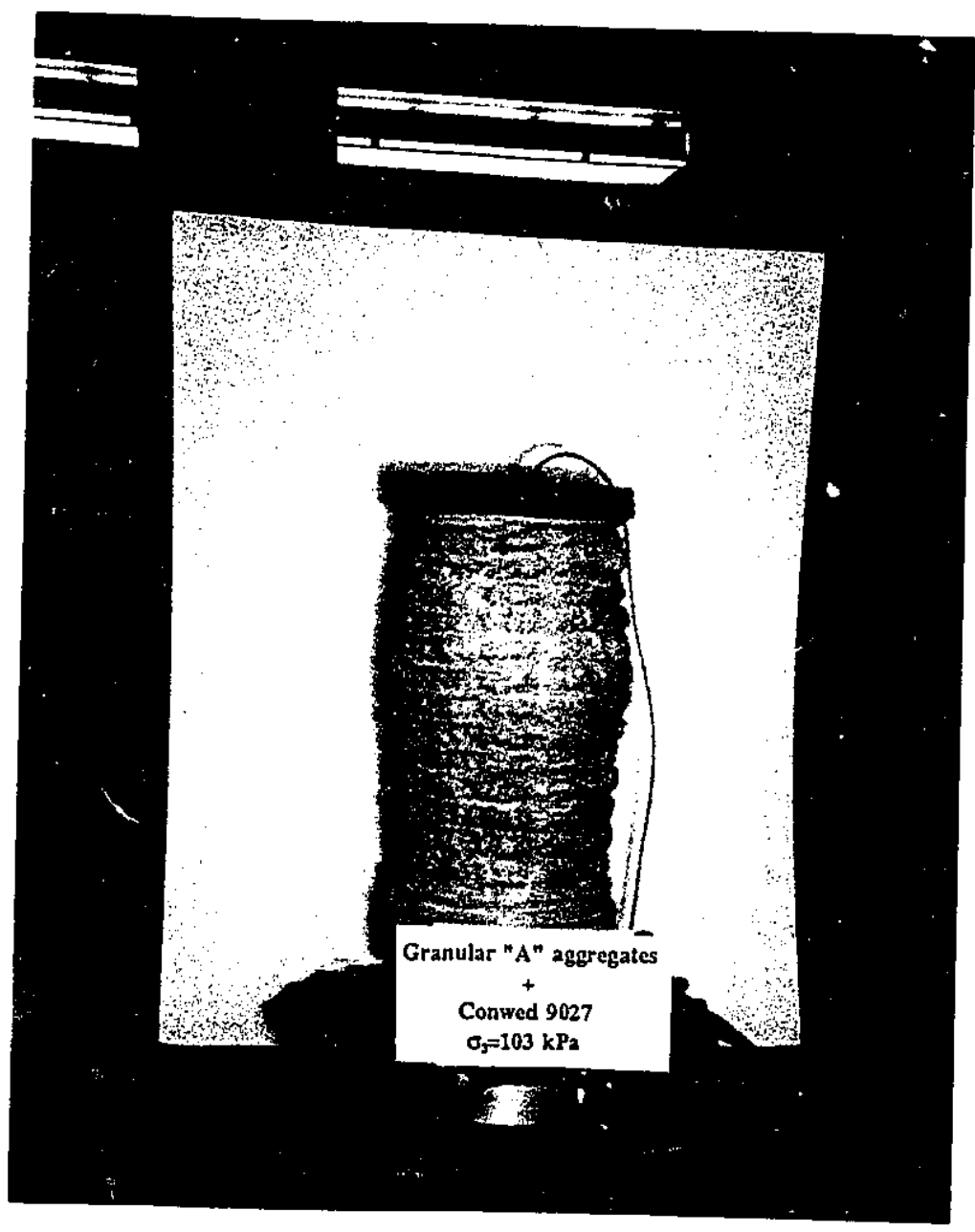

Figure 7.44 : Bulging observed in a triaxial specimen reinforced with Conwed 9027 sleeve 


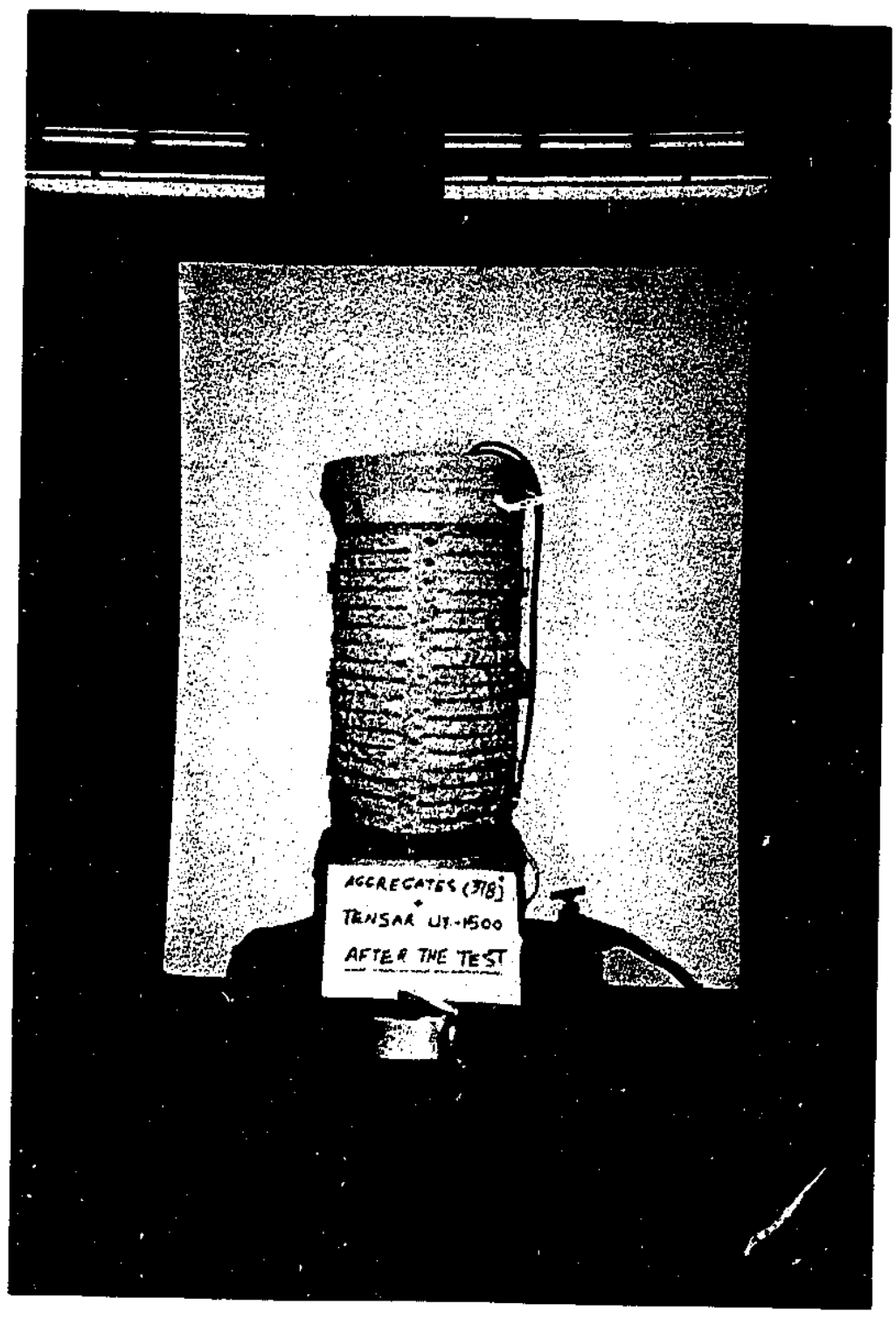

Figure 7.45 : Uniform bulging observed in a triaxial specimen reinforced with Tensar UX-1500 sleeve 


\section{CHAPTER 8}

\section{SUMMARY, CONCLUSIONS AND RECOMMENDATIONS}

\subsection{SUMMARY}

The literature review revealed little information on the behaviour of stone columns confined with polymer sleeves. The application of natural stone columns in geotechnical engineering is primarily to reduce excessive vertical and lateral deformations under sustained loads. The spreading of aggregates of the stone column is also of concern. The availability of high strength polymer grids suggested the research topic in confining natural stone columns with polymer sleeves in order to improve the load carrying capacity and to reduce vertical and lateral deformation of these columns.

The first part of this experimental study consisted of triaxial testing of natural and sleeve reinfoiced stone columns. Two types of granular material were used as backfill for the natural and sleeve reinforced specimens. Two sizes of triaxial specimens were investigated, namely $55 \mathrm{~mm}$ diameter and $110 \mathrm{~mm}$ high samples and $225 \mathrm{~mm}$ diameter and $455 \mathrm{~mm}$ high columns. These specimens were tested under confining pressures ranging from 100 to $345 \mathrm{kPa}$. The cyclic loading behaviour of natural stone columns was also investigated. The stress- strain-volume change relations of the natural columns were considered as reference or control in comparing the effect of poiymer sleeves on the behaviour. Results from triaxial tests of unreinforced specimens showed that the strength increased with confining pressure. A decrease in volume occurred under initial increment of deviator stress for all samples at confining pressures greater than $103 \mathrm{kPa}$.

The effect of three types of polymer sleeves on column strength and deformation was investigated. These geogrids were Tensar UX-1500, Conwed 9027, and fiber glass (GB \#10). The stone columns were tested under static and cyclic load conditions. The behaviour of reinforced columns under zero lateral strain ( $\mathrm{K}_{0}$-condition) were also 
investigated in order to simulate field conditions of "centre" piles within a group.

In the second part of this research, the behaviour of sleeve reinforced stone columns under uniaxial stress conditions was studied. Using the same aggregate types, specimens with different diameter/height ratios were investigated. The minimum stone column size was $0.28 \mathrm{~m}$ in diameter and $0.62 \mathrm{~m}$ in height and the maximum size was $0.38 \mathrm{~m}$ in diameter and $1.32 \mathrm{~m}$ in height. The reinforced columns were tested under uniaxial static and cyclic loading conditions. Two strain rates were used, a slow strain rate of $0.5 \mathrm{~mm} / \mathrm{min}$ for static loading and a rapid rate of $10 \mathrm{~mm} / \mathrm{min}$ for cyclic load applications.

The triaxial test results of natural and sleeve reinforced columns were compared and discussed. The effect of sleeve encapsulation on the angle of shearing resistance, the strength increase ratio (S.I.R.), secant modulus and lateral and axial deformations were presented and discussed. The results of $\mathrm{K}_{0}$-tests for natural and jacketed columns were compared and discussed. The monitored lateral deformation of the columns were used to calculate the hoop stresses mobilized in the sleeves during loading.

The stress-strain behaviour under triaxial and uniaxial stress conditions of sleeve reinforced columns was compared. The stress-strain-volume change behaviour of short and long columns under uniaxial loading was presented and discussed. The hoop stresses mobilized in the polymer sleeves for triaxial and uniaxial specimens were compared.

The tensile strains mobilized in horizontal strands of the sleeves were monitored using resistance strain gauges. These tensile strains were converted to stresses and compared to the calculated stresses based on the lateral deformation of the specimens. The mode of deformation of unreinforced and sleeve reinforced columns were compared and discussed for triaxially and uniaxially loaded columns.

The experimental results of this research were compared to corresponding results from theoretical analyses. The hyperbolic stress-strain model proposed by Duncan and Chang (1970) was employed in the analysis of natural and sleeve reinforced columns. The model parameters were derived from the appropriate triaxial tests of natural and reinforced specimens. The experimental and theoretical stress-strain relationships were compared and discussed. 


\subsection{CONCLUSIONS}

The experimental results of this research validated the concept of application of polymer sleeves to the natural stone columns to increase the strength and reduce the vertical and lateral strains. This new concept can be utilized in field construction to improve the performance of natural stone columns. Based on the experimental and theoretical investigations conducted in this research, a number of general and specific conclusions are presented

The present study has shown that using polymer sleeves to confine stone columns would be effective in increasing the stiffness and in reducing the vertical and lateral deformation of these columns.

The use of well graded granular material with pronounced dilation characteristics will provide a more effective backfill material than a uniform aggregate for sleeve reinforced columns. Such material can mobilize the tensile strength of the sleeves more rapidly. At $10 \%$ of axial strain the capacities of reinforced stone columns with granular " $\mathrm{A}$ " were between 25 to $35 \%$ higher than with corresponding specimens having uniform aggregate.

The sleeves had little or nc effect on the global angle of shearing resistance of the granular material. More specifically, the natural and reinforced stone columns exhibited approximately the same angles of shearing resistance under triaxial compression. The effect of the sleeve confinement manifested itself, however, as an "apparent cohesion" intercept in the Mohr-Coulomb strength envelope. Therefore, it can be concluded that for the range of confining pressures investigated, the strength of a reinforced column can be estimated from the Coulomb strength equation using an "apparent cohesion" intercept and the angle of shearing resistance of the natural aggregate.

The strength increase ratio (S.I.R.) which was defined as the ratio of the "principle stress 
difference" of the reinforced to the unreinforced columns at a given axial strain, was found to be a convenient concept to represent the strength increase due to the sleeve reinforcement. The S.I.R. is a function of aggregate type, polymer grid as well as axial strain and stress levels. The maximum S.I.R. was found to be 4.25 at $12 \%$ of axial strain for a column with granular "A" aggregate and a confining pressure of $103 \mathrm{kPa}$.

The stiffness of a stone column can be given as the secant modulus. The polymer sleeves increased the secant modulus, at $10 \%$ of axial strain, between 1.5 and 3 times as compared to corresponding moduli for the natural columns. Therefore, the polymer sleeves will reduce vertical and horizontal deformations by these factors.

The coefficient of earth pressure at zero lateral strain ( $\mathrm{K}_{0}$-condition) of the reinforced specimens was found to be less than that for unreinforced specimens. The $K_{0}$ value of granular " $\mathrm{A}$ " in this research was 0.34 . The $\mathrm{K}_{\mathrm{o}}$ values for sleeve reinforced columns ranged from 0.26 to 0.20 depending on geogrid type. It is concluded that some tensile stresses in the sleeve are mobilized during the compaction process yielding stiffer columns compared to corresponding natural specimens.

The mobilized tensile stress in the grid sleeves decreased with an increase of confining pressure. Therefore, the maximum tensile stresses in the sleeves were mobilized in stone columns tested under uniaxial stress conditions.

The tensile stresses calculated from the strain gauge readings in the horizontal ribs were found to be approximately the same as those calculated from the lateral strains measured by the "deformation clips". Therefore, the "deformation clips" are a more expedient way to monitor the lateral strain mobilized during a test.

The hyperbolic stress-strain model was shown to be valid for predicting the stress-strain behaviour of sleeve reinforced stone columns. The model parameters needed in the analysis should be derived from appropriate triaxial tests. 


\subsection{RECOMMENDATIONS FOR FUTURE WORK}

1) This study attempted to investigate the behaviour of different sizes of sleeve confined stone columns in the laboratory. Full scale field tests are recommended. Such tests would give further insight and understanding of the actual behaviour of the sleeve confined stone columns surrounded by soil.

2) Additional experimental studies are required to investigate the effect of increasing the number of sleeve layers (wraps) on the capacity and deformation behaviour of stone columns.

3) Theoretical analysis, based on finite element modelling considering the three constituent of the stone column composite (aggregate, polymer grid and soil) would be helpful for a better understanding of the behaviour of sleeve reinforced stone columns.

4) Practical research is necessary to investigate the installation techniques of sleeves and how to compact the granular material. This investigations should focus on the possibility of using a steel casing to insert the polymer sleeve.

5) Creep of polymer grid under sustained load is an important factor. More investigations are necessary to assess the effect of creep on the behaviour of stone reinforced with polymer sleeves. 


\section{REFERENCES}

Aboshi H., Ichimoto E., Enoki M. and Harada K. (1979), "The compozer-a method to improve characteristics of soft clays by inclusion of large diameter sand columns," Proc., Int. Conf. on Soil Reinforcement: Reinforced Earth and other Techniques, March, Vol. $1,211-216$

Al-Refeai T.O. (1985), "Constitutive behaviour of fabric vs. fiber reinforced sand," Ph.D Thesis, Civil Engineering Department, University of Michigan, Michigan

American Society for Testing and Materials (ASTM) (1973), April, Vol. 2, D2049-69

American Society for Testing and Materials (ASTM) (1986), "Standard method for tensile properties of geotextiles by the wide-width strip method," D-4595

Bachus, R.C. and Barksdale, R.D. (1984), "Vertical and lateral behaviour of model stone columns," Proc. Int. Conf. on In-Situ Soil and Rock Reinf., Paris, Oct., Vol. 1, 99-104

Balaam, N.P. and Booker, J.R. (1980), "Analysis of rigid rafts supported by granular piles," Int. J. for Num. and Analyt. Methods in Geomech., Vol. 5, 379-403

Balaam, N.P. and Poulos, H.G. (1983), "The behaviour of foundation supported by clay stabilized by stone columns," Proc. 8th Europ. Conf. on Soil Mech. and Found. Eng., Helsinki, May, Vol. 1, 199-204

Barksdale, R. D. and Bachus, R. C. (1983), "Design and construction of stone columns," Report No. FHWA/RD-83/026, Federal Highway Administration, U.S.A., Vol 1., 194 p.

Barksdale, R.D. and Goughnour, R.R. (1984), " Settlement performance of stone columns in the U.S.," Proc. Int. Conf. on In-Situ Soil and Rock Reinf., Paris, Oct., Vol. 1, 105-110

Barksdale, R.D. (1987), " State-of-the-art for design and construction of sand compaction piles," Technical Report, Repair-Evaluation-Maintenance and Rehabilitation Research Program (REMR-GT-4), US. Corps of Engineers (USCOE), Waterways Experimental Station (WES), Nov., 55 p.

Barksdale, R.D. (1987), "Application of the state of the art of stone columns-liquefaction, local bearing failure, and example calculations," Technical Report, Repair-EvaluationMaintenance and Rehabilitation Research Program (REMR-GT-4), US. Corps of Engineers (USCOE), Waterways Experimental Station (WES), Dec., 84 p.

Bauer, G.E. and Zhao, Y. (1993), "Evaluation of shear and dilatancy behaviour of reinforced soil from direct shear tests," Geosynthetic Soil Reinforcement Testing 
Procedures, ASTM, SPT 1190, 138-151

Baumann, V. and Bauer, G.E. (1974), "The performance of foundations on various soils stabilized by the vibro-compaction method," Can. Geotech. J., Vol. 11, No. 4, 509-530

Bergado D.T., Rantucci G. and Widoo S. (1984), " Full scale load test of granular piles and sand drains in the soft Bangkok clay," Proc. Int. Conf. on In-Situ Soil and Rock Reinf., Paris, Oct., Vol 1, 111-118

Bergado, D.T., Panichayatum, B. and Sampaco, C.L. (1987), " Reinforcement of soft Bangkok clay using granular piles," Int. Geotech. Symp. on Theory and Practice of Earth Reinf., Japan, Oct., Balkema, Rotterdam, 179-184

Besancon D.T., Torio J.P. and Soyez B. (1984), "Analyse des parametres de calcul intervenant dans le dimensionnement des colonnes ballastees", Prc. Int. Conf. on In-Situ Soil and Rock Reinf., Paris, Oct., Vol. 1, 119-126

Brauns, J. (1978), "Initial bearing capacity of stone columns and sand piles," Proc. of Symp. on Soil Reinf. and Stabilizing Techniques, University of New South Wales, Sydney, Australia, 477-496

Briaud, J.-L. (1991), "The Pressuremeter: some special applications," Geotech. Eng. Congress, Geotech. Special Pub. No. 27. Vol. 1, 26-37

Broms, B.B. (1977), "Triaxial tests with fabric-reinforced soil," Proc. Int. Conf. on Use of Fabrics in Geotechnics, Vol. 3, 129-133

Brown, R.E., Jones, J.S., Mayne, P.W. and Dimaggio, J.A. (1979), "Parametric study of stone column behaviour," C.R. Coll. Int. Reinforcement Des Sols., Paris, 175-178

Cannon, E.W. (1976), "Fabric in Civil Engineering," Civil Eng., (U.K.), March, 39-42

Chalaturnyk, R.J., Scott, J.D., Chan, D.H. and Richards, E.A. (1988), "Stresses and deformations in a reinforced soil slope," 3rd Can. Symp. on Geosynth., Kitchener, Ontario, Canada, 79-89

Chambosse, G. and Dobson, T. (1982), " Stone columns II, estimation of embankment stability with soil improvement," GKN Keller Inc.

Charles, J.A. And Watts. K.S. (1983), "Compressibility of soft clay reinforced with granular columns," Proc. 8th Europ. Conf. on Soil Mech. and Found. Eng., Helsinki, May, Vol. 1, 347-352

Clough, G.W. and Duncan, J.M. (1971), " Finite element analysis of retaining wall 
behaviour," J. of Geotech. Eng., ASCE, Vol. 97, SM 12, Dec., 1657-1673

Colleselli, F., Massucato, A. and Spalatro, A. (1983), " Improvement of soil foundation by vibratory methods," Proc. 8th Europ. Conf. on Soil Mech. and Found. Eng., Helsinki, May, Vol. 1, 223-228

Dobson, T. (1987), "Case histories of the vibro systems to minimize the risk of liquefaction," Proc. of Soil Improvement- A 10th Year Update, Geotech. Special Pub. No. 12, ASCE, Atlanta, April, 167-183

Duncan, J.M. and Chang, C.Y. (1970), "Nonlinear analysis of stress and strains in soils," J. of Soil Mech. and Found. Eng., ASCE, Vol. 96, SM 5, 1629-1653

Elgabroni Ali A. (1989), "Structural behaviour of concrete beams reinforced with polymer grids and high strength steel," M. Eng. Thesis, Civil Eng., Carleton University, Ottawa, Ontario, Canada

Engelhardt, K. and Golding, H.C. (1975), " Field testing to evaluate stone column performance in a seismic area," Geotechnique, 25 (1), 61-69

Felio, G.Y. (1980), "Monitoring of a bridge abutment iounded on a granular compacted fill," M.Eng. Thesis, Civil Eng., Carleton University, Ottawa, Ontario, Canada

Fukushima, S., Mochizuki, Y. and Kagawa, K. (1988), "Strength characteristics of reinforced sand in large scale triaxial compression tests," Int. Geotech. Symp. on Theory and Practice of Earth Reinf., Japan, Oct., Balkema, Rotterdam, 93-98

Gerrard, C.M., Pande, G.N. and Schweiger, H.F. (1984), "Modelling of behaviour of soft clay reinforced with stone columns," Proc. Int. Conf. on In-Situ Soil and Rock Reinf., Paris, Oct., Vol. 1, 145-150

Gibson, R.E. and Anderson, W.F. (1961), "In situ measurements of soil properties with the pressuremeter," Civil Eng. and Pub. Works Rev., Vol. 56, No. 658, 615-618

Goughnour, R.R. and Bayuk, A.A. (1979),"Analysis of stone column-soil matrix interaction under vertical load," Proc. Int. Conf. on Soil Reinf. Reinforced Earth and other Techniques, Paris, March , Vol. 1, 271-277

Goughnour, R.R. (1983), "Settlement of vertically loaded stone columns in soft ground," Proc. 8th Europ. Conf. on Soil Mech. and Found. Eng., Helsinki, May, Vol. 1, 235-240

Goughnour, R.R. and Jones, J.S. Jr. (1989), " Design and construction of stone column reinforced cofferdams," Found. Eng. Current Principles and Practices, ASCE, New York, NY, USA., Vol. 1, 231-243 
Gray, D.H. and Ohashi, H. (1983), "Mechanics of fiber reinforcement in sand," J. of Geotech. Eng., ASCE, Vol. 109, SM 3, 335-353

Gray, D.H., Kalkjian, M. and Wu, C. (1989), " Stress-deformation response of geotextile reinforced granular structures," Proc. Geosynth. ' 89 Conf., San Diego, U.S.A., Feb., Vol. $2,373-384$

Greenwood, D.A. and Kirsch, K. (1984), " Specialist ground treatment by vibratory and dynamic methods," State-of-the-Art Report, Piling and Ground Treatment, Thomas Telford Ltd, London, 17-45

Greenwood, D.A. (1970), "Mechanical improvement of soils below ground surface," Proc. Conf. on Ground Eng., Institute of Civil Engineers, London, 21-22

Hausmann, M.R. (1976), " Strength of reinforced soil," Proc. Australian Road Research Board (ARRB), Vol. 8, 1-8

Housner, G.W. (1985), " Liquefaction of soils during earthquakes," Committee on Earthquake Engineering, National Academy Press, Washington, DC.

Huber, T. R. (1978), "Finite element analysis of the load-deformation behaviour of a vibro-replacement stone column foundation," M.Sc. Thesis, University of California, Los Angeles, California

Hughes, J.M.O. and Withers, N.J. (1974), "Reinforcing soft cohesive soil with stone columns," Ground Engineering, May, Vol. 7, No. 3, 42-49

Hughes, J.M.O., Withers, N.J. and Greenwood, D.A. (1975), "A field trial of the reinforcing effect of a stone column in soil," Geotechnique, 25(1), 31-44

Ingold, T. S. (1982), " Reinforced earth," Thomas Telford Ltd., London

Janbu, N. (1963), " Soil compressibility as determined by oedometer and triaxial tests," Proc. 2nd Europ. Conf. on Soil Mech. and Found. Eng., German Society for Soil Mech. and Found. Eng., Wiesbaden, Germany, Vol. 1, 19-25

Jewell, R.A., Milligan, G., Sarsby, R.W. and Dubois, D. (1984), "Interaction between soil and geogrids," Proc. Polymer Grid Reinf. in Civil Eng., Thomas Telford, London, 18-30

Jewell, R.A. (1991), " Application of revised design charts for steep reinforced slopes," Geotextiles and Geomembranes, 10(3), 203-233

Juran, I., Farrag, K. and Richmond, L. (1991), " Short and long term performance of polymeric geogrids," Proc. Geosynth. '91, Atlanta, U.S.A., March, 13 p. 
Kabir. M.H. and Alamgir, M. (1988), "Geotextile and geogrid jacketed stone columns in clay," Proc. 1st Indian Geotext. Conf., Bombay, India, Dec., 45-50

Koerner, R.M. (1990), "Designing with geosynthetics," 2nd Edition, Prentice Hall, Englewood, N.J.

Kondner, R.L. and Zelasko, J.S. (1963), " A hyperbolic stress-strain formulation for sands," Proc. 2nd Pan-American Conf. on Soil Mech. and Found. Eng., Brazil, Vol. 1, $289-324$

Leshchinsky, D. and Field, D.A. (1987), "In-soil load elongation, tensile strength and interface friction of nonwoven geotextiles," Proc. Geosynth. '87 Conf., New Orleans, U.S.A., 238-249

Madhav, M.R., Iyengar, N.G.R., Vitkar, P.P. and Nandia, A. (1979), "Increased bearing capacity and reduced settlements due to inclusions in soil," C.R Coll. Int. Renf. des Sols. Paris, 329-333

Madhav M.R. and Thiruselvam, C. (1988), "Effect of installation methods on granular pile response," Int. Geotech. Symp. on Theory and Practice of Earth Reinf., Japan, Oct., Balkema, Rotterdam, 221-226

Makiuchi, K. and Miyamori, T. (1988), "Mobilization of soil-geofabric interface friction," Int. Geotech. Symp. on Theory and Practice of Earth Reinf., Japan, Oct., Balkema, Rotterdam, 129-134

McGown, A., Anderawes, K.Z., and Kabir, M.H. (1982) ,"Load-extension testing of geotextiles confined in-soil," Proc. 2nd Int. Conf. on Geotextiles, Las Vegas, Nevada, Vol. 3, 793-798

Mckenna, J.M., Eyre, W.A. and Wolstenholme, D.R. (1975), "Performance of an embankment supported by stone columns in soft ground," Geotechnique, 25(1), 51-99

Mitchell, J.K. and Schlosser, F. (1979), "General report," Proc. Int. Conf. on Soil Reinf., Reinforced Earth and Other Techniques, Paris, Vol. 1, 25-74

Mitchell, J.K. (1981), " Soil Improvement," State-of-the-art report, 10th Int. Conf. on Soil Mech. and Found. Eng., Stockholm, Sweden, Vol 4., 509-565

Mitchell, J.K. and Huber, T.R. (1985), "Performance of a stone column foundation," J. of Geotech. Eng. ,ASCE, SM 2, Feb., Vol. 3, 205-223

Mowafy, Y.M. (1986), "Analysis of rigid reinforced earth structure," Ph.D. Thesis, Civil Eng., Carleton University, Ottawa, Ontario, Canada 
Munfakh, G.A., Sarkar, S.D., and Castelli, R.J. (1984), "Performance of a test embankment founded on stone columns," Piling and Ground Treatment for Foundations, Thomas Telford, London

Munfakh, G.A. (1984), " Soil reinforcement by stone columns - varied case applications," Proc. Int. Conf. on In-Situ Soil and Rock Reinf., Paris, Oct., Vol. 1, 157-162

Munfakh, G.A., Abramson, L.W., Barksdale, R.D. and Juran, I. (1987), " In-situ ground reinforcement," Proc. of Soil improvement - A 10th Year Update, Geotech. Special Pub. No. 12, ASCE, Atlanta, April, 1-17

Priebe, H. (1976), " Estimation of settlement in a gravel column consolidated soil" (In German)," Die Bautechnik, 53, 5., 160-162

Razaqpur, A.G. (1990), "Tensile strength and load-deformation characteristics of Conwed stratagrids," Final Report, Dept. of Civil Eng., Carleton University, Ottawa, Canada

Razaqpur, A.G. and Abd El Halim, A.O. (1991), "Determination of tensile strength and maximum strain of Tensar UX-1500 and UX-1600 using three different sets of jaws," Final Report, Dept. of Civil Eng., Carleton University, Ottawa, Canada

Razaqpur, A.G., Bauer, G., Halim A.O.A., Juran, I. and Templeman J.E. (1992), " Generic test methods for polymeric geogrids," Technical Bulletin GS 112, Strata Grid, Conwed, St. Paul, Min., U.S.A.

Romana, M. (1983), " Settlement control with gravel columns under oil tanks," Proc. 8th Europ. Conf. on Soil Mech. and Found. Eng., Helsinki, May, Vol. 1, 301-305

Schlosser, F. and Long, N.T. (1972), "Behaviour of reinforced earth for retaining structures," Proc. 5th. Europ. Conf. on Soil Mech. and Found. Eng., Madrid, Vol. 1, 299306

Schlosser, F. and Long, N.T. (1974), "Recent results in French research on reinforced earth," J. of Const. Div. ASCE, Vol. 100, No. CO3, 223-237

Scott, J.D., Bauer, G.E. and Shields, D.H. (1980), "Triaxial testing on granular aggregate," Ontario Joint Transportation and Communications Research Program, Project 0-1, Final Report, Min. of Transport. of Ontario, Willowdale, Ontario, canada

Seed, H.B. and Idriss, I.M. (1967), " Analysis of soil liquefaction: Niigaa Earthquake," J. of Soil Mech. and Found. Div., ASCE, Vol. 93, SM 3, 83-108

Seed, H.B. and Idriss, I.M. (1971), " Simplified procedure for evaluating soil liquefaction potential," J. of Soil Mech. and Found. Div., ASCE, Vol. 97, SM 9, 1249-1273 
Singh, A. and Mitchell, J.K. (1968), "General stress-strain-time functions for soils," J. of Soil. Mech. and Found. Div., ASCE, SM 1, 21-46

Steuermann, S. (1939), "A new soil compaction device," Engineering News Record, July, U.S.A.

Vautrain, J. (1977), " Mur en terre armee sur colonnes ballastees," Int. Symp. on Geotech. Aspects of Soft Clays, Bangkok, Balkema, R.otterdam, Vol. 2, 612-628

Vesic, A.S. (1972), "Expansion of cavities in infinite soil mass," J. of Soil Mech. and Found. Eng., ASCE, Vol. 98, SM 4, 265-290

Wallace, R.B. and Fluet J.E, Jr. (1987), "Slope reinforcement using geogrids," Geosynth. '87 Conf., New Orleans, U.S.A., Vol 1., 121-132

Wallays M., Delapierre, J. and Van Den Poel, J. (1983). " Load transfer mechanism in soils reinforced by stone or sand columns," Proc. 8th Europ. Conf. on Soil Mech. and Found. Eng., Helsinki, May, Vol. 1, 313-317

Ward, I.M. (1984), "The orientation of polymers to produce high performance materials," Proc. of Conf. on Polymer Grid Reinf. London, March

Wilson-Fahmy, R.F. and Koerner, R.M. (1994), " Experimental behaviour of polymeric geogrids in pull-out," J. of Geotech. Eng., ASCE, Vol. 120, SM 4, 661-677

Wu, C.-S. (1987), "Finite element analysis of fabric reinforced sand," PhD. Thesis, Civil Engineering, Michigan University, Michigan

Yang, Z. (1972), " Strength and deformation characteristics of reinforced sand," Ph.D. Thesis, University of California, Los Angeles, California

Zhao, Y. (1993), " Strength and deformation behaviour of geogrid reinforced soils," Ph.D. Thesis, Civil Eng., Carleton University, Ottawa, Ontario, Canada 


\section{APPENDIX A: COMPUTER PROGRAM}

This computer program, written in Quick Basic, was developed to utilize the hyperbolic model (Version 1) to predict the stone column behaviour.

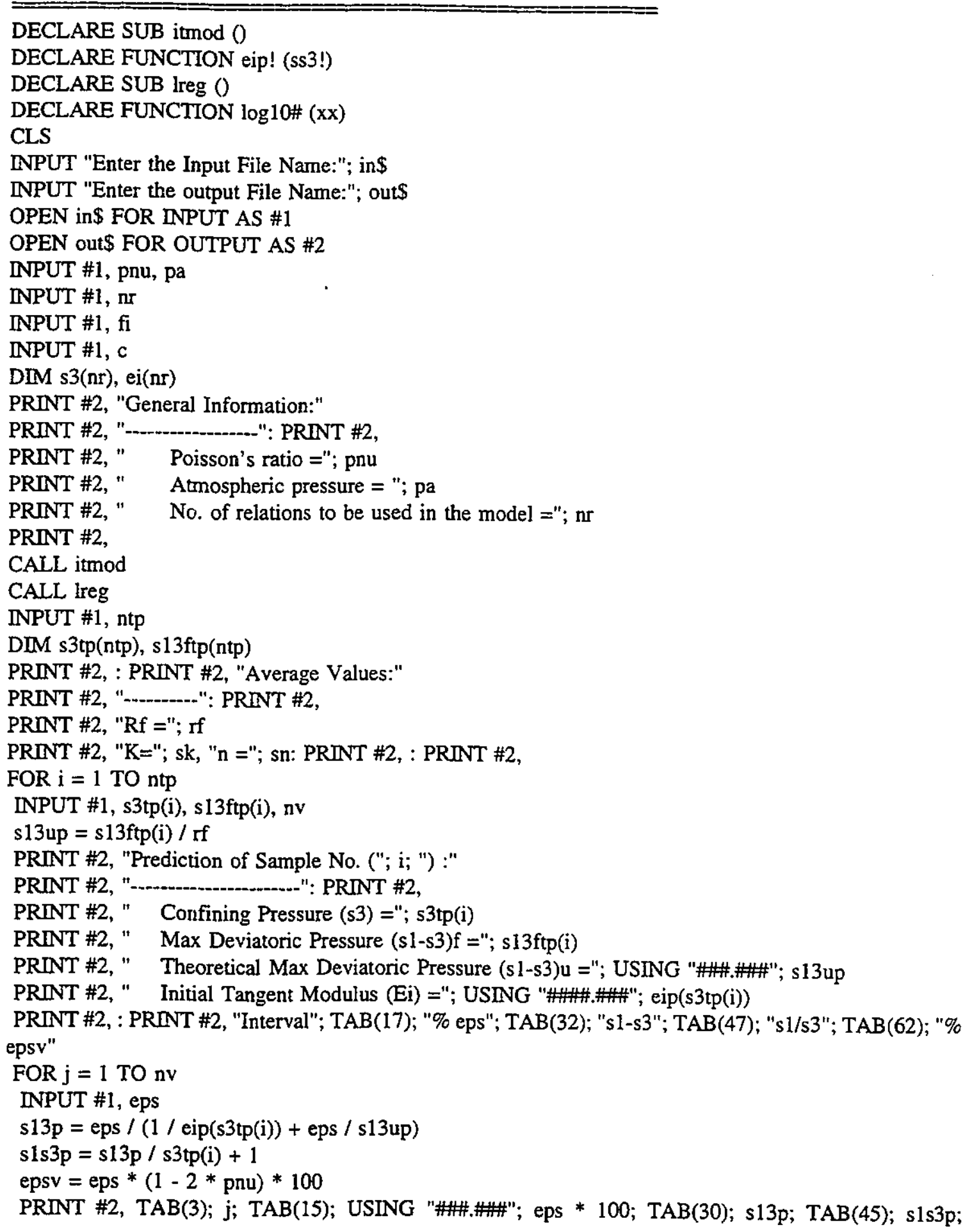


TAB(62); epsv

NEXT: NEXT

CLOSE

END

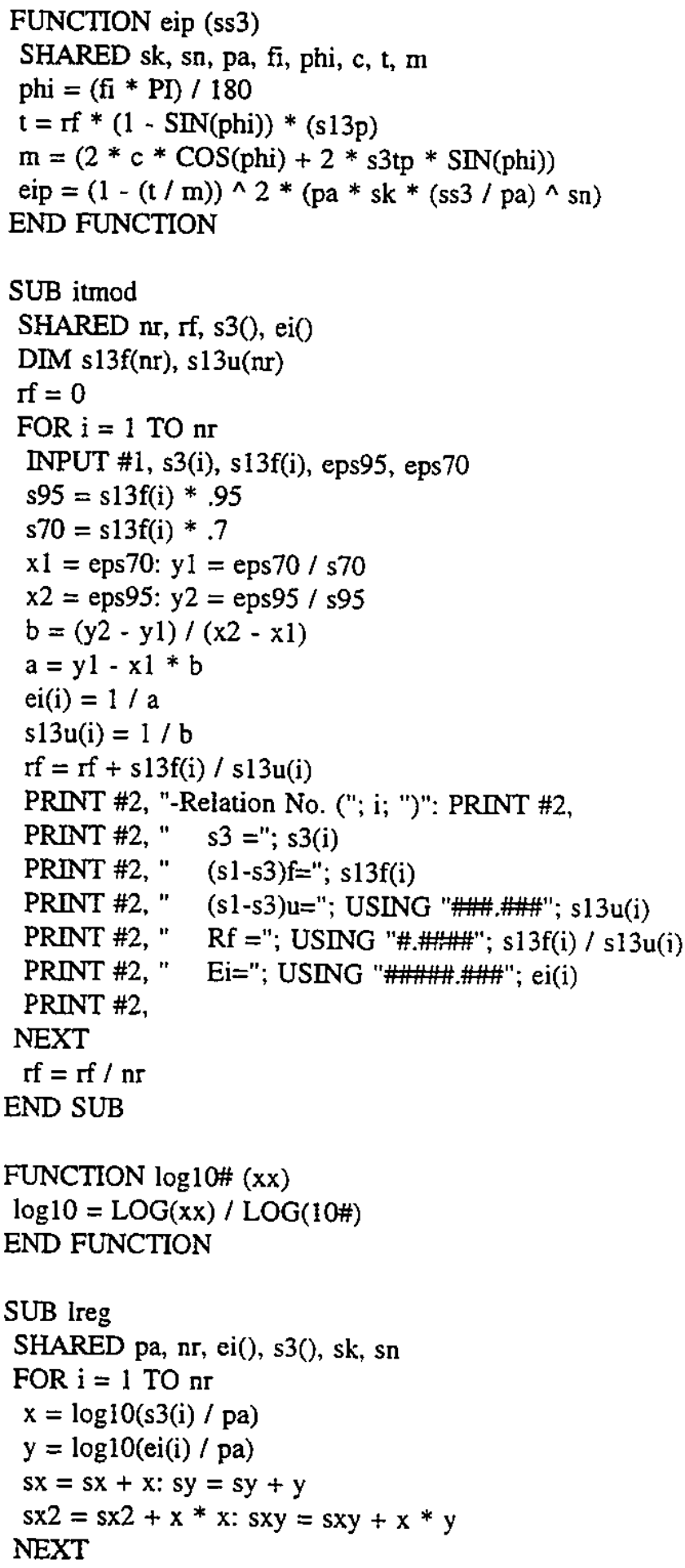




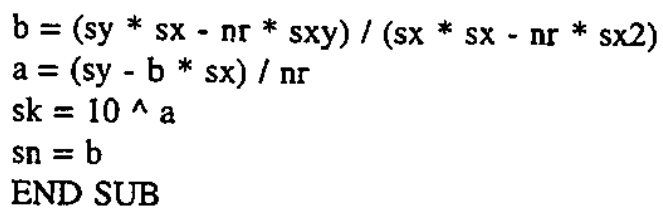

The input data are entered to the program in an input file created by the user. The program asks the user for the name of the input file with this statement:

Enter the Input File Name:

The input file must contain the following data, in the same sequence:

pnu, pa

$\mathrm{nr}$

s3(i),s13f(i),eps95,eps70

ntp

s3tp(i),s13ftp(i),nv(i)

eps $(\mathrm{i}, \mathrm{j})$

where:

$\mathrm{pnu}=$ Poisson, $\mathrm{s}$ ratio for the soil,

pa = the atmospheric pressure,

$\mathrm{nr}=$ no. of relations, samples, to be used in developing the model parameters, $s 3(i)=$ the confining pressure, $\sigma_{3}$, for the ith relation

$\operatorname{si3f}(\mathrm{i})=$ the maximum deviator pressure, $\left(\sigma_{1}-\sigma_{3}\right)_{\mathrm{f}}$, for the ith relation, eps $95=$ the vertical strain at $95 \%$ of the maximum deviator pressure, eps $70=$ the vertical strain at $70 \%$ of the maximum deviator pressure, ntp $=$ no. of relations to be predicted using the developed model, $s 3 \operatorname{tp}(i)=$ the confining pressure, $\sigma_{3}$, for the ith relation to be predicted, s13f(i) = the maximum deviator pressure, $\left(\sigma_{1}-\sigma_{3}\right)_{\mathrm{f}}$, for the ith relation to be predicted,

$\mathrm{nv}(\mathrm{i})=$ no. of points to be predicted for the ith relation, and eps $(i, j)=$ the vertical strain for the ith relation at the jth point.

The program gives the results in an output file named by the user. The program asks the 
user for the output file name with this statement:

Enter the Output File Name:

This output file will contain an input echo for the Poisson's ratio and the atmospheric pressure, some intermediate results and the final results which are the prediction of the deviator pressure, $\left(\sigma_{1}-\sigma_{3}\right)$, and the volumetric strain, $\varepsilon_{v}$. 


\section{APPENDIX B:}

1) Strain Gauge Specifications

Type

Gauge Length

Resistance

Gauge Factor

Temperature Compensation

Thermal Output

Type

Gauge Length

Resistance

Gauge Factor

Temperature Compensation

Thermal Output
: $\quad$ Showa N11-FA-5-120-11

: $5 \mathrm{~mm}$

: $\quad 120 \Omega$

: $\quad 2.11 \pm 3 \%$

: $\quad 11 \mathrm{ppm} /$ deg. C

$: \quad \pm 2 \mu \varepsilon /$ deg. $\mathrm{C}$
Type

Gauge Length

Resistance

Gauge Factor

Temperature Compensation

Thermal Output
: $\quad$ Showa N11-FA-5-120-11

: $5 \mathrm{~mm}$

: $\quad 120 \Omega$

: $\quad 2.06 \pm 1 \%$

: $\quad 11 \mathrm{ppm} /$ deg. C

: $\quad \pm 2 \mu \varepsilon /$ deg. C 


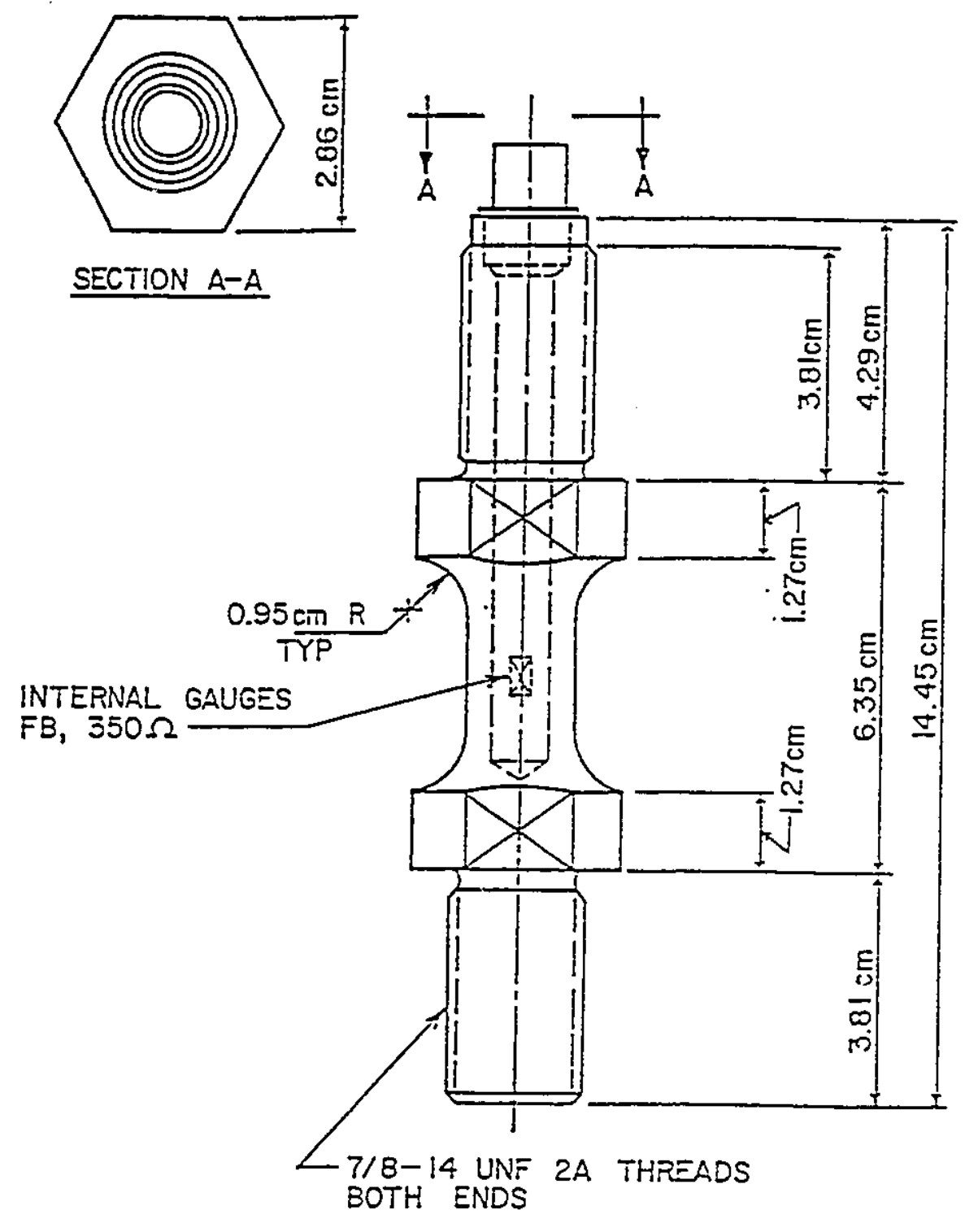

Figure B-1: Load cell 


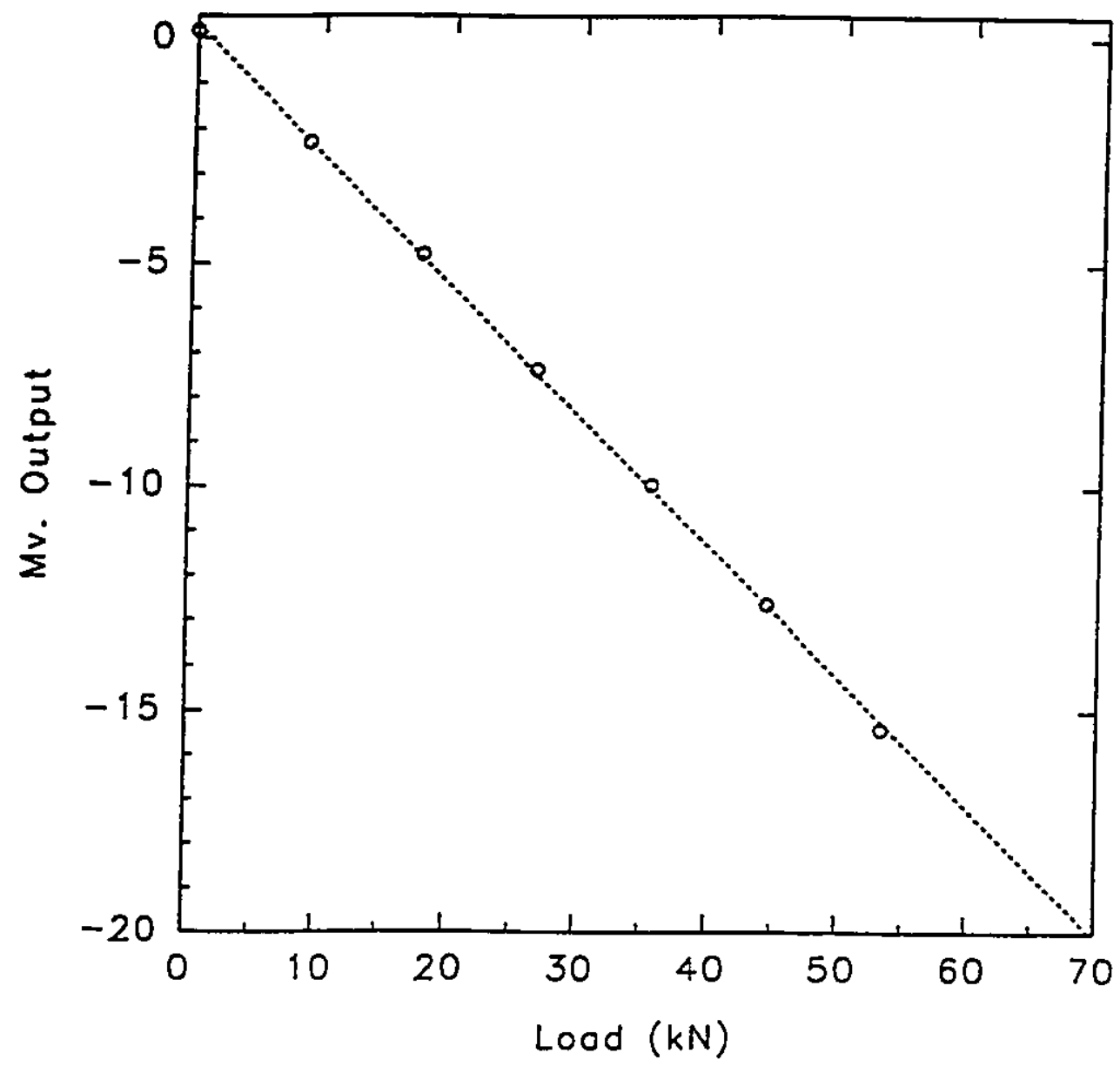

Figure B-2: Calibration curve of load cell Q3491-1 used in the triaxial tests 


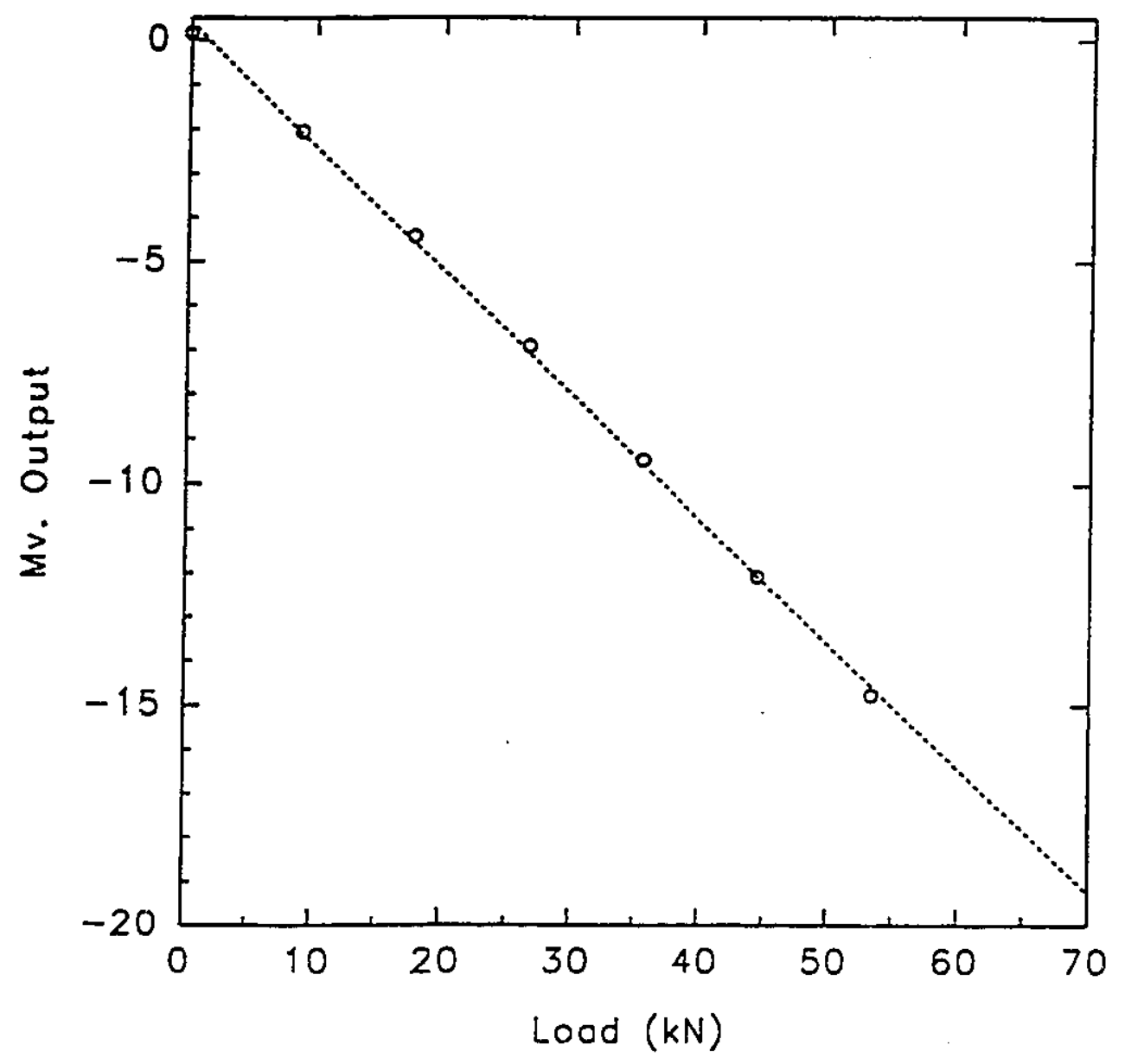

Figure B-3: Calibration curve of load cell Q3491-2 used in the triaxial tests 


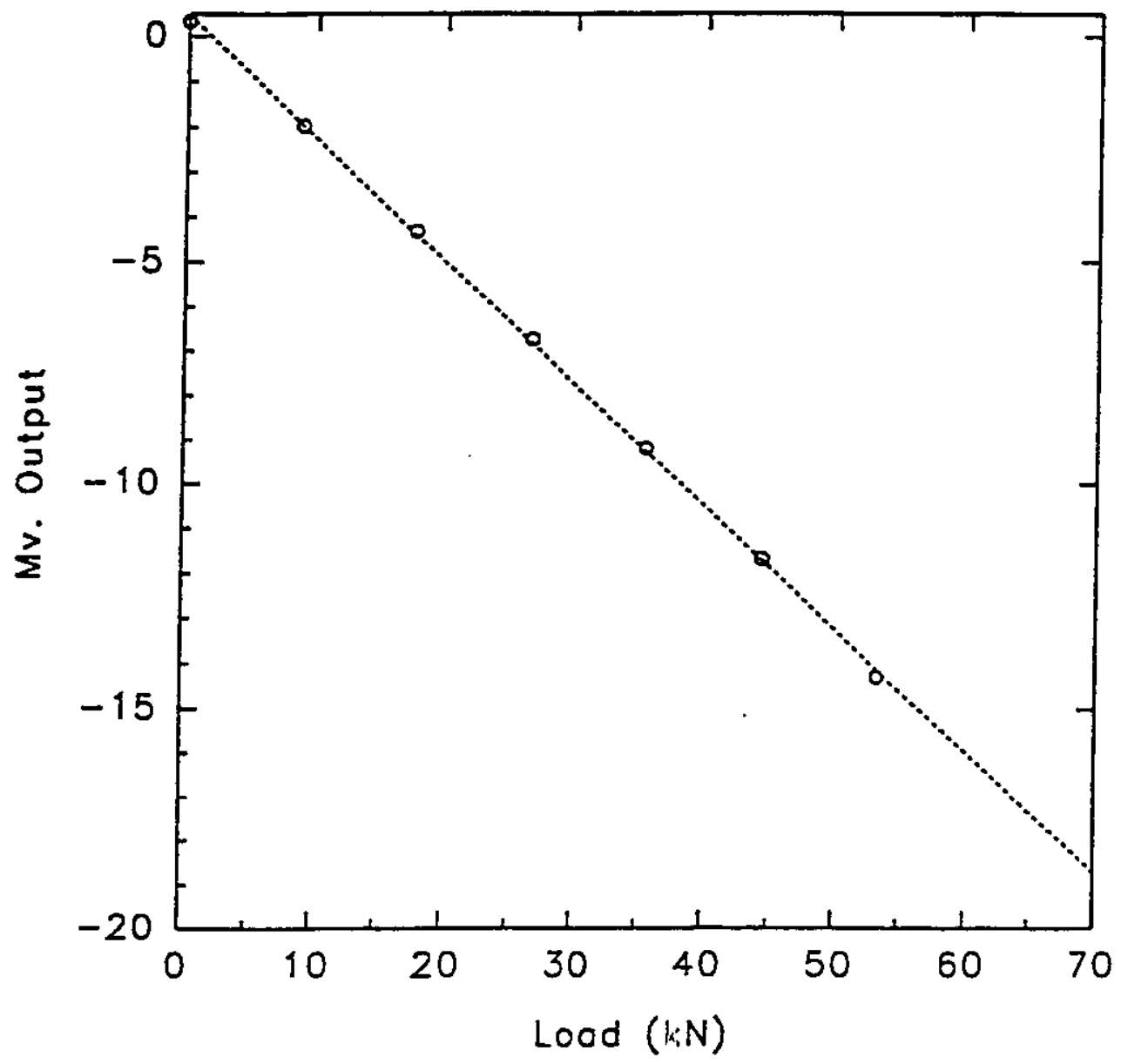

Figure B-4: Calibration curve of load cell Q3491-3 used in the triaxial tests 


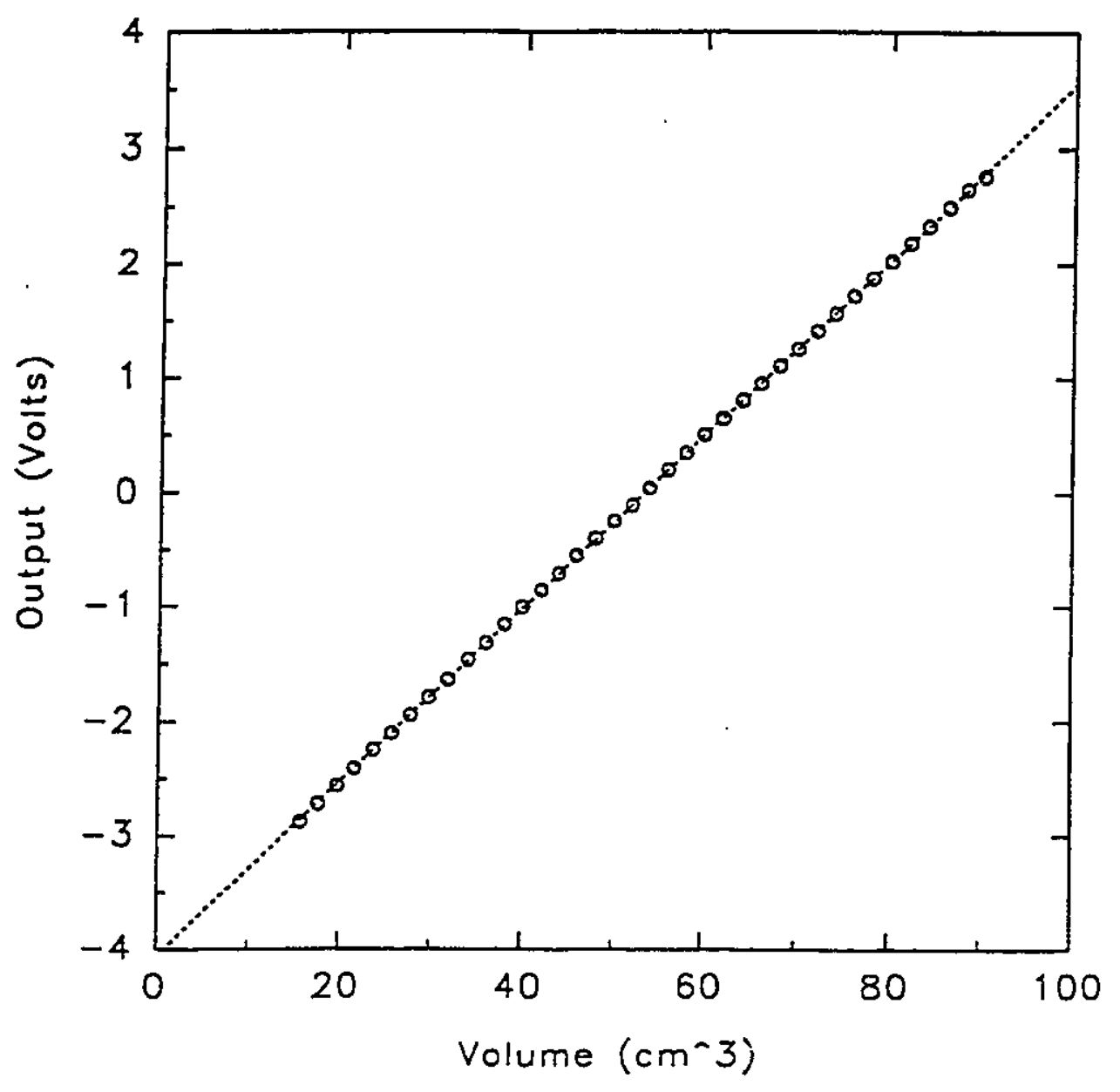

Figure B-5: Calibration curve of volume change device (Calibration pressure $=200 \mathrm{kPa}$ ) 


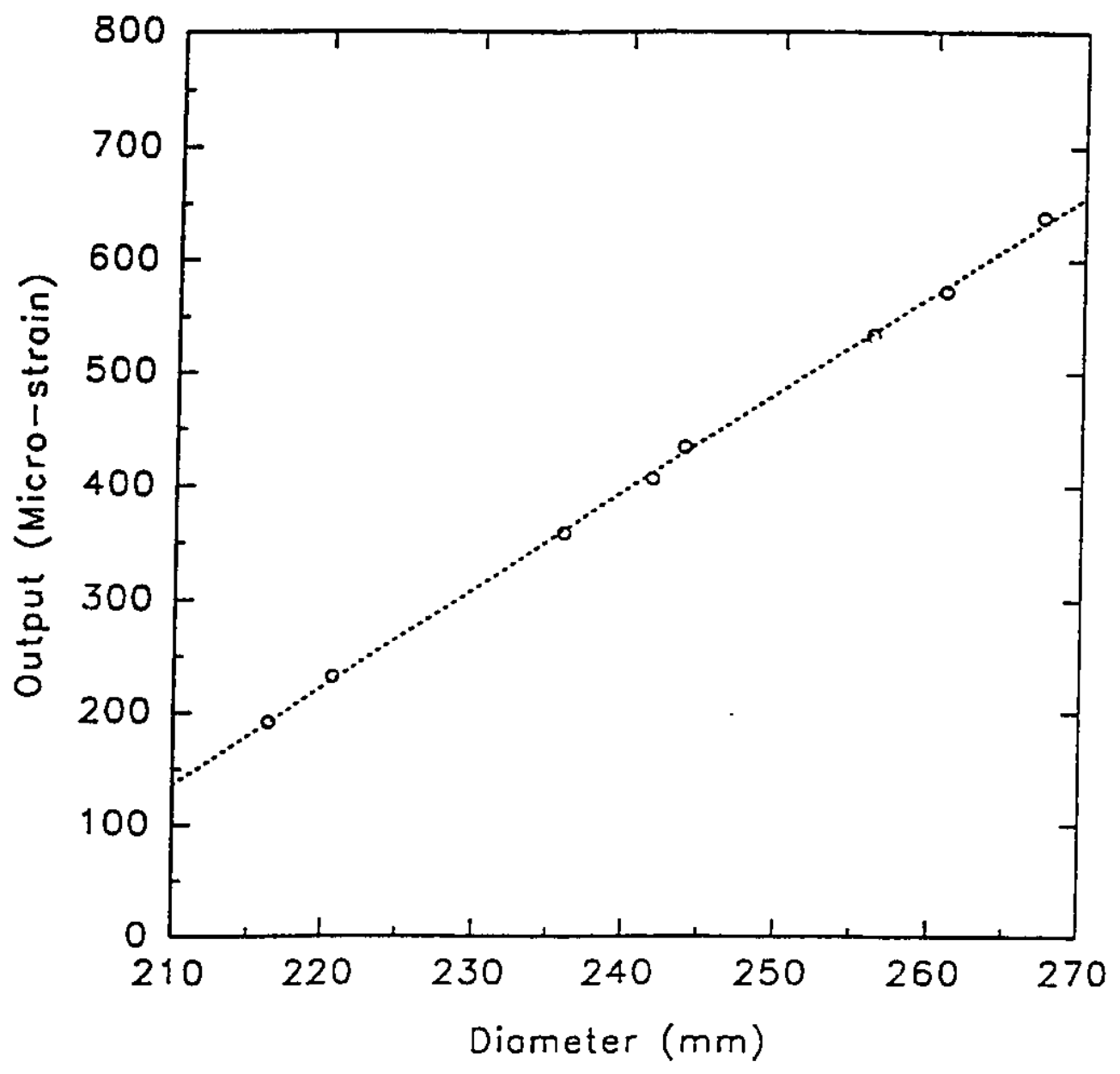

Figure B-6: Calibration curve of lateral deformation clip No. 1 


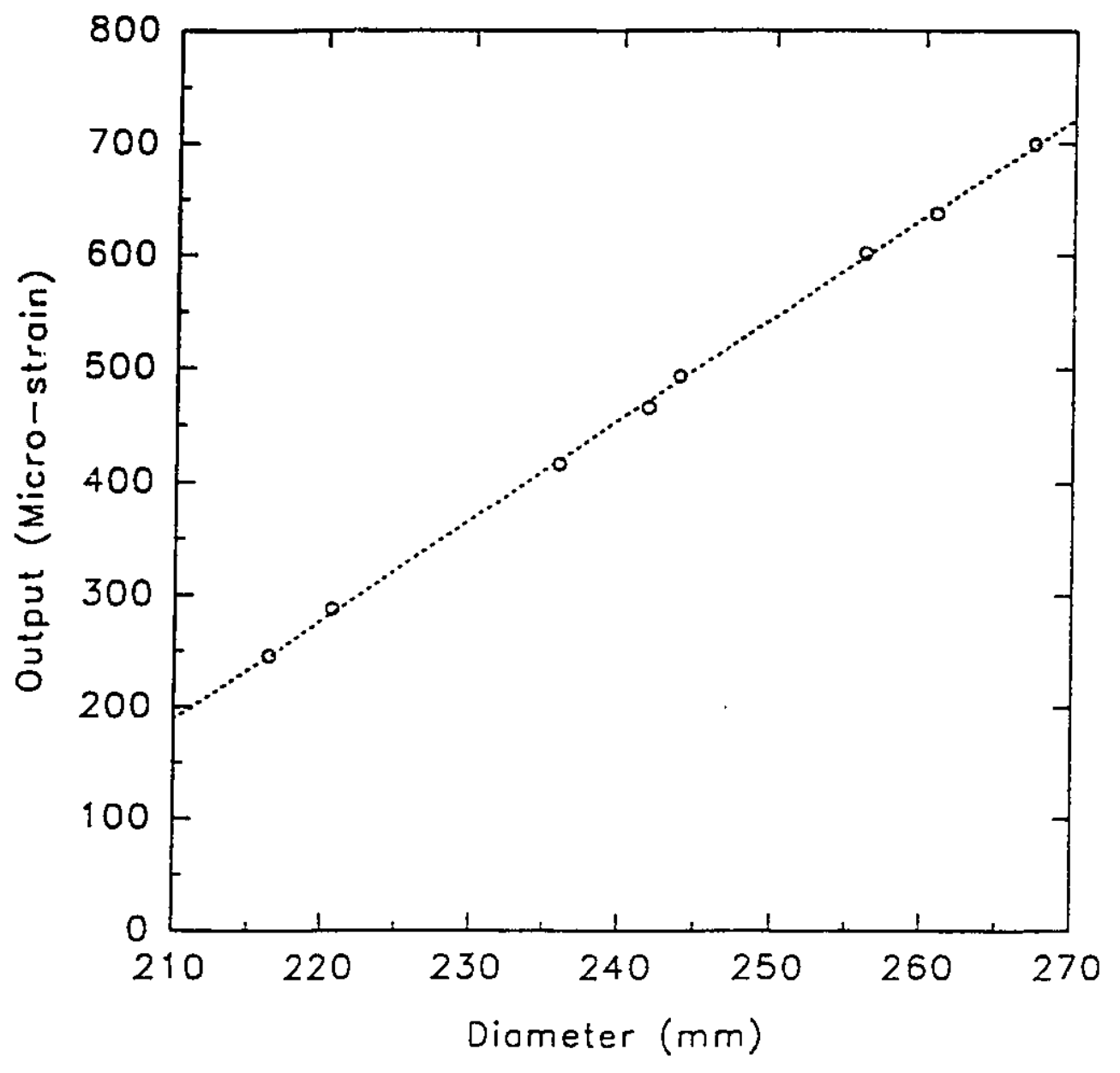

Figure B-7: Calibration curve of lateral deformation clip No. 2 


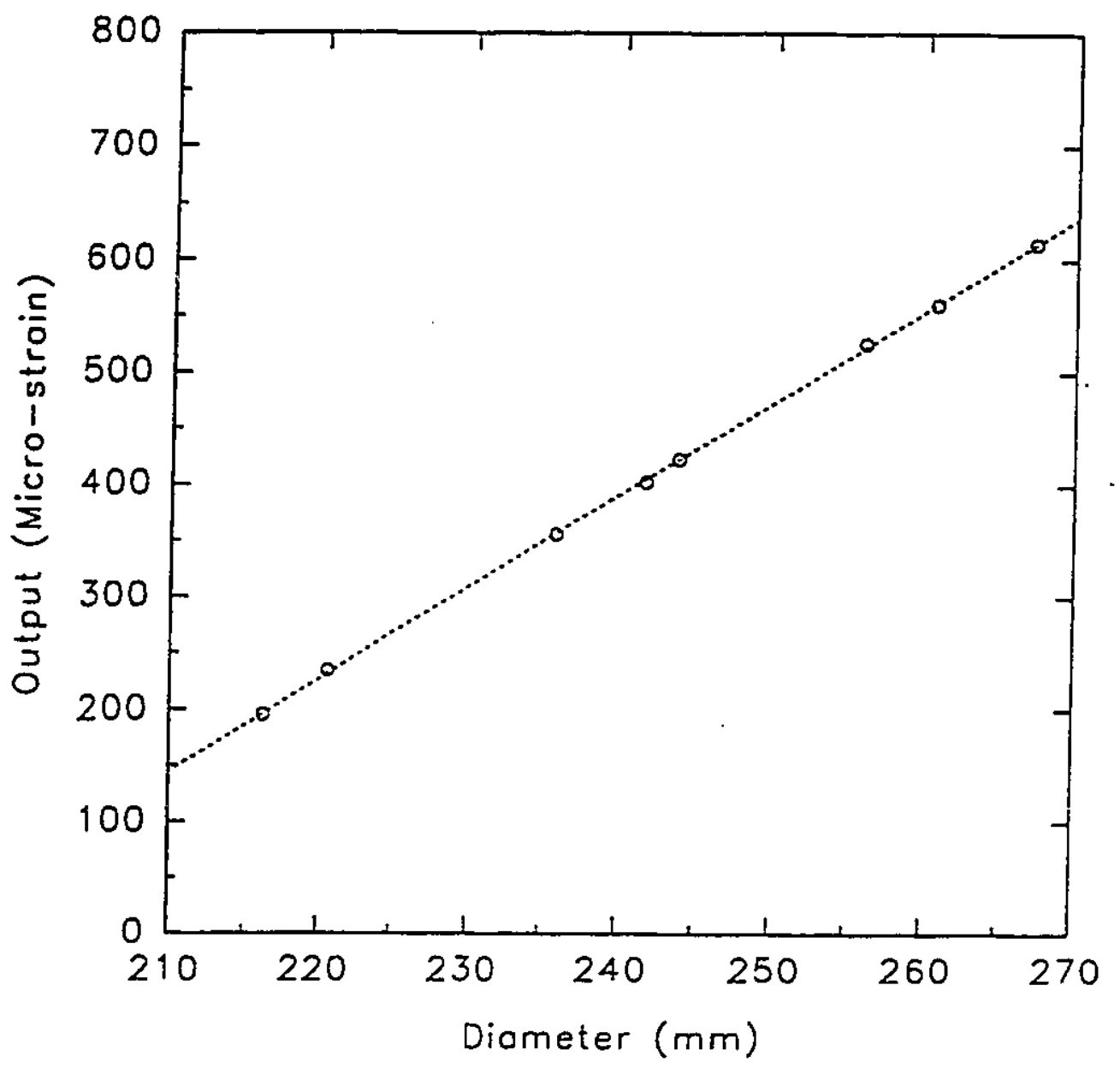

Figure B-8: Calibration curve of lateral deformation clip No. 3 


\section{APPENDIX C:}

MORE EXPERIMENTAL RESULTS 


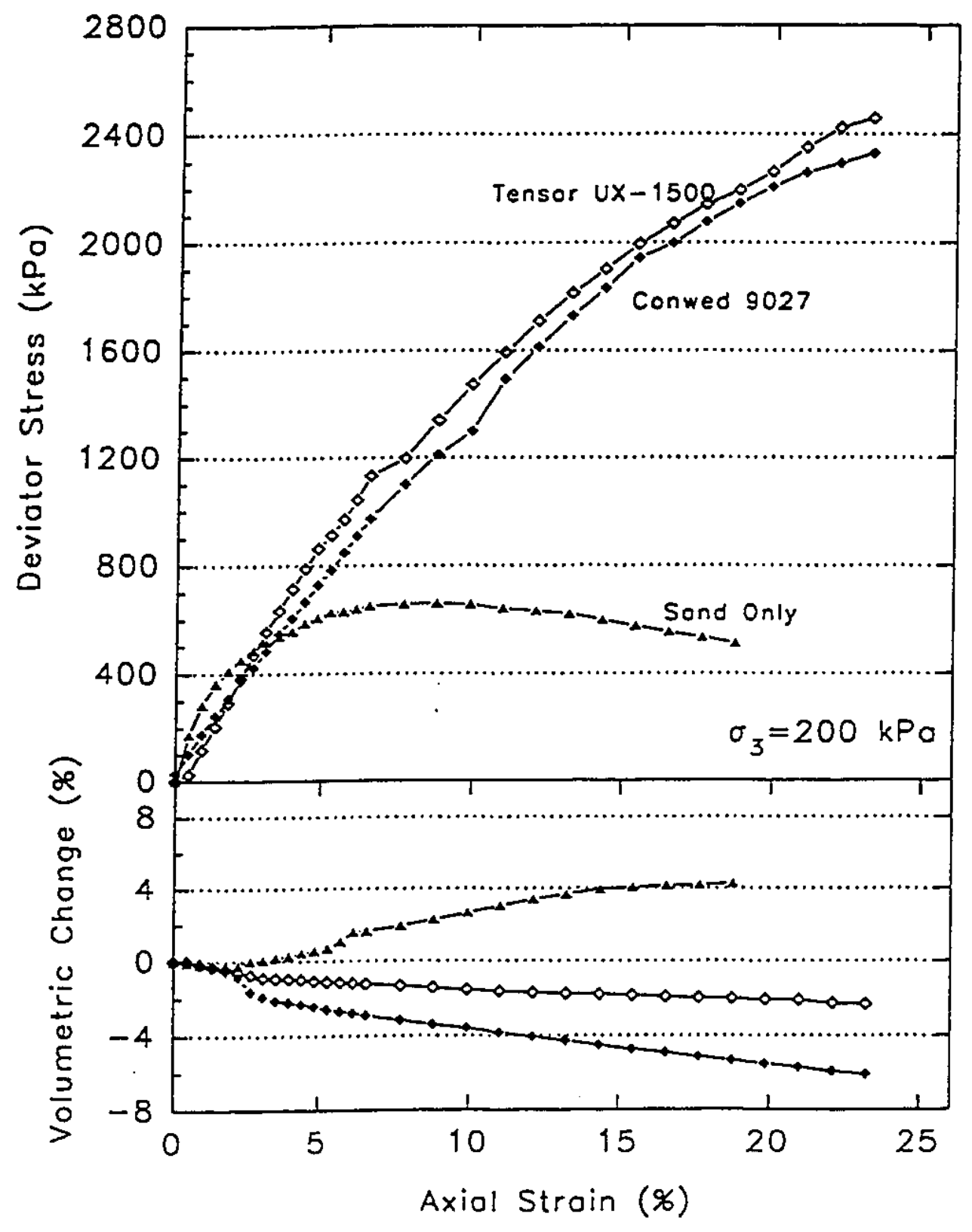

Figure C-1: Stress-strain-volume change behaviour of small specimens with grid sleeve at $\sigma_{3}=200 \mathrm{kPa}$ 


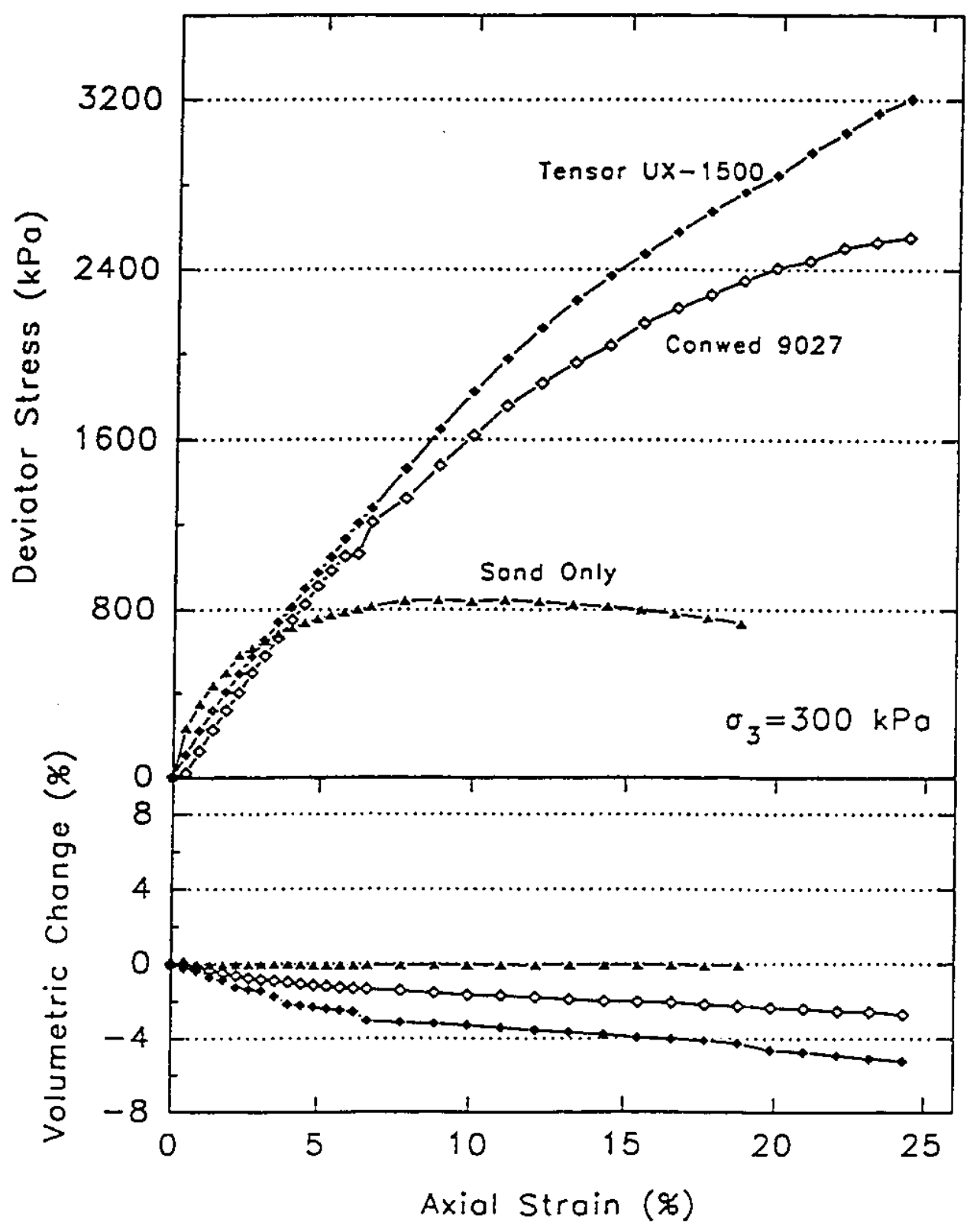

Figure C-2: Stress-strain-volume change behaviour of small specimens with grid sleeve at $\sigma_{3}=300 \mathrm{kPa}$ 


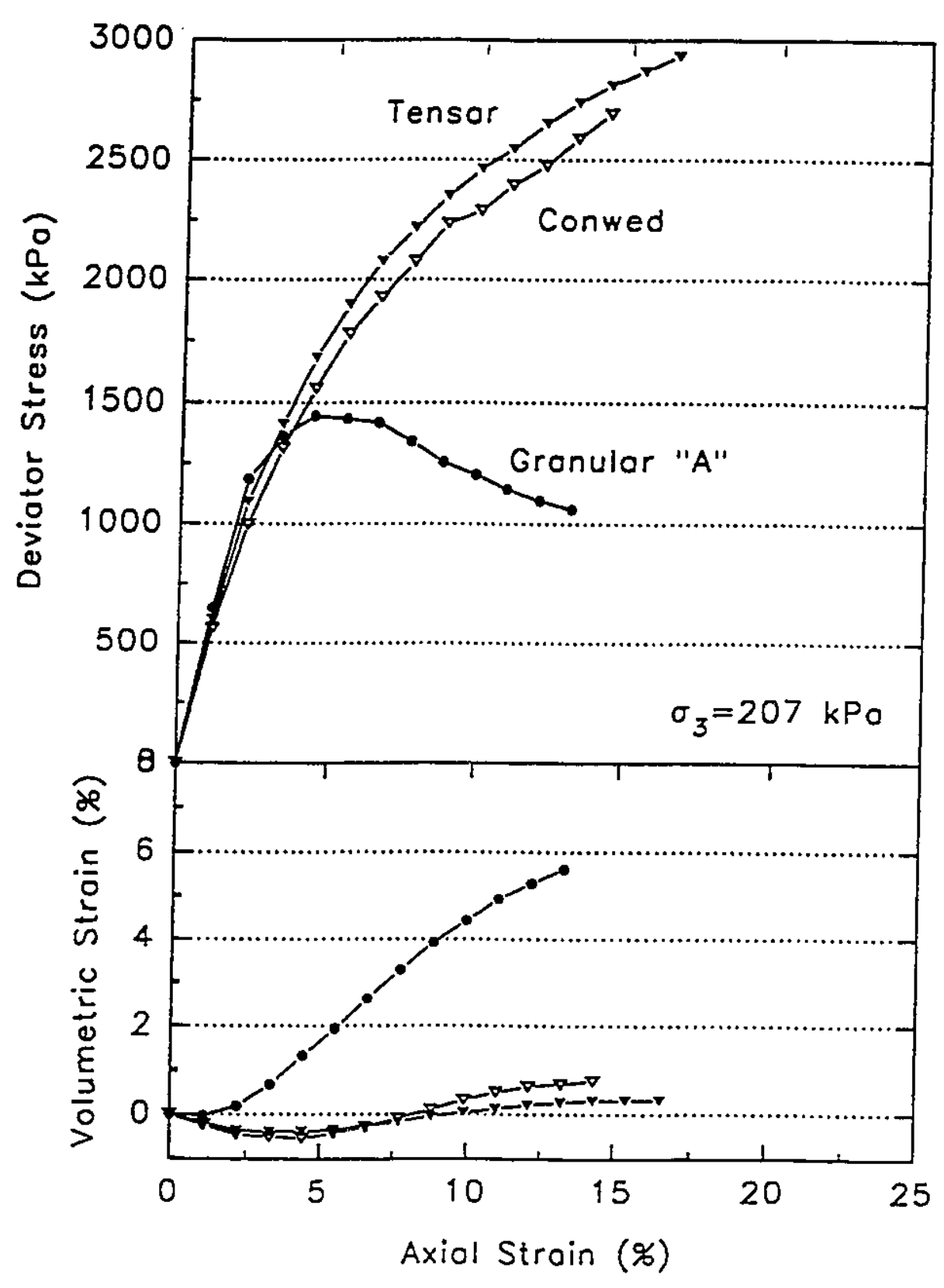

Figure C-3: Stress-strain-volume change behaviour of granular

"A" reinforced stone columns at $\sigma_{3}=207 \mathrm{kPa}$ 


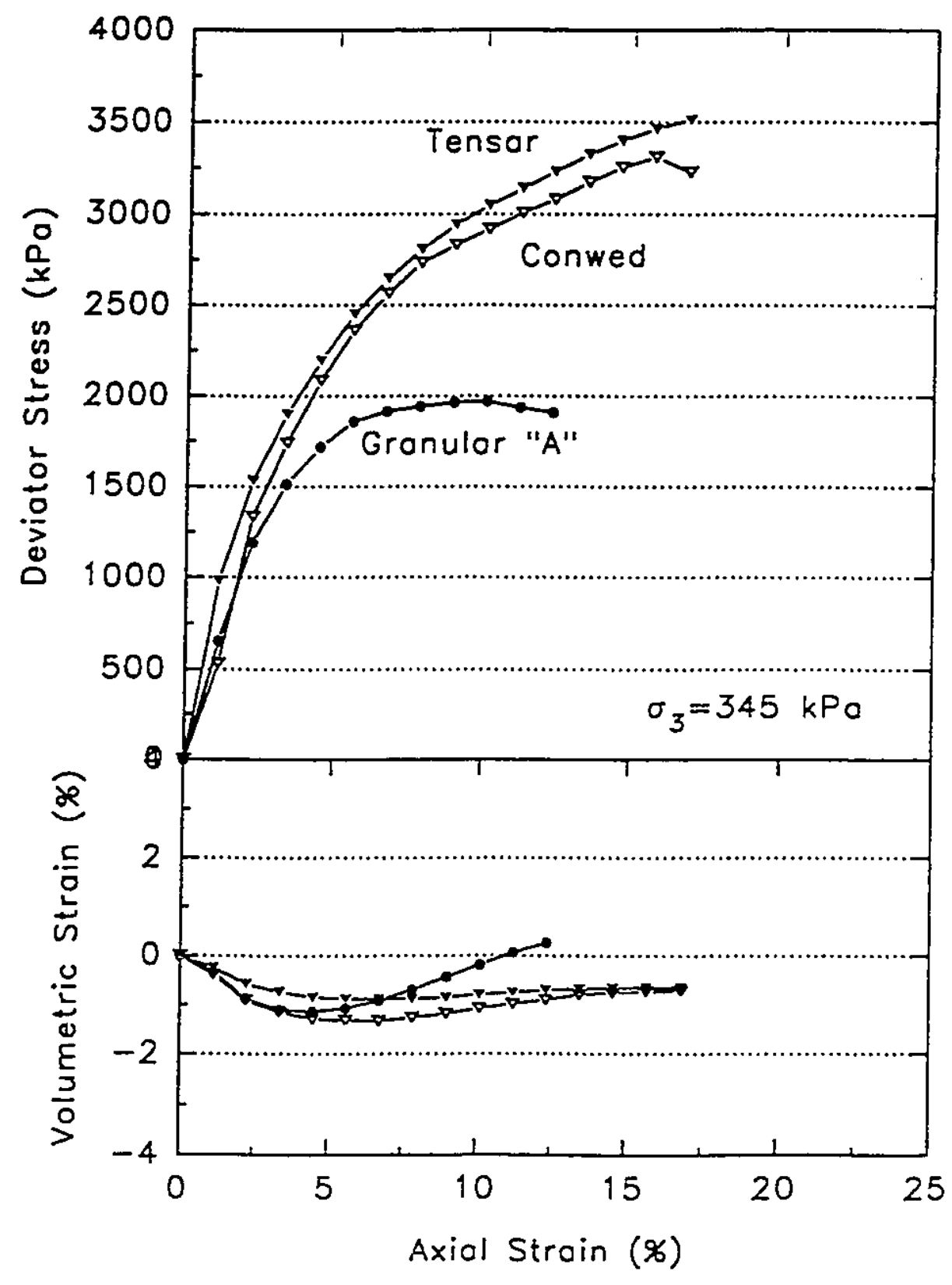

Figure C-4: Stress-strain-volume change behaviour of granular "A" reinforced stone columns at $\sigma_{3}=345 \mathrm{kPa}$ 


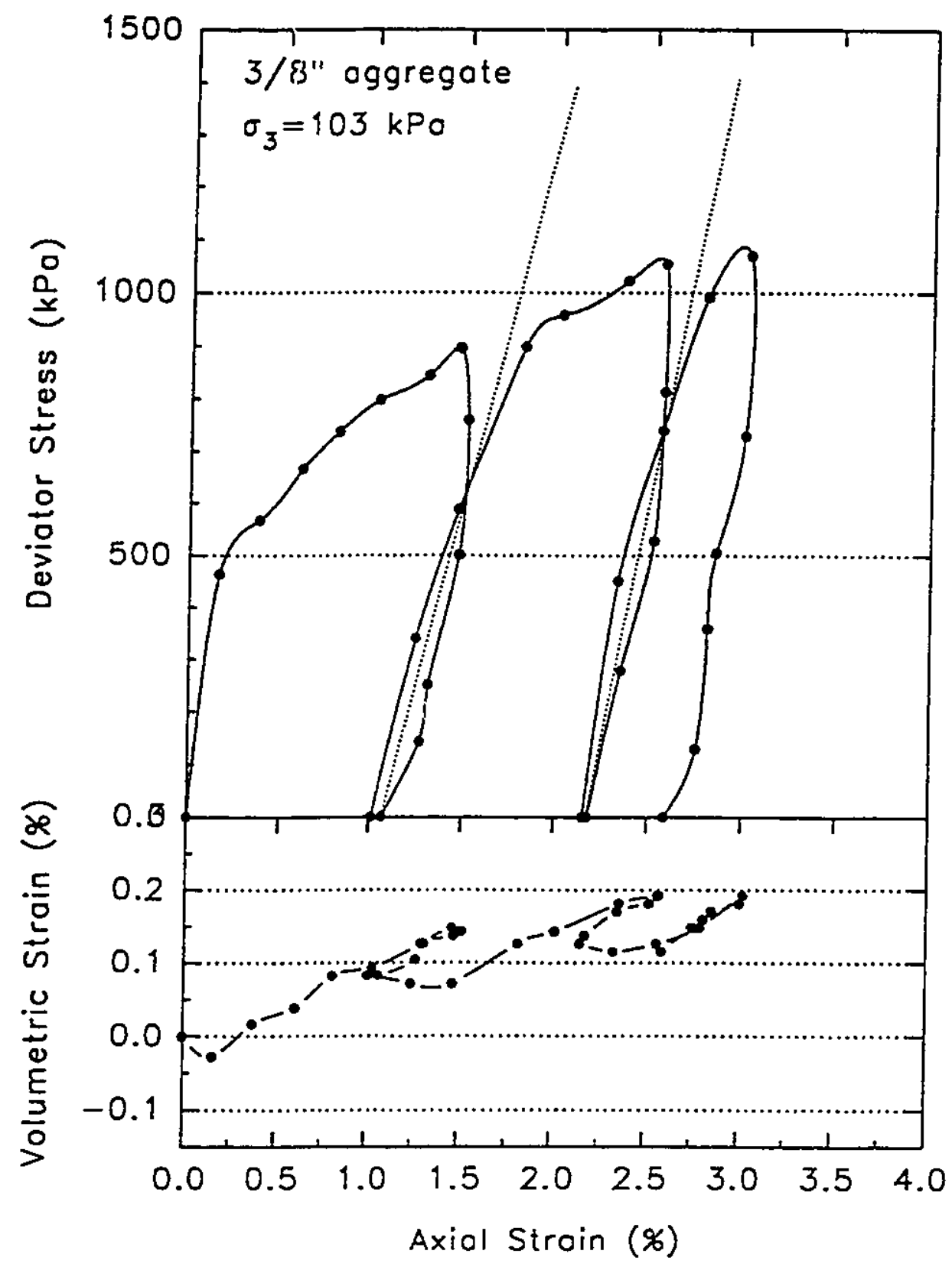

Figure C-5: Cyclic loading stress-strain volume change behaviour of unreinforced stone column 


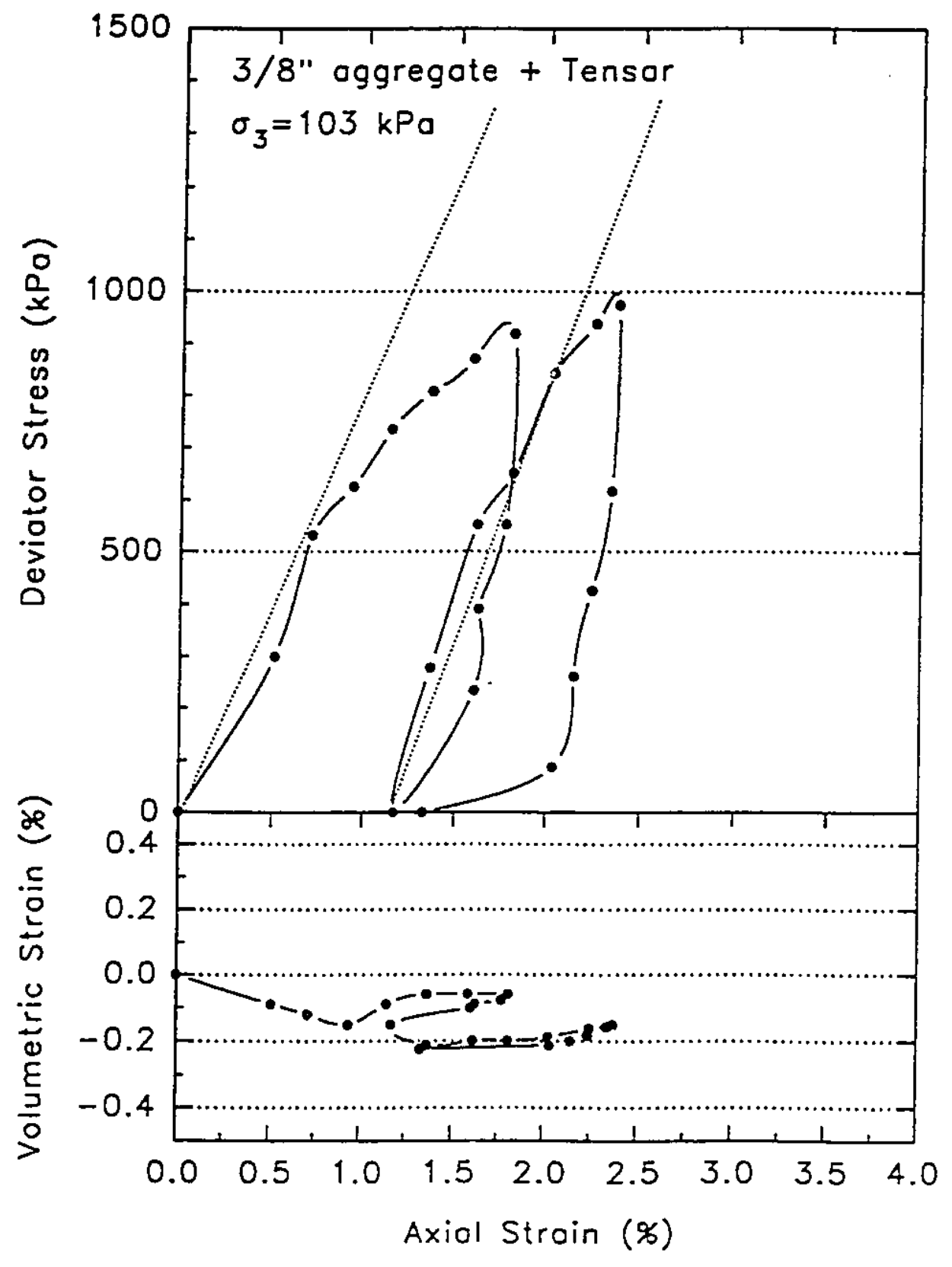

Figure C-6: Cyclic loading stress-strain volume change behaviour of sleeve reinforced stone column 


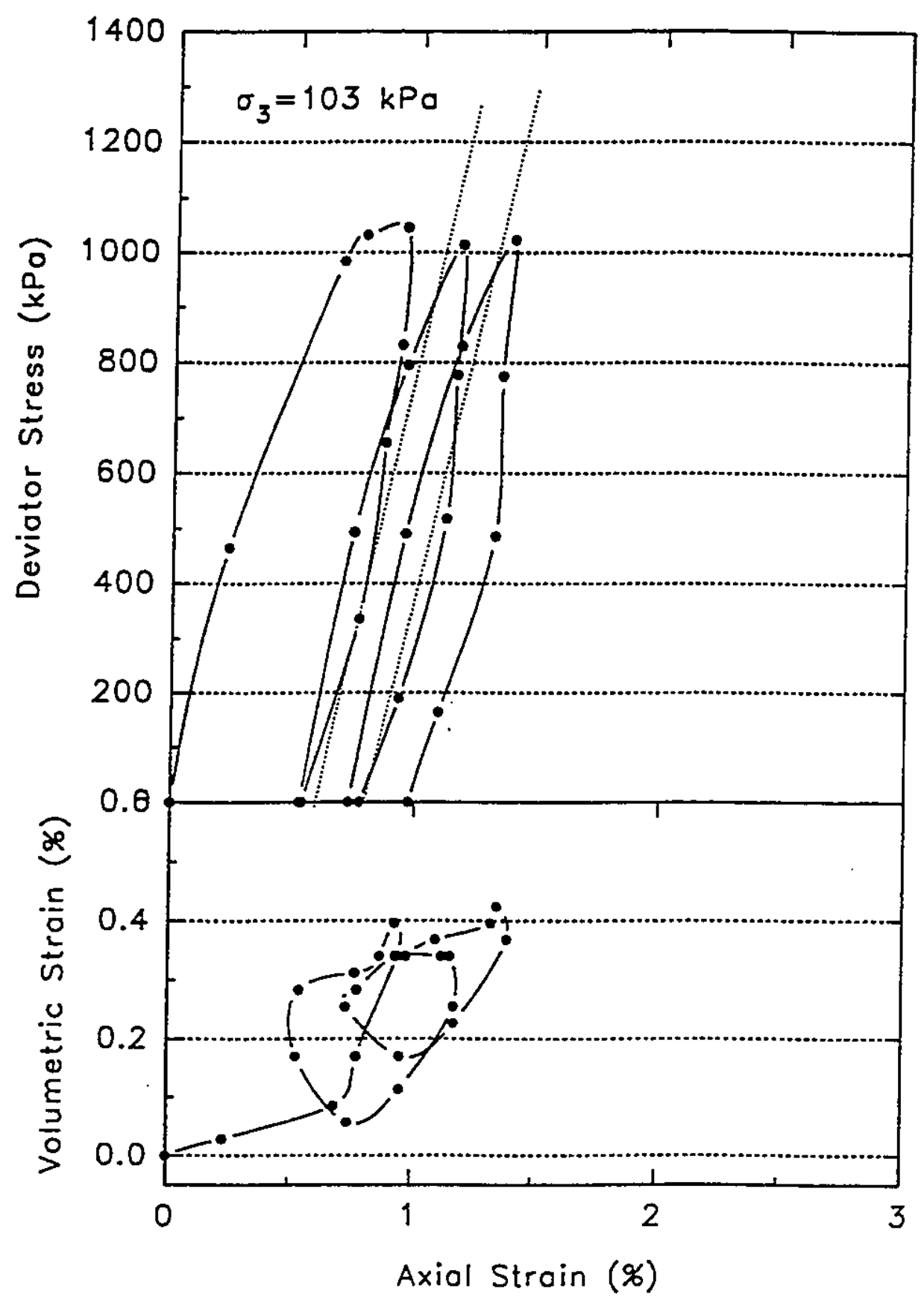

Figure C-7: Cyclic loading stress-strain volume change behaviour of granular " $A$ " aggregate 


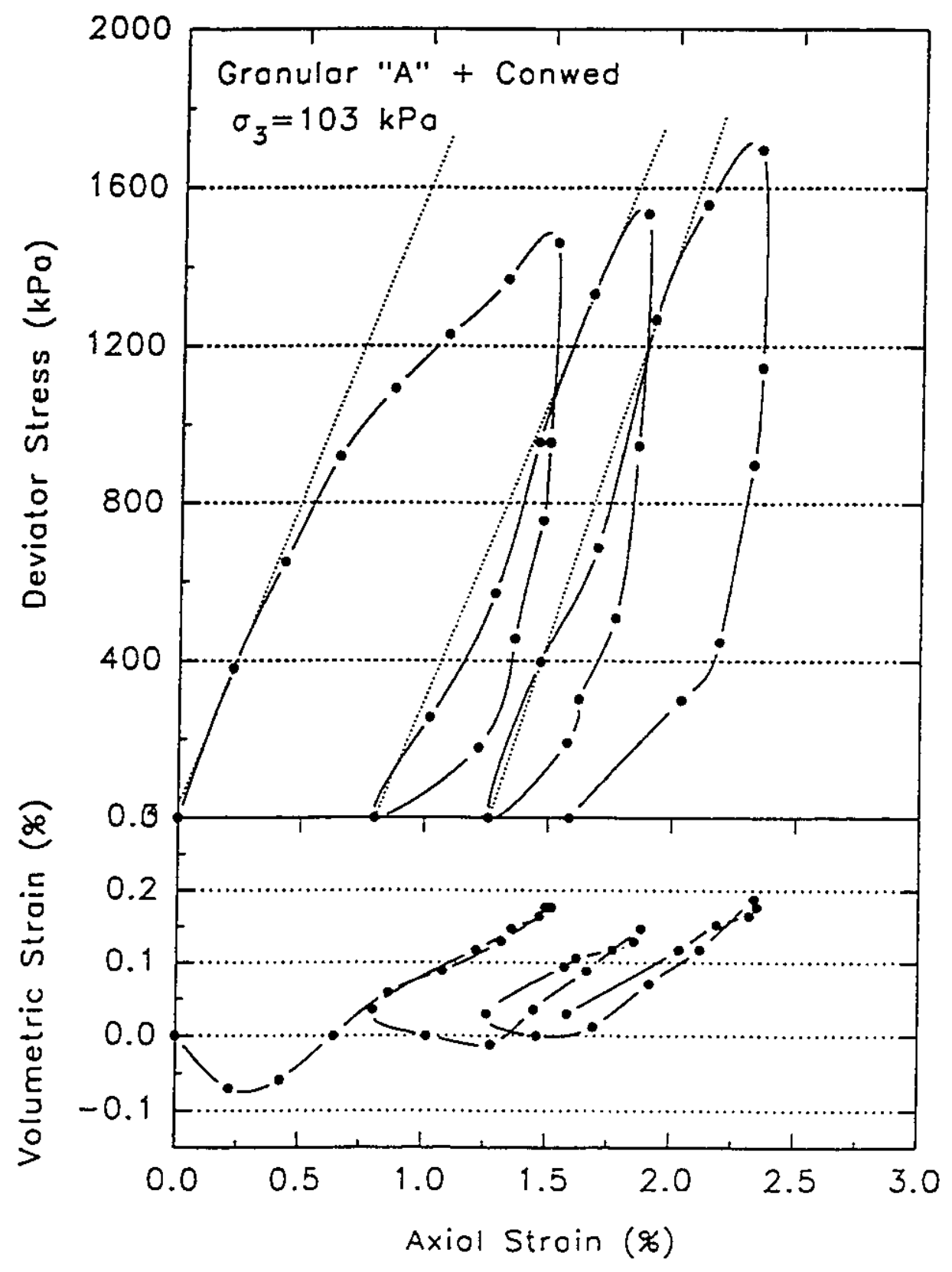

Figure C-8: Cyclic loading stress-strain volume change behaviour of stone column with Conwed sleeve 


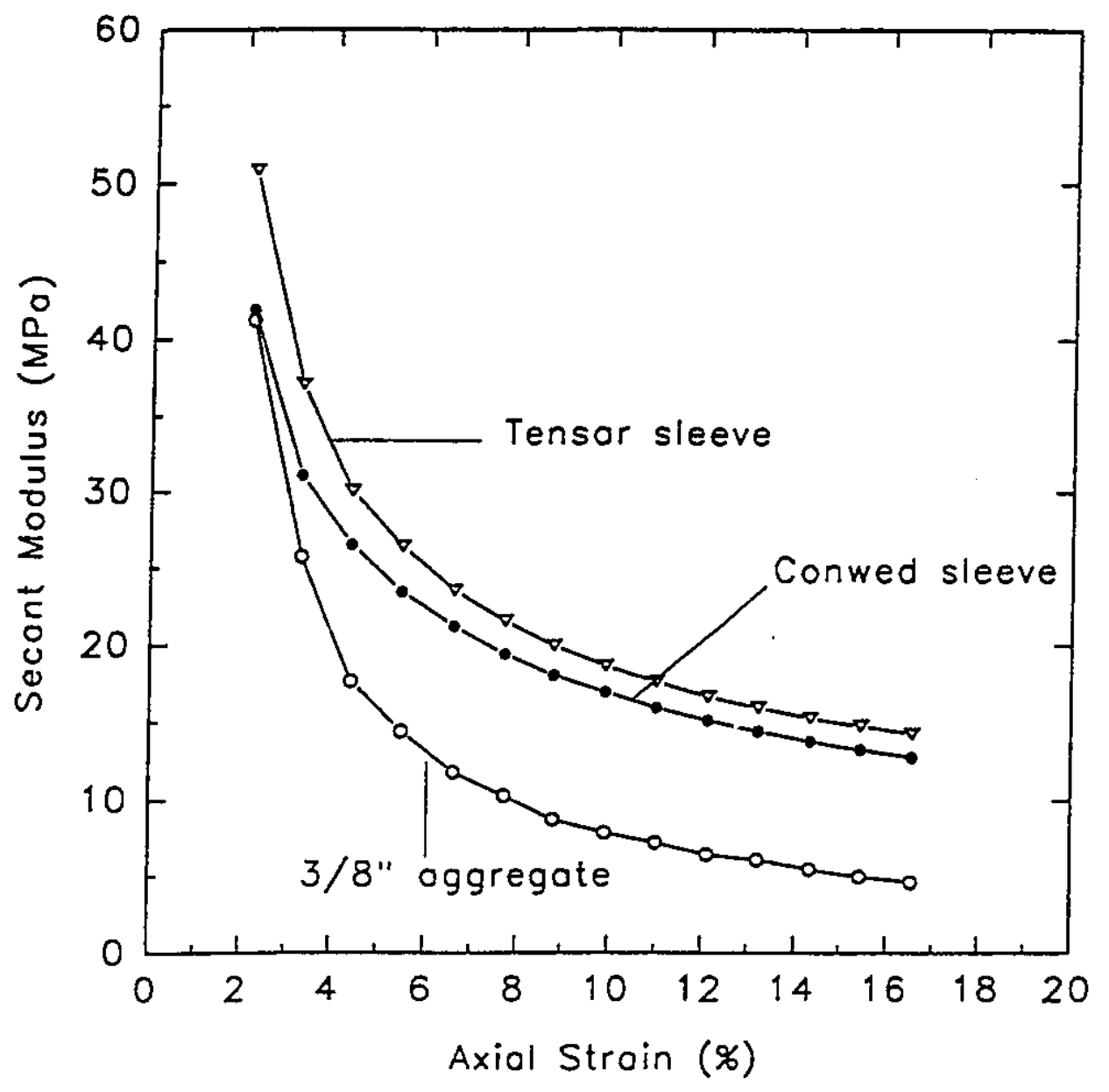

Figure C-9: Comparison of secant modulus for stone columns with $3 / 8^{\prime \prime}$ aggregate and reinforcing sleeve $\left(\sigma_{3}=207 \mathrm{kPa}\right)$ 


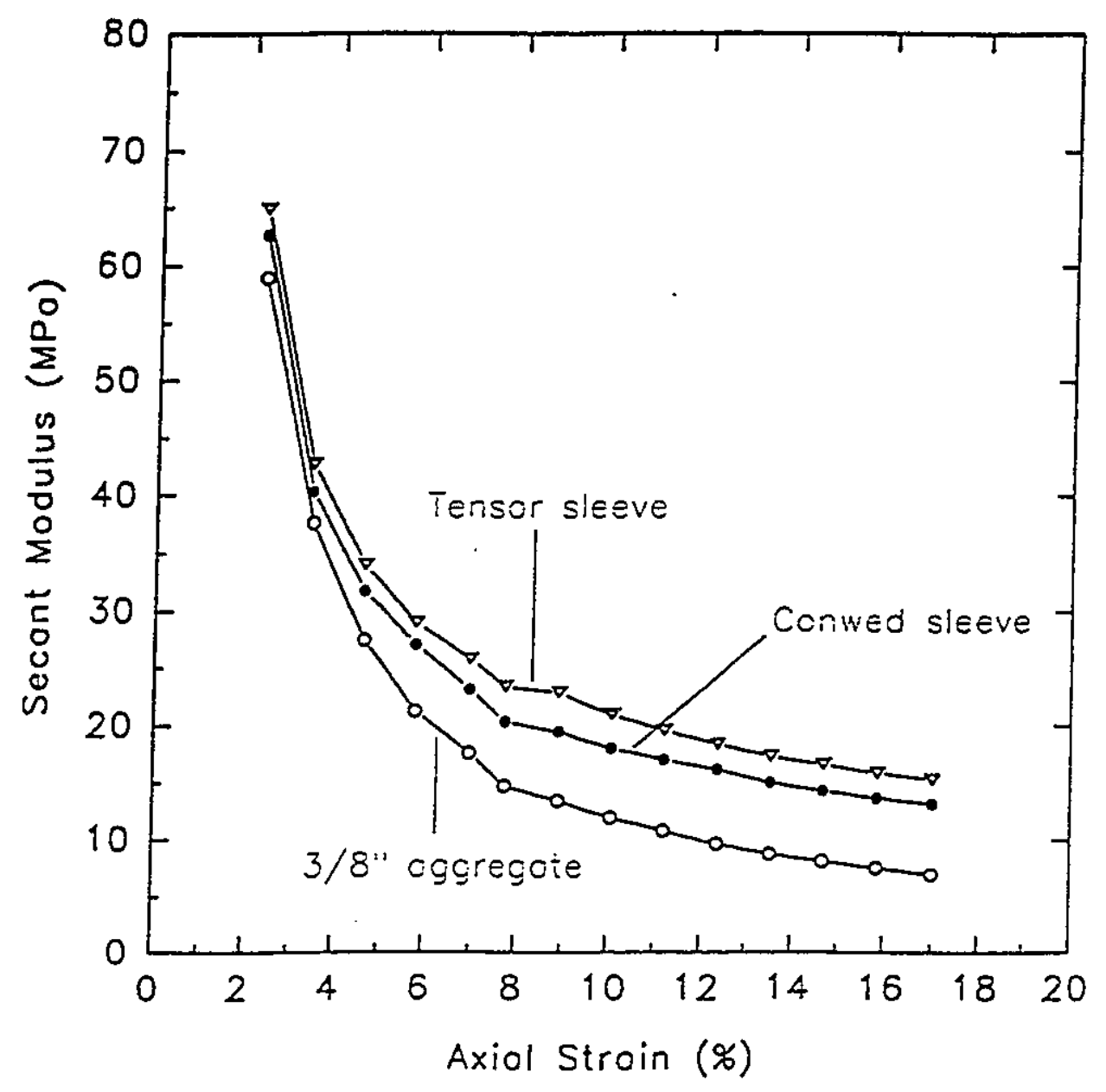

Figure C-10: Comparison of secant modulus for stone columns with $3 / 8$ " aggregate and reinforcing sleeve $\left(\sigma_{3}=345 \mathrm{kPa}\right)$ 


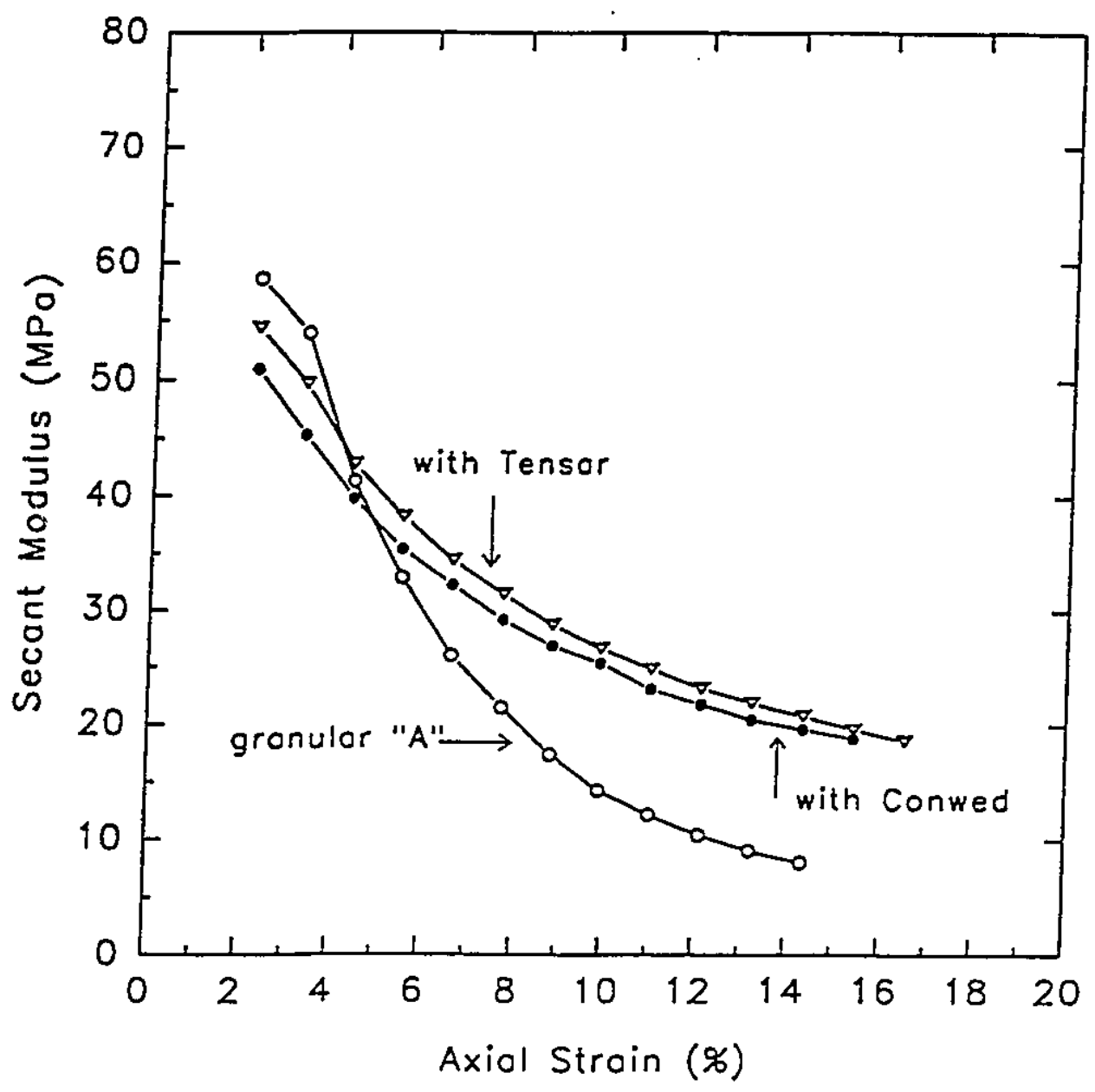

Figure C-11: Comparison of secant modulus for stone columns with granular " $A$ " aggregate and reinforcing sleeve $\left(\sigma_{3}=207 \mathrm{kPa}\right)$ 


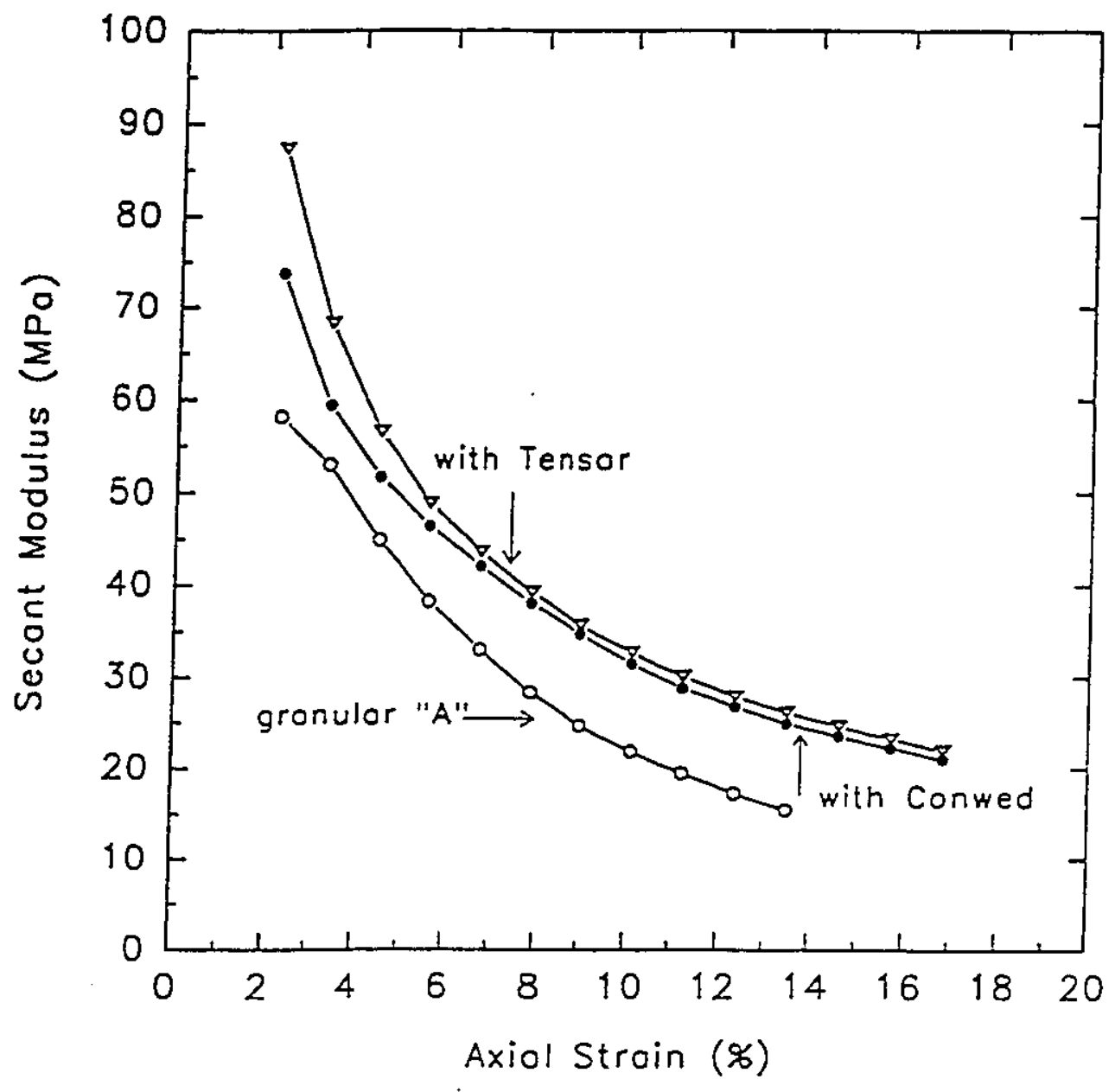

Figure C-12: Comparison of secant modulus for stone columns with granular " $\mathrm{A}$ " aggregate and reinforcing sleeve $\left(\sigma_{3}=345 \mathrm{kPa}\right)$ 


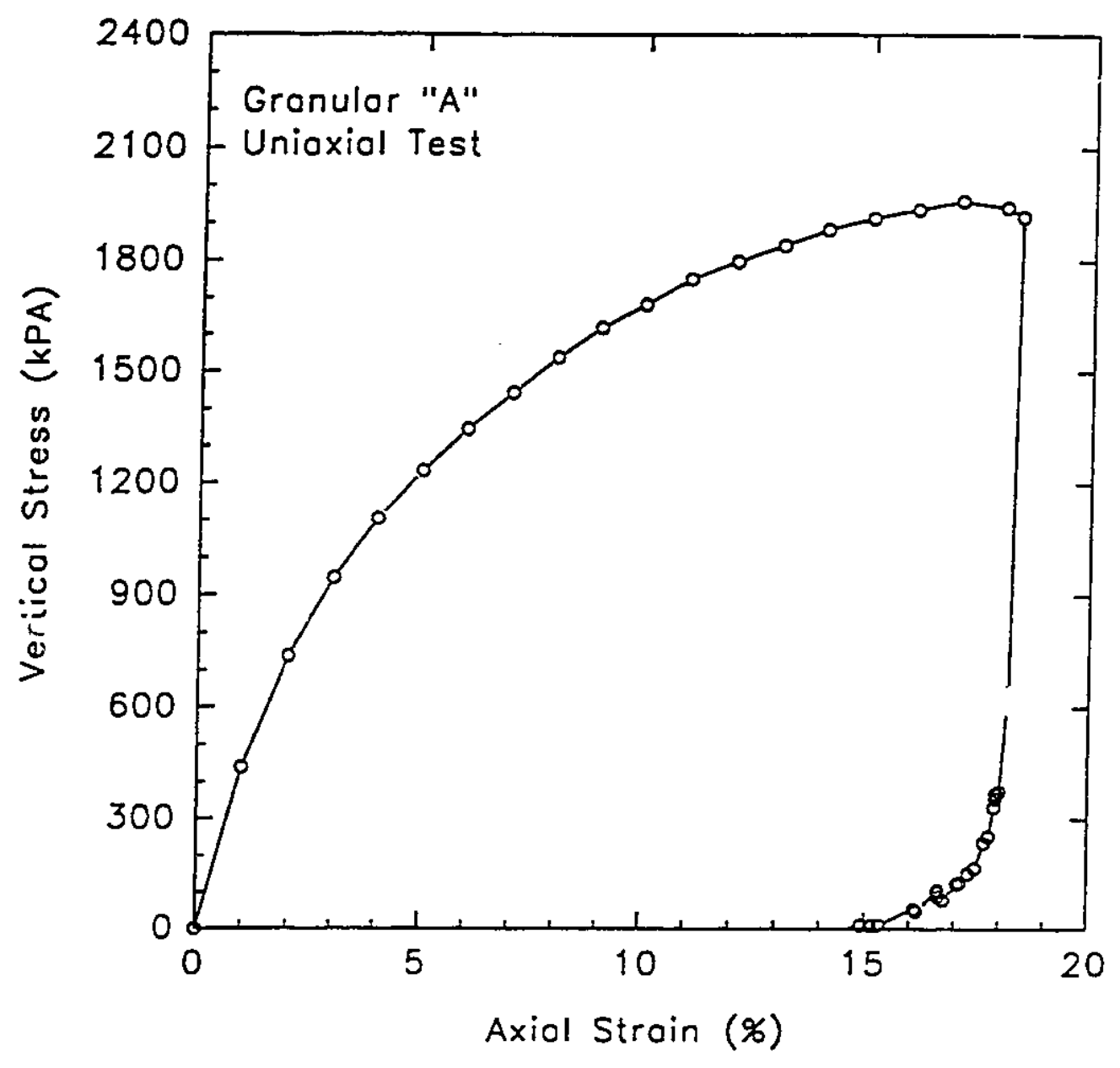

Figure C-13: Stress-strain behaviour of uniaxial stone column with Tensar UX-1600 sleeve $($ Diam. $=0.33 \mathrm{~m}$, Height $=0.68 \mathrm{~m})$ 


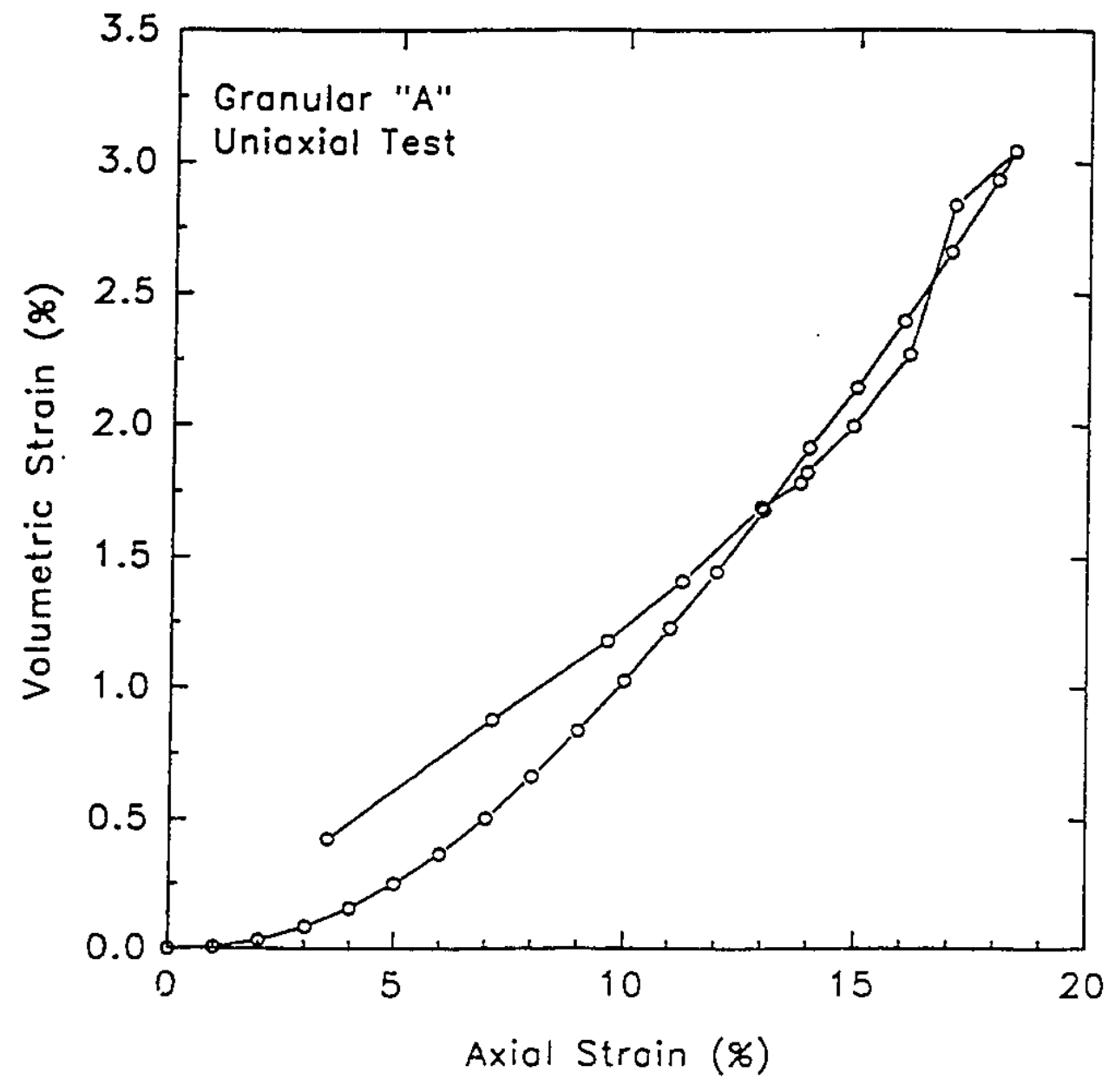

Figure C-14: Volume change behaviour of stone column in Figure C-13 


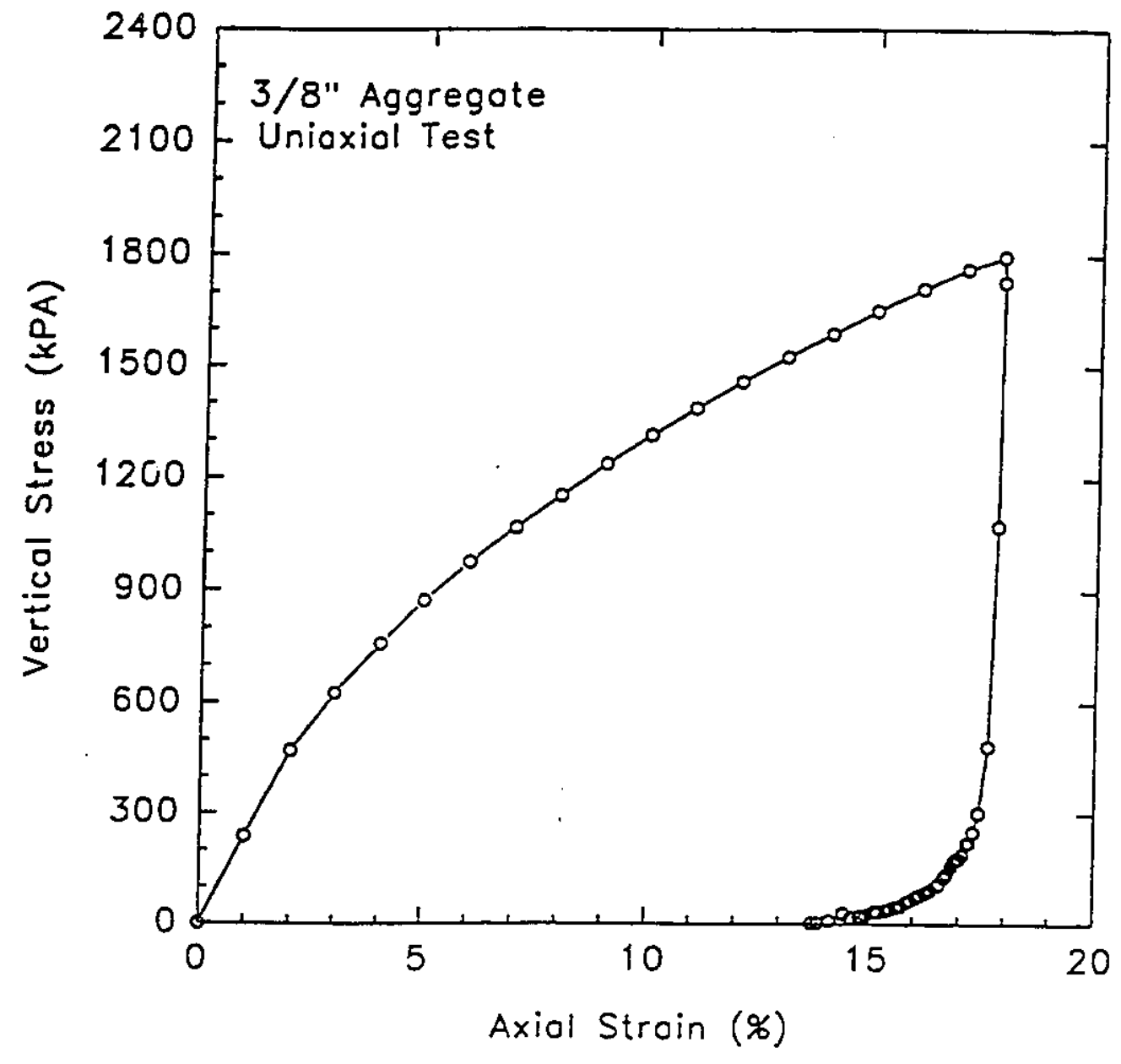

Figure C-15: Stress-strain behaviour of short stone column with Tensar UX-1600 sleeve (Diam. $=0.33 \mathrm{~m}$, Height $=0.68 \mathrm{~m})$ 


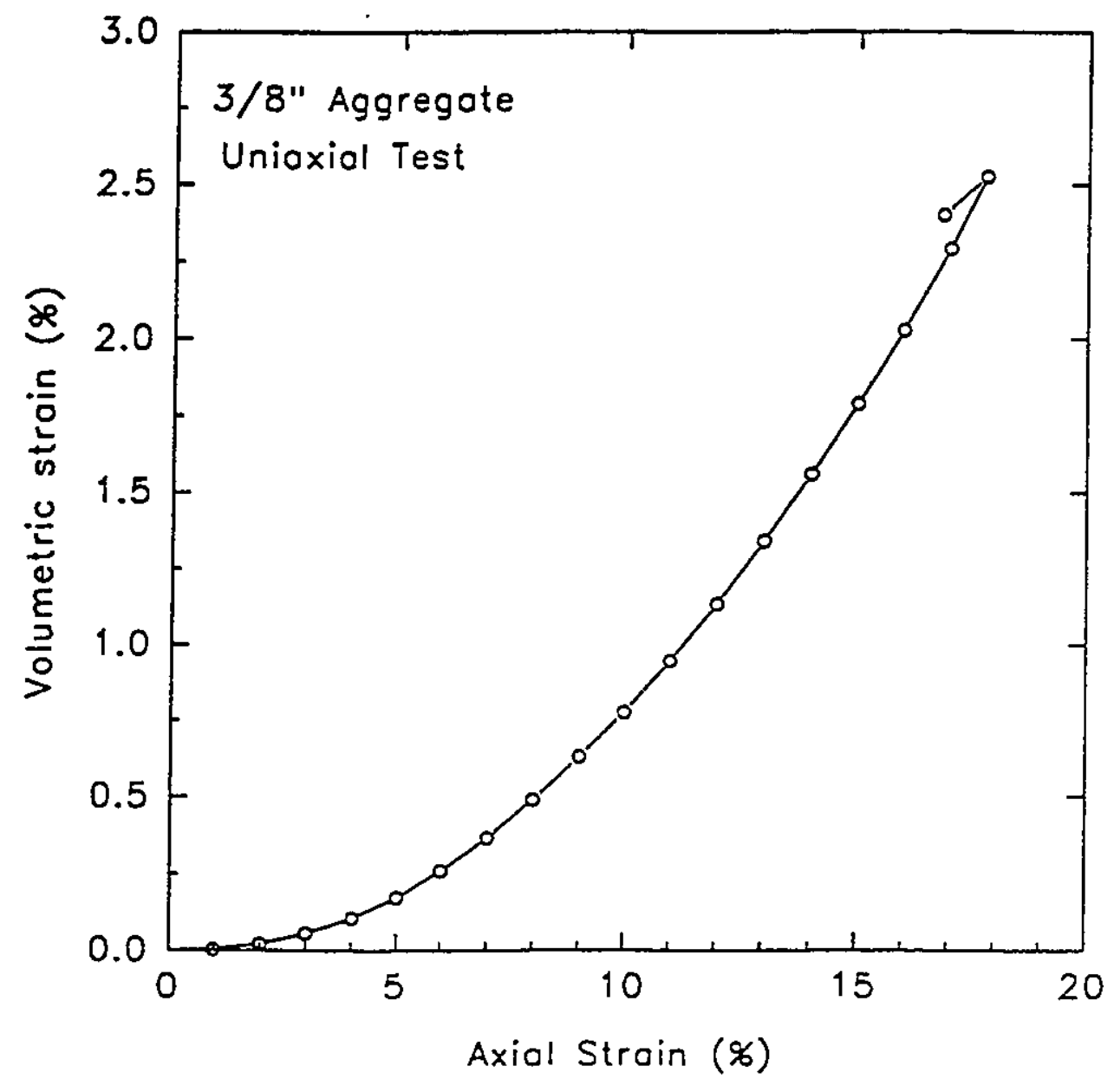

Figure C-16: Volume change behaviour of stone column in Figure C-15 


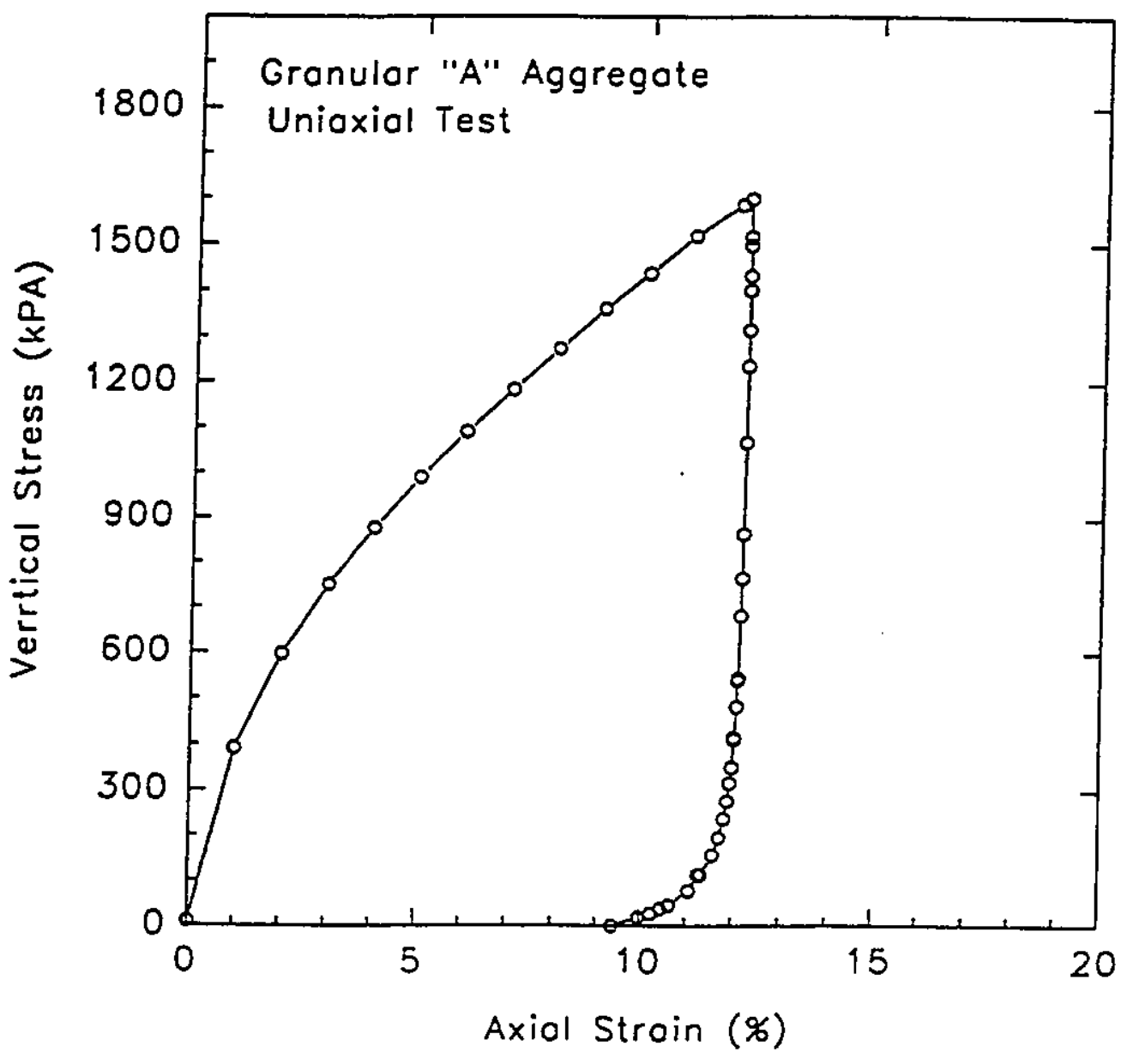

Figure C-17: Stress-strain behaviour of long stone column with Tensar UX-1600 sleeve (Diam. $=0.38 \mathrm{~m}$, Height $=1.32 \mathrm{~m})$ 


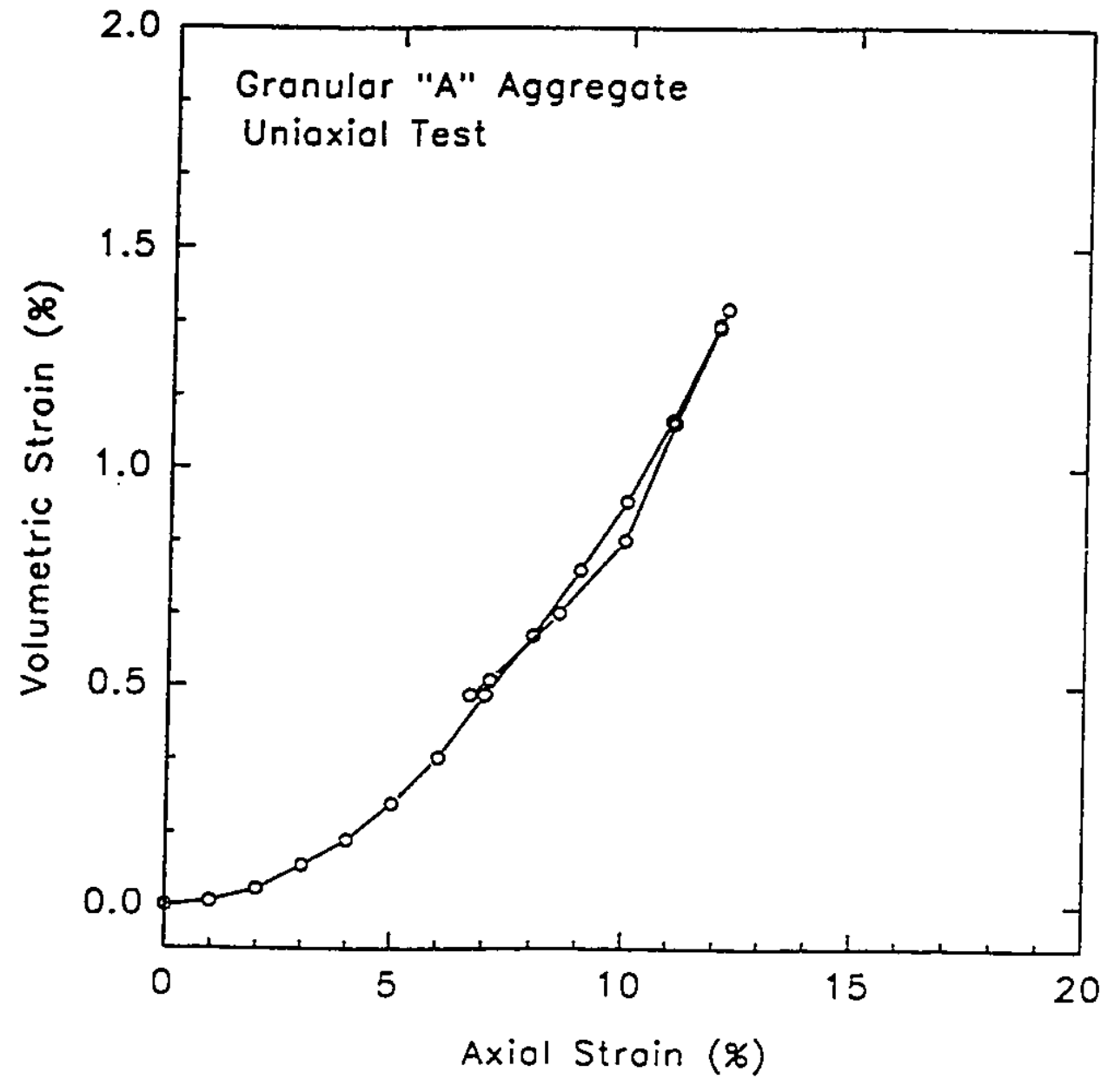

Figure C-18: Volume change behaviour of stone column in Figure $\mathrm{C}-17$ 


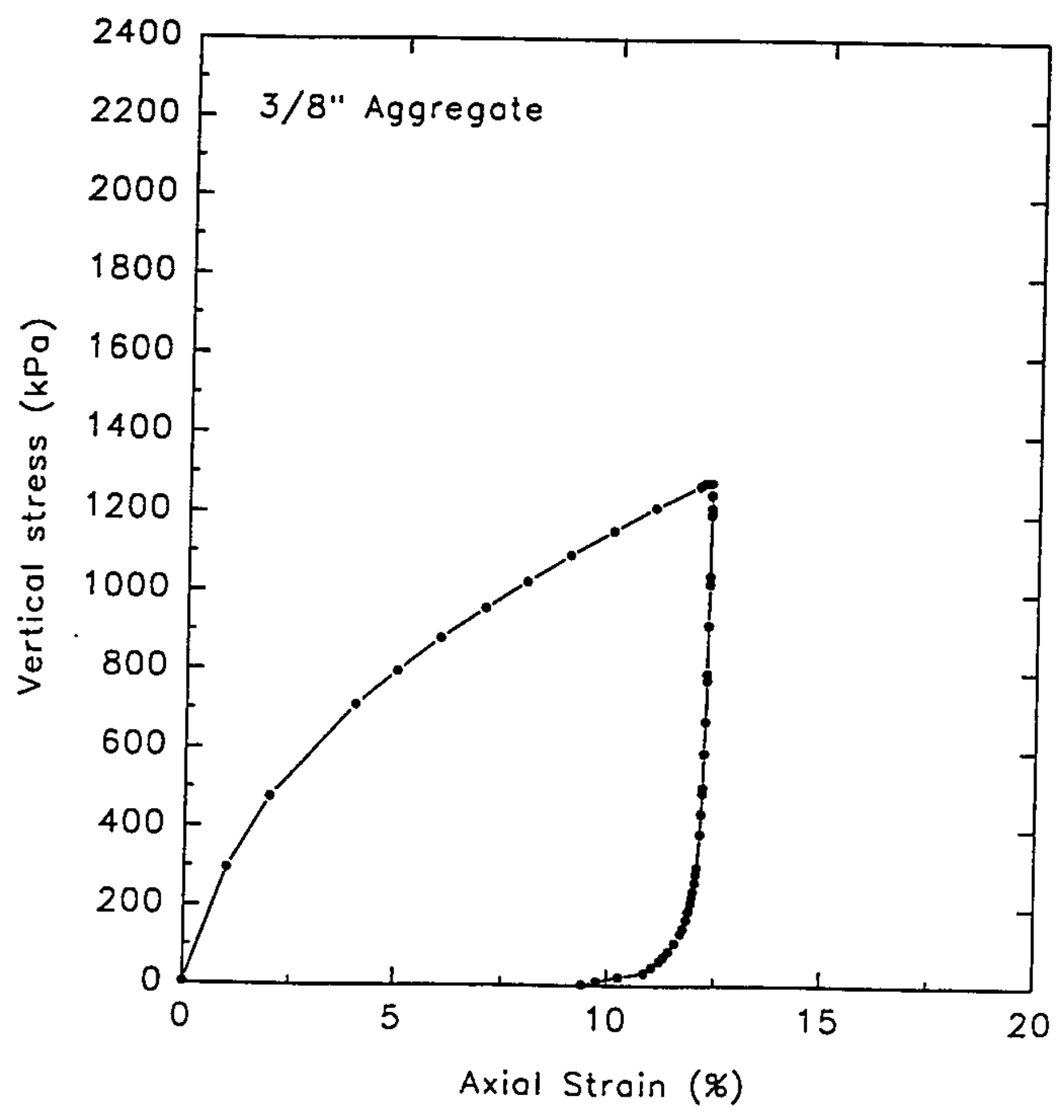

Figure C-19: Stress-strain behaviour of long stone column with Tensar UX-1600 sleeve (Diam. $=0.38 \mathrm{~m}$, Height $=1.32 \mathrm{~m})$ 


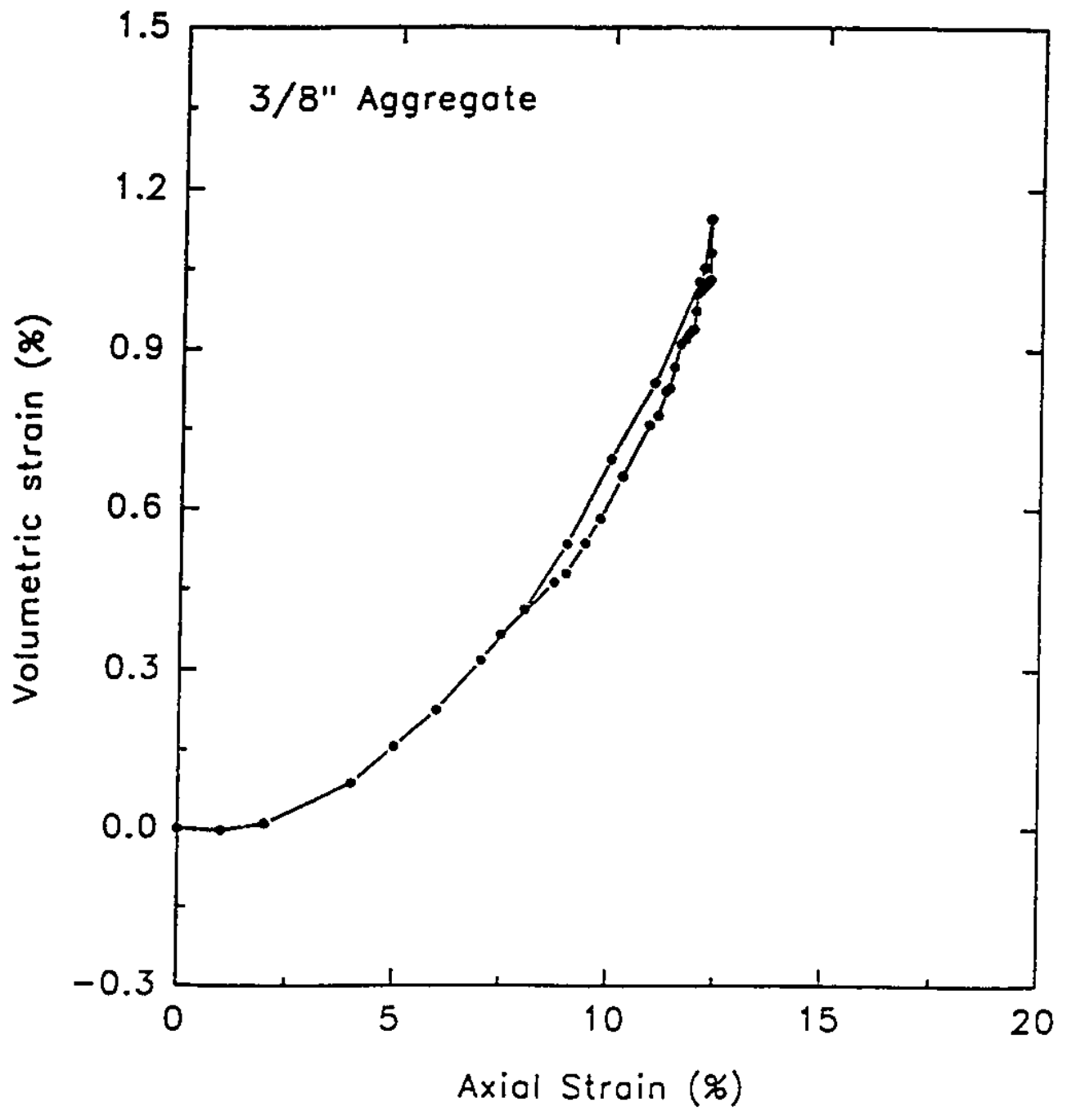

Figure C-20: Volume change behaviour of stone column in Figure C-19 


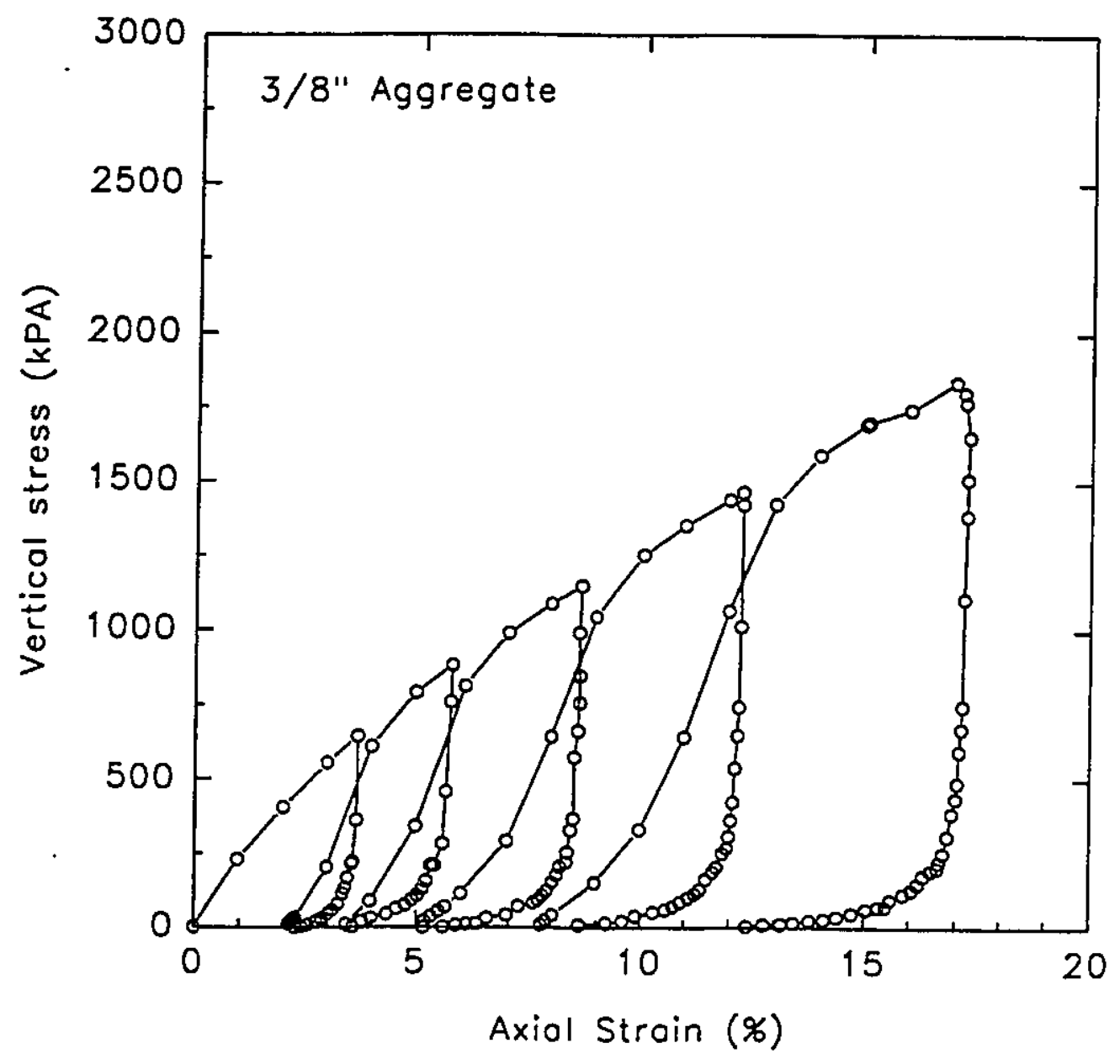

Figure C-21: Cyclic stress-strain behaviour of stone column with Tensar UX-1600 sleeve (Diam. $=0.33 \mathrm{~m}$, Height $=0.64 \mathrm{~m})$ 


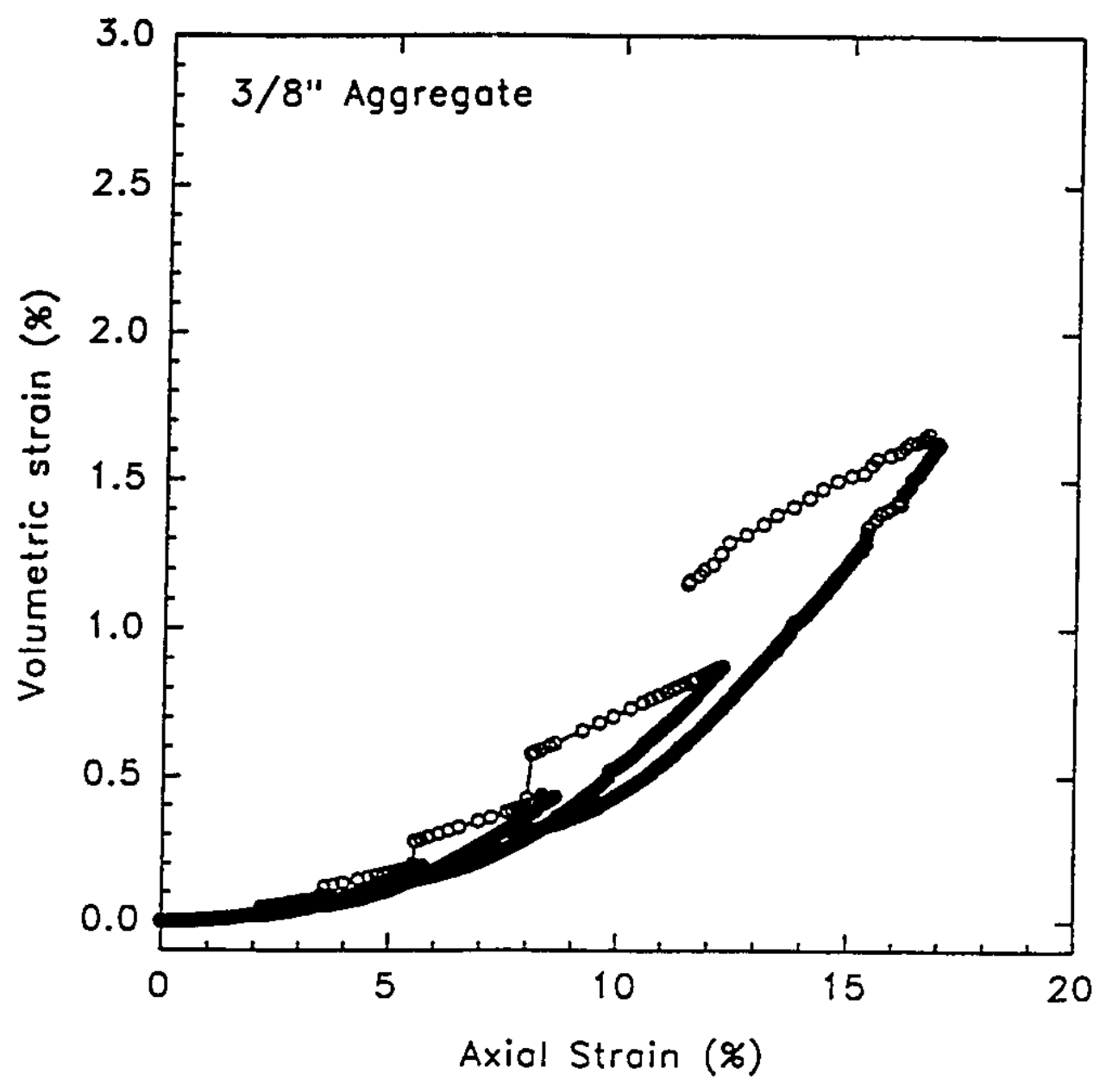

Figure C-22: Volume change behaviour of stone column in Figure C-21 


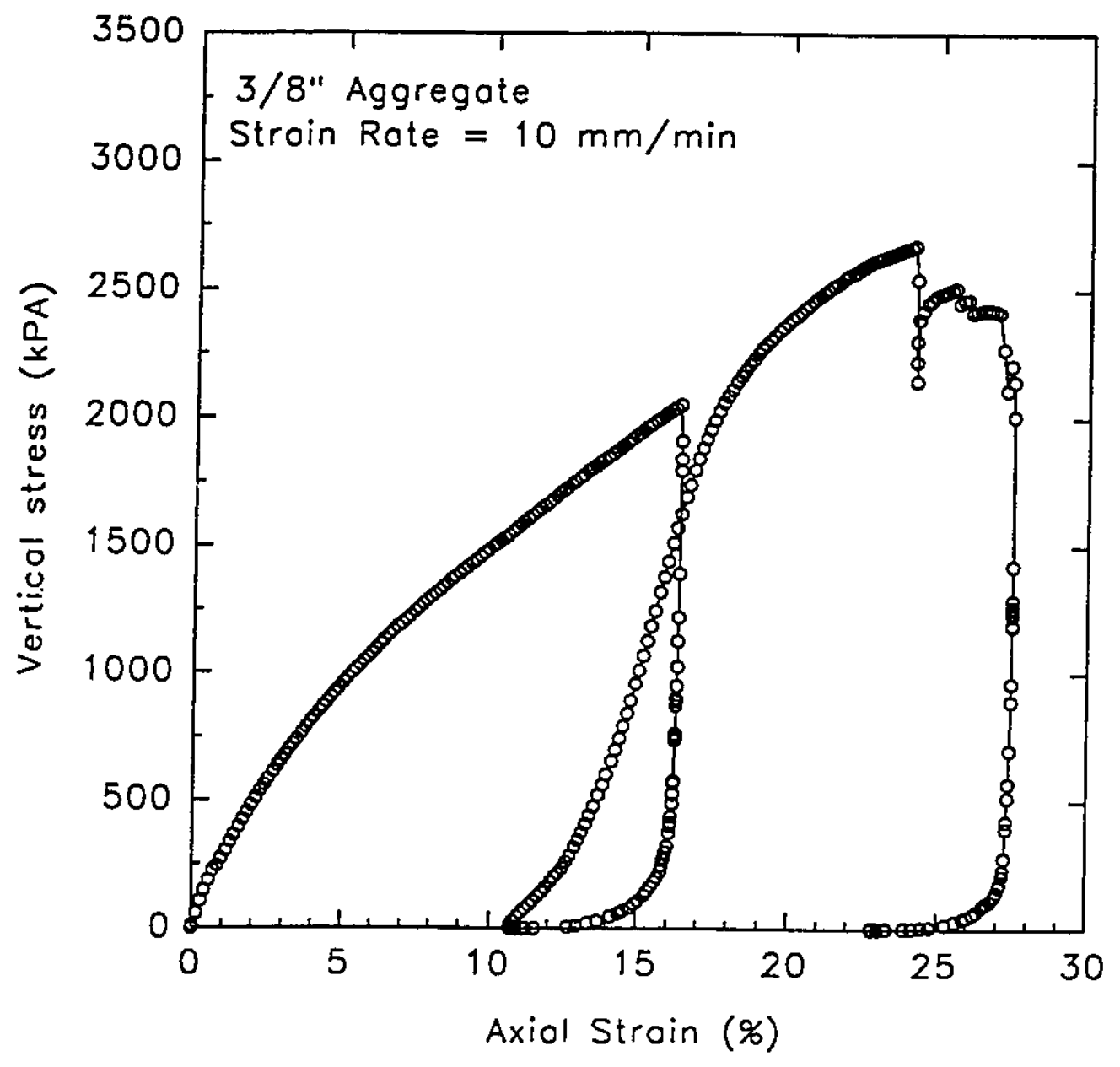

Figure C-23: Cyclic stress-strain behaviour of rapidly strained stone column with Tensar UX-1600 sleeve $($ Diam. $=0.33 \mathrm{~m}$, Height $=0.68 \mathrm{~m})$ 


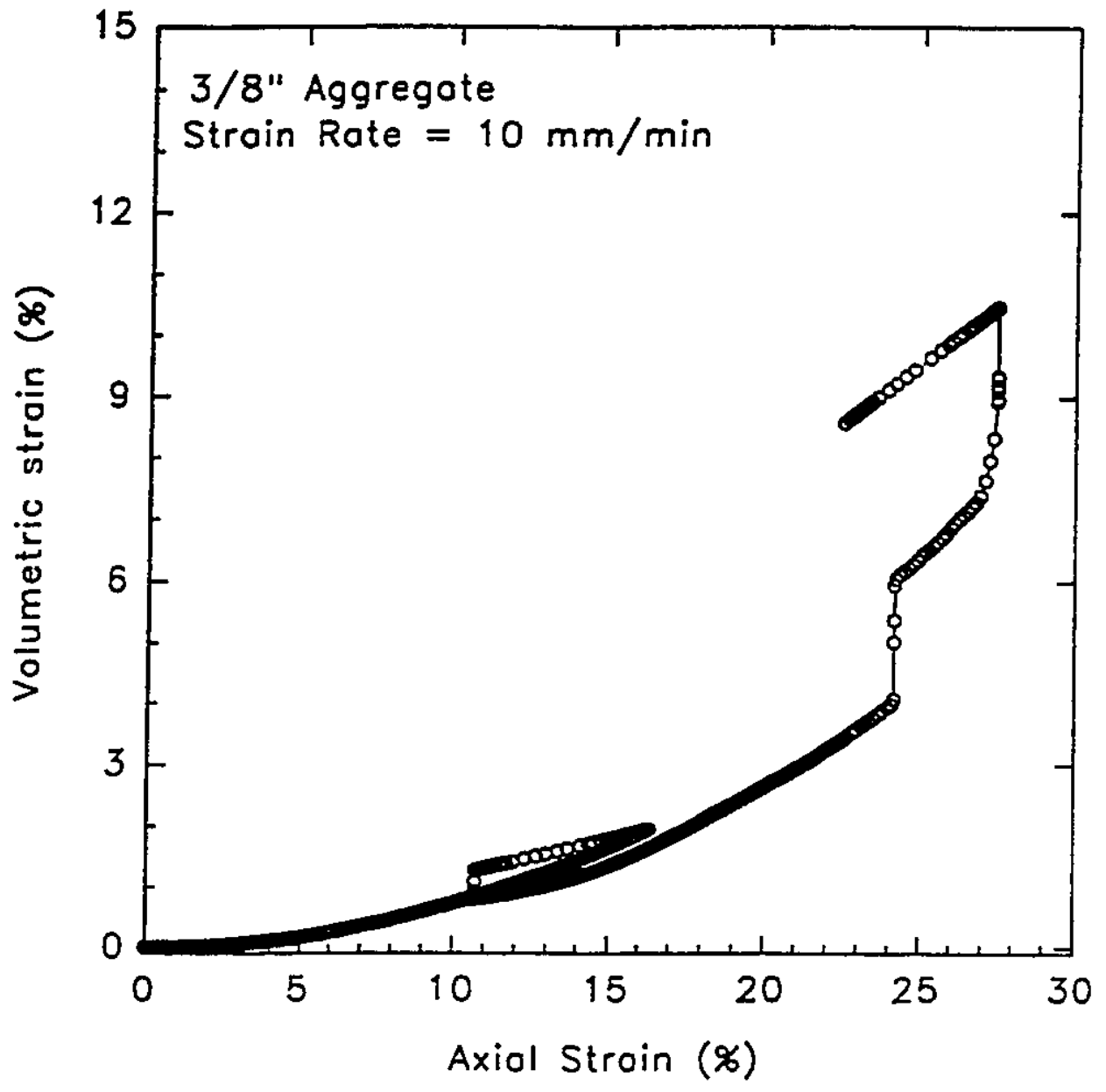

Figure C-24: Volume change behaviour of stone column in Figure C-23 


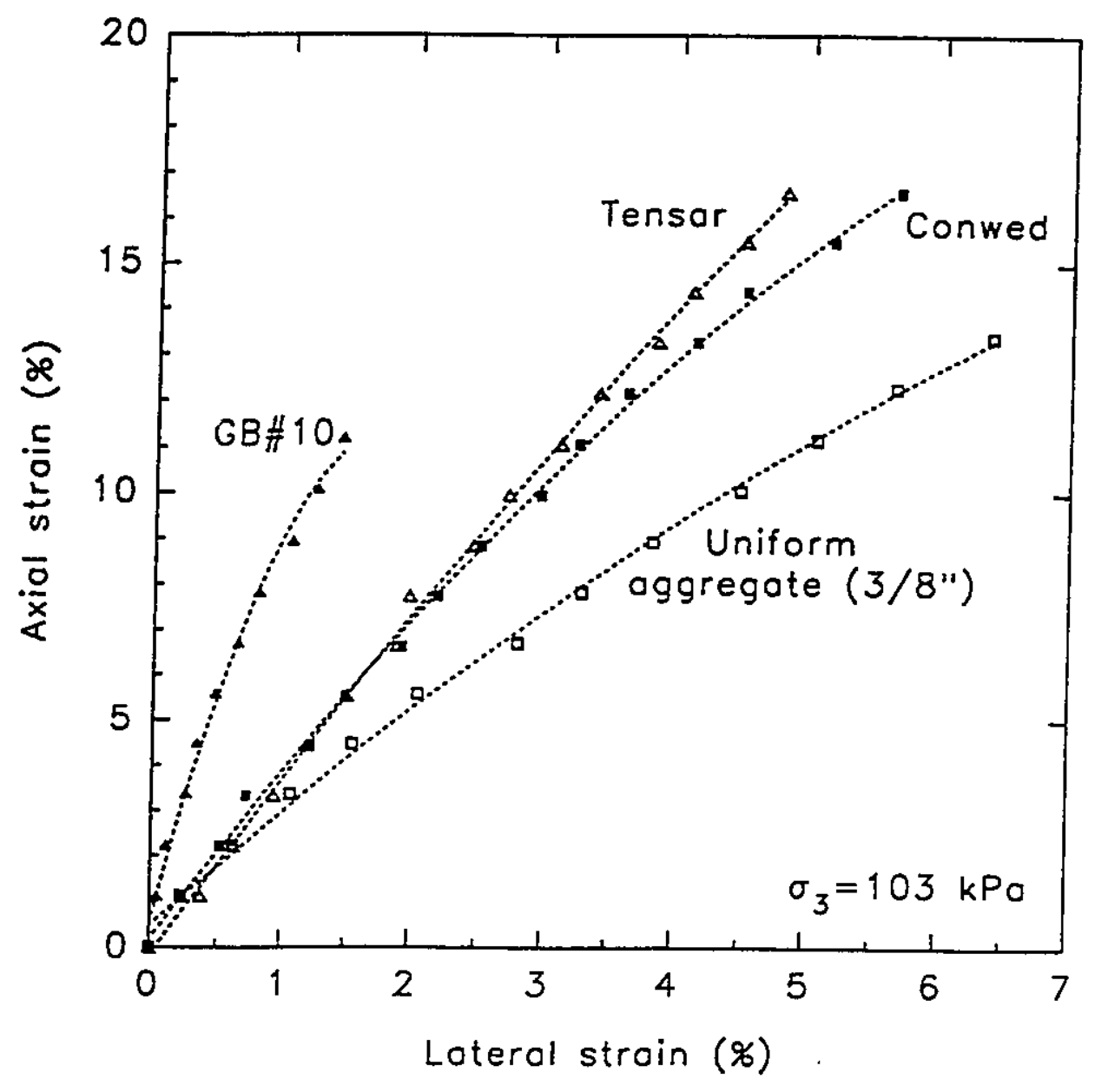

Figure C-25: Average lateral strain behaviour of natural and sleeve reinforced stone columns 


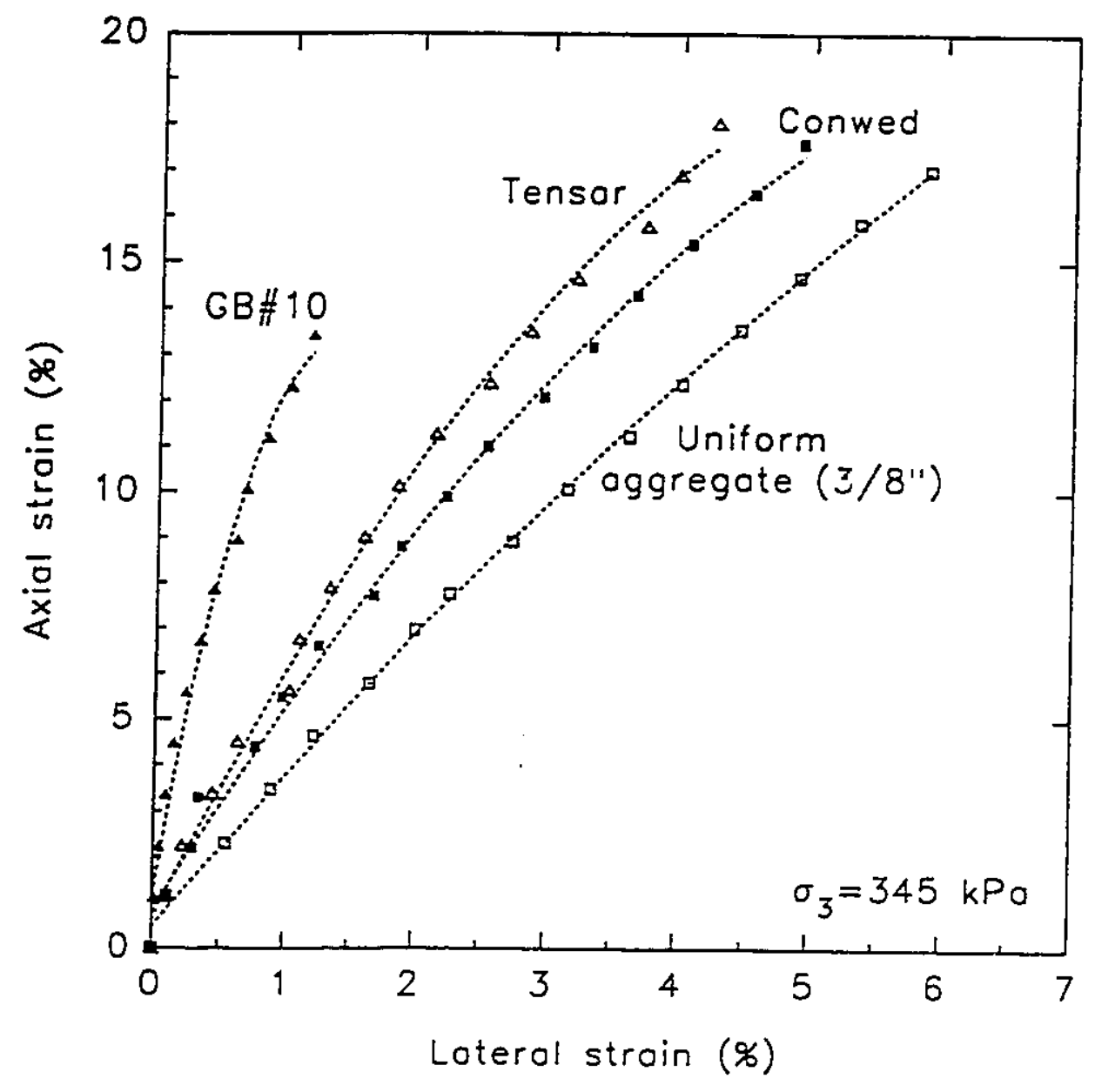

Figure C-26: Average lateral strain behaviour of natural and sleeve reinforced stone columns 


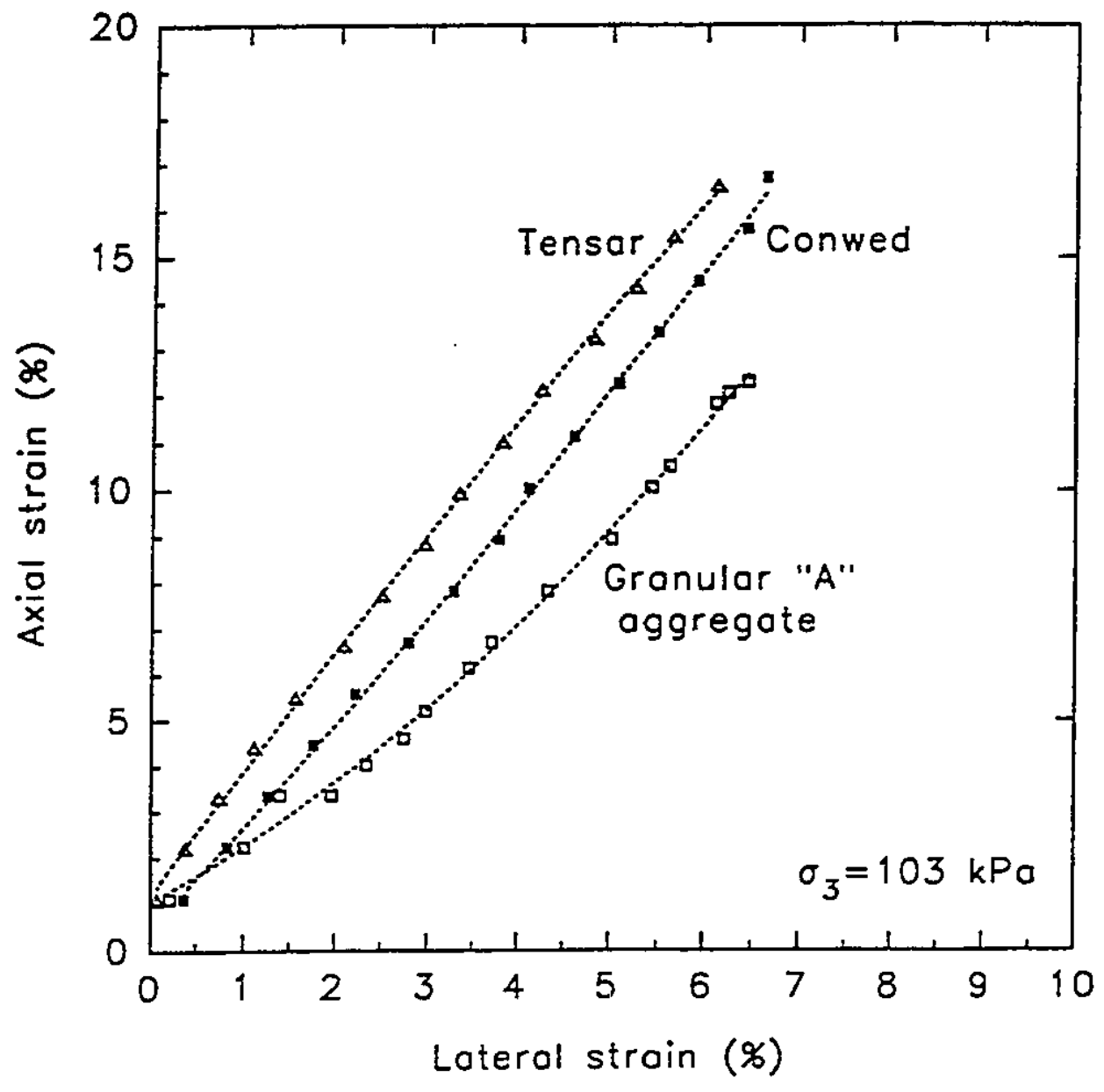

Figure C-27: Average lateral strain behaviour of natural and sleeve reinforced stone columns 


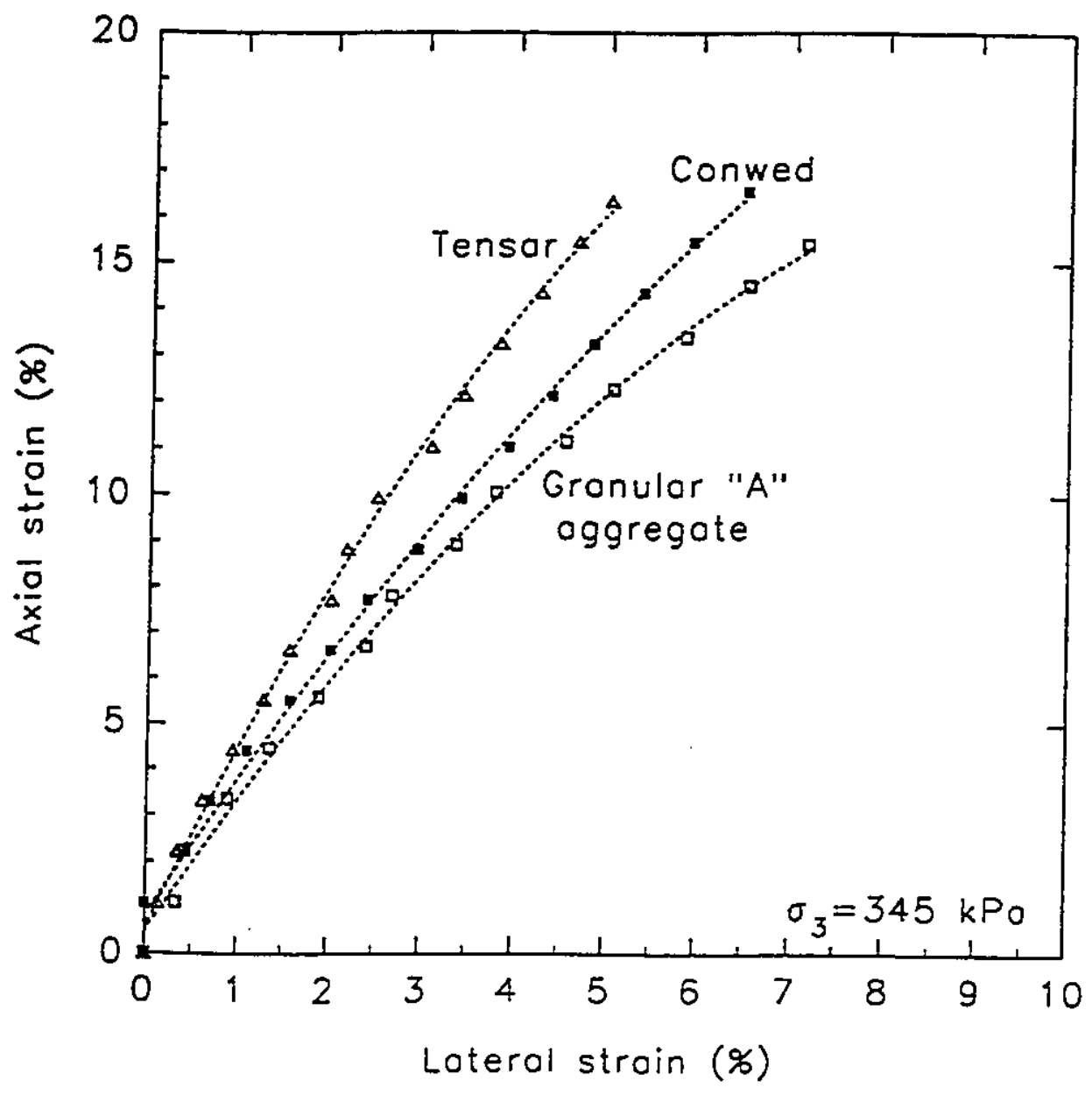

Figure C-28: Average lateral strain behaviour of natural and sleeve reinforced stone columns 
Table C-1: Values of axial strain $\left(\varepsilon_{\mathrm{a}}\right)$ versus $\varepsilon_{\mathrm{a}} /\left(\sigma_{1}-\sigma_{3}\right)$ for $\sigma_{3}=103 \mathrm{kPa}$, granular "A" aggregate+Tensar UX-1500

\begin{tabular}{||c|c|c|}
\hline \multicolumn{3}{|c|}{$\sigma_{3}=103 \mathrm{kPa}$} \\
\hline$\varepsilon_{\mathrm{a}}(\%)$ & $\sigma_{1}-\sigma_{3}(\mathrm{kPa})$ & $\varepsilon_{\mathrm{a}}\left(\sigma_{1}-\sigma_{3}\right)(\mathrm{kPa})^{-1}$ \\
\hline 1.11 & 576 & 0.0019 \\
2.23 & 1028 & 0.0022 \\
3.34 & 1380 & 0.0024 \\
4.46 & 1640 & 0.0027 \\
5.58 & 1873 & 0.0030 \\
6.69 & 2023 & 0.0033 \\
7.81 & 2170 & 0.0036 \\
8.91 & 2279 & 0.0039 \\
10.03 & 2406 & 0.0042 \\
11.15 & 2495 & 0.0045 \\
12.26 & 2562 & 0.0048 \\
13.38 & 2624 & 0.0051 \\
14.49 & 2690 & 0.0054 \\
15.60 & 2734 & 0.0057 \\
16.72 & 2749 & 0.0061 \\
\hline
\end{tabular}

Table C-2: Values of axial strain $\left(\varepsilon_{2}\right)$ versus $\varepsilon_{2} /\left(\sigma_{1}-\sigma_{3}\right)$ for $\sigma_{3}=207 \mathrm{kPa}$, granular "A" aggregate+Tensar UX-1500

\begin{tabular}{||c|c|c|}
\hline \hline \multicolumn{3}{|c|}{$\sigma_{3}=207 \mathrm{kPa}$} \\
\hline$\varepsilon_{\mathrm{a}}(\%)$ & $\sigma_{1}-\sigma_{3}(\mathrm{kPa})$ & $\varepsilon_{\mathrm{a}} /\left(\sigma_{1}-\sigma_{3}\right)(\mathrm{kPa})^{-1}$ \\
\hline 1.11 & 599 & 0.0018 \\
2.23 & 1094 & 0.0020 \\
3.34 & 1413 & 0.0023 \\
4.46 & 1682 & 0.0026 \\
5.58 & 1897 & 0.0029 \\
6.69 & 2077 & 0.0032 \\
7.81 & 2217 & 0.0035 \\
8.91 & 2351 & 0.0038 \\
10.03 & 2465 & 0.0040 \\
11.15 & 2550 & 0.0043 \\
12.26 & 2653 & 0.0046 \\
13.38 & 2740 & 0.0048 \\
14.49 & 2810 & 0.0051 \\
15.60 & 2872 & 0.0054 \\
16.72 & 2934 & 0.0056 \\
\hline
\end{tabular}


Table C-3: Values of axial strain $\left(\varepsilon_{\mathrm{a}}\right)$ versus $\varepsilon_{\mathrm{a}} /\left(\sigma_{1}-\sigma_{3}\right)$ for $\sigma_{3}=345 \mathrm{kPa}$, granular "A" aggregate+Tensar UX-1500

\begin{tabular}{||c|c|c|}
\hline \multicolumn{3}{|c|}{$\sigma_{3}=345 \mathrm{kPa}$} \\
\hline$\varepsilon_{\mathrm{a}}(\%)$ & $\sigma_{1}-\sigma_{3}(\mathrm{kPa})$ & $\varepsilon_{\mathrm{a}} /\left(\sigma_{1}-\sigma_{3}\right)(\mathrm{kPa})^{-1}$ \\
\hline 1.11 & 983 & 0.0011 \\
2.23 & 1533 & 0.0015 \\
3.34 & 1901 & 0.0018 \\
4.46 & 2195 & 0.0020 \\
5.58 & 2451 & 0.0023 \\
6.69 & 2647 & 0.0025 \\
7.81 & 2809 & 0.0028 \\
8.91 & 2944 & 0.0031 \\
10.03 & 3048 & 0.0033 \\
11.15 & 3141 & 0.0036 \\
12.26 & 3232 & 0.0038 \\
13.38 & 3323 & 0.0041 \\
14.49 & 3399 & 0.0043 \\
15.60 & 3462 & 0.0045 \\
16.72 & 3513 & 0.0048 \\
\hline
\end{tabular}

Table C-4: Values of axial strain $\left(\varepsilon_{\mathrm{a}}\right)$ versus $\varepsilon_{\mathrm{a}} /\left(\sigma_{1}-\sigma_{3}\right)$ for $\sigma_{3}=103 \mathrm{kPa}$, granular "A" aggregate+Conwed 9027

\begin{tabular}{|c|c|c|}
\hline \multicolumn{3}{|c|}{$\sigma_{3}=103 \mathrm{kPa}$} \\
\hline$\varepsilon_{\mathrm{a}}(\%)$ & $\sigma_{1}-\sigma_{3}(\mathrm{kPa})$ & $\varepsilon_{\mathrm{a}} /\left(\sigma_{1}-\sigma_{3}\right)(\mathrm{kPa})^{-1}$ \\
\hline 1.11 & 677 & 0.0016 \\
2.23 & 1060 & 0.0021 \\
3.34 & 1334 & 0.0025 \\
4.46 & 1540 & 0.0029 \\
5.58 & 1718 & 0.0032 \\
6.69 & 1823 & 0.0037 \\
7.81 & 1926 & 0.0041 \\
8.91 & 1999 & 0.0045 \\
10.03 & 2086 & 0.0048 \\
11.15 & 2170 & 0.0051 \\
12.26 & 2247 & 0.0055 \\
13.38 & 22351 & 0.0057 \\
14.49 & 2309 & 0.0063 \\
15.60 & 2420 & 0.0064 \\
\hline
\end{tabular}


Table C-5: Values of axial strain $\left(\varepsilon_{2}\right)$ versus $\varepsilon_{2} /\left(\sigma_{1}-\sigma_{3}\right)$ for $\sigma_{3}=207 \mathrm{kPa}$, granular "A" aggregate+Conwed 9027

\begin{tabular}{||c|c|c|}
\hline \multicolumn{3}{|c|}{$\sigma_{3}=207 \mathrm{kPa}$} \\
\hline$\varepsilon_{\mathrm{a}}(\%)$ & $\sigma_{1}-\sigma_{3}(\mathrm{kPa})$ & $\varepsilon_{\mathrm{a}} /\left(\sigma_{\mathrm{1}}-\sigma_{3}\right)(\mathrm{kPa})^{-1}$ \\
\hline 1.11 & 561 & 0.0020 \\
2.23 & 996 & 0.0022 \\
3.34 & 1313 & 0.0025 \\
4.46 & 1558 & 0.0028 \\
5.58 & 1777 & 0.0031 \\
6.69 & 1927 & 0.0034 \\
7.81 & 2075 & 0.0037 \\
8.91 & 2236 & 0.0039 \\
10.03 & 2289 & 0.0043 \\
11.15 & 2396 & 0.0046 \\
12.26 & 2478 & 0.0049 \\
13.38 & 2591 & 0.0051 \\
14.49 & 2693 & 0.0053 \\
\hline
\end{tabular}

Table C-6: Values of axial strain $\left(\varepsilon_{\mathrm{a}}\right)$ versus $\varepsilon_{\mathrm{a}} /\left(\sigma_{1}-\sigma_{3}\right)$ for $\sigma_{3}=345 \mathrm{kPa}$, granular "A" aggregate+Conwed 9027

\begin{tabular}{||c|c|c||}
\hline \multicolumn{3}{|c|}{$\sigma_{3}=345 \mathrm{kPa}$} \\
\hline$\varepsilon_{\mathrm{a}}(\%)$ & $\sigma_{1}-\sigma_{3}(\mathrm{kPa})$ & $\varepsilon_{\mathrm{a}} /\left(\sigma_{1}-\sigma_{3}\right)(\mathrm{kPa})^{-1}$ \\
\hline 1.11 & 529 & 0.0021 \\
2.23 & 1334 & 0.0017 \\
3.34 & 1740 & 0.0019 \\
4.46 & 2086 & 0.0022 \\
5.58 & 2363 & 0.0024 \\
6.69 & 2568 & 0.0026 \\
7.81 & 2735 & 0.0029 \\
8.91 & 2833 & 0.0032 \\
10.03 & 2917 & 0.0035 \\
11.15 & 3008 & 0.0037 \\
12.26 & 3080 & 0.0040 \\
13.38 & 3174 & 0.0042 \\
14.49 & 3254 & 0.0045 \\
15.6 & 3309 & 0.0048 \\
16.72 & 3228 & 0.0052 \\
\hline
\end{tabular}


Table C-7: Values of axial strain $\left(\varepsilon_{\mathrm{a}}\right)$ versus $\varepsilon_{\mathrm{a}} /\left(\sigma_{1}-\sigma_{3}\right)$ for $\sigma_{3}=103 \mathrm{kPa}$, $3 / 8$ " aggregate+Fiber glass (GB \#10)

\begin{tabular}{||c|c|c||}
\hline \multicolumn{3}{|c|}{$\sigma_{3}=103 \mathrm{kPa}$} \\
\hline$\varepsilon_{\mathrm{a}}(\%)$ & $\sigma_{1}-\sigma_{3}(\mathrm{kPa})$ & $\varepsilon_{\mathrm{a}} /\left(\sigma_{1}-\sigma_{3}\right)(\mathrm{kPa})^{-1}$ \\
\hline 1.12 & 554 & 0.002 \\
2.24 & 767 & 0.0029 \\
3.36 & 937 & 0.0036 \\
4.48 & 1012 & 0.0044 \\
5.59 & 1111 & 0.0050 \\
6.72 & 1093 & 0.0061 \\
7.84 & 1167 & 0.0067 \\
8.95 & 1180 & 0.0076 \\
10.08 & 1145 & 0.0088 \\
11.20 & 1129 & 0.0099 \\
\hline
\end{tabular}

Table C-8: Values of axial strain $\left(\varepsilon_{\mathrm{a}}\right)$ versus $\varepsilon_{\mathrm{a}} /\left(\sigma_{1}-\sigma_{3}\right)$ for $\sigma_{3}=207 \mathrm{kPa}$, $3 / 8$ " aggregate+Fiber glass (GB \#10)

\begin{tabular}{|c|c|c|}
\hline \multicolumn{3}{|c|}{$\sigma_{3}=207 \mathrm{kPa}$} \\
\hline$\varepsilon_{\mathrm{a}}(\%)$ & $\sigma_{1}-\sigma_{3}(\mathrm{kPa})$ & $\varepsilon_{\mathrm{a}} /\left(\sigma_{1}-\sigma_{3}\right)(\mathrm{kPa})^{-1}$ \\
\hline 1.12 & 578 & 0.0019 \\
2.24 & 799 & 0.0028 \\
3.36 & 994 & 0.0034 \\
4.48 & 1176 & 0.0038 \\
5.59 & 1217 & 0.0046 \\
6.72 & 1254 & 0.0054 \\
7.84 & 1296 & 0.0060 \\
8.95 & 1284 & 0.0070 \\
10.08 & 1324 & 0.0076 \\
11.20 & 1344 & 0.0083 \\
12.3 & 1351 & 0.0091 \\
13.43 & 1347 & 0.01 \\
\hline
\end{tabular}


Table C-9: Values of axial strain $\left(\varepsilon_{\mathrm{a}}\right)$ versus $\varepsilon_{\mathrm{a}} /\left(\sigma_{1}-\sigma_{3}\right)$ for $\sigma_{3}=345 \mathrm{kPa}$, 3/8" aggregate+Fiber glass (GB \#10)

\begin{tabular}{|c|c|c|}
\hline \multicolumn{3}{|c|}{$\sigma_{3}=345 \mathrm{kPa}$} \\
\hline$\varepsilon_{\mathrm{a}}(\%)$ & $\sigma_{1}-\sigma_{3}(\mathrm{kPa})$ & $\varepsilon_{\mathrm{a}} /\left(\sigma_{1}-\sigma_{3}\right)(\mathrm{kPa})^{-1}$ \\
\hline 1.12 & 600 & 0.0019 \\
2.24 & 837 & 0.0027 \\
3.36 & 1046 & 0.0032 \\
4.48 & 1242 & 0.0036 \\
5.59 & 1358 & 0.0041 \\
6.72 & 1440 & 0.0047 \\
7.84 & 1459 & 0.0054 \\
8.95 & 1601 & 0.0056 \\
10.08 & 1622 & 0.0062 \\
11.20 & 1671 & 0.0067 \\
12.3 & 1698 & 0.0073 \\
13.43 & 1457 & 0.0092 \\
\hline
\end{tabular}

